

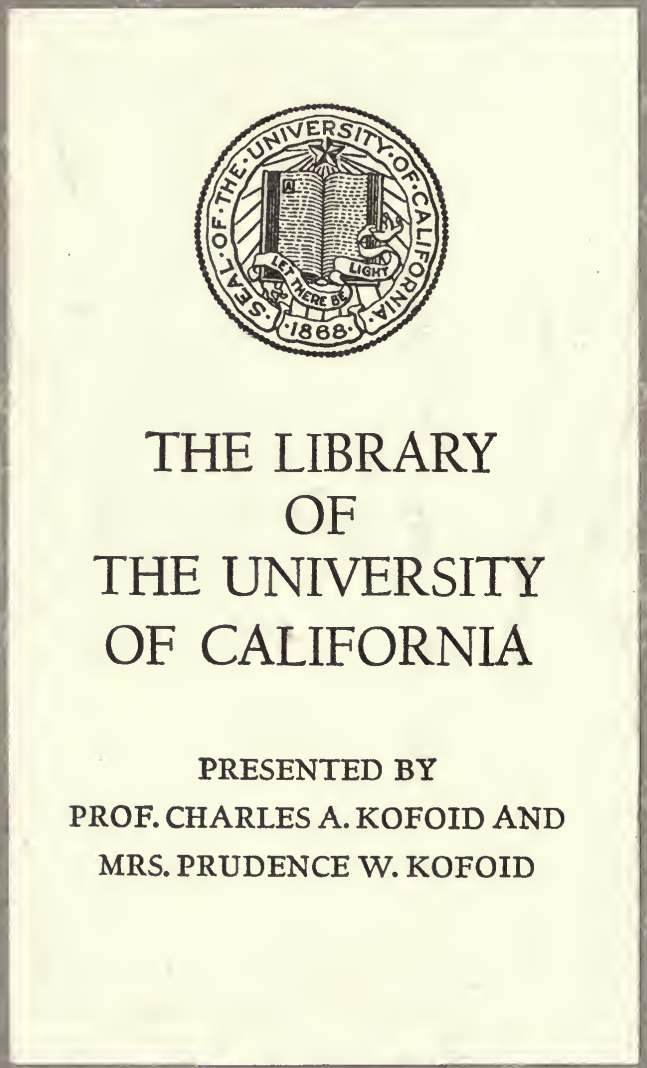




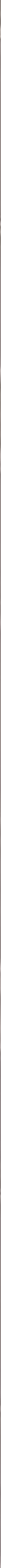





the Right Alouble

Arther Herbert Dy he Aclain, M.P rith the Author' Respecturl Campliments Mithim harment

Srightor, May 31. 1895.

Progress of Science. 
ALLA

SORELLA SUA

L' AUTORE

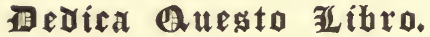




\title{
PROGRESS OF SCIENCE
}

ITS ORIGIN, COURSE, PROMOTERS, AND RESULTS.

\author{
BY \\ J. VILLIN MARMERY.
}

WITH AN INTRODUCTION BY SAMUEL LAING.

"He dies not who gives life to learning."-AuI.

LONDON: CHAPMAN AND HALL, LD.

1895.

[All rights reserved.] 



\section{$2 / 25$ M27}

To the Publishers.

I HAVE now had time to read Mr. Marmery's book, and find it a work of great learning and research, conveying in a clear and intelligible form a mass of most useful and interesting history of the Progress of Science, from its first dawn in Egypt and Chaldæa, through the Greek, Arabian, Mediæval, and Modern periods, down to the present day. It comprises also brief memoirs of the illustrious men to whom we are indebted for the principal discoveries of Science, from Thales and Pythagoras down to Darwin and Herbert Spencer, and I can confidently recommend it as alike interesting and instructive.

S. LAING.

"Rockhills," Sydenham,

December 15 th, 1894 . 



\section{PREFACE.}

THE history of science is a sealed book, generally speaking. To the multitude of readers, including in it scientific students, an historical thread conducting them through the bewildering field of science cannot fail to prove a welcome gain. Men, as a rule, accept the fact of to-day as it stands without troubling themselves about the gradual steps taken in the past to reach it. They have neither the leisure nor the inclination to probe the obscurity of past ages themselves. They leave this task to the historian. Nor have they the inclination and leisure, pressed onward as they are by their daily work, to follow the historian if his account is at all bulky. Time fails them. Some, no doubt, have tried to become acquainted with the subject, but despite its extraordinary fascination, most have given up the attempt from lack of perseverance; for very limited indeed is the number of those who, commanding the time and feeling the curiosity, have the application to undertake the reading, say, of the twenty-four volumes of Herbert Spencer, or only the half-dozen inadequate volumes of 
Whewell. A Cyclopædia presents an amount of matter accurate and varied enough to satisfy the casual inquirer, but the facts conveyed being fragmentary, the onus of mentally constructing a continuous account lies on himself. The reader wants to see a palace, with its foundations, vaults, walls, storeys, stairs, halls, corridors, strong-rooms, store-rooms, loft, roof, skylight; he wants also to understand the process of construction; and he only sees scattered heaps of bricks, cut granite and marble blocks, timber, cement, tiles, good material to build, but no building. A Cyclopædia, besides, is both cumbrous and expensivehence inaccessible to most people. In this busy age of ours, people want small books on large subjects. They read the newspapers, which give them information for business purposes; the reviews, which sum up the trifling questions or the stirring events of the hour; novels, which afford them amusement-not great works.* These are addressed to men of science, to men of exceptional learning or great intellectual activity. Yet there is no doubt that any subject will interest the public, just as it will the student, if it be presented in a desirable form-a form at once concise, clear, cohesive, and attractive. And if this be a desideratum, it should be supplied. Does the public generally care for science? If it involves labour or mental effort, the question must be answered in the negative; if

* In a town of 130,000 people, which enjoys the benefit of a public lending library, the Essays of Herbert Spencer had in six months been issued eighteen times, and of the eighteen readers out of the whole population who had felt desirous of becoming acquainted with the philosopher's views in their simplest form, not one had read the three volumes through, for the writer of the present work found pages uncut in them! 
it involves none, and awakens pleasurable curiosity, the public will follow the expositor of it with eagerness and delight.

The present work has been undertaken with this view, and if it effect only part of the results expected from it, it will have accomplished the object of the Author. A history of science does not yet exist. Partial attempts have been made, some deserving popularity although lacking accuracy or completeness. Of these, Arabella Buckley's is admirably done so far as it goes. Its attractive clearness is beyond praise. But if its accuracy is generally unimpeachable, the gaps which it presents are a grave historical imperfection. Again, this or that science has been adequately treated in a separate historical form; other works, such as Watts' Dictionary of Chemistry, which constitutes an inexhaustible mine of profound science, are real monuments of learning; but colossal as they are, they can be useful to the historian as a source of unexcelled information as regards one branch of research only. H. Spencer, too, has enough material in his works to compose a magnificent history of science; but such a history, we repeat, has yet to be written. The book we now offer the reader is a mere sketch, a simple outline of a vast subject, roughly chalked as it were on the black-board, a thread in the labyrinth, very slender indeed, but sufficiently strong to conduct the inquirer safely from the Greek world to our own without leading him astray. Facts of first-class importance only have been taken into account and connected together so as to show the continuity of scientific development and its natural evolution. This evolution has gone through five 
successive stages, equal in interest if unequal in magnitude: the Greek, the Arabian, the Mediæval, the Revival, and the Modern. This, then, is a modest survey of science, with its origin, growth, and results, and is addressed to the student and the general reader.

And as scientific history rather than science itself is the main object in view here, the majority of the facts recorded are merely stated and enumerated, without those explanatory details which would be indispensable in a didactic work; yet, now and then, the statement has been enlarged upon so as to enable the reader to perceive the importance, the bearings, and the consequences of a scientific fact. This occurs especially in the sketch of the Modern period, for the Author felt that if he confined himself to the simple definition of a law, or the mere enumeration of discoveries, the reader would probably fail to draw right inferences or apprehend the full significance of the case. Besides, more interest is naturally attached by readers to a recent discovery which they have witnessed, so to speak, and about which the whole world may be ringing, than to an older one. They see the railway engine, the telegraph, the electric light, and they welcome an explanation which, exempt from technicalities, enables them to understand the cause of their power. They have heard of the spectroscope, and naturally again they will welcome a brief description which makes plain to them the beauty of its principles, the range of its effects, and the extent of the benefits it bestows. The meagreness of details, consistent with the limited plan of the book and prevalent in some portions of it, has then occasionally been abandoned, and replaced by comparative 
copiousness, so as to satisfy the reader's intuitive desire of knowledge. Yet, we repeat, this work is chiefly historical, and is not meant to teach any of the sciences, although it sets forth their beauty, their grandeur, and their resources.

But as a review of scientific achievements embraces the mode without which they could not have been effected, the method of scientific research has necessarily been described; and as a great deal of misconception generally exists with regard to its discoverer, the writer of this book has not shrunk from facing the great difficulty which arises from the mistaken view on the subject. Accuracy imposed on him a double duty: that of ascribing the discovery of the method to the philosopher to whom it is due, and that of dethroning from his usurped reputation the man to whom it is wrongly assigned. This was the more imperative as the progress of modern science is said by many to be almost entirely owing, not to the men who actually brought it about, but to the influence of one who was in every way, not only a stranger to science and its method of research, but who would have arrested scientific advancement if he had swayed the influence popularly attributed to him. The rectification of the facts has partly been made before this by famed and competent men, but the repetition of the fallacy has nevertheless recurred over and over again, in season and out of season, as if nothing had happened-writers taking no trouble to verify the substance of their statements, and endorsing, often without the least suspicion of inaccuracy, what an author of repute has without due scrutiny once advanced as a fact. So much and so fre- 
quently has this been the case in this instance that the fallacy has taken deep root. To eradicate, then, the oldstanding fiction thus propagated, it was necessary to thrash the question out, to face it from several points of view, and bring forward a variety of proofs which facts furnish against the error.

If, however, the great name of Francis Bacon is stripped of its scientific glamour, the name of Roger Bacon, to whom adequate justice has never been done, will, by compensation, be inscribed in a very high place in the sanctuary of science; and England's scientific repute will gain by the act of fairness performed by the Author-a circumstance at which all Englishmen, fond of truth as they are, will be sure to rejoice with conscious pride, as they will recognise in him the precursor of the men who have made their country the greatest representative nation of science. With Francis Bacon, as a jurist, a moralist, a statesman, an historian, or a dramatist, whatever claim he may have to these titles, we have nothing to do; we have dealt with him in his scientific capacity only-i.e. as a natural philosopher.

The value of this book lies in the amount of information it conveys-the work of some four hundred men of science being considered. Its value is slightly increased by an Appendix, which, for the purpose of substantiating some of the statements made in the work, contains quotations which would have overweighted the historical account if inserted in the main text. Definitions which may be unfamiliar to some readers will also be found there.

The arrangement of the work, it may be added, has been devised in such a manner as to present every series of facts 
in groups-the surest means to make a deep impression on the reader's mind.

The Author begs to acknowledge his most grateful obligations to the numerous writers whose names appear in the following pages, and who have enabled him to carry out his scheme as well, he fondly hopes, as his plan admitted. For part of the scientific matter he has incorporated, he is particularly indebted to Pouchet, Comte, H. Spencer, Liebig, De Maistre, Brewster, Whewell, Draper, Ganot, Rodwell, S. Laing, and Jevons ; for some of the historical and philosophical appreciations he has enunciated, he owes much inspiration to the brilliant works of G. H. Lewes, PrévostParadol, Lecky, and John Morley, who are recognised by all impartial minds, not safe guides only, but, among the distinguished throng of philosophers, as some of the foremost representatives of modern thought. 


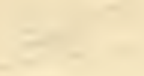

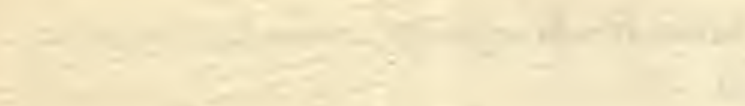

(1)
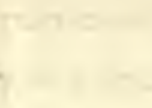

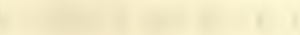

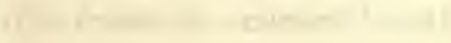

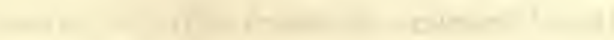

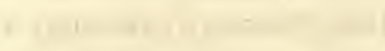

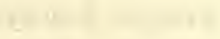

10

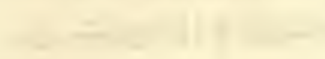




\section{CONTENTS.}

CHAPTER I.

EARLY KNOWLEDGE-METHOD OF RESEARCH.

Museums and Exhibitions-Common knowledge and science-Concrete and abstract knowledge-Utility, an incentive of scienceChaldæan and Egyptian sciences-Early Greek philosophersThales, Anaximander, Pythagoras, Anaxagoras-Plato's deductive process-Aristotle's Induction-His syllogism-His knowledge of natural history, physiology, psychology, astronomy, physics, politics, etc.-Founder of the Objective Method. .

\section{CHAPTER II.}

\section{SCIENCE IN ANTIQUITY.}

Drawbacks to progress-mathematics ; instruments ; slavery ; contempt for industry ; climate ; preconceived theories; material substances; political economy-Interaction of the sciencesNecessary elements of progress-means of transport; perpetuation of ideas; transformation of the Earth's surface; health and morality; social and international intercourseGreat advances in antiquity despite drawbacks . . . .

\section{CHAPTER III.}

\section{Progress in ANTIQUity.}

Discoveries of the Greeks from Hippocrates to Ptolemy-The Alexandrian school-The Museum-The Serapion . . .

\section{CHAPTER IV.}

\section{PROGRESS AMONG THE ARABS.}

Science in Persia-The Arabians become the custodians of science - Character of the Arabian civilisation-The Khalifs-The Arabian cities-Houses and palaces-Schools-Arts of lifeWealth, luxury, revenue-Industry and commerce-Liberal 
policy and government-Men of science and their discoveries: Ben Musa, Alhazen, Averroes, Giaber, etc.-Jews of SpainGreat inventions-Learned institutions-Our mediæval scholars -Arabian pupils-Contrast between Islam and Christendom .

\section{CHAPTER V.}

Progress in the Middle Ages and DURing the Revival.

Heroic character of the mediæval scientists-Legacy of the mediæval period to us-Great inventions-Prominent men of science and their discoveries-Nearly all the sciences fixed on experimental bases-Immense progress in practical and plastic arts-Learned societies founded-"Dark Ages" a misnomer . . . .

CHAPTER VI.

\section{Numerous Causes of SCIENTIFIC PROGREss.V}

Political movements of the mediæval era-The Crusades-Disappearance of drawbacks-Growth of industry and commerce -Creation of commercial wealth-Capital-Progress in art, literature, invention-Social improvement due to the gradual abolition of slavery and serfdom-Scientific growth, partly due to the Arabians of Spain-Encyclopædic works-Influence of Astrology and Alchemy-Filiation of great discoveries, and interaction of the sciences. . . . . . . .

\section{CHAPTER VII.}

\section{ROGER BACON versus Francis BACON.}

Albertus Magnus's Natural History-Parallelism between Roger and Francis : delusions shared by both; errors discarded by Roger; sound notions in common-Roger Bacon, one of the five greatest men of ten centuries-Roger as a mathematician, a chemist, a physicist, an astronomer-The telescope-He is the founder of the Experimental School . . . .

\section{CHAPTER VIII.}

\section{Character of the Revival.}

Duration of the Revival Period-Early emigration from Constantinople-Nicholas V. and Cosmo de'Medici-1453-Capture of Constantinople ; invention of Printing-Effects of these two events-The Classic School-Plato and Aristotle studied-The Revival delayed by the Great Schism . . . . 


\section{CHAPTER IX.}

The Scientists of the XVth and XVIth Centuries.

Mathematicians; naturalists; anatomists and physiologists ; observers; Experimentalists-Tycho Brahe, Gilbert, Harvey - Special eminence of Leonardo da Vinci and of Galileo-The latter discovers the permanency of Law; formulates the three laws of motion; reveals the immensity of the Universe with the telescope-Kepler's laws-Leonardo da Vinci's injunctions to rely upon experiment, induction, and verification - Bacon denounces these achievements and opposes his own to them .

\section{CHAPTER X.}

\section{MODERN SCIENCE.}

Difficulty of such a survey-Vastness of the subject-Classification of the Sciences by Comte ; by Spencer-First Group: Botanists, Anatomists, and Palæontologists, Physiologists, Biologists, Anthropologists, Philologists, Sociologists : their discoveries

Second Group-Geologists, Physical Geographers, and their

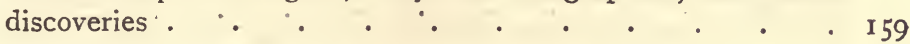

Third Group-Chemists, and their discoveries . . . . 172

Fourth Group-Mathematicians, and their discoveries . . . I9I

Fifth Group-Astronomers, and their discoveries . . . . $\quad$. 198

Sixth Group-Physicists, and their discoveries . . . . 215

Seventh Group-Eminent practical men, and their inventions . 260

\section{CHAPTER XI.}

The VAlue of Instruments.

Instruments among the ancients-They add power to the sensesImpossibility of scientific advancement without them-The telescope; the microscope; the prism; the thermometer; the compass; the pendulum; the barometer; lenses; the camera obscura; the battery; mathematics-The importance of cork, glass, etc.-Accuracy of instruments . . . . . . 266 
CHAPTER XII.

\section{Summary of Four Centuries of Science.}

I. Foundation: The XVIth century-Great discoveries-Spirit of free inquiry-Practical bent of inquirers-Formulation of the inductive process-Discovery of law.-II. Constitution: The XVIIth century - Grand laws discovered - Astronomical advance-Mathematics are extended-Laws of motionAdvance in physics - Physiology. - III. Expansion: The XVIIIth century-Great expansion of astronomy-Appearance of geology and electricity, etc.-Biology vastly extended-Steam machinery-Discovery of several physical laws-Laplace's Hypothesis. - IV. Universality the feature of the XIXth century-The age of steam, electricity, machinery, steel - Laws of light, sound-Importance of chemistry-Geology and biology-Law of evolution . . . . . . .

CHAPTER XIII.

\section{SCientific Countries.}

The four leading nations in science: Italy; France; Germany; England-Other nations-The country at the head of the scientific world : England-Natural causes of the supremacy of England

\section{CHAPTER XIV. V}

\section{GENERAL RESULTS.}

Capital importance of some discoveries and applications of scientific laws-The world transformed, both in its material and its moral aspects-The unfathomable mystery of Creation . . .

\section{CHAPTER XV.}

\section{Material Effects of Scientific Progress.}

How industry promotes social improvement-The growth of milling -Immense importance of the invention of the Water-Mill ; of the Wind-Mill; of the Steam Flour-Mill-Every industry has similar effects-Early benefactors forgotten-How pure science promotes well-being and civilisation: Physiologists; physical geographers; electricians-Division of labour multiplies the agents of production 


\section{CHAPTER XVI.}

Moral Effects of Scientific Progress.

Material welfare does not constitute the best part of civilisationPAGE Importance of political economy-Adherence to its principles promotes peace ; the improvement of the social system ; independence; democracy; liberty and order-Gunpowder led to the improvement of the governmental system-Influence of the scientific spirit on religion and religious government : a higher conception of the Creator-Disappearance of the belief in sorcery: humane government ensues-The demonstration of natural laws brings in kindly feelings-Abolition of burning and torture-Improvement of the penal code-Spirit of mendacity disappears-Rapid spread of modern philanthropy-Our debt to the XVIIIth century- "Love one another" .

APPENDIX A.

Table of Eminent Men of Science

APPENDIX AA.

Definitions of the Sciences

APPENDIX I.

ARIstotle on ExPERIENCE .

APPENDIX II.

ARISTOTLE ON INDUCTION .

APPENDIX III.

ARistotle on the Syllogism

APPENDIX IV.

LeONARDo DA Vinci's Physics - 326

APPENDIX V.

Sir David Brewster on Induction .

APPENDIX VI.

Descartes' Achievements

INDEX 
THE READER will find in

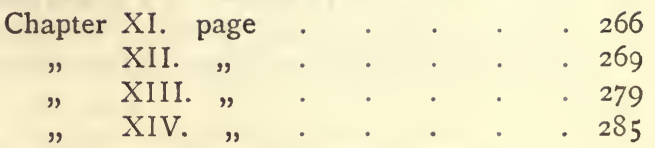

passages which give an idea of the treatment of general views.

At the end of each section (say Biology, or Geology, or Chemistry, etc.) are to be found brief remarks of historical and philosophical importance.

The march of a science can be traced from beginning to end in the successive notices of its promoters. The whole progress of Electricity, for instance, can be found in the notices on

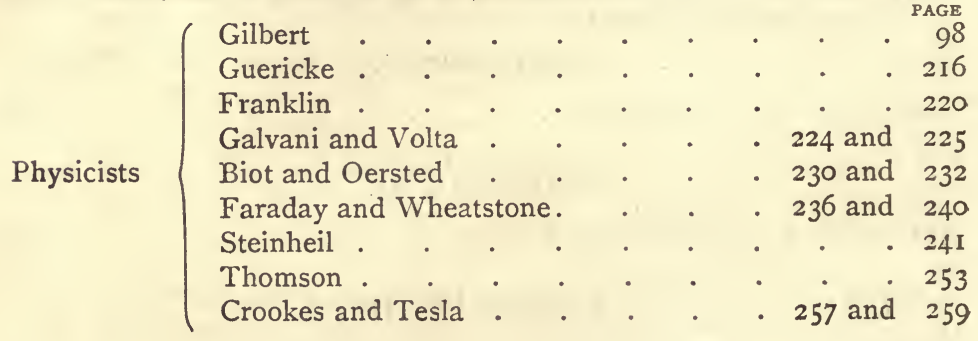




\section{AUTHORS CONSULTED.}

Аввотт

AGASSIZ

AIRY

Allen, Grant

AMPÈRE

ANTHROPOLOGICAL JOURNAL.

ARAGO

ARGYLL

ARISTOTLE

Asa Gray

BABBAGE

BACON, ROGER

BACON, FrañCIS .

BADEN-POWELL

BALFOUR, F. M. . BALFOUR STEWART BALL

BeAle, Lionel . BECCARIA. BECKMANN . . History of Inventions.

BenNetT - . . . Text-Book of Physiology. BERNARD . . . Leçons de Physiologie Expérimentale.
Biographies of Scientific Men. Eloge de Laplace. Eloge de Fresnel. Vie et Travaux de Herschel.

- Reign of Law.

- Works.

- Botany.

- Ninth Bridgewater Treatise.

- Opus Majus. Opus Tertium. De Mir. Pot.

- Works (Spedding-Ellis Edition).

- History of Natural Philosophy. The Unity of Worlds and of Nature.

- Treatise of Comparative Embryology.

- On Heat. Lessons in Elementary Physics. A Short History of Mathematics. Experimental Mechanics.

- On Protoplasm.

Dei Delitti e delle Pene.

E (Nouvelle). 
BLACK .

BLUMENBACH

BOOLE .

BOUILLET

BRANDE

BREWSTER

BUCKLE

BUCKLEY

BUCKNER

BUFFON

BURN.

Carpenter.

Cato

CHURCH, R. W.

Clarke

Clerk Maxwell CLIFFORD

ComTe .

CONDORCET .

COOKE .

COPE

CROLL .

Cuvier.

CYCLOPAEDIA

CYCLOPEDIA

DalToN

DARWIN

DAVIES, BARNARD

Davy

DE MAISTRE

DESCARTES

D'ORBIGNY

DRAPER

DRINKWATER

DUNCAN

DUPUIS.
Elements of Chemistry.

- System of Comparative Anatomy. Skulls of All Nations.

Laws of Thought.

- Dictionnaire des Arts et des Sciences.

- Manual of Chemistry.

Martyrs of Science. Life of Newton. Optics. On New Philosophical Instruments.

History of Civilisation.

- Short History of Natural Science.

- Force and Matter.

- Histoire Naturelle. Epoques de la Nature.

- Handbook of Object Teaching.

Physiography. On the Microscope.

- De Re Rustica.

- Bacon.

A Table of Specific Gravity for Solids and Liquids.

See MAXWELL.

The Elements of Dynamics. Seeing and Thinking.

Philosophie Positive.

Progrès de l'Esprit Humain.

- Elements of Chemical Physics.

- The Origin of the Fittest.

- Climate and Time.

- Histoire des Sciences Naturelles. Révolutions du Globe. Ossements Fossiles. Théorie de la Terre.

- Lardner's.

- Rees'.

- Chemical Philosophy.

Origin of Species. Descent of Man. The Variation of Animals and Plants. Fertilisation of Orchids.

Thesaurus Craniorum.

- Works.

- Euvres.

- La Méthode.

Dictionnaire des Sciences Naturelles.

- Intellectual Development of Europe. Conflict between Religion and Science.

- Life of Galileo.

- Heroes of Science.

- Origine des Cultes. 
ENCYCLOPEDIA BRITANNICA.

ENCYClOPedia METROPOLITANA.

ElliS . . . . . Bacon's Works (Spedding Edition).

Evans . . . . Ancient Stone Implements of Great Britain.

FARADAY . . . Experimental Researches in Electricity. Various Forces of Nature.

Fawcett . . . A Manual of Political Economy.

Flourens . . . . Eloge de Cuvier.

Forbes . . . . Progress of Mathematical and Physical Science. Transit of Venus.

Foster . . . . A Text-Book of Physiology.

FRANKLIN . . . Experiments and Observations on Electricity.

GANOT . . . . Physics.

GARNET • . . . Heroes of Science.

GASSENDI . . . . Life of Copernicus.

Geikie . . . . Text-Book of Geology.

Geoffroy St. Hilairf. - Zoologie Générale.

GLADSTONE . . . . Juventus Mundi.

GOETHE . . . . Euvres Scientifiques.

Grant . . . . History of Physical Astronomy.

GRAY, ASA . . . . Botany.

Greville Williams . . Manual of Chemical Manipulation.

GROTE . . . . . History of Greece.

Guillemin . . . . The Heavens.

Guizot. . . . . La Civilisation en Europe.

HAECKEL . . . . The History of Creation.

Hallam . . . . The Middle Ages of Europe.

Hamilton . . . . Lectures on Metaphysics and Logic.

HAMY . . . . . Palæontologie Humaine.

Helvetius . . . . De l'Esprit.

Herbert Spencer . . Essays. First Principles. Principles of Psychology.

Helmholtz . . . Tonempfindungen, als Theorie der Musik. Herschel, W. . . Familiar Lectures on Scientific Subjects. A Manual of Scientific Enquiry.

HeRschel, J. . . . Outlines of Astronomy. Results of Observations at the Cape of Good Hope. Study of Natural Philosophy.

Hoefer . . . Histoire de la Physique et de la Chimie.

HofmanN . . . . On Liebig and Faraday. Introduction to Chemistry.

Howes. . . . Atlas of Practical Elementary Biology, with Preface by Prof. HuXley. 
Hutchinson . . . Extinct Monsters.

Humboldt . . . Cosmos.

Hutron . . . Theory of the Earth.

Huxley . . . . On Priestley. Hume. Physiography. Elementary Physiology. Physical Basis of Life. On Von Baer. Lectures on the Elements of Comparative Anatomy. On the Classification of Animals.

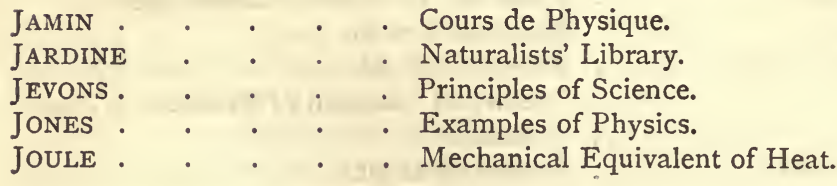

KeILL . . . . Introduction to Natural Philosophy.

KELLAND AND TAIT . . Introduction to Quaternions.

KIRCHHOFF . . . Researches on the Solar Spectrum (Roscoe's Translation).

KNox . . . . . Permanence of Race Types.

LAING . . . : . Problems of Modern Science. Modern Science and Modern Thought. Human Origins.

LAMARCK . . . Philosophie Zoologique.

LANKESTER . . . . The Advancement of Science.

LAPLACE . . . . Théorie Analytique des Probabilités. Système du Monde. Mécanique Céleste. Essai Philosophique.

LARDNER . . . . Cyclopædia.

LAVOISIER . . . . Elements of Chemistry.

LECKY . . . . History of Rationalism in Europe.

LEWES . . . . . Biographical History of Philosophy. Life of Aristotle.

LEwIS, G. C. - . . Astronomy of the Ancients.

LEWIS, J. C. . . . Heroes of Science.

LIEBig . . . . Letters on Chemistry. Introduction to the Analysis of Organic Bodies.

LOCKE . . . . . Essay Concerning Human Understanding. Lockyer, N. . . . Lessons in Elementary Astronomy. Solar Physics. The Chemistry of the Sun. The Evolution of the Heavens and the Earth. The Movements of the Earth. Outlines of Physiography. The Meteoric Hypothesis.

LubBock . . . . Prehistoric Times. Scientific Lectures. Fifty Years of Science. Origin and Metamorphosis of Insects. Ants, Bees, and Wasps. 
LUCRETIUS

LUPTON

LYELL .

MACAULAY

MARSH .

MAYER, A. M.

MAURY .

MAXWELL, CLERK

MEYER, E. VON .

Mill, Stuart

MITCHELL .

MÖHL, VON .
De Rerum Natura.

Numerical Tables and Constants in Elementary Science.

Principles of Geology. Student's Elements of Geology. Antiquity of Man.

Essay on Bacon.

Dinocerata. Monographs.

Forces of Inorganic Nature. Sound.

Geography of the Sea.

Theory of Heat.

History of Chemistry (McGowan's Translation).

System of Logic.

Orbs of the Heavens.

Anatomy and Physiology of Plants. Principles of Anatomy and Physiology of Vegetable Cells.

\begin{tabular}{|c|c|c|}
\hline MOLloy & . & Gleanings in Science. \\
\hline MORLEY & . & Diderot and the Encyclopædists. \\
\hline MORTON & & Heroes of Science. \\
\hline MONTUCLA . & . & Histoire des Mathématiques. \\
\hline MUIR • . & . & Heroes of Science. \\
\hline MÜLLER, MAX & . & Lectures on the Science of Languages. \\
\hline MURCHISON . & . & Siluria. \\
\hline
\end{tabular}

"NATURE."

Nature (La).

NEWTON

NiCOLUCCI .

XIXTH C. REVIEW

NORMAN LOCKYER

OWEN .

- Principia.

- Skull of Etruria.

- (Number for March, I892.)

- (See Lockyer.)

Anatomy of the Great Apes. Lectures on Comparative Anatomy. British Fossil Reptiles.

PARKINSON .

PASCAL.

PEACOCK

PERRY .

Philosophical Magazine.

PLAYFAIR

- Dissertation.prefixed to the Encyclopædia Britannica.

PLINY . Natural History.

PORPHYRY . . . . Introduction to Aristotle's Categories.

PORT ROYAL . . .. Logic (Baynes' Translation).

Pouchet . . . . Les Sciences au Moyen Age. 
Powell, BADEN . . History of Natural Philosophy. The Unity of Worlds and of Nature.

PREECE

PRESTON

PRÉVOST-PARADOL

PRICHARD

Priestley

PROCTOR

\section{On the Telephone.}

Treatise on the Theory of Light.

- Histoire Universelle.

- Physical History of England.

- History of Vision. On Different Kinds of Air.

- Essay on Astronomy. The Universe. Other Worlds than Ours. Shooting Stars and Meteors. The Sun. Transit of Venus.

\begin{tabular}{|c|c|c|c|}
\hline REES • & - & • & - Cyclopædia. \\
\hline REMSEN & • & - & . The Elements of Chemistry. \\
\hline RENAN . & - & . & Averroes. \\
\hline RODWELL, & G. F. & • & Birth of Chemistry. Dictionary of Science. \\
\hline ROMANES & - & • & Scientific Evidences of Organic Evolution. \\
\hline RoscoE & . & • & Spectrum Analysis. \\
\hline ROSSITER & • & • & Physics. \\
\hline RUMFORD & - & • & Essays. \\
\hline
\end{tabular}

St. Hilaire, Geoffroy SCROPE.

\section{SENECA}

SISMONDI

SMILES .

SMITH, ADAM

Smith, PIAZZI

SPEDDING

Spencer, Herbert

SPRENGEL

Stewart, Balfour

STEWART AND GEE

STUART MILL
- Zoologie Générale.

Volcanoes.

- Quæstionum Naturalium Libri Septem.

History of Southern Literature.

- Lives of Boulton and Watt.

- The Wealth of Nations.

- The Great Pyramid.

- Bacon's Works.

- See Herbert Spencer.

- Histoire de la Médecine.

- On Heat. Lessons in Elementary Physics.

Lessons in Elementary Practical Physics.

See Mill.

TAIT . . . . Heat.

TAYLOR . . . . Sound and Music.

Thomson, DR. . . . Outlines of the Necessary Laws of Thought.

Thomson, J. J. . - . A Treatise on the Motion of Vortex Rings. Thomson, Sir W. . . Electrostatics and Magnetism. Popular Lectures and Addresses.

TODHUNTER.

A History of the Mathematical Theory of Probability.

TYLOR . 
TyNDall

VENTURI

WRIGHT

WALLACE

WATTS .

WHEWELL

Williams, Greville.

WOLLASTON.

XENOPHON . . . . Economics.

Young . . . . Lectures on Natural Philosophy.
- Natural Philosophy. On Light. On Sound. Half-hours with Modern Scientists. Heat a Mode of Motion. Faraday as a Discoverer. The Glaciers of the Alps.

- Ouvrages Physico-Mathématiques de Leonardo da Vinci.

Ice Age in North America.

- Natural Selection. Darwinism. Island Life.

Dictionary of Chemistry.

. History of Inductive Sciences.

- Manual of Chemical Manipulation.

- On Dispersion. 


\section{ERRATA.}

Page 37, line 21, for auric chloride

(aqua regia, $A$ ) read auric chloride, aqua regia, $R$.

$$
\begin{aligned}
& \text { "38, , 2, " cupel " cupels. } \\
& \text { " 70, " I, „, CanterburyTales , The Canterbury Tales. } \\
& " \quad " 22, " \text { If they } \quad \text { If the alchemists. } \\
& \text { " 80, " } 24 \text {, " give gave. } \\
& \text { " I29, „ 6, „ membrance " membrane. } \\
& \text { " I47, " 2I, „, points " point. } \\
& \text { " I58, " 7, " of Socialism " to Socialism. } \\
& \text { " I76, " 3, "Manganese " dioxide of Manganese. } \\
& \text { " " } " 4 \text {, metal mineral. } \\
& \text { " " 6, „Prussian } \quad \text { Prussic. } \\
& \text { "210, " 9, "1,21279 \# 1,21279 days. } \\
& \text { "215, "33, " earth's surface " earth's surface, at sea-level. } \\
& \text { "23I, "6, " polaroscope " polariscope. } \\
& \text { "284, "I7, " no less in letters " no less than in letters. } \\
& \text { "256, "29. Hydrogen. Note: In contradiction to the text-books }
\end{aligned}
$$




\section{INTRODUCTION.}

IMAGINE that you have been living in the depth of a narrow valley; that your view has been limited for years by the slopes of the surrounding hills; that you have never seen anything but green fields. Imagine next that, having climbed to the summit of the nearest slope, you suddenly behold an extensive horizon all around; after the monotonous valley, you wonder with delight at the magnificent prospect displayed far and wide; you count forests, rivers, lakes, villages, and cities. Charmed with the novelties afforded by so short a journey, you next ascend an elevated peak whence the prospect may be extended far away, and once there, you are struck with a sight infinitely grander: you behold on the one side ranges of mountains eternally covered with snow and lost in the clouds, whilst on the other side you behold the blue and boundless ocean, whose horizon melts with the azure sky. At this undreamt-of display you are speechless with emotion. You feel you are contemplating a divine work.

The valley pictures the elementary knowledge acquired during early youth. In that condition you can no more 
guess the utility and beauty of study than the hardships of existence. The next prospect pictures more advanced knowledge-the knowledge acquired during the years of growth up to manhood, and necessary to trace through various paths your line of conduct in life. The third prospect pictures the fathomless knowledge which science, art, and literature strive to expound, and of which, in order to know the world we live in, we all should try to get a glimpse, even if we are not destined to become experts or discoverers.

And in the fanciful picture just sketched out you have seen the terrestrial world only. If you now look up in the heavens you see the sun; night comes, you behold the moon and the stars-another world is revealed to you more incomprehensible and sublime, if possible, than the other, for you are facing infinite space, and that is "powdered with suns." This view has awakened deep thoughts. You wonder how these orbs move, and light, and warm us; and remembering the storms you have witnessed before, you wonder how the wind blows, the rain falls, the thunder roars, the lightning kills, the river swells, the ocean rolls. The eyes have discovered marvels to you, and now your mind wants to understand them. Science then steps on the scene, and explains to you the working of these wonders. And when science has unravelled to you some of the secrets of nature, you want to know by what process and by what men these secrets of nature have become known. Such an inquiry is just as full of interest as the history of humanity itself, of which it forms, in a sense, the most vital element; but it is more than interesting: it leads to moral results you were far from conceiving. For the more we realise the vastness of human knowledge, the 
better do we understand the insignificance of our persons. Instead of being engrossed with our own importance, we perceive our individual littleness, and are crushed by the immensity of the Known, the Unknown, and the Unknowable. We acquire modesty; and if we extend our survey even superficially all over the globe, and view the aggregate of men's achievements, not only do we become modest, but we plainly perceive that each civilised nation has a claim to our admiration, and that our own, if great in one or several branches, must nevertheless yield the palm of excellence to other races on different grounds. Nor do we experience new feelings of admiration and modesty simply, but our intellect, also becoming widened, learns how to contemn deeds once thought admirable, and heroes, so-called, who built their fame on the woes of mankind. We henceforth reserve the main portion of the tribute of praise and gratitude we are capable of bestowing - without, nevertheless, ceasing to acknowledge the good legitimately done to progress by the victors of Salamis, Zama, the Armada, or Waterloo-for the real benefactors of the human race, the men of science who have, in a manner at once full of devotion, loftiness, generosity, and nobleness, promoted civilisation in the field of peace towards prosperity and happiness. 


\section{Progress of Science.}

\section{CHAPTER I.}

\section{EARLY KNOWLEDGE-METHOD OF RESEARCH.}

If we imagine that into a gorgeously-decorated hall a rushlight is brought, and, being held near to some part of the wall, makes visible the pattern over a small area of it, while everything else remains in darkness ; and if, instead of thís, we imagine that electric lights turned on reveal simultaneously the whole room with its varied contents, we may form some idea of the different appearance under which Nature is contemplated by the utterly-uncultured mind and by the highly-cultured mind. Whoever duly appreciates this immense contrast will see that, rightly assimilated, science brings exaltation of mental life.

HERBERT SPENCER.

No man visits a museum without being filled with deep astonishment at the sight of the wonders of past ages. The unsurpassable works of art of ancient Greece and Rome are especially what strikes him most. His mind is at once crowded with pregnant thoughts, and his bewilderment deprives him of the power to express definite ideas, so varied, so numerous, so beautiful are the objects presented to his view. In the world of sensations he experiences, an instinctive exclamation rushes to his lips: What people those ancients were!

But whoever has entered a universal exhibition and seen the products of modern arts and industries goes away with feelings of a much more absorbing order. It is not that his admiration is aroused by the beauty of the works only, but the undreamt-of ingenuity and countless diversity, the far-reaching utility and absolute perfection of these works awaken in him 
endless impressions which for the first time, perhaps, make him conscious of the strength and greatness of human energy. Pure intellect, he feels, has conceived marvels, and unerring hands have made them realities. Science, he feels, is in possession of divine principles and laws to which human labour has given a practical application in ways so unexpected and multifarious, that imagination itself is powerless to embrace them in their aggregate. From the gigantic machinery of the factory to the delicate apparatus of the physicist, from the resistless engine of destruction to the minute instrument of surgery, every one of the ten thousand things shown reveals the presence of an enchanter-and that enchanter, the man of science. And the admirer asks: Whence comes he? Who gave him birth? Who trained him?

To this three-fold query these pages supply the answer.

This, then, is a plain inquiry. It has nothing to do with complicated theories. It deals with matter-of-fact all through and goes straight to the point. The student may read it without the fear of being led into paths unfamiliar to him, despite the many-sided aspect of the subject, for common sense puts a simple question, and common sense replies to it in the simplest manner.

The growth of scientific knowledge will be made very comprehensible and clear if we first briefly define science, and show how it originally arose. For this purpose we cannot do better than borrow the substance of what has been said on this matter by a masterly philosopher.*

Science was, and is, an extension of common knowledge, and can, by no possibility, be disconnected from it ; nor can common knowledge and science be severed from the arts. From the earliest times there was "a gradual advance from the more to the less obvious phenomena. Science does not differ from ordinary knowledge : the same faculties are employed in both cases, their mode of operation is the same. Much of our common knowledge is, so far as it goes, rigorously precise; science is only an extension of the perceptions by means of reasoning." Common knowledge then is the root of the sciences and the arts, and the distinction between the * Mr. Herbert Spencer's "Laws in General," and "Genesis of Science." 
three is purely conventional. That science and the arts are an outgrowth from the same root, Mr. Herbert Spencer demonstrates by a masterly and almost exhaustive description of man's advance. "From unmistakable evidence it is clear that the earliest mode of conveying the idea of any number of things, was by holding up the fingers-as many fingers as there were things." There are many tribes in which counting does not exceed ten-the limit of finger notation. The word digit (finger) is significant; likewise are the words cubit, span, foot, palm, inch, hand, grain, carat, orgyia, pace. The Roman numerals, one of the earliest systems of notation, were meant to represent groups of fingers. "The idea of equality--arrived at by this and other means-gave origin to two series of relations-those of magnitude and those of number, from which arose geometry and arithmetic." The simplest unit of time, the day, nature supplies ready-made. The next simplest period, the moneth or month (measurer) "was also thrown upon men's notice by the conspicuous changes constituting a lunation," etc. In this manner can the advance made be shown, not only in these branches, but in all. Such is the truth regarding the starting point of science.

A second point not less important is that the concrete led to the abstract, that is, familiarity with concrete uniformities, as Mr. Spencer so clearly puts it, has generated the abstract conception of uniformity-the conception of law. "Mental advance is necessarily from the concrete to the abstract, from the particular to the general, and, necessarily, the universal, and therefore the most simple truths are last to be discovered. When it is ascertained that the moon completes her cycle in about thirty days, it is manifest that it becomes possible to say in what number of days any specified phase of the moon will recur; and thus is quantitative prevision effected. And following in the same wake came the first known astronomical records which are those of the eclipses, etc." And the same process obtains throughout the entire cycle of knowledge.

The third truth, which it is important to remember, is that utility was the object of early inventions and science. Humboldt was the first celebrated writer who clearly detected this, but to Mr. Herbert Spencer chiefly we owe the weighty 
evidence which proves the fact to have been a universal one. "The properties of the scales and of the lever, involving the first principles in mechanics, were only generalised under the stimulus of commercial and architectural needs. To fix the times of religious festivals and agricultural operations were the motives which led to the establishment of the simpler astronomical periods, so that at first science was merely an appliance of religion and industry."

A later, but not less conspicuous instance of the same fact, we may add, is found in the reform of the Calendar (I $58 \mathrm{I}-2)$, the main object of which was the fixing afresh of the Roman Catholic feasts. "Such small knowledge of chemical relations as was involved in ancient metallurgy, was manifestly obtained in seeking how to improve tools and weapons. In the Alchemy of the later times, the intense hope of private benefit contributed to the disclosure of a certain class of uniformities." "How to fix religious festivals, when to sow, how to weigh commodities, how to measure ground, were purely practical questions out of which arose astronomy, mechanics, geometry."

We need not do more than indicate these facts; for further evidence we refer the reader to the works we have mentioned; but it is not unnecessary to remind the student that throughout the Middle Ages also, utility was the mainspring of activity among inventors and searchers. The windmill, spectacles, stained glass, glazed pottery, mirrors, oilcolours, clocks, fire-arms, the organ, paper, the compass, the violin, printing, the suction-pump, the cross-staff, mathematical symbols, the Rudolphine Tables, etc., were one and all devised to serve a useful purpose, and "the useful and the practical were the incentives" which led to them. The same fact is observable in our times. And considering the interaction of the sciences upon one another, of the arts upon one another and upon science; considering also the natural filiation of discoveries, their evolvement, that is, from one another, we plainly see that science, after springing from common knowledge and being promoted by utility, flows from science itself, and can be promoted by nothing but science, however much genius and chance may at times assist it. It is then easy to perceive that books are 
not, as many people imagine, powerful agents of scientific growth; their function and importance in that respect are completely dwarfed by the smallest discovery; their influence is quite insignificant in comparison with the establishment of the simplest scientific principle. Of this fact we shall have ample evidence in the course of this record.

Science came into existence in the East. GEOMETRy, so far as we know, seems to have originated in EGYPT-to measure each tiller's land after the yearly inundation of the Nile; Astronomy originated possibly in ChaldeA, but more probably in Egypt-to regulate the dates of religious festivals. This last science appears to have been closely, nay indissolubly, bound with Chaldran and Egyptian mythology, and seems to have been pushed very far in Egypt, since numerous sculptures and inscriptions in reference to it are to be found in every part of the Pharaohs' empire, some symbolical only, others as plainly expressed as we could expect. But to speak of few things only, the Egyptians had determined the ECLIPTIC-that is the sun's apparent course through the heavens; they had divided this course into twelve parts (corresponding to the months of the year), each being a constellation, and called the whole circle of constellations ZoDIAC (i.e. circle of animals) because each bore the name of an animal. These signs of the Zodiac are still recognised and accepted among us, although, owing to the precession of the Equinoxes, they do not agree at present with the constellations which bear the same name. The Egyptians had apparently a complete knowledge of the SOLSTICES and the EQUINOXES, and the exact time of their occurrence ; and more, they were acquainted, by centuries of continuous daily and nightly OBSERVATIONS, for the purpose of which most of the TEMPLES WERE BUILT, with the facts brought about by the precession of the Equinoxes, and the changes brought in the position of the stars by this phenomenon, although they had not discovered the precession itself. They only knew of its effects. But there is evidence that all this was only a portion-though undoubtedly the chief portion-of what they knew, as we may have occasion to show. 
The Chaldæans are justly also credited with the knowledge of these facts, and this is precisely what we should expect considering the antiquity of their civilisation. It is certain that they made original observations and discoveries. They so earnestly pursued the study of astronomy that they had ZIGGURATS (temple-observatories) in almost every important city, and from the time of Sargon I. (3800 B.C.) records of eclipses were kept. They determined the SAROS, a cycle of 223 lunations and an extremely successful attempt to predict eclipses. By calculating the saros at $6,585 \frac{1}{3}$ days, and trebling this period, they could predict eclipses to recur in the same part of the heavenly sphere and at the same hour of the day-the total error of the three saros being only 58 minutes 6 seconds. They thought comets revolved in periodic orbits - a wonderful guess. They even knew of the PHASES OF VENUS! as we learn from cuneiform tablets nearly 5,000 years old. Callisthenes (330 B.C.) transmitted to Aristotle Chaldæan observations made 2250 B.C. Want of conclusive, or sufficient collateral, evidence outside cuneiform tablets and Berosus, however, leaves us in doubt on the subject of the priority of some of their discoveries. The evidence, on the other hand, in favour of Egyptian priority is so varied and weighty; the civilisation of the Nile Valley was so complete and homogeneous some 5000 B.C., that, everything considered, Egypt seems on the whole to have been the cradle of science. When we remember that Diogenes Laertius, corroborating, no doubt, Manetho's historical record, mentions that the Egyptians had observed 373 solar and 832 lunar eclipses, and that "the ratio betwcen these two numbers exactly represents that which would be the true estimate of eclipses of some 1,200 or I,300 years," it is difficult to resist the inference just stated. This view is much strengthened by the position, orientation, measurements, and structure of the Great Pyramid, which seem to reveal extraordinary knowledge of geometry, geodesy, and astronomy, since the Egyptians had apparently measured with accuracy an arc of the terrestrial meridian, and inferred that the earth was a sphere of given dimensions.* Chaldæan

* See Proctor's work on the subject, not to speak of Piazzi Smith's. 
science was unborrowed, no doubt, but it was certainly inferior to the Egyptian, for it does not seem to have included much geometry, a branch which Egypt appears to have originated and successfully applied to practical purposes.

After reaching, as early as 3000 B.C., an extension and accuracy all but incomprehensible to us, considering the scanty means of observation and paucity of instruments the Egyptians and Chaldæans possessed, these two sciences, Geometry and Astronomy, remained stationary for ages and ages-until the Greeks became acquainted with them. A Thales (600 B.C.), a Pythagoras (530), a Hippocrates (420) would visit Egypt, and bring back to his own country the knowledge of the Egyptians; and once in the possession of the rudiments, the Greeks extended these branches of knowledge, and made them sciences worthy of the name, concurrently with the other studies they pursued. We owe to the Greeks-whether or not they drew some of their notions from the far-East, China or India, or from Egypt only-all the scientific elements which have enabled us to advance.

These elements cannot, strictly speaking, be said to have existed before Aristotle otherwise than as common knowledge, although some few phenomena were known with " rigorous precision." With Aristotle, and after him, however, the knowledge of a whole series of phenomena developed into science -that is, qualitative prevision became quantitative prevision. Yet, as the roots planted before Aristotle's time were vital roots destined to grow, it behoves us to cast a cursory glance upon the results of Greek inquiry at its earlier stage.

640-548. Thales, one of the Seven Sages, to whom we owe the famous precept, "Know Thyself," was a geometer and an astronomer. He was the first among the Greeks to determine the length of the year, to exhibit the nature of the lunar and solar motions, to give an explanation for the inequality of the days and nights in different seasons, to distinguish the four distinct divisions of the year and to discard the older division into two (solstitial) seasons only; he marked out the equinoctial periods; he stated that the moon reflects the sun's light to us; he foretold A sun's ECLIPSE (May 28, 584 B.C.) Beyond this he formulated 
several of the geometrical propositions we have in Euclid; he also taught that WATER is the origin of everything that exists-a wrong doctrine, but one, nevertheless, which proves him to have been an OBSERVER of nature.

It is probable that much of all this was Egyptian knowledge, for he is known to have visited the valley of the Nile.

610-547. Anaximander introduced the use of the GNOMON into Greece (from Egypt possibly)-which shows that he was a practical observer; invented the SUN DIALteaching the Greelss how to measure the time of day by the shadow of a rod cast by the sun; he understood the phases of the moon; made a MAP of the known world, being thereby the earliest practical geographer known to us.

566-470. Pythagoras, the famous philosopher, exhibited the spherical shape of the earth, made the assertion that the EARTH MOVES in the heavens, although he failed to see that it moves round the sun; he detected the evening star and the morning star, to be one and the same planet. $\mathrm{He}$ does not appear, as it is often asserted, to have entertained the right theory regarding our solar system, although some of his disciples (Philolaus amongst others) seem to have suspected it.* He devised the square multiplication table which bears his name; he formulated and demonstrated the famous XLVIIth proposition in Euclid, which proves him to have been a good mathematician. He might be called the FOUNDER OF GEOLOGY, for he stated that the sea-shells we find on land and in rocks were deposited by the sea, and he understood from what he had observed in Egypt the process of formation of new lands by rivers depositing mud at their mouths. As a physicist, he is said to have made a MONOCHORD, and shown how musical sounds are produced on a stretched string, in accordance with a mathematical scale.

540-500. Xenophanes asserted that the fossil impressions of animals and plants "were real remains of living creatures, and that the mountains in whose rocks they were found must at an earlier period have stood under water."

* Philolaus said : "The earth and planets move in oblique circles (or ellipses) about fire, as the sun and moon do." 
500-428. Anaxagoras, so celebrated as a religious reformer and the precursor of Socrates-teaching as he did the existence of a supreme Intelligence-was a practical astronomer of no mean degree: he declared THE MOON to be another earth like our own; detected THE MOUNTAINS and valleys of our satellite; explained that an eclipse of the sun is caused by the passage of the moon directly between us and the sun, and an eclipse of the moon by the earth's passage directly between the sun and the noon and casting its shadow on the latter. He could hardly have been the discoverer of this phenomenon, as it is asserted of him, since Thales calculated the eclipses of the sun, and the Egyptians (according to Diogenes Laertius) had observed and detected the cause of the phenomenon long since. Anaxagoras understood that the stars do not move, but that the PLANETS Jupiter, Saturn, Mars, Venus, Mercury, MOVE in the revolving heavens. He also held that meteorites are of cosmical origin.

From this point, leaving what is rather legendary than historical, or what is, in the main, Egyptian rather than European knowledge, we pass into the Greek world proper, whence we are enabled, from the reliable data in our possession, to trace with certainty the rapid progress effected in science. For, beholding, as we are able to do, the coming into existence of the method of research, from its gestation with Plato to its birth with Aristotle, we can follow the stream of development in its unbroken course from the Vth century before our era until the present day. Our scientific survey then begins with the two great philosophers.

Every one knows what Plato's deductive method of research was.

Plato ( $429-347$ B.C.), caring less for phenomena (matter, objects, facts) than for his own conceptions, would arrive after deep meditation at a certain doctrine which he deemed a universal truth or law; and, in order to prove his proposition, he would seek round him, and bring forward, a series of phenomena which would agree with it and apparently establish it. But as he left out of his purview many of the phenomena which would have upset his con- 
clusions, HIS DEDUCTIVE PROCESS was necessarily defective. By itself it could at best only become a means of metaphysical inquiry, but used conjointly with inductive reasoning, it ultimately became, and remained, an indispensable instrument of scientific logic.

Aristotle $(384-322$ B.C.) at once perceiving the insufficiency of his master's method, which left so many loopholes for error in physical inquiries, reversed Plato's process, and thereby founded the scientific method of research. This process is called the objective or INDUCTIVE METHOD. The instrument by which Plato sought to arrive at truth was Intellect, whereas Aristotle's was Experience.

In his Organon (Instrument), Aristotle expounds his scientific method, and declares it to consist in observation, experience, and induction.* These, he says, we should persistently pursue. The great inductive philosopher would examine facts, and from facts, duly ascertained, would be led to sound conclusions, and thus establish a scientific law from which other phenomena or truths could be deduced by Plato's process. He would, let us say, inquire into the nature of the sea; he would find that the Atlantic, the Mediterranean, the Adriatic, the Euxine, the Red Sea, the Persian Gulf, the Indian Ocean, were all of them salt water, and he would, after this examination, draw the conclusion that "All seas are salt." If he found a sheet of water, say in Switzerland, to be fresh water, he would conclude that it was not a sea. His chain of reasoning he called "Syllogism". $†$

The dialectical section of the Nyaya ScHool had been using the syllogism of GAUTAMA (died in 543 B.C.) for more than two centuries before Aristotle's time. Whether the Greek philosopher invented the syllogism afresh or borrowed it from the Hindu school is unknown. The latter supposition is quite possible, considering the intercourse between Persia and India $\ddagger$ on the one hand, and between Persia and Greece

* See Appendix I., II.

† See Appendix III.

¥ The Magi of Persia, whose extensive and profound knowledge of philosophy was proverbial, were not likely to have been left unacquainted with the most striking features of Hindu philosophy. 
on the other. The expedition of Alexander to India, which occurred in 327 , would be sufficient even in the absence of Callisthenes, who died early in that year, to account for the similarity of the Greek and the Hindu SyLLOGISM, for Alexander was accompanied by a whole set of learned men, and his expedition did as much to reveal Eastern knowledge as Bonaparte's Egyptian Campaign did to reveal the wonders of the Nile Valley, until then unknown to modern Europe. There is a difference between the two kinds of syllogism, but this difference is only apparent, for the Greek syllogism reduced to three the five terms of the Hindu-the two first terms of the latter being merely eliminated. The NyAYAN SyLlogism runs thus:

I. The mountain burns,

II. Because it smokes ;

III. All that burns smokes ;

IV. The mountain smokes,

V. Therefore it burns.

Remove the two first terms, and you have the Aristotelian form.

Be that as it may, Aristotle's chain of reasoning was the one which we still use, and Induction was, and is, nothing but the syllogism without a middle term. A syllogism:

All sheets of salt water are seas;

The Baltic is salt; therefore,

The Baltic is a sea.

And suppressing the middle term you have an example of induction*:

All sheets of salt water are seas;

therefore,

The Baltic is a sea.

Another example of induction :

All sheets of salt water are seas;

therefore,

The Swiss waters are not seas.

In all cases you arrive at truth, provided you have ascertained the facts.

* See Appendix II. I.

† See Appendix I. 3. 
Such, briefly, is Aristotle's inductive method-so that Aristotle will ever be regarded as the FATHER OF INDUCTIVE Philosophy.

And we must not think, as some writers do, that, having propounded a method, Aristotle thought it sufficiently good for his disciples' use, and did not put it into practice himself ; on the contrary, he did practise it as much as it lay in his power. The briefest outline is sufficient to show this :

Ancient writers record, for instance, that in Natural History, he had specimens collected from every part of the then known world, so as to deal with facts only. He had, it is also said, menageries, collections of plants and minerals of all kinds, in order to write his "Natural History" from observation. "One cannot," says Cuvier, the founder of Palæontology, "turn a page of it without deep amazement." And this statement is justified.

$\mathrm{He}$ classified nature into two classes: Organic and Inorganic-a classification retained to this day by many.

He was the founder of ZOOLOGY, and many of the divisions which he determined are accepted even now-such, for instance, as the two which he called the oviparous and the viviparous.

He foresaw the great law of Evolution: "Animals," he said, "begin where plants end, for some forms are so similar both to plants and to animals that it is impossible to determine in which division they should be classed."

$\mathrm{He}$ pointed out that a continuous chain can be traced from the lowest plant to the most developed animal-each being separated from the next "by almost imperceptible differences." The idea of gradual growth and development from low to high organisms, is, if not expressed in these terms, at least implied in his pregnant exposition of natural history. He based his classification of animals upon their organs and the manner in which these organs are used.

In Physiology, few facts were left untouched by him, and he frequently guessed the real process of nature, as our own XIXth century scientists acknowledge. He discussed and rejected the spontaneous generation theory, and believed in that of Epigenesis (germs the spring of life), which he defended with great power. 
In Psychology, he laid his finger on the secret of the question-regarding this science as a branch of Physiologyjust what our most advanced men of science proclaim it to be. He saw the law of association of ideas: "Ideas," says he, "by having been together acquire a power of recalling one another; or every partial representation awakes the total representation of which it had been a part."-(De Anima.)

In Astronomy he was so practical that he made observations himself - for he mentions an occultation of Mars by the moon, and another of a star in Gemini by Jupiter. "From the rare occurrence of such phenomena, their observation shows that he paid considerable attention to the planetary motions." He was the first plainly to intimate that the earth is a round globe; and he rectified and completed the discoveries of Eudoxus-an evidence of the importance he attached to verification.

In PHysics he was the expounder of ancient knowledge. The ancients had undoubtedly made great advances in physics, since we find they used glass globes filled with water "for concentrating the rays of the sun, and thus producing fire." The refraction of heat was well known to them, since Aristophanes, in the Clouds, alludes to the use of a glass lens for obtaining fire. (Dialogue between Strep. siades and Socrates, beginning with

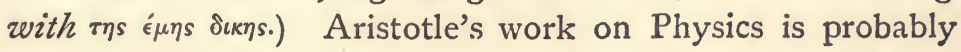
much mutilated, but it contains sound facts as it stands. If he was not always accurate in his explanations, he nevertheless argued with wisdom on Meteorology, Mechanics, Mathematics, Astronomy, Chemistry, Geology, etc., if we may, for brevity, place these branches under one heading. Doubtless he is often weak by the light of Galileo and Newton, but the world took twenty centuries to produce these two physicists, and although Aristotle's Physics may be considered inferior to some of his other writings, yet it is a beautiful work, and one which is justly regarded as fundamental.

$\mathrm{He}$ also wrote, and wrote with rare insight and force, on Metaphysics, Ethics, Theology, Cosmogony, Art, Poetry, and Politics. In this last branch he was not content, like 
Plato and Bacon, to build up a perfect State from his own imagination, but he, on the contrary, made himself acquainted with the history and institutions of the nations which had come into contact with the Greeks up to his time, and he was able thereby to sketch one hundred and fifty-eight Constitutions - a most practical work for politicians and students - far more serviceable than the "Republic" of Plato or the "New Atlantis" of Bacon.

If Aristotle made many mistakes, and even failed to apply his own method as rigorously as he might have done, he none the less left gigantic work behind him; and whatever may be said of him, he is recognised, by all lovers of truth, as the FOUNDER OF SCIENCE and Inductive Philosophy. He left on the one hand a "Cyclopædia of Science," and on the other hand, an instrument of research - Induction. "He made men aware of the permanent importance of fact, and he taught them to seek explanations of phenomena by the objective method." It is men's business to use that immortal creation-induction-rightly. 


\section{CHAPTER II.}

SCIENCE IN ANTIQUITY.

IN spite of Aristotle's stupendous intellect, science in antiquity could not possibly develop and find applications as it did in modern days. And without digressing, we may take note of the important fact that notwithstanding the immense and valuable discoveries of the XVIth century, it is only within the last sixty or eighty years that science has made such unexampled and rapid advance. Much of the recent progress flows from the application of steam to machinery, by means of which innumerable instruments have been either invented or improved, and brought into common use-all, in their turn, assisting in further scientific development. And this in the course of less than a lifetime. To resume.

In antiquity there existed insuperable drawbacks to the advance of science and industry, and amongst others :

I. WANT OF MATHEMATICS - for despite great men such as Euclid, Archimedes, Eratosthenes, and Hipparchus, knowledge, in this branch of science, was limited: Dynamics and Algebra in its higher application came into use after Galileo only, and many new methods were invented in modern times.

II. WANT OF INSTRUMENTS-for apart from the gnomon, the armillary spheres, the quadrant, the planetarium, the dioptra, and the astrolabe, the few other ones which may have existed were insignificant.

III. Slavery deprived the ancient world of the modern 
stimulus to industry - viz., individual and independent ambition and welfare; for slaves had no end in view, not even the bringing up of a family; and they made machinery unnecessary, because they were cheaper than machinery. Slavery, therefore, limited the means of production, and closed the road to competition and mechanical improvements.

IV. On the other hand the universal CONTEMPT in which slavery was held deterred free men from entering the industrial and commercial career which was almost exclusively the pursuit of slaves, and which alone could at one and the same time conduce to the development of wealth, raise the status of civilisation, and lead to that stimulation necessary for the creation of new means of progress in the field of applied science. So long as trade and industry, together with manual labour, were considered as beneath the dignity of free men, practical advancement was well-nigh impossible.

V. The mildness of the CLIMATE in which early civilisation flourished restricted the necessaries of life-and this was a permanent cause of stagnation - for utility was a much weaker incentive of inventions and science than in northern regions.

VI. PRECONCEIVED THEORIES constituted another drawback-for science is very frequently the outcome of practical and physical manual work, and there were relatively too few trades and industries for them to induce scientific researches and lead to many scientific results. Compare theory and practice: Alchemy, for instance, sought the philosopher's stone and the elixir of life and failed; but on its way, through and out of the processes of manipulation it necessitated, it accidentally made many useful discoveries, and finally paved the way to Chemistry. In antiquity the absence of manipulation or the workshop was a bar to the disappearance of the theoretical conceptions which stood in the way.

VII. MATERIAL SUBSTANCES naturally also play an important part in the progress of scientific theories and their application: without glass, for instance, we could have no astronomical nor physiological instruments, hence neither astronomy nor physiology; without coal and iron, the law 
of elasticity of gases would be a mere toy, instead of having led to the construction of steam-engines, steamships, and railways. Many of the substances familiar to us were unknown to the ancients.

VIII. The POLITICAL ECONOMY of the old world was limited to the development of agriculture (mostly by slavelabour). The best and most practical minds, Xenophon and Cato, discountenanced and despised industry and commerce. Capital, where it existed, was either applied to usury, or dissolved in the gratification of sensual enjoyment; so that industry, commerce, capital, the three greatest springs of social progress, were practically non-existent.

When we bear in mind that tools are necessary to construct machines, and machines are necessary to probe the earth, and that in addition to the immense drawbacks just enumerated, the ancients had no machinery to speak of and scarcely any tools, we can at once understand what little progress could be made, how slowly that little progress could be effected, and how easily it was arrested-arrested, that is, in its infancy by the ruthless invasion of the Barbarians and the break-up of the Roman rule.

It is almost a truism to say that the underground resources of the earth, the workshop, the Physicist's room, and the Chemist's laboratory must of necessity be kept in continual connection and INTERCOURSE with one another in order that scientific progress may be effected. These act and react upon one another just as much and in the same manner as pure science and application of science act and react upon each other. From those elements and their reciprocal effects scientific evolution necessarily follows.

Furthermore, and this is of equal importance, in order that improvements should be fruitful and durable, supply a multitude of wants, give enjoyable affluence to peoples, and thus conduce to the establishment of social order and social welfare, and hence to that intellectual maturity which breeds science, there must exist INTERCOMMUNICATION among nations; more, the means of communication are equally indispensable to conquer, and act upon, NatureNature having, for our good, unequally distributed that 
which man requires to feed, to clothe, and to house himself, and which TRADE, or Exchange in its broadest sense and working, can alone distribute evenly.

EXCHANGE rests on foundations absolutely needful, such as-

I. MEANS OF TRANSPORT-from the canoe and cart to the steamship and railway.

II. DURATION or perpetuation OF IDEAS and their spread-which had, and still has, to be secured by writing, the plastic arts, printing, the telegraph, and so forth.

III. The TRANSFORMATION OF THE EARTH to the requirements of man - such as the draining and drying of marshy land, the clearing of a forest, the digging of canals for irrigation, the cutting of roads, and so on-which can only be achieved by the labour, inventions, trades, industries, and arts of generations.

IV. The PHYSICAL AND MORAL HEALTH of humanity - to be ensured by hygiene, medical science, education, and practical morality.

V. The FREE AND ORDERLY INTERCOURSE of all classes with one another in their own country, and of all nations with one another throughout the globe - an end obtained by political development, international law, and social science.

It is clear that all these elements demanded ages upon ages for their birth and growth, and, to make the ancients responsible for their non-appearance in the Greek or Roman world, is equivalent to making them responsible, and reproaching them, for having been our juniors by two thousand years, or for having failed to find out what required two thousand years to discover.

The ancients, far as they were from the point we have now reached, have nevertheless achieved wonderful work, even if we limit our estimate of it by the partial and fragmentary records of their knowledge in our possession. No doubt but they knew vastly more than we give them credit for; but restricted to these limits, the advance they made was so astonishing that we can never be tired of praising them. To their ability, originality, and genius we can but yield the amplest tribute of admiration. 


\section{CHAPTER III.}

\section{PROGRESS IN ANTIQUITY.}

THE first group of scientific facts to be recorded refers to the Greeks after Aristotle's time, and will include only those of primary importance. The briefest outline is imposed upon us by the limits of our sketch.

After the fall of Athens from political greatness, Alexandria, under the strong rule of the Ptolemies (323-43 B.C.), became the centre of learning, and Greek philosophers gathered there from all parts to enjoy the generous and enlightened protection of those princes. For two hundred years after the disappearance of their dynasty, the Alexandrian Museum,* which they had erected, remained the seat of science, so that the school of Alexandria flourished for more than five hundred years as a scientific centre. No city was ever so exclusively the seat of Intellect as the Egyptian capital: for pure philosophy continued to be taught there until 4I5 A.D.-for two centuries, that is, after science had come to be considered of secondary importance. Nor did its influence stop when it ceased to be the abode of learned men: its teachings remained for another thousand years the paramount principles of intellectual growth in the worldhence historians justly mention Alexandria as the city which has exercised the most lengthy and beneficial influence over civilisation.

We have already seen that knowledge, before Aristotle's time, was assuming a scientific aspect; as we approach his

* This Museum was a group of palatial buildings four or five times as extensive as Buckingham Palace. 
period we find this to be more decidedly the case than before; but only when his powerful influence takes effect upon his disciples and followers do we find science grounded upon firm foundations. The reason of his influence lay, as we have seen, in the imposing work he performed, and we shall see in the course of the present survey that this vital work of his was of a nature to evolve, necessarily, a long series of fruitful results. The right method had at last come into existence.

460-357. Democritus made two assertions, no doubt due to profound observation and meditation, which modern science has demonstrated to be well founded, viz.- that the MrLKY WAY is an immense conglomeration of stars, and that the Universe is built up by conglomerations of atoms. The latter doctrine had been held in India by the Nyaya school of philosophers founded by Canade. Whether Democritus derived his notion from the Hindu ATOMIC SYSTEM is quite possible, considering that the Persian empire stretched as far as the Indus, and that glimpses of Hindu philosophy may have reached the Greeks through Persia. The Magi were likely to be well acquainted with neighbouring philosophies.

460-357. Hippocrates, the most famous physician of antiquity, and the FATHER OF MEDICINE, destroyed the theological theory of disease, which consisted in the doctrine that every sickness was due to the anger of an offended Goda theory revived in our Middle Ages. He taught that disease arises from natural causes. This was the great principle which caused him to be considered as the founder of scientific medicine. His Aphorisms, or Maxims, embody his immense experience of pathology and therapeutics. They have been a guide to generations of physicians, on account of their profound wisdom and truth.

432 B.C. Meton having observed that 235 lunar months correspond closely to I9 solar years, introduced (in 432) the METONIC PERIOD* - a cycle of I9 YEARS, by which he adjusted the calendar with the course of the sun and moon.

* This cycle, intended to associate lunations with the year, was known to the Chinese long before Meton. It is still in use in our almanacs; the Golden Number (used to find Easter) is calculated in reference to it. 
406-366. Eudoxus, who had built an observatory at Cnidos, was the first to enunciate the REGULARITY of MOTION of the planets in the heavenly sphere, thereby explaining their periodic reappearance in the same place, and to make a map of the known stars. It is probable, however, that this knowledge had been in the possession of the Chaldæans and the Egyptians for many centuries; but the fact that he had an observatory is full of significance.

362-287. Theophrastus composed a history of Stones and a history of Plants; another work, called "On the Cause of Plants," on gardening and farming, is one of the most practical ever written-combining, as it does, pure science with applied knowledge. It remained a text-book until modern botany came into existence. Theophrastus must be recognised as the FOUNDER OF BOTANY. His descriptions embraced 500 different species of plants, which are grouped or divided into herbs, shrubs, and trees-a very misleading CLASSIFICATION, but a most creditable attempt, nevertheless, being based as it was upon direct observation. He was the first to record the discovery of fossil bones and ivory-this being the earliest gleam of Palæontology after Aristotle; but two thousand years will pass away before this science is born.

330. Calippus corrected the Metonic cycle (which caused an error of one day in $3 \mathrm{I} 7$ years) by establishing (in 330) the CALIPPIC PERIOD of 940 lunations-a cycle of 76 years minus one day. These cycles were intended also to be cycles of eclipses, but they were only approximate in this respect. Calippus assisted Aristotle in correcting Eudoxus's discoveries. This affords another proof of the practical influence of Aristotle and of his method of verification.

330. Berosus invented the HEMISPHERE, one of the most ancient instruments next to the gnomon and the dioptra.

323-285. Herophilus, a worthy successor of Hippocrates, ascribed the pulse to the CONTRACTION OF THE HEART ; was the first to recognise the importance of carefully noting three things in the PULSE-the strength, the quickness, and the regularity of its beats. $\mathrm{He}$ was aware of the existence of the lacteals, and their relation to the 
mesenteric glands; traced the tendons, the ligaments, and THE NERVES. Many of the names used by him and Erasistratus are still accepted; advanced anatomy and physiology through his pursuit of dissection and vivisection of animals and human bodies. ANATOMY, with and after him, became the basis of medical teaching. The school of medicine he and Erasistratus founded was famed for nearly 700 years.

323-283. Euclid compiled his book on GEOMETRY-a standard work to this day. He taught that light travels in straight lines called "rays."

300-26o. Erasistratus, who, like Herophilus, was a worthy follower of Hippocrates, was a great anatomist. He described THE BRAIN and its division into two partsthe cerebrum and the cerebellum-and pointed out its circumvolutions. He described the STRUCTURE OF THE HEART, and discovered it to be the fountain-head of arteries and veins; recognised TWO KINDS OF NERVES, those of motion and those of sensation, and their connection with the brain, apparently understanding the brain to be the thinking and feeling apparatus.

287-212. Archimedes, a mathematical and inventive genius of the highest order, exceeded by none, possessing at once marvellous originality of conception and immense working power, discovered new provinces of inquiry. $\mathrm{He}$ showed "how mathematical theory could be wedded to physical experiments." His works are the application of Aristotle's inductive process in a new field, if they do not constitute by themselves the first true organum, as some writers would have it. He measured the SPHERE, the CYLINDER; discovered the LAW OF THE LEVER-the primary law of mechanics and the base of STATICS; he invented a planetarium representing the movements of the heavenly bodies; he invented, I, the SPIRAL-PUMP (also called water-screw, screw of Archimedes, and cochlea); 2, CONCENTRIC MIRRORS ; 3, POWERFUL LIFTS ; 4, GIGANTIC CATAPULTS. The three last inventions were, if we are to believe Roman writers, used with tremendous effects against the Romans who were besieging Syracuse. He founded 
HYDROSTATICS by the discovery of the principle which bears his name: " $A$ body immersed in a liquid loses a part of its weight equal to the weight of the displaced liquid." "This law is the basis among other things of the calculations in shipbuilding. And the same principle is true for bodies in air; so that Archimedes made the first successful attempt to measure the SPECIFIC GRAVITY of different substances.

285-222. Hero (of Alexandria), one of the great mathematicians of the time, made several mechanical inventions, one of which was the pneumatic experiment called HERO'S FOUNTAIN, in which a jet of water is maintained by condensed air; another, a STEAM-ENGINE-the reaction machine (the Eolipile), of which we have the description; also a double forcing pump used for a FIRE-ENGINE.

280-264. Aristarchus (of Samos) attempted to measure the distance from the earth to the sun and to the moon by a most ingenious method (dichotomy); measured the magnitude of the sun's diameter; calculated the year to be 365 days 6 hours; held the HELIOCENTRIC DOCTRINE (also ascribed to Pythagoras and Philolaus), teaching that it was the earth, not the sun, which travelled round the ecliptic. He understood that the position of the earth from pole to pole is sloping, that is, oblique, to the ecliptic, and that this OBLIQUITY causes the four seasons of the year. He apparently was the first among the Greeks who clearly understood that the change from day to night, and from night to day, is due to the turning of the earth on its axis in 24 hours.

276-196. Eratosthenes made use of the solstitial and equinoctial ARMILS (armillary spheres) which he invented, or received from Ptolemy Euergetes, by means of which he determined the distance between the tropics to be equivalent to $47^{\circ} 42^{\prime} 39^{\prime \prime}$, half of which gives $23^{\circ} 5^{\prime} \mathrm{I}^{\prime} 19^{\prime \prime} \cdot 5$ for the OBLIQUITY OF THE ECLIPTIC. (In 1870 it was calculated to be $23^{\circ} 27^{\prime} 22^{\prime \prime} \cdot 3$ - and is continually diminishing-the rate of decrease having been some twenty minutes per thousand years.) We need hardly point out the great importance of this discovery. Further, by his innovations, Eratosthenes may be considered as the FATHER OF GEOGRAPHY. He constructed a map of the known world; described Libya, Asia, Europe; 
and was the earliest to lay down the FIRST PARALLEL OF LATITUDE (the 36 th), after due observation of the identical duration of daylight ( $14 \% \frac{1}{2}$ hours) on the longest day in the year, from the Columns of Hercules (Gibraltar) to the Hindu Kush. He attempted to measure the MAGNITUDE OF THE EARTH by means of this parallel and the use of the gnomon; from Alexandria to Syene (now called Assouan), which lay exactly south, he drew at right angles to his parallel a straight line which would necessarily pass at the poles; and having ascertained the distance between the two cities (5,000 stadia $=625 \mathrm{miles}$ ), and convinced himself (from the gnomon casting no shadow whatever at Syene on the summer solstice) that Syene was exactly under the sun at noon on that day, he measured the angle of the shadow cast by the gnomon at Alexandria on the same day of the year at midday, and finding it to be the fiftieth part of a circle, he easily found the magnitude of the circumference $(625 \times 50=31,250 \mathrm{miles})$. If the result was incorrect, and such as a rough attempt could be expected to give, the method was admirable and original. $\mathrm{He}$ also studied other geographical problems, such as the direction of mountain ranges, the shape of continents, and the way in which the clouds carry rain. According to some writers, he catalogued 675 fixed stars, and tried to ascertain the distance from the sun and the moon to the earth.

250-220. Ctesibius invented the pump and other hydraulic instruments; perfected the CLEPSYDRA (waterclock) by applying toothed-wheels to it.

250-220. Apollonius of Perga solved the problems of the stations and retrogressions of the planets by means of EPICYCLES and deferents, and next to Hipparchus formed the alliance between Geometry and Astronomy.

I60-I45. Hipparchus, the REAL FOUNDER of astro. nomical science, and the scientific genius of antiquity par excellence, I, verified the determination of the OBLIQUITY of the ecliptic of Eratosthenes-the earliest attempt at an exact determination of the "constants" of nature; 2 , found the length of the TROPICAL YEAR within I2 seconds, making it 365 days 5 hours 49 minutes; 3 , discovered the eccentricity of the solar orbit; 4 , fixed the position of the line of the 
Apsides; 5, formed the earliest Tables of the Sun, and calculated with accuracy when lunar and solar eclipses would occur; 6, determined the period of the moon's revolution, relatively to the stars, to the sun, to her own nodes, and to her apogee-determinations which furnish one of the most delicate tests of the truth of Newton's law of gravitation ; 7, determined the eccentricity of the lunar orbit and its inclination to the plane of the ecliptic ; formed Lunar Tables (and is therefore the discoverer of the mode of constructing solar and lunar tables); 8, approximated to the parallax of the moon; 9 , catalogued I,080 stars, and showed how they are situated and grouped with relation to the ecliptic; Io, invented the planisphere or mode of representing the starry heavens upon a plane, and of producing the solutions of problems of spherical astronomy; II, devised the application of parallax to determine the distances of celestial bodies; I2, demonstrated the methods of calculating triangles, whether rectilineal or spherical - which may be considered as the beginning of Trigonometry; I3, had the happy idea, for assisting Geography, of fixing the positions of spots on the earth by means of the latitudes and longitudes-completing thereby Eratosthenes's Geography; I4, was the first who determined the longitude by the eclipses of the moon; I5, constructed a TABLE OF CHORDS, of which he made the same use as we make of our sines; I6, made use of the dioptra, and invented the parallelic instrument and the ASTROLABE; I7, discovered the PRECESSION OF THE EQUINOXES-a gradual change in the position of the nodes (intersecting points) of the earth's equator on the ecliptic. The nature of this change is such that the nodes of the celestial equator on the ecliptic-in other words, "the first points of Aries and Libra are continually travelling along the ecliptic in a direction contrary to the order of the signs." The intersection this year, for instance, occurs at a point just before last year's point (hence the name of precession), and occurs more to the west every year by $50^{\prime \prime} \cdot 21$; so that the nodes shift retrogressively one degree in $71^{\circ} 6$ years-a complete revolution of the nodes being accomplished in 25,866 years. This is one of the most important discoveries in the world of science, and 
to our thinking the most marvellous feat of scientific genius ever performed. It was reserved to Newton to show the cause of this phenomenon. 18, Hipparchus is said by some authors to have also understood and explained our SOLAR SYSTEM-i.e. the heliocentric theory, revived and demonstrated by Copernicus. It is probable that he thought like Aristarchus on the subject.

I35-5I. Posidonius measured a degree; and, having observed the intervals between successive high TIDES to be equal to the intervals between the moon's passage across the meridian, correctly ascribed the Tides to be due to the motions of the sun and the moon. Pliny, who came to the same conclusion, and who stated it, only recorded or repeated what Posidonius had observed.

I00-45. Sosigenes, under the direction of Julius Caesar, reformed the Roman Calendar, and devised the JULIAN CALENDAR (45 B.C.-I 58 I-2 A.D.)

B.C. $54-24$ A.D. Strabo was a traveller and geographer; he described all he saw with remarkable accuracy; studied VOLCANOES and earthquakes; pointed out that these phenomena are caused by the hot vapour hidden within the earth ; that when the vapour and lava can find a valve of escape as they do in the Etna, the crust of the earth is not disturbed; but when they cannot escape they cause shocks and earthquakes.

B.C. 5-65 A.D. Seneca asserted that comets would be found to revolve in PERIODIC ORBITS and return to sightthe Chaldæans and the Pythagorians (if not Pythagoras himself) entertained a like opinion. He knew that the tails of comets are driven away from the sun; and like Anaxagoras thought Meteorites must be cosmical bodies.

I00-I6I A.D. Ptolemy discovered the EVECTION OF THE MOON; determined the moon's parallax, and made several other discoveries of secondary importance relating to the motions of the moon and the planets; invented the stereographic projection and the quadrant. His SyNTAXIS contains the roots of most of the methods in use among us. He made a regular system of astronomy based upon all the knowledge the Greeks had acquired about the heavenly bodies, and this system was accepted for 1,400 years-until Copernicus. His 
Geography was also taught for fourteen centuries. He drew maps of all the parts of the known world, including BRITAIN (Albion), of which he traced the rivers and coast-lines, laying on these maps the lines of latitude and longitude calculated afresh by the rules of Eratosthenes; but the longitudes are very inaccurate, a defect due no doubt to the uncertainty which existed as regards the shape and magnitude of the earth. His catalogue of fixed stars does not exceed 1,022 -fewer, that is, than the catalogue of Hipparchus.

I 30-200 A.D. Galen experimentally proved what Erasistratus had already intimated-viz., that the nerves and the BRAIN are connected, and that the latter is the CENTRE OF FEELING or sensation. This was the only discovery worth mentioning he made. His pathology and therapeutics which summed up the medical knowledge of antiquity, mixed with much that was imaginary, were the guides from which physicians-until Paracelsus and Vesalius-dared not deviate, so great was his authority. Vesalius (I5I4-I564) proved that Galen had not dissected the human body, and had described it only from the dissection of animals.

We leave on one side mathematicians such as Pappus and others, great masters though they were.

The Alexandrian Museum, founded by Ptolemy Philadelphus (285-247), included Collections, Menageries, Observatories, besides its four Faculties of Literature, Mathematics, Astronomy, and Medicine-the last including the subFaculty of Natural History.

The Temple of Serapis (called also the SERAPION) was used as an hospital where the sick were tended, and the persons studying Medicine became familiar with diseases and their treatment. Surgery and Pharmacy received many improvements there.*

Such are in the main the achievements of the Greeks in antiquity. The foregoing table enables us to appreciate the value of the oft-repeated assertion that up to Harvey no progress to speak of had been made in the arts and sciences since Aristotle.

* For a more adequate presentment of Greek science, see Herbert Spencer's " Genesis of Science," and Whewell's "Physical Science." 


\section{CHAPTER IV.}

PROGRESS AMONG THE ARABS.

\section{(From the IXth to the XVth Century.)}

THE next group of scientific facts belongs to the Arabian period. Science had migrated to Persia after 4I 5 A.D., when Bishop Cyril caused the destruction of the Alexandrian Museum. The Greek men of science, Nestorian and Jewish, escaped death at the hands of the fanatical Christians by flight, and carried away with them the sciences of which they were the teachers. Protected by the Persian kings, science survived the Alexandria catastrophe, and the Persians became its custodians for two centuries-until they were overcome by the Moslem conquerors, the Arabs (64I). The Arabs, their cycle of conquest over, assimilated the Greek learning flourishing in Persia, and in their turn became the representatives, guardians, and teachers of ancient knowledge. Civilisation, or what was of great value in the Greek world, was not dead; it had gyrated; and the Arabs, having received science from the ancients, gave to every branch of it an accuracy and enlargement at once unforeseen and substantial. The following sketch will enable us to see that their triumphs in philosophy, mathematics, astronomy, chemistry, and medicine were both glorious and durable.

In order, however, fully to understand the part which the Arabs have played in the progress of mankind, it is necessary to see what sort of civilisation theirs was-and this necessitates a short description. A similar description was not 
needed in the case of the Greeks, because we all know by what our training, books, museums bring every day to our minds, that our civilisation is partly Greek. The monuments of art, literature, and philosophy which we possess make the Greek world familiar to us. It is not so with regard to the Arabs. Very few people are aware of the grandeur and beautyof their social state in the six centuries during which they stood in advance of the whole world. Our European historians, actuated no doubt by national pride and religious prejudice, have systematically kept out of sight both their magnificent civilisation, and our immense obligations to them. A few writers only, especially Sismondi, Pouchet, Draper, and Renan, have done them justice. It is therefore needful to sketch out what is unfamiliar to most readers.

The Arabian race is gifted with an INTELLECT which, under proper direction and cultivation, yields the most admirable effects. A general fact shows this very forcibly. It took the Greeks six centuries, the Romans seven, ourselves ten, to emerge from barbarism into civilisation; the Arabs' transition did not exceed one hundred years-a phenomenon which speaks volumes with respect to their natural gifts.

The POLICY of the Khalifs and Emirs of Islam was inspired by the two fine maxims of Ali, Mohammed's son-inlaw: "Eminence in science is the highest of honours;" " $\mathrm{He}$ dies not who gives life to learning;" and this liberal policy prevailed for centuries from the Oxus to the Pyrenees. To speak of one instance, AL MANSOR had no less than six thousand learned men at his court. In contrast with this, and during the best part of a thousand years, Christendom was more or less overshadowed by monkish theology, and the Church persecuted learning, regarding it as the work of Satan.

The CITIES which flourished throughout Islam were towns comparable in almost every point with our own in the present day. Samarcand, BAGDAD, Ispahan, Damascus, Bassora, Morocco, Fez, Seville, GranadA, Toledo, Cordova, as well as the towns in Sicily, were, outside the Arabian empire, unrivalled for beauty, luxury, and comfort. To every mosque a school was attached, and in each town besides there were 
either academies, or colleges, or universities. Bagdad exhibited every kind of magnificence. One of its palaces was furnished with 38,500 pieces of carpet, I2,500 of which were of gold brocade. Cordova, which almost rivalled Bagdad, counted two hundred thousand houses, one million of inhabitants, a hundred public baths, nearly as many HOSPITALS ; a man could walk for ten miles of streets in a straight line; the streets were PAVED, AND LIGHTED throughout the night by lamps. In Europe, there was not a city, properly socalled, except Constantinople, which was not vastly inferior in every respect ; towns were pestilential gatherings of hovels, huts, and thatched houses, built of timber and mud. Paris was left unpaved until Louis XI. (I46I-I483) ; London had not one public lamp until Henry VIII. (I509-I547). Our colleges and universities were, only hundreds of years afterwards, instituted in imitation of the Arabian, and to this day our university practices, examinations, honours, and degrees have descended from them.

The HOUSES of the great, and the palaces of the Emirs especially, were enchanting abodes with which the Roman emperors' palaces of previous ages could alone have been compared. But the BEAUTY AND LUXURY of their interior surpassed anything the world had as yet seen. They had walls of alabaster and adorned with coloured designs fretted with gold; halls supported by Spanish, African, Italian, Greek marble columns, surrounded by balconies, and ornamented with perfumed fountains ; towers for ventilation, and caleducts for warm and scented air; mosaic pavements and ceilings of unique workmanship; rooms with conservatories and odorous cascades; stained-glass windows of iridescent hues; marble baths; furniture of citron and sandal-wood incrusted with silver and mother-of-pearl; Persian carpets and rich tapestries; Chinese porcelain and rock-crystal vases; everything which industry and art, luxury and comfort could devise to charm the mind and cheer the heart. Abderrahman III.'s palace had no less than I,200 columns. The Audience Hall was incrusted with gold and precious stones. It contained over 6,000 attendants. And this sovereign (9I2-96I) was not a mere sensual ruler, for, like most Khalifs, he ex- 
hibited that taste for statuary, paintings, and learning which the popes of Rome showed only six hundred years later. When the famous musician Zaryab came from Asia to superintend the Cordova College of MUSIC, the Khalif rode forth to meet him and do him honour. Those who now visit Spain may bear witness to the richness and loveliness of Saracenic architecture-the ALHAMBRA and the CORDOVA CATHEDRAL are specimens of its grandeur. In Europe the kings' palaces were for centuries barbarous and unclean dwellings, chimneyless, windowless, hardly better than stables, and "with a hole in the roof for the smoke to escape;" their furniture consisted of rough wooden benches, stools, tables, and coffers, rushes on the floor and straw mats against the walls. The equipage of a travelling sovereign was an ox-cart. It was only after returning from the Crusades that the kings and barons, who had seen the luxury of the East, began to awake from their coarse usages, and introduce slight improvements in their customs. In this they were wholly indebted to the Arabs; it took them, however, another three hundred years for realising anything like comfort and luxury.

The Arabs were of all peoples those who brought the vastest improvements in the ARTS OF LIFE. They made agriculture a science; it was regulated by a code of laws; they improved it by irrigation, by means of flood-gates, wheels, and pumps. They likewise made a science of the cultivation of plants, of garden and orchard fruits; to them we owe the introduction of rice, cotton, silk, sugar, saffron, spinach, and other vegetables, the Xeres and Malaga wines. They paid great attention to the breeding of cattle, camels, sheep, and HORSES, improving the breeds of those they possessed. From them Europe inherited its love of the horse; likewise of hunting and falconry. They preceded Europe in the practice of true CHIVALRY. They also originated or improved many branches of industry-earthenware, iron, steel, leather, textile fabrics, from the humblest to the most gorgeous. The people's food was wholesome and most varied. The trade of the world for centuries was in their hands and those of their fast allies the JEws OF SPAIN. Over a thousand merchant ships trading between Barcelona and the Levant exchanged 
goods with Constantinople, the Black Sea, the ports of China, India, and thence with the interior of Asia, also with Japan, Madagascar, and the eastern coasts of Africa; and last, not least, books were written on the principles of TRADE. In the high social state which the Arabs enjoyed, prosperity and wealth increased to a prodigious extent-a natural result of industry and trade. The tales of the "Arabian Nights" throw great light upon the thrifty customs of the people, who had put aside warlike and predatory habits, to become peaceful traders and merchants, cleanly, gentle, and sociable. The revenue of the Spanish Khalif, Abderrahman III., was no less than FIVE and a half MILLIONS STERLING-a sum which exceeded the entire revenue of all the sovereigns of Europe; and this enormous taxation was lightly borne owing to the extension of trade and the increase of wealth in the community. (Draper's Intellectual Development.)

All these improvements gradually, though slowly, spread from Spain and Sicily into the south of France, and next into Italy-the rest of Europe remaining in its uncivilised condition for ages-universal war and rapacity tearing it from end to end. There, the people continued to live in huts, to feed on roots, vetches, and beans, to clothe in untanned skins; to vegetate in abject poverty and dirt, without industry and commerce to speak of until the Crusades. Up to the XVIth century the great ladies and princesses of Europe had gowns which lasted for years, the uncleanliness and strong smell of which were concealed by the use of penetrating perfumes.

The fact of capital importance to note here, is the RISE, for the first time in the annals of the world, OF INDUSTRY and commerce on a large scale, and these were not carried on by slaves or slave-labour, but by free men. The industrial spirit which is destined to revolutionise the world has already done so within the confines of Islam. It will spread into Europe, and bring momentous changes. The Saracens will lose the fruit of their progress, as the Romans and the Greeks have lost theirs, by the invasion of a host of irresistible barbarians, the Christians, whose fanaticism, as ruthless in Spain as it had been at Alexandria at the bidding of Cyril (4I5), and in Rome at the bidding of Gregory $I$. 
(590-604), and will be again in Mexico and Peru, will sweep away wealth, industry, commerce, culture, schools, palaces-all that recalled the hated Saracen, and replace all this by the DEADLY InQUiSITION. But the hated Saracen will have left his mark. For, happily, Europe, that part of it at least which was not wholly under the baneful sway of the monks and the popes, Europe we say has inherited much from him, and it has enlarged that heritage for the benefit of the whole of mankind.

We may now prozeed to give a summary of the Arabian achievements in the field of science, beginning it with the mathematical and astronomical branches.

IXth c. Ben Musa, a famous teacher, and the earliest author on ALGEBRA, substituted sines for chords - thus furthering the science of trigonometry-and found the common method of solving quadratic equations. He brought into use the INDIAN NUMERALS, I, 2, 3, 4, 5, etc. Algebra is known to have originated in India. It had been used as early as the Vth century A.D. by the Greek Diophantus of Alexandria; but the Arabs perfected it and brought it to us.

805-885. Albumazar drew up astronomical TABLES calculated from his own observations of the stars.

813-834. Al Mamun (in 830) directed two observations on the obliquity of the ecliptic (to measure it afresh) to be made by the astronomers and mathematicians around him (the result being $23^{\circ} 35^{\prime} 52^{\prime \prime}$ ); he also ordered the accurate measurement of the magnitude of the earth's circumference by the measuring of a DEGREE (found to be $56 \frac{2}{3}$ miles); caused the works of Aristotle, Euclid, Ptolemy, and Hippocrates to be translated into Arabic.

823. Alfergani excelled in astronomical calculations based upon his direct observations. His works on astronomy were translated, and studied in Europe for a long period.

850-900. Geber Al Batani (Albategnius) discovered the motion of the sun's apogee-showing Ptolemy's error (of $17^{\circ}$ ); calculated the length of the year more accurately than Ptolemy, making it 365 days 5 hours 46 min. 24 sec.within two minutes of the exact time. He corrected other errors in the observations of Ptolemy; established tables of 
the motions of the sun, moon, and planets, held in high repute for centuries; measured the obliquity of the ecliptic in 879 -the result being $23^{\circ} 35^{\prime} \mathrm{o}^{\prime \prime}$.

875. Thebit Ben Corrah found out the exact length of the YEAR: 365 days 5 hours $48 \mathrm{~min}$. II $\mathrm{sec}$. As an anatomist he described the ANATOMY OF BIRDS.

975. Aboul Wefa observed at Bagdad the third INEQUALITY OF THE MOON (viz., the variation), by virtue of which our satellite moves quickest when she is at new and full; but he failed to fix the law. This inequality was rediscovered by Tycho Brahe. He also measured the obliquity of the ecliptic in 987 (the result being $23^{\circ} 35^{\prime} \mathrm{O}^{\prime \prime}$ ).

995. Aboul Rihau measured the obliquity of the ecliptic with a QUADRANT of 25 feet radius in 995 (the result $\left.23^{\circ} 35^{\prime} \mathrm{O}^{\prime \prime}\right)$.

1008. Ebn Junis applied mathematics, using algebra and the Arabic numerals in his calculations, in the solution of physical and astronomical problems; drew up the HAKEMITE TABLES; achieved the most valuable of chronometric improvements by applying the PENDULUM to the measure of time. The value of his work is proved by the fact of Laplace making use of his astronomical observations as an evidence of the diminution of the eccentricity of the earth's orbit.

I080. Arzachael measured the obliquity OF THE ECLIPTIC (the result being $23^{\circ} 34^{\prime} \mathrm{O}^{\prime \prime}$ ).

Aboul Hassan used tubes for astronomical observations. to which ocular and object diopters were fixed-and which were a near approach to the invention of THE TELESCOPE.

Sufi (Abderrahman) improved the PHOTOMETRY of the stars-a feat which we should have expected to be reserved' only for modern science to accomplish.

I I98. Geber of Seville constructed the OBSERVATORY of that city-the earliest in Europe and the most complete on record. It was turned into a belfry after the expulsion of the Moors, "the Spaniards not knowing what to do with it."

I259. Tasi (Nessar Eddin) drew up the IlKanic TABLES at the observatory of Meragha (near Tauris).

I394-I449. Ulugh Begh (Prince) by means of a 
gnomon I80 feet high, determined the obliquity of the ecliptic to be $23^{\circ} 30^{\prime} 20^{\prime \prime}$ (?) ; the precession of the equinoxes at $\mathrm{I}^{\circ}$ in seventy years (which gives 25,200 YEARS for the entire cycle-a marvellous approximation); drew up tables scarcely inferior in accuracy to those of Tycho Brahe.

The preceding table enables us to see by how much the Arabs extended Greek astronomy and mathematics. Their originality and genius, however, are far more striking in physics. The discoveries made by Alhazen alone, if made amongst us at the present day, would make a profound impression, and would be considered astounding additions to modern science. It is difficult to understand how this great man arrived at such results; he was the scientific man par excellence of the Arabian race, just as Hipparchus was of the Greek, Galileo of the Italian, and Newton of the English.

I IOO. Alhazen was at once a geometrician, a PHYSICIST, and a physiologist. He was best known in Europe by his Optics-his works having been put into Latin comparatively early.

a. By anatomical and geometrical investigations he corrected the Greek mistake regarding the nature of vision, showing that light-rays come from objects to the eye, and do not issue forth from the organ;

b. Determined the function of the retina, showing that the impressions upon it are conveyed to the brain through the optic nerve-a discovery which implies dissection;

c. Explained SINGLE VISION, by the fact that impressions are made on symmetrical portions of the two retinas.

$d$. He discovered REFRACTION, and showed the untrustworthiness of our sense of sight, and rightly ascribed illusion to refraction and reflection-a discovery of high order, by which he was able to explain numerous phenomena, and which ranks him among the greatest physicists of all times and countries;

e. Discovered that the DENSITY OF THE ATMOSPHERE decreases with increase of height;

f. Explained the curvilinear course of a ray of light 
through the air, and thereby discovered ATMOSPHERICAL REFRACTION ;

$g$. Hence he explained the delusive appearance of the sun, moon, stars before they have risen and after they have set ;

$h$. He justly ascribed increase of refraction to increase of density ;

i. He explained the phenomenon of TwILIGHT-the effect of which is to shorten the night;

j. Was also the first to explain why a CONVEx LENS will magnify objects if it be held at a proper distance between them and the eye-another effect of refraction, due to the converging of light-rays. This was the first step towards spectacles.

$k$. Determined the HEIGHT of the atmosphere $-58 \frac{1}{2}$ miles -and its weight according to density-the very discovery of Torricelli five centuries later. Liais, in I859, estimated the height of the atmosphere to be 2 I 2 miles-but beyond 50 miles it is so attenuated that it does not affect the duration of twilight.

l. In hydrostatics, Alhazen discovered also that a body will weigh differently in a dense or in a rare medium (air), and that a body will LOSE WEIGHT in proportion as air is denser. He therefore found that Archimedes's principle holds good in air as well as in liquids.

$m$. Likewise, he explained the submergence of floating bodies, as ships on the sea.

$n$. He understood the theory of the CENTRE OF GRAVITY and the centre of suspension, and applied it to the investigation of balances and steelyards, showing the relations between the centre of gravity and that of suspension;

o. Recognised gravity as a force-but a terrestrial force, and asserted that it decreases with " the distance"-a Newton was required to demonstrate that it is a universal force, and that its decrease is not as the distance but as its square.

$p$. Discovered the relations between the velocities, spaces, and times of falling bodies-thus anticipating Galileo.

$q$. Discovered CAPILLARY ATTRACTION; 
$r$. Improved the hydrometer, for determining the specific gravities of liquids.

s. Drew up tables of SPECIFIC GRAvities (after Abur Raihân, who was the first to construct them), and they approach very closely to our own. In the case of mercury he was more exact than we were last century.

$t$. In physiology, he upheld the doctrine of the PROGRESSIVE DEVELOPMENT of animal forms-thus anticipating Diderot, Lamarck, and Darwin.

It is hardly necessary to point out that the great discovery of ATMOSPHERIC REFRACTION increased the accuracy of astronomical observations.

The Arabs originated scientific CHemistry-it was an outgrowth of the medical science at first. The discovery of strong acids laid its foundations. They had already defined alchemy as the science of the balance, the science of the weight, the science of combustion-a definition wonderfully accurate.

800. Giaber (also called Geber and Yeber), THE Founder of Chemistry, discovered nitric acid (aqua fortis, $F$ ), sulphuric acid, nitrate of silver, auric chloride (aqua regia, $\mathbb{R}$ ), mercuric chloride (corrosive sublimate), mercuric oxide (red oxide of mercury). His discovery of STRONG ACIDS was a revolution, for most of our chemical experiments would be impossible without them, and before Giaber no stronger acid was known than concentrated vinegar. $\mathrm{He}$ set forth the corrosive power of nitric acid, and how it dissolves gold itself by adding a portion of sal-ammoniac-thus solving the problem of obtaining gold in a potable form. Giaber proved that OXIDATION, or burning, INCREASES THE WEIGHT OF METALS - a fact over which Lavoisier will ponder nine hundred years later, and by which he will be led (I.) to suspect the phlogistic theory of combustion to be wrong, and (II.) to establish the consistent theory of combustion-the basis of chemical progress in modern times. Giaber knew the nature of ALCOHOL and GASES, and was thereby the Priestley or Lavoisier of his time. He described the operations of DisTILlation, FILTRATION, SUBLIMATION (obtained mercury by sublimation from cinnabar); he described also 
various CHEMICAL APPARATUS; water-baths, sand-baths, cupel of bone-earth, for the use of which he gives particularly precise directions; many of the methods which he prescribed are still used in our laboratories.

860-920. Rhazes, "the Observer," discovered also SULPHURIC ACID; the preparation of pure alcohol by distilling spirit of wine with quick-lime. Improved the ART OF DISTILLATION.

XIth (?). Alchid Bechir, a famous manipulator of chemicals, discovered Phosphorus (Hoefer).

VIIIth to XIth c, Marcus Græcus, in his "Liber Ignium," described GUNPOWDER, the rocket, and the cracker in a very precise manner. He also gave the prescription for making the skin incombustible, so that we can handle fire without being burnt-hence the so-called miracle (in our Middle Ages) of sitting on flaming straw.

XIth (?). Kalid was one of the famous physicians often mentioned, who brought about improvements in CHEMICAL MANIPULATION.

In medical science, surgery, and pharmaceutics, the Arabs made important additions to the knowledge left by the Greeks. Medical men called to the assistance of the art of healing both chemistry and botany. They brought in the use of mild purgatives instead of violent drastics, of mild, instead of violent remedies-extracting them mainly from plants. Only the most celebrated physicians need be mentioned.

800. Masué, Al Mamun's physician, studied comparative Anatomy. His "Pharmacopœia" was the guide of Europe for ages.

980-I037. Avicenna, "THE PRINCE OF PHYSICIANS," found new medical remedies. The list of his many achievements is too long for enumeration here. He anticipated Paracelsus in many respects, or more correctly, Paracelsus took many hints from him. Avicenna's "Canon" (of Medicine) in five books is a splendid work treating of Physiology, Pathology, and Hygiene (Books I., II.); of disease (III., IV.) ; of the composition and preparation of remedies (V.). It was the one great work of authority for 
six centuries. He described small-pox, unknown to the Greeks; was the first to use coloured drawings to instruct students. He is the author of an Encyclopædia-which shows the vastness of his acquirements. He explained the GEOLOGICAL FORMATION of mountain-ranges in a very lucid manner; he likewise guessed the correct origin of fossilsa double feat which implies practical and personal observation of nature, thus anticipating the theories of uprisings, alluvion, and erosion. "Fossils," he says, "prove that the rocks were deposited by water." He explained the nature of petrifying waters; mentioned meteorites, and made several discoveries about minerals. He also contributed to the knowledge of the plants of Bactria and Sogdiana, so fertile in medical plants. $\mathrm{He}$ is, besides, the first philosopher who started FREE INQUIRY, and thus inaugurated the age of Reason. This philosophy was developed by Algazzali and Averroes.

I I06. Albucasis, a far-famed surgeon of Cordova, invented and made use of excellent INSTRUMENTS, and did not shrink from the performance of the most formidable operations. Before him, the Arabs had already the lancet (improved), the couching-needle, the probang, etc. He described with great precision and detail complicated distilling apparatus and their use.

I I26-II98. Averroes, one of the most famous men in the world, was also a physician of great renown, although in this capacity he must yield the palm to Avicenna; but his medical work "Colliget" had great weight too. Outside his professional sphere he discovered the SUN-SPOTS, and ascribed a cause to them just as probable as that which Sir W. Herschel explained a century ago. It is, however, by his Commentaries on Aristotle that he deserved the high reputation in which he was held for centuries. It was by this work that his influence on Europe was felt most-this influence being at once profound and decisive. These two great men, Avicenna and Averroes, were conversant with every branch of knowledge, and by their correctness of thought and breadth of view, they gave immense impetus to the learning of the Middle Ages. Their intellectual 
supremacy in Europe, undisputed until the XVIth century, cannot be exaggerated, ranging as it did from matter of fact to free thought.

II70-1262. Ebn Zoar (Avenzoar) enriched PHARMACEUTICS by numerous additions. Discovered the acarus of the ITCH, and the treatment of the disease (a discovery, we might say, which should have saved the future Dukes of Argyll the benevolent lavishness of timber for which they have been proverbially blessed by grateful sufferers).

In connection with these branches, the services done to science by the Jews and their schools in the East, in Spain, France, and Italy, should not be forgotten, all of them fruits of Arabian learning. Some of the most famous men were:

XIth c. Rashi (Isaac Ben Soleiman), a physician who swayed a deserved authority for a long period, made valuable observations on pulse, fever, melancholia, and originated a new system of DIETETICS AND REMEDIES.

XIth c. Ebn Zohr (of Seville) wrote his treatises in Arabic, Hebrew, Syriac-a proof of his fame-both in prose and poetry: one was on the CURE OF DISEASES; two on fevers. He possessed a correct view of the morbific nature of marsh miasm.

XIth c. Ben Ezra (of Toledo), who was at once a poet, critic, astronomer, mathematician, philosopher, and physician, and had travelled in Asia (including India) and Europe, wrote a famous work (Book of Proofs) on theoretical and PRACTICAL MEDICINE, very extensively studied.

The universities of Salerno, Montpellier, Narbonne, Tarentum, Bari, were either founded or directed by Arabian Jews. Nor should we forget to mention

XIIth (?). Abba Mari (of Marseilles), who translated THE AlmaGest of Ptolemy, and Averroes's Commentaries of Aristotle; the latter was the first strong beam of light shot across the whole of Europe.

But we must refer the reader to Draper's Intellectuat Development for further information. The number of Arabian and Jewish physicians is legion-we mean real medical men and surgeons, and not empirical practitioners.

The Arabs showed their taste and aptitude for practical 
science in every direction. They undertook remote travels and explorations with the view to enrich and diffuse the knowledge of geography, botany, natural history, mineralogy. For instance :

720. Assamsh, as early as 720 , created scientific TOPOGRAPHY and statistics.

I 30. Artefius, in his "Key to Wisdom," defined the nature of MINERALS, plants, and animals with as much lucidity and terseness as Linnæus. "Minerals," he says, "derive from the elements, plants from the minerals, animals: from plants." He described the preparation of soap.

I $62-31$. Abdallatif, the favourite of Saladin, described the ANIMALS AND PLANTS OF EGYPT with an accuracy unknown before him. The hippopotamus is described by him better than by Hercdotus, Aristotle, and Pliny. $\mathrm{He}$ rectified Galenus as to the human osteology. Had the Nile mud dug to discover the antiquity of Egyptian civilisation to a depth of 43 feet, counting 13,500 yearly mud layers, and finding pottery at that depth.

XIIth (?). Abn Othman added new facts to the knowledge of ZOOLOGY, too numerous to describe in detail.

I248. Al Beithar did the same for BOTANy. After extensive travels, he composed a General History of Plants alphabetically planned, in which he speaks of many species unknown before, and also of their medical properties.

950. Al Farabi had nearly three hundred years before detected the RESPIRATION OF PLANTS, in the leaves and bark.

XIIth (?). Alberuni extended the knowledge of mineralogy, and of PRECIOUS STONES especially.

I I30. Al Idrisi increased the knowledge of geography; he made a silver GLOBE for King Roger II. of Sicily.

1283. Karwiny's "Wonders of Nature" embraces astronomy, geography, natural history; treats of meteors and other atmospheric phenomena. He ascribed EARTHQUAKES. to vapours which act in the interior of the earth as in a vast laboratory; described two kinds of elementary vapours: I. those above the earth which form clouds, rain, snow; II. those under the earth which cause earthquakes. He also speaks of the displacement of the sea. "A place," he says, 
"has been a town,"a plain, a sea, and land again." No wonder he enjoyed a European reputation for hundreds of years.

Even philosophy had, as we have seen in the case of Avicenna and Averroes, abandoned the metaphysical sphere, and become as positive as it well could be before the XIXth century. In this respect,

I058-IIII. Algazzali is an exceedingly remarkable instance of genius. He composed a work "On the CERTAINTY OF KNOWLEDGE and Science," in which the deceptiveness of the senses and of reason is argued with rare lucidity and soundness-a theory six centuries in advance of his time.

The practical spirit of the Arabs and their passion for natural and experimental philosophy are further exemplified, beyond chronometry, irrigation, agriculture, ceramics, metallurgy, and the industrial arts already noticed, by their application of hydraulics in the construction of waterworks, reservoirs, canals, sluices, wells, in Spain, Africa, Egypt, Syria, and Mesopotamia; by their invention and introduction into Europe of the Semaphoric Telegraph; their study of numismatics and chronology. They invented several kinds of

Clepsydras, particularly a balance clepsydra-a new principle altogether. They invented

Pendulum Clocks; they improved the

Astrolabe ; they introduced the

Compass;

Paper ;

Gunpowder and Artillery. These three things, the compass, paper, and gunpowder, were mighty agents of progress, and brought in innumerable results in the world, in Europe especially: they assisted the evolution of society in every direction. Gunpowder revolutionised the social system by the destruction of the all-powerful feudalism; the compass revolutionised geography, commerce, theology; paper spread ideas, and assisted in the transformation of religious and scientific views. The Arabs invented the

Aerometer; the addition of the

Cypher to the nine earlier INDIAN NUMERALS was a stroke of genius entirely due to them. There is no doubt 
that we owe them these numerals, although they originated in India. From Spain they quickly passed, together with algebra, into Italy, where their advantage was at once recognised in commercial computations.

The Arabs, to speak of another order of facts, cultivated eloquence, taught grammar, rhetoric, and music. Their immense poetical literature, to which celebrated poetesses added a lovely portion, bears witness to the wealth of their luxuriant imagination, just as their science shows the richness of their intellectual faculties. To them we are indebted for the introduction of song into Provence; also for Rhyme, which has enriched the poetry written in our modern languages.

The words nadir, zenith, algebra, cypher, carat, alchemy, alembic, alkali, alcohol, syrup, julep, elixir; together with the words admiral, cotton, chemise, morocco, cordovan, which we have adopted, throw a light upon the contribution of the Arabs to progress in various paths.

All that could shorten or foster research was either invented or instituted by them:

\section{Libraries,}

Observatories,

Laboratories,

Menageries and Aviaries of rare animals and birds,

Surgical Instruments,

Globes, and

\section{Dictionaries.}

They originated dictionaries, those most serviceable of all books; they had every kind-biographical, historical, scientific, written in Arabic, Hebrew, Greek, Latin-some of them in sixty volumes-besides lexicons for the tuition of these languages. They even had dictionaries of celebrated horses and camels.

Their PUBLIC LIBRARIES were numerous, extensive, and rich. There were as many as seventy in Spain alone. Khalif Alhakem's private one was so large that its catalogue filled forty volumes. It had no less than 600,000 works. The Cairo library had 100,000 volumes. The Tripoli library (burnt by the Crusaders!) also 100,000. Such value was attached to books, and so earnest the love of 
learning, that after a successful war it was not rare to insert stipulations in the treaty of peace for the cession of manuscripts-originals or copies-sometimes to the amount of four hundred camel loads!

To sum up, then, the Arabs extended

Geography,

Botany,

Pharmaceutics,

Surgery,

Medicine,
Arithmetic,

Algebra,

Astronomy,

Physics,

Chemistry.

They improved upon mathematical and astronomical knowledge; gave us algebra (solving even cubic equations), extended trigonometry, and thus met the needs of celestial geometry. But they left their mark for all times equally in Medicine, Physics, and Chemistry.

To Spain all those who had a taste for learning repaired, from all parts of Europe : from Italy, from France, England, Germany, and even Scandinavia. All the great men who shone in Europe in the Middle Ages had acquired their knowledge among or from the Arabs, and foremost among them, between 1000 and 1350 :

Stiorn Oddes,

Gerbert (Sylvester II.),

Frederick II. of Germany,

Gaston Phœbus, Comte de

Foix,

Abelard,

Albertus Magnus,
Roger Bacon,

Vincent de Beauvais,

Duns Scotus,

Arnauld de Villeneuve,

Bonaventura,

Albert of Saxony,

Ramon Lulle,

all of whom were nurtured in Arabian learning and inoculated by the Arabs with the spirit of science, and with the habit of thinking and reasoning. And if these early teachers, Albertus Magnus and Roger Bacon, listened to the voice of experience, silent for so many ages in Europe, and founded the EXPERIMENTAL SCHOOL amongst us, they were wholly indebted for it to their Arabian teachers.

We may now contrast Islam with Christendom in a few points which the preceding survey has not sufficiently established : 
I. A comparison between the CREED of the Arabs and that of Europe cannot be drawn here for many reasons, but we may at least point out that with all its inferiority, Mohammedanism has been the only creed, with Protestantism, which has been wholly EXEMPT FROM IDOLATRY ;

Whereas the Greek and Roman Christianity has been polluted by Mariolatry, the WORSHIP OF SAINTS and relics: certainly was this the case during the Middle Ages.

II. The political system of Islam admitted and practised a liberal religious TOLERATION. Provided the subject races paid a trifling tribute to the Khalifs and Emirs, they were allowed to live unmolested in the worship of their fathers ;

Whereas INTOLERANCE of other creeds was one of the principles of government throughout Christendom, and that principle was enforced by extermination.

III. The Saracens and Jews originated the doctrine of the SUPREMACY OF REASON over authority, and this doctrine overthrew among them Supernaturalism and its logic ;

Whereas AUTHORITY stifled reason and its supporters until Luther in the North, and until the XVIIIth century in the South of Europe. It was this difference between the two systems which brought the Arabs' influence into conflict with Christian Europe, and led to the XIIIth century Crusade in South France.

IV. Luxury, the daughter of INDUSTRY and its wealth, and the sign of a high civilisation, existed throughout Islam. Its effects benefited all. Even. small people, to speak of a significant detail only, wore linen or cotton chemises, gay-coloured garments of silk. Cleanliness was commanded by religion and custom;

Whereas industry and luxury were absent from one end of Christian Europe to the other until after the Crusades, and the GENERAL POVERTy was such that people wore their skin-garments until they fell to 
pieces through dirt, vermin, and wear-want of sanitation bringing in frequent plagues.

V. The people of Islam were lifting themselves up by the unchecked cultivation of SCIENCE;

Whereas Europe, then on a par with what Russia was until Peter I., or what Abyssinia is now, was withering in the science of MONK MIRACLES and monkish philosophy.

VI. Particularly striking are the high acquirements of the Saracens and Jews. They applied mathematics to ASTRONOMY AND PHYSICS ; measured the obliquity of the ecliptic, the length of a degree, the earth's radius and circumference, corrected astronomical tables by systematic observations, left Arabian names indelibly written on the firmament, taught geography by the use of globes, measured time by pendulum oscillations ;

Whereas the FLATNESS OF THE EARTH, the denial of the antipodes, the solidity of the firmament, were asserted in Europe, and those who doubted were dealt with as heretics.

VII. DISEASES in Saracenic lands were considered and treated as NATURAL EFFECTS of physical causes. The patient sought the assistance of the physician and the surgeon, who prescribed medicine or performed an operation;

Whereas Christian Europe was taught to consider disease as a SUPERNATURAL VISITATION, which was to be cured by miracle, exorcism, pilgrimage to the nearest shrine, and trust to the efficacy, not of the lancet of the leech or the bandage of the surgeon, but of relics, charms, amulets, talismans, all more or less in the keeping of the ecclesiastics who made their administration a source of boundless profit, as they did with the sale of indulgences later on. So ingrained was the belief in supernaturalism that a man like Francis Bacon believed in talismans and witchery.

VIII. Men of intellect and LEARNING were honoured throughout Islam; 
Whereas they were accused of witchcraft in Europe and PERSECUTED accordingly.

This comparison between Islam and Christendom presents as striking a contrast as any that can be offered in the whole of the historical period. It is, however, only bare justice to state, that although it is absolutely true in the main, yet Christendom during the mediæval epoch was not wholly wrapped in intellectual night. For Christianity, as a creed, besides restraining violence to a considerable extent for hundreds of years, was slowly elevating the European community, and preparing it for that evolution of new morals* and new idealst which must of necessity conduce to enlightenment. The Church, as an organised body, by protecting, as it did, the weak from the strong; the Clergy, as a teaching association, by keeping up the tradition of ancient culture and a taste for letters in a certain measure even in the VIth and VIIth centuries, did an immense amount of good work in the same direction. Furthermore, streaks of light, harbingers of the dawn, were casting a more or less visible glow all through the period, except perhaps two centuries, and were bringing in a lasting and hopeful twilight. Remarkable minds, from the midst of general barbarism and want of knowledge, shed a sort of lustre over each century after the seventh. In the lay world we find a CHARLEMAGNE (742-8I4), and an ALFRED (849-901), who promote progress, and whose efforts are seconded by Paul Diaconus (d. 796), Theodulf of Spain, Clement of Ireland, Peter of Pisa, and still more by Alcuin (d. 804), A NGilbert (d. 8I4), EGINHARD (d. 844), ERIGENA (d. 875), with a certain degree of success. In the Church, also, notable intellects appeared. Gregory I. (590-604), Gregory II. (7I6-3I), Gregory III. $(731-46)$, Leo III. (795-8I6), Hincmar (806882), GERBERT (950-ICO3), Richer of St. Remi (fl. 960-1000),

* Philippe Augustus was compelled to take back his wife Ingeburge (1213) whom he had repudiated.

+ In 1226 there were 200 hospitals and 2,000 leper-houses in France alone.

‡ The only man who knew Greek in the whole West. After him, for five centuries, that language was totally unknown. 
Abbon of St. Germain (fl. 990-roio), Hildebrand (ior $3-$ 1085), Lanfranc (1005-89), Berenger (1050-88), Roscelin (I030-89), St. Anselm (I034-I I09),* all of whom were, and remain, imposing or interesting historical figures, contributed somewhat, in one way or another, to the spread of dight. True it is that the multitude remained steeped in profound ignorance, but so, relatively, it does to this day. But as it is the degree of intellect in conspicuous men which serves as a standard to gauge the stage of advance and improvement of any time, we may be sure that a certain momentum was given to progress by the great men just mentioned. After them, and from St. Bernard (I090-I I 53), the twilight broadens by degrees into daylight, (I.) by the concurrence of momentous events, $\dagger$ fatal to millions it is true, but auspicious of good for the immediate future; and (II.) by the rapid appearance of numerous geniuses, as we shall be able to see in the following chapter.

With this qualification to the contrast we have drawn, the above sketch is the shortest account which can be given of the Eastern contribution to the progress of mankind. Most truly was Islam in the VAN OF CIVILISATION FOR FIVE OR SIX CENTURIES, and we insist on this fact because we moderns, in the legitimate pride we feel for our own achievements, are prone to forget what is foreign to, and remote from, us. The foregoing description will remind the reader of what is due to the Arabs, and it is needless to say that it leaves aside an immense amount of secondary work. We clearly see that they were the connecting link between the Greeks and ourselves, and that the assertion of a standstill for ages was as mistaken as it could possibly be.

Modern scientists, no doubt, have pointed out many flaws in the science of the Arabs, as they have indeed in that of the Greeks ; the vast extension of the field of knowledge among us, our numerous and admirable means of verification have made it easy for us to detect inaccuracies of facts and occasional errors in the conclusions drawn by

* John of Beverley (d. 722) and Bede (d. 735) might be added to those names.

$\dagger$ See Chapter VI. 
the precursors of modern science; but the bulk of their original work nevertheless remains an inheritance which the most captious critics find it impossible either to ignore or despise. Even erroneous theories were steps towards scientific truth, generating as they did a verification which involved additional researches and acquisitions. Our own modern science was often hasty in its conclusions too, as the history of astronomy or of geology shows; but although the Plutonian and Neptunian hypotheses are untenable to-day, yet Hutton and Werner will always be considered scientific men, because, of their theories, part at least has proved true. This applies to the Arabs, and no less to the Arabs than to the Greeks and ourselves. 


\section{CHAPTER V.}

PROGRESS IN THE MIDDLE AGES AND DURING THE REVIVAL.

Continuing our sketch we now arrive at the Mediæval and Revival periods in Europe - the third and fourth eras of scientific advancement-during which science wholly passed from the Saracenic to the European World. The gradual advance during this period is far more astonishing than even the brilliant achievements of the Arabs, considering the formidable and terrifying obstacles which stood in the way. The Saracen pursued his studies in the face of heaven and in full freedom. Science was to him no forbidden fruit, and if he made a discovery he was held in high honour for it throughout Islam. Our mediæval lover of science, on the contrary, was obliged to pursue his researches underground, so to speak, and hide his discoveries from all eyes. He was for ever haunted by the maddening vision of the stake. That science was cultivated at all under such circumstances, in solitude, practically without books, without teachers, was a proof of energy of intellect and will deserving all our sympathy and admiration; but that science thus pursued should have extended its roots and branches, and yielded fresh fruit, is a fact which should make us revere our mediæval teachers as ideal heroes of the most exalted order, for they were staking their lives every day, not as proud knights seeking to win a holy relic or a lady's love with lance on their hip and crest on their helm, but as devoted and defenceless heralds facing the wakeful hydra armed with 
claws and flames, to deliver their fellow-men from unspeakable evils. Bearing this in our minds, the progress of the later Middle Ages and the Revival has been absolutely marvellous.

Those times witnessed:

I. most VALUABLE INVENTIONS;

II. the appearance of some of the most important AGENTS OF PROGRESS humanity can boast of ;

III. the discovery of scientific LAwS of the highest order.

Here again we have to be satisfied with brief records. During this era there came into existence:

IXth c.* Watermills.-The Romans were in possession of them in an imperfect form as early as 500 A.D.

IXth c. The Organ, an orchestra in itself, the sublime instrument par excellence. It gradually grew out of a hand and bellows pipe known among the Romans. Nero had an organ worked by water.

IXth to XIVth c. Clocks were improved in diverse ways, especially after Henry de Wyck (1364). Needless to speak of the Hour-Glass, of which there was a variety.

Xth to XIIth. Music - the creation of a new language (musical notation and harmony) of which Hucbald (d. 930), Guido d'Arezzo (1024), and Franco (1050-1083) were the chief pioneers-a gradual progress in the "use of the phenomena of sound " until the XVIth century, accompanied by the invention of various instruments (harpsichords and clavichords). Bishop Ambrosius of Milan (340-397) and Pope Gregory I. (544-604) were associated with the earlier advance of Music. About I400-20 DUNSTABLE invented polyphony.

XIth, XIIth. Windmills, whether invented in Europe or introduced from the East during the Crusades, spread rapidly during the XIIth century.

III5-I302. The Compass, which effected a fourfold revolution-revolution in theology, astronomy, geography, commerce. The CHINESE (see Klaproth) were possessed of it. They used it on land in the absence of roads as early as the XIIth century before our era. From the VIIth to the * All these dates are approximate only. 
IXth century (A.D.) the Chinese navigated as far as Ceylon and the Persian Gulf with its assistance; it was thus introduced into India, whence the Arabs probably brought it to us; but it was amongst us that it was improved and extensively used in navigation. It certainly was due to neither Marco Paolo (I256-I323) nor Gioja d'Amalfi (I302)-a myth that stands on the same footing as the tradition regarding gunpowder. Mention of the compass is to be found in books written long before Gioja's birth-viz., $L a$ Bible, written by Guyot de Provins in II90; in "Treatise on Things pertaining to Ships," by Alexander Neckam, of St. Albans, born in II57; and in James de Vitry's Chronicle, written in 1220. It was then called the sail-stone. Gioja, who was a navigator, probably improved what was used in his time. He is said to have made a rude compass by means of a round cardboard with a magnetised needle fixed on it, which he laid on the surface of a basin full of water. The card thus rendered sensitive to magnetic action would easily revolve under its influence and foint to the north. But the compass was used in a different way long before Gioja's time.

XIIIth c. Paper, one of the greatest elements of civilisation. Paper seems to have originated in China, and to have been brought to us by the Arabs. These lay a claim to the invention. It was made of rags in Europe during the XIIIth century.

XIIIth c. Gunpowder, the destroyer of Feudalism, the instrument of freedom and political progress, and for blasting purposes in engineering work one of our most useful agents. It was doubtless invented in the East, just as the Greek fire was; the Arabs may justly lay a claim to its discovery-their chemical manipulation led them to it-and they employed it with cannon as early as III $8 *$; but it was Europe which perfected its fabrication, and made an extensive use of it in war. We must reject as a myth the ascription of the invention to the Swiss monk Schwartz, or Roger Bacon. These two merely transcribed the description of gunpowder found in

* The Moors employed artillery against Saragossa in III8, the Spaniards used it against Cordova in 1280 and against Gibraltar in I 306 , the King of Granada at the Siege of Baza in 1325. 
older authors. Gunpowder was the result of gradual modifications of several explosive substances known from time immemorial; there was really no single inventor.

1220. Algebra, which powerfully developed mathematics. The Hindus, as we now know from Sanskrit writings, originated it. It was introduced into Europe by the Arabs, who extended it. But it was greatly improved by our mediæval mathematicians.

I300. Spectacles, which restored the sense of sight to millions and millions, were invented in Italy, by either Alessandra da Spina of Pisa, or Salvinus Armatus of Florence. The Assyrians were already in possession of the magnifying glass-one (now in the British Museum) having been found in Sennacherib's library. The CHINEsE, too, seem to have invented spectacles as early as the VIth century of our era. Alhazen had pointed out the magnifying property of lenses; but our spectacles appear to have been invented independently of these sources.

I310. Watches, a natural outgrowth of the clock, were invented as early as the XIVth century ( 13 IO).

1320. Cannon, known to the Arabs of Spain before I200, but much improved in Europe.

1364. Muskets, a clever modification of the cannon.

I500. Pistols, a most serviceable modification of the musket. These three weapons prove the practical ingenuity of mediæval Europe.

Xth to XIIIth c. Stained Glass, immensely improved;

I 300 . Mirrors, made of glass; Enamelling, and

$\mathrm{XVth}$ c. Glazed Pottery, imitated from the Arabian and Greek, but perfected ;

XVth, XVIth c. Majolica, all of which demanded so much practical knowledge, originated in Italy. DELLA ROBbia (I4I5) and PALISSY (1580) were the masters of the ceramic art.

I4I5. Oil Painting was invented about I4co by Van EyCK BROTHERS. This proves the progress made in practical chemistry. Great strides in art since then.

1440. Engraving, the medium of illustration in art and science. 
I200-1600. The Violin family of instruments, the basis of modern orchestration. It sprung from the ancient string. instrument crwth, which was transformed into the viol about or after the XIth c., and this was improved until the violin form was reached. Fétis traces the use of the bow to India.

XVIth c. The Cross-Staff, and Sea-quadrant-the latter probably of early origin-the Greeks, as we have seen, had a quadrant.

1453. Printing, which rendered the pulpit secondary, and was the propagator of learning, free inquiry, the Reformation-the great civilising agent of Europe. The CHINESE, as early as the VIth c., and probably before, had invented block-printing; but the alphabetical printing was due to European genius-to Guttenberg especially. The assistance which Printing gave science may be estimated by the fact that Vitellio's Optics, Euclid's Geometry, were published as early as I533, Rhæticus's Trigonomical Tables soon after, and so forth.

r560. The Suction Pump, which led Galileo and Torricelli to the discovery of atmospheric pressure.

Then came great men :

I394-I460. Prince Henry, the Navigator, initiated the explorations which led to the discovery of half the world, by the incessant labour, direction, solicitude, and protection he bestowed on navigation. He may be said to have opened Africa and Asia. His scientific claim lies in his having created modern navigation and geography, and applied to both the assistance of mathematics, cartography, astronomical instruments and observations, thereby ensuring the steady development of the two sister sciences, each of which was full of promise for civilisation.

I394-I482. Toscanelli constructed a GNOMON on the Cathedral of Florence in 1468.

1423-146r. Peurbach invented the decimal division, and composed Tables of the Eclipses, and also EPHEMERIDES; re-invented the tangents, and calculated the Tables of Tangents for each degree-a new step in the advancement of mathematics; was the first European who composed a treatise on trigonometry. 
I430-I506. Columbus discovered America (Oct. I2, I492); observed the magnetic declination.

I436-I476. Regiomontanus computed the earliest EPHEMERIDES ever composed.

I $45 \mathrm{I}-\mathrm{I} 504$. Waltherus was the first in Europe to USE: CLOCKS to measure time during astronomical observations.

I452-I519. Leonardo da Vinci advanced MECHANICS before Stevinus and Galileo; also chemistry; traced the origin of fossils; strongly advocated experiments.* He left fourteen valuable books on Natural Philosophy.

I469-I524. Vasco de Gama rounded the CAPE OF Good Hope (discovered by DIAS in I486), and found the sea-route to the East Indies (Nov. 22, I497).

I 470-I 521 . Magellan circumnavigated the globe (1519I522), discovering Cape Horn, the Magellan Straits, the Pacific Ocean, and numerous groups of islands. Magellan, killed in the Ladrone Islands, had not the happiness to complete the voyage; his lieutenant, Sebastian del Cano, reaped the glory of sailing round the earth first.

I473-I543. Copernicus demonstrated the planetary system, "founding his reasonings upon rigid induction." The ancient Greek astronomers seem to have guessed the truth, but failed to demonstrate it. Copernicus's conviction was so thorough that he predicted that we should see the phases of Mercury and Venus. The Copernican system was not generally accepted until Galileo.

1486-1567. Stiefel found the germs of logarithms, the shorthand of Arithmetic-a discovery perfected and made effectual by Napier; invented the use of letters for unknown quantities, and the sign + for plus and - for minus.

I493-I54I. Paracelsus transferred the medical science from books to observation and nature, and by his public lectures on medicine and chemistry, "rid Europe of humoralism, Galenism, and polypharmacy - thus giving the heaviest. blow to the old pathology." Many of his ideas are borrowed from the Arabs. He applied himself to reforming therapeutics, and based the medical art partly upon a knowledge of chemistry. He was the first to lay down the problem of Life * See pages 99, 104-107, and Appendix IV. 
which was to become the ultimate object of future research. As a chemist, he separated gold from silver (in a mixture of the two metals) by means of nitric acid; pointed out that air feeds a flame. As a physician, he applied new remedies (laudanum and antimony amongst others), and discovered the general law of nutrition. His follower Libavius ( $550-16$ I6) continued his chemical work, and discovered the process of making red glass by the oxide of gold. His Alchymia Recognita contains valuable descriptions of old, and new, processes.

I 494-I 555. Agricola was the founder of modern metallurgy, removing it from the alchemist's laboratory to the foundry-an immense stride in practical chemistry. He was also the discoverer of bismuth (I 529 ).

I497-I 558. Fernel measured a DEGREE by the revolution of a wheel in 1527, ascertaining thereby the earth's circumference to be 24,480 Italian miles-nearly the same result as Al Mamun's.

I 500-I550. Tartaglia caused mechanics to progress in several ways; may be called the father of ballistics, having been the first to explain the laws governing the flight of projectiles, which Leonardo had understood sixty years before, but without fully explaining them.

I5OI-r576. Cardan, the inventor of "the CARDAN RULE," also advanced theoretical and practical mechanics.

I 5 IO-I590. Palissy explained the origin of springs and of FOSSILS, and improved the ceramic art. Glazed pottery for domestic use is due to him.

1512-1594. Mercator, after Prince Henry, contributed most to revive GEOGRAPHY on scientific principles (Tabulæ Geographiæ), constructing marine Charts on what is called Mercator's Projection-representing latitudes and longitudes by lines; he also revived astronomical chronology, and restored hydromechanics, at least partially.

1522-1565. Ferrari greatly improved ALGEBRA, and resolved algebraic equations of the third and fourth degrees.

I 526-I594. Palestrina made music AN ART as well as A SCIENCE. His compositions have remained unsurpassed.

1537-16rg. Aquapendente (Fabricius ab), tutor of 
Harvey, discovered the VALVES OF THE VEINS-a great step towards Harvey's own discovery. As an astronomer discovered (Aug. 1596) the variable star Mira (also called $o$ Ceti).

I540-160I. Ubaldi developed the LAWS OF THE LEVER and the point of gravity-his elucidation an important forward step.

1540-1603. Viète invented the mathematical SYMBOLS -an ingenious and most serviceable creation; he also applied algebra to geometry; may be said to have preceded Descartes and Newton on the road of mathematical analysis.

1540-1603. Gilbert showed that a great many substances have the magnetic power of attraction when rubbed, and that this attraction is stronger when the atmosphere is cold and dry; he found out the main principles of electricity after countless experiments-an evidence that experiments were made in earnest. He should be remembered as the FOUNDER of the science OF ELECTRICITY; but he was also one of the masters of the Inductive Method.*

I545-I6I5. Porta invented the CAMERA OBSCURA, used in astronomy and photography; invented also the MAGIC LANTERN, which was perfected by the German Kircher, some time later; showed vision to emanate, not from the eye, but from the light which comes to it-comparing the eye to the camera obscura. Della Porta had also a good notion of the use of two magnifying glasses, but does not appear to have either made or improved telescopes, as it is asserted.

I 546-I60I. Tycho Brahe built a magnificent observatory on the island of Huen, given him by Frederick II. of Denmark, where he observed the heavens night after night for more than twenty-five years; he mapped 777 stars ( 1,000 according to Brewster), and drew up the celebrated RUdolphine TABles (in honour of the Emperor Rudolphus II.)-a work of twenty-five years' observations, the basis of Kepler's labours, and one of the grandest works ever composed. Tycho rediscovered the third inequality of the moon-the variation-discovered before by Aboul Wefa;

* See Appendix V. 
determined that comets are beyond the moon, and cut the firmament in all directions; made numerous beautiful physical and astronomical instruments. $\mathrm{He}$ earnestly advocated experiments, and took nothing for granted without rigid verification.* $\mathrm{He}$ was the reformer of the astronomical science beyond all question.

1548-1620. Stevinus elucidated some of the LAws OF PRESSURE, motion, THE LEVER, and the equilibrium of liquids.

Ab. I546. Lelio reformed the CALENDAR in 1581 -a proof that "observations" were pursued everywhere.

1550-1617. Napier developed and perfected LOGARITHMS-there were several reprints of his works in a few years. This new mode of calculation was a discovery which has multiplied perhaps "hundredfold the working process of every computer, and has rendered easy calculations which were before impracticable."

I550-1600. Bruno (Giordano) lectured on and popularised the COPERNICAN SYSTEM; asserted that other worlds might be inhabited besides ours, entertaining the opinion, as early as I 59I, that the stars may be suns attended by planets like our earth. He attempted to establish the mechanical conception of the universe (Democritus's view). He denounced Aristotle and authority as early as 1580 (in Oxford in 1583 ). For his fourfold offence he was burnt alive in 1600 . He must be remembered as one of the great martyrs of science.

I $560-1621$. Harriot explained the origin of colours in the RAINBOW, more fully than Roger Bacon and Vitellio had done.

I 564-1642. Galileo, the greatest man of science, together with Archimedes, Hipparchus, and Alhazen, the world produced before Newton, invented the THERMOMETER, one of the most important agents in our possession, in 1597 , and from that time the phenomena of heat could be studied, and these of course include a vast number of chemical phenomena. He improved Lippershey's or Janssen's TELESCOPE and microscope-the starting point of modern astronomy and physiology, and with the assistance of the telescope made great discoveries. He created Dynamics-

* See Appendix V. 
the great science of the moderns-after his experiments on the fall of bodies, and the PENDULum. "The pendulum," says one of our best authorities on scientific researches, " "is the most perfect (certainly one of the most perfect) of all instruments, chiefly because it admits of almost endless repetitions. Since the force of gravity never ceases, one swing of the pendulum is no sooner ended than the other is begun, so that the juxtaposition of successive units is absolutely perfect. Provided that the oscillations be equal, I,000 oscillations will occupy 1,000 times as great an interval of time as one oscillation. The excessive value of this instrument arises from two circumstances: (I) the method of repetition-which is invaluable in science-is eminently applicable to it ; (2) unlike other instruments, it connects together three different quantities, those of space, time, and force. (A) A pendulum of invariable length, suspended at the same place where the force of gravity may be considered constant, furnishes a measure of time. (B) The same pendulum, made to vibrate at different parts of the earth's surface, and the times of vibration being astronomically determined, the force of gravity becomes accurately known. (c) With a known force of gravity, and time of vibration ascertained, by reference to the stars, the length is determinate." We have quoted this passage in full-a liberty the author will be the first to forgive us for knowledge' sake-because of the important part the pendulum has played in the science of the last three centuries. We leave Galileo for the present, as we shall again have occasion to speak of him and his scientific discoveries.

I566-I624. Antonio de Dominis explained the true theory of the RAINBOW, in I59I, which Harriot still more perfectly elucidated about the same time or shortly after.

I 566-I627. Ghetaldi published the earliest determinations of SPECIFIC GRAVITIES of metals in I603-a subject which Archimedes and the two great Arabian physicists Abur Raihân and Alhazen had partly treated.

I5 -d. I600. Cavaliere created the ORATORIO, which, with the Opera, constitutes dramatic music.

* Jevons. 
I567-I643. Peri and Monteverde created the OPERA, after attempts at reconstructing the melopeia of the Greeks.

I57I-I630. Kepler formulated the three LAWS OF Motion, together with Galileo's, the basis of Newton's labours; explained the tides, but it was reserved to Newton to formulate the law which regulates them.

I577-I643. Guldinus determined the CENTRE OF GRAVITY-a solution necessary for the progress of mechanics.

I 577-I644. Castelli created HydRaUliCs, showing how to measure running water.

I 577-I644. Van Helmont recognised numerous kinds of GAS-being the first of all writers to use the word; called carbonic acid "wood-gas," the gas rising from fermenting beer, "gas sylvestre." His lectures on chemistry popularised that science.

I 578-I657. Harvey discovered the CIRCULATION OF THE BLOOD, the starting point of modern physiolozy; discovered also that the blood during its passage through the lungs meets the air drawn in at each breath.

As a biologist he made valuable discoveries about generation : he observed the very beginnings of life in the incubated egg of the fowl and in the embryos of mammalian animals-the result of which was the demonstration of the famous dictum, "Omne vivum ex ovo" (all life comes from an egg), which is true of all higher animals if not applicable to plants.

I 59I-1626. Snell measured the length of a DEGREE by means of trigonometry - the result confirming Fernel's calculations; he also discovered the LAW OF REFRACTION(I62I)determining the index of refraction. Snell's law, as it is called, is stated thus: The ratio between the sines of the incident and refracted rays is always the same for the same substancethe index of refraction for water being three-fourths. The importance of this law may be conceived when it is remembered that the power of telescopes could not have been regulated without it.

I600-I6Io. Scarpi, Drebbel, Santorio invented an air THERMOMETER each in $1600,1609,1610$ respectively. They 
also improved hygrometers (for determining the amount of moisture in the air); and as a proof that instruments were made on scientific principles, it may be stated that the spirit of wine and the mercury thermometers were made, the first by the Academy del Cimento in 1655 , the second by Halley about 1680 , on the principle of relative dilatation.

Nearly every branch had been seated, at the end of the XVIth century and the beginning of the XVIIth, on a scientific basis-viz. :

\section{Astronomy, \\ Physics, \\ Mechanics, \\ Hydraulics,}

Hydrostatics,

Optics,

Electricity,

Dynamics.

Furthermore, great strides had been made in other branches, and if the advance in these was less extraordinary, it sufficed nevertheless to place them also on scientific foundations.

\section{Zoology was advanced by}

I 5 I6-I565. Gesner, who continued the work of Aristotle and the Arabs by his countless observations, and published a celebrated work on ANIMALS, in which he described every known animal, its habitat, habits, food, etc.; he travelled over a large area of Europe to study fresh-water and marine fish, and collect numerous minerals and plants; founded the earliest zOOLOGICAL CABINET in Europe. His book on mineralogy describes the forms of crystals of different minerals, besides fossil shells.

I5I7-64. Belon studied BIRDS AND FISHES, adding much to the stock of previous knowledge.

Botany was advanced by

I498-I 554. Tragus, Cæsalpinus, and Lobel.

I5I9-I6o3. Cæsalpinus made valuable additions to this branch; knew some I,500 species, 700 of which had been collected by himself. He distributed them into sixteen classes according to their seeds; was the first to point out the reproductive action of stamens. His CLASSIFICATION was the first attempt of the kind in modern Europe. In other fields he discovered the constant form of CRYSTALLISATION in metals, and the increase of weight of metals by 
oxidation; in physiology, he observed the swelling of veins below ligatures, and inferred from it the refluent MOTION OF THE BLOOD in those vessels.

I538-I6I6. Lobel discovered the two GREAT GROUPS of the vegetable kingdom-the monocotyledons and the dicotyledons.

Physio.ogy had its foundations strengthened by

I56I-I638. Santorio, who introduced the THERMOMETER, HYGROMETER, and the BALANCE into the study of life; discovered the process of cutaneous perspiration.

Anatomy received a powerful impulse from

I405-I464. Piccolomini, who gave a scientific basis to general anatomy by his description of the CELLULAR TISSUE.

I463-I5I2. Achillini observed the course of the cerebral cavities into the inferior cornua; knew of the ileo-cæcal valve and other facts unknown before him; described the malleus and incus-two TYMPANAL BONES; showed the tarsus to consist of seven bones; rediscovered the fornix -a triangular brain lamina, and the infundibulum-braintunnel.

I483-I553. Fracastoro made valuable observations on CONTAGION.

I 509-I553. Servetus nearly detected the course of the circulation by his persevering DISSECTIONS.

I 5 I4-I564. Vesalius, who deserved the title of FOUNDER OF MODERN ANATOMY, showed the discrepancies between the results of dissection and Galen, who had never dissected the human body and had given a wrong description of it. To Vesalius mainly we owe the transformation of anatomy into an exact science, and by that fact a solid foundation was given to medicine. Vesalius's book was illustrated by the best artists of Italy - a great help to students.

I523-I552. Fallopius studied the general anatomy of the BONES; described the EAR with great accuracy, and made assiduous researches into the organs of reproduction.

1527?-I574. Eustachius discovered the EUSTACHIAN TUBE, leading from the ear-drum to the throat.

I 530-1589. Arantus was the first to describe the inferior 
CORNUA of the ventricles of the cerebrum; speaks of the choroid plexus.

I581-1626. Asellius discovered the LACTEALS (1622), which carry from the intestines the nourishing matter of the food to make fresh blood-a discovery made more complete in 1647 by PECQUET, who determined the function of the thoracic duct (which conveys blood-making fluid into the large veins, and then to the heart); and in 1649 still more so by RüDBECK, who detected the lymphatics, which play the same part as the lacteals in other parts of the body. These three anatomists thus supplemented and crowned the labours of Harvey, by finding and tracing the vessels which carry nourishment to the blood.

Medicine and Surgery meanwhile were advancing through

I 5 I7-I590. Paré, who created modern surgery, and was the first to understand the nature and treatment of FIRE-ARM wOUNDS; replaced red-hot iron cauterisation by the binding of arteries after amputation-a reform which saved thousands of lives.

\section{553-i6r7. Alpinus created DIAGNOSIS.}

(Fl. I534.) Coiter created PATHOLOGICAL ANATOMY; he studied the influence of the brain and the action of the heart, and distinguished himself by his researches on the nerves, the bones, and the cartilages.

(F1. 1540.) Plater set forth the CLASSIFICATION of disease.

All these learned men-and many more could be mentioned-contributed in one way or another work done for all times. They did more. By them, men were taught one great lesson: that Aristotle, Ptolemy, Galen, had been far from settling everything for ever as it had been asserted for centuries; that there were whole groups of phenomena they had not suspected, let alone their mistakes; that NATURE, THE SUBLIME TEACHER, must be examined and consulted; and that it exercises more sway over truth than human authorities, however revered for their antiquity, their station, their number, and their unanimity. The Church, the interpretation of Scripture, the science of ages, the testimony 
of the senses of hundreds of generations, the weight attached to fifty centuries of unanimous belief among kings, princes, legislators, thinkers in all countries, the wisdom of humanity may be dead against a theory held by a daring solitary man -and, yet, that one man, armed with a single physical fact, is enough by himself to overthrow for ever the consensus of mankind and the revered opinions of mighty men. ONE FACT PROVES STRONGER THAN HUMAN WISDOM. A Galileo or a Magellan outweighs a thousand generations.

This lesson was the result of the wonderful development of scientific activity and enlightenment in every direction. This scientific activity was made still more evident by the foundation of -

Learned Societies :

The Natural Academy of Naples, created by Porta in 1560 ;

The Lyncean Academy of Rome, created by Prince Cesi in 1603 , soon followed by the creation of

The Accademia del Cimento at Florence (1637),

The Royal Society in London (1645),

The Royal Society of Sciences in Paris (I666).

The Practical Arts, by the side of all this, had advanced immensely, witness Distillation, Glass Making, the Ceramic Art, the application of Chemistry to Art, Medicine, Industry.

The Plastic Arts, besides-Architecture, Sculpture, Painting-had reached incomparable perfection through
BRAMANTE
LEONARDO DA VINCI
MICHAEL ANGELO
Titian
GIORGIONE
RAPHAEL
Correggio
Cellini
(I449-I 5 I4),
(I452-I 5 I9),
(1474-I 564),
(I477-I 576),
(I477-I5 I I),
(1483-I 520),
(I494-I 534),
(I $500-$ I 570 ).

The logic of these facts is irresistible; they cannot be explained away by any sophistry. It is in the face of this surging progress that it has been asserted and repeated again and again, that nothing worth mentioning had advanced since Aristotle until Francis Bacon's time.

How the name of "Dark Ages" was ever given to the 
centuries which are illumined by so many marvels passes all comprehension. If, owing to the deluge of Germanic barbarism, it can justly be applied to the centuries which immediately followed the break-up of the Roman empire, it is wholly inapplicable to those ages which preceded the Revival. And, as we have already hinted, it is a rather misleading appellation even if applied to the earlier period. The wretched social conditions of the times, the anarchy prevailing in the political arena, the sway of a powerful Church dominated by ambition and superstition, made the mediæval era as unlike ours as possible; but these defects, arising from the dislocation of the ancient world, did not necessarily involve the whole of the mediæval era in darkness. Why, the lay world and the Church itself were hardly ever without great and brilliant intellects. The defects lay in the general situation. The world had a new civilisation to elaborate, and its various elements-the sacerdotal, the monarchical, the aristocratic, and the democratic-trying each in turn to be completely dominant, and never succeeding, made the process of gestation very fitful and slow. The conflict was unavoidable and beneficial, leading as it did to two results unattainable any other way, and which no other civilisation had as yet effected: it endowed Europe with immense and durable mental and physical energy; it brought in the live-and-let-live principle of governmentthat is, it conduced either to the welding of the elements just mentioned to form a new society, or to the conciliation of these elements so as to permit them to exist side by side in the same society.

Now, whether a period which produced men like

Urban II.,

Henry IV. of Germany,

Abelard,

Barbarossa,

Innocent III.,

Frederick II. of Germany,

Innocent IV.,

Clement IV,

Louis IX., d. I099, Thomas Aquinas, d. I274, I IOI, Albertus Magnus, I280, I 142, Roger Bacon, I292, I 190, Duns Scotus, I308, I2 16, Dante, I32I, 1250, Petrarca, I374, 1254, Boccaccio, I375, I268, Wiclif, I387, I270, Chaucer, 
and some others,* deserves the epithet of dark, because serfdom, violence, and superstition existed, is more than questionable, considering that slavery still existed in America thirty years ago, and that violence and superstition were almost as prevalent in the XVIIth century-witness the Thirty Years' War and the religious persecutions-as they were five hundred years before. And if we look at the society of the times, we come to the same conclusion. The social conditions described by Boccaccio and Chaucer, which are so striking in many ways, and which reveal so much sense, politeness, wit, and elegance, could not have come into existence in one day. They could only be the results of a lengthy and steady course of moral and mental training. The beautiful correspondence and exquisitely refined poems of Petrarch would, by themselves, suffice us to arrive at the same verdict. Had we such pictures and such works alone before us, we never could apply, if we look at them rightly, the term "dark age" to that in which the society they represent existed. In Art also-architecture and music especially - the progress effected before the XIIIth century set in would lead us to a similar conclusion. But when, in addition to the rulers, thinkers, and writers just mentioned, and to the social state and artistic work we are alluding to, we find a host of great men exploring every field of human knowledge, and making countless beautiful discoveries, it then becomes absolutely impossible to apply the words Dark Ages to the times in which they lived-certainly not, at all events, to the centuries which preceded the Revival and gave birth to the progress in the scientific arena of which we have presented a noble roll. It is therefore as well that we should protest against the indiscriminate use of them, if we wish to see those times under their true

* Damiano of Ravenna (d. 1072), Gaunilon of Marmoutier (d. I IOO), Anselm of Laon (d. Ir17), Hildebert of Tours (d. I133)-all Realists; Champeaux (d. II2I), Hugh de St. Victor (d. Ir 40 ), Robert Pulleyn (d. II 50), Lombardus of Novara (d. Ir64), John of Salsbury (d. I180), Simon of Tournay (d. I200), David of Dinant (d. I200), Alain de Lille (or de Ryssel), (d. 1203)-all famous Nominalists; and after them for a century, a number of Aristotelians, Averroists, Thomists, Scotists, and Lullists. 
The Middle Ages and During the Revival. 67

colour and aspect. After the first Crusade, say after THE YEAR I IOO-to draw a precise line, and conscious that in so doing we are understating the case, as the next chapter will convince us-light dawns rapidly, and the appellation can apply intellectually no longer in any way. The XIIIth century was so fruitful that it would have witnessed a complete revival had it not been for the great wars which slackened the intellectual movement. 


\section{NUMEROUS CAUSES OF SCIENTIFIC PROGRESS.}

Now, in order more fully to account for the immense development of science during the Mediæval and Revival Periods, we must not omit to mention other concurrent causes of progress, at once numerous and powerful, besides. those upon which we have already laid particular stress. The roots of that development were both ancient and deep, and they were of a nature to grow vigorously, if slowly.

By the side of the influence exercised by the Arabs, and through them by antiquity, the social and political changes which took place in Europe, between the time of the Crusades and that of the Revival, constituted a revolution probably, unique in magnitude in the annals of the human race-since the other revolutions, such as the Revival itself and the Reformation, were, in part, offshoots of it-and that revolution, as we will proceed to show, was exceedingly favourable to the scientific advance.

The Crusades caused the birth and rapid growth of European industry, and the latter necessarily led to the individual emancipation from serfdom, and to the communal and political enfranchisement of millions of men, many of whom formed a wealthy Burgess class remarkable for thrift, ambition, and energy. Soon, many of the drawbacks which existed in antiquity began to disappear, while new elements of advancement, all of them irresistible, came into being.*

* See Hallam's "State of Europe in the Middle Ages," Vol. II., chapter ix., part 2. 
The sea, by the fresh rise of navigation, became the main highway of transit, even before the Compass made its appearance, and intercourse between East and West revived. Old barriers, social as well as geographical, were by degrees weakened in every direction. Associations and co-operation gave collective strength to trade. Commercial wealth, now created, widened "Economy," until then agricultural only, and vied with land-wealth in devising novel sources of material welfare. Capital, a new factor, centred in many points, faced vast enterprises. The bill of exchange suppressed the distance of money markets. Mining supplied raw material hitherto limited. The abolition of slavery and serfdom meanwhile gradually induced mechanical contrivances to replace and multiply hand labour. The practical skill and the operations involved in industry and art had natural consequences of a high order: they stimulated competition unknown till then; they raised, by several degrees, the intellectual power of the artisan and burgess multitude; they conduced to improved processes of production, that is, to a vast number of inventions,* many of which were as favourable to the scientific movement, such as it was, as to industry. Warfare itself became scientific from the use of fire-arms. Simultaneously, the practice of art, together with the growth of the æsthetic faculty, and of the activity consequent upon it, was likewise beneficial to practical science, which in its turn no less beneficially reacted upon art and industry. Marvellous cathedrals in every country afford splendid and irrefutable evidence of that fact. In France alone II 28 great churches were built in the XIth and XIIth centuries, besides 989 new monasteries (most of which opened schools) during the XIIth and XIIIth centuries. The creative power which could give birth to such architectural wonders is also to be found in sculpture, in painting, in music; it is evidenced with equal variety in

* As early as the Xth century the mathematical science and mechanical inventions of Gerbert (better known as Pope Sylvester II.), d. 1003, were sufficient to give him a great reputation (Hallam). $\mathrm{He}$ had studied at Cordova. The Indian numerals, algebra, the pendulum clock were introduced into Europe by him. 
literature, from the "Divine Comedy" to "Canterbury Tales" as from the "Decamerone" to "Gargantua," or from the "Song of the Niebelung" to "Reynard the Fox"; it is also displayed in mechanical art, from the organ and clocks to fire-arms and the violin. CThe taste for learning led to the creation of universities in every land,* and soon to that of public libraries. $\dagger$ How could originality at once so exuberant and inexhaustible draw a line at science? It did not. The intellectual evolution was manifold and universal : it varied only in degree. It is undeniable that, under these new circumstances, successive multitudes of students $\ddagger$ were attracted to the universities by Natural Philosophy, just as much as by Jurisprudence and Theology, although natural philosophy was taught in an attenuated form, and under the fiery and watchful eye of jealous and dogmatic churchmen. That natural philosophy was in the air, so to speak, is proved by the numerous adepts in ALCHEMY who, at their peril, were at work everywhere during the Middle Ages. This was the most attractive of the scientific studies then pursued, because it was understood, however vaguely, to be the link between organic and inorganic science, and hence pregnant with potentialities. If they conspicuously failed in the transmutation of metals, they achieved "very considerable success in the department of synthesis" and the formation of new combinations-one of the main pursuits. of the chemists of the present day; for, "to decompose

* At Salerno, Bologna, Paris, Oxford, Cambridge, Padua, Naples, Toulouse, Montpellier, Salamanca, Orleans, Bourges, Angers, Prague, Leipsic, and many others in Germany. Most of these had in time the four Faculties of Theology, Canon-Law, Medicine, and Arts-and the Faculty of Arts gave instruction in the Trivium (Grammar, Logic, and Rhetoric), and in the Quadrivium (Arithmetic, Geometry, Music, Astronomy). The universities were essentially lay centres of learning, and that was an all-important change: Salerno and Montpellier were schools of medicine, Bologna and Orleans great schools of Roman law, Paris the great theological school; but if such was in the main their respective strength, they also afforded instruction in all the other channels of learning.

+ Paris, Oxford, Glastonbury Abbey (400 volumes), St. Albans, Heidelberg, etc.

$\ddagger$ There were as many as 10,000 at Bologna, 5,000 at Oxford, over 25,000 at Paris, etc. 
metals, to re-form them, to change them from one to another, and to realise the once absurd notion of transmutation, are the problems now given to the chemist for solution." This from Faraday, and to show the reader that the alchemists were far from being poor dreamers whose researches were founded on total ignorance. A further evidence of the taste for scientific research is to be found in the ENCYCLOP\&DIC WORKS composed during that time,* large portions of which were, notwithstanding the prevalence of theology and scholastic metaphysics, devoted to the exposition and teaching of the various branches of natural philosophy then in existence. Besides, a vast number of books dealt with each branch in a separate form-a fact which implies the existence of many teachers and countless pupils. So great and ubiquitous was the scientific bent, that numerous didactic poems were composed everywhere, on natural history, mineralogy, geography, astronomy - a fact which speaks volumes about the growing taste. Why, even chroniclers, so meagre and dry before the XIIIth century, became remarkably learned and shrewd. Not only did they show a rare comprehension of important events, of their causes, of their effects, but they inquired into questions of morals, geography, ethnology, natural history. This is particularly the case with William of Tyre and James de Vitry (1200), amongst others-and the fact constitutes a conspicuous sign of the times. Religious ideas no longer despotically swayed the human mind to the exclusion of all else; the Crusades had freed it from that sway, $\dagger$ and one of the main consequences of that eman-

* We need here only mention the work of Albertus Magnus, Roger Bacon, Albert of Saxony, Vincent de Beauvais, Ramon Lulle, Basil Valentine, and later on, Ringelbert of Basel (154I), Alsted (1620). The authors of separate works are to be counted by hundreds. (See Hallam, 499.)

+ The Crusaders had seen their own inferiority to the Greeks and to the Moslems in matters of refinement, art, literature, science; they had seen the Church "at home," in Rome, and had quickly perceived the laxity of morality among the high clergy, detected the selfish policy of the papacy, and the part played by earthly interests in the so-called religious questions; they had seen and understood worldly ambition to have been the spring of action of the nobility which rushed to the East; they had travelled, seen many peoples, monumental cities, two distinct 
cipation was the growth of the scientific spirit in all directions throughout Europe. Roger Bacon was undoubtedly the boldest and most original innovator of the mediæval era; in him the Experimental School had an earnest inquirer and an enthusiastic master; but, had he never existed, the scientific method must nevertheless have resulted, later possibly, from the pursuit for generations of two great series of labours, viz., astrology and alchemy, which, in their higher flight, must not be confounded with the occult sciences, survivals of fetichism more or less, such as magic, necromancy, chiromancy, sorcery, cabalism.

Astrology and alchemy were immensely beneficial to progress. They afforded for a lengthy period the strongest stimulus to scientific investigation. In the absence of scientific analysis, which alone could assign their true position in general physics to astronomical phenomena, "there existed no doctrine, no principle that could restrain the ideal exaggeration ascribed to celestial influences"; astrology was such an exaggeration; but, it rested upon the subjection of all phenomena to immutable natural laws. Astrology, therefore, was in the highest degree serviceable in sowing and propagating a notion (I.) of the unchangeableness of the laws of nature, and (II.) of the subjection of phenomena to those laws, "by which a rational prevision became possible." Alchemy rendered the very same service in that respect; so that these two pursuits contributed largely to the development of human reason on the one hand, and of science on the other: the first (astrology), among other benefits, engendering a "high idea of human wisdom from its power of foresight under natural laws"; the second (alchemy) rousing a noble sense of human power, by "inspiring bold hopes from our intervention in those phenomena which were susceptible of modification." Science, thus, was the outcome evolved from simultaneous causes. It was not, mushroom-like, of sudden, unexpected, unsuspected growth; it was not due

civilisations superior to their own in many ways, and their intellect was enlarged in proportion. Narrow ideas had died out; the sphere of activity had ceased to be solely theological-it had become political, commercial, industrial, literary, artistic, and scientific. 
to one man; it was not the result of a method alone: it owed its birth to concurrent energies, practical in the main; but its final parturition was the work, as we have said, of the great men who preceded Kepler, Galileo, and Harvey, just as its culture and immense advancement after Kepler, Galileo, and Harvey were the work of the great men whom we shall mention - the earlier and the later movements being connected from beginning to end by an unmistakable filiation of discoveries. The concatenation presents a series of powerful links without a single break.* It is obvious at a glance, especially in its main points. The discovery of Copernicus, and the labours of Tycho Brahe consequent upon it, prepared the way for the investigation of Kepler, which constituted the true system of celestial geometry and gave birth to celestial mechanics; Galileo's mathematical theory of motion, and his discovery of the laws of falling bodies, together with Descartes's mathematical revolution, necessarily followed by Huygens's discovery of the law of centrifugal force, led to Newton's final discovery.

This brief summary suffices to demonstrate how unbroken the evolvement of science was without the intervention of an outside agent. The evolutionary law, in fact, worked throughout the Mediæval and Revival Periods with irresistible force, and without any deviation from its natural and necessary course. 


\section{CHAPTER VII.}

\section{ROGER BACON.}

In the preceding chapters the immense scientific progress effected until the end of the Revival Period has been briefly described. In the present chapter the special work of Roger Bacon will be considered; and, as that work is important as a fact of scientific history, whether it be viewed for its intrinsic value, or as a connecting link between the Arabs and the Revival Period-since like the hand of a clock it indicates the height of the flowing tide at the time-it will be interesting to establish a comparison between Roger Bacon and Francis Bacon, which will enable the reader to form a judgment upon their respective originality, worth, and influence. It is acknowledged by his greatest admirers that Francis Bacon was, in scientific acquirements, vastly inferior to his immediate predecessors; but it is not a little surprising to see that men who lived three hundred years before him were also in possession of knowledge far superior to his own. This was particularly the case with regard to Albertus Magnus and Roger Bacon.

Albertus Magnus (1 193-1280). This great man might take whales for fishes and bats for birds-an error shared until more recent times by many writers - but his classification of the Animal Kingdom is admirable, and his work on Natural History is rich in botanical descriptions. $\mathrm{He}$ described the principal forms of flowers; he detected the embryo of seeds; he also detected the sleep of plantshits which are suggestive of the use of the lens. He planted 
the germs of cerebral physiology. He studied in a special manner, besides zoology and botany, both physics and mineralogy - adding, now and then, his own observations to those on record before his time. His mineralogy proves the accuracy of his observations: on the question of aerolites, he gave the different theories still held only fifty or sixty years ago. He explained the origin of thermal springs as a modern observer would have done. It is notorious that Francis Bacon cannot show credentials like these, light as they may seem to us when weighed by the standard of modern knowledge.

It is, however, when we come to

Roger Bacon (1214-I292) and his work that the inference is forced upon us that Francis drew all his inspiration for his own labours from his namesake, for all the sound notions found in the Novum Organum, De Augmentis, etc., can be traced back to Roger's. The parallelism as to plan and ideas is a revelation full of surprises.

The two Bacons take the same direction and have the same goal in view; but the earlier Bacon, it strikes one upon the most superficial examination, is the original thinker, unites theory and practice, seriously labours towards the great object, whereas the Elizabethan Bacon stands in the light of a borrower content to theorise, shamming practice some would say, and working to a great extent from ostentation.

The parallelism between them presents three very striking points. First, we have errors which both men shared alike; second, we have errors which Roger discarded, but which were persisted in by Francis; lastly, we have sound notions shared in common by both.

I. Taking first the errors the two Bacons cherished, we find that $(a)$ Roger believes in the transmutation of metals and the making of gold; so does Francis-both taking their notions chiefly from the Byzantine alchemist Psellus (XIth century). (b) Roger believes in the means of prolonging life; so does Francis-both endorsing one of the most delusive hopes of the alchemists. (c) Roger thinks his method capable of equalising men's minds, and making science easily 
accessible to all in an equal degree; so does Francis-both ignoring the great part played in the history of discovery by native genius, by chance, and by analogy.

II. Taking in the next place the errors which Roger discarded, but of which Francis was a believer, we find that (a) Roger disbelieves in magic; Francis, on the contrary, believes in it. (b) Roger disbelieves in astrology; Francis, on the other hand, believes in that art. (c) Roger, again, disbelieves in talismans, whereas Francis believes in their power, and what is more, strongly believes in witchcraft and spirits besides. This divergence of views, on subjects of such capital importance, between two men who appeared at three hundred years'distance from each other, and who are popularly thought to have been representative characters-the early one of the Middle Ages, the other of the Revival - is a startling fact, since we find here the very reverse of what we should expect. The modern Bacon entertained doctrines which had died out three centuries before among many of the educated class; the earlier Bacon - the man of the XIIIth century - entertained the very views which the present world entertains with regard to these subjects.*

III. Coming lastly to the third series in the parallelism we are drawing, that is, the sound notions which the two Bacons held in common, we find that both (a) projected a dictionary of the Arts and Sciences ; (b) both treated of optics, and called that branch "Perspective"; both also used the expression "prevogatives of experiment." This double coincidence is very remarkable. (c) Both denounced Scholasticism with vehemence, as a school moving in a circle of abstractions, foreign to the sense of reality and the contemplation of nature-a school at once artificial, subtle, disputatious, and pedantic, shutting up the mind within its sphere, and removing it from natural phenomena. Both Bacons therefore denounced Authority. (d) And denouncing Authority, they

* In justice to Francis Bacon, we must not think that he was the only eminent man of his time who believed in magic, astrology, talismans, and spirits. No ; many men of science-Kepler among them-shared these delusions. What is significant, however, is that instead of being in the van of progress in these matters, Francis Bacon was less emancipated by knowledge than some great minds of earlier ages. 
declared war against the ancients as well as against the Schoolmen. Roger protests against the yoke of Aristotle and the ancients in words which it is impossible not to admirewords spoken then for the first time, and which the echo of centuries has repeated as an undeniable truth. "Scarcely half a century ago," says Roger,* "Aristotle was suspected of impiety and proscribed from the schools. And now he is presented as a sovereign master! What is his right to it? $\mathrm{He}$ is learned, they say; granted; but he does not know everything. He has done in his time what was possible then; but he did not reach the utmost boundary of wisdom. Avicenna has made grave mistakes, and Averroes might be criticised upon more than one point. The very saints are not infallible; they were often mistaken, and were obliged to retract, witness St. Augustine, St. Jerome, and Origen. But, says the School, the ancients must be respected. Eh! doubtless, the ancients are venerable, and we must show ourselves grateful to them for having traced the way to us; but we should not forget that these ancients were men, and have erred more than once; they have even committed the more errors in proportion as they were older, for the youngest are in reality the oldest; modern generations must surpass. those of former times in enlightenment, since they inherit all the labours of past ages." A page of wisdom this! Francis Bacon's famous "Juventus Mundi" (the youth of the world), which has been so often quoted, and for which he has been so often praised, is the very embodiment of the idea expressed by Roger, at the end of the passage just cited. But to continue: (e) the two Bacons declared that art, borrowing nature's own forces, must enable men to domineer over nature itself. Roger was the first to expound this grand idea which would ensure the omnipotence of man's genius. $(f)$ Both great men treated of the general causes of ignorance, the chief of which was the influence of Authority in every shape-both detecting four obstacles to science which differ very little except in name : the four offendicula of RogerI. Influence of unworthy authority; II. Custom; III. Imper-

* Compendium Philosophiæ, Cap. II.

+ De Mirabili Potestate Artis et Natura. 
fection of undisciplined senses; IV. Concealment of our own ignorance, become with Francis the Idols of the Theatre, the Idols of the Forum, the Idols of the Tribes, the Idols of the Den. $(g)$ Both men, again, proclaimed Experience to be the sole guide of the scientific pioneer-that is, they advocated the study of the physical sciences, subjecting it to reason. "Experimental science," says Roger, " is the mistress of the speculative sciences, and has three prerogatives. First, she tests and verifies the conclusions of the other sciences; secondly, she discourses on the notions which other sciences deal with-magnificent results to which these sciences are incompetent. Thirdly, she investigates the secrets of nature by her own powers." "I call experimental science,"* says he again, " that one which neglects (puts aside) arguing; for the strongest arguments prove nothing so long as conclusions are not verified by experience." " Experimental science does not receive truth from the hand of the superior sciences ; for it is she which is the mistress, and the other sciences are her servants. She has the right to command all the sciences, since alone she certifies and consecrates their results. Experimental science therefore is the queen of sciences and the bound of all speculation." "In all researches," he goes on, "we must use the best possible method. Now this method consists in studying in their necessary order the diverse parts of science, placing in the first rank what should really be found at the beginning : the easiest before the most difficult, the simple before the composite, the general before the particular. We must also choose as a study the most useful objects on account of the brevity of life. $\dagger$ Science must be exhibited with clearness and certainty, without mixture of doubt and obscurity. Now all this is impossible without experiment, for we have, indeed, various means of knowing-authority, reasoning, experiment; but authority has no value unless it is accounted for (Non sapit nisi detur ejus ratio); it does not enable one to understand, it only makes one believe; it imposes itself upon the mind without enlightening it. As to reasoning, sophistry cannot be distinguished from demonstration, except

* Opus Tertium.

+ Francis Bacon advocated science on utilitarian grounds. 
only by verifying the conclusion by experiment and practice." Again: "There are two modes of investigation, viz., through argument and through experiment. Argument concludes, and makes us conclude the question; but it does not certify, and cannot remove doubt in such a manner that the mind may remain in sight of truth, unless it finds it through experience; because many use arguments towards the knowable, but because they use not experiment they neglect (pass by) attainable things, and neither avoid injurious things, nor strive after good ones. For, if any man who has never seen fire has made it credible through sufficient arguments that fire burns and harms, and even destroys things, the mind of the hearer would never on this account be still, and would not avoid fire before he has put his hand or anything combustible into fire, so that he would prove through experience what argument taught, but by the additional experience of combustion the mind is made certain, and finds rest in the brightness of truth-whence argument does not suffice, but experience does." This pregnant and luminous passage shows what a clear idea of verification Roger Bacon entertained, and what capital importance he attached to experiment. It is impossible to find in any scientific author a clearer explanation and a sounder injunction.

The doctrines of Roger Bacon, we see, are not the germs only, but also the backbone and sinews of Francis Bacon's Novum Organum.

After thus marching side by side the two Bacons part company, the one in pursuit of knowledge, the other in pursuit of shadows; for, over and beyond the objects we have enumerated Francis Bacon does not proceed, whereas Roger performs work at once extensive and significant, which leaves the would-be Instaurator nowhere in the race of progress.

The history of science is at rare intervals summed up, and personified, so to speak, by great encyclopædic minds. Twenty-two centuries have produced but few such onesAristotle first, Humboldt last, and between them Avicenna, Averroes, Albertus Magnus, and Roger Bacon; for Pliny 
and Diderot-to name the most famous-"devoted their labours to researches of erudition only," and were not, like the first, earnest practical inquirers, observers, manipulators, and experimentalists; so that Roger Bacon belongs to the same genus as Humboldt.

Roger Bacon was not only familiar with the science of the ancients and that of the Arabs, but he knew Arabic, Hebrew, Latin, Greek, and was able to compose works in the three last tongues on mathematics, physics, chemistry, astronomy, medicine, geography, physiology, and theology. His equipment in point of scholarship alone was of a far more weighty kind than Francis Bacon's, it is clear. Then he spent his fortune in travels, books, instruments, and experiments, in all of which Francis (books excepted) did not spend half-a-crown. That speaks volumes as regards earnestness; but what is more to the purpose and far more significant, Roger devoted all his time, energy, and mind to scientific pursuits, and suffered years and years of imprisonment for his science; the other devoted his time and faculties to worldly ends, and dabbled in science only for worldly purposes. If he, too, went to prison, it was for debt incurred for diamond rings.

What now were the achievements of Roger Bacon in natural philosophy which give him a unique place in the history of the Middle Ages, and made him the precursor of modern science to the exclusion of his great namesake?

A. In the first place, Roger's clear insight, as G. H. Lewes has pointed out, is displayed in the recognition of the essential connection of all the sciences. "All sciences," says he, "are connected together, and mutually assist one another, like members of the same body, each one of which performs its own function, not only for itself, but for all the others." * Here we have the interaction of the sciences on one another noticed with a force which Francis failed to express when he faintly reproduced the same idea (Nov. Org. I. 107).

* "Omnes scientiæ sunt connexæ et mutuis se fovent auxiliis, sicut partes ejusdem totius, quarum quælibet opus suum peragit, non solum propter se, sed pro aliis." -(Opus Tertium, Iv.) 
B. Next, we find Roger intimating that there are two sorts of observations-the one passive and vulgar, the other active and learned. The latter alone deserves the name of experiment :

"There is," says he, "a natural and imperfect experiment which is unconscious of its own power, which does not understand its proceedings, and is in use among artisans, and not among the learned. Over and above it, above all speculative sciences and all arts, there is the art of making experiments that are neither weak nor incomplete." But how will experiments arrive at precise results? By calculation, for "Physicists must understand," says he, "that their science is powerless, if they do not apply to it the power of mathematics, without which observation languishes and is incapable of certainty."* In Francis Bacon, again, we see the intimation of the fact that observations are of two kinds; but he completely failed to grasp that which lies at the root of this injunction-the importance of calculation in scientific researches-and the absence of this requirement would by itself suffice to vitiate his method and instruction even if these were right in all other respects. The unfortunate fact that he puts mathematics aside as an unworthy and deceptive instrument proves his want of perception of the means and ends of science. Roger, with masterful knowledge, sets forth the foremost importance of mathematics with unerring force; so that it is clear, as Lewes justly observes, that "after having denounced the incompetence of the syllogistic method of the schools, he endeavoured to substitute for it the scientific method and its two handmaidens, mathematics and experiment," thereby founding the Experimental School. And Roger, lest he should seem faint-hearted, fears not to reiterate his injunctions: "The exposition must be demonstration. That is impossible without experiment. We have three means of knowledge-authority, reasoning, experiment. Authority has no value unless its reason be shown: it does not teach ; it only calls for assent."

At a time when authority was supreme and was accepted as an article of faith, he had the courage to write in this * Opus Majus, p. 199 (Jebb's Edition). 
strain - the courage, that is, to defy authority, and to advise men to shake off its yoke, and examine all and everything for themselves! No wonder he spent twenty-four years in confinement. "In reasoning," he continues, "we commonly distinguish a sophism from a demonstration by verifying the conclusions through experiment," and we find him constantly insisting upon the necessity of "verification" and the "futility of argument."*

C. Furthermore, "Armed," says he, "with experiment and calculation, science must not be content with facts, though these may have their utility; it seeks truth; it wants to find out the laws, the causes-canones, miviversales regulce." $\dagger$

D. Roger was not an advocate of calculation only; he was a skilful practical MATHEMATICIAN himself. He rightly considered mathematics as the key of several other branches, and he resolved problems of mechanics, optics, astronomy, by the use of geometry.

E. Roger was a real CHEMIsT, for the way he speaks of the properties of metals alone shows that he handled the things he mentions. He knew that there are different kinds of air (gases), and that one of them extinguishes a flame; he invented the experiment of burning a candle under a bellglass to prove that the candle goes out when the air is exhausted. But his most astonishing conception, perhaps, was his anticipating the suggestion of our greatest modern chemists, that the elements, as we know them, are evolved from a primal matter (whether this be helium or protyle). $\mathrm{He}$ says: "The elements are made out of $\tilde{v} \lambda \eta$ (the stuff of which things are made), and every element is converted into the nature of another element" (De Arte Chymice)-as if indeed he had a correct knowledge of the simple chemical elements, and, at the same time, understood them to have been built up of an earlier and simpler primordial kind of matter endowed with potentialities capable of developing such characters and energies, as the changeable conditions of heat and pressure forced them to assume. It is of all things

* Opus Majus, p. 336-7; Opus Tertium, Cap. XIII.

† De Coelestibus, Cap. I. 
the most unlikely that he should have known as much about the elements as all this; but the fact remains that the idea of chemical evolution is implied in the words we have quoted. The only explanation we can suggest to account for such a pregnant idea is that, as the alchemists sought to effect transformations of all kinds and often succeeded, Roger was led to the conception that nature could transform everything, and at the beginning of things had compounded various elements out of one-a wonderful conception! Need we mention that Francis was unable to appreciate chemistry and its founders?-his knowledge in this respect stopped at boiling sandstone soft! - a comical experiment which no chemist in the world ever accomplished before or since.

F. Roger was also a true PHYSICIST-of high order too. Before we see his more important work as such, we may note in passing that he mentions a phenomenon which seems to have been observed and recorded for the first time by him, viz. the warm temperature of mines (a fact denied by Francis Bacon), and the constancy of that warmth.* "In mineralium vero locis invenitur calidas semper constans." We state this detail for the mere purpose of showing the varied range of his researches. It was in optics, however, that he proved his competence. He treats of this branch in several works. In "Perspectiva" he describes the eye and the sense of sight; explains the anatomy and physiology of the eye; expounds the laws of refraction and reflection; and evidence is also found in that work that he reconstructed the concentric mirrors of Archimedes. In "Mirabili Potestate Artis et Nature," he again treats of refraction of luminous rays, and explains by it the mirage so frequent in the East. In Opus Majus he deals (page 337) with magnifying glasses in a superior manner. After describing concave and convex glasses and the difference of their respective effects, he says: "It is easy to conclude from the laws just spoken of that the largest things may appear small, and vice versâ ; that remote objects may appear quite close, and reciprocally; for we can cut glasses in such a manner, and adjust them in such a way as regards our eyesight and exterior objects, that the beams

* Speculum Alchemiæ, Cap. v. 
are broken and refracted in the direction we choose; so that we shall see a close or a remote object under whatever angle we please; and thus at an incredible distance we should read the most minute letters, we could count the grains of sand and of dust, on account of the great width of the angle under which we should see them, for the distance by itself has no direct importance, but the size of the angle has. And so, a child would look like a giant, a man appear a mountain. And likewise for distance; so that a small army would seem very large, and placed very far would appear very near, and reciprocally. In this manner we could make the sun, the moon, and the stars descend to us so to speak by bringing their figure close to the earth."

From such a description to the telescope the distance is not very great, and it is quite possible, as some writers have thought, * that he constructed a telescope for his own use. For we must remember that the Egyptians, and the Greeks after them, made some of their astronomical observations by the means of a long narrow tube, called dioptra, which permitted them to isolate a star, and so prevent in a certain degree the reflection and refraction that made accuracy of observation well-nigh impossible for the naked eye. This tube passed from the Greeks on to the Arabs, and Roger Bacon must have known and used it. He does not describe it particularly, but neither does he describe particularly any of the instruments and apparatus in common use which he mentions in Opus Tertium. And as he was on the one hand fully aware of the properties of magnifying glasses, a man of his rare ingenuity might very well have tried to adjust magnifying glasses to the dioptra, and thereby have madesome rough kind of telescope. He would soon probably be led to improve it and make it a more serviceable instrument by the insertion into it of a smaller and narrower dioptra, which would slide up and down so as to give a right focus. His recommendation of the reform of the Calendar would not, taken by itself, warrant the belief that he invented thetelescope, since ordinary visual observation and mathe-

* S. Jebb, Wood, Cuvier. Cuvier thought he could even recognise in one of Roger Bacon's descriptions, that of the plain microscope. 
matical calculation would suffice for advocating such a reform; but when, together with that recommendation of his, we consider his knowledge, his practical bent, his creative mind, his probable acquaintance with the dioptra, and when we read the foregoing description, we find it difficult to resist the inference that he had a telescope. Whether he had or not, however, the hints he gave were in themselves almost certain to lead to the invention of that instrument.

Be that as it may, there is no doubt that in Optics he stands as one of the pioneers of modern science. Not only did he know the labours of Alhazen in that respect, but he first had the eminent merit of describing the complicated mechanism of the eye "with rare precision," and even suspected the action of the retina. And not only this, but he maintained, against the authority of Aristotle, that the propagation of light is not instantaneous. "Authors," he says, "Aristotle included, teach that the propagation of light is instantaneous; whereas the truth is that it takes time to be effected-a time very short, but indeed measurable."* $\mathrm{He}$ also held that the light of stars belongs to themselves, and is not reflected solar light. He tried, besides, to account for stellar scintillation, and to explain the curious phenomenon of shooting stars. These bodies, according to him, are not real stars, but bodies relatively small (Corpora parve quantitatis) which traverse our atmosphere and are ignited by the very rapidity of their motion! This, indeed, shows his marvellous scientific intuition. With the same rare power of reading natural phenomena aright, he also explained the rainbow by pointing out that the sun's rays are refracted by the falling drops of rain, for he had noticed the "analogy of the rainbow colours with those produced by drops of water and by crystal"; he desires us to consider "the objects which present the same phenomenon," and he mentions "the hexagonal crystals from Ireland and India, though we are not to suppose the hexagonal form is essential, since similar colours may be detected in many transparent substances." The Polish physicist Vitellio, who lived later on, also ascribed the colours of the rainbow to the same cause.

* Opus Majus, 300, 398. 
G. But Roger Bacon was not a Mathematician, a Chemist, a Physicist only, he was also an ASTronomer, for we have an uncontested proof of his knowledge in astronomy, and that is the reform of the Calendar to which allusion has already been made. In "Specula Mathematica," he devotes a whole chapter to this important subject.

The Calendar. - "The defects of the Calendar," says he, "have become intolerable to the sage and are in horror to the astronomer. Since Julius Cæsar's time, and in spite of the corrections which have been tried by the Council of Nicaia, Eusebius, Victorinus, Cyrillus, Bede, the errors have become only more aggravated; they have their origin in the evaluation of the year, which Cæsar believed to be $365^{\frac{3}{4}}$ days, which every four years brings in the intercalation of an entire day; but this evaluation is exaggerated, and astronomy enables us to know that the length of the solar year is less by $\frac{1}{130}$ th of a day (about I I minutes); thence it happens that at the end of I 30 years, ${ }^{*}$ one day in excess has been reckoned, and this error would be corrected if one day was cut off after that period.

"The Church had at first fixed the Spring Equinox on the 25th of March, and now on the 2Ist; but the Equinox does not arrive at that date. This year (1267), the Equinox has come on the I 3 th of March, and every I25 years or thereabouts it will come sooner by one day. The Church was mistaken from the first: I 40 years after the Incarnation Ptolemy found that the Equinox came on the 22nd of March; that was 1127 years ago. It now comes on the

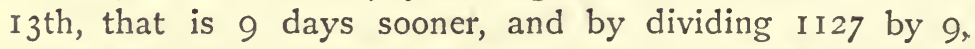
we obtain 125 , which is the number of years at the end of which the Equinoxes are advanced one day. The Church pretends that the Winter Solstice fell on the day of the Nativity of Jesus Christ, the $25^{\text {th }}$ of December. That is a mistake-the verification of Ptolemy having fixed it on the 22nd, in the year 140, it could not, in the year one, be more than a little over one day later-that is to say, between the 23 rd and the 24 th.

"Nor could the Spring Equinox in the year one be on * In reality, 128 years. 
the 25th of March, since Ptolemy for the year I40 fixed it on the 22nd of that month; still less can it be as it is reckoned to-day on the 2 Ist according to Church usage; in reality it comes about the $\mathrm{I} 3$ th, since it advances by one day in I24 years. The Equinoxes then are not fixed occurrences in the first place, and in the second plase they do not come on the days indicated by the Church."

We see that Roger Bacon indicated both the necessity and the nature of the reform with perfect clearness and precision. The Arabs, before him, had determined, it is true, the length of the year to be 365 days 5 hours 48 minutes II seconds; but the fact remains that Roger Bacon had acquainted himself with all the elements of the problem, and by dint of observation and calculation, solved it with remarkable sagacity. Nor was he less exact and sagacious in correcting errors in reference to lunations:

"The present Calendar," says he, "wrongly indicates new moons; in 76 years the new moon anticipates the period fixed by the Calendar by 6 hours 40 minutes ; ${ }^{*}$ so that at the end of 356 years the error will amount to one entire day." And adding other errors to that one, he shows that after 4,266 years there will be full moon in the heavens, and new moon in the Calendar. His petition to the Pope to reform the Calendar ends by the following appeal: "A reform is necessary; men trained in calculation and astronomy are aware of it, and rail at the ignorance of the prelates who maintain the present conditions. Unbelieving philosophers, Arabian and Hebrew, the Greeks who live among Christians, as in Spain, Egypt, and eastern countries, and elsewhere too, have in horror the stupidity which the Christians exhibit in their chronology and the celebration of their feasts. And yet the Christians have at present enough of astronomical knowledge to rely upon a safe basis. Let Your Reverence command it, and you will find men who will be able to remedy these defects-those I have spoken of, and others besides-there are thirteen in all-without counting their infinite ramifications. If this glorious work were to be accomplished in the time of Your Holiness, men would see

* More precisely, 6 hours 8 minutes. 
one of the greatest, best, and most beautiful achievements ever attempted by the Church of God."

This is not all. Roger Bacon had the daring to question the Ptolemaic System on every point, and he attacked it precisely on the point which, later, attracted the attention and labour of Copernicus. Space prevents us from going fully into this matter.

In all this, then, Roger proved that he was an astronomical observer and mathematician of high order.

H. There is another thing which he seems to have studied, or at least deeply pondered over, and the outcome of his meditation on that subject is not the least astonishing evidence of his universality. Alchemy, which he practised with perseverance, led him almost to anticipate the doctrine of animal magnetism. "The soul," says he, "acts upon the body, and its chief act is speech. Now speech, actuated by profound thought, by direct will, by strong desire and a powerful conscience, keeps in itself the power which the soul has communicated to it, and carries that power outside; it is the soul which through speech acts both upon physical forces and upon other souls, which bend to the will of the operator.* Nature obeys thought, and the acts of men have an irresistible energy. Therein are explained characters, charms, and sortileges; therein also lies the explanation of miracles and prophecies, which are only natural phenomena. A soul which is pure and sinless can thereby command elements and change the order of the world; this is why the Saints have wrought so many prodigies."

When we bear in mind all these proofs of scientific genius, we cannot wonder that Humboldt should have considered Roger Bacon as "the greatest apparition of the Middle Ages," $\dagger$ and should have endorsed the eulogium of Leland: "He went round and into the whole of philosophy in such a manner that he left no part of it unexplored."

I. There is still another aspect in which Roger Bacon ought to be considered-his practical prescience, or his faculty of conceiving practical applications. For, when

* Opus Majus, p. 251 ; Opus Tertium, Cap. xxvir.

† Cosmos, Vol. II., p. 398. 
once the laws of nature have been discovered, speculation has ended, and application commences. No force is so hidden in nature but man's mind can reach it; none so tremendous but his will can master it. If here, on the subject.of the possibilities of science, Roger Bacon gives a free rein to his imagination (as he does in a measure when speaking of the power of magnifying glasses-see page 84), it must be owned, nevertheless, that his expectations were not altogether extravagant, since we have now suspension bridges, submarine boats, diving-bells, balloons, steamers, railways - that is, marvels not unlike those which he predicted were possible achievements.

"Instruments will be made," he says,* "to navigate without the assistance of rowers, and float and direct the largest ships, with one man to conduct them, and more quickly than if they were full of sailors; vehicles (carriages) which will roll along with inimaginable speed without any team; instruments to fly aloft, in the middle of which a man will move some spring which will put in motion artificial wings beating the air like those of birds; a small instrument three fingers in length and the same size in height capable of raising and lowering incredible weights without fatigue. With its assistance it will be possible for one to fly with his friends from the depth of a dungeon, and come down on the earth at will. Another instrument will be used to drag any resisting object on an even ground, and will enable one man to carry a thousand persons against their will; there will be an apparatus to walk on the bottom of the sea and of rivers without any danger; instruments to swim and remain under water; bridges over rivers without any piles or columns; in fact, all kinds of marvellous machines and apparatus."

Out of the wonderful variety of his achievements, we have steadily to remember that Roger's pre-eminent work, and therefore paramount claim on us, was the introduction of the EXPERIMENTAL METHOD-the starting-point of modern progress in Europe. To him, then, belongs the glory of having pointed out, and traced, the sole road of science, of having "created both the law and the practice of experimentation." 
It will not appear unfair if we now ask what Francis Bacon has done which can possibly be compared with the wondrous work of Roger?

True it is that Roger Bacon's work was "the continuation of that of the Arabs," as some writers have said with ludicrous. assumption of authority by way of depreciation; but if his was to be truly scientific work, it must of necessity have been a continuation of that science which existed before him. That filiation was the only possible one, and what is more, the only one worth anything. By tradition, training, erudition, originality, practical work, discoveries, the Arabs, as we have seen, had for four centuries been at the head of civilisation. The passion for natural science, which by degrees brought in the conception of a universe ruled by immutable laws, sprang among, and was derived from, the Arabs-and chiefly from Avicenna and Averroes -who were the real ushers of the scientific Revival. They were the sole custodians of knowledge from India to Spain, whilst Europe was intellectually benumbed by anarchy; and the fact that Roger Bacon was their pupil and their continuator constitutes his most invaluable merit, and one of his chief claims to remembrance; for, although he came after such masterly teachers, he left his mark for all times by his daring innovations, and the impetus he cannot fail to have given far and wide in his and subsequent times until the Revival. Francis Bacon, sad to say, with his wont presumption, despised both the Arabs and their pupil-one of the five most admirable geniuses of ten centuries.*

No comment is necessary. The contrast we have drawn between the two Bacons is so strong, that once perceived, it can never be forgotten. The splendid work of the first Bacon enables us to determine the shadowy work of the second; we can measure the distance that separates them; we can distinguish the man of science from the pretender. And if the distance is so great, how much greater is that which separates Francis Bacon from such men as the princes of science, who, before and around him, are the true representatives of the Revival!

* Hildebrand, Thomas Aquinas, Albertus Magnus, Dante, Roger Bacon. 


\section{CHAPTER VIII.}

\section{CHARACTER OF THE REVIVAL。}

THUS far we have seen the advance in science made among the Greeks, the Arabs, and during the Middle Ages of Europe. We have now to give special attention to the era called the Revival, the general character of which it is important to briefly indicate. One hundred and seventy-five years roughly (1450-1625) may be estimated as the time constituting this period. The intellectual movement of the previous half-century tended to bring it about; it certainly prepared the Western world for it. We see this exhibited in the development of modern languages, and the reviving of the Greek language as early as I395. Five years later AURISPA brought to Italy two hundred and thirty-eight Greek manuscripts - including Plato and Pindar. The imminent capture of Constantinople by the Turks induced, thus early too, numerous learned Greeks to leave that capital and seek a safe asylum in Italy. The rapid advance of art and science were other unmistakable indications of the bent taken by the European mind. The Pope Nicholas V. (1447-55) and Cosmo DE' MedicI (1429-64), the first by the foundation of the Vatican Library, the second by his protection of artists, poets, scholars, and scientists, represented the tendency of the age. But the Revival was especially inaugurated by two decisive events, dissimilar in kind but uniting their effects into one stream. The first was the SEIZURE OF CONSTANTINOPLE by the Turks (1453, May 29th) - which caused a general flight of culti- 
vated Greeks to Italy. The refugees brought over the only kind of wealth they could carry-Greek books-the works of the dramatists, the works of poetry, history, jurisprudence, philosophy, and science of the ancient Greeks,* which, together with the discovery of numerous specimens of statuary and architecture, revealed the whole civilisation of the ancient world. The second event was the invention of PRINTING (I453), the weighty and momentous consequences of which were probably never equalled by any other single event in the records of mankind. Its two immediate effects were, first, the cheapening of books and their multiplying to infinity; and, second, the substitution of reading for pulpit teaching. The priest ceased to be the sole instructor of the people. All men could now imbibe information and learning from their authentic sources. Printing propagated the works of antiquity throughout the West. The study and imitation of those precious monuments, as eminent writers have pointed out, were to precede original inspiration. But the universal resurrection of ancient literature, received everywhere with enthusiasm, at once exercised a paramount influence upon the genius of Europe. For gradually, Roman jurisprudence replaced feudal law, Greek and Latin poetry replaced sacred poetry, the philosophers replaced the Fathers of the Church, free inquiry shared with religious ideas imperial authority over the mind, the ideas of political government of the ancient world replaced theocratical and feudal notions. The work of the age is to have created general interests and general notions which affected nations and governments alike. The Revival era hastened the dawn of great monarchies in the political world, and hastened the immense expansion of commerce and industry in the social world, whilst in the religious sphere it caused the growth of freedom of conscience which brought in the REFORMATION, and in the moral sphere it caused that growth of literature, rationalism, and science which resulted in the CLASSIC SCHOOL. This school was

* The Greek refugees did not bring books only, they brought over their own culture as well, and they became teachers and expounders, thus giving momentum to the strength of progress. 
not a literary movement only-that was its outer formbut a much deeper movement which obtained vital sway over the West: "the learned were lost in admiration, not alone for the ancient writers, but for the entire fabric of the society of antiquity," for its manners, for its opinions, its institutions, its arts, its philosophy, its science. No period in history was ever so encouraging, so brilliant, so lofty, so beneficent, and so commanding as that age which spread enlightenment in every direction. Such was the work of the Revival. One of the most direct results bearing on science, which the capture of Constantinople and the invention of the printing-press brought about, was the study of Plato And ARIstotle. For the first time in Europe both these philosophers were seen in their own works, and both were at last understood. The effect of this study was that the unadulterated Plato overcame the Platonism of the Alexandrians, whilst the unadulterated Aristotle extinguished the "base Aristotelian doctrines of the schools," so that their real philosophy and science, speaking for themselves, gave a strong impetus to the sciences which were already taking deep root at the time.

Before completing the outline of the scientific advance made during this eventful era, it will not be inappropriate to clear up a perplexing point of history.

In viewing the universal progress accelerated in Western Europe by the migration of the learned men of Constantinople to Italy, it may seem a mystery that accession to Greek knowledge should not have been gained at a far earlier period than the XVth century. If Greek learning was to be so beneficial, what reason was there for its being confined in the East for so many ages? Were the Greeks averse to sharing a part of the treasure they possessed with any of the nations of the West? It could not be so, since they flocked to Italy as early as the XIVth century bringing ancient manuscripts. Was the West so shrouded in ignorance as to be unaware of the existence of an intellectual world at Constantinople? Or, was it so blinded by barbaric pride as to despise that mental culture? Neither alternative could have been the case after the Crusades, since the 
Crusaders themselves had been struck by the civilisation of the Greek Empire, had admired it as vastly superior to their own, and had brought back therefrom improving notions and novel ideas. Was the want of communications so great as to prove an insuperable difficulty? No; for the renascence of industry, cominerce, and navigation had gradually broken down that obstacle as early as the XIth century. On the other hand, how was it left to the hated Saracens in the first instance to teach Europe science and philosophy, and prepare its mind for a further evolutionary step?

All these questions are satisfactorily answered by a fact which, though it has not escaped attention, has not as yet had one of its consequences pointed out by historians with due force. There were, for nearly a thousand years, roundly speaking, until the XVth century, two Europes in reality-a Greek and a Latin-and they were completely severed intellectually by the GREAT SCHISM, begun with the quarrel of Leo, the Isaurian, with Pope Gregory II. on the question of image-worship (726), and irrevocably established by ritualistic differences, in 1043, in Hildebrandt's time. The severance of Christendom into two unyielding Churches-the Greek and the Roman-consummated that separation of the East from the West, which the removal of the capital of the Empire from Rome to Byzantium by Constantine (330), and the subsequent barbarian invasion of the West, had politically already brought about. The Great Schism proved, between the two sections of Europe, an effective Chinese Wall. The Roman Church forbade the West, under the penalty of excommunication, to have any intercourse with the "heretical" Greeks in matters theological-and the interdict practically extended to Greek learning: any Greek teaching aroused suspicion. The Saracens, on the other side, imposed their presence upon Western Europe by the force of conquest. If their vicinity could not be helped, their learning and teaching at least could be checked by repression, and were, wherever that course could be adopted. This learning, however, slowly filtered through the boundaries of Islam, and, in time, made itself felt in Europe as we have seen. But as it was scientific in the main, and as science could at best attract 
but a small minority, it could not command that general interest or exercise that general influence over the Western mind which the Revival of Greek learning secured after 1453. Varied as the Revival was in its nature, yet it was by its literary element especially that its force powerfully operated. It was on account of its being literary that it was supremely and universally decisive. It may be said that had the Greek world been accessible to the Western mind long before it actually was, the intellectual benefits derived from it would in the same way have been literary-the Greeks, as Christians, devoting but little attention to science and being engrossed by theology and letters. In any case, then, the action of the Arabs upon us would have been just as necessary, and would have affected mediæval Europe in the same manner and degree as it did. Western Europe was irrigated by the scientific stream of the Arabs first, and by the literary and artistic stream of the Greeks at a later period-at a time, that is, when the Arabian plant, dried up in Islam itself but growing up healthily in Christendom, showed that the European soil had been duly fertilised for the reception and cultivation of universal knowledge.

That the Revival was delayed so long was not an unmixed evil, since its postponement permitted Europe to undergo a lengthy period of preparatory training which secured its certain and rapid success, for learning, when it at last came, was propagated like wildfire; that it came so late was mainly due to the Great Schism-an evil, therefore, not altogether without compensation, since it gave Europe the time necessary for its maturation.

Now that the general character of the Revival has been indicated, and the tardiness of its birth accounted for, we may proceed to complete the sketch of its eminent scientists begun in Chapter V., by presenting the aggregate of their work. 


\section{CHAPTER IX.}

THE SCIENTISTS OF THE XVTH AND XVITH CENTURIES.

IN the table of the mediæval and Revival periods, given in that chapter, we set forth two groups of facts-the first embraces the large number of inventions up to the year 1625 ; the second, the large number of men of science-over half a hundred-who appeared before or about the end of the XVIth century. In order now to enable the reader to perceive the aggregate achievements made in the various branches of research, we shall set forth a rapid summary of the same period-presenting it under a somewhat different aspect.

First, then, we have a cluster of Mathematicians, such as Stiefel, Fernel, Tartaglia, Cardan, Ferrari (1522-I 565), VIÈTE, Napier, and SNELL, whose services to pure mathematics, or mechanics, or physics, made rapid progress in these branches a matter of absolute certainty in the near future. Each of these men left sterling work behind him which became in one way or another a new point of departure.

In the Natural Sciences and Medicine we find the labours of Gesner and Belon as regards Zoology ; of Tragus, CASALPINUS, and Lobel as regards Botany; of PARACELsus, Paré, Coiter, as regards Medicine, which base these branches on solid foundations. Nay, more, Anatomy had been studied ever since Mondini (13 I5), and its rise-a radical accession to natural philosophy-may be said to have completed the nascent system of modern science. Achillini, Fabricius, Cæsalpinus, 
Servetus, Solomon Alberti (1 540-I600), Vesalius, Fallopius, Eustachius, Arantus, Santorio, and Asellius had been worthy precursors of Harvey, not by their excellent descriptions of the human frame only, but by their physiological discoveries. They had studied the brain, the nerves, the cartilages, and the bones with success; they had discovered cellular tissue, the lacteal vessels, the choroid plexus, the tube from the throat to the ear-drum, the refluent course of the blood in the veins, the valves in these vessels, the function of the skin, thus laying the foundations of the science, and preparing the way for Harvey.

And all round we find the same tidal advance: some particular facts threw great light upon the practical and intellectual course men were taking and pursuing. A few typical instances will suffice to show this. A Waltherus, in the XVth century, made use of clocks in his astronomical observations to avoid haphazard conclusions; a Roman Churchman, Cardinal Cusa (I4OI-I464), some time before the appearance of Copernicus, believed in the solar system which science has proved to be correct-a fact, this, proving that authority was gradually losing its hold upon men, and that observations were becoming the first principle of research. Within another hundred years or so, this system was all but universally accepted by sound minds, since we find GIORDANO BRUNO actually daring to ventilate that system at Oxford, one of the strongholds of orthodoxy (I580-I583)a forcible evidence of the rapid progress ideas had been making. Such was the tendency of the times.

Further examination of the field shows how extensive and varied it was. In the sphere of Observation, Toscanelli and his gnomon, one hundred and fifty years before Harvey's time, Peurbach and his Ephemerides, Lelio and his reform of the Calendar, Cæsalpinus and his double discovery as regards crystallisation and oxidation, Alpinus and his diagnosis, Plater and his classification of disease, Palissy and his discovery of the origin of springs, Tycho Brahe and his minute description of the "new star" of 1572-74, and Kepler's of the "new star" of 1604, to speak of a few only, stand out in strong relief when opposed to the fanciful records 
of the Schoolmen, and show that Roger Bacon had regal successors.

In Practical and Theoretical Science, in metallurgy, chemistry, geology, astronomy, physics, the XVth and XVIth centuries were equally fruitful of results. AGRICOLA had created modern METALLURGY; Antonio de Dominis had explained the correct theory of the rainbow, which Harriot made clearer still; MERCATOR had created modern GEOGRAPHY; Santorio, with true scientific insight, had shown the use, not only of the thermometer, but also of the hygrometer, and even of the scales in physiological research; Ubaldi had developed mechanical laws; STEvinus had published his book on the principles of equilibrium, determined the fundamental property of the inclined plane, and solved the general problem of forces acting obliquely-elucidating all along some of the LAWS OF PRESSURE, motion, THE LEVER, and the equilibrium of liquids; PORTA had invented the CAMERA OBSCURA, the magic lantern, and demonstrated light to be the cause of vision; Tycho Brahe had constructed several instruments of great precision, catalogued nearly 800 fixed stars, and drawn up the RUDOLPHINE TABLES after twentyfive years' incessant observations-an immortal work; he had determined the COURSE OF COMETS, and shown the third inequality of the moon; CASTELLI had founded hydraulics; SNELL had discovered the LAW OF REFRACTION, one of the most important in optics; GILBERT, one of the great masters of the inductive method, had determined the principles of MAGNETISM and ELECTRICITY after years of experiments-one of the best proofs that the experimental method was used in earnest; he had determined the poles of the magnet, described the DIFFERENCE BETWEEN THE MAGNETIC and the ASTRONOMICAL meridian, demonstrated the POLARISATION OF IRON BARS by being placed in the direction of the magnetic meridian -teaching that the EARTH IS A MAGNET, which accounted, according to him, for the inclination and declination of the compass. Harvey had explained the CIRCULATION OF THE BLOOD - a discovery of supreme importance in physiology, due to deductive and inductive reasoning in an equal degree.

Leonardo da Vinci, "whose knowledge," as Hallam 
justly says, "was almost preternatural," had advanced several branches of science. He had cultivated the MATHEMATICAL AND PHYSICAL SCIENCES, NATURAL HISTORY, chemistry, ENGINEERING, and MECHANICS. In this last branch, he had anticipated by more than a century Stevinus and Galileo with regard to the laws of the lever and the fall of bodies, and even written on the equilibrium of water. "The progress of the science of mechanics was necessary before the Copernican system could be developed," and it was Leonardo who improved this science. He understood the law regulating the flight of projectiles. He gave a clear exposition of the theory of forces obliquely applied on a lever*; was well acquainted with the earth's yearly.motion ; understood the LAWS OF FRICTION, and likewise the principle of VIRTUAL VELOCITIES-the golden rule of mechanics; aërial perspective, the nature of coloured shadows, the use of the iris, the effects of the duration of visible impressions on the eye; he INVENTED water-mills, water-engines, canal and river locks, A WATER PUMP, and anticipated Castelli in

- HYDRAULICS; he invented a spinning machine, a planing machine, an automatic walking lion; designed a STEAM CANNON; described the CAMERA OBSCURA before Porta's invention; he studied the flight of birds; attempted to make an apparatus for flying; occupied himself with the "FALL OF BODIES on the hypothesis of the EARTH'S ROTATION on its axis;" he treated of the TIMES OF DESCENT along inclined planes and circular arcs, and of the nature of machines. $\mathrm{He}$ "considered with singular clearness respiration and combustion, and foreshadowed one of the great hypotheses of geology-the UPRISING OF CONTINENTS "-after tracing the origin of Fossils.t $\mathrm{He}$ also studied chemistry and anatomy: his aratomical designs are the finest in existence.

* Appendix IV.

† "The sea," says Leonardo, "alters the equilibrium of the earth; the shells which are found heaped up in the different layers of soil have necessarily lived in the same place, which was occupied by the sea. The great rivers carry into the ocean the sediment which they roll along in their course. The banks, formed by these deposits, have been covered over by other and later clay layers of various thickness, and what was the bottom of the sea has become the summit of mourtains." 
His labours were pursued with unsurpassed success by one who may be called the greatest representative of modern science with Newton, viz. Galileo.

Galileo invented the earliest (air) THERMOMETER, and improved Janssen's useless TELESCOPE and MICROSCOPE. By the invention of these three instruments, he ensured the rapid development of THERMOLOGY, ASTRONOMY, and PHYSIOLOGY. By means of his telescope, which magnified only eight times, he discovered the SUN'S SPOTS and the revolution of the sun on its axis in 28 days; discovered the four voons oF JUPITER (I6IO)*-demonstrating the Jupiter system to be a miniature of the solar system; discovered Venus to be a planet of our system, and the phases of that body - a discovery which was another solid support of the Copernican doctrine, and caused its general acceptance; explained the revolutions of the planets to be in the same direction as that of the sun on its axis; discovered the mountains and valleys of the moon, also the reflection of the earth-light on its dark disk, and determined the true nature of our satellite; he also determined the true nature of the nebulæ-resolving some into stars; discovered innumerable fixed stars which had never been seen or suspected by man - forty in the PleidDES alone + - a death-blow to the doctrine of the human destiny of the universe, since these bodies could not have been created for the purpose of illuminating the night for human beings. So far the ASTRONOMER. As a MATHEMATICIAN and PHYSICIST, his discoveries were not less important and decisive.

DyNAMICAL MECHANICS are under great obligation to him. He discovered the LAWS OF FALLING BODIES in which the descent is due to the influence of a permanently acting force (attraction), the velocity increasing (at the rate of 32 feet per second) in consequence thereof; saw that a

* A fifth moon was discovered (September 9th, I892) by Professor Barnard (of the Lick Observatory). This is the smallest of Jupiter's satellites; it is close to the planet (I 12,000 miles from the centre), makes two revolutions in one day, and is the fastest satellite known to us with the exception of Mars' minor moon, discovered in 1877.

+ There are no less than 2,600 in that system. 
body moving slowly or swiftly is equally affected by gravity irrespective of its weight-thus eradicating the old Aristotelian error that a light body falls less rapidly than a heavy one; showed also that a body projected horizontally must have a horizontal motion and also an accelerated motion downward-determining, that is, the trajectory described by a body not falling vertically; he determined (before Newton came, as we see) the connection between the spaces of descent and the times-and illustrated facts experimentally by the use of inclined planes; he demonstrated that the earth's ATTRACTION ACTS EQUALLY on all bodies, proving it by the use of hollow spheres in which various substances of different weight suspended by strings of equal length oscillated in equal times; and from the Pisa Tower proved that the velocity of falling bodies is independent of their weight; so that he disclosed the law of falling bodies and that of the composition of forces-two great generalisations of terrestrial physics, being thereby the founder of terrestrial dynamics. But collaterally with these great discoveries he had established the THREE LAWS OF MOTION: I. A body remains at rest or perseveres in uniform motion in a straight line unless disturbed by another force; II. The change of motion is proportional to the motive force impressed and in the direction of the line in which the force is impressed; III. To every action is ever opposed an equal reaction; or, the mutual actions of two bodies upon each other are ever equal and opposite. To Galileo, therefore, we owe the discovery of the law of the uniformity and perpetuity of motion-indeed, he ESTABLISHED the doctrine of the PERMANENT GOVERNMENT OF THE WORLD BY LAW-a doctrine only strengthened by the discoveries of Kepler and Newton. Further, Galileo, concurrently with Cavalieri (1598-1647), found the CALCULUS of THE INDIVISIBLE, and concurrently with Stevinus, placed HYDROSTATICS AND HYDRODYNAMICS on exact foundations, by his discovery of the laws (known by the Alexandrian school) respecting the mechanical properties of water-i.e. the laws of the EQUILIBRIUM OF FLUIDS. He was the first to discover that water raised by the suction pump cannot ascend higher than 34 feet, but it 
was Torricelli who discovered the reason to be due to the pressure of the atmosphere. Galileo also established another LAW OF MECHANICS of great importance in determining the balance of machines, that any force that will lift a weight of two pounds up one foot, will lift a weight of one pound up two feet-the first step towards Joule's great determination. He made excellent observations on sound and MUSICAL NOTES-viz. that the greater the number of vibrations the higher the note will be. He also found the law of the PENDULUM by observing that the vibrations (swings), long or short, of the chandelier of the Pisa Cathedral were made in equal times-hence the invention of the pendulum clock (by Huygens). He also found one of the laws of RADIANT HEAT ; endeavoured to determine the weight of air ; observed numerous phenomena regarding magnetism, gravitation, and acoustics. On the last subject, he taught, like Pythagoras, that SOUND IS A VIBRATION OF THE AIR "which we feel when it reaches the drum of the ear." (See Newton, page 219.)

The importance of Galileo's creative works on Barology cannot be exaggerated: they substantially extended natural philosophy-being nothing less than the opening of a whole department of physics, and the creation of a new class of inquiries, a valuable function of which was to develop the resources of experimentation.*

Galileo by these numerous achievements proved himself a masterly MATHEMATICIAN and ASTRONOMER and a supreme PHYSICIST. But, we repeat, the highest philosophical import of all his discoveries was the pre-eminent fact of the permanency of natural laws.

Closing this glorious list of great men comes Kepler, the contemporary of Galileo, and in some respect his rival. Kepler improved the telescope-using two CONVEX LENSES (instead of a concave and a convex lens as Galileo had done), by which improvement the instrument was made more powerful, and covered a wider span of the heavens at one time. He explained the TIDES to be an effect of the moon's attraction - a view entertained in antiquity by 
Posidonius; was one of the first to notice the rotation of the SUN ON ITS AXIS, "like an orator in the midst of a crowd," he says, "who can face all his auditors simply by turning upon himself"; he indicated for the first time the UNDULATORY THEORY OF LIGHT; determined the refraction of light to be nil at the zenith; expressed his belief in the WEIGHT OF AIR; in the sun being a magnet; put forward the empirical law, known as BODE'S LAW, by which the distances of the planets seem to follow an arithmetical progression (see Piazzi, further on); he correctly foretold the dates of the transits of Mercury and Venus; he also explained the correct use of the different PARTS OF THE EYE; lastly, he formulated the three laws of movement known as KEPLER'S LAWS, which, constituting as they do one of the great triumphs of mathematics, made the discovery of Newton's law of gravitation a possibility. This, Kepler accomplished after perseveringly observing the motions of Mars-and the laws, meant to apply to Mars only, he found to apply to all planets. The result was obtained only after years and years of labour-but they are laws found for all times! Kepler's laws are: I. Orbits, of which the sun occupies a focus, are elliptical (1609); II. The areas described by a line drawn from the planet to the sun are proportional to the times, or, planets describe equal areas about the sun in equal times (1609); III. The squares of the period of complete revolution, or periodic times of any two planets, are proportional to the cubes of their mean distances from the sun-or, the squares of the periodic times of the planets are proportional to the cubes of their distances (I618)-a law which, in 1622, he proved to hold good for the satellites of Jupiter as regards their primary. The third law contains the principle of Newton's laws. ${ }^{*}$ It is not too much to say that the modern system of astronomy deserves far better to be called the Keplerian system than the Copernican. Kepler, speaking of attraction and gravitation, says: "Everything is simple in the variety of nature. Thus, in a river, the simple motion is the tendency of water to repair to the centre of the earth, but as the way is not direct, the

$$
\text { * See page } 201 \text {. }
$$


water follows all the sinuosities of the ground, and the motion is complicated, to all appearances, by foreign causes." And from chapter xxxii. to xlii. (of his great work) every passage, almost, alludes to attraction and gravitation. If Kepler was a MATHEMATICIAN chiefly he should also be remembered as an astronomer, A PHYSICIST, an optician of a high order.

We may suitably complete this brief chronicle of the advance made in the Experimental School during the Revival, by quoting what Leonardo da Vinci said about experiment, verification, and the Inductive Process, to show what a powerful and precise instructor and advocate he was of those very principles which Roger Bacon had already proclaimed as the indispensable requirement of scientific progress. He says-

"Theory is the general and practice the soldiers.

"Experiment is the interpreter of the artifices of nature. It never deceives us; it is our judgment itself which sometimes leads us astray, because we expect from it effects which are contrary to experiment. We must consult experiment by varying the circumstances till we have deduced from it general laws; for it is it which furnishes true laws.

"In the study of the sciences which depend on mathematics, those who do not consult nature, but authors, are not the children of nature; they are only her grandchildren. Nature alone is the master of true genius.

"In treating any particular subject, I would first of all make some experiment, because my design is first to refer to experiment, and then to demonstrate why bodies are constrained to act in such a manner. This is the method which we ought to follow in investigating the phenomena of nature. It is very true that nature begins by reasoning and ends with experiment; but it matters not; we must take the opposite course; as I have said, we must begin by experiment, and endeavour by its means to discover general principles.

"Experience has been the mistress of those who have written sensibly, and I shall in any case proclaim her my mistress. Truth is the daughter of time alone, as wisdom is the daughter of experience.

"Sound judgment is derived from sound understanding. 
(del bene intendere), and sound understanding from reason (ragione), itself born from sound experience, the common mother of all the sciences and all the arts.

"The rules of experience are sufficient means (cagioni) for us to discern the true from the false.

"Before laying down a general rule, experiment two or three times, and see whether the experiments produce the same effects."

This was thought, said, written, and acted upon more than a hundred years before the Novum Organum saw the light. In the face of this plain and direct language it is rather strange that Dr. Whewell should have dared to convey the idea that the writings of those who preceded Francis Bacon were "too abstruse" to be understood-for the unvarnished truth is that the cases are reversed. This misleading statement has been quoted so often that it is only right we should protest against it by showing its complete inaccuracy.

Leonardo despises the Alchemists who seek the transmutation of metals, but recognises them as fruitful inquirers within certain limits-that is as founders of chemistry. He condemns without restriction "the searchers of perpetual motion, necromancers, magicians, who beget nothing but lies." And being a real man of science he does not forget the great part played by mathematics and deduction, without which induction would be inefficacious. He says :

" $\mathrm{He}$ who blames the supreme certainty of mathematics. feeds on confusion, and will never put a stop to the contradictions of the sophistical science which produces nothing but an eternal clamour (un eterno gridore).

"Wherever there is relation and proportion, there is room for calculation; the proportion is not found in numbers and measures only, but likewise in sound, gravity, time, place (space), and in any force whatever." This aphorism, worthy of Newton himself, reveals a masterly insight and grasp of science in its most important bearings.

"True science," he goes on, "is not nourished by the dreams of its investigators; but from the first true and ascertained principles it advances progressively and with true consequences to the very end. This is what we see in the 
first mathematics, whose object, number and measurearithmetic and geometry-treat with sovereign truth of the discontinuous and continuous quantity.

"No human investigation can be called true science if it does not pass through mathematical demonstrations.

"Those who are infatuated by practice without science are like the navigator who sails a ship without helm and compass; he never knows with certainty whither he goes. Practice must always be built upon theory. Study science first, then follow the practice which is born from science. Hence the treatise of the mechanical sciences must precede the treatise of useful inventions.

"We call science a sequence of reasonings (quale discorso mentale) which takes for its starting-point the last principles outside which in nature nothing can be found but is a part of that science." That is experience as a point of departure, and the mathematical form as a point of conclusion; such is his conception of science-a conception endorsed by modern science.

Leonardo respects the ancients, and with discrimination even protects them against the commentators who distort them :

"Some commentators," he says, "blame ancient inventors who gave birth to grammar and to the sciences, and stand forth like errant-knights (e fansi cavalieri) against dead inventors; and because they are incapable to become inventors themselves, they are through sloth and the convenience of books, carelessly occupied to cavil at their masters by false arguments." ... And then we find him consulting the ancients with care and admiring them: with true scientific sense he admired Archimedes beyond any. And respecting the ancients he does not fail to assail the Schoolmen together with authority :

"Many will think they can reasonably blame me, alleging that my proofs go counter to the authority of some great men held in high reverence through their uncontrolled judgments (inesperti), not considering that my ideas are born from pure and simple experiment which is my true mistress. If I do not, like them, quote authors, I shall invoke a thing much higher and more worthy-viz. experiment which is their master's mistress. 
"If we believe them (the Schoolmen), that knowledge is mechanical which is born from experiment, and science that which is born from, and ends in, the mind; semi-mechanical that which is born from science and ends in manual operation. But it appears to me that those sciences are vain and full of error which are not born from experiment (experience), mother of all certainty, and which do not end in a definite experiment (che non terminano in nota experimentia), that is, the principle, the middle or the end of which does not pass through one of the five senses.

"If we are told that the eyesight prevents true and attentive mental knowledge by which one penetrates into the divine science, and that such an obstacle led a philosopher to put his own eyes out, I reply to this that such an eye, as lord of the senses, does its duty to put an obstacle to those confused and lying reasonings (discorsi) about which men, with loud shouts and agitation of hands, for ever go on disputing.

"Avoid the precepts of those speculators who do not confirm their reasonings by experiment."

"Do not trust to those authors," says he again, "who have sought by their sole imagination to become the interpreters between nature and man, but to those only who, by the results of their experiments, have exercised their minds to recognise how experiments deceive him who does not know their nature, because those experiments which often appear identical are very different." This about writers who declared that being given a motor which shoots a weight a given distance off, one may multiply the distance to infinity by dividing the weight to infinity.

The preceding injunction is another evidence of the value which Leonardo da Vinci attached to verification. In fact, in true scientific spirit, he used to write "false" (falso) under a proposition which he had enunciated, after experiments had shown him its unsoundness.*

All this had been done during the Revival when Francis Bacon entered the lists, and stood up as the herald and sole champion of science. "Our only hope," said Francis Bacon, " is in the regeneration of the sciences by regularly raising

* For further evidence of Leonardo's science, see Appendix IV. 
them on the foundation of experience, and building them anew, which I think none can venture to affirm to have been already done or even thought of."-(Nov. Org. I. 97.) And his first proof of qualification as a leader was his denunciation of the progress effected, and his second the display of his own work as a contrast to that of other men. And it is gravely declared urbi et orbi by Ellis, Spedding, Abbott, Buckley, Church, and others, that "he was the first to insist upon the importance of collecting facts and making experiments, and that in doing so he rendered a great service to science."

It is, after our survey, needless to dwell upon the incompetency of Francis Bacon to stand up as a judge. He was so little conversant with science, that he not only denied that any advance had been made since Aristotle, but he was unaware that the objective method, or the inductive process, or inductive philosophy, by whatever name we may call it, had been both promulgated and practised by a host of men. For a hundred and fifty years at least, to speaik of the Revival period only, a multitude of facts had been collected; valuable instruments had been made; experiments without end had been carried on ; countless observations had engrossed investigators; sterling discoveries had been arrived at; and yet he remained in the delusion that the world had stood still. He thought that he alone was moving, whereas he was aliogether behind his age. And what attitude was his, in the face of great facts, when these stirred up mankind? His attitude was still one of sceptical impassiveness. He called for instruments, and slighted the telescope. He advocated observations, and disparaged those of Galileo. He ignored Tycho Brahe's and Kepler's. He recommended experiments, and disdained those of Gilbert. He advised inquiries into the laws of the Cosmos, and, after Copernicus and Kepler, fought against the heliocentric doctrine and gloried in believing the earth was the centre of the universe. Nothing could shake him out of his presumption. How then was he qualified? How was he the Instaurator? the leader of a new era? the initiator of modern progress, as we are so often told he was? We leave the answer to the judgment of the reader. 


\section{CHAPTER X.}

\section{MODERN SCIENCE.}

In the family of studies, science is the Cinderella who hides unknown perfections in obscurity. The whole work of the house has been given to her to do. It is through her skill, intellect, devotion, that we have attained all the commodities and pleasant things of life, and, while she serves others and keeps modestly aloof, her proud sisters display their tinsel beauty to the eyes of the world.

HERBERT SPENCER.

IN the preceding chapters a review has been given of the science of the Greek, the Arabian, the Mediæval, and the Revival periods, which has enabled us to appreciate to its full value the work done in those times. It now behoves us to proceed with the sketch of science in the modern period. This is so vast a subject that no apology need be made for presenting it in an altogether inadequate manner. Insufficient as the presentment of it will prove, it has nevertheless not been undertaken without difficulty, or without a deep feeling of diffidence. Not only does the author acknowledge that he has taken a purview of each branch too restricted in extent fully to satisfy the inquirer, much less the scientific critic, but he is also well aware that he has left out of the list of the masters which follows, many men who stand high in the annals of science. Out of the host of those who have gloriously tilled the field of knowledge, to make a satisfactory selection is scarcely possible. So many have equal claims that to mention them all would be the only way out of the difficulty; but this being impracticable in a sketch, the choice must be determined by what appears typical originality in the 
work accomplished rather than by what is imposing in extent and weight. And this has been the guiding principle in the main here. It will explain why the author has credited the great men he mentions with little more than a fraction of their labours - a deficiency inherent to the nature of the present work of which he is conscious, and upon which he lays particular stress; but he trusts he has fairly succeeded in giving at least the main achievements of the scientists he has brought within his survey. In some instances, he has preferred to enunciate a scientific fact in that plain speech which the ordinary reader is likely to apprehend best, rather than in that technical diction which a thorough adept in this or that branch would have adopted. In so wide a scope, in any case, the author confidently relies upon meeting with the indulgence of the experts. These will consider the exiguity of the limits imposed by the plan and object of his book, and they will no doubt own that within those limits he has carried his scheme out in as accurate and conscientious a manner as the matter permitted.

The progress of modern science, it need hardly be said, necessarily proceeds from the labours carried on and the results obtained before: it is the natural continuation without a break of the work of the XVth and XVIth centuries.

At this point, the threshold, so to speak, of modern science, it is needful to give the student a short classification of the sciences-a matter attended with some difficulty, because every science can be exhibited under two very distinct methods, the historical and the dogmatic; any other method being nothing but a combination of the two, and whatever the procedure, the classification must always be somewhat artificial, it being impossible to present, with entire exactness, the sciences in their natural connection and according to their mutual dependence. By the historical method knowledge is presented in the order in which it was obtained; by the dogmatic, knowledge is presented as it may be conceived by an expert who would begin to reconstitute science as a whole.

Of the many classifications proposed, we shall give COMTE's historical CLASSIFICATION, which is the best of the 
NATURAL SCIENCES (OR NAtURAL Philosophy).

\section{ORGANIC BODIES.}

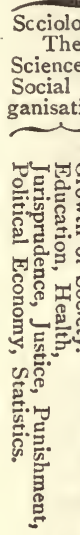

INORGANIC BODIES.

Biology. The Science of Organised Matter (of Life).

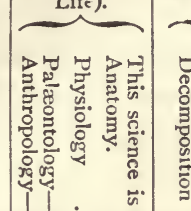

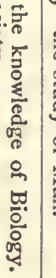

$\stackrel{n}{\tilde{E}}$

$\circ$ 용.

$\sum \rightarrow$

है

प्र : क

Chemistry.

The Science of
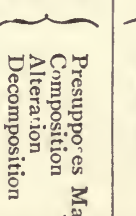

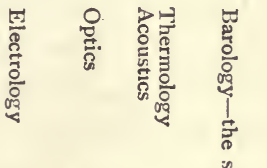

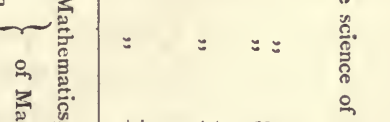

尝 ?. 蜉

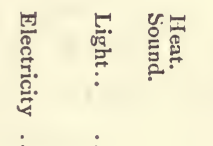

Chemistry.

Physics.
The Science of the Laws regulating
the General Properties of Bodies
(regarded in the mass).

萬.

:

$: \quad$$$
\text { : }
$$$$
\text { : }
$$$$
\text { : }
$$$$
\text { (n) }
$$$$
\text { : }
$$$$
\text { : : }
$$

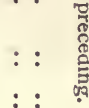

$\mathrm{N}=$

$\delta^{\circ}$

भुํ․ Molecules.

Astronomy. The Science of The Science of Celestial $\overbrace{\longrightarrow 0}^{\text {Bodies. }} \overbrace{0}^{\text {Co }}$ 氙
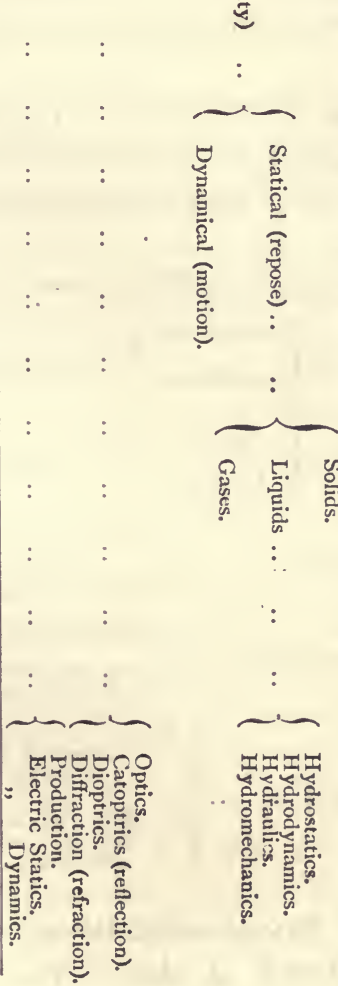

MATHEMATICS.

Magnitudes. 
kind, though in a degree arbitrary, and Mr. Herbert Spencer's dogmatic classification, the only objection to which is that it does not show how science was obtained unless we bear in mind the process of evolution and interaction which the author has not failed satisfactorily to elucidate with his usual grasp and clearness.

Comte classifies the fundamental sciences, which he reduces to six and groups into two classes, according to their natural dependence-the most general phenomena going on successively to the more particular.

"Each of the sciences," says Comte, "presents some indication appropriate to itself, which ought to be studied at its source to be duly appreciated. Mathematical science exhibits the elementary conditions of positivity; astronomy determines the true study of Nature; physics teaches us the theory of experimentation; chemistry offers us the art of nomenclature; and physiology discloses the theory of classification."

Mr. HERBERT SPENCER has proposed another CLASSIFICATION which, though dogmatic in the sense indicated above, is nevertheless strictly based upon the principle of evolution.

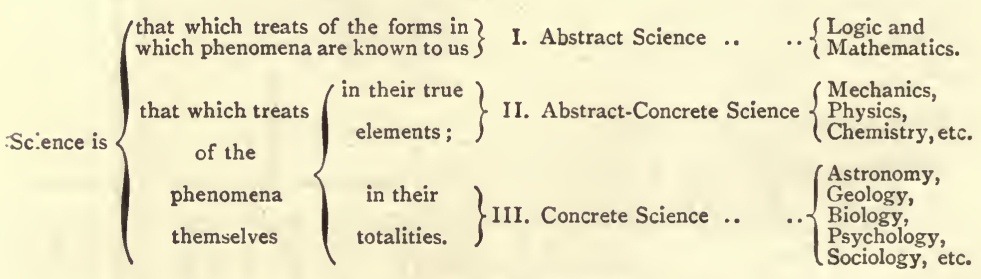

I. Abstract Science treats of $\ldots \quad \cdots\left\{\begin{array}{c}\text { I. The universal law of relation } \\ \text { II. The laws of relations }\end{array}\right\} \begin{gathered}\text { Mostly exclusively } \\ \text { Mathematics. }\end{gathered}$

II. Abstract-Concrete Sience treats of $\left\{\begin{array}{c}\text { I. The universal laws of forces } \\ \text { II. The laws of forces as mani- } \\ \text { fested by matter .. }\end{array}\right\} \begin{gathered}\text { Mostly Statics and } \\ \text { Dynamics. }\end{gathered}$

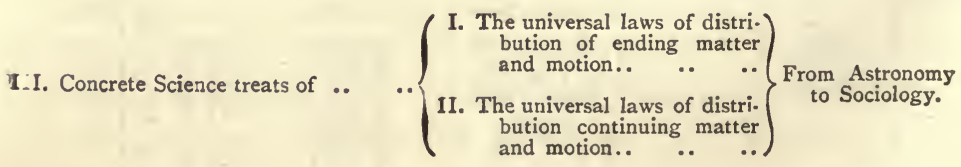

Each of these two classifications has its distinct meritsComte's has the merit of simplicity, Spencer's the merit of 
rigid exactness-but its synthetical character makes it difficult of comprehension for those who are unfamiliar with the philosophy of science.

In the following table of modern science, consulting solely the general reader's convenience, we have been guided by what appears to us a simpler, though less scientific, plan, viz. that of grouping the branches of science in the order of their practical importance, without special regard to their filiation or their logical sequence, observing, however, the chronological succession in which they advanced.

GROUP I.-Taking first Biology—that is, the organic group -we shall successively survey its sub-branches-Botany, Anatomy, Zoology, Palæontology, Physiology, Biology proper, Anthropology, Philology, and Sociology.*

\section{BOTANY.}

1628-1694. Malpighi applied the microscope as an aid to botany, thereby immensely extending the stock of previous knowledge; revealed the minute germs, fibres, and vessels in the structure of plants ( $\mathrm{I} 66 \mathrm{I})$, becoming thus the FoundER of Vegetable Anatomy. Among the numerous discoveries he made in the texture of plants, arrived at by constant watching and observation, he detected the cellular tissue, the ducts, the whole process of growth of seeds, describing the different stages of the germ and pointing out the development to be similar in many respects to the growth of the chick in the egg. GREW (1628-I7II) was pursuing the same investigations at the same time, and made several discoveries. It was Grew who discovered the stomates, and their function. These little mouths open and shut to receive and give out air and moisture. But it was Dr. HALES (I677-176I) who clearly discovered the way in which plants breathe through the stomates, showing these to be the organs of respiration-though he did not find out that plants decompose the air, and absorb carbon and reject oxygen - a discovery which was made later. I628-I704. Ray, after lengthy travels over Europe with * Appendix AA contains a definition of each branch. 
his friend and associate WILLUGHBY, made a CLASSIFICATION of the known plants more perfect than Cæsalpinus's, grouping them into three divisions-the IMPERFECT PLANTS (flowerless ferns, mosses), and the PERFECT PLANTS (flowering), themselves divided into two classes: I, the dicotyledons, the seeds of which "open into two seed-leaves," some having simple flowers (like the pink), and some having compound flowers (like the daisy); 2, the monocotyledons form the other class, "the seeds of which have only one seed-leaf" (like a grain of wheat). This system was made more perfect by Tournefort; but some of Ray's divisions were adopted by Linnæus. Ray was also an excellent zoologist - Willughby's work being partly due to his knowledge and assistance. Ray's History of Insects exhibits a clever classification, based upon either stability of form, or metamorphosis, and then again upon organic characters-wings, feet, habits, food, etc. Ray and Willughby are two names which can hardly be separated. With them botany and natural history take a new departure, after them each step forward is a long stride into rich regions of knowledge.

1656-i708. Tournefort founded the science of geographical DISTRIBUTION of plants after extensive travels in the East and in Europe; described ten thousand plants, and arranged them with great discrimination, establishing the orders and genera in the Vegetable Kingdom according to the general character of species. His classification was an improvement upon Ray's. Of his genera, I30 were preserved by Linnæus. As a descriptor he is regarded as a model, and his work on botany established his reputation all over Europe.

I707-I778. Linnæus pointed out the phenomena of fecundation in plants; classified the Flora according to the organs of reproduction (stamens and pistils)-the most famous ARTIFICIAL CLASSIFICATION. It is artificial because it grouped species without regard to their fundamental likenesses of organisation and structure. He created a scientific language by originating a mnemonic instrument at once ingenious and useful-giving to every plant and animal a second (or specific) name which conveys a description of 
their special character. The Animal Kingdom is indebted to him for its complete classification according to the organs of mastication and of digestion. His nomenclature of genera has been introduced into every branch of science. His definition of the inorganic and organic world is as famous for its truth as for its terseness-" stones grow, plants grow and live, animals grow, live, and feel." The artificial system of classification of plants is now superseded by the natural system, but it retains much of its useful value by the facility it affords of finding the name of a plant or an animal.

1748-1836. Jussieu (Antoine Laurent), continuing the -original work of his uncle Bernard (1699-1767), created the NATURAL SYSTEM, i.e. the method of natural classification founded upon the subordination of characters, structure, organisation, and relations-the structure of the EMBRYO serving as a chief basis. He divided the whole Vegetable Kingdom into three great branches-the acotyledon, the monocotyledon, the dicotyledon-which led to the constitution of the Families, or Natural Orders, as now accepted. This system has been extended and improved by $\mathrm{DE}$ CANDOLLE (I778-I84I), Robert BROWN (I773-I858), ENDLICHER (I804-49), LindLey (1799-1865), Sir William Hooker (I785- I865), the founder of the Kew Garden Museum and Herbarium, and his son, Sir Joseph, both of whom advanced the knowledge of the Flora of the British Empire in a manner never attempted before. Sir Joseph, besides his important contributions to the progress of systematic botany (Genera Plantarum, Flora Indica), was intimately associated with Darwin in the studies preliminary to the publication of the "Origin of Species."

1749-1832. Goethe made valuable observations upon the growth of plants ; pointed out their process of transformation, from primitive stems or leaves into all kinds of varieties according to the work Nature has intended them to do. Among other things, he showed that the stamens and pistil are nothing but the flower-leaves metamorphosed into a particular form so that they may serve to produce seeds. Goethe's theory of METAMORPHOSIS OF PLANTS has proved a sreat discovery, and the study, once started (I790), led to the 
production of fine artificial flower varieties in colour and shape. His facts are in perfect harmony with the process of evolution elucidated by Darwin. The great German philosopher also speculated on the more engrossing problems of life. As a follower of Buffon, he held that "the more perfect organic natures from fishes to mammals, and man at their head, were formed on one original type which still daily changes its form by propagation;" so that, like Lamarck, G. St. Hilaire, E. Darwin, and others, he was an evolutionist. He tried to prove the tendency of Inheritance and of Adaptation in organisms-two laws of development. His study of comparative anatomy led him to the discovery of the mid-jarubone in man-a fact of import, for it argues for man's descent from lower types.

I750-1816. Sprengel was the first (I789) to point out the close connection which exists between plants and insects, and to discover how the FERTILISATION OF PLANTS BY INSECTS is carried on-a subject fully investigated later on by Darwin and others. Sprengel showed that the shape, the colours of a flower, and the honey it secretes are intended by nature to attract insects to it, so that they may carry the pollen-dust which clings to them (while they suck the honey) to other flowers, and so fertilise the ovules in the seed-vessels which would otherwise remain barren. Flowers, he also found, which are neglected by insects are insignificant as a rule, but their variety does not perish because they have a large quantity of pollen-dust, and the wind carries it in every direction to fertilise. It was not until Charles Darwin had pointed out the splendid work done by Sprengel that the worthy German inquirer was appreciated.

\section{Anatomy, Zoology, and Palaontology.}

$162 \mathrm{I}-1675$. Willis studied the BRAIN, traced the course of the NERVES, classified them, and introduced the doctrine of LOCALISATION OF FUNCTIONS in the brain-a branch which, later on, developed into phrenology, a new study unrecognised as yet as a science.

I63I-I687. Steno revealed the existence of the OVARIES 
in viviparous animals and woman-an observation which brought about new ideas regarding the theory of fecundation. He was the first to explain more extensively than Pythagoras, Leonardo, and Palissy the origin of fossils (I669); his observations regarding the PETRIFACTION of rocks are remarkable, but less so than his pointing out the system of STRATIFICATION AND UPRISING which is now admitted-so that he was a real geologist as well as a naturalist. ScIllA, in 1670 , carried this study further by his observations of the rocks and fossils of Calabria.

I635-I672. Willughby, the earliest great naturalist England may be proud of, studied fishes, birds, and quadrupeds; collected with his friend Ray, who took a share in all his labours, a great number of specimens. His book on quadrupeds is an excellent instance of CLASSIFICATION, dividing the whole sub-kingdom into oviparous and viviparous, and subdividing the species according to the kind of feet and teeth they exhibit. The birds he divided into land birds and water birds, and then subdivided them again according to their beak and claws and food. The fishes were classed into groups not very different from those now adopted.

I 707-88. Buffon, by his comprehensive work on natural history, popularised a vast amount of useful knowledge. Animals, their structure, instincts, habits, are so beautifully described; he showed the power and majesty of Nature in a manner so novel and striking that he exercised immense influence. The general interest in scientific researches which he created entitles him to be considered as one of the great promoters of knowledge in the XVIIIth century. The scientific value of his labours is twofold. First and foremost it lies in the fact that he was the earliest writer who clearly formulated the suggestion-derived from practical observation - that all species of plants and animals probably descend from a common origin, and are due to a gradual divergence from the parental type; so that he planted THE SEED OF THE ORGANIC EVOLUTIONARY DOCTRINE-organic development by law. He intimated that man himself forms no exception, and may be considered as a branch of the 
same tree. These views were rapidly propagated, and even enlarged upon by Diderot. By the end of the XVIIIth century, the origin of species had become an important subject of speculation in most parts of Europe. Secondly, the value of Buffon's work lies in his tracing the DISTRIBUTION OF ANIMALS all over the globe, as well as the geographical and climatic causes of such distribution. The anatomical portion of his natural history is the work of Daubenton.

I716-1800. Daubenton gave additional value to Buffon's work in the manner just mentioned. He also supplied Buffon with fine ANATOMICAL DEsIGNS. He besides holds a special place in science by his having been the first to apply COMPARATIVE ANATOMY to the determination of FOSSIL BODIES, thus opening the only road to the study of the Fauna of geological epochs.

I 722-89. Camper discovered (in I 76I) the auditory organs of fishes, and (in I77I) discovered that air penetrates into the bones of birds by the process of breathing, to make them more buoyant in flying; was the first to dissect the orangoutang, and to show the anatomical difference between anthropoid apes and man; determined the FACIAL ANGLE (the profile line of the human face) and made it a criterion of race-though too exclusively-becoming thereby one of the founders of anthropology. His analogy between the human body and that of the quadruped, bird, and fish, is. equally serviceable to the naturalist and to the artist.

I758-I828. Gall, the founder of CRANIOLOGY, is entitled to fame for his marvellous DISSECTION OF THE BRAIN, the: anatomy of which had been unsatisfactory-his work was a revelation to anatomists, despite the fact that his conclusions (phrenology) were far too hasty to find general acceptance.

I769-I832. Cuvier was the most eminent founder of Comparative Anatomy. He embraced the entire Animal Kingdom. He divided it according to organisation into the Vertebrata, Mollusca, Articulata, Radiata- the three last of which had been neglected. Then he divided the four sub-kingdoms into Classes, Orders, Families, Genera, and Species, arriving at a much more satisfactory and complete classification than Linnæus, because he based it upon the 
INTERNAL STRUCTURE and organs. He showed the nature of reptiles. He founded PALæONTOLOGY, too, and had the genius to reconstruct the antediluvian world (so-called) from fossil bones-so that he connected past and present animals by comparative anatomy, and, through this, Zoology had a solid basis of classification, and Physiology extensive elements for the explanation of phenomena. He held the doctrine of the fixity or IMMUTABILITY OF SPECIES-a doctrine combated by Geoffroy St. Hilaire, and completely overthrown by Darwin's investigations, although it is admitted that some of Cuvier's views were to a certain extent reconcilable with those of his opponents. Cuvier founded the PARIS MUSEUM, which stood as a model of classification and arrangement. Lamarck, Geoffroy St. Hilaire, and Cuvier formed a sort of scientific Triumvirate which swayed immense influence, and gave a powerful impulse to the study of several branches of Biology. Cuvier's colossal working power enabled him to accomplish the labour of several naturalists. He was such a master of comparative anatomy that from seeing the fragment of an animal, a bone, or only part of a bone, he could reconstruct the whole: "None of the parts," says he, "can alter without an alteration of the others also. Thus, if the stomach of an animal is made so as only to digest fresh flesh, his jaws must be formed to devour the prey, his claws to seize it and tear it, his teeth to masticate the flesh, and the whole system of his organs of motion to follow and overtake it; . . . so that, not only the class, but the order, the genus, and even the species of an animal are revealed by each part of it." It was by this masterful knowledge that he was able to put together the skeletons of ExTINCT ANIMALS-being the first to reveal to astonished naturalists that past geological eras had produced animals differing from ours in some particulars. And this revelation at once set men pondering over the antiquity of the world. $\mathrm{He}$ threw light upon the newly discovered Ichthyosaur, Plesiosaur, Iguanodon, Pterodactyl ; on the Mosasaur; on Tertiary animals, on the Megatherium, the Mammoth, the Mastodon -types which had puzzled and confounded naturalists until he demonstrated their nature. 
I802-57. D'Orbigny studied and classified the ForAMINIFERA - a most important class, since the accumulation of its remains constitutes geological strata.

I804-92. Owen is the highest authority in many important branches of comparative anatomy through his studies of the GREAT APES, the KANGAROOS, the giant New Zealand Wingless Birds (the DinoRnis), the CEPhalopods, the BRACHIOPODS, etc. ; his anatomical labours are so numerous and important that he may be called the greatest comparative anatomist of his time. He introduced the study of palæontology in England, and no scientist since Cuvier, whose pupil he was for a time, has enriched palæontology to a greater extent than he has. He contributed a vast series of papers on extinct animals and their living representatives, making discoveries which filled up the gaps in past and present species. He was the first fully to describe the GREAT SLOTHS (the Megatherium-I 8 feet long, the Mylodon-II feet), armadilloes, and SAURIANS of South America, the flying reptiles, the swimming lizards and tortoises of the Secondary and Tertiary periods, and to bring into notice countless reptiles, birds, and mammals in British strata. But his investigations of the saurians (so-called antediluvian reptiles), first of those known to Cuvier, and next, of the Cetiosaur, the Megalosaur, the Scelidosaur, and then the Mylodon, and then the Dinornis, may be pronounced his most original and fascinating work. He carried our knowledge about these (socalled) antediluvian animals very far indeed, and by his luminous views left very few anatomical problems concerning them to be solved, though it was reserved to the next generation, as our next notice will show, to give an extension to the science of life in early geological periods undreamt-of in Owen's prime time. Like Cuvier, he applied the law of correlation of structure, and could, with a bone, a vertebra, or a tooth, reconstruct the extinct animal of which it had been a part. By his palæontological researches and discoveries, he caused geology to obtain still greater popular favour than it had obtained before-thereby powerfully assisting the work of William Smith, Sedgwick, Murchison, Lyell, and Agassiz. He believed, with Sedgwick, in the separate origin of distinct 
types, and, with this reservation, he followed Geoffroy St. Hilaire as regards unity of organic composition. Likewise, he believed in the variability of species, rejecting, however, the idea of volition on the part of the lower types-an objection which implies haphazard selection; so that he was an opponent of the Darwinian law of evolution, though he recognised it as a factor in the plan of Creation. But his views regarding Darwinism are rather confused and difficult to reconcile with one another. He discovered the type of the vertebrate skeleton. He founded the Microscopic Society, and organised the Natural History Museum (London)-the finest in the world by far; and thus was the continuator of Cuvier and of Hunter. As a guide to classification he took the brain for some orders, the teeth for others. His "Odontography," on the teeth of different types, is the finest work of its kind.

Since Prof. Owen practically finished his work, palæontology, as we have hinted, has been enriched by numerous and magnificent specimens of extinct species, supplying new links, found chiefly in America.

b. I83 I. Marsh (Prof. O. C.), the most eminent living palæontologist, has probably rendered as much service to science as any of his predecessors taken singly. Some would say that he has surpassed them all, so numerous, varied, important, weighty, and startling are the discoveries that we owe to his indefatigable and intelligent enthusiasm. In estimating the respective work of great men we have, however, to remember that the founders-the Lamarcks, the Cuviers, the Owens-must ever command undivided admiration, for their demonstrations and applications of principles serve as chart and compass to scientific men. Apart from that consideration Prof. Marsh's work is so imposing that it is difficult to set forth all his claims to fame. It might almost be said that before he came into the field, the masters, immense and fruitful as their labours were, had only deciphered the alphabet, interpreted the language, and constructed the grammar of palæontology, whereas Marsh composed the extensive poem describing its unsuspected wonders. He unearthed from every part of 
America, but especially from the rich sepulchre of Colorado, hundreds and hundreds of extinct animals, so that where, in some instances, only one bone, one tooth, one vertebra of a skeleton was known, we now have entire specimens, and specimens not of one species, but of twenty, fifty, eighty species. Just as Lamarck investigated and explained fossil shells, or Cuvier the fossils of quadrupeds, so Prof. Marsh has laid bare before us the Dinosaurian world of the Secondary Period -the world, that is, of the huge monsters which were then the lords of creation. The specimens he discovered are so very numerous that he has divided the Dinosaurs (fourfooted reptiles or lizards-some herbivorous, some carnivorous) into five sub-orders, and these into genera, the animals ranging in size from 2 feet in length to 60 . Of the nine great orders of Reptilia which existed then, the snakes, tortoises, crocodiles, and lizards alone survive. The Ceratosaur was I7 feet, the Megalosaur and the Apatosaur 40, the Diphodocus and the Cetiosaur 50, the Brontosaur 60. The Atlantosaur was 30 feet high and 80 feet long; his thigh-bone was over 6 feet! The Triceratops had a skull 6 feet long. The Scelidosaur was covered with, spines all over his back. The Stegosaur was armed from his head to his tail with a ridge of erect plates on his back, almost triangular in form and some 2 or 3 feet in diameter, and the end of his tail was bristling with four pairs of powerful spines from I to 2 feet long. He had two brains-a small one in the skull, and another, ten times as large, in the sacrum close to the haunches. When we bear in mind that some of these monsters, as large as or larger than elephants, could walk on their hind legs and could have looked in our houses through a window on the second storey, we can imagine what a stupendous spectacle they presented. Prof. Marsh, likewise, found as many as 60 species of Mosasaurs-sea-serpents-ranging from ro to 80 feet in length. He made out four species of Pterosaurs or Pterodactyls-flying reptiles-the largest of these measuring 25 feet across the wings. The Dinocerata-huge mammals not unlike the rhinoceros-were found to have formed no less than thirty species. Marsh discovered, in the Eocene 
lake-basin where he found the Dinocerata, the series of fossil horses which enabled him to prove the present horse to be descended from the small five-toed Eohippus (see Darwin), one of the most beautiful and conclusive examples of the law of animal evolution (1870). By the side of the animals above-mentioned innumerable snakes, crocodiles, tortoises, fishes, marsupials, rodents, insectivorous and carnivorous types, were also found, the species of which were for the most part unknown before. Prof. Marsh, it is hardly necessary to add, has enriched the Yale College Museum, which he has to a great extent reorganised, by countless specimens of all kinds-the Pterodactyls alone are represented by more than 600 individuals, the Mosasaurs by I,400! Marsh handsomely acknowledges the earnest help he received in his labours from Mr. T. B. Hatcher, his assistant, without whose energy and skill some of his explorations would have proved fruitless. To the whole of the work we just attempted to describe, Prof. E. D. CopE, of the Pennsylvania University, and Prof. Joseph Leidy, both American scientists of distinction and learning, have contributed their share, especially as regards the Vertebrates of the Cretaceous and Tertiary formations.

Such is the glorious record of American science within the last twenty or twenty-five years.

\section{PHYSIOLOGY.}

I628-I694. Malpighi, by means of the MICROSCOPE, immensely extended the scope of anatomy and physiology, revealing minute structures hitherto unsuspected; discovered the CAPILLARIES-microscopic tubes connecting the arteries with the veins-an additional evidence of Harvey's theory; also the AIR-CELLS and their membranes in the lungs, from which the blood derives its oxygen and rejects carbonic acid, thereby explaining what was so mysterious even after Harvey. Malpighi studied the tongue and carefully described its vessels, nerves, and coverings; also the SKIN, discovering its several parts-the epidermis, the MALPIGHIAN LAYER, which contains the pigment which colours the skin, the 
dermis or true skin, and the perspiration ducts (1665). He was really the earliest investigator of the lungs, the skin, and the mucous membrane. $\mathrm{He}$ also investigated the formation of the chicken in the egg. He was the first anatomist, too, who studied the ANATOMY OF INSECTS and revealed their marvellous structure : his description of the silk-worm ( 1669 ) in particular made a deep impression, giving as it did an idea of the breathing, circulation, secretion, growth, and metamorphosis of the insect; so that Malpighi started THREE important biological BRANCHES- the physiology of plants, insects, and animals.

1632-1723. Leuwenhoeck, by means of microscopes made by himself, studied the Infusoria, and discovered the Rotifers and other animalcules of the infusorial group living either in water or in the body of other animalsshowing that a speck, no larger than a grain of sand, may be made up of eight or ten thousand living creatures. He was a worthy rival of Malpighi. His "Epistolæ Physiologicæ" were much in advance of his time. The study of Infusoria, of which he was the chief pioneer, has been immensely enlarged by Ehrenberg (I795-I868?), who has demonstrated that these minute creatures have internal structures similar to those of higher animals. He has described over five hundred species, some of which he discovered in fog, rain, and snow.

1637-80. Swammerdam improved the art of dissecting, applying it to the general history of INSECTS; determined the degree of blood-heat in animals by means of a new thermometer; described the rise of lymphatic vessels, lately discovered by Rüdbeck; compared the history of bloodless animals with that of plants; composed the history of bloodless animalcula-a work unsurpassed in anatomical accuracy.

1668-I738. Boerhaave made the medical school of Leyden famous by his successful labours, which attracted to Holland numerous students, several of whom became celebrated physicians. Besides the beneficial impulse he gave to Medicine, he founded ORGANIC CHEMISTRY - the pursuit, that is, of chemical analysis of the substances composing plants and animals. Anatomists had described the structure and 
functions of organs-Boerhaave studied the very materials of those organs, thus extending the area of chemistry, which since Giaber had remained inorganic. He did more ; for after discovering the components of plants, he also found the source out of which plants derived their materials, viz. the chemical substances which made them up out of the soil through the roots, and out of the air and sunshine through the leaves. Likewise, by analysing milk, blood, bile, chyle, lymph, he showed animals to derive their materials from plants, or altered vegetable matter. His determinations were neither perfect nor complete, owing to the ignorance as yet prevailing as regards the constitution of plants, since chemists had not yet discovered the four gases (carbonic acid, hydrogen, nitrogen, and oxygen) which enter into their composition; but he nevertheless opened a new branch - the chemistry of life-and was therefore one of the chief instructors of the age. Among the numerous facts he elucidated, he demonstrated the phenomena of animal structure to be in accordance with the LAWS OF MECHANICS.

I 708-77. Haller, a pupil of Boerhaave just as famous as his master, made the Göttingen university a centre of physiological science. Leaving aside the 180 volumes on science he published with the help of his pupils, and the masterly drawings which illustrate most of them, we owe to him the discovery of the POWER OF MUSCLES TO CONTRACT; he found the cause of their contraction to be due, not to the nerves only, but also to independent irritation. He studied the physiology of the human body in a masterly manner. His services to Comparative ANATOMY were very extensive and important: he was the first to make this branch a separate science. He also collected material for the complete description of the FLORA OF SWITZERLAND.

I720-93. Bonnet added a great deal to the knowledge of the GROWTH of plants and animals; made a vast number of observations and experiments, and discovered vegetables to have the power of seeking and finding that which is indispensable to their development-moisture, air, and sunlight-a department which Darwin will investigate fully, and a fact which is accounted for by law. Bonnet also 
discovered that lower animals (worms, lobiters, polypes, for instance) have the property of growing afresh limbs and organs-lost by fracture, maybe-such as heads, tails, legs, etc.-a study pursued concurrently and carried further by Spallanzani. Some animals (the aquatic salamander, for example) were shown by these two physiologists to grow the same limb eight times in succession. Bonnet in his Contemplation of Nature threw out the first suggestion of PROGRESSIVE EVOLUTION from the lowest organism to the highest-a subject developed later by Lamarck and fully analysed by Darwin.

1729-99. Spallanzani made decisive experiments upon microscopic ANIMALCULA; determined the FORCE OF THE HEART upon the arteries, and the relative speed of the blood through the different channels; showed Infusoria to be oviparous, viviparous, and hermaphrodite; pointed out the principle of DIGESTION IN INSECTS. Like Bonnet, he experimented upon the power of regrowth possessed by lower animals, such as snails, water-salamanders-although some, like the last-mentioned animal, have, as he showed, a heart, red blood, lungs, bones, muscles. Spallanzani also studied the vegetable kingdom, and pointed out numerous phenomena. In the course of the XVIIIth century, biology may be said to have made great strides through the labours of Haller, Bonnet, Spallanzani, and Hunter, independently of the immense work of Linnæus, Buffon, and Lamarck.

1748-I794. Vicq d' Azir studied the NERvous SYSTEM with a thoroughness never surpassed in his time; and he established the LAW OF HOMOLOGY, which will become later the subject of a great scientific battle.

I749-I823. Jenner originated VACCINATION, one of the greatest benefits for which humanity is indebted to science -and an innovation in meeting disease which will bear rich fruit in the XIXth century-inoculation becoming then a subject of deep researches and experiments.

I773-I858. Brown (Robert), concurrently with MoLDENHAUER (1766-1827) and Mirbel (1776-I854), studied the physiology of plants and greatly extended our knowledge of the formation of the seeds, the structure of the cells and 
tissues, and the growth of stems. Robert Brown, in particular, established the existence of the embryo-sac, the function of the funicle (nourishing duct), and the micropyle (fertilising duct) -in fact the whole economy of the SEEDVESSEL-a determining feature in the modern classification of plants. These discoveries are allied to those of Sprengel.

b. 1787. Serres studied the brain, and showed the development of bones to proceed from the PERIOSTEUM (outward envelope).

I80I-I858. Muller (Johann) made the physiology of the senses of SIGHT AND HEARING a special study, even in lower animals; pointed out the anatomical type of glands, the components of blood, and other phenomena; but his capital feat in science lies in his originating COMPARATIVE PHYSIOLOGY. He had an equal influence in the scientific world as a physician, a chemist, a zoologist, and a physicist.

I8II-72. Simpson (Sir James Y.) introduced the use of CHLOROFORM as an anæsthetic, an innovation in the treatment of disease and surgical operations which has relieved humanity from immense suffering.

I8I3-I878. Bernard (Claude) discovered the FUNCTION OF THE LIVER, the pancreas, the salivary gland, and the spinal chord-four capital determinations.

\section{BIOLOGY (proper).}

1683-1757. Réaumur was the first to recognise the nature of coral and CORAL FORMATIONS, and to make a special study of insects and carry investigations over a much more extensive field than his predecessors. As a physicist, he invented the THERMOMETER which bears his name and is divided into 80 degrees from the freezing to the boiling points of water.

I728-94. Hunter, as one of the founders of modern biology and pathological physiology, pointed out, after going through an immense range of important observations and experiments in the vegetable and animal kingdoms, the necessity of embracing and connecting all the studies relating to life, instead of limiting the science of biology to the study 
of simple species through anatomy and physiology only. The influence of his teaching-that is, of a body of physiological doctrines-was equally extensive and durable. $\mathrm{He}$ also raised surgery from a poor empirical art to a noble science by initiating striking improvements. He discovered the electric nature of the Torpedo's commotions; showed the electric nature of the Gymnotus; explained the respiration of birds fully; studied the cetacea; and-one of his main claims upon our gratitude-founded the Hunterian Museum, one of the most beautifully classified collections in existence -each organ being displayed throughout its stages of development from its lowest to its most complicated form. Hunter was the most famous successor of Harvey as a physiologist. It should be mentioned that the Italian Morgagni (1682-I77I) preceded Hunter in the field of pathological anatomy and left invaluable contributions to science, although he did not formulate the broad generalisations which make Hunter famous.

I 73I-I802. Darwin (Erasmus), adopting Buffon's theory of the origin of species by evolution, assigned the main cause of animal development to the actions, wants, and habits of the animals. This is the germ of the theory of organic development; it only wanted the doctrine of natural selection to anticipate Charles Darwin in all points. "As the earth and ocean," says Erasmus Darwin, "were probably peopled with vegetable productions long before the existence of animals, and many families of these animals long before other families of them; shall we conjecture that one and the same kind of living filament is and has been the cause of all organic life ?" In "Zoonomia," we read :

First, forms minute, unseen by spheric glass,

Move on the mud, or pierce the watery mass;

These, as successive generations bloom,

New powers acquire, and larger limbs assume ;

Whence countless groups of vegetation spring,

And breathing realms of fin, and feet, and wing.

"When we revolve in our minds," says Erasmus Darwin, "the great similarity of structure which obtains in all the warm-blooded animals, mankind included, one is led to 
conclude that they have alike been produced from a similar living filament. In some this filament in its advance to maturity has acquired hands and fingers with a fine sense of touch, as in mankind. In others it has acquired claws and talons, as in tigers and eagles. In others, toes with an intervening web or membrance, as in seals and geese. In others, it has acquired cloven hoofs, as in cows and swine, and whole hoofs in others, as in the horse; while in the bird kind this original living filament has put forth wings instead of arms or legs, and feathers instead of hair."

These passages might have been written by his grandson Charles Darwin — so thoroughly do they agree with the latter's teaching. But we must at the same time recognise that they expressed suggestions only, and, profound as these suggestions were, they lacked the authority of that evidence and demonstration which it was the glory of his grandson to furnish, and which alone could carry conviction. They nevertheless gave a strong impetus to the movement of inquiry which was already agitating the European mind.

I744-I829. Lamarck, who may be called the founder of PHILOSOPHICAL ZOOLOGY, divided the animal kingdom into two divisions-the Vertebrata, and the Invertebrataterms which have been retained. He investigated fossil shells (as Cuvier did fossils of quadrupeds)-opening thus a new palæontological area-shells holding a vast place in the classification of geological strata. He studied invertebrate animals-worms, snails, insects, shell-fish, sea-anemones, and sponges; showed for the first time their infinite variety of forms and organisation, together with the important part they perform in nature. Science is also indebted to him for the separation of the crustacea (lobsters, crabs, shrimps) from insects, the introduction of the tribes of the arachnida (spiders), the determination of the class which he called annelida (worms, centipeds), the distinction of the microscopic infusoria from the polypes (radiate animals); he further determined the genera of the mollusca (snails, oysters), many genera and species of coral, and finally described and explained the fossil shells of the Paris chalk in a masterly manner. He crowned his studies of the lower animals by 
classifying them in accordance with their anatsmy, and divided them into classes, orders, and genera-being the first naturalist to begin a classification with the simplest and least highly organised animals. The great work of his life, however, had by far more importance than all this series of laborious researches, and was certain to exert paramount influence over scientific philosophy for all times. His process of classification seems logically to have convinced him (I80 I) that, acting by law, nature commenced with the simplest types, and that from these types had sprung an ever increasing variety of species branching off from one another, so that the present plants and animals are the outcome of those of past geological eras. Therein lay the whole subject of evolution versus creation-a momentous subject which was destined, after Charles Darwin, to force human thought into new regions. From this brief statement it is easy to see that none could have more influence than Lamarck over the modern school of evolutionists. His work, "Philosophie Zoologique," which Robert Chambers popularised in "Vestiges of Creation" (1844), has shaped evolutionary thought and" produced a decisive impression upon scientific men. The last thirty years of his life vere devoted to the elucidation of the problem of origin of species. The core of his teaching lies in the formulation of the idea that gradual modification from one primordial type has produced them all, and he extended this doctrine to the inorganic world-alterations. being in all cases and in every sphere the result of law. Anticipating Lyell, he even held that the ordinary process of natural laws was sufficient to account for all the phenomena presented by the earth's crust. He held the means of animal modification to have been, and to be due, not to differences and changes of habitat only, as is often said of him, but (I) to the direct environment or physical conditions of life, of which climatic and geographical changes form only a part; (2) to the blending, or separating, or crossing of formerly existing types; (3) to the effects of habits, and hence to the use and disuse of certain organs and limbs. The "use and disuse" theory has been considered as of paramount importance by C. Darwin and Herbert Spencer. 
Thus, proceeding further than Buffon, Erasmus Darwin, Goethe, who had only asserted the principle, Lamarck systematically and scientifically laid down the great problem of the variability of species for the first time, and thereby laid the foundation of the LAW OF BIOLOGICAL EVOLUTION, by demonstrating the alteration of types-man included, for he also enunciated the doctrine, first amongst biologists, that man is the descendant of an ape-like ancestor. The essentially original element he brought into science was, let it be remembered, not the evolutionary idea, but the idea that law presides over every process of nature, and hence obtains in biology as in all else.

I772-I844. Geoffroy St. Hilaire (Etienne), believing like Lamarck in the MUTABILITY OF SPECIES, demonstrated the unity of plan of the animal kingdom, and pointed out its branching off into innumerable divisions from a central stream. As a matter of fact, he believed all species to be derived by modification from one or several primitive types (1795). He was, like Buffon, Lamarck, and others, an evolutionist. Cuvier held a contrary view. He thought that each species and variety had been separately created and gifted with special organs to meet its wants. And as creation had left them, so they were now. St. Hilaire held that "Nature has formed all living beings on one plan, essentially the same in principle, but varied in a thousand ways in all the minor parts-all the differences are only a complication and modification of the same organs." And this HOMOLOGY (similarity of structure) runs through all animals, so that the leg of a horse, a lion, an ox, the wing of the bat, the paddle of a porpoise, the hand of man are the same organs made up of the same bones-these being merely altered to meet different purposes. This great principle was demonstrated by St. Hilaire, but it has been fully worked out since by Darwin, Wallace, Haeckel, and others. The divergence of conclusions between Cuvier and Geoffroy St. Hilaire was one which interested and stirred up the whole scientific world for a whole generation. His son (Isidore) was a great authority on variability and correlation.

I779-1851. Oken was the first to suggest the theory of 
UNITY OF ORGANIC COMPOSITION - the life-matter being "original slime." He also suggested that the development of animal forms proceeds from "mile" - cell-growth-a profound idea which SCHLEIDEN (I838) and SCHWANN (1839) worked out and fully demonstrated-the first tracing the plant embryo to a single nucleus-enclosing cell; the second tracing the animal embryo to a similar primordial form - the cell, therefore, being the fundamental unit of which every organism, whether plant or animal, is built up. To Schwann may therefore be ascribed the demonstration of the unity of the composition of animal organism.

I792-I876. Von Baer founded EMBRYOLOGY-a very important branch of biology-tracing as it does all the stages of development of an animal from its first appearance in the egg to its birth (1828). Von Baer, next, showed a very striking phenomenon, viz.: that the embryos of a fish, a lizard, a bird, an ox are not distinguishable from one another -and they continue growing so until a certain stage, and at that stage the fish begins to differ from the three others, and goes on growing into a certain variety of fish; of the three embryos that remain alike still for a time, one, the lizard, begins to branch off from the common appearance; then of the two remaining, alike still for a little time, the bird branches off ; and lastly the ox embryo takes a decided turn, but only some time after. This great fact offered a new basis for classification, for animals could now be differentiated according to the special characters they assumed from the beginning, and some defects of classification were rectified. This discovery had a philosophical importance besides, for it went far to prove that unity of plan upon which G. St. Hilaire had insisted-the embryo showing the same parts developing differently in different animals out of identical beginnings. Von Baer, like Von Buch, anticipated Charles Darwin in believing that a variety may slowly be altered into a permanent type-a doctrine taught long since, as we have seen. In close connection with Von Baer's observations, one of the most instructive additions made to this branch of physiology is due to Mr. Romanes, who, by the use of the microscope again, recognised in the lower class of invertebrates, the jelly-fish 
(medusa), rudimentary indications of organs similar to those we possess : traces of a nervous system, rudiments of eyes, and "sacs of mineral particles" supposed to be a rude hearing apparatus. From such beginnings has the law of evolution brought about all the alterations and complications which can be seen in the organic world.

I $800-72$. Pouchet enunciated the fundamental LAW OF FECUNDATION in mammals; endeavoured to prove the theory of spontaneous generation-but counter experiments carried on by other biologists showed that what might be taken for spontaneous generation was nothing but the hatching of microscopic germs.

I80I-I872. Von Möhl (Hugo) by his study of the anatomy and physiology of plants, especially in relation to the pores of their tissue and the existence of vegetal cells, became next to Oken the originator of the theory of PROTOPLASM-a new area of research. We are entirely indebted to the microscope for this very important addition to knowledge. Much, as regards the structure of cells, tissues, fibres of plants, was already known as we have seen, when Von Möhl discovered, in 1853 , the primitive form of living matter-in other words, life in its most elementary condition-and this matter, he showed, enters into the composition of a cell, and circulates therein with marvellous activity. It is also present in the embryo-sac. And being the simplest form of life known-the clay out of which bodies are formed-the discoverer called it protoplasm (first formative material). Chemically it is a compound of carbon, hydrogen, oxygen, and nitrogen, which is manufactured by the plant out of the soil, air, water, sunheat and light. Thus plants draw directly from chemicals both food and life; some animals feed on plants-that is, on the same chemicals prepared for them by the plants-as other animals, ourselves included, partly feed on vegetable-feedersthat is, on the same chemicals again, further assimilated and prepared as suitable nourishment. Reversing the description roughly, we might say: Man feeds on chemicals turned first into plants, then into ox-flesh. Protoplasm is therefore the most primitive form of life on the one hand, and the material out of which all living bodies are principally supported on the 
other hand. Whether, under the different conditions of pressure, heat, magnetism, electricity, which existed at an earlier stage of the earth's existence, chemical combinations spontaneously occurred which produced this living compound in the first instance, is so far one of the unsolved problems which has exercised the minds of many. We can produce no protoplasm in our laboratories with any of the powers at our disposal, that is certain. What we just stated as a hypothesis is considered by some one of the possible processes of creation-for the spark of life, the seed, once produced, evolved millions of ever-growing varieties. Spontaneous generation may have obtained once.

I809-I882. Darwin (Charles) established the LAW OF BIOLOGICAL EVOLUTION, one of the grandest generalisations on record, after devoting forty years to the close observation and study of plants, insects, worms, birds, animals, and man, finally demonstrating more than the principie laid down by Lamarck, for he proved the variability of species BY NATURAL SELECTION AND THEREFORE THE SURVIVAL OF THE FITTEST (1859). Two strongly-winged pigeons pairing together instead of pairing at haphazard with weaker pigeons (this is sexual selection), their descendants, able to fly more swiftly than most pigeons to escape danger, and to a greater distance to find food, will survive weak pigeon varieties, because, being the fittest, they come off victorious in the struggle for life. Such, in the main, is the theory in a nutshell. The theory of evolution, as the reader is aware, had been repeatedly broached, but the proof that evolution obtained in biology, the way how biological evolution worked itself out, this was the great work of Darwin, and the one which settled the matter for all times. Darwin has supplied us with a prodigious mass of facts-a vast number of evidences-showing that the plants and animals now existing are all descended from common ancestors, whose structure and organisation were less complicated than they are at present. To prove this proposition, which at first offended our prejudices and pride, he has shown us innumerable instances of the gradation of species into one another, so that from the present forms of plants and animals, it has become possible to 
ascend to remote ancestors, and establish the genealogy of many species. Up to the present day, "We have attained," says Prof. Cope, one of our highest authorities on the subject, "the long since extinct ancestor of the lowest vertebrates; we have the ancestors of all the reptiles, of the birds, and of the mammals. And if we consider mammals separately, we have traced up a great many lines to their points of departure from very primitive types. Thus we have obtained the GENEALOGICAL TREE of

$\begin{array}{ccc}\text { the deer, } & \text { camel, } & \text { musk, } \\ \text { horse, } & \text { tapir, } & \text { rhihoceros, } \\ \text { cats, } & \text { dogs, } & \text { lemurs, }\end{array}$

monkeys, and have important evidence as to the origin of man." And the significance of this fact is much increased by the details of the FILIATION in the course of development. Taking, for instance, THE HORSE as we have it at present, we find that its earliest family ancestor (in America) was :

In the Early Eocene (Tertiary Period), the EoHIPpUs, the size of a fox, with four toes and the remnant of one fifth toe;

Then in the Upper Eocene, the OROHIPPUS, whose rudimentary first toe was gone and the fifth toe was reduced to a splint ;

Then in the Lower Miocene, the Misohippus, the size of a sheep, with a rudimentary splint on the foreleg and only three toes ;

In the Upper Miocene came the Miohippus, who comes near the Anchitherium of Europe-the tips of whose outer toes just touched the ground;

In the Lower Pliocene, the Protohippus, the size of an ass, nearly similar to the Hipparion of Europe-three toes only, the middle of which only touched the ground;

In the Middle Pliocene, the Pliohippus, who has lost the small hooflets on the rudimentary toes-in all aspects resembling the horse ;

In the Upper Pliocene finally came the HORSE, with one solid toe covered with a single solid nail (the hoof).

In Europe, the earliest ancestor of the horse as yet found was the PALeotheriun, with three toes, the middle one being the largest; 
Then came the ANCHITHERIUM, with the two outer toes. just touching the ground and the middle toe being the main support ;

Then came the HIPPARION, the immediate ancestor of the horse, with the two side toes so rudimentary as to be useless;

Then came the HORSE, without the side toes.

This genealogy of the horse was elaborately traced out by Prof. O. C. Marsh, the great American palæontologist.

We may remark in passing that the Miohippus of America and the Anchitherium of Europe were first cousins; we may further remark that America was the home of the horse's ancestors; that one of the family, possibly the Misohippus, may have migrated to Europe, when the two continents were joined, and there developed a collateral branch independently, whose descendants were first the Palæotherium, then the Anchitherium, then the Hipparion, then the Horse. The family, which died out in America after the Upper Pliocene epoch, was perpetuated in the European branch until the present day. We find the horse in Europe throughout the Quaternary Period. By tracing a multitude of facts similar to those, Darwin was able to establish his biological evolutionary law, and Herbert Spencer has since shown the law of evolution to be one which applies universally to all orders of facts; that if changes of structure, brought about by new conditions, enable the Flora and Fauna to live on and on, under new forms, despite the successive alterations of the globe, changes of conditions modify with equal energy and variety the whole of the Universe-for, whether we view the organisation of society only, or the construction of the earth or that of the stars, we detect the same adaptation of things to new necessities: geology and astronomy, barring "natural selection" and its mode, teach us the same lesson as biology. Well might Mr. Jevons say "that it is questionable whether any scientific works which have appeared since the Principia of Newton are comparable in importance with those of Darwin and Spencer."

Darwinism, which at first shocked many minds, has now been accepted even by divines of the Church. "It seems," says Bishop Temple, "more majestic, more fitting of Him to whom a thousand years are as one day, thus to impress 
His will once for all on His creation, and provide for all its countless varieties by this one original impress, than by special acts of creation, to be perpetually modifying what $\mathrm{He}$ had previously made."

By Darwin's explanation it is easy to reconcile the divergent views entertained by Cuvier and Geoffroy St. Hilaire. Truth being one, and these two great men being possessed of sound knowledge, it was likely that it would be found that they were both right, and that they were both in the possession of truth in the main was shown by another truth-the one Darwin brought to light. For the law of the survival of the fittest made it imperative that each part of an animal should be exactly fitted to meet its wants and should work harmoniously with the rest of the body, as Cuvier demonstrated it to be the case; whilst the law of natural selection made it equally imperative that if animals have been gradually altered from one another, by the instinct to pair with those exactly like themselves though they might slightly differ from the rest of their species, they should be made on one plan as St. Hilaire showed they were. Cuvier's doctrine of immutability, however, was totally destroyed by the same stroke. Darwinism goes much further: it accounts for the fact that existing animals in one continent are of the same nature as those found in the same area in a fossil state, though slightly differing from them; and finally it accounts for the fact that "lower forms of life are (necessarily) found in the most ancient geological formations."

It is fitting here, in order to prevent misconception, that the place which Darwin holds in the history of evolutionism should be clearly determined. The doctrine of evolution,* as we have repeatedly seen, originated long before Darwin. Buffon had foreshadowed it in the middle of last century; Geoffroy St. Hilaire (1795) thought species derived by modification from one another, and Goethe endorsed that view. At the same time Erasmus Darwin, Charles Darwin's grandfather, adopting the same theory, went further still by enunciating some of the causes of animal development. Lamarck (I80I), besides holding that all species were

* The doctrine can be traced to India. 
descended by gradual modification from one primal form, commanded greater influence still, because he systematised a large number of facts, and brought in the idea that law governed the living world as it governed all else. Later, William Smith pointed out that rocks were deposited in successive order, and thus carried the doctrine of evolution into the domain of geology; and, subsequently, Lyell substantiated the theory as regards the main problems involved in the formation of the earth. In astronomy, as early as 1744 and I799, the same lesson was taught by Kant and Laplace, regarding the origin, constitution, order, and gradual formation of the heavenly bodies. Thus far, we see that the evolutionary law was demonstrated as having obtained in astronomy and geology, and that it had been all but demonstrated in biology. To this last determination-without speaking of Von Buch, Lecoq, Von Baer, and Dean Herbert, each of whom did valuable work-three men, Malthus, Dr. Wells, Patrick Matthew, contributed an important share. Malthus (1798) pointed out the struggle for existence which keeps human reproduction to the same limit as food-supply; Dr. Wells (I8I3) actually hit upon the notion of "natural selection" as regards the races of mankind; Patrick Matthew (I83I) went even further: he not only intimated the same idea, but he applied it to the whole of nature. We thus see that the staircase of biological evolution had been gradually ascended before Charles Darwin reached its upper platform. This is not all. Herbert Spencer, as early as 1852, had published his "Development Hypothesis," which embraced the main arguments, features, and facts of the whole evolutionary doctrine, and enunciated, with luminous force, the doctrine of descent with modification.

It seens, after such a recapitulation, as if there remained nothing for Darwin to do: the evolutionary theory had been strongly established in several branches, and had been fairly sketched even in biology. Yet, for all that, there was a vacant place left, and that vacant place was the most important of all. It was absolutely imperative, before biological evolution could be accepted, that it should be demonstrated beyond doubt by a vast array of proofs of all kinds. This 
was absolutely necessary because the question touched-not heavenly bodies, not the earth's history, about which ordinary mortals feel only secondary interest if they feel any at allbut touched mankind itself, its origin, its history, its feelings, its creed, its destiny; and each individual, attacked so to speak directly by the doctrine, was sure to reject it loftily unless irresistible and overwhelming evidence brought conviction to him, and left him no room for the shadow of a doubt. This was the work left for Darwin to do, and he did it. His contribution to evolutionism was, as we know, not the idea itself; nor was it the idea of descent with modification; it was the idea of " natural selection"-by which he was able to prove plants and animals to have been slowly evolved from simpler forms, "with definite adaptations to the particular circumstances by which they were surrounded." Where an inquirer had seen the law obtaining in flowers only, another inquirer in timber only, a third in mankind only, Darwin showed the law to have held good universally for the whole of organic nature-that is, where some had seen the particular he saw the universal; and he showed this by such a multitude of facts, proofs, instances in so many different species of plants, and so many more of animals, that the conclusion was irresistible. Again, where all the aforesaid philosophers and inquirers had asserted even plausibly, but asserted only, he brought forward innumerable examples of every kind, and silenced dissent by irrefragable proof. Again, where only one line of argument in favour of organic evolution was set forth, Darwin accumulated the argument from palæontological succession, the argument from geographical distribution, the argument from embryological development, the argument from classificatory relationships-i.e., the genealogical tree. Where one had seen "descent with modification," he saw descent with modification by "natural selection"-which is the key of the mystery. Where Malthus, and even Wallace, had expressed suggestive hints, he constructed a vast incluctive system. Finally, where Erasmus Darwin, or Chambers, or Lyell saw the working of a final cause, he saw that of an efficient cause -a fundamental distinction, as we shall have again occasion 
to point out. Darwin sums up the chief features of his theory as follows: "(I) Growth with reproduction; (2) inheritance; (3) variability from the indirect and direct action of the conditions of life and (4) from use and disuse; (5) a ratio of increase (reproduction) so high as to lead to (6) a struggle for life, and as a consequence ( 7 ) to natural selection, entailing (8) divergence of character and (9) the extinction of the less improved forms. Thus from the war of nature, from famine and death, the most exalted objects which we are capable of conceiving, namely, the production of the higher animals, directly follows." If the belief of an efficient cause, instead of a final cause, should offend our moral sense, we should aptly remember the words of Bishop Temple already quoted, supplemented by what a distinguished evolutionist says on the subject. "To the careless and hasty eye," says Crookes, "design and evolution seem antagonistic; the more careful inquirer sees that evolution steadily proceeding along an ascending scale of excellence, is the strongest argument in favour of a preconceived plan." This beautiful thought does not meet the argument of the existence of evil; but it is well calculated, nevertheless, to comfort those who may be disposed to look upon evil, not as a permanent feature in organic nature, but as a transitory process towards the ultimate attainment of good.

For all the reasons we just indicated, Darwin converted the whole world where Lamarck had only aroused interest among the learned. He made evolution comprehensible, and having made it comprehensible in biology, which stirred up an interest in every man, he by the same stroke caused also cosmic evolution to be understcod at last, and to be accepted as a universal law, with the same readiness as gravitation is accepted; so that, although he neither originated the idea of evolution, and although general evolutionary law had been demonstrated; yet, Darwin holds the highest place amongst evolutionists; because, whereas evolution was only a vague and insignificant notion to most before him, he attracted the attention of the world to it, and brought it home to all men, high and low, learned and ignorant, with equal force. 
Having said this much, we have to add that Darwin had exceptional advantages in fulfilling the task he undertook. A five years' cruise round the world (I83I-6) as naturalist on board the Beagle-a Government vessel bound on a voyage of exploration-enabled him to acquire a unique training as an observer, a unique experience as an analyst, as well as a unique collection of specimens for the solution of biological problems. With the study of Erasmus Darwin, Lamarck, Malthus, and their successors; with the uniformitarianism of Lyell; with the general evolution of Herbert Spencer, he was fully equipped, and had actually the whole subject-matter of his "Origin of Species." If he was vehemently attacked at first-a fact which drew universal attention on him and militated for him thereby in the endhe also had the good-will, and even the assistance of men enjoying European reputation - Lyell, Wallace, Haeckel, Hooker, Herbert Spencer. To Herbert Spencer, Darwin is indebted for the expression of "survival of the fittest," which describes more tersely and clearly than "natural selection" the great Darwinian principle. To the organising and systematising mind of Herbert Spencer, too, devolved the task of working out the metaphysical and psychological aspects of evolution, and of adding to Darwinism the force of his application of the evo'utionary method to sociology, to the origin of societies, to the origin and growth of languages, of worship, of customs, manners, institutions, industry, religious polity, political government. Herbert Spencer will always be considered as the greatest philosopher of evolutionism, but Darwin will remain its central pillar, because what other people suspected, suggested, intimated, discussed, and argued, he was the first to prove by observing, experimenting, demonstrating-so that "popular instinct which regards Darwinism and Evolution as somewhat synonymous, is in a certain degree justified." Darwin's work forms the keystone of the evolutionary system, and "supports it by the mass of evidence it has accumulated." His task was to bring evolution from the clouds to our door-step. But to Herbert Spencer alone we owe the entire philosophical conception and fabric of evolution as a "cosmical process," one and con- 
tinuous "from nebula to man, from star to soul, from atom to society." $\mathrm{He}$ is the high-priest of the evolutionary creed. (Grant Allen's Darwin.)

To understand the full import of evolution, we must read the crystalline exposition of the system in Spencer's "First Principles"; but to apprehend its outline we need only recollect its simplest definition. Evolution means a constant and everlasting process of infinite transformation working itself out in regular order, and spontaneously producing new divergences in obedience to, and in harmony with, definite natural laws. In other words, the evolutionists see in evolution " a vast aggregate of original elements perpetually working out their own redistribution in accordance with their own inherent energies." This process applied to the development of plants and animals is very clearly apprehended too, as soon as we admit, as we must, the "struggle for existence" to which all organised things are subjected by the circumstances which surround them; for, in that struggle, "variations, however slight, if in any degree profitable to the individual which presents them, will tend to the preservation of that particular individual; and, being on the average inherited by its offspring, will similarly tend to the increase and multiplication of its species in the world at large." This is the principle of natural selection or survival of the fittestthe great principle which Darwin added to the evolutionism of Lamarck and his followers, and which has revolutionised human thought. Of the cause of variation we know little as yet or nothing, unless Weismann has hit upon it in his theory of the persistence of germ-plasm. That would explain the problem; but the germ-plasm doctrine is far from being as yet an established fact.

Of all the works of Darwin, besides his "Origin of Species" (1859), the "Fertilisation of Orchids" (I862) and the "Descent of Man" (I87I) are the most famous: the first, because it opens the loveliest fairyland of nature; the second, because it contains all the evidence and arguments which science can furnish of the relationship of man with the rest of the animal kingdom. His "Variation of Animals and Plants under Domestication" (I876) is a storehouse of daily 
verifiable facts, whilst his treatise on "Sexual Selection," which expounds the celebrated "Theory of Courtship," explains a very important element of organic evolutionism. We may mention also that his "Effects of Cross and SelfFertilisation in the Vegetable World" (1876) called attention to the now well-known Knight's law-"Crossfertilisation produces finer and healthier offspring, while continuous self-fertilisation tends to final extinction"; and to Sprengel's beautiful work, "Fertilisation in Flowers," which had been lying in the dust of libraries ever since 1789 , despite its intense interest and worth. That more than eight hundred works on the same subject should have appeared since Darwin drew attention to Sprengel may give an idea of the germinal force that lay in his labours.

It is bare justice to state that Mr. Alfred R. WALLACE was working independently in the same direction as Darwin himself, and that he arrived at similar conclusions about the same time, after four years' work in Brazilian forests, and eight years' explorations in the Malay Archipelago. The writings of this fervent servant of science* are worthy of Darwin himself.

Since Darwin's death, Darwinism may be said to present three groups of inquirers : I. the Wallace-Haeckel group, who are orthodox Darwinians; II. the Herbert Spencer group, who are rather inclined to Lamarckianism ; III. the WeismannRomanes group, who explain variation as due to external influences, and among these to sexual reproduction mainly. Weismann thinks his theory of the continuity of the germplasm is the key to the problem. For, the egg-cell (if we may use the common term) will be affected by the spermcell which unites with it, and the offspring receiving the variation inherent in the sperm-cell, is itself different from both parents, and will carry its own variation, by the transmission of its germ-plasm, to its immediate descendant, whose nature will in like manner be affected by the process just indicated and repeated by its progenitor. This theory would clear up the mystery of the cause of variation. Before it is

* "Travels on the Amazons and the Rio Negro," "Tropical Nature," "Geographical Distribution of Animals." 
accepted, the existence of the germ-plasm has to be conclusively confirmed.

b. I82I. Virchow is justly regarded as one of the leading physiologists and biologists of modern times. His researches into CELLULAR PATHOLOGY particularly, deep and thorough in an equal degree, make him one of the great masters of science, for he may be considered as the founder of that branch. He proved the soundness of his own doctrine, "Omnis cellula a cellula" (every cell comes from another cell), by tracing the origin of disease to hereditary cells. This is the fundamental principle of cellular pathology. He discovered new aspects of ulceration and inflammation in berculosis and other affections. His investigations in prehistoric archæology are almost as much prized as those he made in pathological anatomy. Strange to say, he fought for the doctrine of fixity of species against the Darwinian theory-resembling in this Owen and Agassiz, not to speak of Lyell, who accepted Darwinism only after it had conquered the scientific world. It is only fair, both to Darwinism and to its opponents-few nowadays-to state that opposition is grounded on religious belief rather than on scientific considerations. It is a conflict between a sentimental inclination and a powerful fact, in which the latter must of necessity prove victorious in this as in so many cases before.

b. I822. Pasteur studied organised ferments in beer, vinegar, and wine, analysing meanwhile bacilli and bacteria (microbes) with such success that he was able to discover (?) the bacillus of rabies (HYDROPHOBIA), and further, introduce inoculation against this terrible disorder-the effect of which is prevention and cure. His discoveries, which unveiled the mysterious sources of infectious disease, have caused a revolution in medicine and surgery, and led to vast progress in them, making them at once more scientific and efficacious. He may be considered as one of the greatest benefactors of humanity-certainly the greatest of our time-to be remembered in all ages as Paré, Jenner, and Simpson, all of whom have contributed to the decrease of human suffering. I825-92. Bates, with whom Alfred Russell WALLACE 
was at first associated, went to Brazil in order to study tropical life in its richest region. It was these two genuine inquirers who opened an almost virgin soil and made it known to the scientific world. In the depths of Brazilian forests where he wandered for years, Bates, after collecting endless varieties of tropical butterflies, unravelled the history of evolution on the gauze-like wings of these insects. $\mathrm{He}$ also expounded the fine and striking theory of mimicry-a crucial instance of animal development. The phenomena he thus disclosed were precious to biological science: for the strange disguises which insects and birds frequently assume are facts that afforded a new principle to Charles Darwin, "which enabled him with ease to reduce a great number of points to order and symmetry," and supplied him with additional evidences of natural selection. "The Naturalist on the Amazons" was the work which made Bates famous.

b. I825. Huxley, equally great as a writer, a philosopher, and a man of science, is probably the greatest biologist living. He originated researches in oceanic HYDROZOA during a voyage around the world; showed the existence of extensive masses of monera at the bottom of deep oceans, "where they form a sort of live slime" (I868); carefully investigated the development of invertebrates; pursued investigations in PROTOPLASM and advanced this branch rapidly, thereby becoming the highest authority on the origins of life so far as they can be determined by man. In numerous branches of biology, Huxley has contributed facts and conclusions which corroborate with unanswerable force the evolutionary process elucidated by Darwin, so that he is justly regarded as one of the most powerful demonstrators of the law. With keen scientific perception, for instance, he demonstrated birds to be descended from reptiles-from the Dinosaurs-the immense gap between them being filled up by the discovery of intermediate birdlike reptiles and reptilian birds-the linking ancestors of the bird being the Compsognathus and Archæopteryx of the Old World and the Ichthyornis and Hesperornis of the New World-the last two brought out by Prof. Marsh. This genealogy of the bird supplies one of the most 
striking evidences of the evolutionary doctrine. As regards man, to us the most engrossing of all subjects, Huxley showed anatomically that man must be classed in the order of Primates, as one of the many divergent types which that order embraces within its extensive limits. In his work, "Man's Place in Nature," published about the same time as Lyell's "Antiquity of Man" (1863), Huxley arrived at the conclusion that man must necessarily be the descendant, like other mammals, from some common vertebrate ancestor, and that the prevalent view of his origin and of his destiny "must be modified by the evolutionary principle." His "Lectures on Comparative Anatomy," "Introduction to the Classification of Animals," "Address on the Coming of Age of the Origin of Species" (I880), are deservedly held in universal esteem.

b. I834. Haeckel, one of the most brilliant followers of Darwin, might be called the Huxley of Germany, but for his tendency to venture upon speculations at times unsupported by strict scientific inquiry. Apart from this consideration he has rendered sterling services to science. In the first place he, more than all others, contributed to the spread of the evolutionary idea throughout Germany, despite his troublesome terminology. Among other matters finely treated he discussed with unique boldness the successive stages of man's genealogy. In corroboration of Darwinism he undertook a vast inquiry in order to determine the laws governing the form of structure and mutual relations of living things, so as to establish the general principles of biological science. The first part of this labour he expounded in "Generelle Morphologie" (1866). This work was an attempt to found a "natural system" on the basis of genealogy; in other words, to construct hypothetical pedigrees of the various species, including man. To this end he investigated and pointed out several aspects of organic evolution, notably those relating to the metamorphosis of organs, taking care to strengthen his views by working out with remarkable cogency and mastery the Darwinian theory of sexual selection. His "History of Creation" ( 1868 )-a popular work-contains an application of the Darwinian theory to the chief groups of 
animals, and a determination of their mutual relations and lines of descent. His "Anthropogenie" is an elaboration of the same principles to the special problem of the evolution of man. It includes subjects which have been exercising biologists' minds of late years-such as the Gastræa theory, the Cœlum theory, and the nature and origin of segmentation -into which our limits do not allow us to enter. $\mathrm{He}$ vigorously defends what he calls the "fundamental law of biogenesis," known in England as the recapitulation theory, according to which the actual development of an animal is a repetition of the ancestral development of the species; or, as it has been put, animals in their development climb up to their own genealogical trees-a theory generally accepted by biologists. (See Von Baer.) He was amongst the first who realised and taught that doctrine. He strongly dissents from Weismann's teaching with regard to heredity-pointing out that the existence of germ-plasm is as yet a mere conjecture, and maintaining that acquired characters are transmitted. $\mathrm{He}$ holds that the ancestors of the Vertebrates must be looked for amongst the segmented Turbellarian worms. The weak points of Haeckel's teaching lies in human embryology, "the difficulties of the problem of which he lays aside "-a great deal, mainly due to the labours of the celebrated Leipzig Prof. His amongst others, and known for certain, he entirely ignores. Haeckel's works contain genealogical tables, one of his usual modes of exposition, which, strongly suggestive as they are, are not always accepted by naturalists. Yet, his zoological classification is on the whole considered as one of the most perfect ever devised. Haeckel, it should also be remembered, has made sponges a particular study, and is held as one of the few authorities on that special branch of organisms which yields strong evidence of evolution.

Haeckel was not alone in Germany in working out the problems of life initiated by Darwin. To speak of a few only, the two Müllers (Fritz and Hermann) till the same field with earnest conviction and intelligence: the first collected his fine "Facts for Darwin," which abound in instances and evidences of organic development; the second observed with German patience and thoroughness the action 
of butterflies and bees on the fertilisation of flowers; while Ruitimeyer explained with keen perception mammalian relationships in accordance with the Darwinian theory. These contributions to scientific knowledge, it is hardly necessary to say, were only a small percentage of the mass which laborious Germany has accumulated within the last twenty years.

b. I834. Lubbock ( $\mathrm{Sir}$ John) added valuable information to that furnished by Malpighi, Leuwenhoeck, Swammerdam, Spallanzani, Réaumur, and Lamarck, who had paid much attention to insects. Sir John has supplemented our knowledge of BEES AND ANTS by wonderful details. Nothing in nature is more beautiful than the instinct, the habits, the order, the intelligence of these insects, and nothing in science is more admirable than the love, the patience and cleverness Sir John has displayed in this study. To say that he watched one individual insect queen for fourteen years is to give an idea of the thoroughness of his work. His books are delightful reading. Anthropology is also much indebted to Sir John Lubbock for his extensive investigations. His persevering researches resulted in valuable works, the purport of which is accurately described by their titles : "Prehistoric Times," which came out about the same time as Tylor's "Early History of Mankind" (I 865); "Origin of Civilisation" (1870), and "Primitive Condition of Man." In those books the author has accumulated conclusive evidences of the remote antiquity of man and man's slow evolution from the lowest state of brutishness to his civilised condition.

\section{ANTHROPOLOGY.}

I752-I840. Blumenbach founded this new science-was the first who gave a serious attention to the natural history of man, neglected until then. His "Skulls of All Nations" opened the road to the STUDY OF MANKIND in all parts of the globe-the configuration of the.skull, stature, colouration, of the skin, eyes, hair, ethnology, philology, worship becoming so many subjects of serious investigation, and so much material to establish a basis for the divisions of the human. races. 
I788-I868. Boucher de Perthes discovered flint implements and a HUMAN JAW in the drift of the river Somme (I847), thereby causing a revolution in the views held hitherto regarding the antiquity of man. He shattered at one blow the erroneous ideas of mankind as regards the origin of man, his place in creation, and his course of development. His discovery was supplemented in 1853 by antiquarians finding the Swiss Lake dwellings, which are comparatively recent, but which nevertheless added another evidence to the antiquity of man. Other countless discoveries have extended our knowledge on that point (see Broca and Agassiz).

I79I-I862. Knox (Robert) showed in his work, "The Races of Man," the PERSISTENCE of the Jewish, Celtic, and German TYPES, and endeavoured to prove that distinctions were immutable - a theory which, though apparently supported by the evidence yielded by atavism (heredity), can no longer be held in the face of the law of evolution. Knox's facts are of much value, nevertheless, for they add another set of proofs of the remote antiquity of man. For if man has undergone no visible change within such a lengthy period as the whole of the historical epoch, hundreds, perhaps thousands of such periods must have been necessary for the production of the many existing human varieties.

I796-1850. Retzius gave a theory of CRANIOLOGY according to which the whole human race would be divided into two fundamental groups, founded upon the relation between the antero-posterior diameter (length) and the transverse diameter (breadth) of the skull-the autochthons of Europe (natives, aborigines), the stone-man being broadheaded (brachycephalic), and the foreign population, the bronze-man, being long-headed (dolichocephalic); but later researches and discoveries have proved this easy method to be insufficient for a correct classification of races.

b. 1808. Pruner-Bey, after visiting Italy, Greece, Egypt, Syria, Arabia, believed in the persistence of types in historical times solong as there is no change of habitat; founded the differential characters of the human races upon their physiological development; originated the EsTHONIAN THEORY, according to which the Esthonians (who are brachy- 
cephalic) would be the only remnants or survivors of the autochthons of Europe-other anthropologists, however, contending that the Finns, the Lapps, the Basques are also direct descendants from the primitive population of Europe, although they differ in the configuration of their skulls.

b. I8Io. Quatrefages de Bréau believed that the Quaternary man presented TWO TYPES in Europe: viz., a tall and dolichocephalic man (the Cro-Magnon cave man), and a short and brachycephalic man (the Esthonian, or the Loess Valley man), both of which have persisted to this day notwithstanding the invasion of Europe by the so-called Aryan races.

b. I8I7. Vogt pointed out the difference between man and the anthropoid apes, in popular lectures, and contributed to promote the study by numerous observations. His injunction to study the whole race as it lies buried in the strata of the earth, and not as a living genus only, was not the least of his services.

1824-80. Broca, the founder of the earliest Anthropological Society (Paris), proved the Cro-Magnon (and the Eyzies) man, analysed by him, to be different from other known races-a fact which demonstrates the unsoundness of previous anthropologists' belief with regard to the unity or duality of race of the primitive inhabitants of Europe. Broca insisted upon the presence of THREE TYPES, which we may differentiate as the Constadt type, very dolichocephalic (long-headed) and prognathic (with projecting jaw)-of which the Neanderthal is an extreme instance; the CroMagnon (Vézère Valley) type, rather brachycephalic (broadheaded) with good cranial development, tall, not unlike the modern race; the Furfooz type, a dwarfish race with a round head, resembling the modern Laplander-all of them different from the races of Africa, Asia, and America! The discovery of numerous caves, ancient human dwellings, both in Europe and America, has thrown much light upon the antiquity of man and the variety of races and habits, notably, besides those already alluded to, the Brixham cave (Devon), Kent's Cavern (near Torquay), Gower Cave (South Wales), Victoria Cave (Yorkshire), Woking Cave (Somersetshire), King Arthur's 
Cave (Herefordshire), the Chaleux cave (Belgium), the Vézère cliffs (Dordogne), the Danish Kitchen-Middens and Danish Mosses, the Swiss and Italian lake-dwellings, and hundreds of other sites. Innumerable palæontological implements and many human remains discovered everywhere prove the antiquity of man by unmistakable evidence, and reveal the fact that his presence on the earth must have preceded the Glacial period.

The Anthropological Society of London (now Institute), founded by Dr. James Hunt (1863), had not been long in existence before it contributed a wide range of information towards the natural history of man.

\section{PHILOLOGY.}

I765-1837. Colebrooke encouraged the study of Oriental languages bycomposing a SANSKRIT GRAMMAR and Dictionary -bringing to the notice of Europe the Grammar of Pânini, one of the most profound books produced in any language.

I767-1835. Humboldt (C. W.) founded Comparative PHILOLOGY, which was destined to throw so much light upon the growth of civilisation; his "Studies on the Basque Language," and his "Kawi Language in the Isle of Java," constitute valuable documents on the history of speech.

I786-I859. Grimm (Wilhelm Carl) discovered and elucidated the law of the transmutation of consonants, called GRImm'S LAW, between (I.) Indo-European languages (Sanskrit, Greek, Latin), (II.) the Low German languages, and (III.) Old High German - a feat which has assisted the study of our race in a remarkable degree.

I790-1832. Champollion, following the ingenious hint supplied by Thomas Young, deciphered the HIEROGLYPHIC LANGUAGE of the Egyptians-a thing vainly attempted for two centuries, and the most marvellous feat of the kind ever performed. And not only did Champollion accomplish the solution of a problem which had baffled investigation for ages, but he actually constructed a hieroglyphic grammar and a hieroglyphic dictionary - two performances of genius. The key once found, subsequent scholars followed, and now 
hieroglyphic texts can be as easily read as Greek. This great work has caused a revolution in history, revealing as it does an antiquity undreamt of, and a civilisation seven thousand years ago which was in many ways more astonishing than ours. Not one of its least important results is the new light it throws upon the antiquity of our race.

I79I-I8. Bopp investigated the growth of speech, and traced up the connection existing between a certain group of Oriental languages and those of Europe (Sanskrit, Slavonic, Celtic, German, Greek, and Latin), and their common descent from one original language of which there remains no literary trace. This demonstration is almost conclusive as regards the kindred of all the nations of Europe (the Turks, Hungarians, Finns, Laps, Esthonians, and Basques excepted), and their descent from one extinct stock conventionally called Aryan. Bopp's Comparative Grammar, a monument of research and learning, may be called the basis of modern philology; but its value is considerably enhanced by the flood of light it throws on the history of races, coming as it did after ANQUETIL DUPERRON (I73I-I805) by his discovery and translation of the Vendidad (fourth book of the ZEND Avesta), and after Burnouf (I775-i844) and Sir Henry RAWLINSON (I8I6- ) by their discovery of the key to CUNEIFORM LANGUAGES- the lost languages of the Semites, Persians, and Assyrians-had furnished documentary evidence of the Aryan theory.

b. I 823. Max Müller elucidated in a much further degree the science of philology by a series of works unsurpassed for learning and depth, among which his translation of the Hitopadesa and of THE VEDAS, the History of the SANSKRIT LANGUAGE, Lectures on the Science of Language, stand foremost. By these labours and their purport the author has established his title to be considered the champion of the Aryan theory-a theory which seems undisputable as regards language, but which is disputed as regards race: identity of speech by no means necessarily implying identity of race.

Closely connected with anthropology comes : 


\section{SOCIOLOGY.}

I619-83. Colbert patronised science as well as art and literature; was the earliest and greatest representative of the progressive tendency of the industrial movement; made MANUFACTURES, until then so despised by statesmen generally, the permanent form of European industry; encouraged their growth by every means in his power, but chiefly by removing many of the taxes and impositions under which they languished, and protecting their interests wherever they were threatened: was one of the precursors of the Economists. It may not be out of place to mention that this enlightened Minister suppressed execution for witchcraft and accusation for sorcery in France. This act of common sense and justice was the earliest of the kind in Europe.

1694-1774. Quesnay, one of the founders of political economy, advocated COMPLETE LIBERTY of agriculture, commerce, industry, the abolition of customs in the provinces, free circulation of corn. His motto was "Laissez faire et laissez passer." The weak point of his school lies in the doctrine that agriculture alone is capable of accumulating wealth. Adam Smith and his followers rightly showed that exchangeable products constitute real social wealth, and that society benefits in proportion as labour increases their value.

I712-I778. Rousseau has commanded just as wide an influence in another sphere of the social organism by his scheme of SECULAR EDUCATION, which has been adopted by the lay world in all civilised countries through the advocacy of those whom he inspired - Jean Paul Richter, Herder, Basedow, Lavater, Pestalozzi, Jacobi, Schiller, Göthe. The teaching introduced by Rousseau's educational reform involved individual and public freedom, abolition of prejudices and servitude, a new doctrine of happiness consisting in limitation of desire, self-reliance, manhood, patriotism, work as a duty for all (rich or poor), respect for truth, and craving for justice. The system meant no less than the restoration of naturalism. It need hardly be pointed out that, as 
education and government are the two agencies which surround internal and external character, Rousseau, by his action on political organisation on the one hand, and educational organisation on the other hand, has to a vast extent shaped some of the features of modern civilisation, especially when it is remembered that association and collective action are derived from his scheme.

I7I5-I77r. Helvetius, whose views on government and belief seemed offensive to so many and aroused so much indignation once, deserves a place amongst great sociologists, not because he devoted his life to philosophy and DUTY, but because he assailed the social ordering of the ancient régime, and expounded the idea of general UTILITY as the foundation of social morality, which Bentham, in England, carried out in legislation. "The laws," says Helvetius, "should be referred to a single principle such as that of utility of the public"-a principle that contains all the seeds of European legislation in our times. His influence, therefore, is likely to last as long as civilisation.

I723-I790. Adam Smith caused a revolution in trade by his "Inquiry on the Nature and the Wealth of Nations." The principle of WEALTH IS LABOUR, not in commerce and agriculture only, but in every branch of human activity. The yearly labour of a nation is the source from which it derives all the necessaries of life-which consist either in the product of the work of one nation or in what she can purchase from other nations. Another principle is complete LIBERTY OF ACTION-hence FreE TRAdE. Adam Smith also showed the great results of division of labour. Of all economists he had the greatest influence. It is not too much to say that he transformed the social system.

I727-I781. Turgot, one of the earliest practical economists in Europe; his "Valeurs et Monnaies," and his "Reflexions upon the Formation and Distribution of Wealth," together with his economical and commercial policy as a Prime Minister, inspired Adam Smith. He wanted the emancipation of labour at home and freedom of trade abroad. He established FREEDOM IN THE CORN TRADE in 1774 - a reform already tried in 1749 and in 1763 by 
Machault and Laverdy. He also advocated a system of general education.

1738-1794. Beccaria caused the institution of the Jury to be introduced on the Continent; caused the ABOLITION OF TORTURE; denounced the harshness of the penal code; advocated that punishments should be proportionate to the offence-so that he was a beneficent legislator, although his work on Crimes and Punishments is only a philosophical treatise.

$1747-1832$. Bentham, inspired by Beccaria, introduced the principle of IDEAL JUSTICE into legislation and jurisprudence-many reforms due to his action, but the softening of the harsh penal code which existed until then (1830) was the greatest one which he initiated. After him no man could be hanged for forgery or sheep stealing. Practical sociology is indebted to him for two maxims: "Men cannot be happy by making the misfortune of others"; "Legislation should give the greatest happiness to the greatest number." His theory of government, derived from Helvetius, was essentially UTILITARIAN, and has guided legislators to a great extent since the 1832 Reform.

I753-I8I4. Rumford was the first to suppress MENDICITY (in Munich, I790) and to show this evil to be one of the worst forms of social vice.

I766-I834. Malthus was the first (I798) to draw the attention of economists to the tendency of population to multiply to the last limits of food supply, and to the irresistible influence of competition and starvation in restraining its further growth beyond those limits. It was obvious to many thinkers that although he dealt with the subject of human communities only, numerous analogies could be found in other domains of animal and vegetable life, and, as a matter of fact, it was not long before the same principle was seen to apply to all species. "Reproduction is everywhere and in all species for ever outrunning means of subsistence; and starvation and competition are for ever keeping down the number of the offspring to the level average or normal supply of raw material. Animals are all perpetually battling with one another for the food supply of the moment; plants are 
perpetually battling with one another for their share of the soil, the rainfall, and the sunshine. . . And the struggle is chiefly between members of the same species. . . . It is not the soldier, or the sailor, or the ploughman that kills the artisan, but the number of artisans who undersell him and crowd him to fill up every vacant position." Malthus's work, which aroused debate everywhere, exercised enormous influence as a "germinal factor" upon the whole subsequent course of sociological and economical thought. Its influence on the current of biological and speculative opinion was just as farreaching; for Charles Darwin candidly states that he hit upon the idea which made him famous upon reading Malthus. "With my mind prepared (as you know)," says he, "I fortunately happened to read Malthus's Essay on Population, and the idea of natural selection through the struggle for existence at once occurred to me." Hence it has aptly been observed that Darwinism is Malthusianism on a large scale; it is "the application of the calculus of population to the wide facts of universal life."* Given Malthus on the one hand, and Lamarckian evolution on the other, a Darwin must have combined the two and have arrived at the theory of natural selection. Malthus, therefore, by his original Essay, assisted three scientific branches-sociology, anthropology, and biology-in an equal degree. His influence over sociology bore naturally on political economy rather than social questions.

I769-I859. Humboldt, who was a stranger to no science, deserves a place among scciologists, for the light he throws, in his "Essay on the Kingdom of New Spain," on commerce, industry, agriculture, mineral wealth, etc., thereby assisting political economists.

I 798-i857. Comte founded sociology scientifically in his "Positive Philosophy" by analysing the growth of society, the course of its evolution through its theological, metaphysical, and positive stages; by showing its defects and the remedies likely to remove them. The cause of our political and moral anarchy, according to him, lies in our intellectual anarchy, itself due to metaphysical aberrations. 
The remedy can be found in a new system of education only, based upon positive science. He was one of the first systematic exponents of the law of evolution as applied to society.

b. 1820. Herbert Spencer, the great PhILOsopher OF Evolution, and at the same time greatest of all modern expositors and philosophers, scientifically co-ordinated all the elements of progress, and expounded the Evolutionary $\mathrm{Hy}^{\prime}$ pothesis in all its multitudinous aspects-cosmic and astronomical, geological and biological, psychological and social, ethical and religious, etc.-in a series of works unsurpassable alike for grasp, depth, and lucidity, notably those bearing upon the development of the human species, from the human unit to the most complex social system. His views were in the first instance inspired by the doctrines of earlier evolutionists, Buffon, Diderot, Kant, Laplace, Erasmus Darwin, Geoffroy St. Hilaire, Göthe, Lamarck, Malthus, Comte, Von Baer; and then fully corroborated by Lyell's and Charles Darwin's results. But his system of philosophy extends far beyond the limits of his predecessors', and forms a complete SYNTHESIS of positive philosophy and social physics. His working power was on a par with the sterling knowledge he displays, for he seems to have felt at home in every science, and to have, so to speak, "practised" all branches in an equal degree of thoroughness. His mind stands on the same level as those of the very few universal men who have enlightened humanity most in the course of twentyfour centuries. His masterly originality shines in the number and vastness of the inquiries and elucidations he independently pursued and worked out, just as much as his powerful genius shines in the conception and elaboration of a system which, embracing the physical world as well as the spiritual, satisfactorily solves the profoundest problems which lie within the boundaries of our intellectual sphere; for, with unerring sense-and in this he will remain a guide to all future philosophers-he excludes what lies beyond the veil that for ever conceals ultimates from human ken. To descend from heaven to earth-from the Cosmos to Manthe remedy he advocates for the curing of many of our 
social evils lies also in positive and scientific education. It is hardly necessary to point out that our better knowledge of man's nature will modify our present principles of government and legislation, for obviously legislation and government should be in harmony with the nature and requirements of each race. INDIVIDUALISM, in contradistinction of SocIALISM, is the principle of progress which Mr. Herbert Spencer strongly endorses, the neglect of which inevitably dooms society to cruel disappointments.

Such is the record of the organic group in its briefest form. We see how the results of the previous period fade into insignificance; how far they have been left behind by the achievements accomplished in the modern era. Not only do we perceive the great advance made by the very first modern pioneers in the field, such as Malpighi, Willis, Steno, Leuwenhoeck, Réaumur, but we also see each branch rapidly expanding its area, each phenomenon casting new light for deeper and more extensive explorations, each conclusion becoming the point of departure for new inquiries. And although the fresh problems daily arising prove far more complicated than older ones; although they are of such deep import and vast proportions, and offer such difficulties as to appear absolutely insoluble; yet, by unexampled perseverance, hard work, profound thought, they are almost invariably solved, until the veil which hid the prospect is lifted, and the most mysterious aspects of nature yield their secrets one after another. We see how paltry and commonplace the original ideas of the men who were once reputed thinkers are in reality, in the face of the magnitude of those which have exercised the minds of our modern philosophers. For the set of facts embraced by the branches just surveyed would have astonished schoolmen and unpractical thinkers of former ages in no small degree, and aroused their scorn to the utmost. They would have pointed out more suo the worthlessness of the "few observations" biologists, physiologists, palæontologists, and botanists have made, for they left unexplained the reason why the plesiosaurus had no wings as well as the pterodactyl, or, if 
species were variable, why were not the genera, the orders, the classes, likewise variable and interchangeable at will? Vaccination would have been ridiculed by them, because it could prevent one disease only, and not all diseases. Botany would have been declared useless so long as it did not teach us how to grow Brussels sprouts on rose-trees; besides which, modern classifications have a suspicious look of Aristotelian nonsense about them which makes science too ancient to be worthy of attention.

These, or arguments of the same kind, were used against real science at as late a period as the end of the Revival even by men of talent and fame. We mention them for the purpose of showing the gulf which then separated prejudice from science, and which now separates those times from ours.

It is not unnecessary to lay a stress on the fact that many of the immense results enumerated in the last twenty or thirty pages flow with unmistakable directness from Harvey's splendid discoveries and principles.

\section{Group II. Geology.}

Passing now to Geology, we find:

I665-I728. Woodward collected (1695) numerous SPECIMENS of coal, gravel, marble, chalk, sandstone and other rocks. Besides the early students of this branch of science already mentioned-Pythagoras, Leonardo, Palissy, Steno, and Scilla-Ray and Hooke had also paid much attention to it, both offering suggestions regarding the causes of the earth's crust being made up of successive strata. Ray also pointed out that a mere flood could not deposit fossil remains in extensive beds in the regions where they were found, and that there was evidence that the animals must have lived on the different areas for many successive generations. But with Woodward begins a new departure. $\mathrm{He}$ was not content to speculate, he made collections of rocks exhibiting fossils with a view to investigate more deeply. Still, his action going no further, there was no certainty as regards the process of geological formation until Moro and Vallisneri (both Italians) began a series of steady observations. 
I687-I750. Moro was the first to point out that ROCKS must have been DEPOSITED as soft mud, some by the sea, for they contain marine fossils, others by rivers, for they contain fresh-water plants and animals, and that they were subsequently upraised by earthquakes from time to time. After him comes

I726-97. Hutton, who may be called the FIRST GREAT GEOLOGIST in point of time and importance. He travelled and made many scientific explorations in order to collect facts, and from these he was able to ascribe the changes on the earth's surface to volcanic action and subterranean heat, thereby originating the PLUTONIAN (or Vulcanian) THEORY, the exclusiveness of which, entertained by Plutonists generally, though not by Hutton himself, is now discarded. Hutton also indicated the processes of denudation, crosion, formation of valleys, river channels, and the action of running water, which levels mountains, carries their materials to the ocean, and thus helps to prepare the sea-floor to become new continents, when in the course of time it is uplifted by underground forces-all of which modes of action modern geologists have proved to be well founded in fact. He also explained the theory of rain, and threw great light on the study of meteorology. The most important lesson he taught, however, and the one for which he will always be remembered, is that the history of the past must be studied by the changes going on at present, and that THE LAWS which regulated the economy of the globe in past ages were the same as those NOW IN OPERATION (I788); so that he was the precursor of Lyell in teaching the PERMANENCY OF LAW. These theories, owing to the influence of the Wernerian school, and the want of elegance and lucidity of style of Hutton's Theory of the Earth, were held in little repute for some time.

I743-I822. Hauy enunciated the theory of CRYSTALLISATION - that it takes place in accordance with geometrical laws-and classified minerals in accordance with their crystallisation.

I748-I8I9. Playfair (John) studied the geological system of THE ALPS, and threw additional light upon geological laws. It is, however, by his popularising the views of 
Hutton, his master, that he is chiefly to be remembered, for being an excellent expositor he had much influence in advancing the study of the earth.

I748-i8 . Keferstein, in his Geognostic Remarks upon the basalt formations of Western Germany, demonstrated the volcanic FORMATION OF BASALT against the Neptunian school of Werner.

I750-1817. Werner, by observing, like Hutton, the crust of the earth instead of guessing natural processes, powerfully helped to make geology an experimental study, and ground that science on firm foundations. He originated the NEPTUNIAN THEORY, which consisted in believing water to have been the almost exclusive cause of new formations, and in leaving aside other concurrent causes. His sweeping theory is now recognised to be correct only as regards sedimentary rocks, but his fine lectures promoted the advance of the science, for Hutton himself received much profit from Werner's teaching and theories.

I760-i832. Hall (Sir James) founded EXPERIMENTAL GEOLOGY by devising experiments in illustration of the structure and origin of rocks; and this constitutes another service done by Hutton's school to the progress of science. For owing to the influence of the Wernerian school, and Hutton's want of style, Huttonian theories were little known. His friend Hall showed their soundness; he demonstrated basalt to have been once in a molten condition, by fusing some, and pointing that it exhibits a stony texture by slow cooling. He carried out similar experiments upon limestone-converting it into marble under great pressure, and showing it to act on other rocks. Hutton's theories began from that time to command the attention they deserved; but it was only after Playfair's exposition of them that Hutton was at last recognised as a great authority, and appreciated as an earnest and unerring investigator.

I769-I832. Cuvier threw great light on geology by his almost exhaustive study of FOSSILS, but wrongly ascribed changes in the stratification to sudden cataclysms. Lyell, since then, has demonstrated the transformation to be due to slowly-acting laws. 
I769-I839. Smith (William), the father of BRITISH GEOLOGY, formulated the generalisation already foreshadowed by his predecessors as we have seen, that each stratum has been successively the bed of the sea, and contains the fossilised monuments of the races of organic beings then in existence ; that each stratum contains organised fossils peculiar to itself, and may be recognised by examination of them; he distinguished between diluvial and stratified deposits, and laid down that the same strata are always in the same order of superposition, and contain the same fossils. He was the first, in fact, to teach the identification of strata and to determine the succession by means of their embedded fossils. He showed that a fixed order of sequence could be traced among the different superincumbent strata. Scientific geology took its rise from this striking discovery. The doctrine of geological evolution was necessarily implied by his teaching. His geological maps of England and Wales, constructed in I8I5, after twenty-five years' personal observations and surveyings, made over every part of Britain, is a lasting monument of practical scientific industry.

I769-I859. Humboldt (Alexander Von) gave great impulse to the progress of science by his extensive researches in America and Central Asia, in geography, ethnology (human races and customs), botany, natural history, climatology, mineralogy, and geology; was one of the founders of METEOROLOGY and the physical geography of the sea. His Cosmos (or Universe), the result of sixty-six years' labour, is a general view of the world, which sums up the knowledge reached in every branch of science up to his time (1859). The want of absolute accuracy in some details which the work exhibits occasionally is compensated for by the enormous amount of information accumulated in it, a large portion of which was original and due to direct observation on his part. In a work of such proportions in. accuracy was inevitable at times, but the Cosmos will remain a cyclopædical monument worthy of its author, who may be called the modern Aristotle. Climatology is the one branch of science most indebted to him. He carried out the immense undertaking of determining, and tracing across the 
chart of the earth, Isothermal Lines (lines of equal heat), which indicate for all places a given mean temperature for the year. Isothermal lines for the year are called annual isotherms : the isotherms for July and January are respectively called isotherals (summer) and isocheimenals (winter). These charts are most important aids to the study of climatology, "indicating as they do those general laws which apart from latitude and altitude affect the climate of a country. The winter isotherms which cross the British Isles offer a striking feature: they run nearly North and South across Britain instead of lying along parallels of latitude; so that a high temperature is to be sought by travelling. from East to West instead of North to South." Since Humboldt's time this branch of science has rapidly advanced. One of the chief facts ascertained which affects the economy of a country is the action of aqueous vapour in checking (I.) the radiation (loss of heat) of the earth's heat into space, and (II.) the fierceness of the sun's heat on the earth, owing to the power of aqueous vapour to absorb and retain heat. Says Tyndall on the subject: "Aqueous vapour is a blanket more necessary to the vegetable life of England than clothing is to man. Remove for a single summer night the aqueous vapour from the air which overspreads the country, and you would destroy every plant capable of being destroyed by a freezing temperature." And conversely, if the aqueous vapour did not absorb and retain a great portion of the sun's heat in summer, the vegetation would be parched up, and animals would die from the effects of heat. Climate is affected also by altitude, by proximity of large masses of water, evaporation, and sea and wind currehts.

I774-1853. Buch (L. Von) demonstrated the great mountain ranges to have been covered by the sea, but to have been formed by gradual upheavals; discovered the slow and gradual elevation of Sweden, but failed to detect volcanic agency in new formations. As a naturalist he observed the Fauna of the Canaries, and he pointed out that varieties may be slowly changed into permanent species, thereby anticipating Darwin in one point.

I779-I859. Ritter (Carl) created COMPARATIVE GEOLOGY 
by demonstrating the relationship which exists between the different parts of our planet, and the influence of the earth's surface upon the development of humanity.

I785-1873. Sedgwick was the first to notice the separate nature of the CAMBRIAN ROCKS underlying the Lower Silurian, and in a comprehensive survey tried to co-ordinate the whole range of geological facts known in his time. $\mathrm{He}$ mapped the geology of Wales; described the PALAOZOIC (ancient life) DEPOSITS in detail, strongly opposing the theories of derivation.

I787-I856. Prevost established the theory of the geological strata being formed by alternate FLUVIAL AND MARINE DEPOSITS in the same basin by the meeting of sea and river currents.

I790-I852. Mantell, in the midst of a busy professional life, carried on almost continuous geological explorations, in the course of which he elucidated several interesting points of the earth's history-especially studying, with Buckland, the Carboniferous, Wealden, and Tertiary deposits; discovered the bones of four out of the five great DINOSAURIANS known up to I870, and among them the Iguanodon and the Hylæosaurus-thereby rendering signal service to palæontology as well as to geology. It may be said of him that if he left scientific interpretations to Cuvier and Owen, he supplied the two great masters with facts to work upon. He should also be remembered as a popular expositor; his "Medals of Creation," "Wonders of Geology," "Petrifactions and their Teaching," exercised great influence and aroused keen interest in science.

I792-I87I. Murchison found the primitive rocks of Wales to belong to a unique system - THE Silurian; assimilated the stratified rocks of Devon and Cornwall to the red sandstone of Scotland,* calling them the DEvonian

* In his classification of rocks in the Scotch Highlands, Murchison, it should be stated, made a serious mistake, which remained unnoticed for a whole generation until it was overthrown by the observations of Professors Nicol, Bonney, Drs. Charles Callaway, Henry Hicks, Mr. Hudleston, and by the patient investigations of $\mathrm{Mr}$. Charles Lapworth, a private 
SYSTEM; made an immense survey of the geological features of RUSSIA (where he traced the history of the Permian rocks), the Ural mountains, the Himalayas, The CAPE, Spain, Brittany, Chili, and some Pacific groups. A few details may show the practical nature of his work. In Italy and Sicily he studied the action of the Vesuvius and the Etna, and showed the rocks these volcanoes had been building. He accounted for the vast masses of lava and basalt, found in all parts of the earth, by recalling to his readers' mind that the eruption of the Skaptar (Iceland), in 1783 , had produced a stream of lava 90 miles long, 8 , I0, I 5 miles broad, and 500 or 600 feet thick-the mass poured out on that occasion equalling the bulk of Mont Blanc. He studied also the present formation of limestone beds in the Mediterranean, their enormous thickness, and their uprise of some 3,000 feet above the sea level; he pointed out the subsidence of part of the English coast-line and the gradual crumbling of the cliffs far beyond the old site of towns which have been moved further inland. All these facts and many others were the materials out of which Lyell was able to demonstrate his geological laws.

I797-I858. Scrope made a special study of volCANOES ; showed their multifarious action in all parts of the globe ; exhaustively surveyed the Auvergne volcano system, one of the most instructive areas in the world : his work done for all time, so beautifully is it carried out. His two chief books are mines of geological knowledge.

I797-I 875 . Lyell classified the stratification of the crust, and established some of the GEOLOGICAL LAWS, especially that of uniform, continuous, and permanent action of forces-the one great discovery which made him the master of the science. William Smith had already taught that strata were laid successively; but it was Lyell who formally introduced geologist who definitively demonstrated the fact (1883). He proved the Upper Gneisses which overtop the sandstones, conglomerates, and Durness limestones to be identical with the Lower Gneisses-the primeval crust of the earth-and that the Upper Gneisses, therefore, were not of recent formation as Murchison had taught, but as ancient as the earliest stage of the earth's crust; so that the order of succession of rocks in the Highlands is apparent only, and not real. 
the evolutionary principle into geology, instead of the sudden cataclysms and new creations of former geologists, and at their head Cuvier - an immense stride forward. The evolutionism of Lyell, however, was not that of the SpencerDarwin school-for, where thorough evolutionists see an efficient cause, Lyell, influenced by religious considerations, saw a final cause; and the difference is, not important only, but fundamental. For in the former case (in Lyell's evolutionism), a supernatural power would be restraining a warring chaos by a beneficent omnipresent and ubiquitous interference; whereas in the latter case, matter swayed by natural laws is for ever effecting a new redistribution of its elements, in harmony with its own inherent energy. The evolutionary hypothesis explains the existence of evil, from the presence of microbes which destroy life wholesale, to the recurrence of earthquakes which destroy cities-otherwise evil would necessarily be prevented by the superior power. METAMORPHISM, the name Lyell gave to his system of gradual transformation, he based on entirely scientific ground. He holds that nature has formed the crust of the earth, and wrought all the successive changes, renovations, destructions which it has undergone by the working of certain constant and uniform laws, which are now what they ever were-that is, attraction, degradation, denudation, deposition, radiation, evaporation, and contraction have done it all by their permanent action. This great principle of uniformitarianism, for which Lyell stoutly fought, has been accepted by scientific men, but, at present, with the reservation, however, that variations in the energy and in the rate of activity may have occurred, which played an important part in the terrestrial history-otherwise, how are we to account for the Glacial period, which was comparatively sudden? Physicists, too, have sobered the minds of those geologists who claimed a sort of "perpetual motion in the machinery of nature," to use the words of Sir A. Geikie, by pointing out that the gradual loss of solar heat must necessarily modify the laws in future ages, and must likewise have done so in the past. By a striking anomaly, Lyell, who recognised the modification of the globe to be due to natural laws - in fact to evolutionary 
development-refused to accept some of the most obvious evolutionary doctrines, rejecting, for instance, and fighting against the theory of gradual animal development for a long time. It was towards the end of his career only (at sixty-six years of age), and when Darwinism had proved universally triumphant, that Lyell abandoned this attitude at last, and acknowledged the soundness of its doctrines. He even endorsed them completely (if reluctantly) in his famous book the Antiquity of Man-the first work in which evidences of man's antiquity were collected and clearly presented to mankind ( 1863 ).

I798-i87. Elie de Beaumont drew up the geological MAP OF FRANCE (in collaboration with Dufrenoy). His "Revolutions of the Globe" contain the celebrated theory of the uprising and of the direction of mountains.

I803-I879. Dove, in his "Isothermal Lines" (I848-64), enunciated and explained the law of Storms, or the law of ROTATION OF WINDS, by virtue of which the wind veers round according to the sun's motion-i.e., passes from North to North-east, then to East, then South-east, then South, and so on-a course most regularly observed in winter. For a station in south latitude a contrary law of rotation prevails.

I806-I873. Maury assisted geology by his fine studies and demonstrations of the action of the ocean and rivers in the formation and transformation of the crust; his investigations on the wind and sea-currents much advanced the study of meteorology. To his action and work the establishment of innumerable meteorological stations all over the globe is due. His famous work (The GEography of THE SEA) was the result of no less than twelve hundred thousand observations gathered from all parts-a fact which speaks volumes for his earnestness and thoroughness.

I807-74. Agassiz opened a new field in science. $\mathrm{He}$ discovered one of the grandest phenomena of geology by his investigation of a feature of the earth's surface which had escaped the attention of geologists, with the exception of DE SAUSSURE-viz., the formation of glaciers, and the part they played at a certain period of the history of the globe. De Saussure, exploring the Alpine glaciers, had 
noticed the accumulation of deposits in the valleys, due to their action; Agassiz, following up this study, detected other phenomena which revealed the nature of the climate of the earth during a long series of ages which are now called Glacial PERIOD. He discovered that the whole of the Northern American and European continents had been once covered with a field of ice, and therefore with immense glaciers in every valley, which extended as far as the south of Germany and France, and in America as far south as the 5cth, 48th, and even 45 th degree of latitudethe present glaciers being the remnants as yet unmelted of the cap of ice. This cap of ice, as far as it reached, extinguished vegetation and life in the Northern hemisphere. It accounts for several important facts: (I) for the presence of huge boulders or boulder-clay foreign to the region in which they are found, for both boulders and mud must have been brought where found by glaciers; (2) for the presence, too, of drift (glacial débris) in valleys of different formation ; (3) it accounts also for the polished and grooved surface of rocks (striæ); and (4) finally it accounts for the striking difference between the kind of Flora and Fauna which existed over the same area before the Glacial age, and those which exist now in the same habitat. Before the Glacial era, tropical plants and animals flourished all over England and countries of the same latitude; the intense cold, frost, ice, killed these or drove them southward, and their place was taken by Arctic flora and fauna-mosses, lichens, firs; reindeer and Polar bears. And when the icefields retired, the plants and animals which invaded the free area were different from those of the pre-Glacial epoch and from those of the Glacial epoch. Subsequent researches have revealed the same changes at the same period to have occurred also in Asia. The causes of this great catastrophe which overtook the earth are as yet unascertained. It was possibly due to the greater inclination of the earth's axis; or to the periodic elongation of the earth's orbit and the concurrent effects of precession; or again, to an alteration in the shape of the continents which would have diverted the warm sea-currents from their present and pre-Glacial 
course. The first view is entertained by French geologists, the second by James Croll and Sir R. Ball, the third by Lyell; but it is possible that this wonderful phenomenon may have been brought about by the concurrence of the three causes obtaining at the same time, otherwise a glacial era would recur periodically. Another hypothesis is that our siderial system-moving towards Hercules as it does: at the rate of 150 millions of miles per annum, passed through intensely cold regions of space-a supposition of which we have no experience. The phenomenon, whatever the cause, and whether it occurred once or several times. within a certain range of time-for there are traces of two Glacial periods in the Carboniferous and Permian Ages, and undoubted evidences of inter-Glacial period within the time-limits of the Ice Age-teaches us one thing, viz., that the uniformity of geological laws is not absolute. For here we see, at an advanced stage of the terrestrial historythat is, during the Quaternary period, to speak of one period only-a phenomenon overwhelming the earth with comparative suddenness, and this suddenness, so far, baffles every explanation. The knowledge of this great Ice Age is the work of Agassiz.

We may point out that careful computation has enabled us to approximately assign the time of the Glacial period: reckoning backwards, the present or post-Glacial epoch cannot be estimated to have covered less than 60,000 years; the retreat of ice-fields cannot have covered less than 80,000 years; the duration of the Glacial noontide-including in it the inter-Glacial eras-may have covered any number of ages, for we have no evidence for stating whether it declined as soon as it reached its maximum, or whether it remained stationary for ages and ages; but as there is evidence of several partial advances and retreats, and of prolonged inter-Glacial periods, the total duration of this stage cannot have covered less than 80,000 years, taking the very lowest possible estimate. Before that noontide, the advance of ice southward may have covered from 5,000 to 80,000 years. All these estimates are far below those given by some geologists, and especially by Lyell, who has 
computed that for the deposit of the Rhine Valley loess alone, 320,000 years must have been necessary; but taking the minimum estimate, we may boldly say that the Glacial era cannot have begun less than 300,000 years ago. The point is of importance because it bears upon the antiquity, not of the earth only, since the Glacial epoch is a mere fraction of the earth's life, but upon the antiquity of the human race, for there is evidence that man existed throughout the Ice Age, and probably long before, that is, in the Tertiary period; many of the palæontological implements in our possession are clearly the handicraft of pre-Glacial man, for they were found in pre-Glacial deposits.

The brief survey of geology enables us to measure the work performed by modern inquirers in a new field. Two centuries ago mankind was in total ignorance of the earth's history. A few valuable hints had been given by Avicenna, by Leonardo, by Palissy, but they were too slight on the whole to awaken anything beyond curiosity or doubt. The modern era opens a new expanse, where guesses are taken as of no account, and are replaced by ceaseless observation which conduces to substantial knowledge. The first tentative steps are in the right direction and lead at once to creditable results, but the march, gradual and somewhat wayward in the beginning, in time becomes steady, then becomes rapid, and conducts the stout explorers, despite strong barriers and frequent obscurity, to victorious achievements. Patient labour has disclosed the history of the world we live in. Vast regions are as yet virgin soil to the geologist; large tracts in Asia, in Africa, are yet unexplored; but the areas which have been visited and probed are so varied, so numerous, and so distant from, or so close to, one another, that we may proclaim geology a triumphant science all along the line, for it has now accomplished its work-the facts as yet unravelled are relatively mere details. Murchison's labours alone would enable us to describe the growth and the constitution of the earth with almost absolute certainty, so widely did they extend, and so conscientiously were they carried out. But geology does not show us the structure of the earth only; it also teaches us great truths that were not so 
much as suspected three hundred years ago, namely: (I.) the vast antiquity of creation; (II.) the process of the earth's formation; (III.) the remote antiquity of man; (IV.) the confirmation of the permanency of law in the inorganic world, as it is found to exist in the organic world-a fact made plain before, by Galileo, Kepler, Newton, and Laplace, but corroborated here by such plain evidence that it can be verified daily by any plain man. This makes geology a complete and fascinating science. But it is so far removed from the ideas entertained three centuries ago, that we may be sure it would have found powerful opponents then as astronomy did. For instance, we may easily imagine how schoolmen would have exercised their power of raillery at the expense of the benighted geologists for their researches and work; fancy a Humboldt, a Murchison, a Scrope actually exploring the whole globe, to find, what?-just the facts we have mentioned; whereas it was sufficient for them (the schoolmen) to think in order to know all about it. And the geologist, they would have said, shows us only the process of formation of rocks, the composition of those rocks, the order of their superposition, and so forth-but he does not tell us why basalt is not bright yellow, or why the sea fails to produce it as well as volcanoes. The geologist would reply that its constituents being chiefly felspar and augite, it could not be bright yellow, and that being volcanic and the sea not being $a$ volcano (!) the sea could not produce it, a reason which they would have thought very unscientific, and therefore very poor. This remark is no overdrawn analogy of their logic, for they have actually made use of this very kind of reasoning (we could quote instances) in face of natural phenomena. They would have scouted the idea of considering what the geologist teaches us as being worth knowing. What he ought to have sought and done, they would contend, was to transform basalt into schist, and schist into conglomerate, and that into quartz, and that into a jelly-fish, and the jelly-fish into a gooseberry-bush or a turnip at the very least-which he cannot do-therefore he is not a man of science, but only an empirical idler like Gilbert or Galileo, for no doubt they would have called his labours "experiments." 
Once again we repeat that this kind of logic was typical of former ages; new doctrines and new principles of thought were so distasteful to those who considered themselves as "the directors" of opinion, that the most inane pieces of sophistry were put forward as valid arguments in support of extravagant opposition, as if mankind, senseless and ignorant, could be crammed with anything. Brazen assurance seemed the only essential wanted to ensure authority.

\section{Group III. Chemistry.}

I626-9I. Boyle proved by experiments air to be necessary for COMBUSTION; that a candle cannot burn nor animals live without air ; he pointed out that the globe contains other substances than those recognised in his times-earth, water, air, and fire; discovered (I66I) the LAW that bears his name, and which is also called Mariotte's law, of the COMPRESSIBILITY OF GASES-the law, that is, of elasticity of air, the formula of which is, "The temperature remaining the same, the volume of a given quantity of gas is inversely as the pressure which it bears" - in other words, the volume of a gas decreases in proportion as the weight upon it increasesif you double the pressure, you halve the volume. We shall see the vast importance of this great discovery, one of the most serviceable in our possession, our modern industry and wealth being largely dependent upon it. Boyle also improved Guericke's air-pump.

I645-79. Mayow, the best chemist of the XVIIth, pursuing Boyle's experiments on COMBUSTION and respiration, discovered air to be composed of two gases-one, which he called FIRE-AIR (oxygen), and which is heavy, supports a flame and life, and is consumed by combustion and breathing; another, which is lighter, and is useless for breathing and burning-the nitrogen of Lavoisier-thus going further than Harvey in showing air to be the chief agent in respiration, and going half-way towards the discovery of Priestley and Lavoisier in showing air to be a compound gas. He discovered also that "air exists in salpetre and in many acids." 
91. 1660-1734. Stahl pointed out numerous chemical phenomena, and showed the way in which many different substances combine together to form new compounds. Ignoring or disregarding Mayow's experiments, he formulated the PHLOGISTIC THEORY of combustion, by which he assumed that all combustible bodies contained a substance (Phlogiston) which dispersed into air during the process of burning. This theory explained some chemical facts so plausibly that chemists accepted it at once-whereas serious verification would have upset it. The very fact that bodies grow heavier by burning, as Geber had shown nine hundred years before, should have confuted it, for if bodies lost something (their phlogiston, so called) by burning they would become lighter instead of heavier. As it was left unverified, the phlogistic theory held the field for nearly a century, and retarded the progress of chemistry all the time. Even when Lavoisier exploded it, men like Priestley adhered to it still. This baneful effect of a preconceived idea was the last serious delusion which misled science. But the lesson bore fruit : after that very few theories were accepted without repeated verification.

I 728-99. Black (Joseph) found the causticity (burning property) of quicklime ( 1756$)$, and detected its loss of weight after it was burnt. From this fact he was led to the discovery of FIXED AIR (carbonic acid gas*), failing, however, to discover that it was an acid. He was further led by a series of clever experiments to see that a flame would not burn nor animals live in it; also that our breath contains fixed air; at the same time he showed air to be necessary for combustion, thus corroborating Mayow's demonstration from end to end. The discovery of fixed air was an important stride in chemistry. Another capital service rendered to science by Black was his discovery of LATENT HEAT-the heat that is hidden in water and steam ( 1760 ) - the latent heat of water at $0^{\circ}$ (Cent.) being $79^{\circ} 25^{\circ} \mathrm{C}$., and the heat of steam at $100^{\circ} \mathrm{C}$. being $5372^{\circ} \mathrm{C}$. ; so that we have to remember that water

* In one million gallons of London air carbonic acid gas exists to the extent of 380 gallons; over one square mile in the country the carbonic acid gas present weighs 371,875 tons. 
is a solid (ice) plus heat, because the heat used to melt ice is absorbed in the water; whilst a gas is a liquid (say water) plus heat, because the heat used to turn water at boiling point into gas (steam) is absorbed in the steam. By this discovery Black found a law which together with the known law of elasticity of gases (Boyle's law) enabled James Watt, under the guidance of Black himself, to invent practical steam machinery - the new power of the modern world. Black demonstrated also that certain chemical substances are possessed of definite and invariable composition and properties - thereby PARTLY establishing THE LAW (which Lavoisier defined) of the FIXITY OF COMPOSITION of chemical compounds. Black's "Lectures on the Elements of Chemistry" contain a large amount of practical knowledgehis researches on alkalis and fixed air (carbonic acid gas) are excellent examples of the scientific process and manipulation. It may be mentioned in honour to him that he was one of the first to abandon the phlogistic theory after Lavoisier had shown its imaginary character.

I73I-I810. Cavendish found the accurate composition of nitric acid, discovered HYDROGEN (water producer, I766), which he called INFLAMMABLE AIR-an effect of which was to make aërostation safer; formed WATER by sending an electric spark through a mixture of oxygen and hydrogen (I784), which showed water to be a compound of these two gases-another important discovery, also made by Lavoisier. Cavendish invented the EUDIOMETER, for testing the purity of air by ascertaining the quantity of oxygen it contains -now used for examining the composition of gases; he calculated the weight of the earth by means of the Torsion Balance-a wonderful determination.* Cavendish has been called, prematurely we think, the Newton of Chemistry-a title better deserved by Dalton, who came later and made a discovery which is absolutely fundamental. In the absence of Dalton, Lavoisier would no doubt deserve the title of honour.

I733-I804. Priestley discovered $†$ oxygen (I774) from

* Modern computation gives the round number of six thousand trillion tons.

+ Discovered also laughing gas. 
oxide of mercury, by means of a burning glass. He called it "DEPHLOGISTICATED AIR"- the name of oxygen being given to it by Lavoisier, who understood its property and character. The sterility of this great discovery in Priestley's hands is due partly to his blind adherence to Stahl's phlogistic theory, and partly to the carelessness of his experiments. Priestley did great service to science, nevertheless. He determined the properties of NITROUS AIR (nitric acid), vitriolic acid air (sulphuric dioxide), muriatic acid air (hydrochloric acid), and alkaline air (ammonia). His experiments on inflammable air (hydrogen) drew the attention of chemists to this gas, and led them to numerous results. He discovered that PLANTS INHALE the vitiating part (say fixed air) which the atmosphere may contain, and thereby restore air to its purity. This was one more step, after Grew and Hales, towards the explanation of the breathing of plants, but he failed to see the reason why. It is now known that plants absorb carbonic acid, decompose it in order to live on the carbon, which they retain, whilst they reject the oxygen. Priestley assisted MANIPULATION by several inventions-the most serviceable of which is the pneumatic trough.

I735-84. Bergmann studied the theory of elective or CHEMiCAL AFFinities. Newton had shown the powerful attraction of some substances with one another, thus taking the first step in the study which Bergmann pursued. This great chemist drew up a table of those substances which show affinity with one another (called Table of Elective Affinities). The French chemist Geoffroy had drawn up Tables of Affinity (the term is his own) as early as 1718 , indicating the order in which bodies displace each other, and thus marking to some extent the force of affinity. The word as used in chemistry means "a disposition to unite." Bergmann's work extended much further than this study. During his experiments to establish his tables, he found out Black's fixed air to be an acid which he called air acid or AËRIAL ACID; but he failed to find out that it is a compound of two elements. It was Lavoisier who discovered it to be made of carbon and oxygen, and gave it the name of carbonic acid-which describes its character at once. Next to this, Bergmann founded 
CRYSTALLOGRAPHY, and made a chemical classification of minerals-a very valuable performance.

I742-86. Scheele published a famous paper on Manganese, showing the peculiar characters of this metal (I774); found tartaric acid, barytes, fluor-spar and its acid, chlorine, glycerine (the sweet principle of oils), sugar of milk, Prussian acid (while studying Prussian blue); but his great discovery, made in 1775 concurrently with Priestley and Lavoisier, was that of OXYGEN - which was to open a new era in chemistry : so that Scheele should be remembered as one of the greatest chemists of the XVIIIth century, although unfortunately for science he was still imbued with phlogistic views.

I743 - 94. Lavoisier, the FOUNDER OF MODERN Chemistry, gave the death-blow to Stahl's phlogistic philosophy by his DISCOVERY OF OXYGEN (1778), the mysterious character of which he unravelled after it had puzzled generations of chemists. This discovery, made some time after Priestley's and Scheele's, did not remain a fruitless one in his hands; for by it he thoroughly explained the PHENOMENON OF COMBUSTION-a fact of supreme importance in chemistry. He showed that a rusty or heated metal gains the exact weight which air loses by the process -thus demonstrating the process to be the reverse of that imagined by Stahl, since air, instead of receiving something additional by the burning of a substance, loses, on the contrary, a part of its constituents, namely, its fixed air (oxygen). The law may be formulated thus: "All burning and breathing and the change in metals are caused by a gas (oxygen) being taken up out of air, and joined to other substances." Lavoisier next showed oxygen to be the most abundant* and the most useful of all substances in the economy of our earth; and for this reason he made this gas the basis of chemical nomenclature, giving to acids the termination of ic when they contain much oxygen; the termination of ous when they contain less; he designated bases by the name of oxides; and affixed ate or ite, according to the degree of oxygenation of the acid,

* It constitutes more than one-half of the earth's crust, and is present in water to the extent of eight-ninths of the total weight, and in air to the extent of one-fifth of the bulk. 
to salts (i.e., the compounds of acids with their bases). $\mathrm{He}$ divided matter into THREE FORMS (solid, liquid, gaseous) according to the degree of heat; established the principle of the "conservation of mass-that in no process of change is there any alteration in the total mass of matter taking part in that change" ; discovered phosphoric acid, and described some of the substances formed by combining it with various bases; foresaw the existence of the metals potassium and sodium; discovered also the exact composition of water; established the distinction between COMPOUNDS and ELEMENTS, and laid down the definition of the latter; established the law of fixity of composition of chemical compounds; determined the properties of oxygen, calling it " acid-producer," believing it to enter into the composition of all acids-a generalisation which admits of exceptions (see Davy). By his immense work Lavoisier gave a new impulse to the advance of chemistry, so long arrested by Stahl's hypothesis. He showed that there is no such thing in nature as "transmutation" in the alchemical sense of the word. He applied CHEMISTRY to PHYSIOLOGY, and explained the two hypotheses of respiration-one of which, that respiration is a process chemically similar to that of calcination, modern science has confirmed.

We may point out that the successive discovery of the four gases-carbonic acid, hydrogen, nitrogen (found by Rutherford in I772), and oxygen-revolutionised chemistry in a manner the importance of which cannot be exaggerated. These four gases play the main part in the maintenance of vegetable and animal life. "Out of the raw material," says Dr. Crum-Brown, "gathered by Black, Scheele, Priestley, and Cavendish, Lavoisier constructed a consistent and comprehensive theory upon which the subsequent progress is firmly grounded." Chemistry with him and his school became once more a quantitative science (that is, components of a substance were now carefully weighed)-instead of being merely qualitative. Another remark to be made is that Lavoisier's nomenclature aids science by its simplicity and clearness-instead of fixed air we have carbonic acid, which is thoroughly descriptive of the nature of this gas; instead 
of inflammable air, we have hydrogen (water-producer); instead of fire-air, we have oxygen (acid-producer), and so forth. It was Lavoisier, too, who discovered the fixed air of Black, or the air-acid of Bergmann, to be an acid made up of 72 parts of oxygen and 28 parts of carbon, for which reason he called it carbonic acid.

As a physicist, Lavoisier formulated the principle of equilibrium between the effect of heat on the one hand, and that of universal gravitation on the other-heat tending to dilate or separate matter, gravitation tending to keep it together-and enunciated the hypothesis that HEAT IS MOTION in his "Principles of Heat." He also invented, with Laplace, the ice CALORIMETER.

I743-I8I7. Klaproth was the first to publish all the numerical and analytical details of scientific investigations; discovered the elements CERIUM, URANIUM, ZIRCONIUM, and analysed many minerals little known until then.

I748-1822. Berthollet ascertained nitrogen to be one of the essentials to the composition of animal substances; his investigations into the combination of carbon and hydrogen received an application in gas light; the art of dyeing is much indebted to him; discovered the LAwS which govern THE MIXTURE OF GASES.

1762-1807. Richter discovered (I792) THE LAW which rules the proportions of chemical elements: "Elements in compound bodies are mixed in fixed and definite proportions"-a corollary of Lavoisier's law of fixity; but not until Dalton was the significance and truth of this law recognised, although Proust (I754-I826), Wenzel (I777), and Higgins had intimated its importance. Richter's process of investigation largely accelerated the progress of electricity.

I763-I829. Vauquelin discovered CHROMIUM AND GLUCINUM; made the first accurate analysis of beryls and emeralds.

1766-1828. Wollaston discovered PALLADIUM AND. RHODIUM; found the process of rendering platinum malleable; invented a sliding scale of chemical equivalents; was one of the most skilful analysts of his time. Wollaston did, besides, good service to biology. While in Madeira he 
detected, studied, and pointed out the strange adaptations of the local snails and beetles - a series of observations which were duly weighed and made use of by evolutionists. This scientist, as we shall see further, was also a physicist of distinction.

I766-I844. Dalton propounded the ATOMIC THEORY (I 808 ), demonstrating the doctrine held by Leucippus and Democritus (400 B.C.), who, by that marvellous prescience frequently found among the Greeks, had guessed one of the profoundest secrets of nature. Dalton's discovery of the structure of bodies by atoms caused a revolution in the views held hitherto regarding the composition of the universe. It also caused rapid advance in chemistry and science generally, and it is not too much to say that it entitles its author to be called the NewToN OF Chemistry - despite his occasional inaccuracy as an experimenter. The atomic theory rests on three laws which form the foundation of chemical science: (I.) the law of definite proportions-i.e., different chemical elements always combine in definite and invariable proportions: thus water will always contain 2 parts by weight of hydrogen to 16 parts by weight of oxygen; every carbonate of lime contains 56 parts of lime and 44 of carbonic acid, each of these being likewise as unalterable in their composition as water-lime containing $7 \mathrm{I}^{\circ} 43$ per cent. of calcium and 28.57 per cent. of oxygen, whilst carbonic acid contains 27.28 of carbon and 72.72 of oxygen; (II.) the law of multiple proportions, in virtue of which the proportion of one element, having its own weight (atomic), remains constant in forming compounds, whilst the proportion of the other element is a constantly increasing multiple of its weight (atomic): for instance, nitrogen and oxygen will combine to form five chemical compounds-

\begin{tabular}{|c|c|c|c|c|c|c|c|c|}
\hline \multirow[b]{3}{*}{ Nitrous oxide } & \multirow{2}{*}{ - } & & \multirow[b]{3}{*}{ - } & \multicolumn{3}{|c|}{ Volume of } & \multicolumn{2}{|c|}{ Weight of } \\
\hline & & & & \multicolumn{3}{|c|}{ Nitrogen. Oxygen. } & Nitrogen. & Oxygen. \\
\hline & & & & - & 2 & I & $28 \mathrm{gr}$ & 16 \\
\hline Nitric oxide & . & . & . & . & 2 & 2 & 28 & 32 \\
\hline Nitrous anhydr & lride (acid) & & • & . & 2 & 3 & 28 & 48 \\
\hline Nitric peroxide & le (peroxid & $e$ of 1 & Nitrog & gen) & 2 & 4 & 28 & 64 \\
\hline Nitric anhydric & ide (acid) & . & • & . & 2 & 5 & 28 & 80 \\
\hline
\end{tabular}

So that oxygen enters into composition with other elements 
in weights of 16 or multiples of 16 -hence the name of the law-and the law applies to all elements, each having its particular weight; carbon will combine in weights of 12 or multiples of 12 ; nitrogen will combine in weights of 14 or multiples of $14(28,42,56$, etc.) ; sodium in weights of 23 (then 46,69 , etc.); phosphorus in weights of 31 (62, 93, etc.); iron in weights of $28(56,84$, etc.) ; arsenic, 75 (then 150,225 , 300 , etc.) ; mercury, 100 (then $200,300,400$, etc.). The third law on which chemistry rests-is the LAW OF ATOMIC or equivalent PROPORTIONS, which is that "each element in combining with, or displacing other elements, does so in a fixed proportion" which may be stated numerically-the weights just mentioned being equivalent to the parts : if a slip of copper, for instance, be introduced into a solution of mercuric chloride, proportions of the two metals will change places, since chlorine has a stronger affinity for copper than mercury : cupric chloride is formed and mercury deposited -for every 31.7 parts by weight of copper dissolved, 100 of mercury are separated. The atomic theory embraces the question of atomic weight, atomic volume, atom-fixing power, and so forth. The laws involved in the theory, if not all discovered, were all first brought into the light of intellectual day, by Dalton. Whether the doctrine of atoms be absolutely true, as it seems to be now admitted, or a working hypothesis only, as some are still contending, Dalton's atomic theory (as distinguished from the doctrine of atoms) is admitted by every philosophical chemist, and is rendering new services to chemistry every day. Dalton meant by an atom "the smallest possible quantity of any element which can combine with other substances." Dalton fixed the atomic weight of hydrogen, but the atomic weight of elements has not in all cases been determined, nor in some cases determined uniformly-some chemists (Berzelius, Olding, Gerhardt, Watts) differing from one another slightly in their determinations. The atomic system, it should be remembered, has given rise to a system of symbols which has become the universal language of chemistry-a very great advantage to science. Dalton investigated also the dilatation of gases, and numerous chemical phenomena. 
1777-1857. Thenard, in collaboration with Gay-Lussac, obtained sodium and potassium by means of charcoal ; discovered BORON, and also oxygenised water.

I778-I829. Davy (Sir Humphrey) analysed LAUGHING GAS (nitrous oxide); then by the DECOMPOSITION OF WATER into its constituents (oxygen and hydrogen) by means of the ELECTRIC PILE, he established a new method of chemical analysis, called ELECTROLYSIS, or the decomposition of substances by electricity. This was a fact of immense importance because it showed electricity can overcome chemical affinity (or attraction of elements to one another)the power, in other words, which holds several elements together in one compound substance. Faraday developed electrolysis far beyond the point at which Davy left it. After various analyses of compound substances, by means of the powerful electric battery which he constructed for that purpose, Davy established THE LAW: "Chemical affinity is nothing but the energy of opposite electric powers," which led Berzelius to his classification. By the means of the pile Davy separated potassium, sodium, barium, strontium, calcium, and magnesium from fixed alkalis thought to be simple elements until then - a discovery again which opened a new era in chemistry. Davy also studied the production of heat (by friction), and was led to the conclusion that "heat is a peculiar motion, probably a vibration of the corpuscles of bodies, tending to separate themselves"-a proposition which he proved by experiments-thus establishing the doctrine intimated by Lavoisier and Rumford a short time before, and at the same time solving the problem of the cause of latent heat, which had puzzled Black. He also upset the theory (Lavoisier's) that oxygen was a necessary element of all acid substances by his famous discovery of chlorine. After numerous observations on flame, he invented the SAFETYLAMP (1815), which has saved thousands of lives. As early as I 802, soon after Ritter's discovery of chemical rays*, Davy saw the possibility of taking images by means of solar rays acting upon chloride of silver, and with Wedgwood actually took some, but he did not succeed in fixing them perma-

$$
\text { * See W. Herschel. }
$$


nently. This was accomplished later by Niepce and Daguerre. Davy's practical experiment was the earliest step towards photography. He further discovered ELECTRICITY to be AN ILLUMINANT ; for severing the connecting wire of the electric battery, and tipping its points with carbon-a sluggish conductor-he obtained, not a spark, but actually a dazzling arch of white flame, called voltaic arc.* He used carbon, a poor conductor, because the intense heat would melt the wires, whereas carbon is infusible; the carbon points being made to touch, and being then slightly separated, Davy obtained the wonderful result just mentioned-the new illuminating power, electric light. The light, it may be mentioned, is not produced by the combustion of the carbon, but from bringing the solid particles (of it) into intense white heat-a heat in which platinum itself is melted as sealingwax in a candle-flame. With Davy the French school of chemistry, which had headed science for a long time, receded to the second rank, England taking the lead, and keeping under the banner of Davy, Dalton, and Faraday.

I778-I850. Gay-Lussac investigated IODINE, and showed it to be an element analogous in its chief reactions to chlorine, thereby putting an end to the oxymuriatic theory; investigated also cyanogen, and fulminating silver; he discovered THE LAW-"Equal volumes of elementary gases contain equal numbers of atoms" -in other words, correspond to equivalent weights of the substances (1809)-a confirmation of Dalton's atomic theory. Yet, exceptionally, phosphorus, arsenic, mercury, and cadmium, do not conform to this law-the two first giving vapours twice as dense, the two last half as dense, as it is expected they should.

I779-I848. Berzelius, one of the founders of modern chemistry: was familiar with all its branches; discovered several elements, and reduced from their oxides thorium, calcium, barium; developed the use of the BLOWPIPE into a system of qualitative analysis; made the greatest number of accurate analyses of any chemist in his time; identified electrical polarity with chemical affinity-every atom being regarded by him as both positively and negatively electrified,

$$
\text { * See Volta. }
$$


but in unequal degrees, strongly positive atoms showing affinity for negative atoms, and conversely: thus establishing (for a time) his views of the dual structure of chemical compounds - a doctrine partly overthrown by Dumas's unitary theory. By the application of a few rules regarding the combinations of elementary atoms, he extended the bounds of the atomic theory of Dalton: established the fact that the same laws of combination, the same fixity of composition, and the same general features of atomic structure prevail among the so-called organic as among the inorganic compounds, thereby removing the barrier which separated the two branches. He will be remembered beyond all things, however, for his determination of ATOMIC WEIGHTS -an investigation which demanded an amount of labour, perseverance, patience, and working power of which those who are unacquainted with the detail of experimentation have no idea.

I785-I838. Dulong discovered CHLORIDE OF NITROGEN, a powerful explosive; in collaboration with PETIT discovered THE LAW, "The atoms of all solid elements have the same capacity for heat," thus putting a most important generalisation in the hands of the chemist; since guided by it, together with Mitscherlich's law of isomorphism, and GayLussac's law of atomic equality, Berzelius was able to demonstrate Dalton's conception to be applicable to a large range of chemical phenomena. Dulong, in collaboration with Berzelius, determined the exact composition of water (already discovered, but now forcibly corroborated), of carbonic acid, and other bodies.

I786-I889. Chevreul made a deep study of FATTY SUBSTANCES of animal origin (which led to the making of stearic candles) - hence his name of father of the fatty acids; formulated the LAW OF CONTRAST OF COLOURS; published numerous papers ON COLOURS, and the theories expounded therein found a ready application in the colouring of silk, so that several industries are under great obligations to his century of labours.

1794-1863. Mitscherlich discovered the great physicochemical LAW OF ISOMORPHISM (1818), "Compounds the atoms 
of which contain equal numbers of clementary atoms, similarly arranged, have the same crystalline form," which has been slightly modified, but which nevertheless was a powerful assistance in Berzelius's researches in atomic weights.

I 800-69. Dumas invented the method of determining the DENSITIES OF COMPOUNDS in the gaseous state, known as Dumas's vapour density process; established the relations which exist between ethers and alcohols, and ketween ethers and acids; determined the composition of chloral and chloroform; formulated the UNITARY THEORY, in opposition to Berzelius's dualism, by which it is conceived that "the molecule of a compound is regarded as a unitary structure"; originated the conception of types developed by Gerhardt and Laurent.

I803-I873. Liebig, one of the greatest masters of ORGANIC CHEMISTRY (so called); was more successful than any in applying chemistry to PHYSIOLOGY, PATHOLOGY, and AGRICULTURE. His agricultural chemistry has rendered immense service to Europe and America; he taught that the chemical state of the soil affected plants in many wayshence crops and animals; and showed how important it was to preserve the vitality of the soil by sowing it with proper seeds, and how to improve fields by certain processes and manures. Regarding physiology, Liebig was equally scientific and practical ; he showed the changes which food undergoes in our bodies, and what part becomes blood, what part fat, or bone, or muscle-demonstrating that the body of animals is a chemical laboratory always at work, producing, combining, decomposing substances. He improved manipulation by several innovations: his POTASH-BULBS made an organic analysis one of the simplest operations of chemistry, and the process (since I83I) caused rapid advances to be made. He may be said to have changed the whole face of that branch. Invented a condenser for distilling small quantities of liquids. He produced chloroform and chloral (I832), benzoyl, and contributed to establish Dumas's unitary theory. His Letters on Chemistry aroused universal interest in the science.

1805-1869. Graham (Thomas) discovered the LAW OF 
THE DIFFUSION of gases, "The diffusion-rates of any two gases are inversely as the square roots of their densities"; invented the diffusion tube by means of which the rates of diffusion of different gases can be compared; formulated the conception of acids of different basicity; discovered the PROCESS OF DIALYSIS, in which, by reason of the law of diffusion of liquids, the (difficult) separation of colloids and crystalloids is easily effected; discovered also the process of atmolysis, which determines the separation of one gas from another, inventing the tube atmolyser for that purpose; studied the motion of gases, and their absorption by metals; devoted his energy to trace the movements of atoms and molecules, showing that gases pass through walls as they pass through other gases, and, by measuring their speed, showed how it is possible to determine the rate of motion of a molecule, and to follow the molecule into organic membranes - all of which discoveries place their author among the greatest chemists.

(?) I8II. Avogadro contributed to elucidate the atomic theory by discovering the LAW which bears his name: "Equal volumes of all gases, compound as well as simple, measured at the same temperature and under the same pressure, contain equal numbers of molecules"-one of the paramount laws of chemistry; he established the distinction between the ultimate particles of compounds and elements-introducing, and explaining too, the idea of molecules. Avogadro's law has, later, been deduced mathematically from the first principles of the mechanical theory of gases by Prof. Neumann (i 869).

I8I6-56. Gerhardt established a THEORY OF TYPES of great simplicity and convenience: the compounds of ammonia, for instance, are grouped into amides, amines, alkalamides, subdivided according as they are derived from one, two, three molecules of ammonia ; then the compounds containing water are grouped and subdivided according to the same principle, and so forth. In this manner we have tables of multiple and mixed types, such as : Dichloride, Dihydrate, Diamide; then Trichloride, Trihydrate, Triamide; then Chlorid-hydrate, Chlorid-amide, Hydrat-amide. The deter- 
mination of these types was one of great value to the progress of science. It tended among other things to finally remove the distinction between organic and inorganic chemistry. Gerhardt succeeded in obtaining anhydrous organic acids previously unknown; showed the true value of vapour volume as a means of determining atomic weight, and developed the idea of series in organic chemistry.

I 8 I 7-I892. Hofmann (Aug. Wilhelm) studied the BASES OF COAL-TAR, one of the richest sources of chemical products - a fact due to the vegetable origin of the substance, since coal must necessarily contain all the principles and elements of the plants which enter into its composition. Hofmann may be said to have explored a new field, to which the DYE INDUSTRY owes a great part of its development. In his investigations he made many discoveries in the chemistry of the compound ammonias and coal-tar colours; found the composition and chemical character of aniline red, a decisive discovery, being the earliest of a numerous series in the same sphere. Hofmann's studies of the MOLECULAR CONSTITUTION of the organic bases were so important that he was awarded a Royal medal for them.

b. I829. Williams (C. Greville) discovered NEW HYDROCARBONS, Isoprene among them, from the distillation of india-rubber and gutta-percha; also alkaloids, such as parvoline, lepidine, cryptidine-and what Hofmann called one of the most beautiful substances known to chemists, CYANINE, a superb blue colour, used in astronomical spectrum photography; investigated beryls and emeralds. Greville Williams established a TABLE OF the atomic weights of the elements in their calculated positions, showing all THE MISSING ELEMENTS, or gaps, between hydrogen and uranium-a work the decisive value of which chemical discoveries will demonstrate in the near future. This Table is an elaboration of Mendelejeff's periodic law.

b. I832. Crookes, besides his high rank among physicists, holds a similar position among chemists. His address as President of the Chemical Section at the British Association in I886, is famous for the bold exposition of his belief in chemical evolution. In his view, one primal ele- 
mentary matter-that is, one antecedent form of mattercontaining within itself the potentiality of all atomic weights, would have evolved successively, say helium or hydrogen, and then lithium next to it in simplicity of atomic weight, and then glucinum, then boron, then carbon, and, gradually, the rest of the seventy-two elements (which we call simple, but which are in reality compounds), in the same manner that the simplest life-germ, protoplasm, has evolved all organismsso that the elements have been built up from one another according to some general plan. Hydrogen was once thought to have been the unit from which all elements were derived; but this view is now put aside because, granting the soundness of Mendelejeff's principle, the multiple of the atomic weight of hydrogen does not account for twenty-six (if not forty-five) known elements, and leaves too many gaps in the series. It was calculated by $\mathrm{Mr}$. Clarke that about half the atomic weight of hydrogen would satisfactorily account for the weights of all known elements, and of those which would by-and-by be discovered to fill up the gaps from hydrogen to uranium besides. The presence in the sun of an element such as the one which would fulfil these conditions has, it is thought, been detected. Helium, as this element is called, is a much simpler one than hydrogen, for it presents only one ray or line in the spectrum, and its vapour possesses no absorbent power. It would then, if its existence were confirmed, offer the conditions necessary to allow of all the elements to fit in their places, and would therefore be the basis required for the working of the ProutMendelejeff law. Crookes thinks there may have been, before helium or hydrogen came into being as such, an antecedent form of matter-protyle-which evolved either helium or hydrogen, or both in succession-the rest coming into existence in the course of cosmic events. That is his hypothesis. "If he has grasped the key to the arrangement he has gone far to unlock some of the deepest mysteries of creation." This doctrine of chemical evolution was not a conception of Crookes's. Sir Benjamin Brodie as early as 1867, Prof. Stokes about the same time, Graham in '68, and later Newlands, Mendelejeff, Prof. Victor Meyer, Dr. 
Gladstone, Dr. Carnelley, Clarke and others, have held that our supposed simple elements are really complex, and must have come into existence by the evolutionary development of some primordial matter. But Crookes it was who, for years, investigated the question most elaborately, by his analysis of "rare earths"-especially yttria, which he calls his Rosetta Stone-present in samarskite, gadolinite, and other minerals, * through the process of chemical fractionisation. To settle a single point regarding the nature of yttria he performed upwards of two thousand fractionisations! $\mathrm{He}$ does not claim to have demonstrated or established chemical evolution, but he thinks that the balance of evidence fairly weighs in favour of it. If evolution be a cosmic law which enables us to account for the origin and formation of heavenly bodies according to Laplace, of the earth according to Lyell, of plants and animals according to Lamarck, Darwin, and Wallace, then it is difficult to believe that it does not hold good in chemistry-development of matter-as well. All our knowledge tends more and more to force the conviction upon us that unity of energy governs the Cosmos, and that principle almost necessarily involves unity of matter as it involves unity of law. Whether one day this be demonstrated, or whether the contrary be established, Crookes will, in either case, always be considered as one of the keenest pioneers of a wonderful age, and one who forwarded in no small degree the settlement of the deepest questions of scientific philosophy. We shall further on see the services which he has rendered to physics.

b. I837. Perkin (William Henry) discovered (1856) the first of the ANILINE DYES-the source of an immense increase of trade and wealth throughout the world; made a great number of discoveries in organic chemistry, and greatly distinguished himself by applying the measurement of the MAGNETIC ROTATION OF ORGANIC SUBSTANCES to the study of their constitution.

- Mendelejeff formulated the PERIODIC LAw,

* To obtain almost pure yttria cost Crookes fifteen months' work, and another ten months to eliminate from it the $\frac{1}{250000}$ th part of impurity it contained. 
which J. A. R. NEwLAnds had already foreshadowed (1864) by his Law of Octaves-a law in atomic weights which seems to point to the unity of matter, i.e., singleness of one primordial element (perhaps helium, or, according to Crookes, more probably a primal matter which he calls "protyle") out of which other elements are evolved. Be this as it may, Mendelejeff, investigating Prout's hypothesis (that the weight of a large number of the elements is an exact multiple of that of the hydrogen atoms), found and enunciated his periodic law (1869): "The properties of the elements are a periodic function of their atomic weights." From this principle he predicted the existence of several elements required to fill up the gaps in the series of elements, and some of these have since been discovered (Gallium in 1876-one of them), a feat which somewhat resembles that of Leverrier's astronomical deductions which led to the discovery of the planet Neptune.

Such are in the main the results obtained by modern investigators in a field which had been cultivated for thousands of years without bringing in a harvest at all commensurate to the time, labour, ingenuity bestowed upon it. Ancient Egypt, and later, the Arabs, had certainly composed many thingsdyes, perfumes, poisons, medical remedies, pigments; they had invented processes of research, and numerous apparatus; they had taught us the value of experiments; they had founded in Islam, and prepared mediæval Europe also to found, the Experimental School ; they had even discovered many phenomena, either relating to pure chemistry or pure physics, remarkable and important in an equal degree. But they had failed in one capital point: although they were the first to clearly see and clearly intimate that law governed the world of matter, they had found and formulated no specific chemical laws. The modern era shows no decisive advance in that respect until the XVIIth century. But with Boyle commences the discovery of laws, and from that period, though the progress is by no means rapid until Lavoisier, we witness a continuous development which marks the new times with a new character, and stamps them with a different set of 
features. From the moment laws became demonstrated, not only was retrogression impossible, but progress must of necessity grow apace. And this was obviously the case in many directions, as we have seen. One material consequence ensued, and that was the immense benefits derived from chemical advancement in all industries, and which promoted human welfare. Another consequence-scientific this-was doubly beneficial: additional evidence was afforded of the supremacy of law throughout a wide range of the physical world ; next, additional evidence was furnished of the interaction of one science upon another, and the necessity of such interaction was made more plain than ever, since chemistry strongly assisted medicine, physiology, geology, and, as we shall see, terrestrial and celestial physics. The third consequence was mainly philosophical, and, as such, of greater significance if possible than in other respects, since chemical knowledge throws a luminous ray upon the origin of the Cosmos. For, if an electric current or spark is sufficient, not to decompose substances simply, but also to form new compounds, as we have seen it to be the case in Cavendish's composition of water out of two simple elements, then it may be reasonably inferred that many compound substances were in the origin of things formed by a similar process of chemical action; and if it be so it is not unreasonable to infer also that the life cell, that primordial spark of life out of which all life was evolved, may have been produced by the action of forces, at a stage when conditions of pressure, heat, matter, admitted of such a process. This, however, is a hypothesis unsubstantiated altogether as yet. But it is as well to take note of one of the results of chemical research upon human thought.

We perceive then what immense strides have been made in this branch of science; how vastly they have extended the area of knowledge, and how small, relatively, had been the advance before the modern era, despite admirable efforts. These efforts had not been quite fruitless, and we owe much to those who made them. A Giaber, a Rhazes, a Paracelsus, a Van Helmont, are great men still-we inherited their modes of inquiry-and it would be sheer ingratitude or want of 
historical vision to dismiss their names with a shrug of the shoulders, as some have done during the Revival and since. The only chemist we remember who might have won the approbation of these hypercritics was Stahl, who, last century, waylaid many chemists by his Phlogistic theory until it was at last exploded by the discoveries of Lavoisier. They would no doubt have admired a theory which was wholly imaginary, from the very fact that it displayed ingenuity without verification, and that it was in accord with their own way of settling difficulties by what they considered an effort of genius without study. Stahl's theory of combustion furnishes a sound analogy to the SPIRIT THEORY of earlier days, with this enormous difference, however, that whereas Phlogiston affected only a set of phenomena and arrested one branch of science only, the doctrine of spirits affected phenomena universally, and would have blocked the way to every branch of science. Fortunately the scientific method prevailed, and science did wonders "undreamt-of by Baconian philosophy." We need hardly point out that chemistry descends from alchemy through Paracelsus, Libavius, Van Helmont, and partly Gilbert-the transition being fairly steady after Paracelsus had taught the science in public, although modern chemistry cannot be said to have been in existence until the discovery of oxygen.

We now come to a series of branches which are so bound together that they should be treated abreast of one another, namely, mathematics, astronomy, physics, and mechanics. But we must be content with taking them separately. It will be easy for the reader to see their connection as we proceed.

\section{Group IV. Mathematics.}

I596-I650. Descartes found the method of determining the tangents of curves; APPLIED ALGEBRA TO THE GEOMETRY of curves. "He showed," says an excellent master of the subject,* "that every equation may be represented by a curve, or figure in space, and that every bend, point, cusp,

$$
\text { * Mr. Jevons. }
$$


or other peculiarity of the curve, indicates some peculiarity in the equation. It is impossible to describe in an adequate manner the importance of this discovery: the advantage was twofold - algebra aided geometry, and geometry gave reciprocal aid to algebra. Curves such as the well-known sections of the cone were found to correspond to quadratic equations. The way was thus opened for the algebraic treatment of motions and forces, without which Newton's Principia could never have been worked out. He showed the mechanical fact that every curvilinear deflection is due to a controlling force." He understood and explained the RISE OF WATER in an exhausted space: "The weight of water," says he, "counterbalances that of the air." As a physicist, he invented a new barometer, made of mercury and a liquid to magnify the effect of the mercurial barometer. $\mathrm{He}$ enunciated the UNDULATORY THEORY OF LIGHT (see Fresnel and Young), and formulated the two LAWS OF REFRACTION (confirming Snell's results) after experiments by means of A PRISM, which exhibited the exact colours of the rainbow. It was reserved to Newton to explain the cause of the phenomenon which Descartes pointed out, as it was reserved to Fresnel and Young to elucidate and prove the undulatory theory. (See Appendix VI.)

1616-1703. Wallis gave an additional impulse to ANALYTICAL GEOMETRY by his Arithmetica Infinitorum, and his improvement of Cavalieri's method of application.

I623-62. Pascal invented a CALCUlating APPARATUs, much improved by Leibnitz, Babbage, Scheutz, Thomas, Sir W. Thomson, and Tait, which would have reconciled Francis Bacon to the science he despised, for it made "all men equal in arithmetic." Pascal invented also the humble WHEEL-BARROW-an application of the law of the lever; he established the doctrine of THE WEIGHT AND PRESSURE OF AIR, confirming Torricelli's theory, after the barometric experiment carried out under his direction by his friend Perrier on the summit of the Puy de Dôme; he also established the law of equality of pressure in liquids, called PASCAL'S LAW : "Pressure exerted anywhere upon a mass of liquid is transmitted undiminished in all directions, and acts with the same 
force on all equal surfaces, and in a direction at right angles to those surfaces." This law led to the invention of the HYDRAULIC PRESS by Bramah in I796, and later, of many machines of tremendous power, such as levers, jacks, lifts, boring and perforating tools, which save immense time and labour - all being direct applications of it. Of Pascal's mathematical works, his Traité de la Roulette is the most famous, being a treatise on the Calculus of Probabilities.

1629-95. Huygens constructed a PLANETARIUM, in conformity with the Copernican system, and which led to the discovery of CONTINUOUS FRACTIONS; calculated that the centripetal force at the distance of the moon would be only a fraction of 15 feet per second; ascertained the VELOCITY OF A FALLING BODY in any latitude.

1642-I727. Newton worked out his METHOD OF Fuuxions (1665), which, like the Differential Calculus (of Leibnitz), is one of the most powerful instruments in mathematics. This was his first great discovery. We shall see further on that he was a stranger to no science, and turned his attention, not to astronomy only, but to physics also, introducing the idea of attraction even into chemistry; his discoveries on the reflections, refractions, inflections, and colours of light, and likewise on sound, would have sufficed to make him famous.

I646-I716. Leibnitz, like Newton, opened a new field in mathematics, by his discovery of the DIFFERENTIAL CALCUlus - the basis of higher analysis-which is to the mathematician what the microscope is to the naturalist. This Calculus and the Fluxions of Newton are about equal in power, but Leibnitz's Calculus is easier to handle: it almost requires a Newton to handle the formidable Fluxions -hence the Differential Calculus is more used. As a geologist, Leibnitz propounded the doctrine of the GRADUAL COOLING OF THE GLOBE, the subsidence of its strata by fracture, the deposition of sedimentary rocks and their induration. Of Leibnitz's metaphysics, so famous and influential for a time, we cannot speak a word here.

I654-I705. Bernouilli (James), one of the very profoundest mathematicians, by calculating the return of a 
comet, all but demonstrated the planetary nature of comets ; he solved the problem of the ISOPERIMETERS-whence the discovery of the Calculus of Variations by Lagrange ; devoted part of his life to the investigation of combinations, as connected with that of Probability. His "Ars Conjectandi" is one of the deepest mathematical works in existence on the TheORY OF Probability. Bernouilli's Numbers, which show his ingenuity and inventiveness, are among the most familiar natural Constants known. His brother, JOHN BERNOUILLI (I667-I748), also a mathematician, discovered the Exponential Calculus, and made experiments on the elasticity of gases. DANIEL BERNOUILLI (I700-I782John's son), a distinguished physicist, composed a celebrated work called Hydrodynamica-I738. (See Thomson.)

I698-I746. Maclaurin resolved the problem of the form of the earth by means of certain properties of conic sectionsa feat comparable to any performed by Archimedes; found the THEOREM which bears his name, and which is the generalisation of that of Newton upon the Asymptotes.

I707-83. Euler found the method and the general formulas to determine curves or surfaces for which certain indefinite functions are lesser or greater than all others; enlarged the limits of the Differential Calculus by his researches on the series of the Infinites, whilst his INTEGRAL Calculus, a powerful instrument of his creation, simplified the methods in use before him. As a physicist, he also enunciated, after Descartes, Huygens, and Hooke, the UNDULATORY THEORY OF LIGHT.

I728-77. Lambert demonstrated the INCOMMENSURABILITY OF THE ratio of the CIRCUMFERENCE to the diameter; introduced the hyperbolical sinus; and found the series which became the object of Euler's and Lagrange's labours.

I736-I8I3. Lagrange, by his method, called CALCULUS OF VARIATIONS, extended Descartes's discovery in Indeterminate Analysis. His theories of AnAlytical Functions, and his theory of (musical) vibrations, proved the efficacy of MATHEMATICS IN PHYSICAL PROBLEMS, whilst his ANALYTICAL MECHANICS transformed mechanics into a question of 
calculation-two facts which Newton had already made plain. We shall see what magnificent use Lagrange made of his own mathematical conceptions. Lagrange also brought back the attention of geometers to algebra, which was being neglected, by his Resolution of Numerical Equations.

I746-I8I8. Monge improved DESCRIPTIVE GEOMETRY, and caused its universal adoption; founded the nucleus of the Polytechnic School, which became, under and after Napoleon, the highest scientific school in Europe.

I749-I827. Laplace extended the limits of mathematical analysis. His "Celestial Mechanics," a work of mathematics as much as astronomy, places him by the side of Newton in some respects. His "THEORY OF PROBAbILITIES" was a practical revolution: this theory, certainly one of the noblest creations of intellect, is, said its author, "good sense reduced to calculation." This famous work contains Laplace's theory of Generating Functions (Fonctions Génératrices).

I752-1832. Legendre continued Euler's labours in his famous THEORY of Numbers. His Elliptical Functions, his researches on alterations of Homogeneous Spheroids, contain new important theorems, and his THEORY OF PARALLELS contains the famous Method of the Least SQUARES OF ERRORS. These creations of his have given powerful assistance to mathematicians.

1753-1823. Carnot formulated the THEOREM (on loss of forces) which bears his name, and established the great mechanical principle of REVERSIBILITY OF ENERGY-the conversion of heat into mechanical effect: "The amount of mechanical energy obtained from a certain given amount of heat energy, is the same at all times at the same temperature." This thermodynamic law is held to be strictly true of all matter without exception; but Carnot failed to grasp its full significance. It was reserved to Joule and Hirn fully to expound and develop it into modern Thermodynamics. Carnot stands high in the sphere of mathematics by four works : On Infinitesimal Calculus, Correlation of Geometrical Figures, Geometry of Position, Relation between the Respective Distances of Five Points in Space. 
I777-1855. Gauss, one of the masterly mathematicians of the XIXth century, established the theory of the Division OF THE CIRCLE; discovered the LAW OF ERRORS; was a great master in Transcendental Arithmetic; found new methods of calculating planets' orbits, explained in his THEORIA Motus; improved geodesy; invented the MAGNETOMETER for determining the angles which the plane of magnetic meridian makes with the plane of the astronomical meridian; calculated that the total magnetic action of the earth is the same as that which would be exerted if in each cubic yard there were eight bar-magnets each weighing one pound. From data collected by Piazzi, he calculated the whereabouts of Ceres so accurately, that directing his telescope to the probable point he rediscovered this asteroid, which had been lost sight of for months (I80I).

I789-I857. Cauchy discovered the method for finding a priori the number of roots; simplified the THEORY OF ASYMPTOTES.

1793-1880. Chasles introduced the adoption of SIGNS IN PURE GEOMETRY, thereby creating uniformity of method; found the theory of the surfaces of the second degree-the starting point of fine discoveries.

I 805-I865. Hamilton (Sir W. Rowan) brought into existence the system of QUATERNIONS, an extensive method of mathematical reasoning comparable to the invention of logarithms for power, but of infinitely more value in higher mathematics, for "whatever problem involves the threefold dimensions of space, is treated by a symbolic method of the most comprehensive simplicity" (Jevons).

I806-I87I. De Morgan endeavoured to effect the UNION OF LOGIC AND MATHEMATICS- " one of the most important steps in the history of science"-a connection brought about by Boole. De Morgan effected a great generalisation, for his double algebra is true not only of space relations, but of forces, so that the triangle of forces is reduced to a case of pure geometrical addition ; and more; the triangle of lines, the triangle of velocities, the triangle of forces, the triangle of couples, are reduced by analogy to one simple theorem which amounts to this, "that there are two. 
ways, different in length, but identical in their final results, of getting from an angular point of a triangle to another" (Jevons). He also pointed out that "the three symbols of ordinary algebra form but three of an interminable series of conceivable systems."

The foregoing sketch of the work done by mathematicians, the present writer candidly owns, is here both meagre and unsatisfactory. It gives a list of new instruments of calculation it is true; but it neither defines the object for which they were created, nor states what discoveries were made by the use of them; so that the general reader who may not be conversant with mathematical science can form no estimate of the value of the facts just enumerated. But as the two next sections will describe the power of mathematics in solving difficulties in astronomy and physics which would be insuperable without it, the reader will have occasion then to appreciate its effects in a multitude of facts. He will see the imperial sway of mathematics over all other branches, and will plainly understand why it is often called the Queen of Sciences. The names of the mathematicians, which may be names and nothing more to him, will then appear illumined by a halo suddenly revealing all the splendours of genius, for, indeed, in the fame-roll of all times they hold the first rank.

In order to give an idea of the vastness of modern science, a remark may parenthetically be made here, based on a fact of importance.

Mathematics, if considered in detail, embrace pure mathematics and applied mathematics :

I. ARIthmetic, subdivided into

A. Pure Arithmetic :

(a) Theory of Numbers, (b) Ratios,

$\begin{array}{ll}\text { (c) Proportions, } & \text { (d) Scales of Notation. }\end{array}$

B. Applied Arithmetic :
(a) Weights,
(b) Measures.

II. Algebra, into

A. Elementary :

(a) Analysis of Determinate Quantities,

(b) Analysis of Indeterminate Quantities.

B. Higher-Infinitesinal Calculus :
(a) Differential,
(b) Integral. 
III. GeOMETRY, subdivided into

A. Elementary: or Euclidian.

B. Higher or Projective vel Descriptive.

C. Analytical Geometry.

IV. Conics, or Curves of the Second Order:
(a) Ellipse,
(b) Parabola,
(c) Hyperbola.

V. MeChanics :

(a) Statics,

(b) Dynamics,

(c) Kinetics.

VI. Applied Mathematics :
A. Mensuration,
B. Hydrostatics, Dynamics, Mechanics,
c. Geodesy,
D. Astronomy.

Hence mathematics have been the chief instrument by which the physical sciences have progressed; namely, astronomy, gravity, hydrostatics, hydrodynamics, hydromechanics, optics, heat, light, acoustics, magnetism, electricity, meteorology, geography, chemistry, engineering (machinery and surveying), architecture, naval architecture -in fact all the phenomena relating to Force and Matterto which may be added political economy, currency, banking, and insurance. Now, what we have to note and remember is that each branch, so vastly has science extended its area, admits, just as mathematics do, of several important subdivisions-each of which is often extensive enough to engross by itself a man's whole lifetime, each, too, employing an army of earnest workers.

\section{Group V. Astronomy.}

I 592-1655. Gassendi was the first to observe, by means of the camera obscura, MERCURY passing across the disk of the sun (November 7, 1631)-a phenomenon which recurs at intervals of from seven to thirteen years. As a mathematician and physicist, he wrote on the communication of movement.

I6I I-87. Hevelius drew up, after careful observations of the moon, the first SELENOGRAPHICAL MAPS ; increased the catalogue of stars just after Galileo-those in the Zodiac especially; was the first observer of the PHASES OF MERCURY, 
and observed in the camera obscura the transit of this planet (May 3, I66I); measured its diameter; determined the rotation of the sun on its axis to take twenty-seven days, after assiduously observing the sun's spots. He invented the polemoscope, for observing the movements of an army out of sight.

I6I9-4I. Horrocks was the first, with his friend Crabtree, to observe the TRANSIT OF VENUS (over the sun's disk), December 4, I639, by means of a telescope.

1625-I712. Cassini discovered comets to belong to our planetary system, and in some respects to partake of the nature of planets - a somewhat hasty conclusion; he calculated the orbits of a few ; measured the obliquity of the ecliptic ; also the parallax of the sun; also horizontal refraction; showed Jupiter to revolve on its axis, and its rotation to take 9 hours 56 minutes-observing at the same time the flattening of that planet at the poles, a discovery precious to Newton ; discovered FOUR OF SATURN'S MOONS ; and also the ROTATION OF MARS ; drew up the EPHEMERIDES of Jupiter's satellites; originated a method for determining parallaxes still in use; and finally studied the zodiacal light, the nature of which remains as yet undetermined.

1629-95. Huygens, by means of a ten feet long telescope of his own making, was the first to discover one of SATURN'S SATELLITES (Titan), and also to detect Saturn's rings to be detached from the planet (1659); he also discovered the great non-resolvable NEBULA OF ORION.

I638-i703. Hooke determined the PARALLAX OF STARS by a surer way than Galileo had proposed (I660) ; approached in a remarkable manner the discovery of universal gravitation, after making the earth's motion a subject of deep study and calculation.

1642-I727. Newton applying Galileo's principles of terrestrial dynamics to the Universe, demonstrated THE LAWS OF universal attraction and GRAVITATION-his second and greatest discovery - a feat unparalleled in the annals of science, sublime alike for its magnitude and for the labours it involved. Before dealing with the problem, Newton had to resolve, I. the force according to which a body falls; II. the exact 
time of the moon's rotation; III. the exact length of the earth's radius (line drawn from the surface to the centre). The last proposition caused a pause of sixteen years-until Picard (Jean, I620-I682) found the exact measurement of the radius $(20,922,000$ feet). Then came the great law of Newton (1687), "The force of attraction of a body is equal to the mass divided by the square of the distance"-in other words: The attraction varies inversely as the square of the distance-or again: As much as the square of the distance increases, so much the attraction decreases.* By this law Newton accounted, not only for I, the three laws of Galileo and Kepler, but for 2, all the movements of the celestial bodies, then for 3 , the tides of the ocean (spring and neap tides) ; 4 , he proved experimentally the rotation of the earth on its axis; 5 , determined the figure of the earth to be an oblate spheroid-a phenomenon unsuspected, and solved entirely by calculation; 6 , explained the cause of the precession of the equinoxes, and showed it to be due to the flattening of the earth at the poles, and to the additional attraction of the sun and moon exercised upon the extra mass of matter gathered at the equator; 7 , determined the specific gravity of the p'anets - Saturn, for instance, is composed of matter about nine times lighter than that of the earth ; 8, accounted for the elliptical motions of the planets ; 9, for irregularities of planetary movements; I0, saw that some comets must move in parabolas; I I, demonstrated the chief inequalities of the moon; I2, laid down the problem of the nutation of the moon afterwards resolved by Euler, d'Alembert, and Laplace. The great principle Newton discovered made it possible to account for, and determine, all the

* If at a given point a planet is at one million miles from the sun, the sun will attract it, say, at the rate of 100 billions of tons per square foot of its surface; when the planet is as far again--that is two million miles away, the square of 2 being $4(2 \times 2=4)$, the sun will only attract it onefourth part, or at the rate of 25 billions of tons per square foot; if the planet is three million miles off, the square of 3 being $9(3 \times 3=9)$, the sun will attract it one-ninth part only of the rate it drew it at starting. In other words: If the distance be increased from one to two, three, four units, the attraction will be decreased to the fourth, the ninth, the sixteenth part of its former intensity. 
perturbations of the celestial bodies, and even the existence of as yet undiscovered bodies. It is a striking example of the force of prejudice and early training that the great Leibnitz opposed Newton's conclusions. Of all the discoveries made by mankind, Newton's is the sublimest-not only the greatest, but the most universal. Hipparchus's discovery of the precession, so marvellous considering the conditions of science in his time, and Laplace's Nebular Hypothesis, so magnificent as a conception, and so imposing as a scientific solution of the problem of universal genesis, must be placed below the discovery of Newton. It may be added that his work "PRINCIPIA" constitutes par excellence the true MODERN ORGANUM of the scientific method: the laws which he discovered are wonderful, but his example of the manner of establishing them is nearly as marvellous. "The scientific procedure which he disclosed has been to a great extent the germ of a vast development in the physical and mathematical sciences." The philosophical significance of this discovery was at least equal in importance to its physical meaning--for the truth was demonstrated that the government of the planetary system "is under necessity," and that "it is impossible for the laws presiding over it to be other than they are."

I644-I 7 IO. Roemer discovered the VELOCITY OF LIGHT $(1676)$ - one of the greatest discoveries in astronomical and physical science. By a careful observation of the eclipses of Jupiter's moons, he found that instead of recurring at fixed times and intervals, they regularly varied 16 min. $36 \mathrm{sec}$. every six months. If one for instance, say the first satellite, which passes into Jupiter's shadow at equal intervals (of 42 hours $28 \mathrm{~min}$. $36 \mathrm{sec}$.), suffers occultation (hiding) on the Ist of January, at eight o'clock at night, it is found to suffer occultation on the Ist of July at 8 hours 16 min $36 \mathrm{sec}$. of the clock-a retardation of 16 min. $36 \mathrm{sec}$. Roemer, having ascertained this phenomenon, rightly inferred the cause to be due to our being in January nearer to, and in July further from, Jupiter by the whole width (or diameter) of the earth's orbit-viz. 190 millions of miles, and the light of Jupiter therefore taking $16 \mathrm{~min} .36 \mathrm{sec}$. longer to reach us in July than in 
January-because in July we are further removed from Jupiter by 190 millions of miles; and Roemer consequently found light to travel at the rate of some 190 thousand miles per second, and to reach us, roughly speaking, in $8 \mathrm{~min}$. $\mathrm{I} 8 \mathrm{sec}$. from the sun-that is, nine million times faster than an express train or ten thousand times the velocity of the earth. (See Foucault and Fizeau.) Roemer's discovery was a much more conclusive proof of the motion of the earth around the sun than the calculation of an almost imperceptible parallax (the apparent change of position of a heavenly body in consequence of its being viewed from different parts).

I646-I7I9. Flamsteed drew up a TABLE OF THE TIDES, and a catalogue of fixed stars of remarkable accuracy. His observations on the moon were inserted in Newton's Principia. He proved the falsehood of astrology by his Ephemerides.

I656-I742. Halley went to St. Helena $(\mathrm{I} 676)$ to study the heavens, and, there, observed the TRANSIT OF MERCURY, and catalogued three hundred and fifty stars in the SOUTHERN HEMISPHERE; demonstrated the periodical return of comets by his earnest observation (1682) of the one that bears his name, predicting its return in 1758 , and every seventy-six years; pointed out the Secular Inequality of the moon and of the satellites of Jupiter and Saturn; from his observation of the transit of Mercury, and the time it took, he was able to make (1691 and 1716) the happiest suggestions for the measurement of the sun's distance from us, by means of the transit of Venus-a phenomenon which seldom occurs (two coming in eight years, and then only one hundred and twenty-two years after). He left accurate instructions to accomplish that object during the next transit in 176I. The beautiful method he indicated, and which consisted in observing the duration of the transit from two or more stations far apart, east and west, was followed with the best result. Several expeditions, sent out in I76I and I769, enabled astronomers to approximate the distance - the distance found being $91,368,000$ miles, or 108 times the sun's diameter. We may remark that J. N. Delisle (1688I768) proposed another method of observing Venus's transit, 
to be applied at stations where Halley's method cannot be used, and which consists in noting the time of the beginning of the transit at a station in the North where it begins earliest, and at another station in the South where it begins latest. These details are given because of the importance of Venus's transit and the great interest attached to the latest transits, those of 1874 and 1882 , of which most of us have heard. Halley found also a simple formula to measure the ALTITUDE OF MOUNTAINS with the barometer - the mercury sinking one inch in 900 feet; studied the variations of the compass; explained the causes of the inequality of level in the Mediterranean Sea to be due to evaporation. He invented the MERCURY THERMOMETER (1680).

1692-I762. Bradley discovered the phenomenon called the ABERRATION OF FIXED STARS-an apparent displacement of celestial bodies due to the progressive motion of light and the orbital motion of the earth-the aberration depending upon the ratio between the velocity of light and of the carth's motion. This phenomenon is sometimes called "aberration of light"-but rather incorrectly. Bradley discovered and explained the NUTATION (oscillation) of the earth's axis-that is, the small gyration of the axis around the mean position due to the precession of the equinoxes. This motion of nutation takes place in about nineteen years in a small ellipse. These two discoveries are of high importance in the study of astronomy.

I736-I8I3. Lagrange demonstrated, with Poisson, Laplace's theory of the INVARIABILITY OF THE GREAT AXES of the planetary orbits; solved the problem of the libration of the moon - that is, he explained with Laplace, with whom he worked hand in hand, that the moon always presents the same side to us because the globe is not a sphere, but an ellipsoid, i.e., it has its equator elongated towards the earththis elongation being due no doubt to the tide of matter (now solidified) which was caused at one time by the earth's powerful attraction. By this elongation, the moon's earthward hemisphere contains an excess of matter which, by the earth's attraction-the earth having eighty times more matter 
than the moon-necessarily keeps this hemisphere facing us. Lagrange also explained that, owing to the balancing movement called "LIBRATION" to which the moon is subjected by going alternately a little faster or a little slower, it must show us a thin edge of the face which is hidden from us-a glimpse on either side in turn-so that four-sevenths of the moon's surface can be seen instead of one-half only. And owing to the libration, too, the moon's apparent diameter varies from a maximum value of $33^{\prime} 3 \mathrm{I}^{\prime} \mathrm{I}^{\prime \prime}$ to a minimum value of $29^{\prime} 2 \mathrm{I}^{\circ} 9^{\prime \prime}$. Lagrange further solved a question of much vaster importance, viz.: that of the stability of the orbits of the planets (I776). Uniting his own with Laplace's investigations, together with all the facts known on the subject, in one grand mathematical problem, he formulated the generalisation, that, whatever the infinite changes, perturbations, and variations affecting planets, yet, in the course of ages, every part of the system remains absolutely stable, and subjected to the force of gravitation which keeps them eternally moving round the sun; so that he demonstrated, as we said at starting, the theory of the Invariability of the great axes. Laplace, himself a mathematical genius of the first order, justly said, in admiration of Lagrange's achievements, that "of all the inventors who had contributed most to the advancement of human knowledge, Newton and Lagrange appeared to possess, in the highest degree, the happy tact of distinguishing general principles among a multitude of objects enveloping them, and this tact he conceived it to be the true characteristic of scientific genius." We may add that Lagrange considered less astronomical questions than the mathematical analysis to which they might give rise.

I738-I822. Herschel (William), justly called the CoLUMBUS OF THE HEAVENS, was indeed the greatest of all observers, and one of the founders of astronomical physics besides. With a telescope forty feet long, of his own making, he discovered and mapped nearly 2,500 NEBULE in the Northern Hemisphere, and also numerous double stars, only a few of which were known before his time. He detected over 500 DOUBLE STARS disseminated in the heavens, after 
twenty-five years' close observations, and explained their motion to be subject to gravitation, and their revolution to take place around each other, and round a common centre (focus). He also showed that their growing more luminous, and then fainter, was due to their coming nearer to us and then receding further off in the line of our vision. This was the first evident proof of the law of gravitation holding good throughout the universe, and not merely throughout our solar system. Later investigations have revealed systems composed of three and even more stars, and that the increase or decrease of brilliancy in variable stars is due in many cases to other causes than mere motion towards or from us. (See Norman Lockyer and Kirchhoff.) Herschel's theory of the constitution of nebulæ has been confirmed, for some nebulæ are, as he said, masses of luminous vapours out of which stars are formed, and many others are clusters of stars. But his work went further than this; for whereas the naked eye can detect 4, I00 stars only,.Herschel by means of his powerful telescope could in the course of years compute nearly TWENTY-NINE MILLIONS. Recent computations, supported by photography, make this vast number only a fraction of the whole-for it is now thought that 1,000 millions could be mapped. Herschel enunciated the hypothesis that our system belongs to the Milky Way, and is moving along with it towards Hercules, or rather towards $\lambda$ of Hercules, being attracted thereto at the rate of 150 millions of miles a year by a cluster of some I4,000 suns. He explained the probable constitution of the sun, but his view is no longer accepted. He thought the sun to be a dark body around which lies a luminous atmosphere. The reverse seems rather to be the case. The spectroscope has revealed to us the existence of a central hot and luminous body, called photosphere (light-producing sphere); this is surrounded by an atmosphere, about I,000 miles thick, compose $\rfloor$ of metallic gases (iron, lead, copper, zinc, in fact, most of the metals found on the earth); around this lies a 5,000 mile thick chromosphere (a sphere of hydrogen gas), which shoots flames fifty, seventy, eighty thousand miles high - and these eruptions ascend at the rate of 20,000 miles a minute. Beyond and around the chromo- 
sphere is the Corona, whose nature is not yet determined.* We may state that the sun has 700 times more matter than all the planets put together. Herschel discovered (March I3, I78I) the planet Uranus and its six moons with their westerly motion; he measured the diameter of several planets (Ceres, Juno, Pallas, Vesta); he ascribed the streaks of Jupiter and Saturn to be due to clouds driven by regular winds, resembling our trade-winds. He further observed a volcano in activity in the moon, in April, I787. But Herschel is to be remembered as having made three capital discoveries: I. that binary stars are very numerous; II. that nebulæ are existing throughout the heavens in thousands; III. that the Newtonian law of GRAVITATION IS A UNIVERSAL LAW. As a physicist, he made CATOPTRIC TELESCOPES (telescopes by reflection in contradistinction to dioptric telescopes-i.e., by refraction); he also made numerous observations of great value. He was the first to study the SOLAR SPECTRUM (with the thermometer, I800), and thereby caused immense progress in optics-nothing less than the opening of a new area of researches. For, wishing to ascertain with a thermometer which of the coloured rays given by the prism were the hottest, hediscovered HEAT-RAYS - that is, rays of light which are invisible to us beyond the red band of the spectrum. Within a year RITTER (J. W., I776-I8IO) discovered DARK RAYS at the other extremity of the spectrum, beyond the violet band, which have the property of decomposing nitrate of silver and other compounds, for which reason they have been called CHEMICAL RAYS. Herschel's was the first experiment in the history of spectrum analysis. (See Fraunhofer and Kirchhoff.) The discovery made by Ritter was, next to Porta's invention of the camera obscura, the earliest of those which led to photography: we have seen that Davy, in I 802, tried to utilise Ritter's discovery. Herschel's magnificent labours were worthily continued by his son.

I746-1826. Piazzi, following the indications furnished by Kepler's empirical law by which the planets' distances

* Mr. Taylor has calculated that the whole outward envelope of the sun cannot extend to less than 800,000 miles, and the light we receive from the centre must pass through this vast ocean of matter. 
appeared to follow an arithmetical progression, began to observe the heavens between Mars and Jupiter, with a view to discover the missing planet which should, in accordance with the law, be found in that region. This law, called BODE'S LAW, because this mathematician (I747-1826) set it forth clearly and insisted upon its value, is a striking instance of the soundness of empirical knowledge at times, and may be stated thus: If under Mercury we write zero, and under Venus 3, and then go on doubling this number under each planet in succession (from the sun), 6 under Earth, I 2 under Mars, 24 under Asteroids, 48 under Jupiter, 96 under Saturn, 192 under Uranus, 384 under Neptune, and to these numbers add up 4, we obtain the numbers which closely correspond with the relative distances of the planets-Neptune excepted, the discrepancy with regard to it being 88. This law has been of great service to astronomy, for Kepler (and later Titius) expressed his belief, founded upon it, that an undetected planet revolves between Mars and Jupiter, and effectively, after the discovery of Uranus, which afforded an additional proof of the law, Bode having strongly suggested that the gap between Mars and Jupiter should be surveyed, Piazzi, on the first day of our century (January I, I8OI), discovered CERES, the first asteroid known. This planet, lost for a few months, was rediscovered by Gauss after remarkable calculations of its orbit. But CERES was only the first of a multitude of asteroids revolving in the gap ; for soon PALLAS and VESTA were found by Olbers, and Juno by Harding (I802-1807). In I845, a fifth asteroid, ASTRAA, was discovered; in I847, three more were found, and from that time until now, not a year passed without some being added to their number-until there were as many as 389 of them known up to I 894 . Seventeen were found by Karl Luther alone, Io by Hind, 9 by Gasparis, I 4 by Goldschmidt, 7 by Pogson, 9 by Watson, and so forth. It has been suggested that their large number is due to the explosion of a large planet, but as their distances vary between 200 and over 300 millions of miles, and the inclination and eccentricity of their orbits vary beyond those of other planets, it is more probable that the cause of their 
presence and number lies in the principle of which the nebular hypothesis gives a satisfactory explanation. (See Laplace.) Be this as it may, however, Bode's law was shown to be sound, though empirical, and Piazzi was the first discoverer of a multitude of small worlds.

I749-I827. Laplace crowned Newton's scientific edifice by his Mécanique Céleste (I799), in which he enunciated the law of universal gravitation - gravity being only a particular feature of it. He showed the law ruling Jupiter's satellites, explained, in collaboration with Lagrange, the cause of the moon presenting always the same hemisphere to us; and he explained the perturbations of our satellite; why the moon moves round the earth more and more quickly for a lengthy period, and after that gradually more and more slowly. He calculated the long inequality of Jupiter and Saturn, and enunciated therefrom the hypothesis that the mean of the averages in a certain number of planetary revolutions does not vary - a cycle, however, covering necessarily thousands, and even millions, of years. This constitutes his theory of the INVARIABILITY OF THE GREAT AXES of planetary orbits, which was further substantiated by Lagrange's calculations. It applies particularly to Jupiter and Saturn, whose orbital perturbations were very striking, and suggested the possibility of a dislocation of our system. Saturn seemed likely to wander away and escape beyond its limits, whilst Jupiter appeared on the contrary to be coming nearer and nearer to the sun-threatening to fall into it in the course of time. Laplace showed that these planets behaved in this eccentric manner, because Jupiter makes $2 \mathrm{r} / 2$ revolutions round the sun, whilst Saturn makes one only; but as the points of their conjunction (their nearest approach to each other) vary every time, the planets "must right themselves, and resume in time their normal position," and thus obey the law of gravitation. But Laplace is celebrated in particular for propounding the famous theory which bears his name. After long meditations upon the probable origin of the order which reigns in the universe, induced by a striking suggestion due to the genius of Kant (1724-I804), that suns, stars, planets possibly owe their present form to 
the slow cooling and contraction of incandescent gas-clouds, after long and complicated calculations bearing on physical and mechanical questions which the subject involved, Laplace arrived at the conclusion that planets are condensations of the solar atmosphere-at first only rings of gaseous and luminous matter detached from the nebula (sun) by the contraction of the main body, then later on condensed by cooling into solid bodies (planets), which continue to revolve around the sun, in the same orbits as those which they occupied as vapours at starting. This theory is called Laplaçe's Nebular Hypothesis, and is the theory accepted by most physicists and astronomers. It is in complete harmony with the law of evolution, of which Laplace is the earliest scientific exponent and demonstrator. The law of evolution, it is clear, accounts for all the phases through which worlds must pass in the course of their birth, growth, maturity, and decay. It was through this famous hypothesis that evolutionism began to work its way throughout Europe for the first time in a clear form, and to become familiar to scientific minds. The conception of slow natural development, as opposed to that of sudden creation, steadily spread after the publication of the "Mécanique Céleste." Laplace's hypothesis is in the main a mathematical theory, and as such it "explains a number of the most important facts of our solar system." It may be added that spectroscopic astronomy (see Kirchhoff) has been adding a multitude of facts which confirm and strengthen the theory more and more every year. Thus, Laplace, in this as in other respects, advanced the boundaries of science immensely, and must be remembered as one of the most profound philosophers of modern times.

I758-i 840. Olbers discovared Pallas (I 802) and VeSTA (1807), and several comets; formulated the theory of explosion to account for meteorites - a theory, however, which is much opposed by other astronomers and particularly Norman Lockyer. (See his meteoritic hypothesis.)

I79I-I865. Encke, by his accurate observations of the comet which bears his name, and which returns every $3 \mathrm{r} / 4$ years, formulated afresh the theory of the existence in space 
of an ETHER within the whole area of our planetary system -a view now generally accepted, and, since, even extended to universal space, as Huygens had suggested. Encke showed that ether, offering a certain resistance, and decreasing the comet's velocity, enables the sun to attract the body nearer to itself, to contract therefore its orbit, and cause it to reappear; after passing behind the sun, a few hours sooner (two hours and a quarter) than would be the case otherwise. The decrease has been from $1,212.79$ in 1786 to $1,210.44$ in 1858 . The importance of this theory can hardly be exaggerated. It confirms the nebular hypothesis, for the comet must one day be attracted into the sun, and be followed likewise, by virtue of the same law, by all the bodies of the system successively -in thousands of ages, of course-so that in the process of time our system must be merged into a nebula as it was at starting, and begin from that point a fresh course of evolutionary cycle.

I792-I87I. Herschel (John) established a catalogue of 2,000 DOUBLE AND TREBLE STARS (I8I8); and, going to the Cape of Good Hope, he discovered and mapped 2,500 NEBULE in the Southern Hemisphere-thereby completing his father's glorious work (I834-I838). Evidence has thus been furnished, by the observations of the two Herschels on the motions of double stars and the constitution of nebulæ, to show that Newton's law of gravitation and Laplace's theory apply to the whole universe; so that there seem to be features of homogeneity in the structure of all celestial systems which may be looked upon as a demonstration of resistless and unchangeable law-a point upon which it is necessary to insist. John Herschel showed that the vast MAGELLANIC CLOUDS-a distant group of nebulæ and star systems presenting marvellous complexity, since they exhibit 28 kinds of nebulæ-are a portion of the Milky Way of the Southern Hemisphere. But Herbert Spencer has thrown a doubt whether some of these nebulæ are as remote from us as great astronomers state, and the reasons he gives are both weighty and cogent-for, to put it in a nutshell, if they are resolvable into stars by our telescopes they must be within the limits of our sidereal system, otherwise they would not be resolvable 
by the telescopic power we possess. As regards the others, photography has confirmed the views of the Herschels-they are vast masses of luminous gases, which time and cooling will contract into planetary systems in accordance with Laplace's theory. John Herschel's famous Outlines of Astronomy (1838), treated as Arago had already done in France (Astronomie Populaire-1834), is the earliest and finest work it is possible to read in the English language on the subject. For the first time was the general reader put in a position to understand the wonders of the heavens : it is, in point of clearness, simplicity, and eloquence, on a par with Arago's work. As a physicist, John Herschel's treatises on Sound and Light are valuable contributions to science. He carried on, together with Talbot and Brewster, a series of experiments on light and the colours of burning substances, and suggested, like Talbot, to make the flame-colours a means of chemical analysis (I822). He IMPROVED THE SPECTROSCOPE in collaboration with J. Browning (I870). Herschel may be said to have founded practical mineralogy: he was no stranger to any of the physical sciences, and it is not too much to say that they are all indebted to him in one way or another. As an instance of his scientific universality, we may take his determination of the relative luminosity of heavenly bodies. Wollaston had ascertained that the full moon gives 801,072 times less light than the sun; Herschel determined that the light of the full moon exceeds that of a Centauri 27,408 times; so that "the ratio between sunlight and starlight would be that of 22,000 millions to one."

I8II-I877. Leverrier, concurrently with Adams, after calculating the deviation of Uranus from its orbit, ascribed this perturbation to be due to the presence of an unknown body external to Uranus, and this proved to be the case; for (Berlin) astronomers, instructed by precise directions from Leverrier as to the region where the planet was to be looked for, discovered NEPTUNE on the same night (September 23, I846), the orbit of which is thirty times more remote from the sun than ours. This feat, which may be regarded as one of the greatest triumphs yet achieved by Newtonian 
astronomy, showed once more the unrivalled power of mathematics in science. Leverrier rendered a much greater service to astronomy. From I 838 to 1874 he worked out the ANALYSIS OF THE ORBITS OF THE PLANETS, by observing and calculating all the movements of the eight large planets. This vast work-the greatest accomplished in mathematical astronomy in our time-includes a determination of the masses, disturbances and their causes, the interaction of planets upon one another, so that it constitutes a table which will enable future astronomers to ascertain within the next 2,000 years whether the same order, or a different order, obtains. All this was again accomplished by the masterful handling of mathematics - the queen of sciences.

I 8 . Schiaparelli revealed a NEW FEATURE in the constitution of the heavenly bodies. He showed in 1862 that the SIVARM OF METEORS of August $9^{\text {th }}$ to I Ith (that is, the shooting stars called the Perseids) travelled in exactly the SAME ORBIT AS THE COMET which appeared in that year. This was the first time a meteoric orbit was determined. The (I $3^{\text {th }}$ ) November swarm (the Leonids) was next traced out by Leverrier and Adams, the latter calculating it to travel beyond Uranus; and in I866, a comet was seen to move along precisely the same orbit. Adams's masterly calculations proved the cycle of these November meteoroids to be no less than $33 \frac{1}{4}$ years. Since then, meteor swarms have been studied with great care, and an immense number of them, describing rings more or less regular, have been discovered, notably by Schiaparelli, Proctor, and Prof. Newton. It is now ascertained that the earth crosses every year the orbits of the August and November meteoroids, and the meteorites which are met by the earth are ignited by the friction of our atmosphere and dissolved in their course through it, thus causing the phenomenon known as shooting or falling stars. As there are eighteen meteor showers every year, it is concluded that we pass across the orbits of eighteen systems. According to Prof. Newton and Schiaparelli, the August meteoroids are nothing but the continuation of the 1862 comet, whose tail is elongated all along the course of the comet's orbit. 
Schiaparelli has identified the orbits of five meteoritic swarms with the orbits of various known comets. Besides the swarms, there are sporadic (chance) meteorites strewed throughout our system, and so numerous are they that no less than TWENTY MILLIONS enter our atmosphere DAILY according to Prof. Newton, and if all were seen their number would probably exceed one hundred millions; so that "our solar system is a meteoric plenum in which sporadic meteorites and swarms of greater or less density are moving in orbits more or less elongated around the sun." There seems also to be conclusive evidence that they are strewed throughout universal space, and not throughout our system only. This question has been worked out by Norman Lockyer very elaborately, and in his book he has co-ordinated all that is known at present about nebulæ, comets, and meteorites.

I836- Norman Lockyer, besides co-ordinating the labours of other astronomers, physicists, and his own, has contributed important astronomical and SPECTROSCOPIC OBSERVATIONS on meteorites. He has all but proved their ubiquitous presence in countless swarms or streams throughout space as we just mentioned; he has just pointed out the importance of the part they may play: (I) as factors modifying comets, gravity, light, heat, electricity; (2) as possible and probable elements contributing to the preservation of solar energy, $*$ and even the formation of nebulæ and stars; (3) as agents causing the phenomena of variable stars, and Novæ. With regard to the last mentioned phenomena, he has, upon apparently conclusive evidencespectroscopic in the main-supplemented the information given us by W. Herschel and Kirchhoff, by the important fact that the intermittent increase of luminosity presented by many of these variable bodies, and not by them alone, but by comets besides, is due to their colliding with meteoric

* This view is confidently opposed by Helmholtz and Sir William Thomson (now Lord Kelvin), who ascribe the sun's energy to shrinkage by gravity. Lord Kelvin points out that the energy which may be derived from meteoritic impact is insignificant by the side of that derived from shrinkage. 
swarms. These swarms, by the impact, break out into sudden incandescence, and add it to the normal light shed before the collision by the stars and comets. It is, on a large scale, the same phenomenon as that which we witness on our earth when meteorites meet our atmosphere: they are ignited, and become, therefore, intensely luminous. Be this as it may, for the point is not altogether admitted by all astronomers yet, Norman Lockyer, upon what appears to him satisfactory evidence, has broached a new theory of the universe, partially guessed by Waterston, viz., the Meteoritic Hypothesis, as distinguished from the Nebular Hypothesis-Lockyer's theory being that meteorites are the material out of which worlds are formed. The two theories are by no means exclusive of each other-they are easily reconcilable on the contrary, if it be allowed that the two processes actually occur in succession, the meteoritic phase coming after the nebular (gaseous) phase, as an effect of radiation-as an effect, that is, of cooling, contraction, and chemical precipitation-the meteoritic phase in its turn producing the three series of phenomena just mentioned. Norman Lockyer, besides the work just described, and which by the way is the most recent, has enriched science in several departments by numerous investigations and discoveries. $\mathrm{He}$ is a master in spectral analysis and solar physics. He had a great share in the elucidation of the constitution of the sun as sketched out in the paragraph referring to $W$. Herschel. The name of CHROMOSPHERE is due to him, together with our better knowledge of this portion of the sun. A fine example of the excellence of his work we may cite in Mr. Jevons's words: "Wanting some guide as to what more elements to look for in the sun's photosphere, he prepared a classification of the (chemical) elements according as they had or had not been traced in the sun, together with a detailed statement of the chief characters of each element. He was then able to observe that the elements found in the sun were mostly those forming stable compounds with oxygen. $\mathrm{He}$ then inferred that other elements forming stable oxides would probably exist 
in the sun, and he was rewarded by the discovery of five such elements."

It is hardly necessary to say anything about these magnificent results. To state and marshal them is to point out their grandeur. That man, in his acknowledged insignificance and with his confessed limitation of intellect, should have arrived at detecting, in the infinitude of space, innumerable phenomena, each of them a new sphere of further investigation, and after detecting them should have explained their relation to one another, and after showing their relation should have found out the far-reaching laws by which they are regulated, is at once the most beautiful and the most engrossing of all wonders. That this is a subject for meditation which precedes all others in importance, because of the psychological questions it involves, need not be insisted upon, so intuitively do we all feel it. Such was the work of modern astronomers, the sublimest achievement of man, from Copernicus who led the van to Norman Lockyer who closes the march. From the survey of astronomy, we learn as forcibly as in all else the one great lesson of modern knowledge-the government of the world by law.

\section{Group VI. Physics.}

1608-i647. Torricelli, concurrently with Guericke, showed that air has not only weight, but, at the earth's surface, exerts an enormous pressure. By his invention of the BAROMETER he demonstrated this fact, which had apparently been understood by Hero of Alexandria-witness his fountain - though not demonstrated. Torricelli by means of his instrument showed that the whole atmosphere is equal to the weight of an ocean of mercury covering the earth, and about thirty inches in height: from which it follows that a pressure of about fifteen pounds (or more correctly $14.6 \mathrm{lbs}$.) weighs on each square inch of the earth's surface, so that a man of ordinary size bears a weight of about fifteen tons, but as the pressure of that weight is distributed equally on all sides it is unfelt-just in the same manner as the weight of 
water which presses on a fish is unfelt by it because the pressure is equilibrated. Torricelli discovered and formulated THE LAW of velocity of efflux by a theorem which bears his name: "That water falls from a vessel with a velocity equal to that with which a body would fall from the same height as the level of the water above the tap"; so that he was really the founder of hydrostatics.

1602-I686. Guericke, concurrently with Torricelli, demonstrated atmospheric pressure. He invented the MAGDEBURG HEMisPHERES, which fully proved the pressure of air to be exerted on all sides equally. He also invented the AIR-PUMP, to produce a vacuum-the bell-glass, from which the air is exhausted by a pump, being kept down by the outside air pressure. He showed the elasticity of air. He was the first to propose the freezing point of water as the lowest limit of the scale of the thermometer-the boiling point being proposed by Renaldini (in 1694) as the opposite limit. He constructed the FIRST ELECTRIC MACHINEusing a globe of sulphur and charging it with electricity by turning it in a frame, and pressing it with a cloth which caused the required friction. The electricity produced by sealing-wax or sulphur is called resinous electricity. Guericke found out several electrical phenomena: $\mathrm{I}$, that a spark is produced by electricity passing between two separate bodies; 2 , that two bodies charged with the same electricity repel each other-so that he was the practical continuator of Gilbert, and the precursor of Muschenbroeck, Franklin, and Galvani. Not long after him a further advance in this branch was made by DU FAYE, who discovered that there exists another kind of electricity. He obtained it by rubbing the end of a glass rod with silk. This is called vitreous electricity in contradistinction of Guericke's. Du Faye showed that each electricity repels itself and attracts the other. It was for the purpose of generating vitreous electricity that HAWKSBEE made (I740) the SECOND ELECTRIC MACHINE, on Guericke's principle, in which the sulphur was replaced by a glass globe and the cloth by a piece of silk. We shall soon see how these facts conduced to the electrical marvels of our time. I6r8-i663. Grimaldi discovered and demonstrated the 
DIFFRACTION OF LIGHT; after experimenting on the diffraction of light (really on the interference of light), he discovered that light added to light produces darkness-a principle which led Young and Fresnel to arrive at the truth of the undulatory theory; advanced optics generally and prepared the way for Newton.

I620-84. Mariotte discovered the LAW OF COMPRESSIBILITY OF GASES, that is, the contraction or shrinkage of gases in proportion to pressure. This is called Mariotte's law, and also Boyle's law, the latter having also discovered it. (See Boyle.) Mariotte explained the chief laws of motion by experiments which made them clearer than their mere enunciation.

1629-95. Huygens invented the cycloidal PENDULUM, and also PENDULUM CLOCKS (1658); invented the MICROMETER to measure the apparent diameter of planets; improved the barometer, with which he taught how to measure the altitude of mountains. With rare genius Huygens gave a scientific BASIS TO THE UNDULATORY THEORY OF LIGHT ( 1678$)$, rightly thinking "that we can explain light," as he said, "only by supposing it to be a VIBRATION LIKE SOUND." He was THE FIRST modern scientist (Democritus's theory involved as much) to suggest that entire space is filled up with an invisible substance called "ETHER," at once elastic and subtle, and that luminous bodies make it vibrate so that its undulations will strike upon the eye, and give us the sensation called light. He pointed out that in ordinary refraction the velocity of propagation of the wave is equal in all directions, so that the front of an advancing wave is spherical and "reaches equal distances in equal times"- $\mathrm{a}$ wonderful feat of scientific intellect. And his experiments on crystals. prove that he verified his theory. What is especially remarkable and shows he understood the significance of his doctrine, is that he gave a satisfactory explanation of refraction by the undulatory theory. He also explained the phenomenon of DOUBLE REFRACTION (through Iceland spar*) to be due to the greater elasticity of this crystal in one direction than in

* A crystal first made known by Bertholinus observing through it (in 1660) the splitting of a light-ray into two rays. 
the other, so that a ray was divided into two waves moving at different rates through the crystal. From experiments bearing upon this fact, he discovered another phenomenon called POLARISATION of light-the effects of which exhibit "the most gorgeous colours in the whole domain of optics." The explanation of this phenomenon we owe to the beautiful analysis of Fresnel. But, as we see, Huygens anticipated the discoveries of Malus, Fresnel, and Young, though he failed to demonstrate their physical causes as they were demonstrated by these three physicists. The main fact, however, remains untouched : he may be said to have understood and explained the undulatory theory. But as Newton had formulated a different theory, and his authority in science was held to be supreme in all matters, Huygens's labours were laid aside until the beginning of this century, when it was proved he had been right all along the line.

I638-I703. Hooke applied a SPIRAL SPRING to the balance OF A WATCH in I658; invented the dial barometer; the octant, subsequently improved into the sextant; improved the microscope; discovered THE PRINCIPLE OF INTERFERENCE-a principle of great importance in optics. (See Grimaldi and Young.) He expressed his belief in the undulatory theory of light, and with equally rare insight determined the essential conditions of combustion just about the same time as Boyle and Mayow.

I642-I727. Newton, as a physicist, enunciated the corpuscular (or emissive) theory of light (I666), in opposition to the undulatory theory of Kepler, Descartes, Huygens, and Hooke. Newton believed that light consists of an emanation of exceedingly minute particles of matter, projected from the sun and other luminous sources with enormous velocity. Modern science has settled the point. For once Newton proved to be wrong. Optics are, nevertheless, deeply indebted to his marvellous genius for his third great discovery: he found out the composition of white light by the same means as Descartes-THE PRISM : in other words he DECOMPOSED WHITE LIGHT into the prismatic colours, which he called SPECTRUM, a word to be remembered; and then recomposed white light, by the means 
of his disk, out of the colours of the spectrum. He next demonstrated the cause of colours to exist in light (not in the eye), and to be dependent upon the bodies which reflect or refract it (1666-167I). Acoustics are likewise under the greatest obligation to him. He discovered how sound is transmitted through the air-in waves, thus completing the discovery which Pythagoras and Galileo had already made, though not elaborated, that sound is a vibration of the atmosphere "which we feel when it strikes the drum of the ear" (page 102). Newton explained what sort of vibration it is; he calculated also its velocity-the speed of sound ranging between $\mathrm{I}, 090$ feet to $\mathrm{I}, \mathrm{I} \mathrm{I} 2$ feet per second at a temperature of from $30^{\circ}$ to $50^{\circ} \mathrm{Fahrenheit.} \mathrm{In} \mathrm{fact,} \mathrm{his} \mathrm{theory}$ of sound formed a very important epoch in science-opening the way, as it did, to all the later applications of mechanical principles to the insensible motions of molecules. (See Crookes and Thomson.) Even chemistry is indebted to Newton: he pointed out that many substances attract one another and combine to make one compound substance; the instance of the dissolution of copper in nitric acid, and its reappearance after iron had been plunged into the liquid, was the hint which led Bergmann to draw up his table of elective affinities, as we have seen. Newton also enunciated the law of cooling -an important fact determined by mathematical, physical, and chemical considerations, fully elaborated by Dulong. We may finally mention that he constructed the first REFLECTING TELESCOPE. In any one of the branches in which we have had occasion to speak of this unique genius, he would have made his name famous for all time, so important were his labours and discoveries. AVE!

I647-I7I4. Papin was the first to study the effects of the production of vapour in closed vessels; he invented the DIGESTER, now used in the preparation of food and especially in extracting gelatine. This was the earliest steam machine ever invented in the modern era. It is a CYLINDER with a PISTON working inside, and with a SAFETY-VALVE-three of the essentials of the modern steam-engine which made the latter a possibility (I690). Papin improved Guericke's airpump, and showed that the syphon gives the same results 
with limbs of equal length(?) as with limbs of unequal length, pointing out also that air-pressure is the principle of its action.

1653-r716. Sauveur was the first after Galileo who studied musical acoustics, by calculating MUSICAL VIBRATIONS of particular notes by means of organ pipes of different lengths and stringed instruments. From these experiments and later ones made by Daniel Bernouilli (I700-I782), Euler, and Lagrange, it was ascertained that the sound emitted by a stretched string depends upon its tension, length, thickness, and weight, and any alteration in any of these conditions will necessarily determine a different number of vibrations and hence cause a different note to sound.

1678-1709. Stancari computed the number of vibrations of a string emitting musical sounds-thereby contributing also to advance ACOUSTICS and place that branch UPON SCIENTIFIC FOUNDATIONS.

1686-1736. Fahrenheit invented a mercury THERMOMETER divided into $212^{\circ}$-freezing point being at $32^{\circ}$ and boiling point at $212^{\circ}$. Réaumur's thermometer is divided into $80^{\circ}$, from freezing point $0^{\circ}$ to boiling point $80^{\circ}$. Celsius (I7OI-I744) invented one, now universally used by scientific men on account of its convenient simplicity, which is called Centigrade thermometer, because it is divided from freezing to boiling points into exactly $100^{\circ}$.

1692-1761. Muschenbroeck invented (1746) the LEYDEN JAR, wherein electricity was accumulated (bottled-up) like a fluid-a great stride; invented also the pyrometer for measuring high temperatures.

I706-6I. Dollond invented ACHROMATIC TELESCOPES (1757). C. M. Hall had shown as early as I729 that a crown-glass lens and a flint-glass lens acting together blend their coloured rays into white light. Achromatic telescopes and microscopes were a great improvement, the coloured edges around the objects viewed now disappearing.

1706-90. Franklin demonstrated the influence of pressure upon EBULLITION by an experiment which bears his name : an increase of air-pressure raises the boiling point and a diminution of pressure decreases it; hence THE LAW- "The temperature of ebullition, or boiling point, increases with the 
pressure." That is, at a great elevation above the sea-level, say at Quito (Peru), which is 9,54I $\mathrm{ft}$. above the sea, and where the pressure of air is only $20^{\circ} 75$ (barometric height) instead of 30 inches, and therefore no longer $15 \mathrm{lbs}$. on the square inch, water will boil at $194^{\circ} 2^{\circ} \mathrm{Fahr}$., or $72^{\circ}$ Réaumur, or $90^{\circ}$ Cent. That is, water will boil at about $18^{\circ}$ less than at the sea-level, where it boils at $2 \mathrm{I} 2^{\circ} \mathrm{Fahr}$. - the boiling point lowering $\mathrm{I}^{\circ}$ Fahr. (or 0.55 Cent.) for every 590 feet of elevation. But the boiling point varies in different liquids : sulphurous acid boils at $10^{\circ} \mathrm{Cent}$., water at $100^{\circ} \mathrm{Cent}$., mercury at $320^{\circ}$ Cent., cadmium at $860^{\circ}$ Cent., zinc at $1,040^{\circ}$ Cent. All these facts were determined after Franklin had demonstrated the law. Franklin, next, established the IDENTITY OF LIGHTNING AND ELECTRICITY (I749)--the lightning being a spark several miles long, instead of an inch or a few inches, passing from one cloud to another. Through a simple but most ingenious experiment by means of a kite, cord, and key, he caused electricity to pass from a cloud to the key and collect therein, thus proving lightning to be electricity and thunder to be an electric phenomenon. Franklin invented the LIGHTNING CONDUCTOR (1755) - an application of his discovery of the power of points. For, on a sphere or globe, "the electric density is everywhere uniform," but the further a body is removed from the spherical shape, the less regular is its accumulation-hence at the point of a rod the electric density will be greatest. The lightning conductor has the double effect of attracting the (say positive) discharge of electricity from a cloud and dispersing it into the soil, and of discharging into the atmosphere the (say negative) electric fluid withdrawn from the soil by the influence of the cloud; so that it prevents the accumulation of electricity on the surface of the earth, and also restores clouds to their normal state. Franklin proposed a theory of electricity, called the single-fluid hypothesis; but the theory of Symmer, called the double-fluid hypothesis, because it supposes the existence of two fluids, is the one generally accepted, explaining as it does in a more satisfactory manner most of the electric phenomena. To Franklin, however, are due the terms "positive" and "negative," used to distinguish the two kinds of currents. He called 
positively electrified bodies those which had an excess of electric fluid, and negatively electrified bodies those which had less-the current being determined by the want of equilibrium (if we may use the term) between them: abundance flowing to scarcity and establishing a level. By the SYMMER THEORY, however, the purely conventional terms positive and negative have received a more definite signification: positive electricity or pole being synonymous with vitreous, and negative electricity or pole being synonymous with resinous. For the reader's guidance it is necessary to remind him that, whilst we make use of these terms, we are nevertheless in complete ignorance of what electricity is in itself. We know at present that motion, light, heat, mechanical energy, electricity are interchangeable forces, that is, they can be transformed into one another; we also know now that electricity can be produced by friction, mechanical energy, magnetism, chemical energy, heat, and that electricity therefore is, like heat, a mode of motion; but our knowledge goes no further. We really do not know whether its existence depends on one or on two fluids, or whether it is only an affection of matter, or again, whether it is a form of atomic motion (Helmholtz says it is probably as atomic as matter), or a visible manifestation of ethereal energy : all we know is that it is a force presenting itself to us in two distinct modes-in other words, we know of two distinct modes of the force. Hence our terms "positive" and "negative." If the positive force be exhibited, the equivalent negative force is called into action, and so the force is essentially polar, having two opposite currents. The exhibition of the force, though always subjected to certain laws, is infinitely varied, and therefore not limited to the uniformly typical phenomena already indicated. For instance, when two bodies are rubbed together, as wax and flannel or glass and silk, both bodies are found electrified; but the rubber will be positively electrified if the rubbed body is negatively electrified, and conversely. Again, upon the nature of the rubber the kind of electricity depends: glass rubbed with silk will be positively electrified (and the silk negatively), rubbed with cat's skin glass will be negatively 
electrified; again, glass with a rugged surface becomes negatively charged by rubbing with silk. Thus, electric phenomena present a field of investigation absolutely boundless. It is seen by these examples that the terms adopted to indicate the currents elucidate nothing as to the nature of electricity, and are simply conventional labels used for our convenience. It is needless to insist upon the importance of Franklin's discoveries; they caused GREAT STRIDES within a short time.

I732-I8II. Maskelyne determined, in I774, the DENSITY (or weight) OF THE EARTH to be five times that of water by an experiment suggested by Newton, and which consisted in ascertaining the attraction exerted by a mountain, and comparing it with that of the earth as a whole. This was effected by means of the plumb-line. Maskelyne found the mountain SCHIEHALLION (Perthshire) made the plumbline deviate from, instead of pointing straight to, the centre of the earth. The deflection from the perpendicular being calculated, and Hutton having determined the size and weight of the mountain by a series of observations and measurements of its materials, the density of the earth was found out, and it has been confirmed by Cavendish, Baily, Sir Henry James, and Sir Edward Sabine and others who have investigated the question. But the latest verifications (in 1893) give a mean of $5^{\circ} 4$ instead of 5 .

I736-I806. Coulomb discovered the LAWS OF ELECTRIC ATTRACTION and repulsion, and the method of determining magnetic declination - the law, that is, of decrease with distance, "Magnetic attractions and repulsions are inversely as the square of the distances"; proving it by two methods, that of the TORSION BALANCE and that of oscillation. He also showed (1802) that magnets act upon all bodies-an important discovery which Faraday will push much further. Coulomb's main services to science lie in the invention of the TORSION BALANCE just mentioned - an apparatus of extreme simplicity, consisting of a suspended wire, at the lowest end of which a ball, to which an index (or hand) is fixed, revolves over a graduated dial : the rotation of the ball and hand, upon a slight twist being given to the 
wire, indicates on the dial the angle, the elasticity, and the force of torsion of the wire-facts of extreme importance in metallurgy, in mechanics, and in physics. The torsion balance speedily became essential in numerous branches of inquiry. By means of it Coulomb determined the LAwS OF THE TORSION OF WIRES (or elasticity of torsion), one of the properties of solids which had not been investigated, as elasticity of traction, of flexure, tenacity, ductility, and hardness had been or were to be by Wollaston, Savart, Kohlrausch, and others. By means of the torsion balance Cavendish was able to discover the mean density of our globe to be five and a half times that of water, thereby practically determining the weight of the earth. The balance of torsion applied in the galvanometer gives a delicate test of electrical forces; it is indispensable in the thermo-electric pile; the most delicate investigations in the theories of magnetism, electricity, heat are due to it; so that Coulomb, by his invention, not only discovered three sets of important laws himself, but caused rapid progress in several departments of physics.

I737-98. Galvani discovered that the hind-legs of a frog touched by two dissimilar metals were convulsed, and as an interpretation of the result he believed it to be caused by ANIMAL ELECTRICITY as distinct from ordinary electricity (I789). Since then Nobili, Mateucci, Du Bois-Reymond, and others have shown that in living animals' muscles and nerves there exist electric currents (whose laws they investigated); so that Galvani was not wholly mistaken. His error did not consist in his belief that there was electricity in animals, for there is, but that there were two essentially different kinds of electricity, apart from what we call positive and negative electricity.

I740-I8IO. Montgolfier (Brothers) invented AËROSTATION-I783-(hot air balloons), soon made safer by hydrogen gas and coal gas being substituted for hot air. One of the most celebrated ascents was made by Mr. Glaisher, who rose (I86r) to an elevation of 36,000 feet. The balloon, which is probably to become a new means of intercommunication, has already proved useful in warfare, and has been serviceable 
to science as regards atmospheric phenomena, such as pressure, currents, temperature of the air at different levels, and the characters of the different orders of clouds.

I745 - I807. Attwood invented (1783) ATtwood's MACHINE for proving, by a falling weight, the laws of accelerated motion.

I745-I827. Volta invented the hydrogen lamp; he also invented the ELECTROPHORUS (to excite electricity in small quantities), a convenient substitute, on a small scale, for the electric machine and its objects; it offers a good instance of the conversion of work into electro-potential energy. Volta also invented the EUDIOMETER (to ascertain the purity of the atmosphere, or the quantity of oxygen in any given bulk of elastic fluid); he also invented the ELECTROMETER (to indicate the presence, or measure the quantity and intensity, of electricity); and finally (1800) he invented the ELECTRIC BATTERY, partly with the object of disproving Galvani's theory of animal electricity. For he argued that the electricity detected by Galvani was produced by the two dissimilar metals, and not by the frog's leg itself; that it was therefore chemical, not animal, electricity. It was in accordance with this reasoning that he made an apparatus wherein two metals-zinc and copper-brought into contact with moisture, and separated from other substances, produced electricity. That apparatus was the voltaic battery in its simplest form... The voltaic pile, another form of the battery, is made up of alternate plates of zinc and copper, with pieces of flannel between them wetted with water and salt - the top plate being copper and the bottom plate zinc, both connected by a wire, through which a current (or circuit) is produced; or rather, we should say, two currents circulate, the positive current passing from the copper to the zinc and the negative current the opposite way, from the zinc to the copper. Now, if the wire is cut in the middle and each point tipped with a bad conductor such as charcoal, through which electricity runs with difficulty, a spark will glow between the points, and that spark will grow to a brilliant luminous arch of flame (if the battery is a powerful one), and thus become 
our electric light. But this was the work of Humphrey Davy, as we stated in our chemical section. Thus was Volta's invention of the battery the STARTING-POINT OF A REVOLUTION IN SCIENCE, and of a succession of discoveries in the XIXth century which are unparalleled in the history of mankind. WATT AND VOLTA were the two men who will be known to posterity as the originators of the TWO GREATEST AGENTS OF CIVILISATION next to printing-the steam-engine and electric pile. Besides the telegraph, electric light, the telephone, and a thousand other applications, industry, chemistry, medicine, and other sciences owe immeasurable progress to the voltaic battery.

I749-I827. Laplace, so great as a mathematician and astronomer, was also great as A PHYSICIST. He invented with Lavoisier the ICE-CALORIMETER; he demonstrated the statical PROPERTIES OF ELECTRICITY, and showed the force to act like gravitation, that is, in the inverse ratio of the square of distances; made numerous valuable observations on refraction, capillarity, barometrical measurements, prepared for future extension the application of mechanics to corpuscular physics, by demonstrating that the molecular compositions of material bodies present so many new worlds, subjected to the laws of mechanics, which science has to investigate; and the science of our day has already shown that his expectations in that respect were well founded.

I753-I8I4. Rumford, before Arago, Bunsen, and Wheatstone, invented a PHOTOMETER for measuring the relative intensities of light; he also invented a CALORIMETER which bears his name; he made numerous observations on heat and light which received practical applications for domestic purposes-being the first to use steam for cooking and warming. He showed that the quantity of light is in proportion to the vivacity of combustion, and not to the quantity of the matter burnt; likewise that intensity of heat depends on the intensity of the draught, and not on the quantity of fuel. Housekeepers would find many of his suggestions conducing to economy. He showed experimentally the conductivity of steam, air, and the transparency of a flame. He was, too, the first to de- 
monstrate, also by experiments (I798), that HEAT is a KIND OF MOTION, and not a substance as it had been surmised even after Lavoisier's complete and satisfactory theory of combustion; and Rumford showed also that heat can be produced by friction, actually boiling.water by heat so produced. By his laborious experiments and results he brought the attention of scientific men to heat-a power relatively neglected until then.

I756-I 827. Chladni, who may be called the precursor of Helmholtz as regards at least a certain series of the latter physicist's researches, guided by the investigations of Sauveur, Bernouilli, Stancari, and Euler, on musical vibrations, discovered the longitudinal vibrations of strings and the MUSICAL VIBRATIONS OF SOLID BODIES, going in that direction much further than Galileo and those just mentioned. His experiments, which are fully described in his Acoustic Figures and his Die Akustik, are as instructive as they are interesting, showing as they do, numerous phenomena of sound unsuspected till then. He invented the clavicylinder and the euphone-two instruments fashionable for a timethe latter especially on account of its great sweetness and power. Marloye's harp is a fine application of Chladni's elucidation of longitudinal vibrations of rods ; musical boxes are examples of musical vibrations of metallic plates; the harmonicon an example of those of glass plates. The vibrations of plates are governed by the law: In plates of the same kind and shape, the number of vibrations per second is directly as the thickness of the plates, and inversely as their areas. In elastic rods of the same kind, "the number of longitudinal vibrations is inversely as their length, whatever be the diameter and form of their transverse section." Helmholtz has worked out this branch with incomparable fulness and skill.

I758-1815. Nicholson DECOMPOSED WATER by accident by the VOLTAIC BATTERY (I8OI) - a discovery which Davy considered as "the foundation of all that has since been done in electro-chemical science."

I766-I 828. Wollaston invented the CAMERA LUCIDA, and, like Malus, the reflecting GONIOMETER, for measuring 
the angles of crystals; was the first to see the BLACK LINES in the solar spectrum ( 1802 ), but seems to have failed to perceive their significance; he simply noted their existence. This was the second step in the progress of spectrum analysis. Wollaston invented the CRYOPHORUS, to freeze water by means of rapid evaporation; he invented also the HYPSOMETER, to determine the height of a place by means of the boiling point (see Franklin); he devised the construction of the lenses of the microscope known as WoLLaston's DOUBLET. He further investigated the malleability of metals, and found platinum to be the most ductile of all, for he actually obtained a platinum wire 0.00003 of an inch in diameter-so fine that 1,060 yards of it weighed only 0.75 of a grain. He rendered countless services to science.

I766-I832. Leslie (Sir John) advanced the knowledge of THE PHENOMENA of reflection, emission, and absorption OF HEAT-science is mainly indebted to him in these branches. Invented a HYGROMETER, a differential thermometer, and a photometer (I800); also a method of artificial FREEZING BY RAPID EVAPORATION; carried on numerous experiments on the relation of air to heat and moisture (his work on the subject a standard book); invented a reflecting tube (bearing his name) by means of which the reflecting power of substances is determined.

I766-I844. Dalton made fine discoveries in heat: determined the amount of vaporisation of liquids according to heat; discovered and tabulated the SPECIFIC HEAT OF GASES.

I773-I829. Young (Thomas), one of the most original thinkers of our age, was, next to Huygens, the first to indicate the right path and lay down the right principle for the ELUCIDATION of the most important and complicated phenomena of light, the development of which was worked out by Fresnel, and led the latter to establish the UNDULATORY THEORY OF LIGHT, although the credit of this great discovery is often but erroneously assigned to Young alone. Young, as early as I80I, made experiments upon the "interference of light" - and to him is due this denomination of the phenomenon; but Fresnel, once in possession of the con- 
ditions of the problem as stated by Young, seems to have arrived first at the correct solution with the assistance of Arago. Still, it was only after he had communicated his results to Young that decisive experiments were made, and led to the complete settlement of the question (1816)-so that their names cannot be dissociated in reference to it. The undulatory theory once established, Young showed that the phenomena of diffraction are to be explained by it. The wave theory also reveals an intimate connection between light phenomena and heat phenomena; it also shows how completely analogous the phenomena of light are to those of sound; it readily explains the colours of different bodiesopals, mother-of-pearl, butterflies' wings, the feathers of birds, soap-bubbles amongst others. For according to this theory, "certain bodies have the property of exciting undulations of different lengths, and therefore of producing light of given colours" : white light or daylight results from the co-existence of undulations (waves) of all possible lengths. The theory likewise explains the colours of all transparent bodies, as also the colours of the spectrum, and their alteration according to distance. All these phenomena then depend upon wavelengths, and these are infinitely varied. They have been calculated to range in parts of an inch from-

Extreme Red 0.0000266 to Extreme Violet 0.0000167; whilst according , to Sir John Herschel's mathematical investigation, the number of undulations in an inch range from-

Extreme Red 37,640 to Extreme Violet 59,750;

and the number of undulations in a second range from-

Extreme Red $458,000,000$ of millions, to

Extreme Violet 727,000,000 of millions.

But returning to Young, besides the part he took in establishing the undulatory theory, he also laboured to demonstrate the existence in interstellar space of A LUMINIFEROUS ETHER - a hypothesis entertained by Huygens, and almost demonstrated by Encke since, as we have seen-a hypothesis, so far, which is, however, pretty generally accepted. This ether "more solid and elastic than steel," and which must exist if the undulatory theory is true, exerts a pressure 
upon us, according to Sir J. Herschel's calculation, of about seventeen billions of pounds per square inch-that is, I, I48,000 million times more than the pressure of air at the earth's surface, and which is $15 \mathrm{lbs}$. on every square inch. It may be stated, as an evidence of the interaction of the sciences upon one another, that the undulatory theory might be unknown even now, had not the theory of sound suggested an analogy-as it did from the first, for this was Huygens's first idea. Young, who had supplied the principle of research in the case of the wave theory, did exactly the same thing in reference to the HIEROGLYPHICS of Egypt, after his examination of the Rosetta Stone. By indicating the process to be followed, he enabled Champollion to work out the decipherment of the great mystery enveloping the history of the past.

I774-I862. Biot found that a great number of liquids and solutions possess the property of circular or ROTATORY POLARISATION-that is, have their light-waves undulating corkscrew fashion; further, that the deviation of the plane of polarisation-that is, alteration of light and direction of lightwaves-can reveal differences in the composition of bodies where none is exhibited by chemical analysis; explained the colours produced by polarisation; devised an apparatus for measuring the rotatory power of liquids; also found the law of distances in electricity, "that the force decreases as the square of distances." As a mathematician, Biot threw great light upon Egyptian astronomy, and proved it to have been very accurate, and at the same time very ancient.

I775-I8I2. Malus discovered (I808) the POLARISATION OF LIGHT by reflection (also discovered by Huygens, and rediscovered by Brewster). Malus called polarisation the division of a ray into two, and light so divided polarised light. A ray of light, it must be remembered, is caused by the vibrations of the luminiferous ether, occurring in all directions across the path of the ray. A ray of polarised light is caused by these vibrations occurring in one plane only, and Iceland spar (see Huygens) has the property of altering the multifarious directions of light-waves into two onlyvertically and horizontally-thus causing double refraction. 
In other words, a ray of ordinary light passing through Iceland spar is divided into two polarised rays, and by recombining the two polarised rays, common light is reproduced. The NICOL PRISM is used as a polariser or analyser-so that it polarises light, and shows the effects of polarisation; the polaroscope is another instrument for showing the phenomena of polarised light, such as the colours produced, and so forth. We shall see that Fresnel and Young succeeded in elucidating these beautiful phenomena.

I775-I836. Ampère, continuing Oersted's experiments upon the deflection of the magnetic needle, found the north pole of the magnet to act in four different ways according to the direction of the current, and to simplify the description, he gave the following memoria technica, called AMPERE'S RULE, by which all the various directions of the influence of the current can be remembered: "If an observer will fancy himself to be standing (either on his feet or on his head) in such a manner that the positive current will come out of his mouth and return to his feet, the north pole of the magnet will always be on his left-hand side." Upon this fact depend the signals of the telegraph, as we shall partly see. Ampere invented the galvanometer for determining the existence, intensity, and direction of an electric current. This apparatus, combined with the commutator which will reverse the current, has become one of the chief parts of the electric telegraph: the motions of its needle indicate the signs transmitted. Ampère suggested (I830) the working of signals by the motions of the magnetic needle, and made the first APPARATUS OF TELEGRAPHY, which gradually resulted in the telegraph through the labours of Jacobi, Steinheil, and Wheatstone. Ampère also discovered that two electric currents produce magnetic currents at right angles to themselves in the air without needing any steel bar to help them. $\mathrm{He}$ made another important discovery: as electric currents caused magnetic currents, he thought it possible to turn a steel bar into a magnet by passing an electric current round it-and effectively he made ELECTRO-MAGNETS by this means. He was then the founder of ELECTRODYNAMICS, that part of electric science which deals with the attraction 
and repulsion manifested between currents and currents, and between currents and magnets. His fundamental law is that "Two currents flowing in the same direction attract each other; two currents flowing in opposite directions repel each other." He may be said to have been the first to prove electricity to be a motive power. This motive power, applied to machinery which requires enormous action, is as yet less serviceable than steam; but when a comparatively small force with great velocity and regularity of motion is required, it is superior to all other means. It is, moreover, susceptible of a great variety of applications in this respect-as the electric cars and railroads already in existence in America and England conclusively prove. Tesla's experiments will certainly lead to immense development. Ampère propounded a celebrated THEORY OF MAGNETISM, according to which magnetic phenomena would be caused, not by the existence of two fluids, but by the existence of a closed electric current in each individual molecule of a magnetic substance. $\mathrm{He}$ also suggested that since an electric current turns metals into magnets, the electric currents which flow round the earth from East to West may turn our globe, which is partly metallic, into a great magnet. If this be absolutely proved, the view of Gilbert will be substantiated.

I777-I85I. Oersted invented the PIEZOMETER for measuring the compressibility of liquids; discovered ELECTROMAGNETISM, one of the most promising principles in modern science (1820); showed the DISSIMILARITY OF MAGNETISM and electricity by experiments which distinctly demonstrated the action of the one fluid upon the other, for he found an electric current passing near a magnetic needle made the latter turn and lie across the path of the current. This discovery of the directive action that a fixed current exerts. at a distance-and which thus connected magnetism and electricity-became in the hands of Ampere as we have seen, and in the hands of Faraday as we shall see, the root of a new branch in physics.

I778-I850. Gay-Lussac invented a portable barometer, also an ALCOHOLOMETER, the CHRONOMETER, the ALKALIMETER ; made important discoveries in moisture, atmosphere, 
and magnetic force in high altitudes (the result of a BALLOON ASCENSION to the height of 7,016 metres); devised the method of determining the density of vapours; was one of the first to determine the COEFFICIENT OF THE EXPANSION OF GASES, finding it to be 0.00375 between $0^{\circ}$ and $100^{\circ} \mathrm{C}$. He enunciated the two laws: I. All gases have the same coefficient of expansion as air. II. This coefficient is the same. whatever be the pressure supported by the gas. Was as great a chemist as a physicist; proved that gases combine chemically in simple proportions by volume, and that the volume of the product always bears a simple relation to the volumes of the combining gases.

I78I-I868. Brewster made valuable observations on light; found the LAWS OF POLARISATION of light through reflection (see aiso Malus), and that OF DOUBLE REFRACTION, of biaxial crystals, of optical mineralogy, of double refraction by compression; invented the kaleidoscope-depending upon the property of inclined mirrors; he also, concurrently with Sir J. Herschel and Talbot, carried on a series of experiments on the colours produced by different burning lights. In time it was discovered that each substance gives a bright line in the spectrum of a colour particular to itself, so that a particular colour reveals the presence of a particular substance: a blue flame reveals selenium; intense yellow, sodium; violet, potassium; red, strontium - a fact upon which the value of spectrum analysis rests. It is to be remembered that colours depend upon the velocity of undulation, the direction of light-waves, and the difference of wave-lengths. Brewster invented the LENTICULAR SPECTROSCOPE; found the different proportions which the colours of the solar spectrum present according to the lines which produce them; counted 2,000 dark lines in the spectrum (Fraunhofer had found 600), but soon after him the existence of 3,000 dark lines was ascertained; improved the lighthouse system through DIOPTRIC APPARATUS.

I785-I838. Dulong, in collaboration with PETIT, analysed the LAWS OF COOLING, and showed "the velocity of cooling to increase as the difference of temperature between the surrounding medium and the cooling bodies is greater." He made numerous. 
investigations on elastic forces and elastic fluids; determined the heat disengaged during combustion by various substances after experiments corroborated by Favre and Silbermann.

I786-1853. Arago (D. François) showed, with Dulong, that Boyle's law is perfectly exact up to twenty-seven atmospheres; beyond that point of pressure the law suffers an alteration, as Regnault, and also Cailletet, showed. Arago invented, like Rumford, a PHOTOMETER for measuring the intensity of light and investigating its chemical action. $\mathrm{He}$ also made numerous observations on chronometers, on thunder, magnetism, electricity, and optical phenomena, and particularly on the action of polarised rays-an investigation which he carried on in collaboration with Fresnel and in harmony with Young. As an astronomer, his "MUltiple STARS" and "Astronomical and Geodesical Obserzations" proved valuable contributions. He measured the arc of the MERIDIAN OF SPAIN. His "Astronomie Populaire" (1834) and his Lectures on Astronomy are perhaps the most beautiful and clearest exposition of this science extant, the magnificent "Outlines of Astronomy" of Sir John Herschel notwithstanding.

1787-1826. Fraunhofer may be said to have laid the foundations of SOLAR PHYSICS and STELLAR CHEMISTRY; he was the first (I8I4), quite independently of Wollaston, to observe carefully, by means of a prism fixed to a telescope, the DARK LINES OF THE SOLAR SPECTRUM (600 of them). $\mathrm{He}$ pointed out their immense significance; mapped 576 LINES, classifying the chief ones (A to G) and showing their relative positions to be constant. He obtained the SPECTRA OF STARS, and pointed out the presence in them of dark lines wanting in our sun's spectrum, and the absence of dark lines present in the solar spectrum-inferring thereby a difference of constitution between the sun and the stars. Fraunhofer was therefore the first who studied the celestial bodies by means of spectral analysis. But the dark lines remained a puzzle to scientific men for forty-five years-until 1859. (Sce Bunsen and Kirchhoff.) Fraunhofer, and others after him, found that the spectrum is exhibited under three types: (I) continuous spectrum in which the colours of the prism are 
fully displayed, furnished by ignited solids and liquids; (2) band (or line) spectrum consisting of a number of bright lines, and produced by ignited gases or vapours; absorption (or dark line) spectrum produced by the sun and stars. Fraunhofer found an analytic formula as to the laws of light, and invented several physical instruments, improving lenses particularly. He found the haloes seen round the sun and moon to be the diffraction of light by small globules of fog in the atmosphere. But this admirable inquirer is especially to be remembered as the FOUNDER OF SOLAR PHYSICS.

I787-I854. Ohm found THE LAW which bears his name: "The intensity of an electric current is equal to the electromotive force divided by the resistance"; a law which enables us to arrange a battery so as to obtain the greatest effect in any given case. Another electric law was also discovered by another German physicist, POGGENDORFF (I796-I874): "The electromotive force between any two metals is equal to the sum of electromotive forces between all the intervening metals."

I788-I827. Fresnel modified Grimaldi's experiments on the interference of light-that is, the mutual action which two luminous rays exercise upon each other-and fully explained the fundamental PHENOMENON OF INTERFERENCE, viz., that the combined action of two pencils of red light forms a series of parallel bands alternately red and dark; if one ray is cut off, the dark bands disappear. Fresnel rendered this a decisive experiment (test experiment) of the truth of the UNDULATORY THEORY OF LIGHT. For if light, which travels in straight lines, were made of minute particles darting from the sun and shot forward like bullets, there could not be alternate dark bands, as the more particles there were, the more light there should be ; whereas, if light is produced by the vibrations of the luminiferous ether, as sound is produced by the vibrations of air, the dark lines are at once explained. For, the combination of two waves travelling the same distance at the same rate will produce a band of light; but two waves travelling unequally will destroy each other when combining, and thus cause a dark band. This remarkable fact, therefore, 
is explained in the most satisfactory manner by the wavetheory of light, and itself serves to demonstrate the wavetheory. From that moment then the undulatory doctrine was established, one of the finest demonstrations in the field of science. Fresnel and Young, who worked one part of the problem independently, at once accounted for a large number of optical phenomena. Fresnel showed those of polarisation are explicable by the wave-theory; further, by the mere manipulation of mathematical symbols, he was able by the light afforded by the same theory to foresee several complicated phenomena, and explain those of reflection and refraction. In these investigations he had a powerful collaborator in Arago, who is equally celebrated as a physicist and an astronomer, as we have just seen. Fresnel, besides this grand work, made powerful LENSES for LIGHTHOUSES; invented a RHOMB, which bears his name, for converting plane into circular polarised light; by the same instrument light can also be polarised elliptically.

I788-I878. Becquerel (Antoine César) made a thermoelectric battery, an apparatus which has caused rapid advances in heat; was one of the founders of ELECTROCHEMISTRY; made numerous and successful researches on thermo-electric phenomena; invented the electric PYROMETER; also an ELECTRIC THERMOMETER used to ascertain the temperature (I) of plants and animals; (2) of the earth at different depths; (3) of the air at different heights.

I79I-I867. Faraday, one of the most eminent men of science of our age, immensely contributed to the progress of electricity by his experimental researches; discovered the mutual ROTATION OF ELECTRIC WIRES AND MAGNETS-a conclusive proof of the connection between magnetic and electric currents; reversely to Ampère, he obtained ELECTRICITY WITH MAGNETS-a discovery soon to become practically useful in electric telegraphy; showed the action of magnets on light - a phenomenon of high importance. In connection with Coulomb's discovery (of attraction and repulsion), Faraday found (1845) that all solids and liquids are either attracted or repelled by a powerful electromagnet. Those which are attracted he called magnetic 
substances (or paramagnetic); those which are repelled, diamagnetic bodies. He determined the magnetism and DIAMAGNETISM of solids, liquids, and gases; and showed that all flames are repelled when placed between the two poles of the magnet. This discovery of diamagnetism was one of capital importance again - the key to many physical phenomena. Soon after Ampère had made electro-magnets by means of an electric current, and Faraday had PRODUCED ELECTRIC CURRENTS BY means of A MAGNET, the eminent German physicist SEEBECK (I822) discovered THERMoELECTRICITY, that is, the production of electricity by heata new branch of physics which has become very extensive through the investigations of Melloni, Sir William Thomson, Clerk Maxwell, and others. Seebeck's discovery, it has been suggested, would explain the electric currents flowing from East to West round our globe-the sun's heat, acting upon the earth's metals, inducing the terrestrial electric current; and this explanation would also account for the direction of the magnetic needle to the North, because magnetic currents flow across electric currents, and therefore from South to North in accordance with Oersted's experiment and Ampère's rule. Since then, and in connection with the subject, the periodical appearance of spots in the sun has been daily observed for thirty-four years by SCHWABE (from 1826 to 1859), and has been found to attain the maximum every eleven years. These spots are now believed to be great hollows caused by cyclones-possibly electric; but whatever their cause or nature, the SUN SPOTS would, according to eminent scientists-though their theory is strongly opposed by no less an electrician than Sir W. Thomson-exercise a powerful ACTION UPON THE TERRESTRIAL MAGNETISM, for they are believed to cause auroras in both hemispheres, and magnetic storms which will last for several days all over the earth. This at least seemed to be the case in September, 1859, for the first time, and early in the year 1892 for the last time. Thus the electric and magnetic influence of the sun, observed ever since Graham noticed the shifting of the needle in 1722, is a phenomenon of vast importance which would affect the whole earth with boundless energy. The point, 
however, is stoutly contested as we just hinted, and therefore by no means finally determined. Faraday made numerous observations in optics; invented several kinds of optical glasses; discovered the phenomena and the three LAWS OF ELECTROLYSIS- that is, the process of decomposition of substances into their elements by the voltaic battery, which Davy had found-_Electrolysis cannot take place unless the substance be a good conductor," being the most important of the three. He also showed that the current does not depend upon the effect that two metals may have upon each other, which was Volta's theory, but is produced by the chemical action taking place between the water and the zinc; and in order to show the strength of the decomposition taking place, and therefore ascertain the intensity of the current, he invented the VOLTAMETER. The knowledge of this phenomenon led him to demonstrate that the chemical change gives rise to electricity, just as electricity also produces chemical change-another transformation of force. Faraday also formulated the THEORY OF INDUCTION (influence)-the mode of action of electricity-on which a vast number of electrostatic phenomena closely depend, and chiefly the action of electrified bodies on bodies in their natural state. Of all electric phenomena the most important is induction, because it is "on account of induction that we can observe electricity at all; every manifestation-charge, discharge, attraction, repulsion-is preceded by and dependent upon induction. If an uncharged conductor be brought near to an electrified body, and thus placed under its influence, the uncharged body assumes an excited state, one side of it being electrified similarly, the other oppositely, to the charged body. The propagation of electric force across a non-conducting medium is called induction." Faraday, finally, determined the inductive power of various substances. Our limits do not allow us to dwell upon, or even allude to, the very numerous investigations carried on, and the invaluable services rendered to science by this great inquirer.

I79I-I 8 . Pouillet invented the PYRHELIOMETER to ascertain the amount of heat emitted by the sun-the heat would boil 700,000 millions of cubic miles of ice-cold water 
in one hour; the quantity of heat which the earth receives is only $\frac{138 \frac{1}{1000000}}{2}$ of the heat emitted by the sun-invented the electrical pyrometer to measure temperatures so high that the mercurial thermometer could not be used.

I798-I854. Melloni discovered numerous phenomena of RADIANT HEAT; showed radiant heat to have the same general properties as light-i.e., it may be reflected, refracted, polarised, and decomposed-determining at the same time the specific power of each substance for transmitting heat; in other words discovered the DIATHERMANCY (transmission of heat) through various media in various degrees. The term diathermancy bears the same relation to radiant heat that transparency does to light; and "in like manner the power of stopping radiant heat is called athermancy, which thus corresponds to opacity for light." Melloni invented the THERMO-ELECTRICAL MULTIPLIER-such a delicate instrument to measure heat, that the warmth of the hand is enough at a distance of a yard to deflect its needle.

I800-I877. Talbot was the first to propose the bright lines which appear in the spectra of artificial flames as a means of detecting substances too minute in quantity to be detected by any other process-a suggestion which he carried out in 1834, and which a few years later made the spectroscope the finest and surest of all instruments of analysis. After experiments from I 832 to I 840 he applied the discovery of Niepce (Daguerreotype) to paper, giving thereby the finishing stroke to PHOTOGRAPHY.

I80I-I8 . Jacobi (M. H.) discovered the art (called ELECTROMETALLURGY) of precipitating metals from their solutions by the slow action of a galvanic current (1840). This art is divided into Electrotyping, which is used in producing copies of coins, medals, seals, etc. ; and ELECTROPLATING-the art of covering base metals with a thin coating of silver or gold. Jacobi has therefore given birth to a vast and rich industry. He was also the first to propose and fix A UNIT OF ELECTRICAL RESISTANCE (i.e., a standard of comparison of resistances)-a determination of great scientific and practical importance. Finally, using Arago's electro-magnets (made by means of an ordinary electric machine instead of a 
battery), Jacobi, in 1830, established in Russia, between the Emperor's palace and his minister Klamachi's office, the EARLIEST ELECTRIC TELEGRAPH, but for a short distance only-a feat also ascribed to Baron Schiling, of Kanstadt, who seems to have tried to utilise Oersted's discovery. Gauss and Weber, in 1834, constructed a telegraph which communicated signals to the distance of one mile and a quarter. Steinheil made a similar attempt in 1837 . In I832, Jacobi constructed another line twenty-one miles long between the Winter Palace and the Summer Palace of Tsarskoie Selo, the wires running through glass tubes. All these, however, were abortive attempts for practical purposes; but the names of these precursors of Wheatstone should be nevertheless remembered and preserved from oblivion.

I802-1876. Wheatstone made a RINGING APPARATUS for electric telegraphy, the current of which was produced by a constant battery; then he devised RELAYS which ensured the transmission to any distance-an invention which made THE ELECTRIC TELEGRAPH practically WORKABLE at last, and made it one of the scientific marvels of our epoch (1837). Soon afterwards several kinds of telegraphs were invented: one by Steinheil in Germany, another by Morse in America; the latter being much used because the needle pricks holes in a paper strip, and the strips of paper with the messages they convey can be kept. The electrochemical telegraph, invented by Bain, prints the marks on chemical paper; the telegraphic writing machine, invented by Cowper (1879), actually reproduces the handwriting. Wheatstone, completing Steinheil's discovery, detected that the earth, besides being an excellent conductor, actually intensifies electric currents. He also invented the STEREOSCOPE, as well as a photometer; also the RHEOSTAT, by which the resistance of any given electrical circuit can be increased or decreased without opening the circuit; invented the balance or bridge which bears his name, to determine the electrical conductivity of bodies; measured the VELOCITY OF ELECTRICITY, and found it to be 288,000 miles per second, which is about I00,000 miles swifter than light. The speed through a conductor is slower; Maxwell's determination reducing it to 
I74,800 miles per second, slightly less than the velocity of light. Wheatstone also invented the polar clock, for ascertaining the hour by observing the amount of polarisation of the sky.

I804(?)- . Steinheil discovered THE EARTH to be a CONDUCTOR of electric currents-a discovery which saved a back-wire in electric telegraphy; constructed (1837) a telegraph (the current of which was produced by an electromagnetic machine) just after Wheatstone's telegraph had come out. Steinheil was the first to make a three-prism spectroscope. Fraunhofer had made his with one prism only; Bunsen and Kirchhoff, after Steinheil, used four, arranged at convenient angles between two telescopes-an arrangement which constitutes the spectroscope, although improved forms have come out since. We may conclude our notice of Steinheil by stating that he should be remembered as one of the great physicists of Germany, by the side of Jacobi, Bunsen, Kirchhoff, and Helmholtz.

I810-1878. Regnault found the method of estimating the density of gases; showed four methods of ascertaining their expansion-an investigation for which he will always be remembered; determined the COEFFICIENTS OF EXPANSION - another inquiry involving years of patient and skilful labour; devised a method, and made an apparatus for determining specific heat; found the specific heat of air to be 0.2377 ; found that air, nitrogen, hydrogen, carbonic acid deviate from Boyle's law, and become less and less compressible beyond a given pressure-a fact which Despretz, Dulong, Arago also noticed; so that the law is only approximately true, though true up to a certain pressure in all cases. Regnault also cevised a method of discovering the tension of aqueous vapour. He invented a BAROMETRIC MANOMETER for measuring pressures of less than one atmosphere, and invented also a hygrometer. As a chemist, he investigated the action of chlorine upon chlorhydric ether, and carried out countless successful experiments. In him the physicist and the chemist were blended in an equal degree.

$\mathrm{I} 8 \mathrm{II}-\mathrm{I} 8$. Bunsen, in collaboration with KIRCHHOFF, 
invented the four-prism SPECTROSCOPE, and both these physicists were among the first to use this instrument in CHEMICAL ANALYSIS. By means of it they discovered cæsium and rubidium (I860)-a decisive step. Before Bunsen's researches on the chemical action of light-in which branch Roscoe did also valuable work-there was no mode of measuring the ENERGY OF LIGHT. Bunsen invented a serviceable PHOTOMETER for measuring the different intensities of light; his work in photometry alone would ensure him a high place among physicists. He invented also an ice-calorimeter for determinations of heat in a small quantity of substance. This was improved upon by Favre and Silbermann, who invented another calorimeter which furnishes a very delicate means of ascertaining the caloric capacity of liquids, latent heats of evaporation, and the heat disengaged in chemical actions. Bunsen made COUNTLESS DISCOVERIES in the field of pure CHEMISTRY; but his name will always be remembered in association with Kirchhoff's in spectroscopy.

I8II-I8 . Grove (Sir William) showed the CORRELATION OF FORCES, one of the mighty laws of nature; and latterly showed the permanence of the LAW OF ANTAGONISM - being thereby the discoverer of two great generalisations. He also showed the production of heat by magnetism, the ELECTROCHEMICAL POLARITY OF GASES; and decomposed water by heat alone. He invented the electric battery which bears his name-one of the most powerful piles known; also invented the gas battery for the decomposition of some compounds such as water, iodide of potassium, etc.

I8I 8-I889. Joule discovered the law of heat evolved by voltaic electricity; made a THERMOPILE which would indicate a difference of heat of $0^{\circ} \mathrm{OOOI} 14$. But his chief work raised him to the first rank among men of science, for he disclosed and laid down one of the greatest laws of nature, viz., the DYNAMICAL THEORY OF HEAT. The views of Locke, Rumford, Davy, and even Carnot, as regards the production of heat by motion, had no great influence on the progress of scientific investigation. But in 1842 , the French physicist 
SÉGUIN and the German physicist MAYER found a method by which "the mechanical equivalent of heat," as Mayer called it, could be calculated. Joule, independently of them, commenced about the same time a series of experiments on the relation between heat and work, upon which several other physicists, among them Sir W. Thomson, Helmholtz, Regnault, were soon likewise engaged. Joule, after intense labour extending over a period of six years (1843-9), was able to determine the TRANSFORMATION OF HEAT INTO MECHANICAL ENERGY, or of mechanical energy into heat, in a definite numerical ratio-the mean number adopted for the mechanical equivalent of one thermal unit being I, 390 footpounds (on the Centigrade scale). The law of the relation of heat to mechanical energy stands thus: "Heat and mechanical energy are mutually convertible; and heat requires for its production, and produces by its disappearance, mechanical energy in the ratio of $\mathrm{I}, 390$ foot-pounds for every thermal unit"; that is, the quantity of heat by which a pound of water is raised through one degree Centigrade is generated by the expenditure of the same amount of work as would be required to raise I, 392 pounds through one foot, or one pound through I, 392 feet, and this is expressed by saying that the mechanical equivalent of the thermal unit is I, 392 foot-pounds. But Joule's work was a demonstration which had to be supplemented. He had shown that mechanical energy or work can be converted into heat; it was required also to demonstrate that heat can be converted into work. Carnot had already done so by formulating the principle of the reversibility of energy; but the real significance of this principle was proved by HIRN by a long series of experiments, the result of which established the fact that heat can be converted into work in exactly the same equivalent proportion as that determined by Joule, viz., that one degree Centigrade (of heat) would raise one pound to I,392 feet, or I,392 pounds one foot. Great, however, as was Joule's mathematical work so far, he carried it further still by following up its logical, natural, and philosophic al consequence and formulating its corollary-that THE TOTAL AMOUNT OF ENERGY (or power of doing work) possessed by a bo dy ever remains the same; that is, REMAINS UNALTERED whatever 
transformation it may undergo. This energy exists either as: potential (or stored up) energy, which is hidden and invisible, but present nevertheless; or it exists as visible energy, when it is performing work. It may change from one form into another, but its total amount cannot alter ; and this, whether mechanical energy is changed into electrical energy, work into heat, heat into work, and so forth. This is the LAW OF Conservation of ENERGy, which Joule propounded and which makes his name doubly famous. The law is thus stated: "The total amount of energy in the universe is the same at all times." By this great law Joule confirmed the earlier doctrines of Leibnitz. He did more, for this law is a corroboration of Laplace and Lagrange's conclusions as. regards the stability of forces as exhibited in the invariability of great axes of orbits, and in Laplace's Nebular theory. Lastly, in its philosophical bearing, Joule's law substantiates in the widest manner possible the paramount doctrine of science-the permanency of the government of the universe by unchangeable laws. It should be borne in mind that to this result of Joule's, Sir William Thomson, Balfour Stewart, Clerk Maxwell, and others contributed largely. But it was. Joule who demonstrated the law, one of the greatest generalisations, if not the greatest, established since Newton. It should also be stated that Thermodynamics, the subject of Joule's earlier determination, have been developed since by Rankine, Clausius, and the universal genius, Sir William Thomson, who has probably exceeded all his rivals by the vastness and value of the work he has done.

I8I8-93. Tyndall investigated numerous sound phenomena by a series of beautiful experiments, and notably by means of his CHEMICAL HARMONICON-an apparatus by which the air in an open tube may be made to give sounds by the introduction of a luminous jet of hydrogen or gas, a phenomenon known under the name of singing flames. 'The note depends on the size of the flame and the length of the tube. The apparatus was probably suggested by the SYREN of Cagniard Latour, which is used to measure the number of vibrations of a body in a given time: "with the same velocity the Syren gives 
the same sound in air as in water; the same is the case with all gases; any given sound depends on the number of vibrations, and not on the nature of the sounding body." The syren is so delicate that it has been found by its means that the wings of a gnat flap 15,000 times in a second. By combining the effects of the syren with those of the chemical harmonicon, Tyndall has detected very curious phenomena, such as that in which the pulsations of the flame are the optical expressions of the "beats"-i.e., the alternate strengthening and weakening of two sounds acting on each other. Tyndall made researches into the action of SOLAR and of ELECTRIC LIGHT on attenuated vapours, and found that under such conditions they are decomposed-a discovery which put a powerful agent of chemical decomposition into the hands of chemists, and led the discoverer to important conclusions regarding the origin of the blue colour of the sky and the polarisation of daylight, these two phenomena being at length accounted for. He also found the absorptive power of several vapours, and discovered the class of phenomena called by him DYNAMIC RADIATION AND ABSORPTION. Tyndall, with Faraday, discovered the magnetism of gases, and showed that very few substances, if any, are devoid of magnetism. He made decisive researches upon the polar character of the diamagnetic force. Being familiar with every branch of physics, Tyndall has assisted science by numerous investigations, but he is one of the chief instructors of our age in sound, heat, light, and electricity. His works, "Heat as a Mode of Motion," and "On Light," are universally known.

I819-I868. Foucault applied electric light; proved the velocity of LIGHT by striking experiments; determined it in a vacuum, in air, in water. By means of a rotating mirror, which Wheatstone adopted in measuring the velocity of electricity, he found light to travel at the rate of 185,157 MILES PER SECOND. He and Fizeau discovered the velocity of light through water to be slower by one-fourth than through air-an additional proof of the wave-theory of light. He also demonstrated by means of the PENDULUM the gradual 
MOTION OF THE EARTH; invented the GYROSCOPE for detecting the astronomical situation without looking at the heavens.

b. I819. Fizeau (1849) also measured directly the velocity of light by a system comprising a toothed-wheel, a mirror, tubes, and lenses, and found as a result I90,000 MILES PER SECOND-a result which practically is the same as that obtained by Roemer and Bessel. The latter gives 192,000 miles, by dividing the mean distance of the sun, assumed to be $95,274,000$ miles, by 8 minutes I 3 seconds 3-the time taken by a luminous ray to reach the earth.* The last result found (Cornu's) gives I86,660 miles. Roemer calculated the time taken by a ray of light to reach us from the sun to be 8 minutes 16 or 18 seconds, which exceeds the average now accepted by from 3 to 5 seconds. Be that as it may, the velocity of light has become the foot-rule, so to speak, for the measurement of the distances which separate us from the fixed stars whose parallax has been approximately ascertained. The nearest star, $a$ Centauri, is at least 400,000 . times our distance from the sun, its light taking $3 \frac{1}{4}$ years to reach us $-a$ fact which gives us a notion of the incommensurable infinity of space. A beam takes $9 \frac{1}{4}$ years to reach us from 6r Cygni, I2 years from a Lyræ. The light of some stars takes 100 years, I,000 years, 2,000 years to reach us, so that when we see them, we see them not as they are now, but as they were $100,1,000,2,000$ years ago (as they were when the light-ray left them). Likewise, an inhabitant of a star thus remote would see the earth, granting that he could perceive such a speck, not as it is now, but as it was 2,000 years ago; that is, he might at this moment see Julius Cæsar landing in Great Britain.

I820-I8 . Becquerel (Alex. Edward) discovered oxyGEN to be A MAGNETIC BODY, and to be to other gases what iron is to other metals; found chlorine of silver capable of receiving and preserving coloured impressions from light; invented the PHOSPHOROSCOPE.

I82I-94. Helmholtz invented the OPHTHALMOSCOPE for viewing the interior of the eye; analysed sound by

* Sound would take fourteen years. 
means of the resonance-globe (improved by König's apparatus), DECOMPOSING SOUND into its constituents, which he verified by performing the reverse operation, reproducing a given sound by combining the individual sounds of which his resonators had shown that it was composed. By his analytical and synthetical investigations into musical and other sounds of the most varied kinds, he fully succeeded in explaining the different qualities of these sounds, and showed they are due to the various intensities of the harmonics which accompany the primary tones of those sounds; so that he determined, so to speak, their sound-colour. It is difficult to conceive an analysis more exhaustive. (See his "Popular Scientific Lectures," Longmans, I873.) The inner membrane of the ear cochlea is lined (as Corti has shown) with about 3,000 minute fibres, all connected with the acoustic nerve; each of these is tuned for a particular note as if it were a delicate resonator, and only vibrates in unison with this note, being deaf for all others-hence, however complex external sounds may be, these microscopic fibres can analyse and reveal the constituents of which the sounds are formed. Helmholtz has also determined, after numerous experiments on light, the power and limits of microscopic vision, which is not less than one 80,000 th part of an inch in red light. Likewise, various other branches of physics are indebted to him; his investigations regarding heat, gravity, solar energy gave results similar to those obtained by Sir William Thomson. According to these two great physicists, SOLAR ENERGY* is due to the shrinkage by gravity of the mass of matter constituting the sun, and the supply of heat by the sun at the present rate would not probably obtain for more than twenty millions of years from beginning to end. This computation falls far short of that arrived at by geologists and evolutionists, for the evidence upon which they base their calculations, such as denudation, formation of new strata, subsidence and uprising of continents, growth of coal-

* The intrinsic lustre of the sun is nearly four times as great as that of electric light, and 5,000 times that of molten metal in a Bessemer's converter. 
fields superposed one over another, or again the development of the organic world from protoplasm to man, reveals a past so remote, and during which too our present laws were at work, that twenty millions of years is a mere fraction of the time required to give the earth its present form and life. Some would speak of no less than 680 millions of years for the accomplishment of that work. Hence the problem remains unsolved, but the divergence between the two sets of philosophers robs neither of our admiration, for the mathematical results of each, considering the premises, stand among the highest achievements of modern science; the discrepancy existing between the results of geologists and physicists will certainly be bridged one day, and the different conclusions merged into one truth. Helmholtz, like Sir W. Thomson, also directed his attention to molecular physics, and their role in the general economy of the universe, and both physicists pretty closely agree in the propounding of a new hypothesis, viz., the Vortex Theory, which would remove the barriers between the various branches of physics. We owe also to Helmholtz a series of demonstrations tending to prove, and proving, that HEAT IS A MODE OF MOTION. His essay on the conservation of energy is the finest composed on the subject. He traces up all the transformations of energy, as presented by heat, for instance, in wind, plants, animals, coals; in sky, air, and earth; and shows its reappearance in ways as numerous and unlike as it is possible to conceive. It is stored in coal in its smallest compass: I lb. being capable of lifting $100 \mathrm{lbs}$. to a height of 20 miles-the sun, we need scarcely add, being to us on earth the one great fount from which all energy is derived. Well may we admire Helmholtz, one of the most brilliant and solid geniuses of our time.

I824-87. Kirchhoff, in collaboration WITH BUNSEN, invented the four-prism SPECTROSCOPE (1859), and by its means opened a new mode of CHEMICAL ANALYSIS, at once rapid and unerring-the presence of a I80-millionth part of a grain of sodium, for instance, being detected with absolute certainty. The spectroscope is an instrument for separating luminous vibrations of different wave-lengths, 
composed of either two or three telescopes mounted on one foot, and whose axes converge towards a prism or a series of prisms, each of which more and more spreads the light coming through one of the telescopes, and causes its spectrum to fall in a high degree of purity on an object glass. Saving a very considerable amount of labour and time, it immensely facilitates chemical manipulation; for investigations which would demand the repetition of the same experiment perhaps twenty times so as to give an average result, and employ as many days, can be carried out within a few hours' time. Not the least precious value of the instrument lies in its excellence as a means of verification of much laboratory work. We may here point out that, so far, we are in possession of five processes of chemical analysis* or manipulation; each, except the last, divided into sections according as you want only to discover what the constituents of a compound substance are, in which case the analysis is called qualitative, or to determine also in what proportion the constituents are exhibited, in which case it is called quantitative analysis. The five methods are: I, the process of Geber (800)-distillation, supplemented by the analysis of the products; 2 , the testing process-precipitation, due to elective affinity-Bergmann's system (I76I) ; 3, Electrolysis-decomposition by electricity -Davy's process (I806); 4, the blowpipe process-fusion, by means of a fierce flame-the development of which is due mainly to Berzelius (I8I8); 5, lastly, spectral analysis -by means of the spectroscope-due to Fraunhofer (1814), and to Bunsen and Kirchhoff (1860). By these various methods have the SEVENTY-TWO SIMPLE ELEMENTS known been discovered-the seventy-two elements, that is, which constitute the material universe, so far as we have ascertained at present. Qualitative analysis is carried on principally by flame tests and liquid tests, of which there are numberless varieties, and also by the use of the spectroscope, par-

* It should be remembered that, strictly speaking, analysis is the name given to the decomposition of a compound into its elementary parts, just as the name synthesis is given to the process of forming a compound out of two or more elements. 
ticularly in difficult cases. Quantitative analysis, on the other hand, is carried out by two methods, respectively called analysis by weight and volumetric analysis. The spectroscope, then, as we see, is not a physicist's instrument only, it is one which is just as precious to the astronomer as to the chemist. By means of this unique instrument Kirchhoff and Bunsen solved the PROBLEM OF THE DARK LINES OF THE SOLAR SPECTRUM $*$ which Wollaston and Fraunhofer had detected, and this solution enabled Kirchhoff to discover the elements constituting heavenly bodies. Kirchhoff found that the black lines are caused by the passage of light through the vapours of bodies which by themselves would give bright lines in the same position in the spectrum when incandescent, and this theory goes far to explain the constitution of meteorites, comets, nebulæ and stars, as well as the sun. $\dagger$ Some explanation will not be inappropriate here. The illuminating power of the solar spectrum attains its maximum in the yellow, and decreases on each side of it, and intense yellow, produced by incandescent sodium, occupies a certain fixed place in the spectrum of bright lines (as distinguished from the continuous spectrum, and from the absorption or dark line spectrum). Kirchhoff showed in the laboratory that when the vapour of a substance intervenes between the observer and the coloured flame produced by the same kind of substance, the colour is extinguished because it is absorbed by the intervening vapour, and instead of a bright line at its fixed place, a dark line appears. In other words, the intervening vapour has screened (because it has absorbed) the colour of the flame beyond, and therefore there is no light, but darkness, at that point of the spectrum-that is, a black line. Now this holds good for every substance. This is the key of the problem, and the explanation of the dark lines in the solar spectrum. A dark line is due, then, to

* Prof. Stokes intimated their significance as early as 1851 , and so did Prof. Balfour Stewart, a few years later, in 1858 ; but both failed to demonstrate it fully - this was Kirchhoff's great work.

+ Kirchhoff read the paper about this immortal discovery on the 27 th of October, 1859. 
the absorption of the bright ray (shot from the photosphere) in its passage through the solar atmosphere, by the same kind of substance as that which caused it. If we suppose sodium to exist in the sun, a supposition warranted by the yellow colour found in the continuous and bright line spectra, and look for its intense yellow double line through the spectroscope, we see a dark line at the place it should occupy - at the letter D of Fraunhofer's map of dark lines. And knowing that the dark line $\mathrm{D}$ can be produced only by the absorption of the sodium ray by the sodium vapour, it is inferred that the sodium light is shot from a centre - the photosphere - and is arrested or absorbed in its course by an atmosphere of incandescent metallic vapours in which sodium gas is also present. Hence two facts are ascertained, viz., that the sun itself is a luminous body made up of certain substances, and that it is surrounded by an atmosphere composed of (cooler) gases mostly of the same substances, for what is true of sodium is true of other elements. Aluminium, barium, cadmium, calcium, carbon, cerium, chromium, cobalt, copper, hydrogen, iron, lead, magnesium, nickel, potassium, rubidium, strontium, uranium, zinc, etc., are known to be present in the sun, because their lines are suppressed by the solar atmosphere. So far as we know, thirty-six of our terrestrial elements exist in the sun, eight are doubtful, fifteen have not been found yet in the solar spectrum. Likewise, stars seem to be constituted like our sun, and to consist of a nucleus and an atmosphere composed of some of the elements existing in our globe. Meteorites are also composed of some of our elements, iron particularly. Comets differ little from meteorites, if at all. Nebulæ exhibiting no dark lines can be gaseous bodies only, so far as we are aware at present. All these facts have become known to us by the use of the spectroscope, one of our most admirable agents. The services this instrument has rendered science by far surpass in number and importance those done by any other, the telescope and microscope not excepted. It led at once Bunsen and Kirchhoff to the discovery of two new metals, CASIUM and RUBIDIUM. It has enabled astronomers to 
ascertain that the sun's spots are immense hollows or depressions - a fact which would tend to corroborate the cyclone theory. It has made solar and stellar physics a possibility and a reality. Not simply has it revealed, as we just saw, the chemical components and some of the physical arrangements of celestial bodies; but it has also revealed the existence of solar systems unsuspected hitherto-such as binary systems, one body of which is a dark star-the existence of dark suns, already suspected, being thereby demonstrated; and with their existence, the cause of the increase and decrease of light in some of the variable stars was explained, the decrease of light being due to the eclipse of the luminous by the dark star. It has further revealed the rate of velocity of motion of stars and nebulæ, and particularly that of double stars (within less than half a mile per second of time), * together with the distance from each other of such stars, the magnitude of their bodies, the magnitude and the ellipticity of their orbits, hence the time of their revolution. The spectroscope has even revealed the approximate temperature and almost the evolutionary stage of many celestial bodies. THREE THINGS this truly marvellous instrument seems to have MADE PLAIN: (I.) the common or identical nature of the substances composing the cosmos; (II.) the variety of its plan and construction; (III.) the identity of the forces and principles governing it. Many of the facts brought to our knowledge by the spectroscope seemed, only thirty years ago, for ever to lie beyond the scope of human achievement and even beyond the conception of human intellect. To the genius of Kirchhoff mainly we are indebted for these scientific wonders.

I824-I8 . Huggins (Dr.) has advanced celestial physics by his fine SPECTROSCOPIC STUDY of the HEAVENLY BODIES - many of the results described in our notice of Kirchhoff being due to him. He found the spectra of numerous irresolvable nebulæ to consist of three or four bright lines

* Some proceed at the rate of $23,25,26$ miles per second; one 67 miles; our own solar system travels through space at the rate of 18 miles per second, besides the motion particular to each body separately. 
indicating the presence of hydrogen and nitrogen among them - a character showing these nebulæ to be gaseous bodies in an evolutionary stage towards the constitution of suns, thereby strengthening the nebular hypothesis of Laplace. $\mathrm{He}$ also discovered that comets yield a spectrum consisting of a few (three or four) luminous bands much wider apart than those in the nebulæ: they too exhibit the character of gaseous bodies. He discovered in the light of Jupiter, Saturn, and Mars, several lines like those exhibited by our own atmosphere, thus proving that these planets are surrounded by an atmosphere like the earth, though certainly of a different degree of density. Some stars which he studied he found to be wrapped by a metallic atmosphere like our sun: Aldebaran contains antimony, bismuth, mercury, and tellurium, which are not found in the sun, and hydrogen, iron, calcium, magnesium, and sodium which are present in the sun. In $\beta$ Pegasi and Batelgeux ( $a$ Orionis), he found no hydrogen, although he found that gas in all the other stars which he has studied by the side of many other substances, some of which have not yet been found upon the earth. Dr. Huggins, among other phenomena as regards the motion of stars, found that SIRIUS was moving away from us at the rate of 25 miles per second. That in our ignorance of the actual distance from us of Sirius and of a multitude of very remote stars, for we indeed know the distance of very few-the nearest - yet we should be able to determine the velocity of their motions is another wonder due to the magical spectroscope, for the instrument reveals the motion of distant bodies, "by the alteration which it causes in the apparent rapidity of vibration, and consequently in the refrangibility of rays of light of definite colour." For it must be remembered that (I) the undulations of the luminiferous ether cause the points of the retina to vibrate and produce the sensation of light; (2) that any given colour depends upon the rapidity of light waves impinging upon the eye; (3) that the eye will receive in a second less undulations from a body receding from it, and more undulations from a body moving towards it, just as an anchored boat will be struck 
by less waves than if it were moving towards them. By this principle, which Doppler (1803-53) discovered in reference to sound (I84I), but which holds good for light, it is clear that if a celestial body moves towards us, the succession of light waves upon the eye will be more rapid than if it recedes from us; and therefore the spectral colour will shift towards the red end of the spectrum if the body be approaching us, and towards violet if the body be receding. Now this shift of the spectral lines from their normal position in the spectrum is detected with absolute certainty by the spectroscope, and by that means we are able to tell not only that a star moves, but also in what direction it does move, and the rate at which it moves. Thus THE SPECTROSCOPE which can reveal to us what bodies are made of, whether these bodies be air, straw, paper, wood, lava, stone, or heavenly bodies; whether heavenly bodies are gaseous, liquid, solid; whether they shine by intrinsic or reflected light, can also reveal NEW WORLDS, together with the DIRECTION AND RATE of their MOTION. In these researches Dr. Huggins, Dr. Miller, and Mr. Alexander HERSCHEL contributed their share - the last mentioned finding different kinds of spectra among meteorites-Norman Lockyer meanwhile working in the same direction, and gathering data upon which to build his meteoritic hypothesis as we have seen.

b. I 824. Thomson (Sir William), now Lord Kelvin, invented the MARINE GALVANOMETER, which made MARINE CABLE telegraphy a complete success; invented the electrometer for measuring the amount of electrical charge; also an apparatus for investigating atmospheric electricity; in collaboration with Prof. Haughton, determined the numerous varieties of ocean tides (lunar diurnal, solar diurnal, lunar fortnightly, monthly, yearly; solar semi-annual and annual, etc.); applied, with John Hopkinson, to lighthouses a SYSTEM of SIGNALS, suggested by Babbage, by which each lighthouse perpetually spells its own number or name "by flashes or obscurations of various duration and succession." Concurrently or conjointly with other physicists, and amongst others, Clausius, Clerk Maxweli, and Helmholtz, Sir William Thomson 
has ascertained that a MOLECULE of hydrogen MOVES to and fro about 6,200 feet per second, but in such a limited space that it rebounds from other molecules in a second of time 17,000 million times. Further, pursuing the investigations of Loschmidt and Stoney, Clausius and Clerk Maxwell, Thomson was able to determine the size of a molecule: two millions of them in a row would measure one millimetre in length-which makes fifty millions in one halfinch-the concussions causing waves of coloured light just as a ringing bell causes vibrations and waves of sound. Again, among the problems he has investigated and solved by mathematical or experimental demonstration, Sir W. Thomson may be said to have successfully expounded (I852) the LAW OF Dissipation OF ENERGY, which has exercised the ingenuity of several other physicists. According to Sir W. Thomson, "there exists a predominating tendency to the conversion of all other forms of physical energy into heat, and to the uniform diffusion by conduction and radiation of all heat throughout all matter"-a fact which would conduce to the uniform cooling, hence extinction of life, of the universe, but which would be counteracted by the general law of conservation of energy determined by Joule, and further, probably, by the Reconcentration of Energy (of Rankine), if the latter be not a mere speculation, for otherwise there would be an end to all physical phenomena. In close connection with this problem Sir W. Thomson has assisted science by removing some of the barriers between its different branches, for "our views of the phenomena of light and heat, of electricity and magnetism, and even of matter and motion, are rapidly merging into a general theory of molecular physics, which is perhaps best expressed by his 'VORTEX RING THEORY,' which was expounded in 1868." According to this theory, "the whole of space is filled up with a fluid-ether"-as we have already seen in previous notices. Huygens, Encke, Young, Huggins, and others who helped to establish this hypothesis, may be considered as the founders of the present school of Plenum -so-called because it holds the doctrine of the existence of one universal and omnipresent ether for (the transmission 
of) light, heat, electricity, and magnetism. This fluid is "almost infinitely thin and elastic." Now, then, Thomson holds that all that which we know as matter consists of vortices or whirlpools of this ether, which, from their rapid rotating motion, "resist displacement, and therefore show the common properties of hardness and strength in the same way as a spinning-top or gyroscope tends to keep its axis in a fixed position." But whether the molecules or particles of what we know as matter are independent matter, or whether they are ether whirlpools, we know that they keep up an incessant hammering one on another, and thus on everything in space. This atomic bombardment was in the first instance one of Daniel Bernouilli's theories, but in a restricted sense only, for to his mind "the pressure exerted by a gas on the walls of the vessels enclosing it was due to the constant hammering of the walls by the atoms of which the gas consisted." Sir W. Thomson, Helmholtz, and Crookes see in this fact a law which applies universally to all matter throughout space. The future will disclose whether the "vortex theory" is a mere hypothesis or an absolute law.

I 8 . Cailletet and Pictet LIQUEFIED and solidified GASES hitherto held to be permanent. Faraday was the first physicist who liquefied gases, and soon after him all of them, with the exception of oxygen, hydrogen, nitrogen, carbonic oxide, nitric oxide, and marsh gas, have been liquefied. Cailletet and Pictet succeeded at last (I877-8) in liquefying and even solidifying oxygen, nitrogen, and hydrogen, mainly by intensity of cold. The belief in "permanent gases" was destroyed by these fine results : all substances, according to conditions, were proved capable of assuming the solid, liquid, and gaseous forms-a fact which points to the unity of matter. In the course of I892, Pictet showed that substances subjected to extreme cold "lose the power of chemical combustion, and under this process can be produced in a state of purity hitherto unattainable." In experiments on the compressibility of gases, Cailletet carried the pressure as high as 600, and Petit 650, atmospheres. The decisive experiments proving the liquefaction 
of gases have (in January, 1893) been supplemented by the beautiful discovery of Prof. Dewar, who succeeded in LIQUEFYING AIR ITSELF, as distinguished from its constituents. This result was obtained by getting a vacuum approaching a point vastly nearer the ideal vacuum than had ever been obtained before, since exhausted vessels contain less than the 900,000th of the air which the best airpumps of thirty years ago left in them. This almost perfect vacuum is, he found, an absolute barrier to the passage of heat rays, and allows the liquid air to remain permanently in its vacuum envelope. Should verification permit the formulation of a new law, this law, it is surmised, would lead to a revision of some of our astronomical conclusions. These discoveries, it is almost needless to add, imply the highest skill in investigation, not to speak of an adequate command of means.

b. I8 . Faure invented the ELECTRIC ACCUMUlatora new and fruitful apparatus for storing power, which makes the electric train or car an inexpensive possibility.

1832-18. Kirk invented an ICE MACHINE depending upon the cold produced by the expansion (or rarefaction) of air-gas compression causing a rise, and expansion a decrease, of temperature (because a quantity of sensible heat disappears when a gas increases in volume). This law explains the cold produced by nocturnal radiation. In Bengal the nocturnal cooling is used in manufacturing ice. "Large flat vessels containing water are placed on nonconducting substances such as straw or dry leaves." In consequence of the radiation the water freezes, even when the temperature of the air is ten degrees Centigrade.

b. I832. Crookes invented a SPECTRUM MICROSCOPE which overcomes some of the difficulties due to slightness of light dispersion; discovered (I86I) Thallium with the spectroscope-the third metal found by that means; invented the RADIOMETER (April, I875), by means of which he claimed to have discovered and proved light to be a motive power-a conclusion which, however, has not found general acceptance, for it is suggested that the mechanical action seen in the instrument is probably due to the more 
rapid and powerful motion of the molecules which still remain in the vacuum glass bulb-the increased velocity of their motion being caused by the undulatory progress of light. $\mathrm{Be}$ this as it may, the radiometer is capable of giving much useful assistance to the photographer for regulating the light (I) in the operating room, so as to obtain negatives of the same quality; (2) in the dark room, so as to prevent all injury to the sensitive surfaces there exposed. "The instrument is also capable of giving much information in climatology, since the amount of light received at any given place has its effect upon life and health, vegetable, animal, and human, and its relative amount at any given place is hence a point of no small physiological moment. For we can now ascertain and distinguish how much of the annual temperature of a place is due to the direct influence of the sun alone, and how much to the other factors, such as geological influence. altitude, atmospheric and oceanic currents, warm or cold, which sweep over or near it." In connection with the radiometer Crookes made wonderful experiments ON ATOMS AND MOLECULES BY THE APPLICATION OF ELECTRICITY, which demonstrated the bombardment of particles on one another - so that Crookes at one stroke seems to have disclosed and substantiated the soundness of numerous theories which hitherto were held as mere speculations. It should be stated that in I87I, Varley, unknown to Crookes, had made an almost similar discovery, by controlling a molecular current by a magnet. Concurrently also, although not directly connected with Crookes's experiments, the famous physicist Hertz-well known for his discovery of a finite velocity of propagation of electro-magnetic action, and his demonstration of electro-magnetic waves in air, and their reflection - worked in the same direction as Varley and Crookes. The one result which surpasses all others in importance, and adds immensely to our knowledge of the elementary forces which govern the universe, is the ascertaining that atomic energy as shown by Crookes, Thomson, and Tesla is millions of times greater and more powerful than any with which we were acquainted; for if a stream 
of molecules, reduced to a minimum in a glass bulb by the air-pump, is focussed by means of electricity on any point, and a piece of platinum is placed at that point, its hammering is so mighty that the platinum becomes white-hot in a few moments. Mr. Crookes believes that he is on the track of a fourth condition of matter, as distinct from the gaseous as the gaseous is from the liquid condition, and the liquid from the solid; and the assumption does not seem unfounded. The certainty of the existence of this tremendous force opens a field to human possibilities the extent of which it is impossible to exaggerate, as the following paragraph will show. Crookes has already described, with that fertility of imagination which distinguishes him, some of the multifarious and beneficent applications which science may devise from the knowledge he has imparted to us. Crookes, as we have seen in our Chemical section, has carried on researches of the very highest import in Chemistry.

b. 1863 (?). Tesla (Nikola) constructed a dynamo which gives 20,000 ALTERNATIONS per second instead of I00; and by means of condensers he multiplied the alternations until they exceeded I,500,000 PER SECOND-obtaining thereby a current 15,000 times more powerful than hitherto.* Once in possession of this undreamt-of engine, he launched into a series of experiments the phenomena of which open a new and mysterious region: (I.) Whereas a current of less than 2,000 volts kills a man, a current of 50,000 as obtained by Tesla gives no shock-it cannot even be felt-so that the experimenter is able to play with flashes of lightning; (II.) whereas our insulators effectually stop an ordinary current, the Tesla current will shoot a stream of sparks between two poles through such a safe insulator as vulcanite just as it would through air; (III.) whereas in Crookes' radiant matter experiments the aid of 'wires is necessary, the Tesla forces take effect at a considerable distance through space, and "if metal plates are fixed on the roof and walls of a room, and connected with the terminals,

* Nineteenth Century Review. March, 1892, Number. J. E. H. Gordon. 
such a violent electro-atmospheric storm will ensue, that globes from which air has been partially pumped out will glow and throb as if powerful electric currents were directed upon them." These and other unsuspected phenomena were disclosed by Tesla (as recently as February, 1892) which will probably be the starting-point of a new series of discoveries of natural laws and applications, as already hinted in the preceding notice, that will effect changes in humanity even "more general and more wonderful than those brought about by steam and electricity." For, if we once are able to make direct use, as we do in the case of electricity, of the molecular ocean which surrounds us and which "we have let slip through our fingers since the beginning of time," we shall then, as M. Tesla put it, "hook our machinery on to the machinery of nature, or harness natural forces to our machinery, and obtain unlimited power, so that manual labour would become unnecessary."

\section{Group VII. INVENTORS.}

To those great men of science we should add a few of the practical men who made important applications of scientific laws, mentioning only those whose inventions have proved to be powerful springs of progress.

I647-I7I4. Papin applied to his steam-pump his invention of. the PISTON, the CYLINDER, and the SAFETY VALVE (I690).

I736-I8I9. Watt invented the SEPARATE CONDENSER and the DOUBLE-ACTION STEAM-ENGINE-the essentials of all steam machinery - and made the law of elasticity of gases (explained to him by Black) a new power.

I765-I8I5. Fulton, after the STEAMBOATS of Jouffroy D'AlBANS (I783)* and of W. SyMington (1789), arrived at the practical application of STEAM TO NAVIGATION, and

* Jouffroy d'Albans (1751-1832), whose original drawings can be seen in the South Kensington Museum, built a paddle-steamer which was launched on the 15 th of July, 1783 , and plied for traffic on the Saône and Rhone for more than a year. Fulton is said to have been a pupil of his, but this is doubtful. 
I78I-I848. Stephenson (G.), after SÉGuIN's invention of the TUBULAR BOILER, invented the LOCOMOTIVE, the culminating triumph of a series of wonders which transformed the world.

The filiation of the foregoing is, be it observed, absolutely unbroken.

In connection with this rapid progress of steam application, we should remember, as a real benefactor of humanity,

1728-1809. Boulton, who, by the encouragement, workshops, capital which he magnanimously gave James Watt (I769), rapidly enabled the latter to propagate the use of steam machinery all over the world. Boulton was therefore one of the powerful PROMOTERS OF MODERN INDUSTRY, to whom the English capitalist and the English artisan should be equally grateful. $\mathrm{He}$ is said to have introduced gas-lighting at Birmingham as early as 1798 .

I759(?)- . Murdoch, of Redruth (Cornwall), discovered COAL GAS, and applied it to lighting purposes (1792); but London enjoyed the new lighting system only in 1817 , after Birmingham, where Boulton introduced it in I798, and even after Paris, where Winsor had successfully lighted the Passage des Panoramas.

1765-1833. Niepce (Nicéphore), by succeeding in fixing images produced by the camera obscura-a thing attempted by Davy in I802-invented PHOTOGRAPHY (I 824); but it was his partner Daguerre who, after Niepce's death, propagated the new art-hence the name of Daguerreotype. DAGUERRE (1787-185I) invented the DIORAMA. The photographic apparatus is one of the most serviceable in our possession. The assistance it gives to sundry branches of knowledge (light, physiology, anthropology, zoology, geography, history) is unrivalled. In art it has become of immense value. It is to astronomy, however, that it renders the most valuable services; for it not only maps the heavens with absolute precision, records the phenomena of momentary eclipses, reveals events of cosmical history, such as the evolutional stage and form of nebulæ (the nebulæ in Andromeda, Orion, Ursa Major, Canes Venatici), but it also records with complete accuracy the small shift of the celestial (spectrum) 
lines from their true spectroscopic position, and thereby corroborates the beautiful exactness of the spectroscopic revelations (due to the working of Doppler's principle) as regards the speed and direction of stars' motions. But more wonderful than all this, it detects and shows us stellar and nebular systems existing far beyond the reach of telescopic and spectroscopic power, thereby opening new regions of astronomical knowledge in a way wholly undreamtof by Newton or Laplace.

I77I-I834. Senefelder invented LITHOGRAPHY, which has proved so useful to industry and the propagation of artistic works.

I79I-I872. Morse invented the TELEGRAPHIC APPARATUS which bears his name and has been all but universally adopted.

I803-I859. Stephenson (Robert) by his gigantic construction of the BRITANNIA TUBULAR BRIDGE across the Menai Straits (I850), and the Victoria tubular bridge across the St. Lawrence, near Montreal, proved engineering to be capable of overcoming every mechanical problem; a fact of which living engineers have afforded us numerous evidences by their colossal structures-witness the Eiffel Tower and the Tay Bridge.

1803-r887. Whitworth (Sir Joseph) invented a whole set of MACHINE-TOOLS that have revolutionised the labour of our workshops, and thereby was one of those who ushered in the Age of Steel. Before him the rule of thumb was pretty universal. Whitworth introduced ACCURACY of machine-tools. Such a thing as a true lathe did not exist before him. We owe to him a measuring machine to the 200,000th part of an inch, so true, that if a rod of iron is laid upon it and the hand holding it is not removed, the expansion of the rod by the heat of the hand will be at once indicated. Whitworth also introduced a UNIVERSAL THREAD in screws-an improvement which every one can appreciate.

1808-1890. Nasmyth (James) invented the steam hammer, without which the modern steel industry could. never have been carried out (1842). 
6. I8r3. Bessemer (Sir Henry) discovered a rapid and inexpensive process of MANUFACTURING STEEL (1856). By passing a blast of air through liquid cast iron and thereby removing from the molten mass the whole amount of carbon it contains, the cast iron is converted into malleable iron; into this decarbonised metal a measured quantity of cast iron is introduced which restores the quantity of carbon requisite to constitute steel (about $I^{\cdot} 5$ per cent.). An idea of the WEALTH CREATED by Bessemer may be obtained by the fact that the amount of steel rails made in England and America by the Bessemer process up to I892, would make 52 SOLID BLOCKS of steel 50 feet square and 400 feet high each, the value of which would be a solid COLUMN OF GOLD 4 feet in diameter and 400 feet high. Physics are also indebted to Bessemer for devising a process of dividing an inch into 14,000 lines - a feat which has aided the development of spectroscopy in a striking manner, by enabling physicists to divide the spectrum into minute sections. Sir Henry Bessemer, it may be added, will have rendered another service to science when his great telescope, to the construction of which he has devoted sixteen years, is finished-a result anticipated to be accomplished in the course of the present year (1894). In connection with Sir H. Bessemer as a metallurgist, we should not omit to mention Benjamin Huntsman (1704-76), the Bessemer of his times, who invented cast steel, and was therefore one to whom we are deeply indebted. Again, the contribution of Sir Henry Bessemer to the grandeur of the Age of Steel was almost equalled by Henry CORT (1740-1800), who should be remembered as the inventor of "puddling" (converting cast iron into wrought iron). His various improvements in iron manufacture are said to have added more to the wealth of England than the whole amount of the national debt.

b. I847. Edison invented the TELEPHONE, the PHONOGRAPH, and devised numerous APPLICATIONS OF ELECTRICITY, by which he is recognised as one of the most creative geniuses, if not indeed the most creative genius of which humanity has reason to be proud. 
The telephone, which has been so rapidly adopted after Edison's improvements had made it serviceable, was, like photography, of comparatively slow growth. Attempts to produce a workable apparatus were begun in 1837: Reiss and De la Rive on the Continent, Varley in England, Page and Gray in America, tried to solve the problem of transmitting sound-vibrations to a great distance. Prof. GRAHAM BELL (of Boston) succeeded at last (in 1876) in constructing the desired instrument. To Edison, however, is due the credit of having made the telephone capable of transmitting a conversation to a distance of hundreds of miles. It is one of our modern wonders, like the spectroscope of Kirchhoff. But marvellous as these two instruments are, the phonograph strikes the imagination still more, and seems even more extraordinary: for what indeed can be so fascinating, so prodigious, so impressive, what in the world can in an equal degree appeal to the emotions, as this apparatus which stores up speech and melodies, and will reproduce them at any future period any number of times? which has preserved the tone of Browning's voice for us, as it would have Homer's, Shakespeare's, Milton's, and as it will preserve the speech of Gladstone and Tennyson? This is, undoubtedly, the marvel of the XIXth century, and probably of all times.

Next to those admirable men come the numerous inventors of PRIME-MOVERS for the transmission of energy, by means of high-pressure water, compressed air, steam, gas, electricity, the civilising potency of whose labours cannot be too much valued and praised. We have already natural forces, such as waterfalls, generating and transmitting power to a great distance: a wire transmits the energy generated by a waterfall from Lauffen, on the Neckar, to Frankfort, IO8 miles distant, and that city is partly lighted by electricity through this means; Rome is lighted at night by electricity by power transmitted from the Tivoli Falls, across the Campagna, a distance of 15 miles; the Niagara Falls will within a few years transmit energy round within a radius of over 300 miles so as to light cities as it did the Chicago Exhibition, and 200,000, perhaps 400,000 horse- 
power-a fraction derived from the cataract-will turn the machinery of Buffalo and some other neighbouring towns. The Niagara Falls are capable of producing 15 million horse-power. The Rhone, the Falls of the Rhine have likewise been utilised either to generate electric light or drive machinery at a great distance, and other rivers will be used in the same way.

Soon, no doubt, the tidal power of the sea will be pressed into service and turned to similar advantage. The time is probably not far distant when sunlight and heat will be stored directly, and turned into mechanical energy. Modern science has brought the solution of every physical problem within the compass of possibility. 


\section{CHAPTER XI.}

THE VAI.UE OF INSTRUMENTS.

WE cannot leave the survey of facts without alluding to the value of instruments in scientific research.

With true instinct did the ancients, as soon as they began to study nature, see the necessity of "endowing the human senses with additional power," and of creating aids which could "increase the steadiness of the hand, the strength of the arm," the keenness, compass, accuracy of vision, the grasp of the mind. To assist the hand, the ruler and the plumb-line; to assist the arm, the lever and the balance; to assist the eye, the gnomon and the dioptra; to assist the mind, numbers and imaginary lines (arithmetic and geometry) were ingeniously devised, all of which increased man's natural gifts and guided his early footsteps in the path of knowledge. This fact, which history, philology, and archæology show us to have obtained in remote antiquity, was one which every age, every country, every race has accentuated more and more as time rolled on. In Egypt, in Greece, in Asia, in Europe, century after century contrived new means, invented new agents, created new implements, machines, appliances, until such a degree of progress was reached that it became impossible to take one step in any pursuit without the succour of instruments - the senses becoming secondary guides, and being reduced to the function, so to speak, of simple supervisors and controllers. It is not too much to say that a history of instruments would well-nigh amount to a history of science 
itself. We have been able to perceive the priceless value of some scientific instruments in the foregoing pages. It has become commonplace to say that the invention of an instrument may change the face of a science and give it a new start. Remove the telescope from our scientific development, and at once astronomy is dwarfed into common knowledge: its scientific aspect disappears. Mathematics, it is undeniable, would have done much, and had indeed done much, to elucidate the constitution of the heavens. Copernicus, by means of calculation, empirical observations aiding, arrived at the truth. But his conclusions would have remained a field of controversy, and seemed to many mere speculations, without Galileo's instrument and Tycho Brahe's accurate observations by the use of it: the telescope substantiated his doctrines. The calculations of Kepler were grounded on telescopic data, and would have been valueless without. Newton himself would have been powerless in the absence of the same telescopic revelations. He would have remained a great physicist instead of being the prince of astronomers and mathematicians. The telescope settled the problem irrevocably, and set doubt at defiance. Take away the microscope, and physiology ceases to exist as a science, and not physiology merely but a large number of chemical and physical facts would never have been ascertained, or even so much as investigated at all. The prism, simple and unassuming as it seems, was the key to celestial physics, and more, to a vast area of philosophical solutions. Thermology would have been not so much as a word, without the thermometer. We"have been able in the course of our rapid survey to gauge, not indeed the whole extent, but at least the main bulk of the services rendered by instruments. As we owe the knowledge of our planet's size and configuration, geography, to the compass; so we owe to the pendulum and the barometer our mastery of barology and meteorology; to magnifying glasses our mastery of optics; to the balance mainly, our mastery of chemistry; to the camera obscura, photography; to the battery, our mastery of electricity and a wide range of phenomena. How mathematics, which are a means to an 
end, and therefore an instrument of varied powers, how mathematics have stamped with the mark of truth countless solutions in chemistry, physics, geology, mineralogy, astronomy, we cannot for a moment doubt after reading the preceding chapters of this work, much less after reading the history of any of these branches. Even unpretentious instruments have proved invaluable. It has been well pointed out by Liebig that chemistry is deeply indebted to four things which to all appearance are insignificant agents, viz., glass, cork, India rubber, and gas; the absence of any one of these four things would have caused the impossibility of undertaking a certain number of investigations, and their collective absence would have made chemistry relatively barren in recent times; whereas their united effects have secured a harvest of products which have enriched the whole of the working world. Thus does human intellect derive powerful assistance from materials and appliances, little in themselves perhaps, but fruitful of innumerable benefits. Another standard of the value of instruments, besides their material and profitable assistance, lies in the reliance we can repose in their accuracy in the solution of problems which demand minute exactness: we can now perceive the 9,000 th part of a degree in temperature, $1,000,000$ th of a second in time, $I, 000,000$ th of an inch in space, $1,000,000$ th of a gramme in weight, the presence of the I0,000,000th part of a gramme of a substance. We can in fact observe "quantities $300,000 \mathrm{cr} 400,000$ times as small as in the time of the Egyptians." Where would the eye or the intellect be without instruments? We owe to them our most surprising results. 
CHAPTER XII.

SUMMARY OF FOUR CENTURIES OF SCIENCE.

THE preceding survey, by its arrangement, presents the progress of each branch without a break, the author wishing by that means to convey an idea of the accelerated pace at which the scientific march has been proceeding. But as a pause at the end of any historical period, for the purpose of viewing its striking features at a glance, would help the reader to get a clear impression of the distinct characters of the modern era, the writer will now briefly point out the separate nature of each century since the beginning of the Revival.

I. Foundation.-The XVIth century has several strongly marked characteristics. I. It was essentially an age of PARTURITION. It was during that century that many branches of science came into existence, as we have shown (Chapters V. and IX.) - the work done in some of them being exceedingly important. This certainly was the case in astronomy, physics, geography, anatomy, and natural history. When we consider the magnitude of the discoveries made by the navigators, and chiefly Magellan, early in the century; then by the astronomers, and chiefly by Copernicus and Tycho Brahe; then by the physicists, and chiefly by Galileo and Porta; then by the anatomists and naturalists, chiefly Gesner, Cæsalpinus, Paracelsus, and Vesalius, we at once feel that we are witnessing an intellectual revolution unsurpassed in its effects in the history of civilisation. 2. The second character of the XVIth century is not less 
striking, since it includes the one just described and all those which we shall define, and that was the general contempt of authorities allied to SPIRIT OF FREE INQUIRY. Men of learning refused to take anything for granted, and began to examine everything for themselves - hence the new roads struck out in all directions: in the spheres of religion, politics, philosophy, literature, art, and science. We find this to be the common feature of men broadly separated by their training or way of life: Copernicus exhibits it just as much as Paracelsus, Galileo just as much as Bruno. "Let nature replace Aristotle," was the motto. Spirit of emancipation was the spring of all that was done in that age. 3. A third characteristic of that revolutionary time, an effect of the preceding one, was the craving for PRACTICAL, as strongly distinguished from theoretical, WORK. Among men keeping abreast of their time-a qualification which of course excludes the schoolmen from the movement-experiment and verification became the test of all things. This spirit had been growing for generations, fostered as it had been by the alchemists ever since Roger Bacon, and it became ingrained in the habits of the XVIth century inquirers. This hunger for practical results explains the great number of inventions, of instruments, of discoveries which make the age so dissimilar from the past. 4. A fact typical of the century, due again to independence of spirit, and one to which we desire to give particular weight, was the promulgation of the TRUE METHOD OF RESEARCH-INDUCTION-by some of the great men of the age-a fact proving that practical spirit or experimental pursuit was no haphazard, happy-go-lucky, or empirical bent; but a consistent line of conduct, a well-conceived and maturely-considered course, a well-thought-out resolve, a well-laid scheme of procedure. Leonardo, embodying the moods of the times, may be said to have given a code of research to all inquirers by his forcible injunction to observe phenomena, to resort to nature for information, to question her by experiments, to verify experimental results, and then, only then, to venture to formulate a law. This was so completely the plan of action that we see it followed 
by every man of science, insisted upon and often recommended by them to their disciples. 5. The XVIth century is marked by another character which clearly makes its appearance in the European world for the first timenamely, the discovery of the existence of NATURAL LAWS - the recognition of which is a fact of the highest import, for it will end in gradually altering the spiritual, and the temporal, world. To sum up, then, this century is marked by discoveries of the first order and the foundation of the sciences; spirit of free inquiry; experimental work; the working and formulation of the inductive process; the recognition of natural laws. These are the five features of the modern world, for the following ages, while striking out new roads in unbeaten fields, accentuate these features more and more, without, however, altering their nature, so truly and unmistakably was the XVIth century an age of real science- $\mathrm{a}$ fact which is unanswerably demonstrated by its work.

II. Constitution.-In many respects the XVIth century is grander altogether than the following age. Its startling discoveries, its varied revolutionary movements, naturally strike the imagination far more deeply. The Reformation, which is the main expression of the energetic spirit of the period, would be sufficient to make it a colossal century. Yet the XVIIth century is, scientifically, more imposing. If it is less original and versatile, it is also less tentative and more sterling. The feature which distinguishes it strongly is the discovery of GRAND LAWS, and the extremely rapid development of four branches-astronomy, mathematics, physics, and physiology. The march in these is the same as in the XVIth century. Facts are first collected with patient and untiring labour, then laws are determined after careful experimentation. I. Astronomy enters a new stage. The telescope has revealed a universe undreamt-of, and from this fact two consequences ensue: the Copernican system is proved to be true, and authority receives its death-blow, although it will die hard, and during its agony exercise its might with desperate cruelty for a time. 2. Mathematics also enter a new era. Des- 
cartes, Newton, Leibnitz, gifted with intellectual power of extraordinary originality, create methods of calculation at once infallible and mighty which will enable men to solve the deepest problems in astronomy, mechanics, and physics. 3. Three men of exceptional genius, Galileo, Kepler, and Newton, discover the LAWS OF MOTION, and all of them are found by the immortal Newton to be due to one primary principle-the law of GRAVITATION-by which the heavenly bodies are ruled. This was the greatest feat of the century -and, it may be added, of all times. 4. For PHysics, likewise, fresh horizons are opened. The new departure begins with Galileo's discoveries in barology, followed by those of Torricelli, Pascal, Guericke-who formulate ATMOSPHERIC LAwS; then come Huygens, Roemer, and Newton, who investigate the LAWS OF LIGHT; whilst a new power, practically unknown till then-ELECTRICITY-becomes a recognised force through Guericke. 5. Physiology, founded in the previous century, also accelerates its rate of progress, by the beautiful discoveries of Harvey, Malpighi, Rüdbeck, Leuwenhoeck, and Swammerdam. In this branch a new world has been revealed through the microscope, neither less wonderful nor less varied than the one discovered by the telescope. The philosophical lesson of the XVIth century is repeated and learnt more earnestly: that is, THE IDEA OF LAW becomes more widely and more deeply rooted, and the recognition of this principle militates against superstition and for truth, with all the vigour which inspires the great thinkers of the end of the XVIIth century.

III. Expansion.-The work of the XVIIth century lies chiefly in the discovery of grand laws. The XVIIIth century presents different features. I. It witnesses in ASTRONOMY a VAST ACCUMULATION OF FACTS which at one and the same time corroborates those laws, and extends their application universally. This is the work of W. Herschel, Lagrange, and Laplace. The study of the heavens which Cassini, Bradley, Halley, Flamsteed, Huygens, and Newton had apparently exhausted, was in reality found to be an inexhaustible field of search; and the XVIIIth century, as indeed the XIXth, showed that the great astronomers. 
just mentioned had seen only the fringe of space. 2. The next distinguishing feature of the XVIIIth century is that it witnesses the appearance of scientific GEOLOGY, ushered in by Hutton; of scientific CHEMISTRY, ushered in by Lavoisier; of ELECTRICITY, ushered in by Franklin and Volta; of THERMOLOGY (heat), ushered in by Black-four great branches rich in material and philosophical consequences. 3. Another character of the age lies in the rapid growth of BIOLOGY in all its branches: Linnæus classifies, Buffon describes, Boerhaave analyses chemically, Haller anatomically, Hunter comparatively, and Lamarck throws his luminous philosophy over it all-ascending to the origins of life. Thus the XVIIIth century inaugurated two natural sciences of deep interest: the study of the earth, and the study of the organic world on the earth. 4. A fourth characteristic is given to the century by the sudden appearance of STEAM MACHINERY, the combined wonder of Watt and Black-a new agent of immeasurable variety and power, the creator of wealth on a large scale, and more, the most beneficent destroyer of misery, poverty, wretchedness among the toiling millions of mankind - one, therefore, of the greatest blessings of the modern era; so that the XVIIIth century, which was beyond all things a humanitarian age, contrived also by a happy coincidence an irresistible means of giving effect to its main idea. 5. The same age is also marked by another feature which embodies the result of profound investigations and scientific interaction, namely, the discovery of numerous PHYSICAL LAWS-not, indeed, so striking as those discovered in the XVIIth century, but valuable and important all the same-some of the laws of heat, of compressibility, of magnetism, of electricity, of sound, of light, of chemical action, of biology, besides the invention of numerous apparatus and instruments illustrating those laws. 6. Finally, as a synthetical result of the enlargement of so many branches, but mainly of mathematics, astronomy, mechanics, and physics, the century ends with the broaching and formulation of a THEORY OF THE UNIVERSE by Laplace, which later investigations to a great extent substantiate, and prove, despite the mysteries it involves, to be one of 
the grandest conceptions of our race. Such are the labours of the beautiful XVIIIth century. We are able to see the powerful CRESCENDO which science has exhibited since the Revival: the three centuries just summed up may be characterised each by one word-FOUNDATION, CONSTITUTION, EXPANSION.

IV. Universality.--I. UNIVERSALITY is the general and striking character of the XIXth century. To whatever point of the scientific compass we may direct our glance, we see progress; and the diversity of the progress is so complex, its advance so rapid that it is quite impossible to embrace it all, much less to generalise it in the same manner as we have done in the case of the three previous centuries. We must therefore be content to indicate its most wonderful features. 2. The two marvels of the XIXth century are steam and electricity. The application of steam to machinery, introduced before, becomes a ubiquitous fact. STEAM becomes the prevalent means of industry and of transport by sea and by land. The steamer, so strange and astonishing, is within less than twenty years succeeded by a prodigy still more surprising and bewildering-the railway train. The age of steam has become stupendous. Manufacture and trade are completely revolutionised, and the same force at work, by gigantic strides, multiplies wealth and diminishes misery in an equal degree. The law that Boyle, Mariotte, and Black have elucidated has become the spring of production and welfare. 3. ELECTRICITY, by the side of steam, finds applications even more unexpected and more fascinating. A force which is capable of abolishing distances, of flashing thought round the world seven times in a second, of carrying the voice 500 miles, nay, of bringing the face of your interlocutor before your eyes from that distance, is one thing; but another thing is to devise means of mastering, controlling, directing that force, and make it our servant. Yet the ingenuity, inventiveness, the genius of the XIXth century man of science found the means, after discovering the laws which govern the force. 4. Apart from these two wondrous facts, which will for ever give our time the title of "AGE OF STEAM 
AND ELECTRICITY," the same period has seen the progress of Mechanics as such, and, as a consequence, the farreaching development of machinery, whether it be moved by air, water, hand, steam, or electric labour; so that, failing the title we have just mentioned, the XIXth century would have been known as the "AGE OF MACHInERy." But this is only a part of what the knowledge of the laws of mechanics has done for us : this knowledge led to the performance of engineering works, the conception of which would have seemed senseless and extravagant in the last century; so that again the XIXth century may claim another title, that of the "AGE OF ENGINEERING." 5. Again, the discovery of further physical laws-shall we call them PHYSICO-CHEMICAL LAwS?-conduced to another effect, the powerful use of iron and steel, for which our period deserves the name also of the "AGE OF STEEL." 6. The study of physics, which became the absorbing attraction of genius, conduced to the elucidation of the LAWS OF LIGHT AND SOUND, and, as a consequence, to the comprehension of terrestrial and celestial phenomena, which is one of our greatest triumphs. What rash mind only a couple of generations ago would have ventured to predict that we should ever arrive at the knowledge of the constitution and composition of heavenly bodies? Yet, the problem has been propounded and solved! Who could have conceived the possibility of your voice, your speech, your song, your laughter, your sighs being "bottled up," and being reproduced to those who love, admire, and remember you? Yet, an Edison has achieved that miracle! Who would have thought we could have a picture of a ball-room, or a battlefield, or the remotest regions of space in a few moments? Yet, the photographer does this with faultless accuracy. 7 . One of our difficulties, when we wish to gauge the XIXth century, is that it is impossible to say, even after meditation, the thing in which the age is greatest. If, being impressed by the power of steam and electricity and the applications of them, we declare them to be the main points, we are met by the claims of the Engineer, the claims of the Physicist, the claims of the Chemist, each 
of whom may justly intimate that without him the success in this or that branch would have been problematical; and this is true, for the XIXth century has made the INTERACTION of the sciences a fact so commanding that all the mathematical, astronomical, mechanical, physical, chemical sciences tend to become one, so intimately and indissolubly are they connected with one another. Look at the labour accomplished by chemistry. Do not the metallurgist, the astronomer, the geologist, the biologist, the physicist, the photographer rely upon the data or the analyses furnished by the chemist in order to carry out their own work? It might almost be said that chemistry has become the key of the secret palace of science. But CHEMISTRY is even more intrinsically: it has devised new means of analysis, through which it has revealed to us the components of the universe. That, by itself, would be sufficient to make the XIXth century equal to the age of Newton. 8. In the natural sciences, our time has been no less thorough than in other departments; the earth is now known, thanks to geology, which has raised the veil which concealed the past ages, and shown us the growth of the crust, the revolutions it has undergone, the life it has supported, the age it has lived; so that the XIXth century has given us the knowledge of our EARTH, and has completed -or at least immensely extended-the knowledge of the HEAVENS. 9. Another feature, as engrossing as the others if indeed it be not more so, is that afforded by the rapid advance and grand revelations made in all the branches of biology, including anthropology. Here again the XIXth century inquirer found the secret of nature, life, describing its innumerable delineations, explaining its countless varieties, ascending to its primitive forms. And not this only, but his brother, the physiologist, the good magician, has discovered the means of abolishing pain, and of preventing disease. IO. Finally, in all the branches just alluded to, laws have been found, and of all these laws, one which could never have been elucidated in earlier ages - the grand LAW OF EVOLUTION, which embraces a sheaf of others.

In all branches the XIXth century has touched the 
bottom, found the principles that rule phenomena, and arrived at the barriers of ultimates beyond which the limitation of the human intellect forbids us to proceed. But within these limits universality stamps each science in all its ramifications, as universality stamps the age as a whole. Such is the XIXth century in its main characters, if it be not sheer presumption to point out in a brief and inadequate form its most magnificent achievements in science. 



\section{CHAPTER XIII.}

SCIENTIFIC COUNTRIES.

THE description of modern scientific achievements would be incomplete as an historical presentment, if the contribution of each country to the advancement of knowledge was not clearly indicated.

Four countries may be said to have run almost abreast of one another in the race of progress and far in the van of European science-Italy, France, Germany, England. These four nations were not equal to one another in the rapidity of their advance, for Italy preceded the others in the scientific revival and kept the lead for a long time, so that she acted as the instructress of other nations, and these owe to her on that account as much affection and gratitude as healthy and intellectual daughters owe to the mother who nurtured and trained them. But each of these four has the right to consider herself entitled to proudly stand in the front rank.

The following table of eminent men in each country will prove the most convenient form of exposition : 
PROGRESS OF SCIENCE.

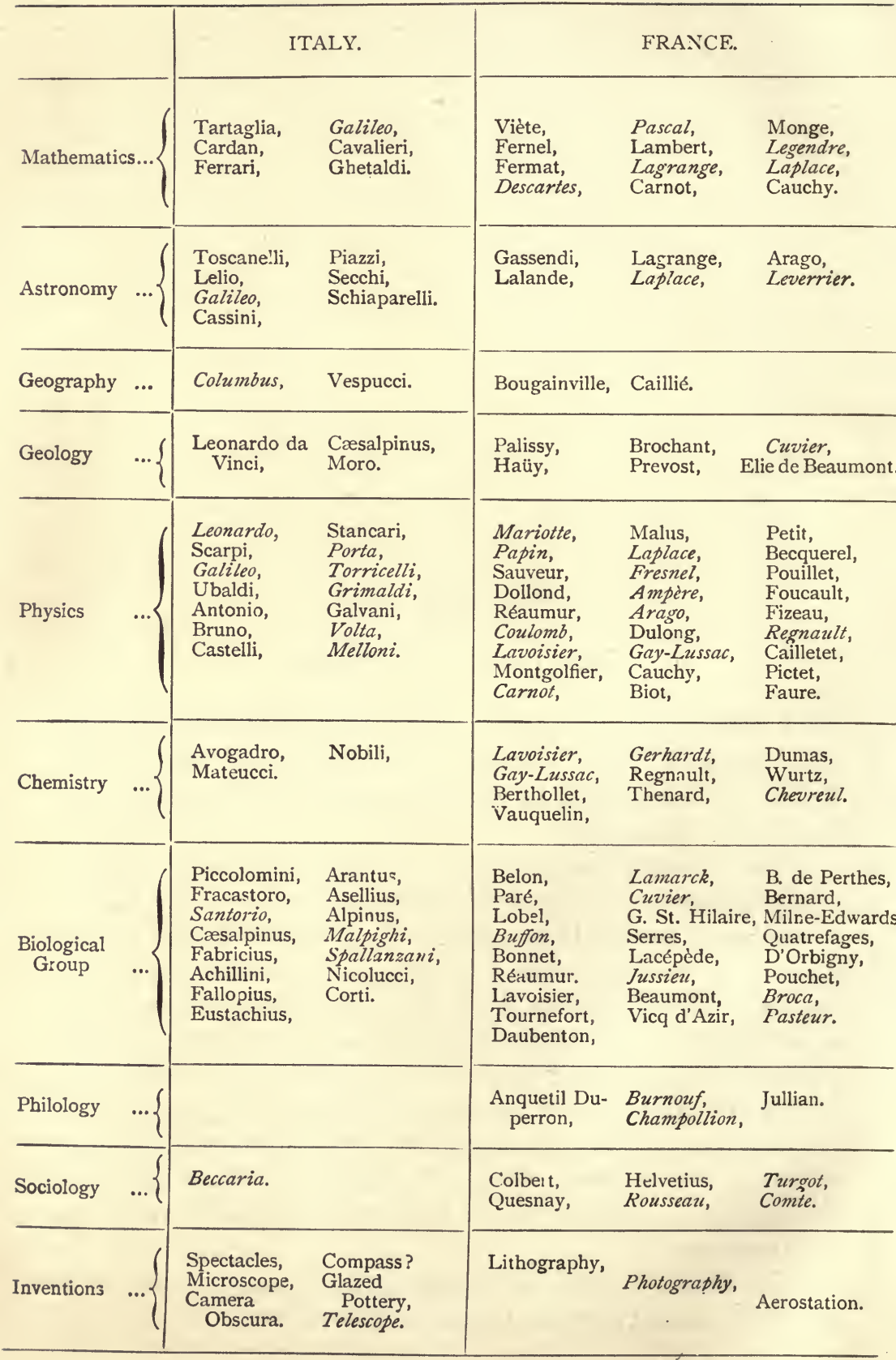




\begin{tabular}{|c|c|c|c|c|}
\hline & GERMANY. & & ENGLAND. & - \\
\hline Mathematics... & $\begin{array}{l}\text { Stiefel, } \\
\text { Kepler, } \\
\text { Leibnitz, }\end{array}$ & $\begin{array}{l}\text { Napier, } \\
\text { Wallis, }\end{array}$ & $\begin{array}{l}\text { Nezwton, } \\
\text { Maclaurin, }\end{array}$ & $\begin{array}{l}\text { Hamilton, } \\
\text { De Morgan. }\end{array}$ \\
\hline Astronomy & $\begin{array}{l}\text { W. Herschel, } \\
\text { Biela, } \\
\text { Humboldt, A. } \\
\text { Encke. }\end{array}$ & $\begin{array}{l}\text { Horrocks, } \\
\text { Hooke, } \\
\text { Flamsteed, } \\
\text { Sir R. Ball, }\end{array}$ & $\begin{array}{l}\text { Bradley, } \\
\text { Halley, } \\
\text { Nezuton, }\end{array}$ & $\begin{array}{l}\text { J. Herschel, } \\
\text { Huggins, } \\
\text { Lockyer. }\end{array}$ \\
\hline Geography & $\begin{array}{ll}\text { Behaim, } & \text { C. Ritter, } \\
\text { Waldseemuller, Humboldt.A. }\end{array}$ & $\begin{array}{l}\text { Sir H. Gilbert, } \\
\text { Davis, } \\
\text { Cook, }\end{array}$ & $\begin{array}{l}\text { Bruce, } \\
\text { Parry, } \\
\text { Livingstone, }\end{array}$ & $\begin{array}{l}\text { Burton, } \\
\text { Baker, } \\
\text { Stanley. }\end{array}$ \\
\hline Geology & $\begin{array}{l}\text { Keferstein, } \\
\text { Humboldt. A. }\end{array}$ & $\begin{array}{l}\text { Woodward, } \\
\text { Hutton, } \\
\text { Hall, } \\
\text { Playiair, }\end{array}$ & $\begin{array}{l}\text { Mantell, } \\
\text { Murchison, } \\
\text { Sedgwick, } \\
\text { W. Smith, }\end{array}$ & $\begin{array}{l}\text { Buckland, } \\
\text { Lyell, } \\
\text { Scrope, } \\
\text { Geikie. }\end{array}$ \\
\hline Physics & $\begin{array}{ll}\text { Kepler, } & \text { Ohm, } \\
\text { Guericke, } & \text { Seebeck, } \\
\text { Fahrenheit, } & \text { Schwabe, } \\
\text { W. Herschel, } & \text { Kirchhoff, } \\
\text { Chladni, } & \text { Bunsen, } \\
\text { Fraunhofer, } & \text { Steinheil, } \\
\text { Jacobi, } & \text { Helmholtz, } \\
\text { W. Ritter, } & \text { Dove, } \\
\text { Gauss, } & \text { Hirn. }\end{array}$ & $\begin{array}{l}\text { Roger Bacon, } \\
\text { Harriot, } \\
\text { W. Gilbert, } \\
\text { Hooke, } \\
\text { Hawksbee, } \\
\text { Halley, } \\
\text { Boyle, } \\
\text { Watt, } \\
\text { Bradley, } \\
\text { Maskeline, } \\
\text { Nezoton, } \\
\text { Kirk, }\end{array}$ & $\begin{array}{l}\text { Wollaston, } \\
\text { Dollond, } \\
\text { Faraday, } \\
\text { Brewester, } \\
\text { Talbot, } \\
\text { J. Herschel, } \\
\text { Murdoch, } \\
\text { Grove, } \\
\text { Leslie, } \\
\text { Wheatstone, } \\
\text { Young, }\end{array}$ & $\begin{array}{l}\text { Joule, } \\
\text { Maxwell, } \\
\text { Nicholson, } \\
\text { Crookes, } \\
\text { Thomson, } \\
\text { Balfour Stewart } \\
\text { Tyndall, } \\
\text { Lockyer, } \\
\text { Attwood, } \\
\text { Huggins, } \\
\text { Bessemer. }\end{array}$ \\
\hline Chemistry & $\begin{array}{ll}\text { Agricola, } & \text { Bunsen, } \\
\text { Stahl, } & \text { Liebig, } \\
\text { Richter, } & \text { Mitscherlich, } \\
\text { Klaproth, } & \text { Hofmann. }\end{array}$ & $\begin{array}{l}\text { Boyle, } \\
\text { Mayow, } \\
\text { Black, } \\
\text { Priestley, }\end{array}$ & $\begin{array}{l}\text { Cavendish, } \\
\text { Wollaston, } \\
\text { Davy, } \\
\text { Dalton, }\end{array}$ & $\begin{array}{l}\text { Graham, } \\
\text { Williams, } \\
\text { Perkin, } \\
\text { Crookes. }\end{array}$ \\
\hline $\begin{array}{l}\text { Biological } \\
\text { Group }\end{array}$ & $\begin{array}{ll}\text { Tragus, } & \text { Göthe, } \\
\text { Haller, } & \text { Gall, } \\
\text { Blumenbach, } & \text { Pruner-Bey, } \\
\text { Vogt, } & \text { Von Möhl, } \\
\text { Sprengel, } & \text { Haeckel, } \\
\text { Oken, } & \text { Virchow, } \\
\text { Schwann, } & \text { Weismann, } \\
\text { Humboldt, A. Schleiden. } \\
\text { J. von Müller, }\end{array}$ & $\begin{array}{l}\text { Harvey, } \\
\text { Grew, } \\
\text { Willis, } \\
\text { Ray, } \\
\text { Willughby, } \\
\text { Hunter, } \\
\text { Brown, } \\
\text { Sydenham, }\end{array}$ & $\begin{array}{l}\text { Jenner, } \\
\text { E. Darwin, } \\
\text { Sir J. E. Smith, } \\
\text { Mantell, } \\
\text { Owen, } \\
\text { Knox, } \\
\text { Simpson, } \\
\text { Darwin, }\end{array}$ & $\begin{array}{l}\text { Wallace, } \\
\text { Brodie, } \\
\text {, Gould, } \\
\text { Huxley, } \\
\text { Bates, } \\
\text { Romanes, } \\
\text { Lubbock. }\end{array}$ \\
\hline Philology & $\begin{array}{l}\text { Bopp, } \quad \text { Roth, } \\
\text { Bunsen, } \quad \text { Grimm, } \\
\text { Humboldt, C. W. Max-Müller. }\end{array}$ & $\begin{array}{l}\text { Jones, } \\
\text { Colebrocke, }\end{array}$ & Rawlinson, & Geo. Smith. \\
\hline Sociology & Humboldt. A. & $\begin{array}{l}\text { Adam Smith, } \\
\text { Malthus, }\end{array}$ & Bentham, & Herbert Spencer \\
\hline Inventions & Spectroscope. & $\begin{array}{l}\text { Steam-engine, } \\
\text { Steam-ship, } \\
\text { Railway, } \\
\text { Panorama, }\end{array}$ & $\begin{array}{l}\text { Telegraph, } \\
\text { Machine-tools, } \\
\text { Gas, } \\
\text { Steel, }\end{array}$ & $\begin{array}{l}\text { Safety-lamp, } \\
\text { s, Steam-ham- } \\
\text { mer. }\end{array}$ \\
\hline
\end{tabular}


In a second group, in the order of their importance, come :

\begin{tabular}{|c|c|c|c|}
\hline AMERICA. & POLAND. & PORTUGAL. & DENMARK. \\
\hline $\begin{array}{l}\text { Franklin } \\
\text { Rumford } \\
\text { Morse } \\
\text { Maury } \\
\text { Edison }\end{array}$ & Copernicus & $\begin{array}{l}\text { Vasco de Gama } \\
\text { Magellan }\end{array}$ & $\begin{array}{l}\text { Tycho Brahe } \\
\text { Steno } \\
\text { Roemer } \\
\text { Malte-Brun } \\
\text { Oersted }\end{array}$ \\
\hline Sweden. & HOLLAND. & SWITZERLAND. & RUSSIA. \\
\hline $\begin{array}{l}\text { Linnaus } \\
\text { Bergmann } \\
\text { Scheele } \\
\text { Berzelius } \\
\text { Retzius }\end{array}$ & $\begin{array}{l}\text { Snell } \\
\text { Stevinus } \\
\text { Van Helmont } \\
\text { Grotius } \\
\text { Drebbel } \\
\text { Mercator } \\
\text { Vesalius } \\
\text { Huygens } \\
\text { Leuwenhoeck } \\
\text { Muschenbröck } \\
\text { Swammerdam } \\
\text { Boerhaave } \\
\text { Camper } \\
\text { Maleschott }\end{array}$ & $\begin{array}{l}\text { Guldinus } \\
\text { Paracelsus } \\
\text { Gesner } \\
\text { Gall } \\
\text { Agassiz } \\
\text { Pictet } \\
\text { Bernouilli }\end{array}$ & $\begin{array}{l}\text { Baer } \\
\text { Mendelejeff }\end{array}$ \\
\hline
\end{tabular}

From the foregoing exposition it is clear that, although it seems almost invidious to award the palm to one of the four great scientific countries; although each has such strong claims to the obligations of the others; although Italy led the van; yet it is clear that ENGLAND, when the number and weight of her achievements are considered, must be declared the leading country in the world of science. She gave birth to a score of men, every one of whom either created, or extended, branches of knowledge in a manner unapproached by the great scientists of other nations in the same departments; and this, notwithstanding the fact that ITALY has the glory of having given birth to Columbus, Leonardo, Galileo, Cassini, and Volta ; Germany to Leibnitz, Humboldt, Fraunhofer, Kirchhoff, Bunsen, and Helmholtz; 
France to Descartes, Pascal, Lavoisier, Jussieu, Laplace, Lamarck, and Cuvier. In almost every great branch, if not the initiator in the same sense as Italy, England has been the improver and perfecter. She has given the decisive, the finishing stroke of genius necessary to carry science or its application to its culminating point. After such physiologists as Servetus, Vesalius, and Cæsalpinus, there comes HARVEY, who towers over them by his beautiful discovery; after the Arabs and the alchemists, there comes William GILBERT, who founds a new science; after Copernicus and Leonardo, Galileo and Kepler, all giants, after Tycho, Torricelli, and Pascal, there comes NEwTon with his unsurpassable results ; after a Quesnay and a Turgot, there comes ADAM SMITH with his economical revolution; after Papin, there comes JAMES WATT with his steam machinery; after Jouffroy d'Albans and Marc Séguin there comes STEPHENSON and his flying locomotive; after Scheele and Lavoisier, Richter, Berzelius, great discoverers all, there comes DALTON with his atomic law; after Volta and Ampère, there comes WhEATSTONE with his electric telegraph; after a number of practical metallurgists in all countries, there comes BESSEMER who opens the Age of Steel; after Werner and Cuvier, LyeLL comes with his geological laws ; after Lamarck and Geoffroy St. Hilaire, there comes DARWIN with his evolutionary law of natural selection; after Carnot, Coulomb, Lagrange, and the great Laplace, there comes JOULE with his conservation of energy; after Comte and Diderot, there comes Herbert SPENCER and his magnificent synthesis - just as in the Middle Ages there had been a ROGER BACON and a WiCLIF. In very few branches indeed can it be said that the climax was reached outside England.

If the English were of Jewish extraction and were swayed by theological ideas, they would, no doubt, ascribe their greatness to a supernatural cause, and aver that they were "the chosen people"; but their success is due to natural causes easily detected. Their MIXED ANCESTRY, descending as they do from Iberians and Celts, Romans and Scandinavians, Teutons and French, has left an indelible impress upon their race. They have inherited the different characters 
of their parent-stocks, and are gifted with the spirit of enterprise and fearlessness which distinguished one, the tenacity and seriousness which distinguished another; with the inventiveness and spirituality of this stock, the reflectiveness and depth of that one, the strength and adaptiveness of all. And added to that primary cause, two other causes, besides, have tended to accentuate their native disposition and characteristics, viz., INSULARITY, due to their habitat, and LIBERTY, due to their institutions. These two elements have endowed the race with a strong individuality, and every man has his own strongly marked idiosyncrasy, his own independent spirit which hardly ever excludes that flexibility of adaptation-the common heritage of all-which is the product of heterogeneous ancestors. This doubtless is the powerful spring, the fruitful source of the PRODIGIOUS SUCCESS which has attended the progress of England in so many ways, and in the pursuit of science, no less in letters, politics, colonisation, and empire. 


\section{CHAPTER XIV.}

\section{GENERAL RESULTS.}

As a conducting thread through the maze of science the brief outline we have given will suffice; but it is by no means, as we have already said, a commensurate presentment of what science has accomplished. Yet, the facts recorded, fractional though they be, constitute an aggregate at once so weighty, pregnant, and substantial, so vast, stupendous, and imperishable, that no one can possibly appreciate and realise its full significance. We need only remember that each discovery, each law, each invention, is a new source of immeasurable development to entire mankind, both intellectually and materially, to form an idea, if not an estimate, of what science has done for us. Chemistry, steam, electricity no sooner sprang into life, than they became the greatest elements of progress and wealth in the world. A man handles a crystal, gives it a geometrical shape, polishes it; another man adapts it to a tube, and, lo! men see the same components as those which make up the earth, burning in stars so remote that a cannon ball would not reach them in ten millions of years. A Bessemer makes a new kind of steel, a Perkin finds a new kind of dye, and, behold, England reaps millions upon millions, by scores and scores, and untold wealth circulates throughout East and West: capital is increased a hundredfold and labour is multiplied a thousandfold! A Gilbert demonstrates a law which a Volta fructifies, and, at once, the pile ensures progress by leaps and bounds 
to numerous industries, to medical science, to chemistry, and the electric light, the telegraph, the telephone, the phonograph appear! A modest genius finds out the law of elasticity of gases, another genius constructs a ship, another an engine, and, see, man crosses a sea or a continent with the eagle's speed, while innumerable markets are opened in all regions and resistless machines move the countless arms of industry! And so forth without limits.

And the general consequence? The whole world is transformed! Short words, these, and soon said, but slowly apprehended. THE WORLD IS TRANSFORMED! Industry and trade are ubiquitous and incessant, enlightenment spreads like a fertilising inundation, misery is reduced, health is made more secure, barbarism yields to humane influences, nations visit one another, the most distant countries are brought within a few days' journey, Pekin speaks with London, new continents open new homes for the European races and nourish the Old World, the Western peoples see trade and wealth flowing to and from the East, the seat of civilisation is being transferred to other climes and younger nationalities, brotherhood and kindliness soften and elevate humanity, and lastly morality and freedom, in the wake of knowledge, extend the horizon of peace-the supreme blessing. And all this the fruit of our scientific men's labours, the fruit of a certain number of discoveries of divine laws-divine indeed in their simplicity, grandeur, and bountifulness.

By the side of material results, Intellect has reaped results equally beneficent, fruitful, and admirable; each step forward leading it to a new field of reflection and exploration, and ensuring its enlargement, elevation, and depth. Of the results which the preceding survey records, there is one particularly to which we are compelled to attach paramount importance, because of the immense consequences it involves both in the scientific and in the philosophical spheres, affecting as it does almost everything which the human mind prizes in the highest degree-we mean the establishment of the doctrine of the universal predominance of natural law in the government of the world. As the 
sciences obtain a sounder footing we see them revealing to us, one after another, all the great principles pervading the Cosmos. First the laws of motion are discovered, soon followed by the discovery of the law of gravitation, and these are found to be ruling principles of all heavenly bodies, and to pervade the whole of space. And what mathematics and astronomy have done for space, geology does for time; time is shown to have brought about all the changes which have been necessary to metamorphose the gaseous mass which formed a nebula into rings, then into planets with a central sun, and then each planet into a harmonious little world giving life to myriads and myriads of plants and animals: the law of evolution gives an explanation of this everlasting Becoming. Next, chemistry shows us law universally and uniformly obtaining from suns to atoms, and through the spectroscope reveals "the identity of matter and energy throughout this extreme range." Then the laws of conservation of energy and matter, and their transformation into new forms or modes of action, are found, which reduce "all the phenomena of the inorganic universe to one of law of universal simplicity and generality." Lastly, the demonstration of the theory of natural selection and the survival of the fittest extends the domain of law to the organic world-a law confirmed every day more strongly by the discovery of intermediate forms on the one hand, and by our better knowledge of embryology on the other; both guiding us back from the present forms of life to liss complex ancestral forms, and from these further back still to simpler primitive ancestral links until we arrive at the lowest original form of organism -the cell.

It is unnecessary to dwell upon the scientific consequences, both theoretical and practical, which the certainty of knowledge of the presence of unchangeable laws must inevitably bring about, for the preceding survey itself affords numerous instances of the effects due to the discovery of the permanence of law; but it is needful we should point out the one effect which most intimately affects every one of us personally, and that is the revolution or modification 
in religious belief it has caused. The sense of this revolution is the extinction of the belief in a supernatural agency presiding over, ordering, and directing the working of the universe, from the making of a new world to the fall of a stone. Whether we should deplore this profound change or rejoice at it is a grave question which shall be dealt with in the ending chapter of this book; all we need notice at present is the fact itself-the most momentous by far of all those which can touch the heart of mankind. The knowledge of the existence of law leaves the integrity of pure belief untouched: science has explained only the working of the Cosmos, but neither its cause, nor its creation, nor its meaning. And more, science has brought conviction to us of the limited range of the human intellect. It has owned itself powerless ever to discover ultimates. It has owned that the existence of an atom is as much beyond its grasp as the existence of a million of stars; it owns that mystery meets man just as much now as it ever did, or more; but it has removed that mystery further back into the infinity of the Unknowable, and thereby removed also into further depths the Object of belief, making it more awful and incomprehensible. Whether it can be said that by killing anthropomorphism science has purified belief will no doubt be solved affirmatively at no distant date by all the schools of theology, as it has already been by some of the highest. Such are the chief bearings of the most important effect which science has produced and brought home to us with irresistible might. 


\section{CHAPTER XV.}

MATERIAL EFFECTS OF SCIENTIFIC PROGRESS.

Now that we have sketched the sources and march of the sciences, there only remains to describe their outcome; to their effects then we shall now devote remarks of great importance.

The benefits accruing to civilisation from the advance of the sciences and their practical applications have been pointed out at pages $285-7$ in general terms, but as it may be interesting to the reader to understand how material welfare is promoted either by a scientific discovery or a mechanical invention, it is fitting that several instances of the matter-of-fact increase of prosperity and well-being should be described.

Let us take the invention of the flour-mill as an example.

Men at an early stage of social life have no other means of preparing corn for food, beyond boiling it, than by manual labour. Corn is spread on a flat or a hollowed stone, and then crushed by hammering at it with another stone. Each family prepares corn in this way for its own consumption, and the work, whether it be done by the head of the family or his wife or children, is slow and roughly done; the flour resulting from the crushing is coarse and scarcely fit for kneading into dough. A time comes when a savage of genius conceives the idea of grinding corn between two heavy flat stones, the upper of which is moved backward and forward or in a circular manner by one or several hands. This manipulation gives finer flour than before and does so in less 
time too. A double benefit is at once effected; the corngrinder has obviously saved time, and provided better and more digestible food. The process spreads quickly among the community and a rise of material welfare ensues, for those who feed on the improved nourishment are more healthy and stronger, so that they can accomplish their work more efficiently, and the time spared by the new system can be spent in the pursuit of other kinds of work, whether it be hunting game for food, or tilling the soil for any purpose, or weaving, or implement-making. Time comes when the two grinding-stones are replaced by a handmill. The inventor of this machine is a greater benefactor than the first; the upper stone is now moved round and round rapidly by one hand; the work is far more satisfactory than by the previous process; for, as one person is sufficient to grind corn for the whole tribe, the other members of the tribe are relieved from the necessity of grinding for themselves, and can, undisturbed, attend to various occupations. The benefit is not limited to this; with the new appliance there also arises a new state of things : the corn-grinder is paid in kind for his labour, and if the tribe be a numerous one, he has to hire assistance in order tocarry out the whole work; and thence there come to be two orders of men, the master and the workmen. The latter have secured a means of existence; they can marry and bring up a family with their earnings, be the wages what they may-corn, fruit, garden produce, game, or garments. Later, say during the Egyptian or the Roman period, the watermill is invented-an improvement by which numerous benefits are secured: I, hand-labour is now replaced by machinery; 2, a natural force, water, becomes man's servant, and saves the employment of a score of hands; that is, it has economised or, more properly, multiplies labour ; 3, the miller making flour for the whole district now becomes a trader; he buys corn from the grower, thereby benefiting the tiller of the soil, who gets a return for his labour sufficient to keep himself and his family, and to pay working hands; 4, the miller also sells his flour to the bakers, who obtain it from him at a lower rate than if they had to grind their own corn; 5 , the consumer buys ready-made bread at a mode- 
rate price, since the machinery used has reduced the first cost by saving wages to the miller, and certainly far cheaper than if he had to leave off his own pursuit, say, weaving, for a whole day in order to procure corn, grind it himself, make and bake his loaves. The consumer would lose work, wages, and eat dearer and worse bread into the bargain. 6 . The consumer has a family, and the whole family benefits by the invention of the water-mill; 7 , the miller, saving hand-labour as he does, nevertheless employs as many or more men than before the new invention, no longer as corn-grinding hands, but as porters, drivers, buyers, sellers, travellers ; 8 , the trade thus extended necessitates the making of sacks, hence weavers have more work and more food; the making of carts, hence wheelwrights, if they do not exist already, are brought into existence; smiths have more to do; harness-makers have more work, and in their turn increase the leather trade; this promotes cattle-breeding, and the landowner finds a new source of profit in the improved industry. 9. But the general distribution of benefits does not stop there; the water-mill has to be built, and its construction gives work, hence wages and food, to a crowd of people: labourers to excavate the soil for the foundations; wood-cutters to fell trees; carpenters to prepare and fit the timber; smiths to make cog-wheels, tires, bolts, nails ; mill-stone quarriers and mill-stone cutters; tool-makers to provide implements for all these; brick-makers, bricklayers, tile-makers, and tilers; an architect or clever artisan to plan, direct, and supervise the building. The new invention thus does good to the whole community, for the general increase of prosperity, on account of the greater purchasing power of the people, improves the clothing and building trades-in fact everything. And not material good only has been brought about, but moral good also. Work being easily obtainable, men who, from want, might have been driven into violence and crime, respectably bring up a family, use their natural abilities to improve their social condition, live orderly lives, and benefit the country. Some will even spend their leisure time in mental and mechanical work which may be fruitful of ulterior benefits to all. One thing is clear: crime has decreased, order and discipline have 
become a habit, peace has become dear-that is, relatively speaking. And when it is remembered that the new process of milling finds a ready acceptance everywhere, that watermills are constructed wherever a water stream is available for the purpose, it is easy to see how immensely beneficial it is to mankind, and what a great benefactor its inventor has proved. His invention has made life easier to every one, has secured a living to a multitude, has, with the prosperity it has caused, permitted a large increase of population. The increase of people extends the area and power of peaceful labour (if the word civilisation be inapplicable), since they will spread beyond the former limits of the community, cultivate more land, raise the amount of produce, and thus add to the augmentation of the general prosperity. After the water-mill comes the windmill, which at once doubles the results obtained by the water-mill, and in addition causes competition, a new factor which works to the consumer's advantage. Later comes the steam flour-mill, which multiplies these results a hundred times! The modern miller stands intellectually and socially far above his predecessor. He has travelled and has acquired an extensive knowledge of the world; he is more than a trader; he is to a certain extent a learned man: he is conversant with some questions of political economy, and somewhat, maybe, with chemistry-a branch of knowledge which enables him to know the different properties of every description of wheat grown in various countries, each weed being affected by the climate and soil. Socially, too, he stands very high; his sons are brought up to become merchants, engineers, manufacturers, politicians, writers, lawyers, scientific men, each of them an agent of progress or a centre of social influence.

Each industry has a history similar to that of milling; so that the preceding description of growth and results applies to brewing, from the poorest beverage to the richest product of the modern brewery; weaving, from sackcloth to silk, velvet, lace, tapestry, and so on ; glass-making, from opaque glass to lenses, spectacles, the telescope, the microscope, the spectroscope; metallurgy, from the rough bronze weapon and implement to the steel engine, physical implements, 
cannon, bridges, tunnels, steam trading and war ships, railways ; paper, from packing-paper to the finest vellum, papiermâché trays, tables, and cabinets; furniture, from the rough stool to the throne; printing, from the label to the book, advertising placards, printed calico, engravings; lighting, from the primitive torch to the oil-lamp, gas, and electric light; and so forth continuously. Each cause producing a multitude of effects, all good and beneficial ; progress being initiated in the main by the four things which mark the great strides of civilisation-THE TOOL which enabled men to face and overpower the wild beast, and to protect themselves by garments and dwellings against climatic evils; the machine, and first THE PLOUGH, which enabled them to work the ground and grow food; THE SWORD, which enabled them to secure the survival of the fittest by mastering the unfittest races, and founding society; THE BOOK, which enabled them to preserve and propagate accumulated experience.

But how thoughtless and ungrateful humanity has been! It remembers the names of early "men-of-prey" and surrounds those names with a glorious halo, whilst, of its early benefactors, none is known even by name. The inventor of the plough, the earliest and greatest of them, is forgotten utterly; equally unknown, to speak of a few only, are the inventors of the mill, the compass, the clock, the organ, glass, paper; and just as unknown are the creators of astronomy, arithmetic, geometry, algebra, alphabetical writing, and many other men, all of them progenitors of human happiness. Let every one of us cherish the remembrance of the forgotten ones; we owe them the life we live to-day, for, "the discoveries of great men," as Buckle has finely observed, "never leave us; they are immortal ; they contain those eternal truths which survive the shock of empires, outlive the struggles of rival creeds, and witness the decay of successive religions."

And turning from mechanical applications to pure science, the material benefits to civilisation resulting from the latter are still more astonishing and fruitful than those spread by the former. In the forefront of all the benefits which science has succeeded in bestowing upon humanity, we must name 
that which is felt in a direct manner by every man, woman, and child, viz.: prevention of disease by inoculation - a scientific result which has saved many lives every year in every country, and preserved us from much suffering and sorrow. And so, the names of Jenner and Pasteur should be revered universally. And the system having been extended to animals, husbandmen have been spared losses which might have involved them in total ruin during epidemic times. Akin to the same category are the daily wonders wrought by medical science: every living man knows by personal experience those priceless results. If we go beyond that sphere, we find science again acting the part of a rich and bountiful fairy, never tiring from outpouring her gifts upon us. Take, for instance, meteorology allied to physical geography. The discovery of the permanency of the trade-winds and sea currents has led to the scientific and practical development of navigation. Vessels taking advantage of these currents make a voyage more rapidly than before the scientific discovery. The rapidity of transit decreases the cost of freight, the amount of wages to sailors, and thereby benefits universal trade, and also the consumer, who obtains cheaper and a greater quantity of goods-that is, cheaper and more food-stuff, cotton, wool, raw material of every kind. Increase of wealth and prosperity ensues as a matter of course, and in its wake brotherhood and love of peace among nations, together with intellectual and moral progress. The discovery of the law of the elasticity of gases applied to industry has led to transformations in humanity which it is impossible to gauge, so universal and multifarious they are, ranging from clothing and transport to political economy and colonisation, which are in the modern world dependent chiefly upon steam machinery. Electricity, in its essence, is a force unknown to us just as gravitation is; we cannot explain what it is, but we are certain of its existence as a power, and we control and use that power for our benefit. We have electric machines, phonographs,* TELEGRAPHS, TELEPHONES, the

* The phonograph, though not an electric apparatus, is an offshoot of the telephone, hence a grandchild of electric applications. 
manufacture, fitting, and working of which secure the existence to two hundred thousand families at least in England alone; and the use of which enables a merchant, say in the corn trade, to know the climatic situation of the day in every latitude in Asia, America, Africa, Europe, Australia; to know also the prices of every market in the world on that day; and at the same time to know also the quotations in every stock in all the Exchanges of the whole world on the same day!

With that knowledge before his eyes he is able to regulate his purchases in America, India, Russia, Australia; to order his shipments at Odessa, New York, San Francisco, Valparaiso; to direct the landing and delivery of corn, maize, oats at Liverpool, Hull, Amsterdam, Marseilles, Trieste. He does all this from his desk in his own office, or from the Mark Lane Exchange, or from "the Baltic." And he does all this by SPEAKING to his correspondents. He does it in a few words. He speaks to fifty people in one short hour instead of sending them as many different messages, most of them fruitless, or as many written communications, most of them incomplete at best. In the course of an hour he has transacted business which would have taken six months to transact fifty years ago, and that business amounts in bulk to a hundred times more than that which his father would have dared to face at a time. He has not saved time only; he has also saved the salary of ten or twenty clerks; and the rapidity and increase of trade is such that the corn trade which his father carried on before him in its entirety, but on a small scale, has now been divided in thirty or forty separate branches, of which he takes up two or three only. He takes up perhaps only Russian wheat, or Indian wheat, or American or English wheat; or perhaps only maize, either American, or Danubian, or Russian; or perhaps only oats, either Swedish, or Russian, or American ; or maybe barley, and of this only brewing or feeding, French or Russian; or again it may be beans, peas, lentils, gram, and mutter; putting aside the flour and meal trade which is almost as large and just as divided into sub-branches too. And then all these are again subdivided into specialities, such as parcels, cargoes, options -each of which constitutes a separate trade. So, our corn 
merchant transacts a hundred times more business than his father, but of the trade, he only deals in a couple of branches. The other branches are taken up probably by the men who, without that division of labour, would be his own salaried clerks. This division of labour has just been explained in detail in order to show the reader how men, who otherwise would have remained unproductive trade units (clerks), have become productive springs for the fructification of capital, and the expansion and remuneration of labour. The consumer, meanwhile, is the chief benefiter of the vast improvement effected by electricity, for he obtains cheaper food at an almost uniform rate without the fear of having to face either famine or famine prices. If India and Russia suffer from these two evils still, it is due to the comparative absence of our means-scientific appliances, railway and telegraphic communication.

What is the case as regards electricity is the case with every scientific discovery, with more or less general consequences. The man who makes one is a benefactor to the whole of mankind. He provides for the existence of ten thousand, a hundred thousand, a million of families; he gives life to a whole population. Photography, steel-making, chemical manufacture, and so forth, are so many sources from which flow untold wealth, well-being, and peace, in a continuous and ever more powerful stream. That is why chemists like Lavoisier, Davy, Dalton, Liebig, Perkin; electricians like Volta, Ampère, Wheatstone, Morse, Thomson, Edison; physicists like Faraday, Brewster, Kirchhoff, Grove; experimentalists like Watt, Murdoch, Niepce, Bessemer; engineers like Fulton, Stephenson, Lesseps; physiologists like Harvey, Jenner, Huxley, Pasteur, together with their scientific brethren in any branch, are more glorious and deserving of fame, each of them, than the greatest conquerors whose deeds are the subject of historians-for conquerors, even those who spread civilisation, have destroyed thousands and hundreds of thousands of lives, whereas men of science have given life to millions and millions: a theme for reflection this, and one which necessarily makes us lovers of science and its promoters. 


\section{CHAPTER XVI.}

MORAL EFFECTS OF SCIENTIFIC PROGRESS.

BUT the preceding description may leave as a main im. pression on the reader's mind that the promoters of science have been agents of material welfare, and little more; and as material welfare does not after all constitute the best part of a high civilisation, he may doubt whether science has contributed much to the development of the moral and intellectual condition of modern Europe; he may vaguely suspect that the deep sentiments which animate us nowadays with regard to religion, religious and political government, justice, truth, virtue, philanthropy, humanity, devotedness have sprung from other sources than science. It therefore behoves us to demonstrate that science has been the chief fount from which moral and intellectual progress has flowed. Not that science has been the sole source. By no means. That the Christian idea, sown broadcast for ages, had exercised a vast and beneficent influence, despite the superstition, the craftiness, the craving for wealth and power of its Roman ministers, is too obvious a fact to be disputed for a moment.* Its essential doctrines-charity and godliness - had sunk deep into the heart of many, and nurtured Europe for a higher civilisation; they had even produced, and shown to the world, model men whose lives and characters would compare with the highest poetical ideals. But the spiritual force of those doctrines and those men was buried alive, so to speak, under the weight 
of the ecclesiastical army, and was insufficient to overcome and kill the dominant evils. Slavery, despotism, oligarchy, injustice, violence, rapine, cruelty, war were supported by churchmen as things belonging to Cæsar, and were therefore represented as natural and lawful rights. It was reserved to science to overcome these at last. Other factors, and foremost among them literature, naturally worked in the same direction as science, and preceding it, powerfully assisted it; but of these factors some owed their very existence to the growth of science, so that the latter has been on the whole the most potent and ubiquitous mainspring of human elevation.

It has been already pointed out that Industry, by the very fact of its coming into being, brought about SOCIAL CHANGES of great importance, the principal of which were the emancipation of Europe from serfdom; next, decrease of violence; then municipal liberties; next, increase of population; then the disappearance of the stigma attached to labour. But as industry depends on machinery chiefly, and machinery is an application of scientific principles, whether these be properly reduced to law or empirical only, it follows that ordinary knowledge at first and the sciences afterwards were the causes of the social changes just recited, the Crusades being the paramount event which accelerated them and strongly cooperated in several ways to bring them about. The progress, however, goes much further. Industry has, ever since the XIIth century, knit into greater and closer commercial intercourse nations of different creeds, amongst whom a feeling of reciprocal amity arose in consequence, in the place of the unreasoning animosity which was prevalent before. From the same period also date the great mercantile companies and enterprises; also the commercial leagues of great cities, which grew powerful enough to become independent republics. Social order, too, began to grow, despite the popular disturbances due to the aggression of the aristocracy, for it was felt that prosperity - and that of the working class especially-depended upon the stability of the state, property, and capital, if we may 
use words of modern speech. Later, Political Economya science of pure reasoning-demonstrated principles for a long time hidden from men's eyes, yet inherent in industry and commerce, which brought about results of immense magnitude and variety: the principle, for instance, that trade suffers from restriction-free trade and the partial disappearance of evil interference, monopolies, exorbitant and prohibitive duties followed accordingly; next, the principle that not precious metals, but labour, is the basis of value; next, the principle that capital-and therefore its accumulation - is a necessity for the expansion and remuneration of labour; the principle, too, that labour in its turn is a necessity to the fructification of capital-the co-operation of both conducing to the increase of national wealth. Concurrently, a new factor, due to the progress of trade, had been created, viz., Credit*-an increment 'of capital artificial, but nevertheless effective, since it permits a vast number of extensive transactions and long enterprises which ready capital could not possibly cover. Now credit has had two consequences-one moral, the other political. It has been a great moralising agent in all communities by the importance it attaches to character, and therefore by the influence it exercises over it. Second, it has become a guarantee or pledge of peace., Political Economy and the working out of its principles tend to universal peace"each nation having an interest in the prosperity of those with which it trades, and the richest and most solvent being its best market." $\dagger$ War is in consequence deprecated as a folly, a sort of national suicide; warlike habits are weakened and tend to disappear. Political economy will ultimately destroy militarism and the last vestiges of despotism, both of them remnants of the age of violence. It also tends to bring a closer and closer union of the different classes of society, the capitalist and workman alike being tied to the same undertaking. It goes further

* The Bill of Exchange dates from the Middle Ages. Banks date from the XVIIth century ; the Bank of Amsterdam, the earliest, was founded in 1609 .

+ See Lecky's Rationalism. 
still in its effects: the working classes, relying upon labour and being made independent by it, cease to be the tools of their masters, and democracy ensues. Finally, the desire for wealth gives a new impulse to human energies, whilst wealth itself promotes the expansion of science, art, and literature. All this chain and interaction of consequences, it is clear, have in the main originated from science.

In the sphere of POLITICS we find the same fact. The invention of gunpowder and the use of it by scientific appliances altered the political organisation of Europe. Cannon, the arm of royalty, destroyed feudalism; the castles of the Barons could not hold on against powder and shot, and the aristocracy, ruled by a power superior to its own, ceased to wage universal war; whilst the musket, against which the armour was no longer proof, destroyed the ascendency of the knight on the battlefield. Cavalry had to yield to infantry. "Force passed from the hands of the nobility to those of the people"; the further ascendency of foot over horse, of musket over lance and sword, being secured by Vauban's bayonet. Gunpowder also permitted dynasties to weld into nations the people of the same kindred - a result which feudalism rendered impossible. It had another effect : it made battles less lengthy, less bloody, and thus had a share in the growth of humanising feelings. The downfall of the political power of the nobility was so much gain to democracy; the desire for political equality was parent to it, and grew apace from the confidence in their own strength which the people gradually felt. Meanwhile, the civil power, too, so arbitrary and inhuman for centuries, underwent numerous alterations beneficial to the multitude. The rise and force of public opinion became a factor with which civil power had to reckon to prevent rebellion and revolution. The influence exercised by the middle classes and due to their possession of wealth; the democratic sentiment due to the craving for freedom-both offspring of the industrial spirit-compelled governments to yield to the aspirations first of the burgess class, and next to those of the working class. The executive became less and less despotic; the franchise 
was granted and extended; savage laws were repealed; numerous laws protecting labour were passed, which embodied the philanthropic tendencies of modern times; liberty of conscience, of speech, of meeting, of publication were demanded and obtained. Class privilege disappeared. Equality before the law came to be a recognised principle in legislation and in the administration of justice. The governmental fabric itself became the embodiment of popular wishes-the people making and unmaking cabinets, and gradually altering the oligarchal form of the body politic until government became either a mixed monarchy or a republic. These vast changes were brought about by the concurrence of numerous causes, no doubt, some of which were distinct or more or less remote from science. They did not come without political convulsions, but these were the explosions of the INDUSTRIAL SPIRIT and its tendencies, struggling for existence and recognition, and breaking up the superficial obstacles which opposed natural growth, so that the industrial spirit, fostered and made day by day more resistless by science and its applications, has been from beginning to end at once the most powerful, permanent, and general cause of the eventful changes just indicated.

Passing on now to RELIGION and RELIGIOUS GOVERNMENT, we find science more mighty than in all else. The conceptions of God and the World which priests and men had formed before the advent of scientific knowledge were very limited and baleful. The earth constituted the universe, the sun, moon, and stars being attached to a solid firmament for the lighting of it. Suddenly Columbus and Copernicus revealed the constitution of the world we live in. A little later, Galileo's telescope revealed a universe undreamt of. The sun, moon, stars are no longer mere flames. The earth becomes a speck-an appendage of the sun; the stars become suns, and their numbers, where none were visible before, are counted by millions and millions; man, who thought himself the centre and purpose of creation, becomes an atom; theological conceptions, in a word, are revolutionised. The universe and its creation, God and His work, appear in their true light, and the notion of the Divinity 
becomes overwhelming. Puerile ideas are swept away, and the whole majesty and incomprehensibleness of the creation are enhanced a thousandfold. God can no longer be represented as an angry Jehovah, swayed like ourselves by petty passions, and ever ready to chastise and scourge His people, but as the Essence of all good, ever shedding beneficence on all the beings and worlds to which it has given existence. Religion became more exalted and sublime. Furthermore, Galileo, after many tentative efforts to the same end for centuries, demonstrated the predominance of law, of which astronomy and physics gave then numerous proofs, but which geology later on made strikingly evident to all minds. This had results of different kinds: it brought about, by its influence on man's thoughts, changes in religious and civil government, which had far greater practical beneficent effects than all the others put together. For the substitution of the conception of permanent law for that of daily supernatural intervention destroyed, though only gradually, but in the end entirely, the belief in witchcraft, evil spirits, magic, necromancy, theurgy, thaumaturgy, sortilege, and sorcery of every kind. This mental disease had for centuries been the cause of abominable horrors. Thousands of victims were daily burnt alive upon suspicion of witchery, by batches of twenty, two hundred, four hundred at a time, even in small towns, and the burnings were regarded as popular festivals - witchery being considered as the working of Satan and heresy. Religious government had become religious terrorism, in comparison with the evil of which the revolting atrocities of the Roman emperors, or the violence of the French Revolution, or the savagery of Dahomey sink into insignificance-into insignificance because these evils were only intermittent and momentary, whereas the religious Reign of Terror lasted without intermission for centuries and centuries, and was a relentless ever-present and ever-active scourge from which no escape was possible. All religions seemed heresies in the eyes of the one in power, and the heretics were looked upon as enemies whom it was righteous to visit with massacre, exterminating wars, torture, and the stake. All these frightful things gradually ceased 
by the evidence which science furnished of the non-existence of witchcraft.

\section{RELIGIOUS GOVERNMENT BECAME MORE HUMANE.}

But the belief in supernatural agency had also demoralised men, clerical or lay: the contemplation of suffering had blunted and even destroyed emotional instincts. Indifference to acts of barbarity, familiarity with the spectacle of daily cruelties, callousness at the sight of the infliction of torture, insensibility to the natural affections had debased humanity as it had never been since it had emerged from the lowest condition of cannibalism.*

The scientific demonstration of the permanence of natural laws revived MEN'S GOOD INSTINCTS.

One of the effects of the belief in witchcraft was of a different kind. It had induced men to entertain a hatred of all intellect and intellectual honesty; "it had induced a negation of everything that was good and noble in morality." * Provided a man believed, the rest did not matter. Justification by faith, not by work, was the one dogma which sanctified all acts-hence denunciations, confiscations, disabilities, imprisonments, tortures, and burnings. Often, too often, alas! faith was only a mask, and those evils were perpetrated for private or corporate benefits regardless of conscience-the clergy seeking the gratification of their greed for lucre and craving for power, the laity the gratification of their passions. So long as the victims were only heretics or persons suspected of heresy or witchcraft, it mattered not.

The promulgation of the doctrine of the permanency of natural law restored mankind to a SENSE OF JUSTICE. And likewise, the belief in the eternal damnation of all but Christians also gave way to the teachings of science and the intellectual elevation it brought in its train; so that science can boast of one of the greatest triumphs of civilisation.*

The intellectual movement originated by science had other effects besides the decay and disappearance of religious persecution. It gave a higher incentive to the performance

* Mr. Lecky. 
of duty, for it decreased the influence of fear as the motive of duty, and substituted for it the "motive of DUTY FOR ITS OWN SAKE." It likewise destroyed the importance of dogmatic teaching, and thereby contributed to bring in the Reformation. It further established the SUPREMACY OF CONSCIENCE, and this now became the prime mover of individual and collective actions.

In the MORAL SPHERE the improvements have been equally important, and are due principally to the same cause -elevation of intellect consequent upon science. Conscience, it was just said, dictates most of our acts nowadays; it also gives us all a notion of right and wrong, and right is no longer considered as based upon statute law, or tradition, or dogma, but upon the notion of ideal justice -hence the substitution of the SENSE OF RIGHT for the fear of punishment as the chief incentive of virtue. In other words, we pursue VIRTUE FOR ITS OWN SAKE. Next, the intellectual movement had a consequence of extreme importance with regard to legislation and the improvement of the penal code, and that was the ABOLITION OF TORTURE in religious, political, and civil procedure. And when we remember the cruelty of its infliction and the variety of its means-fire, water, red-hot pincers, the rack, the wheel, the boots; when we remember that the innocent, even when found so, generally died or were frightfully crippled for life from its effects; that witnesses might be, and were, tortured as well as the accused, we can but bless the movement which swept away this appalling barbarity. So that the humane alteration of the law, together with proportioning the penalty to the offence, is one of the most precious conquests of the present knowledge upon the past.

The elevation of moral sense is seen again in another sphere, that is the search, the LOVE OF TRUTH for its own sake-an element of good which had been absent in Europe for more than a thousand years, from the time of Augustine to the time of Galileo and even Newton's. The Christian Church "supported its teaching by what it called pious fraud"-the name given to imposture and falsehood. This had become a principle of religious government 
and was due "to the doctrine of exclusive salvation." St. Augustine first, and all the doctors who came after him for centuries, made it an act agreeable to God to propagate and strengthen the faith by it mattered not what means, "provided they conduced to the edification of the people" - hence forgeries of sacred revelations, divine decrees, papal bulls, spurious miracles, twenty-five thousand of which are known to have been recorded as actual occurrences between the Vth and XVIth centuries. Mendacity of every description practised by the priesthood of Europe was the usual device resorted to to keep a hold upon the converts and the faithful. Absolute credulity, as all writers have remarked since the XVIIIth century, was inculcated as a virtue, and doubt punished as a crime. The moral type had become perverted.

Science and its intellectual consequences brought back TRUTHFUL SPIRIT. It caused the disappearance of doctrines which clashed with conscience and are opposed to our moral sense. "Science made men intolerant of what is false"; scientific truth, whatever its effects, is now received as the revelation of divine law, whilst the practice of truthfulness has become the principle of our conduct.

Modern Philanthropy is another sphere in which the intellectual movement inaugurated by scientific knowledge has played a conspicuous part. Philanthropy is the essence of true humanity. It existed before science. The poor were tended, and tended tenderly, it is only fair to acknowledge, by the religious power. But it was limited to the distribution of alms and the institution of hospitals. Modern philanthropy is far deeper and wider. It has become, as it has justly been observed by recent writers, what asceticism was in the Middle Ages, a ubiquitous fact which pervades the whole European community. Sympathy with suffering, so restricted until the XVIIIth century, is one of the vital sentiments which makes our age so superior to all ages. It is the soul of philanthropy. It has caused the disappearance of barbarous habits and cruel amusements; it has extended to the enemy fallen on the battlefield; it has brought in tenderness in the treatment of the epileptics and lunatics who were tortured as demoniacs; 
it has led to the creation of innumerable beneficent institutions and associations, of friendly societies, all of them regardless of creed; it has induced the wealthy to consider it a duty to use part of their wealth in benefactions; it has killed indifference to the misery of the disinherited, drawn every one of us nearer to the lonely, elicited help from all to all; it has led to the abolition of slavery-the shame of modern times; it is being extended to subjected races; it has, in short, given new features to Europe and America. It is not too much to say that the XIXth century laws protecting the weak and the laborious are the living embodiment of UNIVERSAL SYMPATHY. To this great work many simultaneous causes may again be assigned; but the paramount cause was intellectual elevation born of science, and this embraces several of the concurrent elements. The movement was made decisive and irresistible by the descriptions of the appalling miseries of the poor classes and the impetuous torrent of splendid eloquence of Rousseau, the father of the poor and of democracy.

The ideas which SWEPT away RELIGIOUS TERRORISM and PERSECUTION, TORTURE, MENDACITY, and BROUGHT in PHILANTHROPY, were exceedingly slow to germinate. They took over two hundred years to have practical effects. They were at first opposed by an aggravation of the evils they were intended to destroy; they were combated by men-of-tradition, by scholars, by princes and law-makers; they were anathematised by the churches. of all denominations; they were checked by fire and sword, exile, confiscations, expulsion, law, by the whole "panoply of brute force;" but they were triumphant in the end, just as the Christian idea had been against the might of the Roman Empire fifteen hundred years before. And they conquered because they were supported by advocates of intellect and eloquence, who devoted their lives and energies to their propagation, fearless of prison and gibbet. These benefactors of the human race are to this day denounced by those who were stripped of their sway and who cannot brook their defeat. The weapon used by the vanquished to revile 
the victors is the only one that remains in their hands, viz., calumny. The benefactors are called scoffers, abettors of Satan, atheists; the faithful are warned against reading their execrated works if they cherish religion, and the innocent and pious Christians live on in the ignorance of the evils destroyed and the good done by John Weir and Cornelius Agrippa, by Montaigne and Charron, by Descartes and Locke, by Bayle and Voltaire, by Middleton and Rousseau. Nor should we omit Raynal, whose animated cosmorama, which rapidly went through twenty successive editions and was read by all in every part of the world, gave currency to the ideas of the time and universally popularised them.* These were the true deliverers.

They did not attack things truly holy any more than Luther had done before. Nor did they use the extreme violence, crudity, virulence, and coarse invectives which Luther poured out in his six thousand pamphlets. Far from assailing the essence of the Christian teaching, they on the contrary fertilised the precept of the modern world, "Love one another." This sublime precept had until then practically remained a dead letter in Europe. For ages it had been replaced by the Inquisitors' tacit command, "Hate one another," "Kill all those who differ from us in opinion" -a command not expressed in words, but acted upon with ferocious ruthlessness against the so-called heretic, Mussulman, Jew, Indian; against Protestants in Roman Catholic kingdoms, against Romanists in Protestant countries. Whereas Christian charity, so distorted by fanatical teachers and so barren until the XVIIIth century, was of all others the one seed which the benefactors we just mentioned disseminated all round. They it was who brought into fruition the radiant doctrine of brotherly sympathy, enlightened as they were, not by dogma, but by the SPIRIT OF TRUE HUMANITY. But they attacked, and attacked fiercely, "with an eloquence and force never surpassed," $\dagger$ a religious tyranny and an unscrupulous sacerdotal order. They, like

* Mr. Fohn Morley's Encyclopadists.

† Mr. John Morley. 
Luther, assaulted illegitimate and untenable dogmas and a spurious and despotic hierarchy. Their onslaught was, with equal energy, also directed against social and political evils. And because the privileged interests they overthrew were more numerous than those assailed by Luther, their traducers are also more numerous than those of Luther-they include all the social, political, and religious supporters of bygone systems. The representatives of the dethroned castes, still trained in the traditions of the past, raise a cry which appeals to the indiscriminating feelings of artless souls. For in order to decoy the pious into credulity and enlist their aid; in order to keep on their remaining authority ; in order to put out of sight the real causes of the conflict, they raise the cry of "Religion in danger!" Once more, it was not religion which was attacked, but its pseudo-priests.

The victors were not faultless; they were in the fierceness of the strife, often unjust and one-sided; they were assisted by a few irreverent, offensive, and discreditable coadjutors; they often were inexact and superficial; they frequently were extravagant and paradoxical; the lives they led were not exemplary-all this is true. But they fought stoutly and well the great BATTLE OF HUMANITY AGAINST INJUSTICE; they thought not of themselves but of mankind alone; they daily risked imprisonment, fines, exile; and when we are told, "Touch not their books," let us at least remember that the authors above mentioned did more than armies for the abolition of persecution, of torture, of mendacity, and the rise of modern philanthropy, liberty of conscience, political equality, and social regeneration.* And they did so much because they were the exponents of the ideas born of the sciences, without which all human efforts would have remained fruitless.

The proposition which was laid down at the beginning of this concluding chapter has now, so far as this survey permits, been fairly substantiated: science has been, in the main, the prime mover of all that is highest in civilisation, .as it has been in all that is material. It is, from all

* Mr. John Morley. 
points of view, the chief force which has directed progress, improved society, embellished man's life, shaped the modern world. Such are its results. And if by the side of this philosophical conclusion, the writer has in any degree succeeded in conveying a pretty clear notion of the origin and growth of science to the student of scientific history, he will have contributed a spark to the present enlightenment, and thus accomplished his humble task. 

APPENDICES. 
Appendix A. Eminent

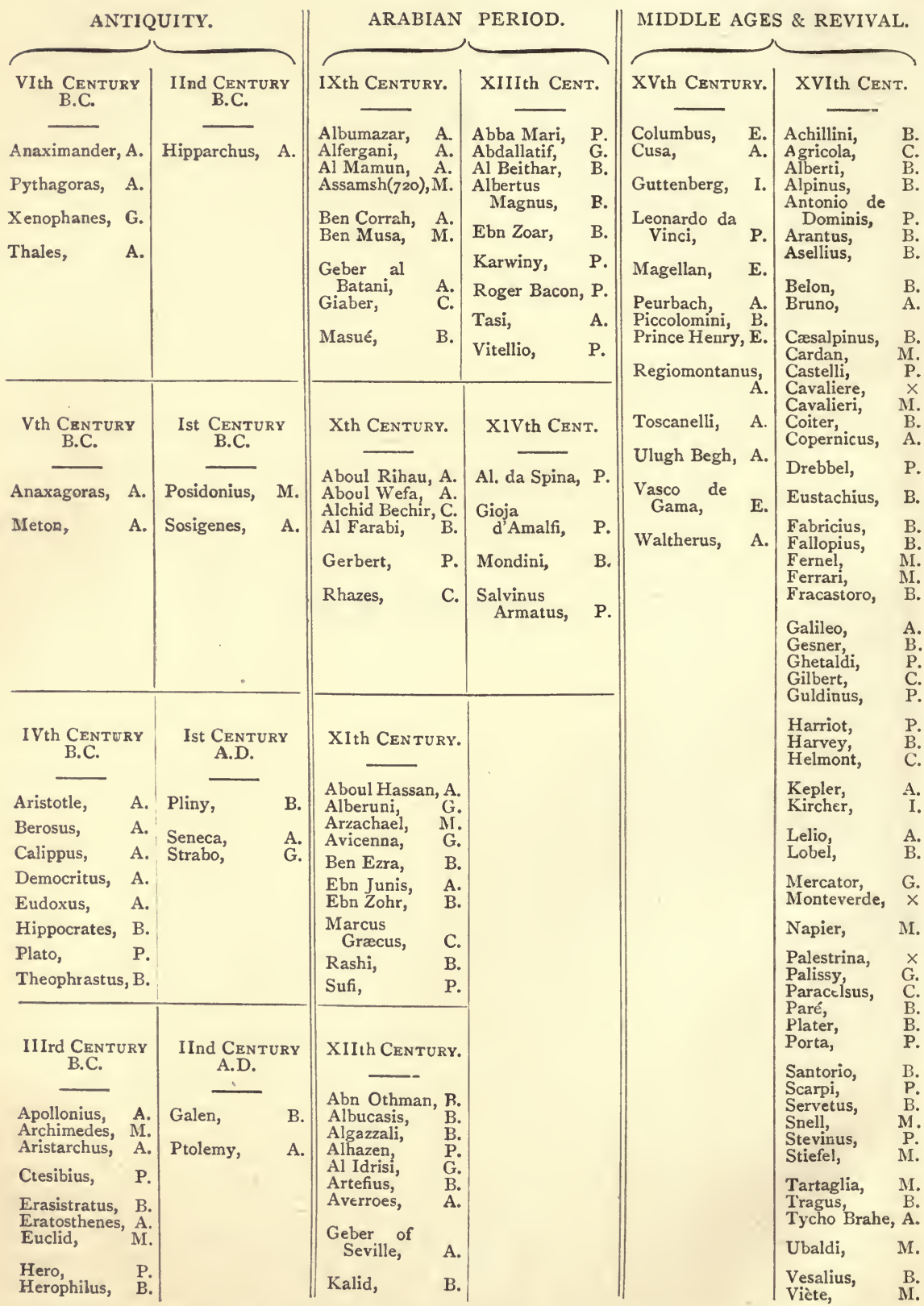

* The letters A, B, C, E, G, I, M, P, S, respectively stand for Astronomer, Biologist, Chemist, Explorer, Geologist, 
MODERN PERIOD.

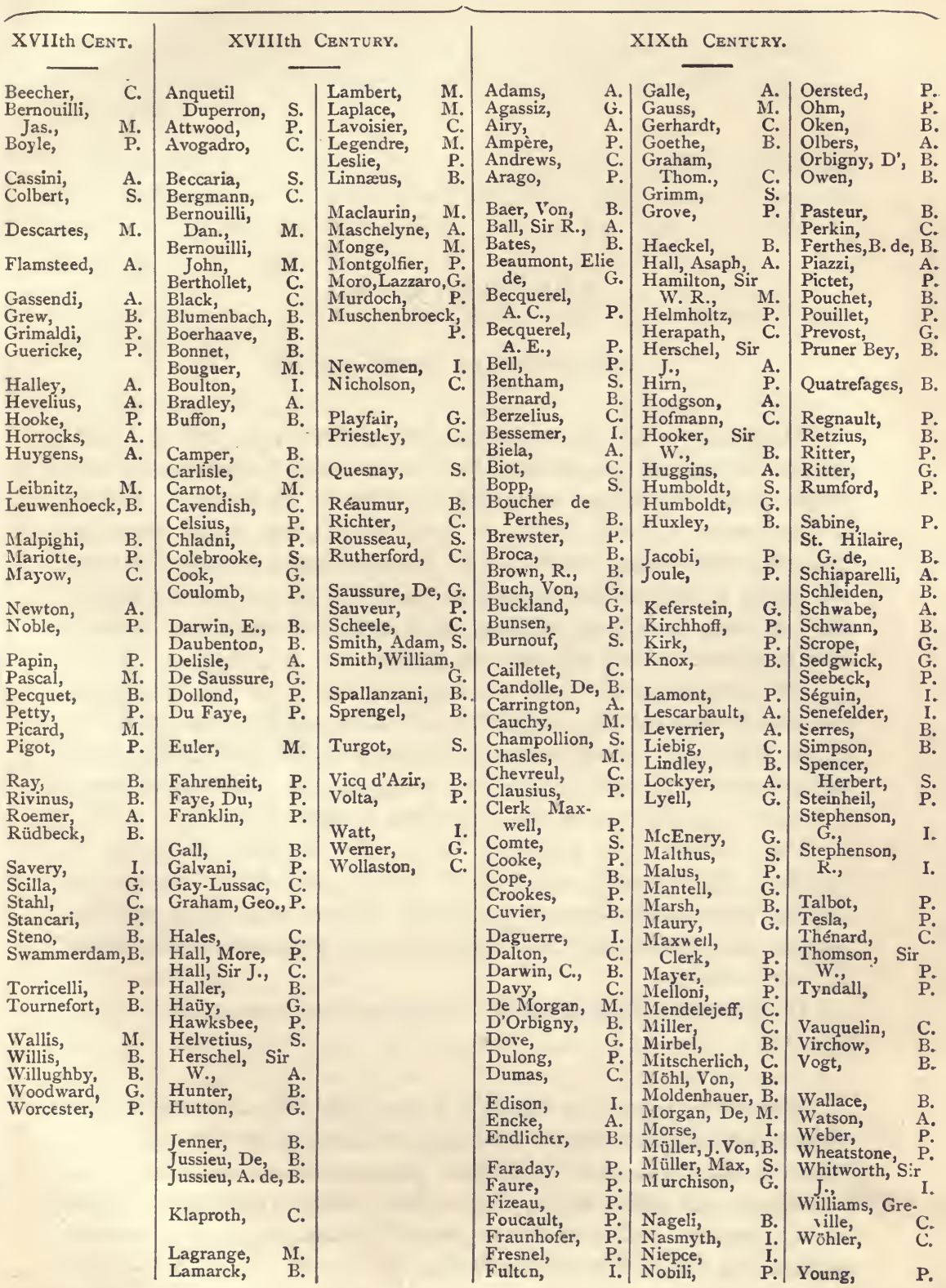

Inventor, Mathematician, Physicist, and Scciologist, taking these titles in their widest sense. $\times$ Music. 


\section{APPENDIX AA.}

\section{Definitions of the Sciences.}

Mathematics (Greek, $\mu a \theta^{\prime} \mu a \tau a$, from $\mu a \nu \theta a \nu \epsilon \nu$, to know). This science is that of magnitudes (or of quantities) whether in time or in space; it bears upon rigorous truths which reason is capable of discovering without the aid of experiments, but which, nevertheless, experiments can confirm. It is a deductive science-so that it is wrong to believe that deductive reasoning should be discarded; the fact being that both deductive and inductive reasoning must be used in science-both are equal in power.

Mathematics is an exact science par excellenie. It is divided into two chief branches : arithmetic (of which algebra is an offshoot), or the science of numbers, and geometry and its offshoots (trigonometry, conic sections, mechanics, etc.), or the science of space or extent. (A fuller subdivision is given at page 197.)

This science was cultivated from the earliest antiquity, in Chaldæa, Egypt, India, and even China. It passed from Egypt into Greece, where its limits were extended. It was reserved to modern times to make mathematical discoveries and applications which may be called sublime.

The practical importance of this science has been pointed out at page 198.

Mechanics ( $\mu \eta \chi a \nu \eta$, a machine), that branch of mathematics which considers the nature and laws of moving powers with their effect in machines, and the nature, generation, and communication of motion; in other words, the science which treats of the laws of equilibrium and motion, or which demonstrates the laws of motion and mechanical combinations. 
Statics ( $\sigma \tau a ̂ r o ́ s$, remaining still). A branch of mechanics. That branch of mechanics which considers the relations of forces which act upon bodies at rest.

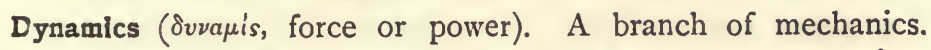
That branch which treats of the action of force in producing motion. It is divided into two parts :

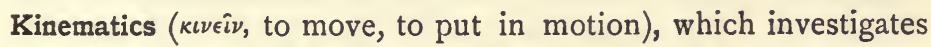
the circumstances of mere motion without reference to the bodies moved, the forces producing motion, or to the forces called into action by the motion;

Kinetics (кiveiv), which investigates the nature and relation of the forces which produce motion.

Astronomy ("̋ $\sigma \tau \rho o v$, a star, voros, law) is the science of celestial bodies. It includes every notion relating to planets and stars, to their motions, distribution in space, their respective distances, their physical constitution, and the reciprocal influence which they exercise upon one another.

The utility of astronomy, apart from its sublimity, gives it the first rank among sciences. Astronomy, in the first place, serves to measure time and fix chronological periods; secondly, to determine the different points on the surface of the globe ; thirdly, to regulate navigation.

This science-although it degenerated into astrology at times, and thus hardly deserved the name of science-is one of the most ancient; but it was in modern times only that a real knowledge of the constitution of the world was attained.

Geography ( $\gamma \hat{\eta}$, earth, $\gamma \rho a ́ \phi \epsilon \iota$, to describe) is the description of the earth; it embraces everything relating to the state or condition (either natural or artificial) of the globe which we inhabit. It is divided into three branches:

(I) Mathematical geography, the object of which is to determine the shape and dimensions of the earth, its relation to the heavenly bodies, the relative positions and distances of places on its surface, and the representation of the earth upon globes or maps;

(2) Physical geography, the object of which is the description of the principal features of the globe's surface (seas, continents, islands, mountains, valleys, rivers) with their extent and configuration. Meteorology and climatology belong to this branch, and hence, also, the distribution of plants and animals in every part of the earth; 
(3) Political geography, the object of which is to consider the earth as the habitat of the human species. It defines the territories of different nations, and treats of population, morals, religion, government, wealth, civilisation. It might be considered as a branch of history and statistics.

Geography has deserved the name of science only in modern times, although the Arabs made great advance in it; for in modern times only have we arrived at a complete knowledge of our planet.

Geology ( $\gamma \hat{\eta}$, earth, גóyos, discourse), or the science of the earth, treats of the physical constitution of our globe. It is called geognosy when it is limited to the study of the structure, the respective situation, and the nature of the matter composing the earth; but it receives the name of geogeny when it aims at combining observed facts in order to ascend to the causes, finding the laws which regulated the formation, and explaining the very origin of our globe.

This science is quite modern, although antiquity (Pythagoras, Aristotle, and Strabo, for instance) had very clear notions about geological problems; but until the Arabs and Leonardo da Vinci, none of the germs of its study, which is one of persevering observation, can be said to have existed.

As a practical science it is hardly necessary to point out how important to our material welfare the study of the earth's crust is, especially in these days when mining has become the greates industry of mankind; in its philosophical bearings it is of greater importance still, throwing light as it does upon the history of extinct species and the antiquity of man.

Physics or Natural Philosophy ( $\phi \dot{v} \sigma \iota s$, nature). The most extensive sense of natural philosophy is that which Sir John Herschel has given to it, viz.: "to describe the phenomena of nature, to show their causes, and to analyse the constitution of the Universe." But the study of nature has developed so immensely in recent times, that natural philosophy has been divided into many branches, each of which has received its characteristic denomination, such as heat, optics, acoustics, magnetism, electricity, chemistry, etc.-the lastmentioned becoming an entirely distinct science. The chemist studies the phenomena which depend upon the specific properties of substances, whereas the physicist studies the phenomena which result from the aggregate properties of bodies. At present, therefore, the name of natural philosophy is more or less restricted to the knowledge of matter independently of the molecular composition of bodies. 
Archimedes's discoveries were, strictly speaking, the startingpoint of physics, but Galileo immensely extended the area of the science by connecting isolated facts with general principles, and by founding dynamics. To Aristotle we owe the scientific method of studying the phenomena of nature, namely, observation, experiment, and induction - what is, in fact, called the inductive method.

It is scarcely necessary to add that science has been revolutionised by the discoveries made in physics in modern times, and that humanity is indebted to them for the increased prosperity it now enjoys.

Barology (Bápos, weight, or $\beta a ́ p \epsilon \iota \nu$, to weigh down), the science of weight (gravity) in solids, liquids, and gases. The study of gravity in liquids is subdivided into four branches :

Hydrostatics ( $\tilde{\delta} \delta \omega \rho$, water), the science of equilibrium of liquids and of the pressure they exert, whether within their own mass or on the sides of the vessels in which they are contained;

Hydrodynamics is that branch of physics which considers the motion of liquids;

Hydraulics considers the application of liquid motion to machinery, and the application of mechanical force to procure required motion in liquids; in other words, hydraulics is the application of the principles of hydrostatics to conducting and raising water in pipes ;

Hydromechanics is concerned with the energy of machinery in its application to fluids.

Thermology ( $\theta^{\prime} \rho \mu \eta$, heat), the science of heat, the phenomena of which are, next to those of gravity, the most universal in the economy of the world. Heat is the chief antagonist of gravity. Gravity presides over the geometrical and mechanical action of bodies, while heat relates either to the state of aggregation or the composition of molecules. Gravity tends to agglomerate bodies, heat tends to disintegrate or separate them. The application of heat constitutes the chief action of man upon nature.

The study of heat is quite modern, since it was the great discovery of Black (at the end of last century) which imparted to it a scientific character.

Acoustics (ảkov́єtv, to hear) is the science which considers the phenomena of sound. 
Optics (örтона, to see) considers the phenomena of light (and vision). It is subdivided into:

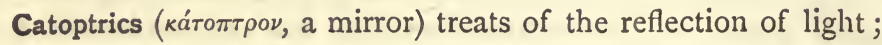

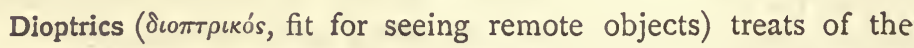
effects produced on rays of light passing through different media, as through glass, water, air ; in other words, it treats of the refractions of light ;

Diffraction is a change which light undergoes, when, passing very close to the borders of an opaque body, it forms parallel bands or fringes.

Electrology ( $\eta \lambda^{\prime} \lambda \kappa \tau \rho o \nu$, amber) is the science which considers the phenomena and laws of electricity - a subtle fluid or agent, usually excited by friction. The phenomena of electricity are such as attraction, repulsion, certain luminous appearances, physiological effects, light, heat, mechanical violence, etc. It is the most powerful agent with which we are acquainted.

Although it has exercised the attention of men ever since Thales (600 B.C.), it has become a subject of study only since Gilbert ( 1600 A.D.). But it advanced only after Franklin and Volta. The services it has rendered to science and the application of science, to the material improvement of the social system, since it vies with steam in procuring us the benefits to be derived from rapid intercommunication, are too numerous and too well known to necessitate more than an allusion here.

Chemistry ( $\chi v \mu \epsilon^{\prime} a$, mixture). Physics is divided into two principal branches-physics and chemistry-each distinct from, although intimately bound with, the other. Physics embraces the phenomena and laws regulating the general properties of bodies regarded in the mass ; chemistry embraces the particular phenomena modifying the specific properties of matter-it relates, not to masses, but to molecules. Chemistry has, therefore, for its object the modifications that all substances may undergo in their composition, alteration, decomposition, in virtue of their molecular reactions. Without this new order of phenomena, the most important operations of terrestrial and celestial nature would be incomprehensible to us, and there is no other class of phenomena so intimate and so complex.

Theoretical chemistry was until lately divided into inorganic (mineral and gaseous) and organic (plants and animals) chemistry; but the more advanced chemists refuse to admit this distinction. 
Applied chemistry (or practical chemistry) is subdivided into many branches-medical, industrial, agricultural, etc.

It is a modern science, although chemical processes were known in antiquity and the Middle Ages, since metallurgy, pottery, the use of alkaline, acid, and saline substances, the preparation of drugs, perfumes, colouring matters, were by no means unknown; but the want of knowledge of the laws which govern matter led experimental observers into alchemy, or attempts to convert common metals into gold. The alchemists, it must be owned, made many important and useful discoveries, but the XVIth, XVIIth, and XVIIIth centuries witnessed their gradual disappearance. Like steam, chemistry has become one of the greatest elements of progress and wealth in the world.

Biology (Bios, life) embraces the study of the phenomena of life, whether vegetable or animal. Some of these phenomena are explained by the general laws of physics and chemistry; others, on the contrary, escape all explanation of that kind, and constitute what may be called the vital phenomena properly speaking, and these are the object of biology. This science therefore includes anatomy, physiology (of plants and animals), palæontology, and anthropology. Biology may be said to have received its first impulse from the anatomists of the Revival period.

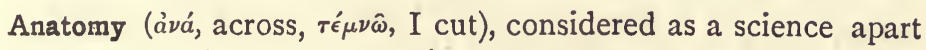
from dissection, is concerned with the study of organised beings (whether vegetal or animal), to discover the organs and elementary parts which enter into their composition, not only as regards form, structure, connections, physical properties and functions, but also as regards texture, chemical properties, development, and alteration. It is the basis of zoology, physiology, and medical science, and therefore intimately bound to these. It is divided into human, comparative, and vegetal anatomy.

The science originated among the Greeks, but in modern times only was it cultivated with success after Mondini and Leonardo da Vinci.

Physiology ( $\phi \dot{v} \sigma \iota s$, nature) deals with the phenomena of life, and is almost synonymous with biology-yet, there is a difference, for if in many instances the scope of biology and physiology is absolutely identical, biology embraces the phenomena of life which are more intimately bound with the exterior world-that is, the most general phenomena of life, whilst physiology is more intimately bound with the classes of phenomena which affect particular individual orders 
of beings (vegetal or animals). The phenomena resulting from change of habitat, food, temperature, health would fall more within the domain of physiology than within that of biology. The fact that physiology may affect the moral and political sciences makes it one of the most important studies we can pursue.

This study may be said to have been originated by the Greeks, but in recent times only has it been completely detached from metaphysics, which impeded its progress.

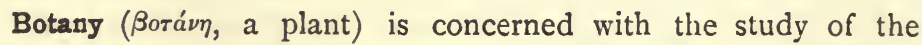
vegetable world. It is of extreme antiquity, but modern botany was inaugurated by Linnæus and Jussieu.

Zoology ( $\zeta \hat{\omega} o \nu$, animal) is that part of natural history which treats of animals. It embraces the study of exterior organs (descriptive zoology), interior organs (comparative anatomy), and the functions of each organ (which is a section of physiology). The ancients, Pliny particularly, left very interesting descriptions of animals. The science was revived by Gesner in the XVIth century. It has been immensely extended in recent times.

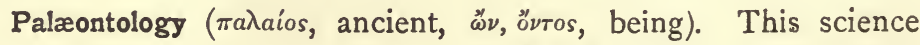
treats of the beings whose remains are found buried in the crust of the earth, or who lived at different geological periods before the species which inhabit its surface at the present time. This term is generally applied to the study of fossil zoology, but it also refers to the fossil vegetable kingdom, so that palæontology is an extension of botany and zoology. It is, of course, closely connected with geology, and is, like the latter, of modern growth.

Anthropology ( $a \theta \rho \omega \pi \omega s, \mathrm{man})$ is the natural history of man considered and studied in his diverse varieties. It is altogether of recent origin. It will acquire the greatest importance when time has matured its results, for laws and governments will be framed more in accordance with the physical and mental requirements of each race than in accordance with tradition and abstract ideas.

Sociology (socius, an ally), or social science, treats of every question relating to the organisation and well-being of communities. It embraces therefore, jurisprudence, government, education, punishment, legislation, public morality, public health, and political economy. Of all these, political economy was the latest founded, at the end of last century. 


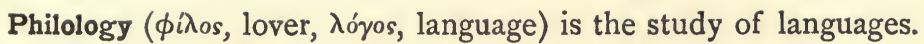
As an instrument of historical research and anthropological studyespecially in questions of origin, descent, and race-philology has proved one of the most interesting and fruitful branches of human knowledge. On the Continent, comparative philology has received the name of linguistique, the term philology referring only to the study of a particular language in its entirety (i.e., grammar, etymology, lexicology, filiation, interpretation, and criticism). Phịlologists are inclined to settle question of origin and distinctions of race by philology; but we must beware of hasty conclusions of this kind, for identity of speech by no means implies identity of race; distinction of race mainly rests upon physical and mental characteristic differences which are not affected by language; in other words, a form of speech may have spread by conquest or otherwise to different races, and these races remain distinct, the co-existence of speech notwithstanding. 


\section{APPENDIX I.}

\section{Aristotle on Experience.}

I. "Let us first understand the facts, and then we may seek for the cause." (De Part. I. I, 639.)

2. "Reasons not drawn from the inherent principles of things are hollow. The hollow argument seems potent, but is powerless." (De Gener. Animal. III. Iо, 760.)

3. "There are not facts enough to warrant a conclusion, and more dependence must be placed on facts than on reasonings, which must agree with facts." (On the Parthenogenesis of Bees, De Gen. Animal. III. Io, 760.)

4. "The peculiar principles indeed in every science are many, hence it is the province of experience to supply (furnish) the principles of everything ; for, from phenomena being sufficiently apprehended, demonstrations have thus been invented (found) in every art and science." (Prior Anal. 1. 30.)

5. "From sense, therefore, as we say, memory is produced, but from repeated remembrance of the same thing, we get experience, for many remembrances constitute one experience." (Post An. II. I8.)

6. "The reason why men do not sufficiently attend to facts is their want of experience. Those who are accustomed to physical inquiries are more competent to lay down the principles which have an extensive application. It is easy to distinguish those who argue from facts and those who argue from notions." (De Gen. I. 2, 3 I6.)

7. "We do not possess scientific knowledge through sensation, neither is sense science, though they are employed about the same things, for sense apprehends particulars (facts), science universals (laws)." (Post Anal. 1. 3r.) 
8. "Some philosophers, treating of phenomena, say things which by no means correspond with the phenomena-the cause being that they have not rightly conceived principles, but reduce everything to prescribed notions, and they persist in these, despite all the contradiction which phenomena give them." (De Coelo II. I3; III. 8.)

(Is not this last citation the severest censure ever passed on the schoolmen's process and Bacon's work ?)

9. "Aristotle's reliance was on experience and induction-the one furnishing (particular) facts, from which the other found a pathway to general facts (laws)." This remark is quoted from the Life of Aristotle by G. H. Lewes, who cites numerous passages from Topics I. Io, also Post Anal. I. 31, Hist. Animal. I. 6, in support of it. Our limits do not allow us to do more than refer to the works.

Io. "Without sensation thought is impossible. It is from sense that we gain knowledge of particulars (facts). It is from induction that we gain knowledge of universals (laws) - and these can be reached only through experience."

This is a summary of what is explained in De Sensu vi. 445 ; De Anima iIr. 3, 8, 432 ; Metaph. Iv. 5, and elsewhere.

II. We have to remind the reader that Aristotle's Organon includes 242 chapters, and is all devoted to the elucidation of the Syllogism, Induction, and Experience-so that the quotations we have given are but an insignificant fraction of the whole; but they will, we think, be sufficient to prove Aristotle's lucidity and competence. 


\section{APPENDIX II.}

\section{ARISTOTLE ON INDUCTION.}

I. "Induction is nothing but the Syllogism without a middle term." (Prior Anal. II. I2.)

2. "Induction is the pathway which leads from the particular to the general." (Topics I. ro.)

3. "There is no induction without generality." (Pr. An. II. 22.)*

4. "Induction is a progression from singulars to universals. . It is more persuasive, clear, more known according to the sense, and common to many things; syllogism, on the other hand, is more cogent and efficient against opponents in disputation" (on account of the presence of the middle term). (Top. I. 12.)

5. "We believe all things either through syllogism or from induction. ... Induction, then, is the inductive syllogism. ... It is occurrent in those demonstrations which are proved without a middle term. ... Induction is more evident" (because general). (Prior An. II. 23.)

6. "Universals (general laws) depend upon induction, but induction depends upon sense." ... "It is (also) clear that if any sense be deficient, a certain science must also be deficient (i.e., a blind man could not study colours, astronomy) . . . since we learn either by induction or by demonstration. Now, demonstration is from universals, but induction from particulars (i.e., particular facts). . . . It is impossible for those who have no sense to make an induction, for sense is conversant with singulars (i.e., particular facts), since the knowledge of them cannot be received, nor can that knowledge be obtained from universals without induction, nor through induction without sense." (Post An. I. 18.)

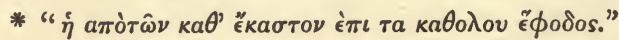




\section{APPENDIX III.}

\section{Aristotle on Syllogism.}

I. "A syllogism is a sentence in which ascertained things being laid down, something else different necessarily results, in consequence of their existence." (Examples are given all through. Prior An. I. I.)

2. "A syllogism, then, is a discourse in which certain things being laid down, something different from the posita (premises) happens from necessity through the things being laid down." (Top. II. I.)

3. "Evidently, then, all syllogisms are produced through the middle figure." (Pr. An. II. I2.)

4. "The enthymeme is a kind of syllogism-a short syllogism -an argument of two propositions-one antecedent, another a consequence deduced therefrom."

5. "The enthymeme is that discourse which forces consent through propositions assented to." (Rhet. II. 22, Pr. An. II. 27.)

In like manner are all the different kinds of syllogism, the catasyllogism (Pr. An. II. I9), the parasyllogism (Top. I. I), the elenchus (Pr. An. II. 20), the epichereme (Top. II. 5, viII. II), and others, defined and explained.

We have only to add that Aristotle, having shown the laws of the syllogism and its many varieties, and furnished examples to illustrate its transformations in all ways, never used, nor taught any one to use, the syllogistic method (i.e., the schoolmen's process) in any of the rational or experimental sciences. The schoolmen reduced Aristotle's process to a mere method of argumentation. 


\section{APPENDIX IV.}

\section{Leonardo's Physics.}

Dr. Whewell, who seems to have studiously screened from view the claims of Leonardo da Vinci to be considered as a powerful exponent and advocate of experiment and induction more than a century before Bacon, has to acknowledge Leonardo's greatness as a scientist.

I. "Leonardo," he says, " understood before Stevinus the oblique action of pressure;

2. "Entertained the hypothesis of the earth's rotation;

3. "Gave a perfectly correct statement of the proportions of the forces exerted by a cord which acts obliquely and supports a weight on a lever. He distinguishes between the real levers and the potential levers; i.e., the perpendiculars drawn from the centre upon the directions of the forces. Nothing can be more entirely sound than this. It is quite as good as the proof of Stevinus. These views must have influenced Galileo's reasonings concerning the lever.

4. "Leonardo," he goes on, "also anticipated Galileo in asserting that the time of descent of a body down an inclined plane is to the time of descent down its vertical height, in the proportion of the length of the plane to the height."

The reflection which these quotations suggest, Dr. Whewell has the good grace to own, is that "both the heliocentric doctrine and truths of mechanics were fomenting in the minds of intelligent men, and gradually assuming clearness and strength, some time before they were publicly asserted."

And this being the case, what are we to think of Dr. Whewell's award of the palm of knowledge and influence to one who knew 
nothing of such matters, and scorned them as trumperies if they were pointed out to him? It is simply incredible-and yet it is a fact.

It would have been easy for Dr. Whewell to give a fuller and more adequate sketch of Leonardo's scientific worth, had he been animated by a sincere desire to tell the whole truth and nothing but the truth, instead of seeking to inflate a huge air-bag, for he had only to quote the language of the great Italian which we have cited (pp. 104-107), or give the passages which show that Leonardo understood before Galileo the problem of the acceleration of velocity in falling bodies :

5. "If a weight falls from 200 fathoms, how much quicker will it fall through the second Ioo fathoms than through the first 100 fathoms" (le seconde cento braccia che le prime).*

6. When we bear in mind that Leonardo was a musician, an inventor, a mechanist, a chemist, an engineer, an anatomist, a poet, a painter of the highest order, besides being a philosopher, a mathematician, a physicist, a geologist, an artillerist (for there exist in the British Museum specifications, with drawings by himself, of a steamcannon which he suggested!), it is doubtful whether the world ever saw a genius so universal and marvellous as this great man. $\mathrm{He}$ had, beyond all others, that practical and scientific training which enabled him to formulate the law of research with the authority of a thorough master who had manipulated and investigated all he spoke about. Yet, we find people who do not even deign to mention Leonardo among inductive philosophers-a judgment on their part which it is only charitable to ascribe to ignorance.

* For further information see Ventori's Essay on Galileo's Physics, and Essay on the Physico-Mathematical Works of Leonardo. Paris, I797. 


\section{APPENDIX V.}

Sir David Brewster on Induction.

"In a letter from Tycho Brahe to Kepler, the great observer urges his pupil 'to lay a solid foundation for his viezes by actual observations, and then by ascending from these to strive to reach the cause of things." "

"The reasonings of Copernicus, who preceded Bacon by more than a century, were all founded upon the most legitimate induction."

"Leonardo da Vinci had described in the clearest manner the proper method of philosophical investigations."

"The whole scientific career of Galileo was one continued example of the most sagacious application of observation and experiment to the discovery of general laws."

"Dr. Gilbert had exhibited in his treatise on the Magnet the most perfect specimen of physical research." (Nezuton, p. 33 r.) 


\section{APPENDIX VI.}

\section{Descartes' Achievements.}

As the short notice we have on Descartes fails to do full justice to this great man, a few more remarks about him will not be inappropriate.

His influence is twofold: philosophical and scientific. It is easy to detect the consequences of Descartes' philosophy on the one hand, and those of his scientific labours on the other.

His Philosophy, in the first place, ruined Scholasticism definitively; in the second place, it brought in the taste for psychological analysis, which was to distinguish the age of Louis XIV.; in the third place, it supplied material for Idealism, Pantheism, Materialism, and Positivism, since it gave birth successively to the philosophy of Malebranche, to Spinoza's, to Leibnitz's, Locke's, Berkeley's, Hume's, Cabanis's, Condillac's, and, through Spinoza, to Kant's, Schelling's, Fichte's, Hegel's, and last, Comte's.

With reference to Science, he was the first in modern times to sketch the theory of association of ideas (see Aristotle); he discovered the theory of reflex action-a profound idea which modern science has expounded. He analysed musical sounds geometrically, and found out that the number of vibrations producing the notes are in the inverse ratio of the lengths of the chords; he was the first to maintain that Major Thirds are not discordant but concordant. But his greatest scientific feat was mathematical-his application of algebra to geometry extended the power of mathematics tenfold, and made the road of Newton, Laplace, Legendre, Gauss, and others less arduous to ascend. By his inquiry into the nature of certainty-his best known claim upon us- "he stands as the founder, not of modern philosophical criticism only, but of 
modern philosophy itself" (Huxley). And look at the effect suddenly produced by the appearance of a genuine philosopher ! Descartes' influence was immediate and lasting. No sooner had he conceived his philosophical scheme than an immense sensation was created throughout Europe. He was at once read, discussed, commented, admired in every country. His reputation was so universal that Queen Christina invited him to come to her. His "Physics," though unsound, (?) were nevertheless taught everywhere for one hundred years, so commanding was his influence. His theory of Vortices at least propagated the general notion of regular laws. If his doctrine of Vortices was discredited, the cause must not be sought in the fact, as some think, that it was intrinsically absurd and inconceivable, but in the fact that it could not give results in accordance with the heavenly bodies (Jevons). Besides, may it not be said to be revived in a different form by the theory of Vortices of Helmholtz and Thomson (Lord Kelvin)?

The Cartesian School-the effect of which was the complete severance of ethics from revealed theology-affected all the branches of moral philosophy - logic, ethics, theology, metaphysics - and bears witness to the weight and greatness of its founder. It may be doubted whether any genius, ancient or modern, Aristotle-and perhaps Galileo and Newton-excepted, ever exercised so powerful and universal an influence as Descartes, considering the impulse which his ideas, doctrines, and principles gave to philosophical thought and scientific activity. 


\section{INDEX.}

AвbA Mari, "Almagest," 40.

Abbon of St. Germain, 48. Abdallatif, Animals and Plants, Nile Mud, 4I.

Abderrahman III., 30.

Abelard, 44, 65.

Aberration of Fixed Stars, 203.

Abn Othman, Zoology, 4r.

Abolition of Torture, I 55, 304 .

Aboul Hassan, Diopters, 34 .

, Rihau, Ecliptic, Quadrant, 34

"Wefa, Variation (of the

Moon), Obliquity, 34.

Abur Raihân, Tables of Sp. Gr., 37.

Academy del Cimento, 6r.

Accumulation of Astronomical

Facts in the XVIIIth Century,

272.

Accumulator, Electric, 257.

Accuracy of Instruments, 268.

Achillini, 62, 96.

Acids, 37, 38 .

Acoustics, 219, 220, 227 ; Definition

of, Appendix AA.

Acquirements in Islam and Christendom, 46.

Aerolites, 212.

Aerometer, 42.

Aerostation, 224.

Affiliation of Discoveries, 73.

Agassiz [Geol.], I44; Ice Age, I67.

Age of Engineering, 275.

" Machinery, 275.

" Steam and Electricity, 274 .

" Steel, 262, 263, 275, 283.
Agricola, 56, 98.

Air, Pressure and Weight of, I92, 215, 216.

Air Pump, 216, 2 I9.

Al Batani (Albategnius), The Year,

Tables, 33.

Al Beithar, Botany, 4I.

Alberti, 97.

Albert of Saxony, 44.

Albertus Magnus, 44, 65 ; Work of, 74,90 (note).

Alberuni, Minerals, 4I.

Albucasis, Surgical Instruments, 39.

Albumazar, Tables, 3.3 .

Alchemy, Importance of, 70, 72 .

$$
\text { , 270, } 283 .
$$

Alchid Bechir, Phosphorus, 38.

Alcohol, 37.

Alcoholometer, 232.

Alcuin, 47.

Alessandra da Spina, 53.

Alexandria, I9.

Alexandrian Museum, 19, 27.

Al Farabi, Respiration of Plants, 4I.

Alfergani, Astronomical Calculations, 33 .

Alfred the Great, 47.

Algazzali, Certainty of Knowledge, 42.

Algebra, 33, 44, 53, 56 .

" applied to Geometry, IgI.

" Double, 196.

Alhakem's Library, 43.

Alhambra, 31. 
Alhazen, Density of Atmosphere, Nature of Vision, Optics, Refraction, Retina, 35; Atmospherical Refraction, Capillary Attraction, Centre of Gravity, Convex Lens, Gravity, Height and Weight of the Atmosphere, Hydrostatics, Twilight, Velocities, 36; Hydrometer, Physiology, Specific Gravity of Liquids, Tables of Specific Gravity, 37; Doctrine of Evolution, 37.

Ali, 29.

Al Idrisi, Geography, Globe, 4I. Alkalimeter, 232.

"Almagest," 40.

Al Mamun, 29; Obliquity of the Ecliptic, Degree, 33 .

Al Mansor, 29.

Alpinus, 63,97 .

Altitude of Mountains, 203.

Ambrosius (Bishop), 5 I.

America, 282.

Ampère (Physicist), 283 ; his Rule, $23 \mathrm{I}$; the Founder of Electrodynamics, 23I ; his Law, 232.

Analysis, Chemical, 2 IO, 242.

$" \quad$ Five Methods of, 248.

$"$ of Orbits of Planets, 2 I2.

" Qualitative, 249.

" Quantitative, 249.

" Spectrum, 2 IO.

Analytical Functions, 194.

» Geometry, 193.

" Mechanics, 195.

Anatomists, Discoveries of, see Discoveries.

Anatomy, 22, 27, 38, 57, 60, 62, 63, 96, I 16,269; Def. of, Appendix AA. Anaxagoras, s.

Anaximander, 8.

Ancestry of the English People, 283. Ancients (The), our Juniors by 2,000 Years, 18.

Angilbert, 47.

Animal Electricity, 224.

Animals and Plants of Egypt, 4I.

Anquetil Duperron [Philologist],

I 52.
Anthropologists, Discoveries of, see Disco:eries.

Anthropology, I48, 276 ; Definition of, Appendix AA.

Antiquity, Drawbacks to Science in, 15.

" of Man, I16, I29, I30, I42, I 46-149, I67, I70. Political Economy in, 17 . Science in, 15.

Antonio de Dominis, 59.

Apollonius, 24.

Apparatus, 38 ; Calculating, I92 ; Ringing, 240.

Appendix A., Eminent Men of Science.
9

9

9

99

9)

9

99
AA., Definition of the Sciences.

I., Aristotle on Experience.

II., Aristotle on Induction.

III., Aristotle on the Syllogism.

IV., Leonardo's Physics. V., Brewster on Induction.

VI., Descartes' Achievements.

Apsides, 25 .

Aquapendente (Fabricius ab), 56, 96.

Aquinas (Thomas), 65, 90 (note).

Arabian, Arts of Life, 3I ; Astronomy, 33; Chemistry, 37 ; Chivalry, 3r ; Cities, 29; Civilisation (Grandeur of), 29; College of Music, 31 ; Commerce, 32 ; Contributions to Progress, 43 ; Discoveries, 46 ; Horses, 31 ; Houses, 32 ; Industry, 32 ; Intellect, 29 ; Libraries, 43 ; Men of Science, 43; Merchant Navy, 3I, 32 ; Palaces, 32 ; Physicians, 38 ; Policy, 29; Positive Philosophy, 42 ; Practical Science, 40 ; Revenue, 32 ; Trade, 32 ; Wealth, 32.

Arabs, 283. 
Arabs, in the Van of Civilisation for Centuries, 48.

Arabs, the Precursors of Modern Science, 49.

Arago [Physicist], 228, 229, 234, 239, 24 I.

Arantus, 62, 97.

Archimedes, 22.

Aristarchus, 23.

Aristophanes ("Clouds" of), I 3.

Aristotle, 7, 9, 21, 39.

Aristotle, Inductive Process of Research, Io ; Organon, Io ; Syllogism, II ; on Evolution, I2 ; the Father of Inductive Philosophy, 12 ; on Natural History, I2 ; on Physiology, 12; on Association of Ideas, 13 ; on Astronomy, 13 ; on Physics, 13; on Politics, 13; on Psychology, I3; the Founder of Science, I4; the Founder of the Objective Method, I4; Correction of Eudoxus' Discoveries, 13 ; on Experience, Appendix I. ; on Induction, Appendix II.; on the Syllogism, Appendix III.

Arithmetic, 44.

Arithmetica infinitorum, 193.

Armils (armillary spheres), I5, 23.

Arnault de Villeneuve, 44 .

Artefius, Minerals, Soap, 4I.

Artificial System, II4.

Artillery, 42 ; Moorish, 52 (note).

Arts, Practical, 64.

\# the Plastic, 64 .

Aryan Languages, 152.

Arzachael, Obliquity, 34 .

Asellius, 63, 97.

Assamsh, Statistics and Topography, $4 \mathrm{r}$.

Asteroids, Discovery of, 207.

Astrolabe, 1 5, 25, 42.

Astrology, Importance of, 72.

Astronomers, Discoveries of, see Discoveries.

Astronomy, 44, 61, 100, 198, 261, 269, $27 \mathrm{I}, 272,280,28 \mathrm{I}$.

Astronomy, Definition of, Appendix AA.
Astronomy, General Remarks on, 215. in Chaldæa, 5 . in Egypt, 5. in Greece, 7-9, 13, 20, 2 I, 23-27.

in Islam, 33-35.

Atmosphere, Density, 35; Height, 36 ; Refraction, 36, 37 ; Weight, I03.

Atmospheric Laws, 272.

\# Phenomena, 224.

Atomic Bombardment, 255.

" Energy, 258.

" Heat (Law of), 183 .

” Law, 283.

"System, I79.

" Theory, I79.

, Weights, 183.

Atoms and Molecules, 258.

Attraction (Capillary), 36, 193 ; (Chemical), 2 I9.

Attwood [Physicist], his Machine, 225.

Authority in Islam and Christendom, 45.

Authors Consulted, xix.

Avenzoar, see Ebn Zoar.

Averroes, "Colliget" (medical work), Comments on Aristotle, Influence of, Sun Spots, 39.

Aviaries, 43.

Avicenna, "Canon" of Medicine, 38 ; Encyclopædia, Fossils, Free Inquiry, Geological Formations, Medical Plants, Small-pox, 39.

Avicenna, Influence of, 39.

Avogadro [Chemist], his Law, 185.

BABBAGE, 254.

Bacon, F., behind his Age in Science, 108.

Bacon's "New Atlantis," I4; his Claim as a Natural Philosopher, I08.

Bacon, R., 44, 52, 65, 72, 74, 75, 270, 283 .

Bacon, R., his Work, Discoveries, and Errors, 75 ; his Correct No- 
tions, 76; Criticism of Aristotle and "Offendicula," 77 ; on Experiment, 78 ; Founder of the Experimental School, 78, 89; Encyclopædic Mind, 79 ; a Mathematician, 81,82 ; a Chemist, 82 ; a Physicist, 83; an Astronomer, 86 ; his Reform of the Calendar, 86; attacks the Ptolemaic System, 88; his Confidence in Science, 89; a Pupil and "Continuator" of the Arabs, 90 ; one of the Five Great Men of Ten Centuries, 90.

Bacon, R. v. Bacon, F., x., xiv., 74. Baer (Von) [Biol.], Founder of Embryology, I32, I38.

Bagdad, 29.

Baily [Physicist], 223.

Bain [Physicist], 240.

Balance, 62, 223, 267 ; Torsion, 174.

Balfour Stewart, 244.

Balloons, 233.

Banks, 299 (note).

Barbarossa, 65.

Barology, 102, 272; Definition of, Appendix AA.

Barometer, 21 5, 218, 267.

Barometric Manometer, 24I.

Basalt, 16r.

Bates [Biol.], I44.

Battery, 225; Electric, 267; Gas, 242 ; Voltaic, 227 ; Thermoelectric, 236.

Battle of Humanity against Injustice won by Benefactors, 308 .

Bayonet, 300.

Beaumont (Elie de) [Geol.], I67.

Beccaria [Sociol.], $\mathbf{5 5}$.

Becquerel [Physicist], 246.

Bede, 48 (note).

Bell (Graham), 264.

Belon, 6r.

Ben Corrah, The Year, Anatomy of Birds, 34 .

Ben Ezra, Travels, Practical Medicine, 40.

Benefactors, Great Social, 307.

Benefits (Material) from Electricity, 294.
Benefits (Material) from Hand, Water, Wind, and Flour Mill, 29I, 292.

Benefits (Material) from Industries, 293.

Benefits (Material) from Meteorology, 294.

Benefits (Material) from Physical Geography, 294.

Benefits (Material) from Pure Science, 293, 294.

Benefits (Material) from Steam, 294. Benefits (Moral) from Political Economy, 299; from 'Science generally, 300-309.

Ben Musa, Algebra, Indian Numerals, 33 .

Berenger, 48.

Bergmann [Chemist], Crystallography, Theory of Chemical Affinities, 176, 248.

Bernard [Physiol.], I27.

Bernouilli (Daniel) [Math.] I94, 255.

(James) \# $\quad$ 193. (John) " I94, 227.

Berosus, $2 \mathbf{I}$.

Bertholinus [Physicist], 217 (note). Berthollet [Chemist], Laws of Mixture, 178.

Berzelius [Chemist], Blowpipe, Determination of Atomic Weights, $182,248,283$.

Bessel, 245 .

Bessemer, 262, 263, 283, 285.

Bessemer Steel, 263.

Beverley (John of), 48 (note).

Bill of Exchange, 299 (note).

Binary Stars, 204, 209.

Biological Group, II3; Remarks on, 158.

Biologists, Discoveries of, see Discoveries.

Biology, 60, 127, 273, 276, 210 , $28 \mathrm{I}$.

Definition of, Appendix AA.

General Remarks on, 158. Biot [Physicist], his Law, 230. 
Black [Chemist], Latent Heat, 230. Blowpipe, 182.

Blumenbach [Anthropol.], 148.

Boccaccio, $65,66$.

Bode's Law, 103, 206.

Boerhaave [Physiol.], Founder of Organic Chemistry, 124, 273.

Boiler (Tubular), 26r.

Boiling Point, 220.

Bombardment of Particles, 258.

Bonaventura, 44.

Bonnet [Physiol.] held the Doctrine of Progressive Evolution, I25.

Book (The), 293.

Boole [Math.], 196.

Bopp [Philologist], I 52.

Botanists, Discoveries of, see Discoveries.

Botany, 21, 4r, 44, 6r, 62, 96, II3 ; Definition of, Appendix AA.

Boucher de Perthes [Anthropol.], 149.

Boulton, 26r.

Boyle [Chemist], Combustion, his Law, 172, 274.

Boyle's Law, I72; Deviation from, $24 \mathrm{I}$.

Brain (The), 22, 27.

Bradley [Astron.], 203, 272.

Bramante, 64.

Brewster on Induction, xviii., Appendix V.

Brewster as a Physicist, $210,233$.

Bridge (Tubular), 262.

Britain, 27.

Broca [Anthropol.], I 50.

Brown [Physiol.], 126.

Browning (J.) [Physicist], 210.

Browning's Voice, 264.

Bruno, 58, 97, 270.

Buch (Von) [Geol.], 138, 163.

Buckle quoted, 293.

Buffon [Naturalist and Biologist], held the Doctrine of Organic Evolution, II 7, 273.

Bunsen [Chemist and Physicist], 24 I, 242, 247, 248, 282.

Burgess Class, 68.

Burnouf [Philologist], 152.
Cæesalpinus, his Classification, $6 \mathrm{r}$, $96,97,269,283$.

Cæsar, 26, 246.

Cailletet [Chemist and Physicist], 234, 256.

Calculating Apparatus, 192.

Calculus, Differential, 193.

" Exponential, 194.

" of the Indivisible, Ior.

" Infinitesimal, 195.

" Integral, 194

" of Probabilities, 193, I94, I95.

of Variations, 194.

Calendar, 4 ; Julian, 26, 58, 86.

Calippus (Cycle of), 2 r.

Callisthenes, 6, Ir.

Calorimeter, 226 ; Ice, 226, 242.

Cambrian Rocks, 164 .

Camera Lucida, 227.

" Obscura, 57, 98, 198, 267.

Camper [Anat.], I 8 .

Candolle [Botanist], I 15.

Cannon, Muskets, and Pistols, 53, 300.

"Canon" of Avicenna, 38.

Capillary Attraction, 36.

Capital, 69, 299.

Capture of Constantinople, 9 r.

Cardan, 56.

Carnot [Math.], 243, 283; his Law, 195; his Theorem, 195 .

Cassini [Astron.], 199, 272, 282.

Castelli, 6o, 98.

Catapults, 22.

Cathedrals, 69.

Cato, 17.

Catoptrics, Definition of, Appendix AA.

Cauchy [Math.], 196.

Causes of Scientific Progress, xiv., 68.

Cavaliere, 59.

Cavalieri, ror.

Cavendish [Chemist], Hydrogen, Water, 174, 223.

"Celestial Mechanics," 195, 208.

Cellini, 64.

Cellular Tissue, 62. 
Celsius [Physiçist], 220.

Centigrade Thermometer, 220.

Centre of Gravity, 36, 60.

Centuries XVI., 269.

$$
\begin{aligned}
& " \quad \text { XVII., } 271 . \\
& \quad \quad \text { XVIII., } 272 . \\
& \quad \text { XIX., } 274 .
\end{aligned}
$$

Chaldæan Astronomy, 5, 6 .

$\begin{array}{ll}" & \text { Saros, 6. } \\ " & \text { Science, 6, 7. } \\ & \text { Ziggurats, 6. }\end{array}$

Chambers, I 39.

Champollion [Philologist], Hieroglyphics, I 5 I, 230.

Changes, Political, due to Science, 300.

Changes, Social, due to Industry, 298.

Character of the Revival, xv., 9I.

Charlemagne, 47.

Chasles [Math.], 196.

Chaucer, $65,66$.

Cheap Food, 289, 296.

Chemical Action of Light, 242.

Analysis, 2 10, 242, 247.

Attraction, 219.

Effects of Cold, 256.

Elements, 242, 257, and see Discovery of.

Evolution, 186, 187; Chemists holding the Theory, 187 .

99

Fractionisation, I 88 .

Harmonicon, 256.

Laws, 180.

Manipulation, 37, 38 .

" Rays, 206.

Chemico-physical Laws, 275.

Chemists, Discoveries of, see Discoveries of.

Chemistry, 243, 273, 275, 276, 280, $28 \mathrm{I}, 283,285$.

Chemistry (Arabian), 37, 44, 60 ; Definition of, Appen$\operatorname{dix}$ AA.

" General Remarks on, I89.

Modern, I72.

Organic, I24, 184 .
Chemistry, Solar and Stellar, 234.

Chevreul [Chemist], Fatty Substances, his Law of Colours, 183.

Chinese (The), 2 I (note).

" (The Compass of the), 5 I54.

Chivalry, 3r.

Chladni [Physicist], 227.

Christian Idea (The), 297.

Christian Times witness Great Evils, 298.

Chromosphere, $2 \mathrm{I} 4$.

Chronometer, 232.

Circle (Division of), 196.

Circulation of the Blood, 6o, 62 .

Circumference(Incommensurability of), 194 .

Civilisation (Strides of), through the Tool, the Plough, the Sword, and the Book, 293.

Classification, 2 $\mathrm{r}, 6 \mathrm{r}$.

$\begin{array}{ll}" & \text { Artificial, I I } 4 . \\ " & \text { Comte's, I Io. } \\ & \text { Natural System of, } \\ & \text { II } 5 . \\ & \text { Spencer's, I I } 2 .\end{array}$

Clausius, 244, 254.

Clavicylinder, 227.

Clement IV., 65.

$"$ of Ireland, 47.

Clepsydra, 24, 42.

Climate of Greece, 16 .

Climatology, I62, 258.

Clocks (Pendulum), 42, 55.

"Clouds" of Aristophanes, I3.

Coal, I6, 247.

"Gas, 26r.

" Tar, 186.

Cœlium Theory, 147.

Coefficient of Expansion of Gases, 233, 24I.

Coiter, 63, 96.

Colbert [Sociol.], I 53.

Cold (Chemical Effects of), 256.

Colebrook [Philologist], I 5 I.

"Colliget" of Averroes, 39.

Colours (Law of Contrast of), 183.

" of the Sky, 257.

" (Prismatic), 218. 
Columbus, 55, 282.

Combustion, 172, 173, 176.

Comets, 98, I94 ; Encke's, 2 I I , 212.

Commentaries on Aristotle, 39.

Common Knowledge, 2.

Compass, 42, 5I-54, 267.

Competition, 292.

Compressibility (Law of), I72, 217 ; of Liquids, 232.

Comte [Sociol.], Founder of Positive Philosophy, 156.

Comte, Classification of the Sciences, I IO, II I, 283.

Concentric Mirrors, 22.

Concrete and Abstract Knowledge, H. Spencer on, 3 .

Condenser (Separate), 26o.

Conscience, 304.

Conservation of Energy, 244, 283.

Constants (Naturai), 194.

Constitution of the Heavenly Bodies, 250.

" of the Sun, 205.

" of Science, $27 \mathrm{I}$.

Contempt of Authorities, 270.

"

Industry in Antiquity, I6.

Continuous Fractions, 193.

Contrast between Islam and Christendom, 44.

Cope [Palæontologist], I 23.

Copernican System, 58, 99, 193, 27 I, 272.

Copernicus, 55, 270.

Cordova, 29, 3 I.

Cork, 268.

Corn Grinding, 289, 290.

" Trade, 295.

Corpuscular Physics, 226.

Corpuscular Theory of Light, 218 .

Correggio, 64.

Correlation of Forces (Law of), 242.

Cort, 263 .

$$
\text { Structure, I } 20 .
$$

Corti's Fibres, 246.

Cosmo de' Medici, 9r.

Coulomb [Physicist], Torsion Balance, 223, 283.

Countries (Scientific), xvi., 279-284.
Countries (Scientific), Table of, 280282.

Craniology, 149.

Credit, 299.

Creed in Islam and Christendom, 44.

Crookes [Chemist and Physicist]. his Theory of Chemical Evolution, 186, 187, 256, 257 ; Analysis of Rare Earths, I88; Chemical Fractionisation, 188.

Cross-Staff, 54 .

Cruelty, 298.

Crusades, 68, 7 I, 298.

Cryophorus, 228.

Crystallisation, 6 r.

Crystallography, 176.

Ctesibius, 24.

Currents, Electric and Magnetic, 237.

Cusa, 97.

Cuvier, Founder of Comparative Anatomy and of Palæontology, II 8, I6I, 283 .

Cycle of Calippus, 2 I.

" Meton, 20.

Cyclone Theory, see Sun Spots.

Cylinder (The), .22, 219 ; Papin's, 260.

Cypher, 42.

Cyril, 32.

DAGUERREOTYPE, 239, 26r.

Dalton, John, the "Newton" of Chemistry, the Atomic Theory, I79; [Physicist], 228, 283.

Dante, 65, 90 (note).

"Dark Ages" a Misnomer, 64.

Dark Lines in Spectra, 223, 228, 234, 249.

Dark Rays, 206.

Darwin, Charles [Biol.], established the Law of Biological Evolution, 134; proved the Variability of Species by Natural Selection, 134 ; his place among Evolutionists, I38; his Works, I42, I43, 283.

Darwin (Erasmus) [Biol.], held the 
Doctrine of Organic Evolution, I 28, I39, I 4 .

Darwinism in the Present Day, 143. Daubenton [Anat.], i 18.

Davy [Chemist], 243, 248; Electrolysis, $18 \mathrm{I}$; his two Laws, I8I ; Safety Lamp, I8r ; Electricity an Illuminant, 182, 226; Photography, 182 .

Decay of Belief in Witchcraft, 302, 303.

Decomposition of Light, 218.

"

Vapour by Light, 257.

Sound, 246.

Deductive System of Plato, 9.

Definition of Acoustics, App. AA.

Anatomy, ",

Anthropology, ",

Astronomy, ",

Barology, "

Biology, "

Botany, "

Catoptrics, ,

Chemistry, "

Diffraction, "

Dioptrics, "

Dynamics, "

Electrology, ",

Geography, ,

Geology, ",

Hydraulics, ",

Hydrodynamics, "

Hydromechanics, ",

Hydrostatics, ",

Kinematics, ,

Kinetics, ",

Mathematics, ,"

Mechanics, ",

Optics, "

Palæontology, ,"

Philology, "

Physics, ",

Physiology, "

Sociology, ",

Statics, ",

Thermology, "

Zoology,

the Sciences, ",
Degree, 33, 56, 60.

De la Rive, 264.

Delisle [Astron.], 202.

Democracy, Rise of, 300.

Democritus, Discoveries of, 20.

De Morgan [Math.], 196.

Denmark, 282.

Density of the Earth, 223.

Deposits, Fluvial and Marine, 164 ; Palæozoic, I64.

Descartes [Math.], I91, 272, 283, Appendix VI.

Descriptive Geometry, 195.

Despotism, 298.

Despretz, 24I .

Deviation from Boyle's Law, 24I.

Dewar [Physicist], 256.

Dialysis, 185.

Diamagnetism, 237.

Dias, 55 .

Diathermancy, 239.

Dictionaries, 43.

Didactic Poems, 7 I.

Diderot, 283.

Dietetics, 40.

Differential Calculus, 193.

Diffraction, 217; Definition of, Appendix AA.

Digester, 219.

Diogenes Laertius, 6, 9 .

Diophantus [Algebra], 33 .

Diopters, 34 .

Dioptra (The), 15.

Dioptrics (Apparatus), 233; Definition of, Appendix AA.

Diorama, 26I.

Discoveries of Anatomists, 22, 27, $38,57,60,62,63$, $96,116$.

Anthropologists, 148. the Arabs, 46.

Astronomers, 5-9, $21-23,25,26,33$, $34,54-58,86,97$, 98, 100, 102, 198.

Biologists, 37, 127.

Botanists, 4I, II 3 .

Chemists, 37, 38,

$55,57,60,82$, I 72 . 
Discoveries of Geographers, 23, Drebbel, 60.

$$
54-56 .
$$

Geologists, 8, 22, 4I, 159 .

the Greeks, 7-I4, 20-27.

Mathematicians, 25, $55,56,60,82,96$, 100-102, I9I.

" the Mediævalists, 5I-64, 70 .

9

9

,

9

9

, Physiologists, 22,
Du Bois-Reymond [Physicist], 224.

Du Faye [Physicist], z 16.

Dulong [Chemist], his Law, I83; [Physicist], 233, 24I.

Dumas [Chemist], Density of Compounds, Unitary Theory, 184.

Duns Scotus, 44, 65.

Dunstable, $5 \mathrm{I}$.

Duration of Ideas, 18.

$" \quad$ Solar Energy, 247.

Duty (Performance of), 304 .

Dyes, I86, I 88.

Dynamical Theory of Heat, 242.

Dynamic Radiation and Absorption, 257.

Dynamics (Galileo's), 58, 6I ; Definition of, Appendix AA.

Dynamo (Tesla's), 259.

EARLy Knowledge, xiii., I.

Earth, Density of, 223.

" an Electric Conductor, 240, $60,62,96,98$.

Discovery of America, 55 . $37-4 \mathrm{I}, 55,57$, Asteroids, 207.

\section{"}

"

Chemical Elements, 38, $172-178,187$.

Dissipation of Energy, 254.

Distance of Stars, 245.

Distillation, 38.

Division of the Circle, 190.

$" \quad$ "Labour, 296.

Doctrine of Evolution (Progressive Development), I2, 37, 82, I16, I17, I26, I28-148, 157, 167, 187, 209, $211,276,287$.

Dollond [Physicist], 220.

Dominis (Antonio de), 59.

Doppler's Principle, 253, 262.

D'Orbigny [Naturalist], 120.

Double Refraction, 217.

Stars, 204, 209, 251, 252.

Doublet of Wollaston, 228.

Dove [Geol.], I67.

Draper, 29, 46.

Drawbacks to Science in Antiquity,

I 5.

\section{5.}

" Knowledge of the, 276 .

" Magnitude of, 24.

" Motion of, 246.

Earthquakes, 4r.

Ebn Junis, Hakemite Tables, Pendulum, 34 .

Ebn Zoar (Avenzoar), Acarus of the Itch, Pharmaceutics, 40.

Ebn Zohr, Cure of Diseases, 40.

Ebullition (Law of), 220.

Eclipses, 6.

Ecliptic, 5 .

Economy, 69, 283, 299.

, of Cato, 17.

" of Xenophon, 17 .

Edison, 260, 275.

Eginhard, 47.

Egypt, Astronomy in, 5 .

" Geometry in, 5 .

Egyptian Science, 5, 6, 7.

"Temples, 5 .

Ehrenberg [Physiol.], I24.

Eighteenth Century, Character of, 272.

Elastic Forces and Fluids, 234. 
Electrical Applications, 263.

Resistance, Unit of, 239.

Electric Accumulator, 257.

" Attraction and Repulsion.

(Law of), 223.

Battery, 225.

Car, 257.

Currents, 237.

Induction, Theory of, 238 .

Light, 182, 225.

Machine (First), 216 ;

(Second), 216, 220, 294.

Metallurgy, 239.

Pile, 225.

Plating, 239.

Telegraph, 23I, 240, 283, 286, 294.

Thermometer, 236.

Typing, 239.

Electricity, 57, 61, 98, 243, 272-274, $283,285$.

Electricity and Lightning (Identity of), $22 \mathrm{I}$.

\begin{tabular}{|c|c|}
\hline 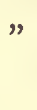 & $\begin{array}{l}\text { " Steam, Great } \\
\text { Agents of Pro- } \\
\text { gress, 226. }\end{array}$ \\
\hline & Animal, 224 \\
\hline & $\begin{array}{l}\text { Application of, to Mole- } \\
\text { cules, } 258 \text {. }\end{array}$ \\
\hline & $\begin{array}{l}\text { Benefits from, } 294 . \\
\text { an Illuminant, } 182 .\end{array}$ \\
\hline & $\begin{array}{l}\text { Statical Properties of, } \\
226 .\end{array}$ \\
\hline & $\begin{array}{l}\text { Theory of, } 221 \text {. } \\
\text { Two Kinds of } 25\end{array}$ \\
\hline & $\begin{array}{l}\text { Two Kinds of, } 216, \\
22 \mathrm{r} \text {. } \\
\text { Velocity of, } 240 .\end{array}$ \\
\hline
\end{tabular}

Electro-chemical Theory, 181, 182.

Electro-chemistry, 236.

Electrology, Definition of, Appendix AA.

Electrolysis, 18I ; Law of, 238.

Electro-magnet, $23 \mathrm{I}$.

Electro-magnetic Action and Waves, 258.

Electro-magnetism, 232.

Electrophorus, 225.

Elements, Chemical, 242, 248, 250, 25I, 259.
Elements, Chemical, Discoveries of, see Discoveries.

Elements, Chemical, Mendelejeff, 188.

Missing, 187.

Williams, 186.

Eminent Men of Science (Table of), Appendix AA.

Enamelling, 53.

Encke [Astron.], his Comet, 209, 229, 255.

Encyclopædia, 39, 71.

Endlicher [Botanist], II 5 .

Energy, 283.

" Conservation of, 244.

" Dissipation of, 254.

" Mechanical, I95.

" of Light, 242.

" Reversibility of, 195 .

" Solar, 246.

"Transmission of, 264 .

Enfranchisement, 68.

Engine, Fire, Steam, 23 ; Railway, 26 I.

Engineering, 262.

England, 279; the Leading Country in Science, 282, 283.

English Ancestry, 283.

" Greatness, 284.

Engraving, 53.

Ephemerides, 54, 55 ; of Jupiter's Satellites, 199.

Epicycles, 24.

Equality and Justice, 301.

Equinoxes, 5 .

Equivalent (Mechanical, of Heat), 243.

Erasistratus, 22.

Eratosthenes, 23.

Erigena, 47.

Errors, Law of, 196 ; Least Square, of, 195.

Esthonian Theory, 149.

Ether, 211, 217, 229, 255.

Euclid, 22 ; "Geometry," 54.

Eudiometer, 225.

Eudoxus, 13, 21 .

Euler [Math.], 194 ; [Physicist], 227.

Euphone, 227. 
Eustachius, 62, 97.

Evection of the Moon, 26.

Evils despite Christianity, 298.

Evils swept away by Science, 306 .

Evolution, Chemical, 187.

Evolutionists, 157.

Doctrine of, 12, 37.

Exalted Idea of God, 30I, 302.

Exchange (Trade), I 8.

Executive Power less despotic, 300.

Exhibitions, I.

Exodus of Greeks to Italy, 92.

Expansion of Gases, Coefficient of,

233, 24I, 242.

the Two Laws of, 233.

”

of Science, 272.

Experience, Aristotle on, xviii., Appendix A.

" R. Bacon on, 78-9, 8I-2.

" Leonardo on, I04-7.

Experimental Geology, 16I.

" School, 44, 72.

Experiments on High Electric Currents, 259.

" on Molecules, 258.

Exponential Calculus, 194.

Extension of Modern Industry, 26r.

Eyck (Brothers), 53.

Facts, Astronomical, Accumulation

of, in the XVIIIth Century, 272.

Facts stronger than Wisdom, 64 .

Fahrenheit [Physicist], Thermometer, 220.

Falling Bodies, Velocity of, 193.

Fallopius, 62, 97.

Faraday [Physicist], 236, 257.

Faure [Physicist], 257.

Favre [Physicist], 234, 242.

Fernel, 5 I.

Ferrari, 56.

Fétis on the Indian Bow, 54 .

Fixed Stars, 24, 27 ; Aberration of, 203.

Fixity of Composition (Law of), 174. „ Species, I19, 137.

Fizeau [Physicist], 246.

Flame Phenomena, 257.

Flamsteed [Astron.], 202, 272.
Flaws in Arabian Science, in Greek Science, in Modern Science, 48.

Flour Mill, Benefits from, 292.

Fluvial Deposits, 164.

Fluxions, Method of, 193.

Foot $v$. Horse, 300 .

Force (Molecular), 226.

Fossils, 39, 56, 169.

Foucault [Physicist], 245.

Foundation of Science, 269.

Four Centuries of Science (Summary), xvi., 269.

Fracastoro, 62.

Fractionisations (Chemical), 188.

Fractions (Continuous), 193.

France, 279, 282.

Franco, 51 .

Franklin [Physicist], 273; his Law of Ebullition, 220; his Theory of Electricity, 22I .

Fraunhofer [Physicist], Founder of Solar Physics and Stellar Chemistry, 234, 24I, 248, 250, 282.

Frederick II., 44, 65.

Free Inquiry, 39, 270.

"Trade, 299.

Freezing by Evaporation, 228.

Fresnel [Physicist], 192, 217, 218, 228, 235; his Rhomb, 236.

Friction, 227.

Fulton, 260.

Functions, Analytical, 194.

$" \quad$ Geometrical, 195.

GALEN, 27.

Galileo, 13, 36, 58, 100, 270, 272, 282, 283.

Galileo's Barology, I02.

" Doctrine of Permanent Law, Ior.

Dynamics, 100.

" Dynamics, roo.

" Laws of Falling Bodies, IOO.

Laws of Motion, IoI.

" Mathenatics, Ioo.

" Mechanics, Ioo.

Gall [Anatomist], 108.

Galvani [Physicist], 224.

Galvanometer (Marine), 253. 
Gas, 268.

"Battery, 242.

" Lighting, 26r.

Gases, Coefficient of Expansion of, 233.

, Fundamental Importance of, 177.

, Law of Compressibility of, 233.

" Liquefaction and Solidification of, 255.

Gassendi [Astron.], 198.

Gastræa Theory, 147.

Gaston Phœbus, 44.

Gauss [Math.], I96, 240.

Gautama, Syllogism of, 10.

Gay-Lussac [Chemist], his Law of

Volumes, 182; [Physicist], 232.

Geber, see Giaber.

Geber Al Batani, 33.

Geber (of Seville), Observatory, 34 .

General Progress, 289.

General Results of Science, xvi., 285.

Generating Functions, 195.

Geoffroy St. Hilaire [Biol.], held the Doctrine of the Mutability of Species, I3I.

Geoffroy St. Hilaire (Isidore) [Biol.], I3I.

Geographers, Discoveries of, see Discoveries.

Geography, 24, 26, 4I, 44, 56, 269, 281; (Physical), 167; Definition of, Appendix AA.

Geological Laws, 165, 283.

Geologists, Discoveries of, see Discoveries.

Geology, 39, 273, 281 ; Definition of, Appendix AA.

Geology, British, I62.

" Comparative, 163.

"Early, I59.

Experimental, 6

" Experimental, I6I

, General Remarks on, 170.

Geometry, Analytical, 193.

, Descriptive, 195.

" in Egypt, 5, 22, 195, 196.

, Signs in Pure, 196.
Gerbert, 44, 47, 59 (note).

Gerhardt [Chemist], his Theory of Types, 185 .

Germany, 279, 282.

Gesner, 6r, 269.

Ghetaldi, 59.

Giaber, Founder of Chemistry, Chemical Manipulation and Apparatus, Alcohol, Gases, Oxidation, Strong Acids, 37, 248.

Gilbert, 57, 98, 283.

Gioja d'Amalfi, 52.

Giorgione, 64 .

Glacial Period, 167-169.

Glaisher [Physicist], 224.

Glass, I6, 268.

Glazed Pottery, 53.

Globe (The), 4I.

Globes, 43.

Gnats' Wings, Flapping of, 257.

Gnomon (The), I 5, 24, 266.

Goethe [Botanist and Biologist], I 5 .

Golden Number, 2 I (note).

Goniometer, 227.

Government (Religious), 301, 302.

Graham [Chemist], his Law of Diffusion, 184; his Process of Dialysis, 185 .

Grammar, Comparative, $\mathbf{I} 52$.

Granada, 29.

Grand Laws discovered, 27 I.

Gravitation, Laws of, 200; Universal, 206, 272.

Gravity, Centre of, 36, 60.

, Force of, 36.

, Specific, 23, 59.

Gray, 264.

Great Men in the Middle Ages, 65 , 66 (note).

Great Pyramid, 6.

Great Schism caused the Delay of the Revival, 94.

Greatness of XIIIth Century, 67.

Greek, 47 (note).

, Discoveries, 7 .

" Exodus to Italy, 92.

" Science passes to the Persians and Arabs, 28. 
Greek Syllogism, I0, I I.

Gregory I., 32, 5 I.

Gregory I., II., II I., 47.

Grew [Botanist], II 3 .

Grimaldi [Physicist], 224.

Grimm [Philologist], I 5 I.

Grimm's Law, I 5 I.

Growth of Milling, 289-292.

" of Science rapid in the

Middle Ages, 7 I-73.

Grove [Physicist], 242.

Guericke [Physicist], Air Pump,

Magdeburg Hemispheres, First

Electric Machine, 216, 272.

Guido d' Arezzo, 5 r.

Guldinus, 60.

Gunpowder, 38, 42, 52, 300.

Gyroscope, 245 .

HaEckel [Biol.], I4I ; one of the

Pillars of Darwinism, 146 .

Hales [Botanist], I I 3 .

Hall [Geologist], Experimental

Geology, 16r.

Hall, C. M. [Physicist], 220.

Hallam, 99.

Haller [Physiol.], 125, 273.

Halley [Astron.], 202, 272.

Hamilton, W. R. [Math.], 196.

Hand Mill, Benefits from, 290.

Harmonicon (Chemical), 256.

Harp of Marloye, 227.

Harriot, 58.

Harvey, 60, 98, 272, 283.

Hatcher [Palæontol.], I23.

Haughton, 254.

Haüy [Geol.], I6o.

Hawksbee [Physicist], 2 I 6.

Health (Physical and Moral), 18.

Heart (The), 2 I, 22.

Heat, Dynamical Theory of, 243.

" Latent, I73.

" Mechanical Equivalent of, 243.

9)

a Mode of Motion, 227, 247, 257.

" Phenomena, 228.

" produced by Friction, 227, 228, 236.
Heat, Radiant, 102, 239.

" Rays, 206.

"Solar, 239.

" Specific, of Gases, 228.

Heavenly Bodies, Composition of, 250.

Heavens, Knowledge of the, 276.

Heliocentric Doctrine (Solar System), 23, 26, 55, 58, 99, 193, 27 I272.

Helium, 187.

Helmholtz [Physicist], 213 (note), 222, 227, 24I, 243, 246, 254, 255, 282.

Helmont (Von), 60.

Helvetius [Sociol.], 154.

Hemisphere, 21.

Henry IV. of Germany, 65.

Henry VIII., 30.

Henry (Prince), the Navigator, 54.

Herbert (Dean), 138 .

Hero, 23, 215.

Heroism of Mediæval Inquirers, 50.

Herophilus, 2 I.

Herschel (Alexander), 253.

Herschel (John) [Astron.], 210; [Physicist], 229, 230.

Herschel (W.) [Astron.], the "Columbus of the Heavens," discovered and mapped Nebulæ, Double Stars, 204, 272.

Hertz, 258.

Hevelius [Astron.], 198.

Hieroglyphics, 15 I, 230.

Hildebrand, 48, 90 (note).

Hincmar, 47.

Hindus, 54, 137 (note).

Hindu Syllogism, IO, I I.

Hipparchus, 24, 201.

Hippocrates, Aphorisms, 20.

Hirn [Physicist], 244.

Hofmann [Chemist], Basis of Coal

Tar, Dye Industry, Molecular Constitution, 186.

Holland, 282.

Hooke [Astron.], 199.

Hooke [Physicist], Dial Barometer, Interference of Light, Spiral Spring, 218. 
Hooker, William and Joseph [Botanists], I I 5, I4I.

Hopkinson, 254.

Horrocks [Astron.], 199.

Horse (Pedigree of), 135 .

Hospitals, 47 (note), 305.

Hucbald, 5 I.

Huggins, his Spectroscopic Studies, 252-255.

Humane Influence of Science, 286.

Human Ingratitude, 293.

Humanitarian Age, 273.

Humanity (Spirit of), 307.

Humboldt (A.) [Sociol.], I 56, 282 ;

[Geol.], Founder of Meteorology, 162 ; on Utility, 3.

Humboldt (C.W.) [Philologist], 15 I.

Huntsman, 263.

Hunt (Dr. J.) [Anthropol.], I 51 .

Hunter [Biol.], 127, 273.

Hutton, 49, 273.

Hutton [Geol.], his Great Idea of Law, I60; Plutonian Theory, 160.

Huxley [Biol.], his Immense Services to Science, Pedigree of Birds, his Works, 145.

Huygens [Astron.], 199, 272 ; [Math.], I93; [Physicist], Micrometer, Pendulum and Pendulum Clocks, Undulatory Theory, Ether, 217; Double Refraction and Polarisation of Light, 218.

Hydraulic Press, I92.

Hydraulics, 6o, 6I, I0I ; Definition of, Appendix AA.

Hydrodynamics, 194 ; Definition of, Appendix AA.

Hydrogen, 174.

Hydromechanics, Definition of, Appendix AA.

Hydrometer, 37.

Hydrostatics, 23, 36, 6I, 101, 192, 216 ; Definition of, Appendix AA.

Hygrometer, 62, 228, $24 \mathrm{I}$.

Hypsometer, 228.

Hyperbolical Sinus, 194.

Hypothesis, Evolutionary, 157. Meteoritic, 214, 253.

Nebular, 209.
Hypothesis, Single and Double Fluid, 221.

ICE Age, I67.

„, Calorimeter, 226, 242.

" Machine, 242.

Iceland Spar, 217.

Idea of Law, 272.

Identity of Lightning and Electricity, $22 \mathrm{I}$.

Ilkanic Tables, 34 .

Inch, Division of, 263 .

Incommensurability of the Circumference, 194.

Increase of Population, 292, 298.

$$
\text { , Wealth, } 263 .
$$

India, 54, 137 (note).

Indian Numerals, 33, 42.

India-Rubber, I 86, 268.

Induction, Aristotle on, Appendix II.

" Brewster on, Appendix V.

" Leonardo on, 104.

" (Electric), Theory of, 238.

Inductive Method, 10, 55, 57, 78, 98, I04, Appendices II. and V.

9)

Process of Research of Aristotle, Io.

„ Process of Leonardo da Vinci, 104-107.

Industrial Spirit, 300, 301.

Industries, Benefits from, 292, 293. Industry (Dye), 186.

" 45.

Infinitesimal Calculus, 195.

Influence of Science on Belief, 288.

" , in the Moral Sphere, 304 .

" $"$ on Philan. thropy, 305.

" $"$ on Religion, $301-303$. on Religious Government, 301 303 . on the Social System, 298-30I. 
Injustice, 298.

Innocent III., IV., 65.

Inquisition, 33; Doctrine of the, 307.

Instruments, Accuracy of, 268.

$\begin{array}{ll}" & \text { Surgical, } 39,43 . \\ " & \text { Value of, } 266 . \\ & \text { Want of, in Antiquity, }\end{array}$
I 5 .

Insularity, 284 .

Integral Calculus, 194 .

Intellectual Results of Science, 286.

Interaction of the Sciences, 17,190 , 276.

Intercommunication, 17 .

Intercourse (Social), I8.

Interference of Light, 217,218 , 235.

Intolerance, 307.

Introduction, xxix.

Invariability of the Great Axes, 203, 208.

Inventions (Mediæval), 54, 69, 99.

Inventors, 260.

(Modern), 260, 280, 28I.

Isoperimeters, 194 .

Isothermal Lines, I63, 167 .

Italy, 279, 282.

Itch, 40 .

JACOBI [Physicist], 23I ; founded Electrometallurgy, 239, 24r.

James [Physicist], 223.

Janssen, 58.

Jenner, 294.

Jevons, 59, 1 36, 196, 197, Appendix VI.

Jewish Teachers, 28.

Jews (The) of Spain, 3I, 40.

Jouffroy d'Albans, 260, 283.

Joule [Physicist], 242; his Law, $244,283$.

Jupiter's Moons, 100.

Jussieu (Antoine and Bernard)

[Botanists], II $5,283$.

Justice and Equality, 301.

" Ideal, I 55.

" Revival of Sense of, 303.
KALID, Improvements in Chemical Manipulation, 38 .

Kant [Philosopher], 208.

Karwiny, Earthquakes and Vapours, 4I.

Keferstein [Geol.], I6I.

Kepler, 6o, 97, 272, 283; Telescope, Tides, I02 ; Attraction, I03, I04 ; Laws of Motion, I03; Optics, Physics, Rotation of the Sun, IO3. Kindly Instincts revived, 303.

Kinematics, Definition of, Appendix AA.

Kinetics, Definition of, Appendix AA.

Kircher, 57.

Kirchhoff [Physicist], 24I, 242, 248, 282.

Kirk [Physicist], 257.

Klaproth [Chemist], I78.

Knight's Law, 143.

Knowledge, Common, the Root of Science, 2.

" Common, H. Spencer on, 3.

" Concrete and Abstract, 3 .

" Early, xiii., I.

Uncertainty of, 42 .

Knox [Anthropol.], 149.

Kohlrausch [Physicist], 224.

LABORATORIES, 43.

Labour, I 54, 299.

„ Division of, 296.

Lagrange [Math.], I94 ; [Astron.], 203, 244, 272, 283 .

Laing (S.), xi., xxii.

Lamarck [Naturalist, Anat., Biol.], the First Demonstrator of Biological Evolution, I29, 14I, I42, $275,283$.

Lambert [Math.], Incommensurability of the Circumference, 194.

Lanfranc, 48.

Languages, Aryan, 152.

Cuneiform, I 52.
$\quad \quad$ Greek, 47 (note), 91, 92,
$\quad 95$.


Languages, Hieroglyphics, I 5 I, 230.

" Kawi, I 5 I.

, Persian, I 52.

" Sanscrit, I 5 I, I 52.

Laplace [Math.], 34, 138, 195, 208 ; [Physicist], 226, 244, 272, 273, 283.

Latent Heat, 173.

Latitude, First Parallel of, 24.

Latour (Cagniard), 256.

Lauffen Waterfall, 264.

Lavoisier, 37 ; Founder of Modern

Chemistry, Nomenclature, Oxygen, 176 ; [Physicist], I78, 226.

Law, Idea of, 272.

" Notion of, 72 .

Law of Adaptation, i 16.

Antagonism, 242.

"Atomic Equality (Gay-

Lussac), I83.

Atomic Heat (Dulong), 183.

Avogadro (Molecules), 185.

Biogenesis (Recapitulation

Theory), I 47.

Bode, I03, 206.

" Boyle, 172.

" Compressibility, I72.

" Conservation of Energy, 244.

" Contrast of Colours (Chevreul), 183 .

Correlation of Forces, 242. Definite Proportions, 178.

Diffusion of Gases (Graham), 184 .

Dissipation of Energy, 254.

Distances in Electricity, 230.

Ebullition (Franklin), 220.

Elasticity of Torsion, 223.

Electric Attraction and Repulsion, 223.

Electric Current, 232.

" Resistance, 234.

Electromotive Force, 235.

Embryological Developments, 132

Equivalent Proportions, 180.

Errors, 196.
Law of Evolution, 276.

Fecundation, 133 .

Fertilisation, I 16.

Fixity of Composition, 174.

Grimm, 15 r.

Homology, 126.

Hydrostatics, 23.

Inheritance, I 16 .

Isomorphism(Mitscherlich), 183.

Joule, 244 .

Knight, I43.

the Lever, 22, 57, 98.

Mariotte, I72, 217.

Mechanical Energy, 195.

Mechanics (in Animals), I25.

Metamorphosis, I 5.

Octaves (Newlands), 189.

Organic Evolution, I 17, I2 I, 126, 130, 131, I38, I41, I42.

See Doctrine of Evolution.

Periodic, 188.

" Pressure (Pascal's), I92.

" Thermodynamics, 195.

" Torricelli, 2 I6.

" Volumes (Gay-Lussac), I82.

Laws, Atmospheric, $27 \mathrm{r}$.

"Geological, 283.

" Grand, 27 I.

" Natural, 27 I.

" Universal, 286, 287.

Laws of Chemistry, 179, I80.

s)

Cooling, 233.

Davy, I8r.

Double Refraction, 233.

Electrolysis, 238.

Equilibrium of Liquids, IOI.

Expansion of Gases, 233.

Falling Bodies, 100.

Geology, 165.

Gravitation, 200.

Light, 272, 275.

Mechanics, I02, 125.

Mixture, 178.

Motion, 60, 10I, 103, 20I, 225, 272, 283.

Polarisation, 233. 
Laws of Pressure, 98.

" Refraction, 62, 192.
Sound, 275.
Torsion of Wires, 223.
Vibration, 227.

Learned Societies in the Revival, 64.

Learning in Islam and Christendom, 46.

Lecky quoted, 299.

Lecoq, I 38 .

Legendre [Math.], 195.

Leibnitz [Math.], 193; [Geol.], I93, 244, 272, 282.

Leidy [Palæontol.], I23.

Lelio, 58, 97.

Lens (Convex), 36, I02, 267.

Lenses for Lighthouses, 236.

Lenticular Spectroscope, 233.

Leo III., 47.

Leonardo da Vinci's Discoveries, $55,56,64,98,282,283$.

Leonardo da Vinci's Geology, 99.

Leonardo da Vinci's Inductive Process, and Injunctions thereon, 104-107, 270.

Leonardo da Vinci's Inventions, 99, I04.

Leonardo da Vinci's Physics, Appendix IV.

Leslie [Physicist], 228.

Leuwenhoeck [Physiol.], I24, 272.

Lever, The Law of the, 22, 57, 98.

Leverrier [Astron.], 2 I I.

Leyden Jar, 220.

Liais, Height of the Atmosphere, 36.

Libavius, 56.

Liberty, 284 .

Libraries, Arabian, 43 ; Cairo, 43.

$\begin{array}{ll}" & \text { European, 70. } \\ " & \text { Spanish, 43. } \\ & \text { Tripoli, 43. }\end{array}$

Libration, 204.

Liebig [Chemist], Chemistry applied to Agriculture, Organic Chemistry, Potash Bulbs, I84.

Life, 55. See Primitive Forms of Life.
Lifts, 22.

Light, 2 ro.

" Decomposition of, 218.

" Diffraction of, 217,235 .

"Electric, 182, 225, 227.

" Energy of, 242.

$" \quad$ Interference of, $217,218,235$.

" Laws of, 272, 275.

" Polarisation of, 218.

"Solar, 257.

" of Stars, 2 Ir.

"Undulatory Theory of, I03, 192, 194, 21 7, 21 8, 228, 229.

„Velocity of, 199, 245 .

"Zodiacal, 199.

Lighthouses, 236.

Lightning and Electricity, Identity of, 22 I.

Lightning Conductor, $22 \mathrm{I}$.

Lindley [Botanist], I 15 .

Linnæus [Botanist], I 1 5, 273.

Lippershey, 58.

Liquefaction of Gases, 255; (of Air), 256.

Liquids, Compressibility of, 232.

Literature, 43, 66, 70, 9 I-2, 95, 298, 307.

Lithography, 26 r.

Lobel, 62, 96.

Lockyer (Norman) [Astron.], 213; his Meteoritic Hypothesis, 214.

Locomotive, 261, 283.

Logarithms, 55, 58 .

Logic and Mathematics (Union of), I96

Longitudes, 25.

Louis IX., 65. „XI., 30 .

Love of Truth revived, 304, 305.

Lubbock [Biol.], I48.

Luminiferous Ether, 21 1, $217,229$.

Luther's Attacks on the Church, 307.

Lyell [Geol.], 138, 139, 141, 283 ; Geological Laws, I65.

MaChaUlt [Sociol.], I 55.

Machinery, Electric, 216.

" Steam, 219, 275, 283. 
Machine Tools, 262.

Maclaurin [Math.], 194.

Magdeburg Hemispheres, 216.

Magellan, 55, 269.

Magellanic Clouds, 2 Io.

Magi of Persia, Io (note), 20.

Magic Lantern, 57.

Magnetic Currents, 237.

" Rotation of Organic Substances, 188.

Magnetism, 98, 237.

" of Gases and other Substances, 257.

, Theory of, 232.

Magnetometer, 196.

Magnets, 236, 237.

Magnifying Glass, 53.

Majolica, 53.

Malpighi, Founder of Vegetable Anatomy, II3 ; [Physiologist], I23, 272.

Malus [Physicist], 218, 227, 230.

Malthus [Sociol.], I38, 155 .

Man, Antiquity of, I16, I29, I30, I 42, I 46, I 48, I 49, I67, I70.

, of Science the Greatest of Benefactors, 296.

Manetho, 6.

Manipulation, Chemical, 37, 38 .

Manometer, Barometric, $24 \mathrm{I}$.

Mantell [Geol.], Saurians, 164 .

Marco Paolo, 52.

Marcus Græcus, Gunpowder, 38.

Marine Deposits, I64.

Mariotte [Physicist], I72 ; his Law, 217, 274.

Marloye's Harp, 227.

Mars, Rotation of, 199.

Marsh, Palæontologist of the Highest Order, I21, 136 ;

Descent of the Horse, 135.

Maskelyne [Physicist], Density of the Earth, 223.

Masué, Comparative Anatomy, 38. Material Effects of Scientific Progress, xvii.

" Progress, 289.

" Results of Science, 286, 289.
Material Welfare, how Promoted, 289-296.

Mateucci [Physicist], 224.

Mathematics, 267, 27 I, 272, 280, $28 \mathrm{r}$.

" Definition of, Ap. pendix AA.

General Remarks on, $197,198$.

and Logic, Union of, 196.

in Physics, 100, 194.

Power of, 198.

Queen of Sciences, 197.

Subdivisions of, 197.

Want of, in Antiquity, 15 .

Mathematicians, Discoveries of, see Discoveries.

Mathematicians of $\mathrm{XV}$ th and XVIth Centuries, 96.

Matter, Unity of, 256.

Matthew, I38, I4I.

Maury [Geol.], Meteorology and Physical Geography, 167.

Maxwell [Physicist], 240, 244, 254.

Mayer [Physicist], 243.

Mayow [Chemist], Combustion, 172.

Means of Transport, I8.

"Mécanique Céleste," 195, 208.

Mechanical Energy, 195.

Equivalent of Heat, 243.

Mechanics, 6I, 272, 275; Definition of, Appendix AA. Analytical, 195. Celestial, 195.

Mediæval Contributions to Science, 5 I.

„) Discoveries, 70.

" Europe not in Profound Darkness, 47.

Inquirers, Heroism of, 50.

Inventions, $5 \mathrm{I}$.

Medical Plants, 39.

" Treatment in Islam and

Christendom, 46. 
Medicine, 20, 38, 40, 44, 63, 96.

Melloni [Physicist], 239.

"Melopeia" of the Greeks, 60.

Menageries, 43.

Mendacity in the Middle Ages, 305.

Mendelejeff [Chemist], his Periodic Law, 188.

Mendicity, 155.

Mercantile Companies, 298.

Mercator, 56, 98.

Mercury, Phases and Transit of, 198, 199, 202.

Meridian of Spain, 234.

Metallurgy, 98, 283.

Metamorphism, 166.

Meteorites, 26, 253.

Meteoritic Hypothesis, $214,253$.

Meteorology, 162, 167.

Method of Fluxions, I93.

\section{, Oscillation, 223.}

" Research, xiii., I, 270.

" Torsion Balance, 223.

Meton, Cycle of, 20.

Michel Angelo, 64.

Microscope, 100, 123, 267, 273;

Spectrum, 257.

Milky Way, 20.

Miller, Dr., 253.

Milling, Growth of, 289-292.

Minerals, $4 \mathrm{I}$.

Mirbel [Physiol.], 126.

Mirrors, Concentric, 22, 53 .

Misery, Decrease of, 274.

Mitscherlich [Chemist], Law of Isomorphism, 183.

Modern Discoveries, rog.

, Industry (Extension of), $26 \mathrm{I}$.

$״ \quad$ Inventions, $280,28 \mathrm{I}$.

" Merchant, 295.

" Science, ro9.

Möhl (Von) [Biol.], originated the

Theory of Protoplasm, I 33.

Moldenhauer [Physiol.], I26.

Molecular Constitution, I86.

$\begin{array}{ll}" & \text { Current, 258. } \\ " & \text { Force, 226. } \\ \text { ", } & \text { Ocean, 262. } \\ \text { " } & \text { Physics, 255 }\end{array}$

Molecules, I 85, I 86.

Motion and Size of, 254.

Mondini, 60.

Monge [Math.], Descriptive Geometry, I95.

Monteverde, 60.

Montgolfier [Physicist], Balloons, 224.

Moon, Evection of, 26.

Moons of Jupiter, Ioo.

Moral Effects of Scientific Progress,. xvii.

" Progress, 297.

"Results of Science, 297-309.

Morgagni [Biol.], I28.

Morley (J.) quoted, 307, 308.

Moro [Geol.], 160.

Morse [Physicist], 240.

" Telegraph, 262.

Motion, 247, 257.

" Heat a Mode of, 227.

" of the Earth, 245.

" " Planets, 20.

" $"$ Stars, 262.

Mountains, Altitude of, 203.

Müller, Fritz and Hermann Biol.],. I 47.

" Johann [Physiol.], I27.

" Max (Philologist], I 52.

Multiple Stars, 234.

Multiplier, Thermo-electric, 239.

Municipal Liberties, 68, 298.

Murchison [Geol.]., Silurian and

Devonian Systems, I64.

Murdoch, 26I.

Muschenbroeck [Physicist], Leyden Jar, 220.

Museums of Alexandria, 19, 27.

Museums, I.

Music, 5 I.

Musical Vibrations, I02, I9I, I94, $220,227$.

NAPIER, 55, 58.

Nasmyth, 262.

Natural Constants, I94.

" History, 96, 269.

" Laws, $27 \mathrm{I}$.

" Philosophy, 70. 
Natural Sciences (Medicine, Anatomy, Zoology, Natural History, Botany), 96.

" Selection, 283.

" System, II 5 .

Nature a Great Teacher, 63 .

" of Vision, 35 .

Navigation, 3I, 69.

Nebula of Orion, 199.

Nebulæ, 26r.

" in the Northern Hemisphere, 204 .

in the Southern Hemisphere, 210.

Nebular Hypothesis, 209.

Neckam (Alexander), 52.

Neptune, Discovery of, 2 I I.

Neptunian Theory, 44, $16 \mathrm{I}$.

Nero, 5 I.

Nerves (The), 22, 27.

Nestorian Teachers, 28.

Neumann [Chemist], I85.

Newlands [Chemist], Law of Octaves, 189.

Newton, 13, 26, 272, 283 ; Acoustics, 219; [Astron.], 199; [Math.], 193; [Physicist], Corpuscular Theory of Light, 218.

Niagara Falls, 264.

Niagara, Supply of Horse Power, 264.

Nicholas V., 91.

Nicholson [Physicist], 227.

Nicol Prism, 230.

Niepce, 239, 26I.

Nile Mud, $4 \mathrm{I}$.

Nineteenth Century, Character of, 27.4-277.

Nobili [Physicist], 224.

Numbers, Bernouilli's, I94. Theory of, 195.

Nutation, 203.

Nyaya School, Io.

ObLIQUity of the Ecliptic, 23, 24, 33,34 .

Observatories, 5, 6, 34, 43, 97 .

Oersted [Physicist], 232, 240.

Oil Paintings, 53.
Oken [Biol.], I3I.

Olbers [Astron.], 209.

Oligarchy, 298.

Opera, 60.

Optics, 35, 61, 103, 217, 218 ; Definition of, Appendix AA.

Oratorio, 59.

Orbits of the Planets (Analysis of), 2 I2.

Order (Social), 290.

Organ, $5 \mathrm{I}$.

Organic Chemistry, I24, I84. ,, Group, II3.

"Organon" of Aristotle, Io. Oscillation (Method of), 223.

Owen [Naturalist, Anat., Palæontol.], held the Doctrine of Fixity of Species, I20; Founder of the Microscopic Society, I2I ; organised Natural History $\mathrm{Mu}-$ seum, I2 I.

Oxidation, 37, 176 .

Oxygen, $174,176$.

Oxygen a Magnetic Body, 25r.

PAGE, 264.

Palæontologists, Discoveries of, see Discoveries.

Palæontology, Ir6; Definition of, Appendix AA.

Palæozoic Deposits, I64.

Palestrina, 56.

Palissy, 53, 56, 97.

Pallas, 209.

Panini [Philol.], I 5 I.

Paper, 42, 52.

Papin [Physicist], 219, 260.

Paracelsus, 55, 96, 269, 270.

Parallax of Stars, 199.

Parallels, Theory of, 195.

Paré, 63, 96.

Pascal [Math.], his Law, 192, 272, 283.

Pasteur [Biol.], I44, 294.

Pathology, 63.

Peace promoted by Science, 286 , 299.

Pecquet, 63.

Pendulum, 34, 59, 102, 21 7, 245, 267. 
Pendulum Clocks, 42, 217.

Performance of Duty, 304.

Peri, 60.

Periodic Law [Mendelejeff], 188.

Perkin, W. H. [Chemist], Aniline Dyes, 188; Magnetic Rotation of Organic Substances, I 88, 285.

Permanency of Laws, I01, 102, I60, 165.

Persecution, Religious, 302.

Perthes, see Boucher de Perthes.

Perversion of Moral Type, 305.

Peter of Pisa, 47.

Petit [Physicist], 233.

Petrarca, 65, 66.

Peurbach's Ephemerides, 54, 97.

Pharmacy (Pharmaceutics), 38, 40, 44.

Phases of Venus, 6.

Phenomena, Atmospheric, 224.

$" \quad$ Heat, 228.
$" \quad$ of Flames, 257.
$" \quad$ of Sound, 256.

Philanthropy, Immense Expansion of, due to Scientific and Industrial Spirit, 306.

Philanthropy the Feature of Recent Times, 306.

Philippe Augustus, 47 (note).

Philologists, Discoveries of, see Discoveries.

Philology (Comparative), 151, 280, 28I ; Definition of, Appendix AA.

Phlogistic Theory, I73, I9I.

Phonograph, 263-4, 275, 286, 294.

Phosphoroscope, 252.

Phosphorus, 38.

Photography, 182, 239, 258, 261, 275.

Photometer, 226, 234, 242.

Photometry, 142.

$$
\text { " of Stars, } 34 .
$$

Physical Geography, 167.

\section{" Laws, 273.}

Physicists, Discoveries of, see Discoveries.

Physics, 44, 6I , 100, 215, 269, 272, $28 \mathrm{o}, 28 \mathrm{I}$.
Physics, Alhazen's, 35.

" Corpuscular, 226.

" Definition of, Appendix AA.

Solar and Stellar, 234.

Physico-Chemical Laws, 275.

Physiologists, Discoveries of, see Discoveries.

Physiology, 22, 37, 4I, 55, 57, 60, $62,96,98,123,272,283$. Comparative, 127.

" Definition of, Appendix

AA.

Physiological Chemistry, I77.

Piazzi [Astron.], 206.

Piccolomini, 62.

Pictet [Physicist], 256.

Piezometer, 232.

Pile, Electric, 225.

Piston, 2 19, 260.

Planetarium, 15, 193.

Plants, Medical, 39.

" Respiration of, 175 .

Plastic Arts, 64.

Plater, 63, 97.

Plato and Aristotle brought to Italy, 93.

Plato's Deductive Process of Research, 9.

"Republic," I4.

Playfair (John) [Geol.], I60.

Pleiades, 100.

Plenum (Universal), 255.

Plough (The), 293.

Plutonian Theory, 49, I6o.

Poggendorff [Physicist], his Law, 235.

Poisson [Math.], 203.

Poland, 282.

Polar Clocks, 24 I.

Polarity of Gases, 242.

Polarisation of Light, 218, 230.

$$
\text { " Rotatory, } 230 .
$$

Political Changes due to Science, 300.

$\begin{array}{ccc}" & \text { Economy, I } 53-156,283 . \\ " & " \quad \text { in Antiquity, I7. } \\ " \quad & \Rightarrow \quad \text { Moral Benefits }\end{array}$

from, 299.

Porta (G. Della), 57. 
Portugal, 282.

Posidonius, 26.

Positive Philosophy, 42.

Potash Bulbs, I84.

Pottery (Glazed), 53.

Pouchet [Biol.], 29, I 33 .

Pouillet [Physicist], 238.

Practical Art, 64.

" and Artistic Skill, 69.

" Men and their Inventions, 260.

Science, 98.

" Work, 270.

Precession of the Equinoxes discovered by Hipparchus, 25, 35, 201.

Preconceived Theories in Antiquity, I6.

Preface, v.

Pressure of Air, 192.

Prevost [Geol.], I64.

Priestley [Chemist], 37; Oxygen, I74.

Prime Movers, 264.

Primitive Forms of Life, I16-7, 126, I28, I30-133, 135, 138-9, 147, 276.

Prince Henry, the Navigator, 54 .

"Principia," 136, 201.

Printing, 54, 92.

Prism, 192, 267 ; Nicol, 230.

Prismatic Colours, 218.

Probabilities, Calculus of, I93, 194. Theory of, 195.

Problem of Dark Lines in Spectrum, 249.

Progress among the Arabs, xiv., 28.

$" \quad$ in Antiquity, xiii., I9.

$" \quad$ in the Middle Ages and during the Revival, xiv., 50.

General, 282.

Material, 289.

Moral, 292.

Protyle, 187.

Prout's Theory, 189.

Pruner Bey [Anthropol.], I49.

Ptolemaic System, 19.

Ptolemies (The), 19.
Ptolemy, 26.

Public Opinion, 300.

Puddling, 263.

Pulse, 2 I.

Pump, Air, 216, 219.

"Spiral, 22.

" Steam, 260.

" Suction, 54 .

Pyramid, The Great, 6.

Pyrheliometer, 238.

Pyrometer, 220, 236.

Pythagoras, 8.

QUADRANT (The), I5, 34.

Qualitative Analysis, 249.

Quantitative Analysis, 249.

Quaternions, System of, 196.

Quatrefages [Anthropol.], I 50 .

Quesnay [Sociol.], I 53, 283.

RADIANT Heat, IO2, 239.

" Matter, 26I.

Radiometer, 257.

Railway Engine, 26I.

" Train, 274.

Rainbow, 58, 59.

Rankine, 244.

Raphael, 64 .

Rapine, 298.

Rashi, Dietetics and Remedies, 40,

Rawlinson [Philol.], I 52.

Ray [Botanist], II 3 .

Rays, Heat and Dark, Chemical, 206.

Réaumur [Biol.], 127 ; as a Physicist, $127,220$.

Refraction, 35, 37, 60, 98.

$$
" \quad \text { Double, } 217 .
$$

Regiomontanus, 55 .

Regnault [Physicist], 234, 24I, 243.

Reign of Terror, 302.

Reiss, 264.

Religion and Religious Government, 30I-2.

Religious Government more Humane through Science, 302-3.

Remarks (General) or Biol., 158 ; 
on Geol., I70; on Chem., I89; on Mathem., 197, 198; on Astron., 215.

Remedies, 40.

Renaldini [Physicist], 216.

Renan, 29.

Requirements of Progress, I7.

Resentment of Dethroned Castes, 308.

Respiration of Plants, 4I ; of Animals, I72, I73, I77.

Results of Science, General, 285 ; Material, 286, 289; Intellectual, 286 ; Moral, 297.

Retina, 35 .

Retzius [Anthrop.], I49.

Reversibility of Energy, 195.

Revival (The), Character of, 9I ; of Kindly Instincts and Sense of Justice, 303 ; of Sense of Right, of Love of Truth, 304.

Revolution in Science, 226.

Rhætius's Tables, 54.

Rhazes, Sulphuric Acid, Distillation, 38 .

Rheostat, 240.

Rhomb of Fresnel, 236.

Richer of St. Remi, 47.

Richter [Chemist], Law of Definite

Proportions, I78, 283.

Ringing Apparatus, 240.

Rise of Democracy, 300.

, Industry, 32.

Ritter, C. [Geol.], I63.

”. W. [Physicist], I8r.

Robbia (Lucca Della), 53.

Roemer [Astron.], 201, 245, 272.

Romanes [Biol.], I32, I43.

Roscelin, 48.

Roșcoe, 242.

Rotation of the Sun, I03, I99; of

Winds, I67; of Organic Substances, I88; of Mars, I99; of Electric Wires, 236.

Rousseau, 153; Social Influence of, 306.

Royalty versus Feudalism, 300.

Rüdbeck, 63, 272.

Rudolphine Tables, 4, 59, 98.
Rumford [Physicist], 155, 226, 243.

Russia, 282.

Sabine [Physicist], 223.

Safety Lamp, I81. Valve, 219, 260.

Salvinus Armatus, 53.

Santorio, 60, 62, 97.

Sargon I., 6.

Saros, Chaldæan, 6.

Saturn's Satellites, 199.

Saurians, 164.

Sauveur [Physicist], 220, 227.

Savart [Physicist], 224.

Scarpi [Physicist], 60.

Scheele [Chem.], Oxygen, 176, 283.

Schiaparelli [Astron.], 212.

Schiehallion Experiment, 223.

Schiling, 240.

Schleiden [Biol.], 132 .

Schoolmen, 97, 158, 170, 270.

Schools, 69.

Schwabe [Physicist], 237.

Schwann [Biol.], I32.

Schwartz, Monk, 52.

Science, an Extension of Common

Knowledge, 2.

Chaldæan, 5, 6 .

Egyptian, 5, 6.

" Four Centuries of, and

Foundation of, 269;

Constitution of, 27I ;

Expansion of, 272;

Universality of, 274 .

in Antiquity, 15.

in Egypt and Chaldæa,

Stationary, 7.

in Islam and Christendom, 46.

in the Middle Ages, 70.

in Modern Times, I09.

the Prime-mover of the

Highest Civilisation, 308.

Sciences, Definitions of, Appendix

AA, page 3I4.

Scientific Countries, 279-284.

\# Influence on Belief, 288.

$" \quad$ Interaction, 276.

, Revolution, 226. 
Screw of Archimedes, 23.

Screws, 262.

Scrope [Geol.], 165.

Sedgwick [Geol.], 164.

Seebeck [Physicist], 237.

Séguin, 261, 283.

Selection, Natural, 283.

Semaphoric Telegraph of the Arabs, 42.

Seneca, 26.

Senefelder, 26r.

Sense of Justice, Revived, 303 ; of

Right, Revived, 304.

Serapion (The), 27.

Serres [Physiol.], I27.

Servetus, 62, 97, 283.

Seventeenth Century, Character of, $27 \mathrm{I}$.

Signals, System of, 254 .

Signs in Pure Geometry, 196.

Silbermann [Physicist], 234, 242.

Simpson [Physiol.], I27.

Singing Flames, 256.

Sinus, Hyperbolical, 194.

Sismondi, 29.

Sixteenth Century, Character of, 269.

Sky, Colour of, 257.

Slavery a Drawback to Science in Antiquity, 15, 298.

Small-pox, 39.

Smith, Adam [Sociol.], I 54, 283.

"W. [Geol.], 138, 162 .

Snell, 60, 96.

Soap, 4 r.

Social Changes due to Industry, 248-9.

"Intercourse, 18 .

$" \quad$ Order, 298.

Societies, Learned, 64.

Sociologists, Discoveries of, 153 .

Sociology, 153; Definition of, Appendix AA, 280, 28I.

Solar Energy, 246; Duration of, 247.

Heat, 239.
$" \quad$ Light, 257.
$\Rightarrow \quad$ Physics, 234.
$\Rightarrow \quad \begin{aligned} & \text { System, Heliocentric Doc- } \\ & \text { trine, 23, 26. }\end{aligned}$

Solstices, 5.

Sosigenes, 26.

Sound, 102, 210 ; Velocity of, 245

(note) ; Decomposition of, 246 ;

Phenomena of, 256, 275.

Spain, the Centre of Arabian Learning, 44 .

Spallanzani [Physiol.], 126.

Specific Gravity, 23, 59.

" Heat of Gases, 228.

Spectacles, 53.

Spectra of Stars, 235.

Spectral Lines, 262.

Spectroscope, 210, 233, 24I-2, 247-8, 251, 263.

Spectroscopic Observations, 213.

Spectrum, 218 ; Analysis, 210.

" (Dark Lines of), Explained, 249.

Microscope, 257.

" Solar, 206 ; Dark

" Solar, 206 ; Dark Lines, 233-234.

Spencer (Herbert) on Common Knowledge and Science, 3 .

" his Genesis of Science, 27 (note).

,

on Concrete and Abstract

Knowledge, 3.

$" \quad$ on Evolution, 157, 283.

$"$ on Science, Iog.

" on Utility, 3 .

Spencer's Classification of the

Sciences, I 1 2, I38, I41-2.

Sphere (The), 22.

Spiral Spring (of Watches), 218.

Spirit of Free Inquiry, 269.

" of True Humanity, 307.

Sponges, 147.

Sprengel [Botanist], I I6.

Square (Least) of Errors, 195.

Stahl [Chemist], Phlogistic Theory, I73, $18 \mathrm{I}$.

Stained Glass, 53.

Stancari [Physicist], 220, 227.

Stars, Fixed, 24, 27 ; Photometry of, 34 ; Parallax of, 199; Double, 204, 209; Treble, 209; Multiple, 234. 
Stars in the South Hemisphere, 202.

" Aberration of Fixed, 203.

" Distance of, 245 ; Velocity of, 251 ; Motion of, 262.

Statics, 22 ; Definition of, Appendix AA.

Statistics, 41 .

St. Anselm, 48.

St. Augustine's Doctrine of Religious Government, 305.

St. Bernard, 48.

St. Hilaire (Geoffroy), 283.

Steam, 274, 285 ; Age of, 274.

Steam and Electricity, Great Agents of Progress, 226.

Steamboats, 260.

Steamer, 274.

Steam-engine, 260.

" Hammer, 262.

„ Machinery, 26I, 273, 280.

\# Navigation, 26r.

" Pump, 260.

Steel, Age of, 262, 263.

", Bessemer, 262.

Steinheil [Physicist], 23I, 240, $24 \mathrm{I}$.

Steno [Anat. and Geol.], I I6.

Stephenson (G.), 26I, 283.

$$
\text { , (R.), } 262 .
$$

Stellar Chemistry, 234.

Stereoscope, 240.

Stevinus, 57, 98, IOI.

Stiefel, 55 .

Stiorn Oddes, 44.

Stewart (Balfour), 244, 249 (note).

Stokes, 250 (note).

Stoney, 254 .

Strabo, 26.

Sufi, Photometry of Stars, 34 .

Sun, Constitution of, 205, 250.

" Light and Heat, 265.

" Rutation of, 103, 199.

„Spots, 39; Action of, 237, 250.

Supremacy of Conscience, 304.

Surgery, 44, 63.

Surgical Instruments, 43.

Swammerdam [Physiol.], I24, 272.

Sweden, 282.

Switzerland, 282.
Sword (The), 293.

Syene, 24.

Syllogism, Greek and Hindu, Io, I I.

Symbols (Algebraic), 57 .

Symington, 260.

Sympathy (Universal), 306.

Symmer (Physicist), 22 I.

Syntaxis of Ptolemy, 26.

Syren, 256.

System, Artificial, I I4.

$\begin{array}{ll}" & \text { Atomic, 20. } \\ " & \text { Copernican, 58, ro8. } \\ " & \text { Devonian, Silurian, I64. } \\ " & \text { Natural, I1 5. } \\ " & \text { of Laplace, 209. } \\ " & \text { Ptolemaic, 26, 108. } \\ & \text { of Quaternions, I96. }\end{array}$

TABLE of Albumazar, 33.

, Chords, 26.

" Hakemite, 34 .

" Ilkanite, 34 .

" Rhætius, 54 .

" Rudolphine, 4, 57, 98.

" Specific Gravities, 37.

" the Sun, the Moon, 26.

" Tides, 200.

" Scientific Countries, 280-2.

Table of Eminent Men, Appendix A.

Talbot [Physicist], 210, 239.

Tartaglia, 56.

Tasi, Ilkanite Tables, 34 .

Taylor [Physicist], 206 (note).

Telegraph, Semaphoric, 42 ; Elec-

tric, 23I, 240, 283, 286, 294-5.

Telegraphy, 24, 262 ; Marine, 253.

Telephone, 263-4, 286, 294-5.

Telescope, 34, 58, 206, 219, 220, 263, 267, 27 I.

Temple, Bishop, 140 .

Temples, Egyptian, 5.

Temple of Serapis, 27.

Tesla [Physicist], 232, 258, 259-260.

Thales, Discoveries of, 7 .

Thebit Ben Corrah, 34 .

Thénard [Chemist], I8I.

Theodulf of Spain, 47.

Theophrastus, 2 I. 
Theorem of Maclaurin, 194; of Carnot, 195.

Theoria Motus, 196.

Theoretical Work, 270.

Theory of Asymptotes, 196.

" Atomic, I79.

" of Chemical Affinities, 175 .

" " $" \quad$ Evolution, 187.

„ Cœlum, I47.

" Corpuscular, 218.

" of the Division of the Circle, 195 .

Dual, I83.

" Dynamical, of Heat, 243 ; of Vortices, 247, 255, Appendix VI., 230.

of Electricity, Single and Double Fluid, 22 I.

Electro-chemical, 182-2. of Electric Induction, 238. Esthonian, I49.

Gastræa, I47. of Laplace, 209.

, Norman Lockyer, 214.

" Magnetism, 233.

Neptunian, 49, I6I. of Numbers, 195.

„, Parallels, I95.

Phlogistic, I73, I9I.

Plutonian, 49, I60.

of Probabilities, 195.

" Prout, I89.

"Recapitulation, 132, 147.

"Symmer, 222.

„, Types, I85.

Undulatory, 103, 192, 194, 21 7-8, 228-9.

Unitary, 184.

of Unity of Organic Composition, I3I.

" " the Universe, 273.

Thermo-dynamic Law, I95.

Thermo-dynamics, I95, 244.

Thermo-electrical Multiplier, 239.

Thermology, Definition of, Appendix AA, 273.

Thermometer, 58, 60, 62, 100, 203, 220, 228, 236, 267.

Thermopyle, 243.
Thomas Aquinas, 65.

Thomson (Sir W., Lord Kelvin), 2 I 3 (note), 243-4, 246-7, 254, 258. Tides, 26, I02, 200 ; Kinds of, 254. Tidal Power, 265.

Tissue (Cellular), 62.

Titian, 64 .

Tivoli Waterfall, 264.

Toleration in Islam and Christendom, 45 .

Tool (The), 293.

Tools (Machine), 262.

Topography, 4I.

Torricelli [Physicist], 36, I02, 21 5 ; his Law, 216, 272, 283.

Torsion Balance, I74, 223.

$" \quad$ Elasticity of, 223.

$"$ of Wires, 223.

Torture, Abolition of, I 55, 304.

Toscanelli, 54, 97.

Tournefort [Botanist], II 4 .

Trade, 18,69 .

Tragus, 6I, 96 .

Transformation of the Earth, I8; of the World, 286.

Transformation of Heat into Mechanical Energy, 243-4.

Transformation of Mechanical Energy into Heat, 243-4.

Transmission of Energy, 264.

Trigonometry, founded by Hipparchus, 25, 54 .

Tripoli Library, 43.

Tubular Boiler, 261 ; Bridge, 262.

Turgot [Sociol.], I 54 .

Twilight, 36 .

Tycho Brahe, 34, 57, 97-8, 283.

Tyndall [Physicist], 244.

Types, Theory of, 185 .

UBALDI, 57, 98.

Ultimates (Unknowable), 288.

Ulugh Begh, Obliquity, 34 .

Undulations of Light, 229.

Undulatory Theory of Light, I03, I92, 194, 21 7, 21 8, 228, 230, 235.

Union of Logic and Mathematics, 196.

Universal Laws, 286, 287. 
Universal Sympathy, 306.

Universality of Science in the XIXth Century, 274.

Universities, 40, 70.

Unit of Electrical Resistance, 239.

Unity of Matter, 82, 187, 256.

Uranus, 206.

Urban II., 65.

Utility (an Incentive to Science),

H. Spencer on, 2-3.

Humboldt on, 3 .

$"$ in the Middle Ages, 4.

" in Modern Times, 4 .

Vaccination, 126.

Vacuum now Obtained, 256.

Value of Instruments, 266.

Valve, 219.

Van Helmont, 60.

Vaporisation of Liquids, 228.

Vapours, 4I ; Decomposition of, by Light, 257 .

Absorbing Power of, 257.

Variation (of the Moon), 34.

Variations (Calculus of), I94.

Varley, 258, 264.

Vasco de Gama, 55, 85.

Vauquelin [Chemist], 178 .

Velocity of a Falling Body, I93; of Electricity, 240.

" of Light, 199, 24I, 245 ; of Sound, 245 (note).

, of Stars, 252-4.

" "Vibrations, 257.

Velocities, 36, 99.

Venus, Phases, 6; Transit, 198, zo3.

Vesalius, 67, 97, 269, 283.

Vesta, 209.

Vibrations (Musical), I02, I91, 194, 220 ; Rod, Glass, Metallic Plates,

Laws of, 227.

Vicq d'Azir [Physiol.], I25.

Viète, 57.

Villeneuve (Arnault de), 44.

Vincent de Beauvais, 44.

Violence, 298.

Violin, 54 .

Virchow [Biol.], Founder of Cellular Pathology, 144.
Virtue, 304.

Vision, Nature of, 35 .

Vitellio's Optics, 54 .

Vitry (James de), 52, 7 I.

Vogt [Anthrop.], I 50.

Volcanoes, 26, 165 .

Volta [Physicist], 225, 273, 282-3.

Voltaic Battery and Pile, 225, 227.

Voltameter, 238 .

Vortex Theory, 247, 255, Appendix VI., 330.

Von Baer, see Baer.

" Buch, see Buch.

" Mohl, see Mohl.

WALLACE [Biol.], I39, I4r, I43-4.

Wallis [Math.], 192.

Waltherus, 55, 97.

Want of Instruments in Antiquity,

15.

" of Material Substances in

Antiquity, 16.

of Mathematics in Antiquity, I 5.

War, 298; Decline of, 299.

Warfare, 69.

Watches, 53, 218.

Water, Decomposition of, 227.

Watermills, Windmills, 51 ; Bene-

fits from, 290, 292.

Watt, I74, 226, 260-I, 273, 283.

Watts' Dictionary of Chemistry, vii.

Wave Lengths (of Light), 229.

Wealth, Increase of, 263, 274.

Weber, 240.

Weight and Pressure of Air, 192, 215-6.

of the Earth, 223.

Weismann [Biol.], 142-3.

Wells, Dr., I38.

Werner [Geol.], 49; Neptunian Theory, I6I, 283.

Wheatstone [Physicist], 23I, 240, $245,283$.

Whitworth, 262.

Whewell, Dr., 27 (note).

Wiclif, $65,283$. 
William of Tyre, $7 \mathbf{I}$.

Williams [Chemist], Missing Elements, 186.

Willis [Anatomist], I 16.

Willughby [Naturalist], 117 .

Witchcraft, Decay of, 302-3.

Wollaston [Chem., Biol.], I78; [Physicist], 224, 227. " his Doublet, 228.

Woodward [Geol.], I 59.

Work, Practical and Theoretical, 270.

Workshops, 26r.

World (The) Transformed, 286.

Wyck, Henry de, $5 \mathrm{I}$.
Xenophanes, 8.

Xenophon's Economics, 17 .

YEAR (The), 26.

Yeber, see Giaber.

Young [Physicist], 192, 217, 218, 228, 236, 255.

ZERO, 42.

Ziggurats, Chaldæan Observatories, 6.

Zodiac, 5 .

Zodiacal Light, 199.

Zoology, 4I, 6I, 96, I I6.

" Definition of, Appendix AA, 320.

THE END. 


it, Henrietta Street, Covent Garden, W.C.

JULY, 1894.

A

\section{Catalogue of glooks PUBLISHED BY}

\section{CHAPMAN \& HALL} LIMITED.

A separate Illustrated Catalogue is issued, containing Drawing Examples, Diagrams, Models, Instruments, etc., ISSUED UNDER THE AUTHORITY OF

THE SCIENCE AND ART DEPARTMENT, SOUTH KENSINGTON,

FOR THE USE OF SCHOOLS AND ART AND SCIENCE CLASSES. 


\section{NEW AND FORTHCOMING BOOKS.}

MR. MEREDITH'S NEW NOVEL.

LORD ORMONT AND HIS AMINTA. By GroRge MEREDITH. 3 vols. Crown 8 vo.

GUN, RIFLE, AND BOUND IN EAST AND WEST. By "SNaffle." With Illustrations. Demy 8vo. [In the Press.

THE LIFE OF WARREN HASTINGS. By COL. G. R. Malleson, C.S.I.

IIn the Press.

INCIDENTS OF FOREIGN SPORT AND TRAVEL. By Colonel Pollok, Author of "Sport in British Burma," etc. With Illustrations. Demy 8vo, r6s.

A WATERBIOGRAPHY. By RcBert C. Leslie, Author of "A Sea Painter's Log," etc. With Illustrations by the Author. Crown 8ro.

[In the Press.

A PRACTIOAL HANDBOOK OF DRAWING FOR MODERN METHODS OF REPRODUCTION. By ChaRLES G. HARPER. With many Illustrations showing comparative results. Large crown $8 \mathrm{vo}, 7 \mathrm{~s} .6 \mathrm{~d}$.

AGRICULTURAL ZOOLOGY. By DR. J. Ritzema Bos. Translated by Professor J. R. Ainsworth Davis, B.A., F.C.P. With a Preface by Miss ORMERod. Containing 149 Illustrations. Crown 8vo.

[In the Press.

FIVE MONTHS' SPORT IN SOMALI LAND. By IORD Wolverton. With Illustrations. Crown 8vo, 7s. 6d.

CREATURES OF OTHER DAYS. By REv. H. N. Hutchinson, Author of " Extinct Monsters." With a Preface by Sir W. H. Flower, K.C B., F.R.S., and numerous Illustrations by J. Smit and others. Large Demy Demy 8vo, r4s.

TRAVEL AND ADVENTURES IN THE CONGO FREE STATE AND ITS BIG GAME SHOOTING. By BULA N'ZAU (Captain H. Bailey). Illustrated from the Author's sketches and Map. Demy 8vo, I4s:

TEE CLAIMS OF CHRISTIANITY. By W. S. Lilly. Demy 8vo, i2s.

THE NESTS AND EGGS OF NON-INDIGENOUS BRITISH BIRDS. Ily Charles Dixon, Author of "The Migration of Birds," etc. With Coloured Front spiece. Crown 8 vo.

NAVAL ARCHITECTURE AND SHIP BUILDING. By George C. V. Holmes, Secretary to the Institution of Naval Architects.

[In the Press.

A TEXT-BOOK OF MECHANICAL ENGINEERING. By Wilfrid J. Lineham, late Professor of Engineering at the School of Science and Art and Technical College, Newcastle-on-Tyne, M.I.M.E., etc. Fully Illustrated with Cuts and Diagrams. Crown 8 vo.

[In the Press.

THE MYSTERY OF THE PATRICIAN CLUB. By AlbBRT D. VANDAM. 2 vols. Crown 8 vo.

'MIDST THE WILD CARPATHIANS. By Maurus Jokai. Translated by R. Nisbet BAin. Crown 8vo, 3s. 6d. 


\section{$\mathrm{B} \mathrm{O} \mathrm{O} \mathrm{K} \mathrm{S}$}

PUBLISHED BY

\section{CHAPMAN \& HALL, LIMITED.}

ABOUT (EDMOND)-

HANDBOOK OF SOCIAL ECONOMY; OR, THE WORKER'S A B C. From the French. With a Biographical and Critical Introduction by W. FRASER RAE. Second Edition, revised. Crown $8 \mathrm{vo}, 45$.

ADAMS (HENRY), M.I.C.E., etc.-

BUILDING CONSTRUCTION. Key to Examinations of Science and Art Department. By Henry Adams, M.Inst.C.E., M.I.Mech.E., F.S.I., etc., Professor of Engineering at the City of London College. Cro $* n$ $8 \mathrm{vo}, 4 \mathrm{~s}$.

AFLALO (F. G.) and PASKE (SURGEON-GENERAL C. T.)-

THE SEA AND THE ROD. With Illustrations. Crown $8 \mathrm{vo}, 4 \mathrm{~s} .6 \mathrm{~d}$.

AGRICULTURAL SCIENCE (LECTURES ON), ANU OTHER PROCEEDINGS OF THE INSTITUTE OF AGRICULTURK, SOUTH KENSINGTON, x883-4. Crown 8vo, sewed, 2 .

ANDERSON (ANDREW A.)-

A ROMANCE OF N'SHABE: Being a Record of Startling Adventures in South Central Africa. With Illustrations. Crown 8vo, $5 \mathrm{~s}$.

ANDERSON (CAPTAIN LINDSAY)-

THE STORY OF ALLAN GORDON. With Illustrations Crown 8vo, 5 s.

AMONG TYPHOONS AND PIRATE CRAFT. With Illustrations by Stanley Wood. Crown 8vo, 5 s.

A CRUISE IN AN OPIUM CLIPPER. With Illustrations, Crown 8vo, 6s.

AVELING (EDWARD), D.Sc., Fellow of University College, London-

MECHANICS AND EXPERIMENTAL SCIENCE.

As required for the Matriculation Examination of the University of London.

MECHANICS. With numerous Woodcuts. Crown 8 vo, $6 \mathrm{~s}$.

Key to Problems in ditto, crown 8 vo, 3s. 6 d.

CHEMISTRY. With numerous Woodcuts. Crown $8 \mathrm{vo}, 6 \mathrm{~s}$.

Key to Problems in ditto, crown 8vo, 2s. $6 \mathrm{~d}$.

MAGNETISM AND ELECTRICITY. With Numerous Woodcuts. Crown 8vo. 6s.

LIGHT AND HEAT. With Numerous Woodcuts. Crown 8vo, 6 s.

Keys to the last two volumes in one vol. Crown 8 vo, 5 s.

BAILEY (CAPTAIN H.), (BULA N'ZAU)-

CONGO FREE STATE AND ITS BIG GAME SHOOTING, TRAVEL AND ADVENTURES. Illustrated from the Author's sketches. Demy 8 vo, I4s.

BAILEY (FOHN BURN)-

FROM SINNER TO SAINT; OR, Character TransFORMATIONS. Crown $8 \mathrm{vo}, 6 \mathrm{~s}$.

MODERN METHUSELAHS; or, Short Biographical Sketches of a few advanced Nonagenarians or actual Centenarians. Demy 8 vo ros. 6d.

BAKER (W. L.), A.M.I.C.E.-

THE BEAM; OR, Technical Elements of Girder Construction. Crown 8vo, 4 s. 
BEATTY-KINGSTON $(W)-$.

A JOURNALIST'S JOTTINGS. 2 vols. Demy 8vo, $24 \mathrm{~s}$.

A WANDERER'S NOTES. 2 vols. Demy 8vo, 24 s.

MUSIC AND MANNERS: Personal Reminiscences and Sketches of Character. 2 vols. Demy $8 \mathrm{vo}, 30 \mathrm{~s}$.

BELL (FAMES, Ph.D., E.c.), Principal of the Somerset House Laboratory-

THE CHEMISTRY OF FOODS. With Microscopic Illustrations.

PART I. TEA, COFFEE, COCOA, SUGAR, ETc. Large crown 8vo, 2s. 6d. PART II. MILK, BUTTER, CHEESE, CEREALS, PREPARED STARCHES, ETc. Large crown 8vo, 35.

BENTLEY (H. CUMBERLAND)-

SONGS AND VERSES. Illustrated by Finch MASON, and dedicated to J. G. Whyte Melville. Crown 8vo, 45.

BIRDWOOD (SIR GEORGE C. M.), C.S.I.-

THE INDUSTRIAL ARTS OF INDIA. With Map and r74 Illustrations. New Edition. Demy 8vo, r4s.

BLACKIE (FOHN STUART), F.R.S.E.-

THE SCOTTISH HIGHLANDERS AND THE LAND LAWS. Demy 8vo, 9 s.

ALTAVONA: FACT AND FICTION FROM MY LIFE IN THE HIGHLANDS. Third Edition. Crown $8 \mathrm{vo}, 6 \mathrm{~s}$.

BLATHER WICK (C.)-

IN THE SHADE OF SCHIEHALLION. With 8 Illustrations. I vol. Crown $8 \mathrm{vo}$, rs.

CYNTHIA. With 4 Illustrations. Crown 8vo, is. $B L E U N A R D(A)-$.

BABYLON ELECTRIFIED: The History of an Expedition undertaken to restore Ancient Babylon by the Power of Electricity, and how it Resulted. Translated from the French. Illustrated. Royal 8vo, r2s.

BLOOMFIELD'S (BENJAMIN LORD), MEMOIR OFMISSION TO THE COURT OF BERNADOTTE. With Portraits, 2 vols. Demy 8vo, 28s.

BONVALOT (GABRIEL)-

THROUGH THE HEART OF ASIA OVER THE PAMIR TO INDIA. Translated from the French by C. B. Pitman. With 250 Illustrations by Albert PÉpIN. Royal 8vo, 32 s.

BOS (DR. J. RITZEMA)-

AGRICULTURAL ZOOLOGY: Translated by Professor J. R. Ainsworth DAvis, B.A., F.C.P. With an Introduction by Miss E. A. ORMEROD, F.R.Met.S., F.R.M.S., etc. With 149 lllustrations. Crown 8vo.

BOYLE (FREDERICK)-

FROM THE FRONTIER : Sketches and Stories of Savage Life. Crown 8vo, 3 s. 6 d.

ABOUT ORCHIDS. A Chat. With Coloured Illustrations. Large crown $8 \mathrm{vo}, 8 \mathrm{~s}$.

THE PROPHET JOHN. A Romance. Crown 8vo. $5 \mathrm{~s}$. BOYLE (FREDERICK) and RUSSAN (ASHMORE)-

THE ORCHID SEEKERS : A Story of Adventure in Borneo. Illustrated by AlFred Hartley. Crown 8vo, 7s. 6d. 
BRACKENBURY (COL. C. B.)-

FREDERICK THE GREAT. With Maps and Portrait.

Large crown 8vo, 4 s.

BRADLEY (THOMAS), Royal Military Academy, Woolwich-

ELEMENTS OF GEOMETRICAL DRAWING. In Two

Parts, with Sixty Plates. Oblong folio, half bound, each Part 16 .

$B R I D G M A N(F . A)-$.

WINTERS IN ALGERIA. With 62 Illustrations. Royal 8 vo, ros. $6 \mathrm{~d}$.

BRITISH ARMY, THE. By the Author of "Greater Britain." Demy 8vo, 12s.

BROCK (DR. F. H. E.), Assistant Examiner in Hygiene, Science and Art Department-

ELEMENTS OF HUMAN PHYSIOLOGY FOR THE HYGIENE EXAMINATIONS OF THE SCIENCE AND ART DEPARTMENT. Crown 8vo, is. $6 \mathrm{~d}$.

BROMLEY-DAVENPORT (the late W.), M.P.-

SPORT: Fox Hunting, Salmon Fishing, Covert Shooting, Deer Stalking. With numerous Illustrations by General CREALOCK, C. B. New Cheap Edition. Post 8vo, 3s. 6d.

BUCKLAND (FRANK)-

LOG-BOOK OF A FISHERMAN AND ZOOLOGIST. With Illustrations. Sixth Thousand. Crown 8 vo, 3s. $6 \mathrm{~d}$.

$\operatorname{BUFFEN}(F . F)-$.

MUSICAL CELEBRITIES : Portraits and Biographies. Second Series. Crown 4 to, 21s.

BURCHETT (R.)-

LINEAR PERSPECTIVE, for the Use of Schools of Art. New Edition. With Illustrations. Post 8vo, cloth, 75 .

PRACTICAL GEOMETRY : The Course of Construction of Plane Geometrical Figures. With 137 Diagrams. Eighteenth Edition. Pcst 8 vo, cloth, $5 \mathrm{~s}$.

BURGESS (EDWARD)-

ENGLISH AND AMERICAN YACHTS. Illustrated with 50 Beautiful Photogravure Engravings. Oblong folio, 42s.

BURTON (LADY ISABEL)-

THE LIFE OF SIR RICHARD FRANCIS BURTON. With Portraits, numerous Coloured and other Illustrations, and Maps. 2 vols. Demy 8 vo, $42 \mathrm{~s}$.

BUTLER (A. F.)-

COURT LIFE IN EGYPT. Second Edition. Illustrated. Large crown 8 vo, r2s.

CARLYLE (THOMAS)-

THE CARLYLE BIRTHDAY BOOK. Second Edition.

Small fcap. 8vo, $3^{\text {s. }}$

CARSTENSEN (A. RIIS)-

TWO SUMMERS IN GREENLAND : An Artist's Adventures among Ice and Islands in Fjords and Mountains. With numerous lllust ations by the Author. Demy 8vo, 14s. 


\section{CHAPMAN \& HALL'S SHILLING SERIES,}

THE HELTER-SKELTER HOUNDS. By G. F. UNDERHIL. Crown 8 vo.

HOW TO BUY A HORSE. With Hints on Shoeing and Stable Management. By Pelagius. Crown 8 vo.

in THE Shade of SChiehallion. By Charles Blatherwick. With 4 Illustrations. Crown 8 vo.

CYNTHia. By Charles Blatherwick. With 4 Illustrations. Crown 8 vo.

IN AND OUT OF THE PIGSKIN. By G. F. UNderhill. Crown 8 vo.

THE CHUMPLEBUNNYS AND SOME OTHER ODDITIES. Sketched from Life. By W. BeatTy-Kingston. Illustrated. Crown 8 vo.

A SUBURB OF YEDO. By the late Theobald A. Purcell. Illustrated.

ARCADIAN LIFE. By S. S. Buckman, F.G.S. With lllustrations. Crown 8 vo.

A POPPY'S TEARS. By Mannington CAFFyn.

NOTCHES ON THE ROUGH EDGE OF LIFE. By Lynn Cyril. D'Oyle.

WE TWO AT MONTE CARLO. By Albert D. VANDam.

WHO IS THE MAN? A Tale of the Scottish Border. By J. S. TAIT.

THE CHILD OF STAFFERTON. By Canon Knox Little.

THE BROKEN VOW. By Canon Knox Little.

PADDY AT HOME. By Baron E. DE MANDAT-Grancey.

CHARACTER IN THE FACE. Physiognomical Sketches. Our Looks and what they mean. Crown $8 \mathrm{vo}, 5 \mathrm{~s}$.

CHARLOTTE ELIZABETH, LIFE AND LETTERS OF, Princess Palatine and Mother of Philippe d'Orléans, Regent of France, 1652-1722. With Portraits. Demy 8vo, 10s. 6d.

CHARNAY (DESIRÊ)-

THE ANCIENT CITIES OF THE NEW WORLD. Being Travels and Explorations in Mexico and Central America, 1857-1882. With upwards of 200 Illustrations. Super Royal 8vo, 3rs. 6d.

CHURCH (PROFESSOR A. H.), M.A. Oxon.-

FOOD GRAINS QF INDIA. With numerous Woodcuts. Small 4 to, 6 s.

ENGLISH PORCELAIN. A Handbook to the China made in England during the Eighteenth Century. With numerous Woodcuts. Large crown 8vo, 3 s.

ENGLISH EARTHENWARE. A Handbook to the Wares made in England during the 17 th and $x 8$ th Centuries. With numerous Woodcuts. Large crown $8 \mathrm{vo}, 3 \mathrm{~s}$.

PLAIN WORDS ABOUT WATER. Illustrated. Crown 8 vo, sewed, 6d.

FOOD : Some Account of its Sources, Constituents, and. Uses. A New and Revised Edition. Large crown 8vo, cloth, $3 \mathrm{~s}$.

PRECIOUS STONES : considered in their Scientific and Artistic Relations. With a Coloured Plate and Woodcuts. Second Edition. Large crown 8vo, 2s. 6 d.

COBDEN, RICHARD, LIFE OF. By the Right Hon. JohN MorLex, M.P. With Portrait. New Edition. Crown 8vo, 7s. 6 d.

Popular Edition, with Portrait, 4to, sewed, Is.; cloth, 2 s.

COLLIER (THE HON. MARGARET), Madame Galetti di Cadilliac-

RACHEL AND MAURICE, and OTHER TALES.

Crown 8vo, 3s. 6d. 
COLLINS (WILKIE) and DICKENS (CHARLES)-

THE LAZY TOUR OF TWO IDLE APPRENTICES. With 8 Illustrations. Crown 8 vo, 5 s.

CONGO FREE STATE AND ITS BIG GAME SHOOTING, TRAVEL AND ADVENTURES. Bg BULA N'ZAU. Illu'trated from the Author's sketches. Demy 8vo, $x_{4} \mathrm{~s}$.

COOKERY-

ST. JAMES'S COOKERY BOOK. By LOUISA ROCHFORT. Crown 8vo, 3s. 6d.

DINNERS IN MINIATURE. By Mrs. Earl. Crown 8vo 2s. 6 d.

HILDA'S "WHERE IS IT ?" OF RECIPES. Containing many old CAPE, INDIAN, and MALAY DISHES and PRESERVES; also Directions for Polishing Furniture, Cleaning Silk, etc. ; and a Collection of Home Remedies in Case of Sickness. By Hildagonda J. Duckitt. Fifth Thousand. Crown 8vo, 4s. 6d.

THE PYTCHLEY BOOK OF REFINED COOKERY AND BILLS OF FARE. By MAJOR L- Fifth Edition. Large crown $8 \mathrm{vo}, 8 \mathrm{~s}$.

BREAKFASTS, LUNCHEONS, AND BALL SUPPERS. By Major L-. Crown 8vo, 4s.

OFFICIAL HANDBOOK OF THE NATIONAL TRAINING SCHOOL FOR COOKERV. Containing Lessons on Cookery, forming the Course of Instruction in the School. Compiled by "R. O. C." Twenty-fourth Thousand. Large crown $8 \mathrm{vo}, 6 \mathrm{~s}$.

BREAKFAST AND SAVOURY DISHES. By "R. O. C." Ninth Thousand. Crown 8vo, xs.

THE ROYAL CONFECTIONER : English and Foreign. By C. E. Francatelli. With Illustrations. Sixth Thousand. Crown 8vo, 58. COOPER-KING (LT.-COL.)-

GEORGE WASHINGTON. Large crown 8vo. With Portrait and Maps.

[In the Press.

COUPBRUS (LOUIS)-

ELINE VERE. Translated from the Dutch by J. T. GrRin. Crown 8 vo, $2 \mathrm{~s}$.

COURTNEY (W. L.), M.A., LL.D., of Nerw College, Oxford-

STUDIES AT LEISURE. Crown 8vo, 6s.

STUDIES NEW AND OLD. Crown 8vo, 6s.

CONSTRUCTIVE ETHICS : A Review of Modern Philosophy and its Three Stages of Interpretation, Criticism, and Reconstruction. Demy 8vo, r2s.

CRAIK (GEORGE LILLIE)-

ENGLISH OF SHAKESPEARE. Illustrated in a Philological Commentary on "Julius Cæsar." Eighth Edition. Post 8vo, cloth, 5s.

OUTLINES OF THE HISTORY OF THE ENGLISH LANGUAGE. Eleventh Edition. Post 8vo, cloth, 2s. 6d.

CRAWFURD (OSWALD)-

ROUND THE CALENDAR IN PORTUGAL. With numerous Illustrations. Royal 8vo, x8s.

CRIPPS (WILFRED JOSEPH), M.A., F.S.A.-

COLLEGE AND CORPORATION PLATE. A Handbook for the Reproduction of Silver Plate. With numerous Illustrations. Large crown $8 \mathrm{vo}$, cloth, 2s. $6 \mathrm{~d}$. 
CURZON (LOUIS HENRY)-

A MIRROR OF THE TURF; or, The Machinery of Horse-racing Revealed, showing the Sport of Kings as it is to-day. Crown 8vo, 8s.

DAIRY FARMING-

DAIRY FARMING. To which is added a Description of the Chief Continental Systems. With numerous Illustrations. By JAmES Long. Crown 8 vo, 9 s.

DAIRY FARMING, MANAGEMENT OF COWS, etc. By Arthur Roland. Edited by William Ablett. Crown 8vo, 5 s.

$D A L Y$ (J. B.), LL.D.-

IRELAND IN THE DAYS OF DEAN SWIFT. Crown 8vo, 5s. $D A S(D E V E N D R A N$.) -

SKETCHES OF HINDOO LIFE. Crown 8vo, 5 s.

DAUBOURG (E.)-

INTERIOR ARCHITECTURE. Doors, Vestibules, Staircases, Anterooms, Drawing, Dining, and Bed Rooms, Libraries, Bank and Newspaper Offices, Shop Fronts and Interiors. Half-imperial, cloth, $\Varangle_{2}$ 12s. $6 \mathrm{~d}$.

DAVIDSON (ELLIS A.)-

PRETTY ARTS FOR THE EMPLOYMENT OF LEISURE HOURS. A Book for Ladies. With Illustrations. Demy 8vo, 6s،

DAWSON (WILLIAM HARBUTT)-

GERMANY AND THE GERMANS: Social Life, Culture, Religious Life, etc., etc. In 2 vols. Demy 8vo, $26 s$.

$D A Y(W I L L I A M)-$

THE RACEHORSE IN TRAINING, with Hints on Racing and Racing Reform. Fifth Thousand. Demy 8va gs.

$D E \quad B O V E T$ (MADAME)-

THREE MONTHS' TOUR IN IRELAND. Translated and Condensed by Mrs. Arthur Walter. With Illustrations. Crown 8vo., 6s,

UE CHAMPEAUX (ALFRED)-

TAPESTRY. With numerous Woodcuts. Cloth, 2s. 6d.

DE FALLOUX (THE COUNT)-

MEMOIRS OF A ROYALIST. Edited by C. B. Pitman. 2 vols. With Portraits. Demy 8vo, 32s.

$D E$ LESSEPS (FERDINAND)-

RECOLLECTIONS OF FORTY YEARS. 2 vols. Demy 8vo, 24s.

DELILLE (EDWARD)-

SOME FRENCH WRITERS. Crown 8vo, 5 s.

Contents: Bourget, Pierre Loti, Baudelaire, Guy de Maupassant, Verlaine, Maurice Barres, \&c.

DE LISLE (MEMOIR OF LIEUTENANT RUDOLPH), R.N., of the Naval Brigade. By the Rev. H. N. Oxznham, M.A. Third Edition. Crown 8vo, 7s. 6d.

$D B$ MANDAT-GRANCEY (BARON E.)-

PADDY AT HOME; OR, IRELAND AND THE IRISH AT the Present Time, as seen by a Frenchman. Fifth Edition. Crown 8vo, rs. ; in cloth, Is. $6 \mathrm{~d}$.

$D E$ WINDT (H.)-

SIBERIA AS IT IS. With numerous Illustrations. Demy 8vo, r8s. 
DE WINDT (H.)-continued-

FROM PEKIN TO CALAIS BY LAND. With numerous Illustrations by C. E. FR1PP from Sketches by the Author. New and Cheaper Edition. $7 \mathrm{~s}$. 6d.

A RIDE TO INDIA ACROSS PERSIA AND BELUCHISTAN. With numerous Illustrations. Demy 8vo, 16s.

DICKENS (CHARLES)-

THE CHARLES DICKENS BIRTHDAY BOOK. With Five Illustrations. In a handsome fcap. 4to volume, r2s.

THE HUMOUR AND PATHOS OF CHARLES DICKENS. By Charles Kent. With Portrait. Crown 8vo, $6 \mathrm{~s}$.

THE DICKENS DICTIONARY. A Key to the Characters and Principal Incidents in the Tales of Charles Dickens. New Edition. Large crown $8 \mathrm{vo}$, $5 \mathrm{~s}$.

DICKENS (MARY A.)-

CROSS CURRENTS : a Novel. Third Thousand. Crown 8vo, 3s. 6d. In boards, 2 .

DILKE (LADY)-

ART IN THE MODERN STATE. With Facsimile. Demy 8vo, 9 s.

DINARTE (SYLVIO)-

INNOCENCIA : A Story of the Prairie Regions of Brazil. Translated from the Portuguese and Illastrated by James W. WeLls, F.R.G.S. Crown 8vo, 6s.

DIXON (CHARLES)-

THE NESTS AND EGGS OF NON-INDIGENOUS BRI'TISH BIRDS. [In the Press.

THE NESTS AND EGGS OF BRITISH BIRDS : When and Where to Find Them. Being a Handbook to the Oology of the British Islands. Crown 8vo, $6 \mathrm{~s}$.

** A Large Paper Edition, coniaining 57 Coloured Illustrations, Demy 8vo, I5s. net.

JOTTINGS ABOUT BIRDS. With coloured Frontispiece by J. Sмrт. Crown 8vo, 6s.

THE GAME BIRDS AND WILD FOWL OF THE BRITISH ISLANDS. Illusirated by A. T. Elwes. Demy 8vo, r8s.

THE MIGRATION OF BIRDS : An Attempt to Reduce the Avian Season-flight to Law. Crown 8vo, 6s.

THE BIRDS OF OUR RAMBLES: A Companion for the Country. With Illustrations by A. T. Elwes. Large Crown 8vo, 7s. 6d.

IDLE HOURS WITH NATURE. With Frontispiece. Crown 8vo, $6 \mathrm{~s}$.

ANNALS OF BIRD LIFE: A Year-Book of British Ornithology. With Illustrations. Crown 8vo, 7s, 6d.

DOUGLAS (JOHN)-

SKETCH OF THE FIRST PRINCIPLES OF PHYSIOGRAPHY. With Maps and numerous Illustrations. Crown 8vo, 6s.

DRA YSON (MAJOR-GENERAL A. W.)-

THIRTY THOUSAND YEARS OF THE EARTH'S PAST HISTORY. Large Crown 8vo, 5 s.

EXPERIENCES OF A WOOLWICH PROFESSOR during Fifteen Years at the Royal Military Academy. Demy 8vo, 8s.

DUCKITT (HILDAGONDA J.)-

HILDA'S "WHERE IS IT?" OF RECIPES. Containing many old CAPE, INDIAN, and MALAY DISHES and PRESERVES ; also Directions for Polishing Furniture, Cleaning Silk, etc. Fifth Thousand Crown 8vo, 4s. 6d. 
DUCOUDRAY (GUSTAVE)-

THE HISTORY OF ANCIENT CIVILISATION. A

Handbook based upon M. Gustave Ducoudrays "Histoire Sommaire de la Civilisation.' Edited by Rev. J. Verschoyle, M.A. With Illustrations. Large crown 8vo, 6s.

THE HISTORY OF MODERN CIVILISATION. With Illustrations. Large crown $8 \mathrm{vo}, 9 \mathrm{~s}$.

$D Y C E$ (WILLIAM), R.A.-

DRAWING-BOOK OF THE GOVERNMENT SCHOOL OF DESIGN. Fifty selected Plates. Folio, sewed, $5 \mathrm{~s}$. ; mounted, r8s.

ELEMENTARY OUTLINES OF ORNAMENT. Plates I. to XXII., containing 97 Examples, adapted for Practice of Standards I. to IV. Small folio, sewed, 2s. 6d.

SELECTION FROM DYCE'S DRAWING BOOK. 15 Plates, sewed, 1s. 6d.; mounted on cardboard, 6s. 6d.

TEXT TO ABOVE. Crown 8vo, sewed, 6d.

EARL (MRS.)-

DINNERS IN MINIATURE. Crown 8vo, 2s. 6d.

EDWARDS (MRS. SUTHERLAND)-

THE SECRET OF THE PRINCESS. A Tale of Country, Camp, Court, Convict, and Cloister Life in Russia. Crown 8vo, 3s. 6d.

ELLIOT (FRANCES MINTO)-

OLD COURT LIFE IN SPAIN. 2 Vols. Demy 8 vo, 24 s.

BLLIS (A. B., Colonel ist West India Regiment)-

THE YORUBA - SPEAKING PEOPLES OF THE SLAVE COAST OF WEST AFRICA: their Religion, Manners, Customs, Laws, Language, \&c. With an Appendix and Map. Demy 8vo, ros. 6d.

HISTORY OF THE GOLD COAST OF WEST AFRICA. Demy 8vo, Ios. 6d.

THE EWE-SPEAKING PEOPLE OF THE SLAVE COAST OF WEST AFRICA. With Map. Demy 8vo, ros. 6d.

THE TSHI-SPEAKING PEOPLES OF THE GOLD COAST: their Religion, Manners, Customs, Laws, Language, \&c. With Map. Demy 8vo, xos. 6d.

SOUTH AFRICAN SKETCHES. Crown 8vo, 6s.

ENGEL (CARL)-

MUSICAL INSTRUMENTS. With numerous Woodcuts. Large crown 8vo, cloth, 2s. $6 \mathrm{~d}$.

ENGLISHMAN IN PARIS: NOTES AND RECOLLECTIONS DURING THE REIGN OF LOUIS PHILIPPE AND THE EMPIRE. Eighth Thousand. Crown 8vo, 7s. 6d.

$\operatorname{ESCOTT}(T$. H. S.)-

POLITICS AND LETTERS. Demy 8vo, 9s.

ENGLAND: ITS PEOPLE, POLITY, AND PURSUITS. New and Revised Edition. Eighth Thousand. Demy 8vo, 3s. 6d.

EUROPEAN POLITICS, THE PRESENT POSITION OF. By the Author of "Greater Britain." Demy 8vo, ras.

FANE (VIOLET)-

AUTUMN SONGS. Crown 8vo, 6s.

THE STORY OF HELEN DAVENANT. Crown 8 vo. In boards, $2 \mathrm{~s}$.

FIELD (HENRY M.)-

GIBRALTAR. With numerous Illustrations. Demy 8 vo, 7s. 6d. 
FISKE $(J O H N)$ -

LIFE AND LETTERS OF EDWARD LIVINGSTONE YOUMANS. Comprising Correspondence wi:h Spencer, Huxley, Tyndall, and others. Crown 8 vo, $8 \mathrm{~s}$.

FITZGERALD (PERCY), F.S.A.-

HENRY IRVING : A Record of Twenty Years at the Lyceum. With Portrait. Demy 8vo, x4s.

CHRONICLES OF BOW STREET POLICE OFFICE. New and Cheaper Edition.

THE HISTORY OF PICKWICK. An Account of its Characters, Localities, Allusions, and Illustrations. With a Bibliography. Demy $8 \mathrm{vo}, 8 \mathrm{~s}$.

FLEMING (GEORGE), F.R.C.S.-

ANIMAL PLAGUES: THEIR HISTORY, NATURE, AND PREVENTION. 8vo, cloth, $15 \mathrm{~s}$

PRACTICAL HORSE-SHOEING. With 37 Illustrations, Fifth Edition, enlarged. 8vo, sewed, 2s.

RABIES AND HYDROPHOBIA: THEIR HISTORY, NATURE, CAUSES, SYMPTOMS, AND PREVENTION. With 8 Illustra. tions. $8 \mathrm{vo}$, cloth, $15 \mathrm{~s}$.

EORSTER $(\mathcal{F O H N})$

THE LIFE ÓF CHARLES DICKENS. Original Edition. Vol. I., 8vo, cloth, r2s. c II., 8vo, cloth, I4S. Vol. III., 8vo, cloth, r6s.

Uniform with the Illustrated Library Edition of Dickens's Works. 2 vols. Demy 8 vo, 2os.

Uniform with the "C. D." Edition. With Numerous Illustrations. 2 vols. $7 \mathrm{~s}$.

Uniform with the Crown Edition. Crown 8vo, $5 \mathrm{~s}$.

Uniform with the Household Edition. With Illustrations by F. BARnard. Crown 4 to, cloth, 5 s.

Uniform with the Pictorial Edition. With 40 Illustrations by F. BARNARD and others. Royal 8vo, 35. 6d

FORSTER, THE LIFE OF THE RIGHT HON. W. E. By T. Wemyss Reid. With Portraits. Fourth Edition. 2 vols. Demy 8vo, 32s. FIFTH EDITION, in one volume, with new Portrait. Demy 8vo, ros. 6d.

FORSYTH (CAPTAIN)-

THE HIGHLANDS OF CENTRAL INDIA : Notes on their Forests and Wild Tribes, Natural History and Sports. With Map and Coloured Illustrations. A New Edition. Demy 8vo, 12s.

FURTNUM (C. D. E.), F.S.A.-

MAIOLICA. With numerous Woodcuts. Large crown 8vo, cloth, 2s. $6 \mathrm{~d}$.

BRONZES. With numerous Woodcuts. Large crown $8 \mathrm{vo}$, cloth, 2s. $6 \mathrm{~d}$.

FOSTER (ALBERT J.), M.A.-

ROUND ABOUT THE CROOKED SPIRE. With Illustrations. Crown 8vo, 5 s.

FOUQUE (DE. LA MOTTE)-

UNDINE: a Romance translated from the German. With an Introduction by JUlia Cartwright. Illustrated by Heywood SUmare. Crown 4 to, 5 s.

FRANCATELLI (C. E.) -

THE ROYAL CONFECTIONER: English and Foreign. A Practical Treatise. With Illustrations. Sixth Thousand. Crown 8vo, 5 s. FRANKS (A. W. -

JAPANESE POTTERY. Being a Native Report, with an Introduction and Catalogue. With numerous Illustrations and Marks. Large crown 8 vo, cloth, 2 s. 6 d. 
FROBEL, FRIEDRICH ; a Short Sketch of his Life, including Fröbel's Letters from Dresden and Leipzig to his Wife now first Translated into English. By Emily Shirrefr. Crown 8vo, 2S.

GALLENGA (ANTONIO)-

ITALY: PRESENT AND FUTURE. 2 vols. Dmy.8vo, 2 Is. GARDNER (J. STARKIE)-

IRONWORK. From the Earliest Time to the End of the Mediæval Period. With 57 Illustrations. Large crown $8 \mathrm{vo}, 3 \mathrm{~s}$.

GASNAULT (PAUL) and GARNIER (ED.)-

FRENCH POTTERY. With Illustrations and Marks. Large crown $8 \mathrm{vo}, 3 \mathrm{~s}$.

GILLMORE (PARKER)-

THE HUNTER'S ARCADIA. With numerous Illustrations. Demy 8vo, ros. 6d.

GIRL'S LIFE EIGHTY YEARS AGO (A). Selections from the Letters of Eliza Southgate Bowne, with an Introduction by Clarence Cook. Illustrated with Portraits and Views. Crown 4 to, 12s.

GLEICHEN (COUNT)-

WITH THE CAMEL CORPS UP THE NILE. With numerous Sketches by the Author. Third Edition. Large crown 8vo, 9s.

GORDON (GENERAL)-

LETTERS FROM THE CRIMEA, THE DANUBE, AND ARMENIA. Edited by Demetrius C: Boulger. Second Editioni Crown 8vo, 5 S.

GORST (SIR F. E.), Q.C., M.P.-

AN ELECTION MANUAL. Containing the Parliamentary Elections (Corrupt and Illegal Practices) Act, $188_{3}$, with Notes. Third Edition. Crown 8vo, 1s. 6d.

GOWER (A.R.), Royal School of Mines-

PRACTICAL METALLURGY. With Illustrations. Crown 8vo, 3s.

GRESWELL (WILLIAM), M.A., F.R.C.I.-

OUR SOUTH AFRICAN EMPIRE. With Map. 2 vols. Crown $8 \mathrm{vo}, 2 \mathrm{ss}$.

GREVILLE-NUGENT (THE HON. MRS.)-

A LAND OF MOSQUES AND MARABOUTS. Illustrated. Demy 8vo, r4s.

GRIFFIN (SIR LEPEL HENRY), K.C.S.I.-

THE GREAT REPUBLIC. Second Edition. Crown 8vo, 4s. 6d.

GRIFFITHS (MAFOR ARTHUR), H.M. Inspector of Prisons-

SECRETS OF THE PRISON HOUSE. With numerous Illustrations by GEORGE D. Rowlandson. 2 vols. Demy 8vo, 30 s.

FRENCH REVOLUTIONARY GENERALS. Large crown 8 vo, 6s.

GRIMBLE (A.)-

SHOOTING AND SALMON FISHING: HINTS AND RECOLLECTIONS. Second Edition. With Illustrations. Demy 8vo, r6s.

GUNDRY (R. S.)-

CHINA AND HER NEIGHBOURS. France in IndoChina, Russia and China, India and Thibet, \&c. With Maps. Demy 8vo, gs.

GUN, RIFLE, AND HOUND IN THE EAST AND WEST. By "SNAFF:E." With Illustrations. Crown 8vo. [In the Press.

HALL $(S I D N E Y)-$

A TRAVELLING ATLAS OF THE ENGLISH COUNTIES. Fifty Maps, coloured. New Edition, including the Railways, corrected up to the present date. Demy $8 \mathrm{vo}$, in roan tuck, ros. $6 \mathrm{~d}$. 
HARPER (CHARLES G.)-

A PRACTICAL HANDBOOK OF DRAWING, for modern methods of Reproduction, with many Illustrations showing comparative results. Crown 8 vo, $7 \mathrm{~s}$. $6 \mathrm{~d}$.

HARRIS (FRANK)-

ELDER CONKLIN, and Other Stories. Crown 8vo.

HARRISON (FOHN)-

THE I In the Press.

OF METALS, CHASING,

REPOUSSE AND SAW PIERCING. With 180 Illustrations. Cr. 8vo, 3s. 6d. HARTINGTON (EDWARD)-

THE NEW ACADEME: An Educational Romance. Crown 8vo, 5 s.

HATTON (RICHARD G.), Durham College of Science, Newcastle-on-Tyne-

ELEMENTARY DESIGN : being a Theoretical and Practical Introduction in the Art of Decoration. With rio Illustrations. Crown 8 vo, 2s. 6d. Science and Art Series.

HAWKINS (FREDEKICK)-

THE FRENCH STAGE IN THE EIGHTEENTH CENTURY. With Portraits. 2 vols. Demy 8 vo, 30 s.

ANNALS OF THE FRENCH STAGE: FROM ITS ORIGIN TO THE DEATH OF RACINE. 4 Portraits. 2 vols. Demy 8 vo, 28s. HILDEBRAND (HANS)-

INDUSTRIAL ARTS OF SCANDINAVIA IN THE PAGAN TIME. With numerous Woodcuts. Large crown 8vo, 2s. $6 \mathrm{~d}$.

HILL (MISS G.) -

THE PLEASURES AND PROFITS OF OUR LITTLE HOLBEINPOULTRY FARM. Small $8 \mathrm{vo}, 3 \mathrm{~s}$.

TWELVE HEADS AFTER HOLBEIN. Selected from Drawings in Her Majesty's Collection at Windsor. Reproduced in Autotype, in portfolio. $E_{\mathrm{I}} \mathrm{I} 6 \mathrm{~s}$.

HOLMES (GEORGE C. V.), Secretary of the Institution of Naval Architects-

NAVAL ARCHITECTURE AND SHIP BUILDING.

MARINE ENGINES AND BOILERS With [ $[n$ the Press. Woodcuts. Large crown 8 vo, 3 s.

HOPE (ANDREE -

THE VYVYANS; or, The Murder in the Rue Bellechasse. Crown 8vo, 3s. 6d.

CHRONICLES OF AN OLD INN; or, a Few Words about Gray's Inn. Crown 8vo, 5s.

HOUSSAYE (ARSENEE)-

BEHIND THE SCENES OF THE COMÉDIE FRAN. CAISE, AND OTHER RECOLLECTIONS. Translated from the French. Demy $8 \mathrm{vo}, \mathrm{I} 4 \mathrm{~s}$.

HOVELACQUE (ABEL)-

THE SCIENCE OF LANGUAGE : LINGUISTICS, PHILOLOGY, AND ETYMOLOGY. With Maps. Large crown 8vo, cloth, 3s. 6d.

HOW TO BUY A HORSE. With Hints on Shoeing and Stable Management. By Pelagius. Crown 8vo, is.

HOZIER (H. M.)-

TURENNE. With Portrait and Two Maps. Large crown

HUDSON $\stackrel{8 \mathrm{vo}, \stackrel{45}{W} .}{W}$ H.), C.M.Z.S. Joint Author of "Argentine Ornithology"-

BIRDS IN A VILLAGE. Square crown 8vo, 7s. 6d.

IDLE DAYS IN PATAGONIA. With numerous Illustrations by J. Smit and A. Hartley. Demy 8vo, 14s.

THE NATURALIST IN LA PLATA. With numerous Illustrations by J. Smit. Second Edition. Demy 8vo, r6s. 
HUEFFER (F.)-

HALF A CENTURY OF MUSIC IN ENGLAND r837-r887. Demy 8vo, 8 s.

HUGHES (W.R.), F.L.S.-

A WEEK'S TRAMP IN DICKENS-LAND. With upwards of roo Illustrations by F. G. Kitton, Herbert Rallton, and others. Second Edition. Demy 8vo, 7s. 6d.

HUNTLY (MARQUIS OF)-

TRAVELS, SPORTS, AND POLITICS IN THE EAST OF EUROPE. With Illustrations. Large Crown 8vo, r2s.

HUTCHINSON (REV. H. N.), F.G.S.-

CREATURES OF OTHER DAYS. With a Preface by SiR W. H. Flower, K.C.B., F.R.S., and numerous Illustrations by J. Smit and others Large Demy 8vo, I $_{4}$.

EXTINCT MONSTERS. A Popular Account of some of the larger forms of Ancient Animal Life. With numerous lliustrations by J. Smit and others. Third Thousand, Revised and Enlarged. Demy 8vo, r2s.

INDUSTRIAL ARTS: Historical Sketches. With numerous Illustrations. Large crown $8 \mathrm{vo}, 3 \mathrm{~s}$.

IRVING, HENRY. A Record of Twenty Years at the Lyceum.

By Percy Fitzgeralo, M.A., F.S.A. With Portrait. Demy 8vo, r 4 s.

FACKSON (FRANK G.), Master in the Birmingham Municipal School of Art-

THEORY ANI PRACTICE OF DESIGN: An Advanced Text Book on Decorative Art. With 700 Illustrations Large Crown 8vo, gs.

DECORATIVE DESIGN. An Elementary Text Book of Principles and Practice. With numerous Illustrations. Second Edition. Crown 8vo, 7s. 6d.

ҰAMES (HENRY A.), M.A.-

HANDBOOK TO PERSPECTIVE. Crown 8vo, 2s. 6d

PERSPECTIVE CHARTS, for use in Class Teaching. $2 \mathrm{~s}$.

IEAFFRESON (J. CORDY), B.A.-

MIDDLESEX COUNTY RECORDS. Indictments, Recogrizances, Coroners' Inquisitions Post Mortem, Orders, Memoranda, and Certificates of Convictors of Conventiclers, temp. Ig Charles II. to 4 James II. 4 vols. With Portraits, Illustrations, and Facsimiles. Demy 8vo, 25s. each.

FBANS (W. T. ) -

CREATORS OF THE AGE OF STEEL. Memoirs of Sir W. Siemens, Sir H. Bessemer, Sir J. Whitworth, Sir J. Brown, and other Inventors." Second Edition. Crown 8vo, 7s. 6d.

JOKAI (MAURUS)-

PRETTY MICHAL. Translated by R. NisBet BAIN.

Crown 8vo. New Edition, 2s.

'MIDST THE WILI CARPATHIANS. Translated by R. Nisbet Bain. Crown 8vo, 3s. 6d.

FOPLING (LOUISE)-

HINTS TO AMATEURS. A Handbook on Art. With Diagrams. Crown 8 vo, rs. $6 \mathrm{~d}$.

FUNKER (DR. WM.)-

TRAVELS IN AFRICA. Translated from the German by Professor KEANE.

Vol. I. DURING the YEARS 1875 to 1878 . Containing 38 Full-page Plates and 125 Illustrations in the Text and Map. Demy 8 vo, 215.

Vol. II. DURING the YEARS 1879 to $x 883$. Containing numerous Full-page Plates, and lllustrations in the Text and Map. Demy 8vo, 2 rs.

Vol. III. DURING the YEARS 1882 to 1886. . Containing numerous Full-page Plates and Illustrations in the Text and Maps. Demy 8vo, 2 rs. 
KELLY ('A MES FITZMAURICE)-

THE LIFE OF MIGUEL DE CERVANTES

SAAVEDR.1: A Biographical, Literary, and Historical Study, with a Tentative Bibliography from 1585 to 1892 , and an Annotated Appendix on the "Canto de Calíope." Demy 8 vo, $16 \mathrm{~s}$.

KEMIPT (ROBERT)-

CONVIVIAL CALEDONIA: Inns and Taverns of Scotland, and some Famous People who have frequented them. By RonErT KeMPT. Crown 8vo, 2s. 6d.

KENNARD (EDWARD)-

NORWEGIAN SKETCHES : FISHING IN STRANGE

WATERS. Illustrated with 30 beautiful Sketches. Second Edition. $14 \mathrm{~s}$.

KENNARD (H. MARTYN)-

PHILISTINES AND ISRAELITES : A New Light on the World's History. Demy 4to, 6 s.

KING (LIEUT.-COL. COOPER)-

GEORGE WASHINGTON. Large crown 8vo. [I $n$ the Press. LACORDAIRE (PERE)-

JESUS CHRIST; GOD; AND GOD AND MAN. Conferences delivered at Notre Dame in Paris. Seventh Thousand. Crown 8vo, 3s. $6 \mathrm{~d}$.

LAING (S.)-

HUMAN ORIGINS: EVIDENCE FROM HISTORY AND SCIENCE. With Illustrations. Twelfth Thousand. D my 8vo, 3s. 6d.

PROBLEMS OF THE FUTURE AND ESSAYS. Thirteenth Thousand. Demy 8vo, 3s. 6d.

MODERN SCIENCE AND MODERN THOUGHT. Nineteenth Thousand. Demy 8vo, 3s. 6d.

A MODERN ZOROASTRIAN. Eighth Thousand. Demy 8vo, 3s. 6d.

LAMENNAIS (F.)-

WORDS OF A BELIEVER, and THE PAST AND FUTURE OF THE PEOPLE. Translated from the French by L. E. Martineau. With a Memoir of Lamennais. Crown 8vo, 4s.

LANDOR (W. S.) -

LIFE AND WORKS. 8 vols.

Vol. x. Out of print.

VoL. 2. Out of print.

VoL. 3. CONVERSATIONS OF SOVEREIGNS AND STATESMEN, AND FIVE DIALOGUES OF BOCCACCIO AND PETRARCA. Demy $8 \mathrm{vo}, 14 \mathrm{~s}$.

Vol. 4. DIALOGUES OF LITERARY MEN. Demy 8vo, 14s.

Vol. 5. DIALOGUES OF LITERARY MEN (continued). FAMOUS WOMEN. LETTERS OF PERICLES AND ASPASIA. And Minor Prose Pieces. Demy 8vo 14S.

Vor. 6. MISCELLANEOUS CONVERSATIONS. Demy 8vo, r4s.

Vol. 7. GEBIR, ACTS AND SCENES AND HELLENICS. Poems. Demy 8vo, 14 s.

Vol. 8. MISCELLANEOUS POEMS AND CRITICISMS ON THEOLANIN (E. B.) CRITUS, CATULLUS, AND PETRARCH. Demy 8vo, r4s.

RUSSIAN CHARACTERISTICS. Reprinted, with

Revisions, from The Fortnightly Review. Demy 8vo, I4s.

LAVELEYE (EMILE DE)-

THE ELEMENTS OF POLITICAL ECONOMY.

Translated by W. Pollard, B.A., St. John's College, Oxford. Crown 8vo, 6s. 
$L E$ CONTE (JOSEPH), Professor of Geology and Natural History in the University of California-

EVOLUTION: ITS NATURE, ITS EVIDENCES, AND ITS RELATIONS TO RELIGIOUS THOUGHT. A New and Revised Edition. Crown 8vo, 6s.

LEFEVRE (ANDRÉ)-

PHILOSOPHY, Historical and Critical. Translated, with an Introduction, by A. W. KEANE, B.A. Large crown 8vo, 3s. 6d.

LE ROUX (H.)-

ACROBATS AND MOUNTEBANKS. With over 200 Illustrations by J. GARNirr. Royal 8vo, r6s.

LEROY-BEAULIEU (ANATOLE)-

PAPACY, SOCIALISM, AND DEMOCRACY. By Anatole Leroy-Beavliev, Member of the Institute of France. Translated by Professor B. L. O'DonNel. Crown 8vo, 7s. 6d.

LESLIE (R. C.)-

A WATERBIOGRAPHY. With Illustrations by the Author. Crown 8 vo.

THE SEA BOAT: HOW TO BUILD, RIG, AND SAIL HER. With numerous Illustrations by the Author. Crown 8vo, 4s. 6 d.

LIFE ABOARD A BRITISH PRIVATEER IN THE TIME OF QUEEN ANNE. Being the Journals of Captain Woodes Rogers, Master Mariner. With Notes and Illustrations by ROBERT C. LESLIE. A New and Cheaper Edition. Large crown 8vo, 3s. 6d.

A SEA PAINTER'S LOG. With I 2 Full-page Illustrations by the Author. Large crown 8vo, I2s.

LBTOURNEAU (DR. CHARLES)-

SOCIOLOGY. Based upon Ethnology. Large crown 8vo, 3s. 6d.

BIOLOGY. With 83 Illustrations. A New Edition. Demy 8vo, 3s. 6d.

LILLY $\left(W . S_{.}\right)-$

THE CLAIMS OF CHRISTIANITY. Demy 8vo, r2s.

ON SHIBBOLETHS. Demy 8vo, r2s.

ON RIGHT AND WRONG. Second Edition. Demy 8vo, 12s.

A CENTURY OF REVOLUTION. Second Edition. Demy 8vo, r2s.

CHAPTERS ON EUROPEAN HISTORY. With an Introductory Dialogue on the Philosophy of History. 2 vols. Demy 8vo, 2 rs.

ANCIENT RELIGION AND MODERN THOUGHT. Second Edition. Demv 8vo, r2s.

LINEHAM (MRS. RAY S.)-

THE STREET OF HUMAN HABITATIONS. Fully Illustrated. Crown 8vo, 6s. Science and Art Series.

LINEHAM (WILFRID J.), Member of the Institute of Mechanical Engineers, Ec., E. C. -

A TFXT-BOOK OF MECHANICAL ENGINEERING. Fully Illustrated with Cuts and Diagrams. Crown 8 vo.
[In the Press.

LITTLE (THE REV. CANON KNOX)-

THE WAIF FROM THE WAVES : a Story of Three Lives, touching this World and another. Fifth Thousand. Crown 8vo, 3s. 6d.

THE CHILD OF STAFFERTON : A Chapter from a Family Chronicle. Twelfth Thousand. Crown 8vo, boards, Is.; cloth, Is. 6d.

THE BROKEN VOW. A Story of Here and Hereafter. Eighteenth Thousand. Crown 8vo, boards, is. cloth, rs. 6 d. 
LLOYD (W. W.), late 24th Regiment-

ON ACTIVE SERVICE. Printed in Colours. Oblong 4 to, $5 \mathrm{~s}$.

SKETCHES OF INDIAN LIFE. Printed in Colours. 4 to, $6 \mathrm{~s}$.

LONG (JAMES)-

DAIRY FARMING. To which is added a Description of the Chief Continental Systems. With numerous Illustrations. Crown $8 \mathrm{vo}, \mathrm{gs}$.

LOW (WILLIAM)-

TABLE DECORATION. With I9 Full Illustrations, Demy 8vo, 6s.

M'DERMOTT (P. L.)-

BRITISH EAST AFRICA. A History of the Formation and Work of the Imperial British East Africa Company. Compiled with the Authority of the Directors from Official Documents and the Records of the Company. With Maps and Illustrations. Crown 8vo, $6 \mathrm{~s}$.

$M A C D O N A L D\left(A . F_{\text {. }}\right)$

OUR OCEAN RAILWAYS; or, The Rise, Progress, and Development of Ocean Steam Navigation, etc., etc. With Maps and Illustrations. Large crown $8 \mathrm{vo}, 6 \mathrm{~s}$.

$\operatorname{McCOAN}($ J. C.) -

EGYPT UNDER ISMAIL: a Romance of History. With Portrait and Appendix of Official Documents. Crown $8 \mathrm{vo}, 7 \mathrm{~s}, 6 \mathrm{~d}$.

MALLESON (COL. G. B.), C.S.I.-

THE LIFE OF WARREN HASTINGS.

[In the Press.

PRINCE EUGENE OF SAVOY. With Portrait and Maps. Large crown 8vo, 6s.

LOUDON. A Sketch of the Military Life of Gideon Ernest, Freicherr von Loudon. With Portrait and Maps. Large crown 8vo, $4 \mathrm{~S}$.

$M A L L E T(R O B E R T)-$

PRACTICAL MANUAL OF CHEMICAL ASSAYING, as applied to the Manufacture of Iron. By L. L. Dв Koninck and E. Dietz. Edited, with notes, by Robert Mallet. Post 8 vo, cloth, $6 \mathrm{~s}$.

$M A L L O C K\left(W . H_{0}\right)-$

A HUMAN DOCUMENT. Sixth Thousand. Crown 8vo, 3s. 6d.

MARCEAU (SERGENT)-

REMINISCENCES OF A REGICIDE. Edited from the Original MSS. of Sergent Marceau, Member of the Convention, and Administrator of Police in the French Revolution of 1789 . By M. C. M. SiMPSON. Demy 8 vo, with Illustrations and Portraits, $x_{4}$ s.

MASKELL (ALFKED)-

RUSSIAN ART AND ART OBJECTS IN RUSSIA. A Handbcuk to the R.eproduction of Goldsmiths' Work and other Art Treasures. With Illustrations. Large crown 8vo, 4s. $6 \mathrm{~d}$.

MASKELL (WILLIAM)-

IVORIES : ANCIENT AND MEDIAVAL. With numerous Woodcuts. Large crown 8 vo, cloth, 2 s. 6 d.

HANDBOOK TO THE DYCE AND FORSTER COLLECTIONS. With Illustrations. Large crown 8vo, cloth, 2s. $6 \mathrm{~d}$.

MASPÉRO (G.), late Director of Archeology in Egypt, and Member of the Institute of France-

LIFE IN ANCIENT EGYPT AND ASSYRIA. Translated by A. P. Morton. With 188 Illustrations. Third Thousand. Crown $8 \mathrm{vo}, 5$ s. 


\section{GEORGE MEREDITH'S WORKS.}

LORD ORMONT AND HIS AMINTA. 3 Vols., 3 Is. 6 d.

A Uniform Edition. Crown 8vo, 3s. 6d. each.

ONE OF OUR CONQUERORS,

DIANA OF THE CROSSWAYS.

EVAN HARRINGTON.

THE ORDEAL OF RICHARD FEVEREL.

THE ADVENTURES OF HARRY RICHMOND.

SANDRA BELLONI.

VITTORIA.

RHODA FLEMING.

BEAUCHAMP'S CAREER.

THE EGOIST.

THE SHAVING OF SHAGPAT; AND FARINA.

The 6s. Edition is also to be had.

MILLS ( $(\mathcal{O O H N})$, formerly Assistant to the Solar Physics Committee-

ADVANCED PHYSIOGRAPHY (PHYSIOGRAPHIC ASTRONOMY). Designed to meet the Requirements of Students preparing for the Elementary and Advanced Stages of Physiography in the Science and Art Department Examinations, and as an Introduction to Physical Astronomy. Crown 8vo, 4s. 6d.

ELEMENTARY PHYSIOGRAPHIC ASTRONOMY. Crown 8vo. is. 6d.

ALTERNATIVE ELEMENTARY PHYSICS. Crown $8 \mathrm{vo}, 2 \mathrm{~s} .6 \mathrm{~d}$.

MILLS ( $(F O H N)$ and NORTH (BARKER)-

QUANTITATIVE ANALYSIS LESSONS ON). With numerous Woodcuts. Crown 8vo, 1s. 6d.

HANDBOOK OF QUANTITATIVE ANALYSIS. Crown $8 \mathrm{vo}, 3 \mathrm{~s} .6 \mathrm{~d}$.

MITRE (GENERAL DON BARTOLOME)-

THE EMANCIPATION OF SOUTH AMERICA. Being a Condensed Translaticn, by William Pilling, of "The History of San Martin." Demy 8vo, with Maps, ז2s.

MOLESWORTH (W. NASSAU)-

HISTORY OF ENGLAND FROM THE YEAR I830 TO THE RESIGNATION OF THE GLADSTONF MINISTRY, 1874. Twelfth Thousand. 3 vols. Crown 8 vo, $x 8 \mathrm{~s}$.

MOLTKE (FIELD-MARSHAL COUNT VON)-

POLAND : AN HISTORICAL SKETCH. With Biographical Notice by E. S. Buсннетм. Crown 8vo, is. 
MOOREHEAD (WARREN K.)-

WANNETA, THE SIOUX. With Illustrations from Life.

Large crown $8 \mathrm{vo}, 6 \mathrm{~s}$.

MORLEY (THE RIGHT HON. FOHN), M.P.-

RICHARD COBDEN'S LIFE AND CORRESPON.

DENCE. Crown 8vo, with Portrait, 7s. 6d.

Popular Edition. With Portrait. 4to, sewed, Is. Cloth, 2s. MURRAY (ANDREW), F.L.S.-

ECONOMIC ENTOMOLOGY. APTERA. With numerous Illustrations. Large crown $8 \mathrm{vo}, 3 \mathrm{~s} .6 \mathrm{~d}$.

NECKER (MADAME)-

THE SALON OF MADAME NECKER. By Vicomte D'Haussonvillz. 2 vols. Crown $8 \mathrm{vo}, 18 \mathrm{~s}$.

NELSON (W.), Organizer, Manual Instruction, Manchester School Board-

WOOD-WORKING POSITIONS. Twelve Illustrations

by Herbert Cole. Royal 4to, 2s. 6d. Large size, 6s.

NESBITT (ALEXANDER)-

GI.ASS. With numerous Woodcuts. Large crown 8vo, cloth, 2s. $6 \mathrm{~d}$.

NEWEY (H. FOSTER), Birmingham School of Art-

ELEMENTARY DRAWING: A Few Suggestions for Students and Teachers. Illustrated. Crown $8 \mathrm{vo}$.

NORMAN (C. B.)-

TONKIN; OR, FRANCE IN THE FAR EAST. With Maps. Demy 8vo, r4s.

O'BYRNE (ROBERT), F.R.G.S.-

THE VICTORIES OF THE BRITISH ARMY IN THE PENINSULA AND THE SOUTH OF FRANCE from $x 808$ to 1814. An Epitome of Napier's History of the Peninsular War, and Gurwood's Collection of the Duke of Wellington's Despatches. Crown 8vo, $5 \mathrm{~s}$.

O'GRADY (STANDISH)-

TORYISM AND THE TORY DEMOCRACY. CrOwn $8 \mathrm{vo}, 5 \mathrm{~s}$.

OLIVER (D.), LL.D., F.L.S., F.R.S., E.c.-

ILLUSTRATIONS OF THE PRINCIPAL NATURAL ORDERS OF THE VEGETABLE KINGDOM, PREPARED FOR THE SCIENCE AND ART DEPARTMENT, SOUTH KENSINGTON. New Edition, revised ly Author. With rog Plates. Coloured, royal 8vo. 165 .

OLIVER (E. E.), Under-Secretary to the Public Works Department, Punjaub-

ACROSS THE BORDER; or, PATHAN AND BILOCH. With numerous Illustrations by J. L. KIPLING, C.I.E. Demy 8 vo, 14s. PAPUS-

THE TAROT OF THE BOHEMIANS. The most ancient book in the world. For the exclusive use of the Initiates. An Atsolute Key to Occult Science. With numerous Illustrations. Large crown 8vo, $7 \mathrm{~s} .6 \mathrm{~d}$.

PATERSON (ARTHUR)-

A PARTNER FROM THE WEST. Crown 8vo, 5 s. PAYTON (E. W.)-

ROUND ABOUT NEW ZEALAND. Being Notes from a Journal of Three Years' Wandering in the Antipodes. With Twenty original Illustrations by the Author. Large crown 8vo, 12s. 
PELAGIUS-

HOW TO BUY A HORSE. With Hints on Shoeing and Stable Management. Third Thousand. Crown 8vo, is.

PERROT (GEORGES) and CHIPIEZ (CHARLES)-

A HISTORY OF ANCIENT ART IN GREECE. With about 500 Illustrations. 2 vols.

IIn the Press.

A HISTORY OF ANCIENT ART IN PERSIA. With 254 Illustrations, and 12 Steel and Coloured Plates. Imperial 8vo 2IS.

A HISTORY OF ANCIENT ART IN PHRYGIALYDIA, AND CARIA-LYCIA. With 280 Illustrations. Imperial 8vo, 155.

A HISTORY OF ANCIENT ART IN SARDINIA, JUDAEA, SYRIA, AND ASIA MINOR. With 395 lllustrations. 2 vols. Imperial $8 \mathrm{vo}, 36 \mathrm{~s}$.

A HISTORY OF ANCIENT ART IN PHCENICIA AND ITS DEPENDENCIES. With 654 Illustrations. 2 vols. Imperial $8 \mathrm{vo}, 42 \mathrm{~s}$.

A HISTORY OF ART IN CHALDÆA AND ASSYRIA. With 452 Illustrations. 2 vols. Imperial $8 \mathrm{vo}, 42 \mathrm{~S}$.

A HISTORY OF ART IN ANCIENT EGYPT. With 600 Illustrations. 2 vols. Imperial $8 \mathrm{vo}, 42 \mathrm{~s}$.

PETRRBOROUGH (THE EARLOF)-

THE EARL OF PETERBOROUGH AND MONMOUTH (Charles Mordaunt): A Memoir. By Colonel Frank Russelz, Royal Dragoons. With Illustrations. 2 vols. demy 8 vo. 325.

PITT TAYLOR (FRANK)-

THE CANTERBURY TALES. Selections from the Tales of Ghoffrey Chaucer rendered into Modern English. Crown 8vo, 6s.

POLLEN (F. H.)-

GOLD AND SILVER SMITH'S WORK. With numerous Woodcuts. Large crown $8 \mathrm{vo}$, cloth, 2s. 6 d.

ANCIENT AND MODERN FURNITURE AND WOODWORK. With numerous Woodcuts. Large crown 8vo, cloth, 2s. $6 \mathrm{~d}$.

POLLOK (COLONEL)-

INCIDENTS OF FOREIGN SPORT AND TRAVEL. Author of "Sport in British Burma." With Illustrations. Demy 8vo, I6s.

POOLE (STANLEY LANE), B.A., M.R.A.S.-

THE ART OF THE SARACENS IN EGYPT. Published for the Committee of Council on Education. With ro8 Woodcuts. Large crown 8vo, $4 \mathrm{~S}$.

POYNTER (E. F.), R.A.-

TEN LECTURES ON ART. Third Edition. Large crown $8 \mathrm{vo}, \mathrm{gs}$.

PRATT (ROBERT), Headmaster School of Science and Art, Barrow-in-Furness-

SCIOGRAPHY, OR PARALLEL AND RADIAL PROJECTION OF SHADOWS. Being a Course of Exercises for the use of Students in Architectural and Engineering Drawing, and for Candidates preparing for the Examinations in this subject and in Third Grade Perspective conducted by the Science and Art Department. Oblong quarto, 7s. 6d. 
PUSHKIN (A. S.)-

THE QUEEN OF SPADES AND OTHER STORIES. With a Biography. Translated from the Russian by Mrs. Sutherland Edwards. Illustrated. Crown 8vo, 3s. 6d.

RADICAL PROGRAMME, THE. From the Fortnightly Review, with additions. With a Preface by the Right Hon. J. Chamberlarn, M.P. Thirteenth Thousand. Crown 8vo, 2s. 6d. In Paper Covers, Is.

$R A E(W . F R A S E R)-$

AUSTRIAN HEALTH RESORTS THROUGHOUT THE YEAR. A New and Enlarged Edition. Crown 8vo, 5s.

RAMSDEN (LADY GWENDOLEN)-

A BIRTHDAY BOOK. Containing 46 Illustrations from Original Drawings. Royal 8vo, 2rs.

RAPHAEL : his Life, Works, and Times. By Eugene Muntz. Illustrated with about 200 Engravings. A New Edition, revised from the Second French Edition. BV W. ARMSTRONG, B.A. Imperial 8vo, 25s,

READE (MRS.R. H.)-

THE GOLDSMITH'S WARD; A Tale of London City in the Fifteenth Century. With 27 Illustrations by W. Bowcher. Crown 8vo, 6s.

REDGRAVE (GILBERT)-

OUTLINES OF HISTORIC ORNAMENT. Translated from the German. Edited by GILBERT REDGRAve. With numerous Illustrations. Crown 8vo, $4 \mathrm{~s}$.

REDGRAVE (RICHARD), R.A.-

MANUAL OF DESIGN. With Woodcuts. Large crown $8 \mathrm{vo}$, cloth, 2s. 6d.

ELEMENTARY MANUAL OF COLOUR, with a Catechism on Colour. 24mo, cloth, gd.

REDGRAVE (SAMUEL)-

A DESCRIPTIVE CATALOGUE OF THE HISTORICAL COLLECTION OF WATER-COLOUR PAINTINGS IN THE SOUTH KENSINGTON MUSEUM. With numerous Chromo-lithographs and other Illustrations. Royal 8vo, $£$ I Is.

RENAN (ERNEST)-

THE FUTURE OF SCIENCE: Ideas of 1848. Demy $8 \mathrm{vo}, 18 \mathrm{~s}$.

HISTORY OF THE PEOPLE OF ISRAEL.

First Division. Till the time of King David. Demy 8vo, r4s.

SEcond Division. From the Reign of David up to the Capture of Samaria. Demy 8vo, r4s.

Third Division. From the time of Hezekiah till the Return from Babylon. Demy 8vo, r4s.

RECOLLECTIONS OF MY YOUTH. Translated from the French, and revised by Madame Renan. Second Edition. Crown 8vo, 3s.6d.

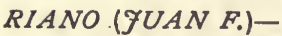

THE INDUSTRIAL ARTS IN SPAIN. With numerous Woodcuts. Large crown 8vo, cloth, $4 \mathrm{~S}$.

RIBTON-TURNER (C. J.)-

A HISTORY OF VAGRANTS AND VAGRANCY AND BEGGARS AND BEGGING. With Illustrations. Demy 8vo, 2rs. 
ROBERTS (MORLEY)-

IN LOW RELIEF : A Bohemian Transcript. Crown 8vo, 3s. 6d. In boards, $2 \mathrm{~s}$.

ROBINSON (7AMES F.) -

BRITISH BEE FARMING. Its Profits and Pleasures. Large crown 8vo, $5 \mathrm{~s}$.

ROBINSON (尹. C.)-

ITALIAN SCULPTURE OF THE MIDDLE AGES AND PERIOD OF THE REVIVAL OF ART. With 20 Engravings. Royal $8 \mathrm{vo}$, cloth, 7s. 6d.

ROBSON (GEORGE)-

ELEMENTARY BUILDING CONSTRUCTION. Illustrated by a Design for an Entrance Lodge and Gate. ${ }_{5}$ Plates. Oblong folio, sewed, $8 \mathrm{~s}$.

ROCK (THE VERY REV. CANON), D.D.-

TEXTILE FABRICS. With numerous Woodcuts. Large crown 8 vo, cloth, 2s. 6 d.

ROLAND (ARTHUR)-

FARMING FOR PLEASURE AND PROFIT. Edited by William ABlett. 8 vols. Crown 8 vo, 5 s. each.

DAIRY-FARMING, MANAGEMENT OF COWS, etc.

POULTRY-KEEPING.

TREE-PLANTING, FOR ORNAMENTATION OR PROFIT.

STOCK-KEEPING AND CATTLE-REARING.

DRAINAGE OF LAND, IRRIGATION, MANURES, etc.

ROOT-GROWING, HOPS, etc.

MANAGEMENT OF GRASS LANDS, LAYING DOWN GRASS, ARTIFICIAL GRASSES, etc.

MARKET GARDENING, HUSBANDRY FOR FARMERS AND GENERAL CULTIVATORS.

ROOSEVELT (BLANCHE)-

ELISABETH OF ROUMANIA: A Study. With Two Tales from the German of Carmen Sylva, Her Majesty Queen of Roumania. With Two Portraits and Illustration. Demy 8vo, I2s.

ROSS (MRS. FANET)-

EARLY DAYS RECALLED. With Illustrations and Portrait. Crown 8vo, 5 .

RUSSAN (ASHMORE) and BOYLE (FREDERICK)-

THE ORCHID SEEKERS: a Story of Adventure in Borneo. Illustrated by Alfred Hartley. Crown 8vo, 7s. $6 \mathrm{~d}$.

RUSSELL (W. CLARK)-

MISS PARSON'S ADVENTURE, and OTHER STORIES by W. E. Norris, Julian Hawthorne, Mrs. L. B. Walford. J. M. Barrie, F. C. Philips, Mrs. Alexander, and William Wrstall. With i6 Illustrations. One volume." Crown 8vo, 5 s.

$R Y A N(C \dot{H} A R L B S)$, Late Head Master of the Ventnor School of Art-

EGYPTIAN ART. An Elementary Handbook for the use of Students. With 56 Illustrations. Crown 8vo, 2s. 6d. Science and Art Series.

SCHAUERMANN (F. L.)-

WOOD-CARVING IN PRACTICE AND THEORY, AS APPLIED TO HOME ARTS. With Notes on Designs having special application to Carved Wood in different styles. Containing 124 Illustrations. Second Edition. Large crown 8vo, $5 \mathrm{~s}$. 
SCIENCE AND ART SERIES-

EGYPTIAN ART: An Elementary Handbook for the use of Students. By Charles Ryan, late Head Master of the Ventnor School of Art. With 56 Illustrations. Crown 8 vo, 2s. $6 \mathrm{~d}$.

ELEMENTARY DESIGN : Being a Theoretical and Practical Introduction in the Art of Decoration. By Richard G. HATton, Durham College of Science, Newcastle-on-Tyne. With r Io Illustrations. Crown 8vo, 2s. 6d.

THE STREET OF HUMAN HABITATIONS. By Mrs. Ray S. Lineham. Fully Illustrated. Crown 8vo, 6s.

BUILDING CONSTRUCTION : Key to Examinations of Science and Art Department. By Henry Adams, M.Inst.C E., M.I.Mech.E., F.S.I., etc., Professor of Engineering at the City of London College. Crown $8 \mathrm{vo}, 4 \mathrm{~s}$.

THE DECORATION OF METALS : Chasing, Repoussé, and Saw Piercing. By John Harrison. With r8o Illustrations. Crown 8vo, 3s. 6d.

ELEMENTARY DRAWING : a Few Suggestions for Students and Teachers. By H. Foster Newey, Birmingham School of Art. Illustrated. Crown 8 vo.

$\operatorname{SCOTT}(J O H N)-$

THE REPUBLIC AS A FORM OF GOVERNMENT; or, The Evolution of Democracy in America. Crown 8vo, 7s.6d.

$S E E M A N(0)-$.

THE MYTHOLOGY OF GREECE AND ROME, with Special Reference to its Use in Art. From the German, Edited by G. H. BianchI. 64 Illustrations. New Edition. Crown 8vo, 5s.

SETON-KARR (H. W.), F.R.G.S., etc.-

BEAR HUNTING IN THE WHITE MOUNTAINS; or, Alaska and British Columbia Revisited. Illustrated. Large Crown, 4s. 6d.

TEN YEARS' TRAVEL AND SPORT IN FOREIGN Lands; or, Travels in the Eighties. Second Edition, with additions and Portrait of Author. Large crown 8vo, $5 \mathrm{~s}$.

$S E X T O N(A$. HUMBOLDT)-

THE FIRST TECHNICAL COLLEGE : a Sketch of the History of "The Andersonian" and the Institutions descended from it 1796-1894. With Portraits and Illustrations. Crown $8 v 0$.

SHEPHERD (MAJOR), R.E.-

PRAIRIE EXPERIENCES IN HANDLING CATTLE AND SHEEP. With Illustrations and Map. Demy 8vo, Ios. 6d.

SHIRREFF (EMILY)-

A SHORT SKETCH OF THE LIFE OF FRIEDRICH FROBEL; a New Edition, including Fröbel's Letters from Dresden and Leipzig to his Wife, now first Translated into English. Crown 8vo, 2S.

HOME EDUCATION IN RELATION TO THE KINDERGARTEN. Two Lectures. Crown 8vo, is. 6d.

SHORE (ARABELLA)-

DANTE FOR BEGINNERS : a Sketch of the "Divina Commedia." With Translations, Biographical and Critical Notices, and Illus. trations. With Portrait. Crown 8vo, 6s.

$S I M K I N(R)-$.

LIFE IN THE ARMY : Every-day Incidents in Camp, Field, and Quarters. Printed in Colours. Oblong $4^{t} \mathrm{to}, 5 \mathrm{~s}$.

SIMMONDS (T. L.) -

ANIMAL PRODUCTS : their Preparation, Commercial Uses, and Value. With numerous Illustrations. Large crown 8vo, 3s. $6 \mathrm{~d}$. 
SINNETT (A. P.)-

ESOTERIC BUDDHISM. Annotated and enlarged by the Author. Seventh Edition. Crown 8vo, 3s, 6d.

KARMA. A Novel. New Edition. Crown 8vo, 3 s. SMITH (MAFOR R. MURDOCK), R.E.-

PERSIAN ART. With Map and Woodcuts. Second Edition. Large crown $8 \mathrm{vo} 2 \mathrm{~s}$.

SPENCER (HERBERंT)-

APHORISMS FROM THE WRITINGS OF. With a Photogravure Portrait. Second Thousand. Crown $8 \mathrm{vo}, 3 \mathrm{~s}$.

STANLEY (H. M.) : HIS LIFE, WORKS, AND EXPLORATIONS. By the Rev. H. W. Little. Demy 8vo, Ios. 6d.

STATHAM (H. H. - )

FORM AND DESIGN IN MUSIC : A Brief Outline of the Esthetic Conditions of the Art, addressed to General Readers. With Musical Examples. Demy 8vo, 2s. 6d.

MY THOUGHTS ON MUSIC AND MUSICIANS. Illustrated with Frontispiece of the Entrance-front of Handel's Opera House and Musical Examples. Demy 8vo, I8s.

STEELE (ANNA C.)-

CLOVE PINK. Crown 8vo, 3s. 6d.

$S T O D D A R D(C . A)-$.

SPANISH CITIES : with Glimpses of Gibraltar and Tangiers. With $x 8$ Illustrations. Large crown 8vo, 7 s. $6 \mathrm{~d}$.

ACROSS RUSSIA FROM THE BALTIC TO THE DANUBE. With Numerous Illustrations. Large crown 8vo, 7s. 6d.

STOKES (MARGARET)-

EARLY CHRISTIAN ART IN IRELAND. With IO6 Woodcuts. Crown 8vo, $4 \mathrm{~s}$.

STORIES FROM "BLACK AND WHITE." By GRANT Allen, Mrs. Lynn linton, J. M. Barrie, Mrs. Oliphant, W. Clakk Russell, Thomas Hardy, W. E. Norris, and James Payn. With numerous Illustrations. Crown 8 vo, 5 s.

STORY $(W . W)-$.

CASTLE ST. ANGELO. With Illustrations. Crown $8 \mathrm{vo}$, ros. $6 \mathrm{~d}$.

SUTCLIFFE (FOHN)-

THE SCULPTOR AND ART STUDENT'S GUIDE to the Proportions of the Human Form, with Measurements in feet and inches of Full-Grown Figures of Both Sexes and of Various Ages. By Dr. G. Schadow. Plates reproduced by J. Sutclifre. Oblong folio, 3is. $6 \mathrm{~d}$.

SUVÓROFF, LIFE OF. By Lieut.-Col. Spalding. Crown $8 \mathrm{vo}, 6 \mathrm{~s}$.

SWIFT: THE MYSTERY OF HIS LIFE AND LOVE. By the Rev. James Hay. Crown 8vo, 6s.

SYMONDS ( $7 O H N$ ADDINGTON)-

ESSAYS, SPECULATIVE AND SUGGESTIVE. New Edition. Demy 8vo, 9 s.

TANNER (PROFESSOR), F.C.S.-

HOLT CASTLE; or, Threefold Interest in Land. Crown 8vo, 4s. 6d.

JACK'S EDUCATION; OR, HOW HE LEARNT FARMING. Second Edition. Crown 8vo, 3s. 6d. 
TAYLOR (EDWARD R.), Head Master of the Birmingham Municipal School of Art-

ELEMENTARY ART TEACHING: An Educational and Technical Guide for Teachers and Learners, including Infant School-work; The Work of the Standards; Freehand; Geometry; Model Drawing; Nature Drawing; Colours; Light and Shade; Modelling and Design. With over 600 Diagrams and Illustrations. 8vo, ros. $6 \mathrm{~d}$.

TBMPLE (SIR RICHARD), BART., M.P., G.C.S.I.-

COSMOPOLITAN ESSAYS. With Maps. Demy 8vo, 16s.

THOMSON (D. C.)-

THE BARBIZON SCHOOL OF PAINTERS: Corot,

Rousseau, Diaz, Millet, and Daubigny. With $x 30$ Illustrations, including 36 FullPage Plates, of which 18 are Etchings. 4to, cloth, $42 \mathrm{~S}$.

THRUPP (GEORGE A.) and FARR (WILLIAM)-

COACH TRIMMING. With 60 Illustrations. Crown 8vo, 2s. 6d.

THRUPP (THE REV. H. W.), M.A.-

AN AID TO THE VISITATION OF THOSE DISTRESSED IN MIND, BODY, OR ESTATE. Crown 8vo, 3s. 6d.

TOPINARD (DR. PAUL)-

ANTHROPOLOGY. With a Preface by Professor PAUL Broca. With 49 Illustrations. Demy $8 \mathrm{vo}, 3 \mathrm{~s} .6 \mathrm{~d}$.

TOVEY (LIEUT.-COL., R.E.)-

MARTIAL LAW AND CUSTOM OF WAR; or, Military Law and Jurisdiction in Troublous Times. Crown 8vo, 6s.

TRAHERNE (MAFOR)-

THE HABITS OF THE SALMON. Crown 8vo, 3s.6d.

TROLLOPE (ANTHONY)-

THE CHRONICLES OF BARSETSHIRE. A Uniform

Edition, in 8 vols., large crown $8 \mathrm{vo}$, handsomely printed, each vol. containing Frontispiece. $6 \mathrm{~s}$. each.

THE WARDEN and BAR.

CHESTER TOWERS. 2 vols.

DR. THORNE.

FRAMLEY PARSONAGE.

THE SMALL HOUSE AT

ALLINGTON. 2 vols.

. LAST CHRONICLE OF

BARSET. 2 vols.

TROUP (F. ROSE)-

WITH STANLEY'S REAR COLUMN. With Portraits

and Illustrations. Second Edition, Demy 8vo, 16s.

UNDERHILL (G. F.)-

THE HELTERSKELTER HOUNDS: or, Mr. Flopkin's

Sporting Memoirs. With numerous Illustrations by L. THACKERAv. Crown 8vo, xs.

IN AND OU'T OF THE PIGSKIN. With Illustrations by Wallis Mackay. Second Edition. Crown 8vo. is.

$Y R R O N(E U G E N E)-$

ESTHETICS. Translated by W. H. Armstrong. Large crown $8 \mathrm{vo}, 3 \mathrm{~s} .6 \mathrm{~d}$.

WALFORD (MAJOR), R.A.-

PARLIAMENTARY GENERALS OF THE GREAT CIVIL WAR. With Maps, Large crown 8vo, 4S. 
WALKER (MRS.)-

UNTRODDEN PATHS IN ROUMANIA. With 77 Illustrations. Demy 8vo, Ios. 6d,

EASTERN LIFE AND SCENERY, with Excursions to Asia Minor, Mitylene, Crete, and Roumania, 2 vols., with Frontispiece to each vol. Crown 8vo, 2Is.

WALL $(A)-$.

A PRINCESS OF CHALCO. With Illustrations. Crown $8 \mathrm{vo}, 6 \mathrm{~s}$.

$W A R D(J A M E S)-$

ELEMENTARY PRINCIPLES OF ORNAMENT. With 122 Illustrations in the text. 8vo, $5 \mathrm{~s}$.

THE PRINCIPLES OF ORNAMENT. Edited by George Aitchinson, A.R.A Crown 8vo, 7s. 6d. $W A R D(R)-$.

SUPPLEJACK: a Romance of Maoriland. With 8 Illustrations. Crown 8vo, $6 \mathrm{~s}$.

WATSON $(\mathcal{F O H N})-$

POACHERS AND POACHING. With Frontispiece. Crown 8vo, 7s. 6d.

SKETCHES OF BRITISH SPORTING FISHES. With Frontispiece. Crown $8 \mathrm{vo}, 3 \mathrm{~s} .6 \mathrm{~d}$.

WEGG-PROSSER (F. R.)-

GALILEO AND HIS JUDGES. Demy 8vo, $5 \mathrm{~s}$.

WHITE (WALTER)-

A MONTH IN YORKSHIRE. With a Map. Fifth Edition. Post 8vo, 4 s.

A LONDONER'S WALK TO THE LAND'S END, AND A TRIP TO THE SCILLY ISLES. With 4 Maps. Third Edition. Pos: 8 vo, 4 E. WIEL (HON. MRS.)-

CHURCH EMBROIDERY-DESIGNS FOR. By A. R. Letterpress by the HoN. MRS. Wiel. With numerous lllustrations. 4to, I2S. net.

WOLVERTON (LORD)-

FIVE MONTHS' SPORT IN SOMALI LAND. With Illustrations. Demy 8vo, 7s. $6 \mathrm{~d}$.

WOODGATE (W. B.)-

A MODERN LAYMAN'S FAITH CONCERNING THE CREED AND THE BREED OF THE "THOROUGHBRED MAN." Demy 8 vo, I 4 S.

WORNUM (R. N.)-

ANALYSIS OF ORNAMENT: THE CHARACTERISTICS OF STYLES. An Introduction to the History of Ornamental Art. With many Illustrations. Ninth Edition. Royal 8vo, cloth, 8s.

WORSAAE (F. F. A.)-

INDUSTRIAL ARTS OF DENMARK, FROM THE EARLIEST TIMES TO THE DANISH CONQUEST OF ENGLAND. With Maps and Woodcuts. Large crown 8vo, 3s. $6 \mathrm{~d}$.

WRIGHTSON (PROF. FOHN), M.R.A.C., F.C.S., E.c ; President of the

College of Agricullure, Downton.

PRINCIPLES OF AGRICULTURAL PRACTICE AS AN INSTRUCTIONAL SUBJECT. With Geological Map Second Edition. Crown 8vo, 5 s.

FALLOW AND FODDER CROPS. - Crown 8vo, 5s. YOUNGE (C. D.)-

PARALLEL LIVES OF ANCIENT AND MODERN HEROES. New Edition. 12mo, cloth, 4s. 6 d. 
SOUTH KENSINGTON MUSEUM SCIENCE AND ART HANDBOOKS,

Handsomely printed in large crown 8vo. Published for the Committee of the Council on Education.

IRONWORK: From the Earliest Times to the End of the Mediæval Period. By J. STARKIE GARDNER. With 57 Illustrations. Crown 8vo, 35.

MARINE ENGINES AND BOILERS. By GEORgE C. V. HoLmes, Secretary of the Institution of Naval Architects, Whitworth Scholar. With Sixty-nine Woodcuts. Large crown 8vo, 3s.

EARLY CHRISTIAN ART IN IRELAND. By MARGARET Stokes. With ro6 Woodcuts. Crown $8 \mathrm{vo}, 4 \mathrm{~s}$.

A Library Edition, demy 8vo, 7s. 6d.

FOOD GRAINS OF INDIA. By Prof. A. H. Church, M.A., F.C.S., F.I.C. With Numerous Woodcuts. Small 4to, $6 \mathrm{~s}$.

THE ART OF THE SARACENS IN EGYPT. By Stanley LANB POOLE, B.A., M.A.R.S. With ro8 Woodcuts. Crown 8vo, 4s.

ENGLISH PORCELAIN : A Handbook to the China made in England during the $x 8$ th Century. By Prof. A. H. Church, M.A. With numerous Woodcuts. 38.

RUSSIAN ART AND ART OBJECTS IN RUSSIA: A Handbook to the reproduction of Goldsmiths' work and other Art Treasures from that country in the South Kensington Museum. By Alfred Maskell. With Illustrations. $4 \mathrm{~S}, 6 \mathrm{~d}$.

FRENCH POTTERy. By Paul Gasnault and Edouard GARnier. With Illustrations and Marks. 3s.

ENGLISH EARTHENWARE: A Handbook to the Wares made in England during the 17 th and $x 8$ th Centuries. By Prof. A. H. CHURCH, M.A. With numerous Woodcuts. $3 \mathrm{~s}$.

INDUSTRIAL ARTS OF DENMARK. From the Earliest Times to the Danish Conquest of England. By J. J. A. WorsaAk, Hon. F.S.A., \&c. \&c. With Map and Woodcuts. 3s. 6d.

INDUSTRIAL ARTS OF SCANDINAVIA IN THE PAGAN TIME. By Hans Hildebrand, Royal Antiquary of Sweden. With numerous Woodcuts. 2s. 6d.

PRECIOUS STONES: Considered in their Scientific and Artistic relations. By Prof. A. H. CHURCH, M.A. With a Coloured Plate and Woodcuts. 2s. $6 \mathrm{~d}$.

INDUSTRIAL ARTS OF INDIA. By Sir GeORge C. M. Birdwood, C.S.I., \&c. With Map and Woodcuts. Demy 8vo, r4s.

HANDBOOK TO THE DYCE AND FORSTER COLLEC. TIONS in the South Kensington Museum. With Portraits and Facsimiles. 2s. 6d.

INDUSTRIAL ARTS IN SPAIN. By JUAN F. Riaño. With numerous Woodcuts. \&s.

GLASS. By AleXander Nesbitt. With numerous Woodcuts. 2s. 6d.

GOLD AND SILVER SMITHS' WORK. By JOHN HUNGERFORD POLLEN, M.A. With numerous Woodcuts. 2s. 6d.

TAPESTRY. By Alfred de Champeaux. With Woodcuts. 2s. 6d.

BRONZES. By C. Drury E. Fortnum, F.S.A. With numerous Woodcuts. 2s. 6d. 
SOUTH KENSINGTON MUSEUM SCIENCE \& ART HANDBOOKS-Contimued

PLAIN WORDS ABOUT WATER. By A. H. ChURCh, M.A. Oxon. With Illustrations. Sewed, 6d.

ANIMAL PRODUCTS : their Preparation, Commercial Uses, and Value. By T. L. Simmonds. With Illustrations. 3s. $6 \mathrm{~d}$.

FOOD : Some Account of its Sources, Constituents, and Uses. By Professor A. H. Church, M.A. Oxon. New and Revised Edition. 3e.

ECONOMIC ENTOMOLOGY. By ANDREW MurRay, F.L.S. APtrRA. With Illustrations. 3s. 6d.

JAPANESE POTTERY. Being a Native Report. With an Introduction and Catalogue by A. W. FRANks, M.A., F.R.S., F.S.A. With Illustrations and Marks. 2s. $6 \mathrm{~d}$.

HANDBOOK TO THE SPECIAL LOAN COLLECTION of Scientific Apparatus. 35 .

INDUSTRIAL ARTS: Historical Sketches. With Numerous Illustrations. 3 s.

TEXTILE FABRICS. By the Very Rev. DANIEL Rock, D.D. With numerous Woodcuts. 2s. 6 d.

JONES COLLECTION IN THE SOUTH KENSINGTON MUSEUM. With Portrait and Woodcuts. 2s. $6 \mathrm{~d}$.

COLLEGE AND CORPORATION PLATE. A Handbook to the Reproductions of Silver Plate in the South Kensington Museum from Celebrated English Collections. By Wilfred JosepH CRIPPS, M.A. E.S.A. With Illustrations. 2s. $6 \mathrm{~d}$.

IVORIES: ANCIENT AND MEDIFVAL. By WILLIAM MASkelc. With numerous Woodcuts. 2s. 6 d.

ANCIENT AND MODERN FURNITURE AND WOODWORK. By John Hungerford Pollen, M.A. With numerous Wooderesse 2S. 6 d.

MAIOliCA. By C. Drury E. Fortnum, F.S.A. With numerous Woodcuts. 2s. 6 d.

THE CHEMISTRY OF FOODS. With Microscopic Illustrations. By James Brl, Ph.D., \&c., Principal of the Somerset House Laboratory. Part 1.-Tea, Coffee, Cocoa, Sugar, \&c. 2s. 6d.

Part Il.-Milk, Butter, Cheese, Cereals, Prepared Starches, \&c. 3 s.

MUSICAL INSTRUMENTS. By CARL ENgel. With aumerous Woodcuts. 2s. $6 \mathrm{~d}$.

MANUAL OF DESIGN. By Richard Redgrave, R.A. By Gilbert R. REDGRAVE. With Woodcuts. 2s. 6d.

PERSIAN ART. By MAJOR R. MURDOCK SMIth, R.E. With Map and Woodcuts. Second Edition, enlarged. 2s. 


\section{CARLYLE'S (THOMAS) WORKS.}

\section{THE ASHBURTON EDITION.}

New Edition, handsomely printed, containing all the Portraits and Illustrations, in Twenty Volumes, demy 8vo, 8s. each.

THE FRENCH REVOLUTION AND PAST AND PRESENT, 2 vols. SARTOR RESARTUS; HEROES AND HERO WORSHIP. I vol. LIFE OF JOHN STERLING-LIFE OF SCHILLER. I vol.

LATTER-DAY PAMPHLETS-EARLY KINGS OF NORWAY ESSAY ON THE PORTRAIT OF JOHN KNOX. I vol.

LETTERS AND SPEECHES OF OLIVER CROMWELL. 3 vols. HISTORY OF FREDERICK THE GREAT. 6 vols. CRITICAL AND MISCELLANEOUS EJSAYS. 3 vols. TRANSLATIONS FROM THE GERMAN. 3 vols.

\section{IIBRARY EDITION COMPLETE.}

Handsomely printed in 34 vols., demy 8vo, \&15 3 s.

SARTOR RESARTUS. With a Portrait, 7s. 6d.

THE FRENCH REVOLUTION. A History. 3 vols., each $9 s$.

LIFE of FREDERICK SCHILLER AND EXAMINATION OF HIS WORKS With Supplement of 1872 Portrait and Plates, gs.

CRITICAL AND MISCELLANEOUS ESSAYS. With Portrait. 6 vols., each 9 s.

ON HEROES, HERO WORSHIP, AND THE HEROIC IN HISTORY. 7s. 6d.

PAST AND PRESENT. 9S.
OLIVER CROMWELL'S LET. TERS AND SPEECHES. With Portraits. 5 vols., each $9 s$.

LATTER - DAY PAMPHLETS. gs.

LIFE OF JOHN STERLING. With Portrait, gs.

HISTORY OF FREDERICK THE SECOND. Io vols., each 9".

TRANSLATIONS FROM THE GERMAN. 3 vols., each 9 s.

EARLY KINGS OF NORWAY ESSAY ON THE PORTRAITS OF JOHN KNOX; AND GENERAL INDEX. With Portrait Illustrations. $8 v 0$, cloth, 9s.

\section{PEOPLE'S EDITION.}

37 vols., small crown 8vo, 37s.; separate vols., Is. each.

SARTOR RESARTUS. With Portrait of Thomas Carlyle.

FRENCH REVOLUTION. A History. 3 vols.

OLIVER CROMWELL'S LET. TERS AND SPEECHES. 5 vols. With Portrait of Oliver Cromwell.

ON HEROES AND HERO WORSHIP AND THE HEROIC IN HISTORY.

PAST AND PRESENT.

CRITICAL AND MISCELLANEOUS ESSAYS. 7 vols.
THE LIFE OF SCHILLER, AND EXAMINATION OF HIS WORKS. With Portrait.

LATTER-DAY PAMPHLETS.

WILHELM MEISTER. 3 vols.

LIFE OF JOHN STERLING. With Portrait.

HISTORY OF FREDERICK. THE GREAT. Io vols.

TRANSLATIONS FROM MUSEUS, TIECK, AND RICHTER. 2 vols.

THE EARLY KINGS OF NOR. WAY; Essay on the Portraits of Knox.

Or in sets, 37 vols. in 18, 37 s. 


\section{CARLYLE'S (THOMAS) WORKS.-Continued.}

\section{A RE-ISSUE OF}

\section{THE WORKS OF THOMAS CARLYLE.}

\section{Price 2s. 6d. a Volume.}

This Edition will include the whole of his writings and translations, together with the Portraits and Maps,

\section{The Volumes ready are}

SARTOR RESARTUS AND LATTER-DAY PAMPHLETS. With a Portrait of Thomas Carlyle.

PAST AND PRESENT AND ON HEROES AND HERO WORSHIP. LIFE OF JOHN STERLING AND LIFE OF SCHILLER.

CRITICAL AND MISCELLANEOUS ESSAYS, EARLY KINGS OF NORWAY AND ESSAY ON THE PORTRAITS OF KNOX.

FRENCH REVOLUTION; a History. In two volumes.

OLIVER CROMWELL'S LETTERS AND SPEECHES, with Portrait of Oliver Cromwell. In three volumes.

\section{To be followed by}

HISTORY OF FREDERICK THE GREAT. In five volumes Vol. I. in July, Vol. II. in August, Vol. III. in September, Vol. IV. in October, Vol. V. in November.

WILHELM MEISTER. In two volumes.

TRANSLATIONS FROM MUSEUS, TIECK AND RICHTER. In oxe volume.

\section{CHEAP ISSUE.}

THE FRENCH REVOLUTION. One volume. With Portrait. Crown $8 \mathrm{vo}, 2 \mathrm{~s}$.

SARTOR RESARTUS, HEROES AND HERO WORSHIP, PAST AND PRESENT, AND CHARTISM. One volume. Crown 8vo, $2 \mathrm{~s}$.

OLIVER CROMWELL'S LETTERS AND SPEECHES. Crown 8vo, 2S. 6d.

CRITICAL AND MISCELLANEOUS ESSAYS. 2 vols. 4s.

WILHELM MEISTER. One volume, 2s.

LIVES OF SCHILLER AND STERLING. With Portraits. One volume, $2 \mathrm{~s}$.

\section{SIXPENNY EDITION.}

$$
\text { 4'o, sewed. }
$$

SARTOR RESARTUS. Eightieth Thousand.

HIEROES AND HERO WORSHIP.

ESSAYS: Borns, Johnson, Scott, The Diamond Necklace.

The above in I vol., cloth, 2s. $6 d$. 


\section{DICKENS'S (CHARLES) WORKS.}

ORIGINAL EDITIONS.

In demy 8vo.

THE MYSTERY OF EDWIN DROOD. With Illustrations by S. L. Fildes, and a Portrait engraved by Baker. Cloth, 7s. $6 \mathrm{~d}$.

OUR MUTUAL FRIEND. With Forty Illustrations by Marcus Stone. Cloth, $\notin \mathrm{I}$ is.

THE PICKWICK PAPERS. With Forty-three Illustrations by Seymour and Phiz. Cloth, $\ell_{I}$ is.

NICHOLAS NICKLEBY. With Forty Illustrations by Phiz. Cloth, $€$ I Is.

SKETCHES BY "BOZ." With Forty Illustrations by George Cruikshank. Cloth, $€ I$ Is.

MARTIN CHUZZLEWIT. With Forty Illustrations by Phiz. Cloth, $\ell_{2}$ xs.

DOMBEY AND SON. With Forty Illustrations by Phiz. Cloth, $£$ I rs.

DAVID COPPERFIELD. With Forty Illustrations by Phiz. Cloth, $\ell_{I}$ Is.

BLEAK HOUSE. With Forty Illustrations by Phiz. Cloth, tI Is.

LITTLE DORRIT. With Forty Illustrations by Phiz. Cloth, EI Is.

THE OLD CURIOSITY SHOP. With Seventy-five Illustrations by George Cattermole and H. K. Browne. A New Edition. Uniform with the other volumes, $f_{I}$ Is.

BARNABY RUDGE: a Tale of the Riots of 'Eighty. With Seventy-eight Illustrations by George Cattermole and H. K. Browne. Uniform with the other volumes, $€ x$ Is.

CHRISTMAS BOOKS: Containing-The Christmas Carol; The Cricket on the Hearth; The Chimes; The Battle of Life; The Haunted House. With all the original Illustrations. Cloth, $\mathbf{~} 2 \mathrm{~s}$.

OLIVER TWIST and TALE OF TWO CITIES. In one volume. Cloth, $6 \mathbf{I}$ is.

OLIVER TWIST. Separately. With Twenty-four Illustrations by George Cruikshank. Cloth, rrs.

A TALE OF TWO CITIES. Separately. With Sixteen Illustrations by Phiz. Cloth, gs.

* The remainder of Dickens's Works were not originally frintid' in c'en. $y$ 8. o. 


\section{DICKENS'S (CHARLES) WORKS.-Continued.}

\section{LIBRARY EDITION.}

In post 8vo. With the Original Illustrations, 30 vols., cloth, £12.

PICKWICK PAPERS

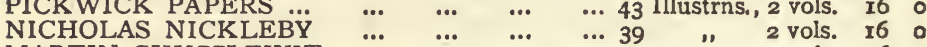

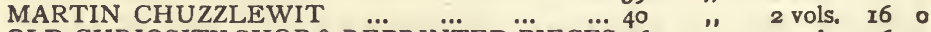
OLD CURIOSITY SHOP \& REPRINTED PIECES $36 \quad ", \quad 2$ vols. 160

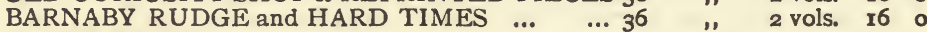
BLEAK HOUSE.

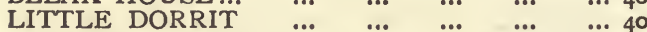

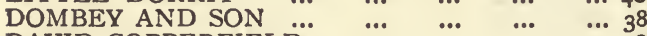

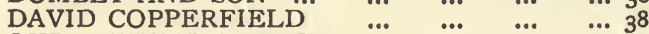

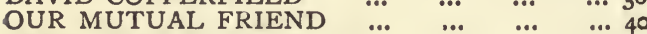

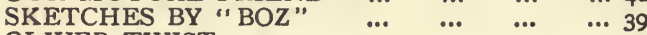

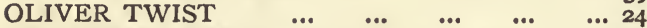

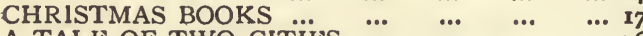

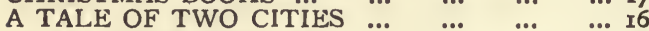
GREAT EXPECTATIONS $\ldots$... PICTURES FROM ITALY \& AMERICAN NOTES 8

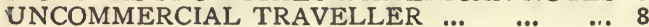
CHILD'S HISTORY OF ENGLAND $\quad \ldots . \quad \ldots 8$ EDWIN DROOD and MISCELLANIES ... $\quad .$. I2 CHRISTMAS STORIES from "Household Words," \&c. 14 ", 2 vols. 160 2 vols. 16 o 2 vols. 160 2 vols. 160 2 vols. 160 I vol. 80 I vol. 80 I vol. 80 I vol. 80 I vol. 80 I vol. 80 I vol. 8 o I vol. 80 I vol. 80 I vol. 8 . Uniform with the above, ros. $6 d$.

THE LIFE OF CHARLES DICKENS. By JOHN FORSTER. With Illustrations.

\section{THE "CHARLES DICKENS" EDITION.}

In Crown 8vo. In 21 vols., cloth, with Iilustrations, f3 $16 s$.

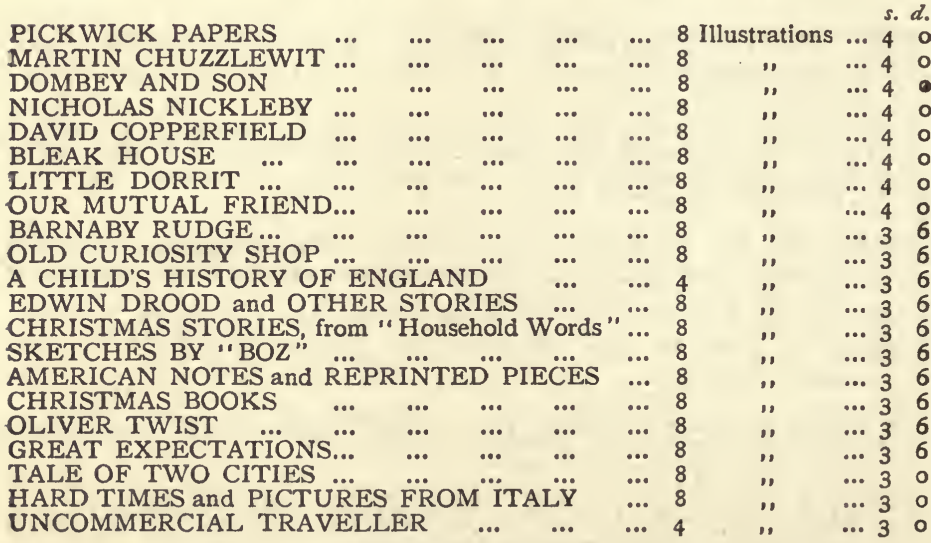




\section{DICKENS'S (CHARLES) WORKS.-Continued.}

\section{THE ILLUSTRATED LIBRARY EDITION.}

\section{(WITH LIFE.)}

Complete in 32 Volumes. Demy 8vo, ros. each; or set, £I6.

This Edition is printed on a finer paper and in a larger type than has been employed in any previous edition. The type has been cast especially for it, and the page is of a size to admit of the introduction of all the original illustrations.

No such attractive issue has been made of the writings of Mr. Dickens, which, $v$ arious as have been the forms of publication adapted to the demands of an ever w.dely-increasing popularity, have never yet been worthily presented in a really handsome library form.

The collection comprises all the minor writings it was Mr. Dickens's wish to preserve.

SKETCHES BY "BOZ." With 40 Illustrations by George Cruikshank.

PICKWICK PAPERS. 2 vols, With 42 Illustrations by Phiz.

OLIVER TWIST. With 24 Illustrations by Cruikshank.

NICHOLAS NICKLEBY. 2 vols. With 40 Illustrations by Phiz.

OLD CURIOSITY SHOP and REPRINTED PIECES. 2 vols, With Illustrations by Cattermole, \&c.

BARNABY RUDGE and HARD TIMES. 2 vols. With Illustrations by

Cattermole, \&c.

MARTIN CHUZZLEWIT. 2 vols. With 40 Illustrations by Phiz.

AMERICAN NOTES and PICTURES FROM ITALY. I vol, With

8 Illustrations.

DOMBEY AND SON. 2 vols. With 40 Illustrations by Phiz.

DAVID COPPERFIELD. 2 vols. With 40 Illustrations by Phiz.

BLEAK HOUSE. 2 vols. With 40 Illustrations by Phiz.

LITTLE DORRIT. 2 vols. With 40 Illustrations by Phiz.

A TALE OF TWO CITIES. With 16 Illustrations by Phiz.

THE UNCOMMERCIAL TRAVELLER. With 8 Illustrations by Marcus Stone. GREAT EXPECTATIONS. With 8 Illustrations by Marcus Stone.

OUR MUTUAL FRIEND. 2 vols. With 40 Illustrations by Marcus Stone.

CHRISTMAS BOOKS. With 17 Illustrations by Sir Edwin Landseer, R.A.,

Maclise, R.A., \&c. \&c.

HISTORY OF ENGLAND. With 8 Illustrations by Marcus Stone.

CHRISTMAS STORIES. (From "Household Words" and "All the Year Round.") With I4 Illustrations.

EDWIN DROOD AND OTHER STORIES. With 12 Illustrations by S。 L. Fildes.

LIFE OF CHARLES DICKENS. By John Forster. With Portraits, 2 vols. 


\section{DICKENS'S (CHARLES) WORKS.-Continued.}

\section{HOUSEHOLD EDITION.}

(WITH LIFE.)

In 22 Volumes. Crown 4to, clo:h, $£ 4$ 8s. $6 d$.

MARTIN CHUZZLEWIT, with 59 Illustrations, 5 s.

DAVID COPPERFIELD, with 60 Illustrations and a Portrait, 5s.

BLEAK HOUSE, with 6 I Illustrations, 55 .

LITTLE DORRIT, with 58 Illustrations, $5 \mathrm{~s}$.

PICKWICK PAPERS, with 56 Illustrations, 55 .

OUR MUTUAL FRIEND, with 58 Illustrations, $5 \mathrm{~s}$.

NICHOLAS NICKLEBY, with 59 Illustrations, $5 \mathrm{~s}$.

DOMBEY AND SON, with 6r Illustrations, $5 \mathrm{~S}$.

EDWIN DROOD; REPRINTED PIECES; and other Stories, with 30 Illustrations, $5 \mathrm{~s}$.

THE LIFE OF DICKENS. By JOHN FORSTER. With 40 Illustrations, $5 \mathrm{~s}$.

BARNABY RUDGE, with 46 Illustrations, $4 \mathrm{~s}$.

OLD CURIOSITY SHOP, with 32 Illustrations, 45.

CHRISTMAS STORIES, with 23 Illustrations, $4 \mathrm{~s}$.

OLIVER TWIST, with 28 Illustrations, $3 \mathrm{~S}$.

GREAT EXPECTATIONS, with 26 Illustrations, 35 .

SKETCHES BY " BOZ," with 36 Illustrations, 3 s.

UNCOMMERCIAL TRAVELLER, with 26 Illustrations, 35 .

CHRISTMAS BOOKS, with 28 Illustrations, 35.

THE HISTORY OF ENGLAND, with I5 Illustrations, $3 \mathrm{~s}$.

AMERICAN NOTES and PICTURES FROM ITALY, with 18 Illustrations, 35 . A TALE OF TWO CITIES, with 25 Illustrations, 38.

HARD TIMES, with 20 Illustrations, 2s. 6 d.

\section{CHARLES DIGKENS'S CHRISTMAS BOOKS.}

REPRINTED FROM THE ORIGINAL PLATES,

Illustrated by JOHN Lezch, D. MaClise, R.A., R. DOyle,

C. Stanfield, R.A., etc.

Fcap. cloth, Is. each. Complete in a case, 5 s.

A CHRISTMAS CAROL IN PROSE.

THE CHIMES: A Goblin Story.

THE CRICKET ON THE HEARTH : A Fairy Tale of Home. THE BATTLE OF LIFE. A Love Story.

THE HAUNTED MAN AND THE GHOST'S STORY.

\section{SIXPENNY REPRINTS of DICKENS'S WORKS.}

OLIVER TWIST. With 28 Illustrations by J. Mahoney. Medium 8vo.

READINGS FROM THE WORKS OF CHARLES DICKENS. As $s$ lected and read by himself and now published for the first time. Illustrated. A CHRISTMAS CAROL, AND THE HAUNTED MAN. Illustrated.

THE CHIMES: A Goblin STORY, AND THE CRICKET ON THE HEARTH. Illustrated.

THE BATTLE OF LIFE: A LOVE STORY, HUNTED DOWN, AND A HOLIDAY ROMANCE. Illustrated 
DICKENS'S (CHARLES) WORKS.-Continued.

\section{THE CROWN EDITION,}

Complete in 17 vols. Containing ALL THE ORIGINAL ILLUSTRATIONS.

And the Letterpress is printed from Type expressly cast for this Edition.

LARGE CROWN OCTAVO.

PRICE FIVE. SHILLINGS EACH.

I. -THE PICKWICK PAPERS. With Forty-three Illustration; by SEYMOUR and PHiz.

2. NICHOLAS NICKLEBY. With Forty Illustrations by PHIz.

3.-DOMBEY AND SON. With Forty Illustrations by PHIz.

4. -DAVID COPPERFIELD. With Forty Illustrations by PHIz.

5.-SKETCHES BY "BOZ." With Forty Illustrations by GEo.

CRUIKSHANK.

6.-MARTIN CHUZZLEWIT. With Forty Illustrations by РнI7.

7. -THE OLD CURIOSITY SHOP. With Seventy-five Illustrations by George Cattermole and H. K. Browne.

8. - BARNABY RUDGE : a Tale of the Riots of 'Eighty. With Seventyeight Illustrations by George CatTermole and H. K. Browne.

9.-OLIVER TWIST and A TALE OF TWO CITIES. With Twenty-four Illustrations by CroikshaNk and Sixteen by PHIz.

I0.-BLEAK HOUSE. With Forty Illustrations by PHIz.

II. - LITTLE DORRIT. With Forty Illustrations by PHIz.

12.-OUR MUTUAL FRIEND. With Forty Illustrations by MARcUs STONE.

I3.-AMERICAN NOTES; PICTURES FROM ITALY; and A CHILD'S HISTORY OF ENGLAND. With Sixteen Illustrations by MARCUS STONe.

I4.-CHRISTMAS BOOKS and HARD TIMES. With Illust ations by Landseer, Maclise, Stanfield, Leech, Doyle, F. WALKER, etc.

15.-CHRISTMAS STORIES AND OTHER STORIES, including HUMPHREY'S CLOCK. With Illustrations by DALZIEL, Charies Green, Mahoney, Phiz, Cattermole, etc.

I6.-GREAT EXPECTATIONS. UNCOMMERCIAL TRAVELLER. With Sixteen Illustrations by MARCOS STONE.

I7.-EDWIN DROOD and REPRINTED PIECES. With Sxteen Illustrations by LuKe FILOES and F. WALKER.

Uniform with the above.

THE LIFE OF CHARLES DICKENS. By JOHN FORSTER. With Portraits and Illustrations. Will be added at the request of numerous Subscribers.

THE DICKENS DICTIONARY. A Key to the Characters and Principal Incidents in the Tales of Charles Dickens. By GILBERT PIERCe, with additions by William A. WheELer.

THE LAZY TOUR OF TWO IDLE APPRENTICES; NO THOROUGHFARE; THE PERILS OF CERTAIN ENGLISH PRISONERS. By CHARLES DICKENS and WILKIE Collins. With Illustrations. Crown 8vo, 5 s.

* * These Stories are now reprinted in complete form for the first time. 


\section{DICKENS'S (CHARLES) WORKS.-Continued.}

\section{THE CABINET EDITION.}

In 32 vols. small fcap. 8vo, Marble Paper Sides, Cloth Backs, with uncut edges, price Eighteenpence each.

Each Volume contains Eight Illustrations reproduced from the Originals.

In Sets only, bound in blue and red cloth, with cut edges, $£_{2} 8$ s.

CHRISTMAS BOOKS.

MARTIN CHUZZLEWIT, 2 vol s. DAVID COPPERFIELD, 2 vols. OLIVER TWIST.

GREAT EXPECTATIONS.

NICHOLAS NICKLEBY, 2 vols.

SKETCHES BY "BOZ."

CHRISTMAS STORIES.

THE PICKWICK PAPERS, 2 vols. BARNABY RUDGE, 2 vols, BLEAK HOUSE, 2 vols.

AMERICAN NOTES AND PIC-

TURES FROM ITALY.
EDWIN DROOD; AND OTHER STORIES.

THE OLD CURIOSITY SHOP, 2 vols.

A CHILD'S HISTORY OF ENGLAND.

DOMBEY AND SON, 2 vols.

A TALE OF TWO CITIES.

LITTLE DORRIT, 2 vols.

MUTUAL FRIEND, 2 vols.

HARD TIMES.

UNCOMMERCIAL TRAVELLER REPRINTED PIECES.

\section{THE HALF CROWN EDITION.}

PRINTED FROM THE EDITION THAT WAS CAREFULLY CORRECTED BY THE AUTHOR IN 1867 AND 1868 .

Complete in $2 \mathrm{r}$ vols. Containing the whole of the original Illustrations. Crown 8 vo, 2s. 6 d. each.

THE PICKWICK PAPERS. With 43 Illustrations by SEYMour and PHIZ.

BARNABY RUDGE: A Tale of the Riots of 'Eighty. With 76 Illustrations by Grorge Cattermolr and H. K. Browne.

OLIVER TWIST. With 24 Illustrations by CRUIKSHANK.

THE OLD CURIOSITY SHOP. With 75 Illustrations by GEORGE CATTERMOLE and H. K. BROWNE.

DAVID COPPERFIELD. With 40 Illustrations by PHIZ.

NICHOLAS NICKLEBY. With 40 Illustrations by PHIZ.

MARTIN CHUZZLEWIT. With 40 Illustrations by PHIZ.

DOMBEY AND SON. With 40 Illustrations by PHIz.

SKETCHES BY "BOZ." With 40 Illustrations by GEORGE CRUikshaNk.

CHRISTMAS BOOKS. With 64 Illustrations by LANDSEER, DOYLE, MACLISE, LeECH, etc.

BLEAK HOUSE. With 40 Illustrations by PHiz.

LITTLE DORRIT. With 40 Illustrations by PHIz.

CHRISTMAS STORIES, from "Household Words." With $x_{4}$ Illustrations by Dalziel, GREEN, MAHONEY, etc.

AMERICAN NOTES and REPRINTED PIECES. With 8 Illustrations by MARCUS STONE and F. WALKER.

HARD TIMES and PICTURES FROM ITALY. With 8 Illustrations by F. WALKer and MARCUS Stone.

A CHILD'S HISTORY OF ENGLAND. With 8 Illustrations by MARCUS STONE.

GREAT EXPECTATIONS. With 8 Illustrations by MARCUS STONE.

TALE OF TWO CITIES. With I6 Illustrations by PHIz.

UNCOMMERCIAL TRAVELLER. With 8 Illustrations by MARCUS STONE.

OUR MUTUAL FRIEND. With 40 Illustrations by MARCUS STONE.

EDWIN DROOD and OTHER STORIES. With I2 Illustrations by LUKE FILDES. 
DICKENS'S (CHARLES) WORKS.-Continued. THE PICTORIAL EDITION, UPWARDS OF NINE HUNDRED ENGRAVINGS.

Complete in 17 vols. Royal 8vo, 3s. 6d. each.

DOMBEY AND SON. With 62 LITTIE DORRIT. With 58 IllusIllustrations by F. BARNARD. 3s. $6 \mathrm{~d}$.

DAVID COPPERFIELD. With 63 Ilustrations by F. BARNARD. 3s. 6d.

NICHOLAS NICKLEBY. With 59 Illustrations by F. BARNARD. 3s. 6d.

BARNABY RUDGE. With 46 Illustrations by F. BARNARD. 3s. 6 d.

OLD CURIOSITY SHOP. ' With 39 Illustrations by CHARLES GReEN. 3s. 6d.

MARTIN CHUZZLEWIT. With 59 mustrations by F. BARNARD. 35. 6d.

OLIVER TWIST and A TALE OF TWO CITIES. With 53 Illustrations by J. MAHONEY and F. BARNARD. 3s. 6d.

OUR MUTUAL FRIEND. With $5^{8}$ Illustrations by J. MAHONEY. 3S. 6d.

BLEAK HOUSE. With 6r Illustrations by F. BARNARD. 3s. 6d.

PICKWICK PAPERS. With 57 Mlustrations by PHIz. 3s. 6d. trations by J. MAHONEY. 3s. 6d.

GREAT EXPECTATIONS and HARD TIMES. With 50 Illustrations by J. A. FRASER and H. FRENCH. 3s. 6d.

AMERICAN NOTE:, PICTURES FROM ITALY, and A CHILD'S HISTORY OF ENGLAND. With 33 Illustrations by FROST, GORDON, THOMSON, and RALSTON. 3s. 6d.

SKETCHES BY "BOZ" and CHRISTMAS BOOKS. With 62 Illustrations by $\mathrm{F}$. BARNARD. 3s. $6 \mathrm{~d}$.

CHRISTMAS STORIES and UN: COMMERCIAL TRAVELLER. With 49 Illustrations by E. G. DALziex. 3s. 6 d.

EDWIN DROOD, REPRINTED PIECES, AND OTHER STORIES. With 30 Illustrations by L. FILDES, E. G. DALZiEL, and F. BARNARD. 3s. 6d.

THE LIFE OF CHARLES DICKENS. By JOHN FORSTER. With 40 Illustrations by F. BARNARD and others. 3s. 6d.

\section{THE TWO SHILLING EDITION.}

Each Volume contains a Frontispiece. Crown 8vo, 2s.

The Volumes now ready are-

DOMBEY AND SON.

MARTIN CHUZZLEWIT.

THE PICKWICK PAPERS.

BLEAK HOUSE.

OLD CURIOSITY SHOP.

BARNABY RUDGE.

DAVID COPPERFIELD.

NICHOLAS NICKLEBY.

CHRISTMAS STORIES.

AMERICAN NOTES.

HARD TIMES and PICTURES

FROM ITALY.

GREAT EXPECTATIONS.
OUR MUTUAL FRIEND.

CHRISTMAS BOOKS.

OLIVER TWIST.

LITTLE DORRIT.

TALE OF TWO CITIES.

UNCO MMERCIAL TRA-

VELLER.

SKETCHES BY "BOZ."

A CHILD'S HISTORY OF ENGLAND.

EDWIN DROOD and OTHER STORIES.

\section{MR. DICKENS'S READINGS.}

Fcap. 8vo, sewed.

CHRISTMAS CAROL IN PROSE. STORY OF LITTLE DOMBEY. IS. IS.

CRICKET ON THE HEARTH. IS.

CHIMES : A GOBLIN STORv. Is.

PJOR TRAVELLER, BOOTS AT THE HOLLY-TREE INN, and MRS. GAMP. IS. 


\section{SCIENCE·AND ART AND \\ TECHNICAL EDUCATION.}

\section{Edited by JOHN MILLS, F.R.A.S. \\ A Journal for Teachers and Students.}

PRICE SIXPENCE.

The Journal contains contributions on Science, Art, and Technical Sub. jects by distinguished men; short papers by prominent teachers; leading articles; correspondence; answers to the questions set at the May examinations of the Science and Art Department (which will in future be confined to the Magazine, and not be published in separate pamphlet form), and interesting news in connection with the scientific and artistic world.

With the beginning of a new volume (April 1, 1893) the Journal is to be enlarged.

Whilst retaining the special features which have given it a well-defined conştituency to which no other paper directly appeals, it is proposed to give yet more varied matter, superior illustrations, and an improved appearance in type and paper, hoping thereby to make it the most popular sixpenny monthly of this class of literature in the United Kingdom.

In addition to its purely Science and Art readers, it is hoped to attract others by matter suitable for a large number of people who desire to be made conversant with current topics and new discoveries in Science, but owing to the too exclusively technical and detailed treatment in most magazines cannot now spare the time which is necessary if they would derive much advastage from their perusal.

A portion of the paper will be devoted and, as a rule, in equal degree to Biographical sketches of leading representatives of Science and Art The doings of the various County Councils will continue to be noted in its pages, and no pains will be spared in the effort to increase the usefulness of the papsr in the propagation of technical information among the many workers under these important bodies.

\section{TERMS OF SUBSCRIPTION.}

ONE YEAR'S SUBSCRIPTION (including postage) .. $\quad . . \quad \ldots$ 6s. 0 d. HALP "

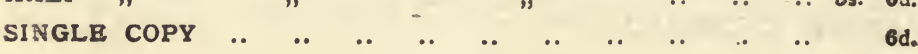




\section{Works published at Three Shillingss \& Sixpence each.}

THE WAIF FROM THE WAVES. A Story of Three Lives, touching th is World and another. By Canon Knox Littre. Crown 8vo.

LIFE ABOARD A BRITISH PRIVATEER IN THE TIME OF QUEEN ANNE. Being the Journal of CAptain Woodes Rogers. With Notes and Illustra. tions by Robert C. Leslie. New and Cheaper Edition. Crown 8 vo.

THE ST. JAMES'S COOKERY-BOOK. BY LOUISA ROCHFORT, Large crown 8 vo.

THE VYVYANS; or, The Murder in the Rue Bellechasse. By ANDREe HOPE. Crown 8 vo.

SUSPECTED. By Louisa STRATENUS.

AUSTRALIAN LIFE. By Francis Adams.

THE SECRET OF THE PRINCESS: a Tale of Country, Camp, Court, Convict, and Cloister Life in Russia. By Mrs. Sutherland Edwards.

THE STORY OF HELEN DAVENANT. By VIOLET Fane.

A DEPUTY PROVIDENCE. By HeNry MurRay.

SPORT: Fox Hunting, Salmon Fishing, Covert Shooting, Deer Stalking. By the late W. Bromley Davenport, M.P. With Illustrations by General CreaLOCK, C.B.

LOG-BOOK OF A FISHERMAN AND ZOOLOGIST. By Frank BUCKLAND. With Illustrations. Fifth Thousand.

THE haBITS OF THE SALMON. By Major Traherne.

ENGLAND: ITS PEOPLE, POLITY, AND PURSUITS. By T. H. S. Escotr. New and Revised Edition.

JESUS CHRIST; GOD; AND GOD AND MAN. Conferences delivered at Notre Dame in Paris. By Père Lacordaire. Seventh Thousand.

RECOLLECTIONS OF MY YOUTH. By ERnEST RENAN. Translated from the French and revised by Madame Renan. Second Edition.

HUMAN ORIGINS: EVIDENCE FROM HISTORY AND SCIENCE. By SAMUrL LAing. With Illustrations. Twelfth Thousand.

PROBLEMS OF THE FUTURE AND ESSAYS. By SAMUEL Laing. Thirteenth Thousand.

MODERN SCIENCE AND MODERN THOUGHT. By SAmuel Laing. Seventeenth Thousand.

A MODERN ZOROASTRIAN. By SAMUel LAING. Eighth Thousand.

THE SCIENCE OF LANGUAGE: LINGUISTICS, PHILOLOGY, AND ETyMOLOGY. By Aber. Hovelacque. With Maps.

SOCIOlOGY. Based upon Ethnology. By Dr. Charles Letourneau.

Biology. By Dr. Charles Letourneau. With 83 Illustrations.

PHILOSOPHY, Historical and Critical. By ANDRÉ LEFÈvRE:

ANTHROPOLOGY. By Dr. Paul Topinard. With a Preface by Professor

Paul Broca. With 49 Illustrations.

ESTHETICS. By Eugene Veron. 


\section{THE FORTNIGHTLY REVIEW.}

THE FORTNIGHTLY REVIEW is published on the rst of every month, and a Volume is completed every Six Months.

The following are among the Contributurs:-

ADMIRAL LORD ALCESTER. SIR RUTHERFORD ALCOCK. PROFESSOR BAIN. SIR SAMUEL BAKER. SIR R. BALL, F.R.S. PROFESSOR BEESLY. PAUL BOURGET.

DR. BRIDGES.

HON. GEORGE C. BRODRICK. FERDINAND BRUNETIERE.

JAMES BRYCE, M.P.

EMILIO CASTELAR.

RT. HON. J. CHAMBERLAIN, M.P.

PROFESSOR SIDNEY COLVIN.

THE EARL COMPTON.

MONTAGUE COOKSON, Q.C.

L. H. COURTNEY, M.P.

G. H. DARWIN.

PROFESSOR A. V. DICEY.

RIGHT HON. SIR C. DILKE, BART. PROFESSOR DOWDEN.

RT. HON. M. E. GRANT DUFF.

ARCHDEACON FARRAR.

EDWARD A. FREEMAN.

J. A. FROUDE.

MRS. GARRET-ANDERSON, M.D.

J. W. L. GLAISHER, F.R.S.

SIR J. E. GORST, Q.C., M.P.

THOMAS HARE.

FREDERIC HARRISON.

ADMIRAL SIR G. P. HORNBY.

LORD HOUGHTON.

PROFESSOR HUXLEY.

PROFESSOR R. C. JEBB.

LADY JEUNE.

LORD KELVIN, P.R.S.

ANDREW LANG.

E. B. LANIN.

EMILE DE LAVELEYE.

W. E. H. LECKY.

T. E. CLIFFE LESLIE.

W. S. LILLY.

MARQUIS OF LORNE.

PIERRE LOTI.

SIR JOHN LUBBOCK, BART., M.P.
W. H. MALLOCK.

DR. MAUDSLEY.

PROFESSOR MAX MÜLLER.

GEORGE MEREDITH.

RT. HON.G. OSBORNE MORGAN, Q.C., M.P.

RT. HON. JOHN MORLEY, M.P.

WILLIAM MORRIS.

PROFESSOR H. N. MOSELEY.

F. W. H. MYERS.

F. W. NEWMAN.

PROFESSOR JOHN NICHOL.

W. G. PALGRAVE.

WALTER H. PATER.

RT. HON. LYON PLAYFAIR, M.P.

SIR HENRY POTTINGER, BART:

T. E. REDMOND, M.P.

PROFESSOR SAYCE.

PROFESSOR J. R. SEELEY.

LORD SHERBROOKE.

PROFESSOR SIDGWICK.

HERBERT SPENCER.

M. JULES SIMON.

(Doctor L'Academie Franchises? HON. E. L. STANLEY.

SIR J. FITZJAMES STEPHEN, Q.C LESLIE STEPHEN.

J. HUTCHISON STIRLING.

A. C. SWINBURNE.

DR. VON SYBEL.

J. A. SYMONDS.

SIR THOMAS SYMONDS. (ADMIRAL OF THE FLERT).

THE REV. EDWARD F. TALBOT

(Warden of Keble Colleger).

SIR RICHARD TEMPLE, BART.

HON. LIONEL A. TOLLEMACHE.

COUNT LEO TOLSTOI.

H. D. TRAILL.

PROFESSOR TYNDALL.

ALFRED RUSSELL WALLACE. SIDNEY WEBB.

A. J. WILSON.

GEN. VISCOUNT WOLSELEY.

THE EDITOR. ETC., ETC., ETC.

The Fortnightly Review is published at 2s, $6 d$.

CHAPMAN \& HALL, LIMITED, II, HENRIETTA STREET, COVENT GARDEN, W.C. 





\section{DAY USE BORROWED RETURN TO DESK FROM WHAN DEPT.}

This book is due on the last date stamped below, or on the date to which simmediate recall.

Renewed books are subject to in

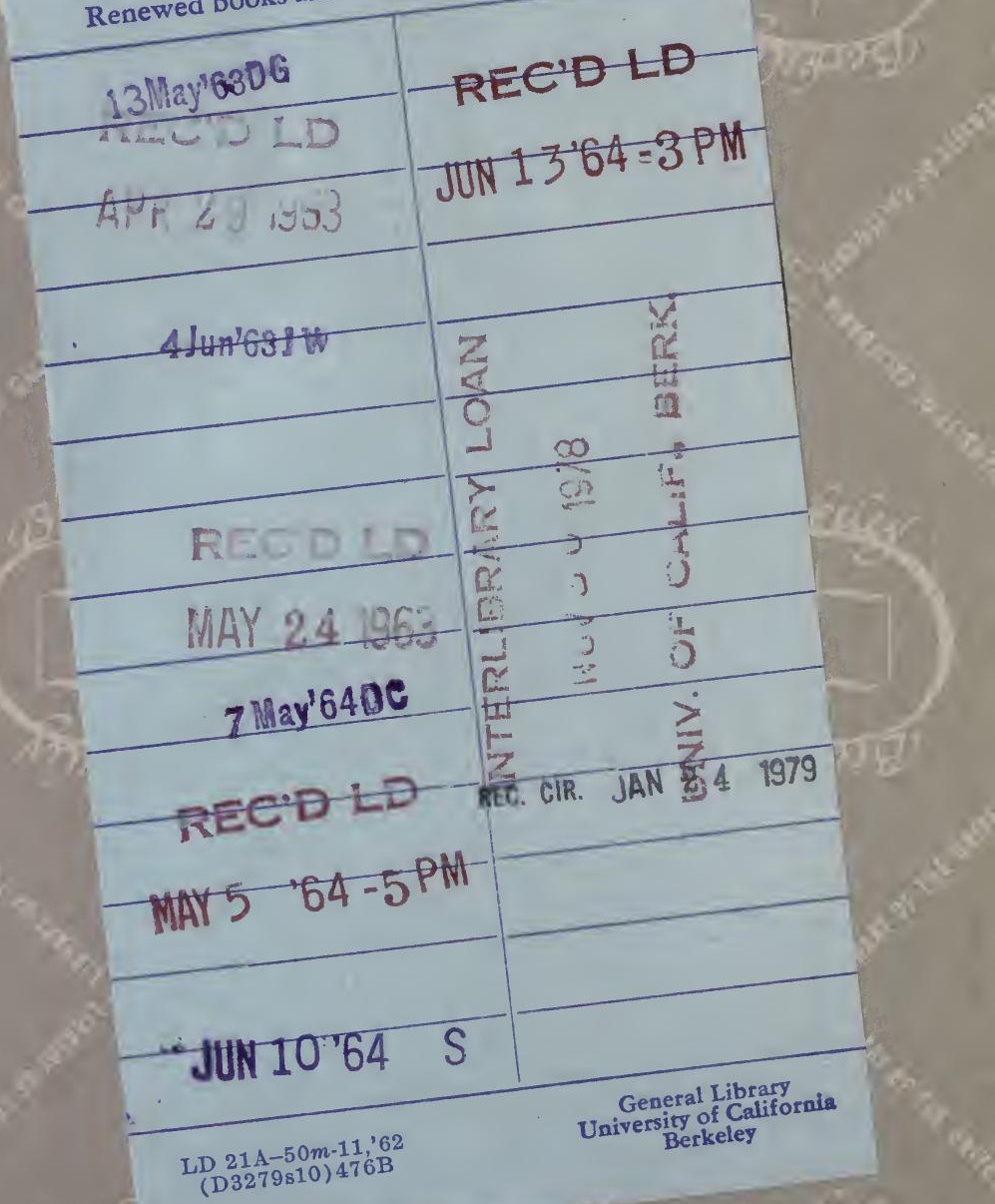




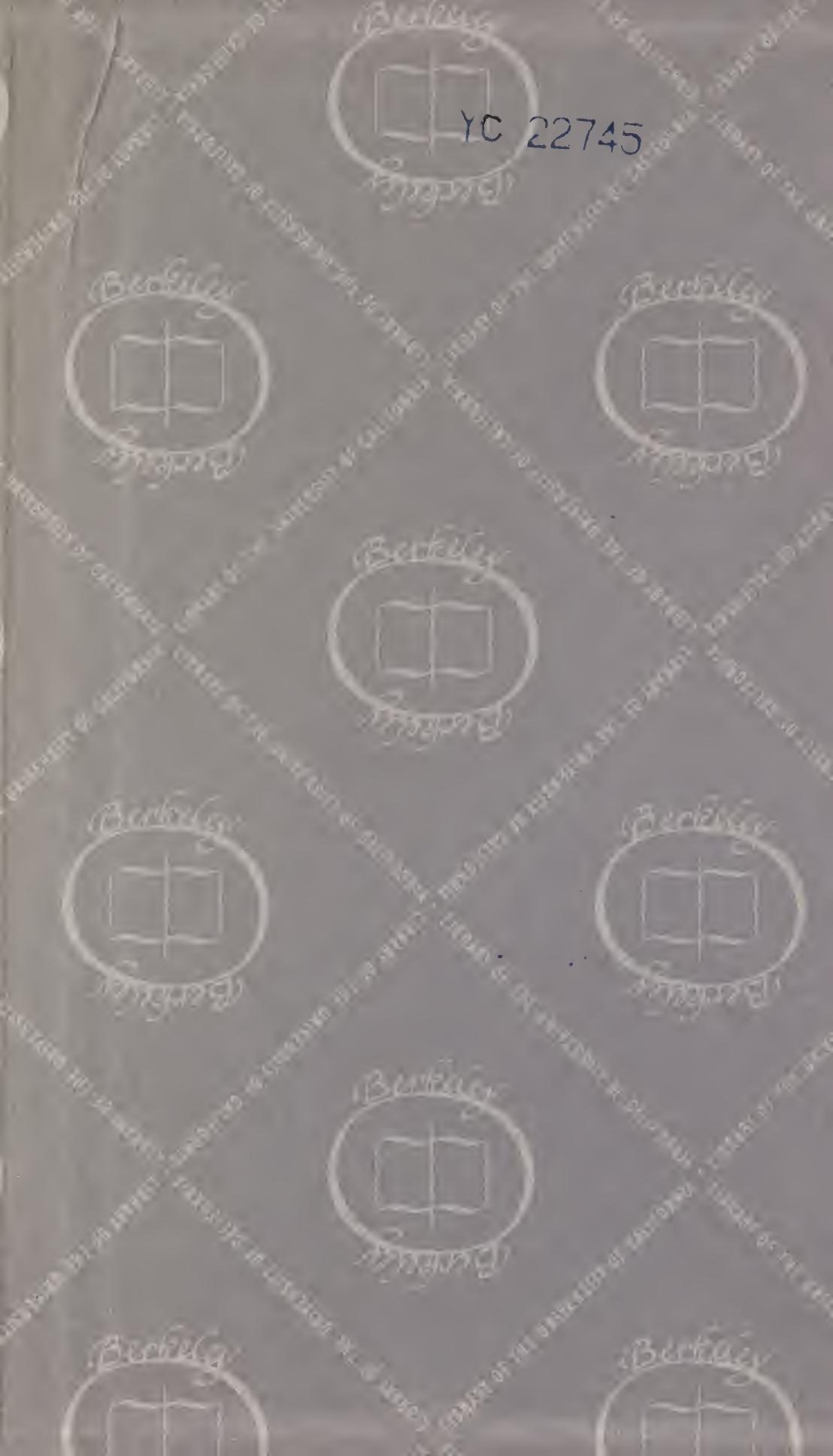


